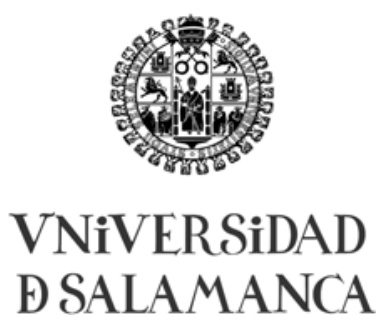

FACULTAD DE PSICOLOGÍA DEPARTAMENTO DE PERSONALIDAD, EVALUACIÓN Y TRATAMIENTO PSICOLÓGICOS

Doctorado en Psicología Clínica y de la Salud

\title{
EFECTOS EMOCIONALES, AFECTIVOS Y SOCIALES DE LA PRIVACIÓN DE LIBERTAD Y TORTURA POR MOTIVOS POLÍTICOS EN CHILE DE 1973 A 1990
}

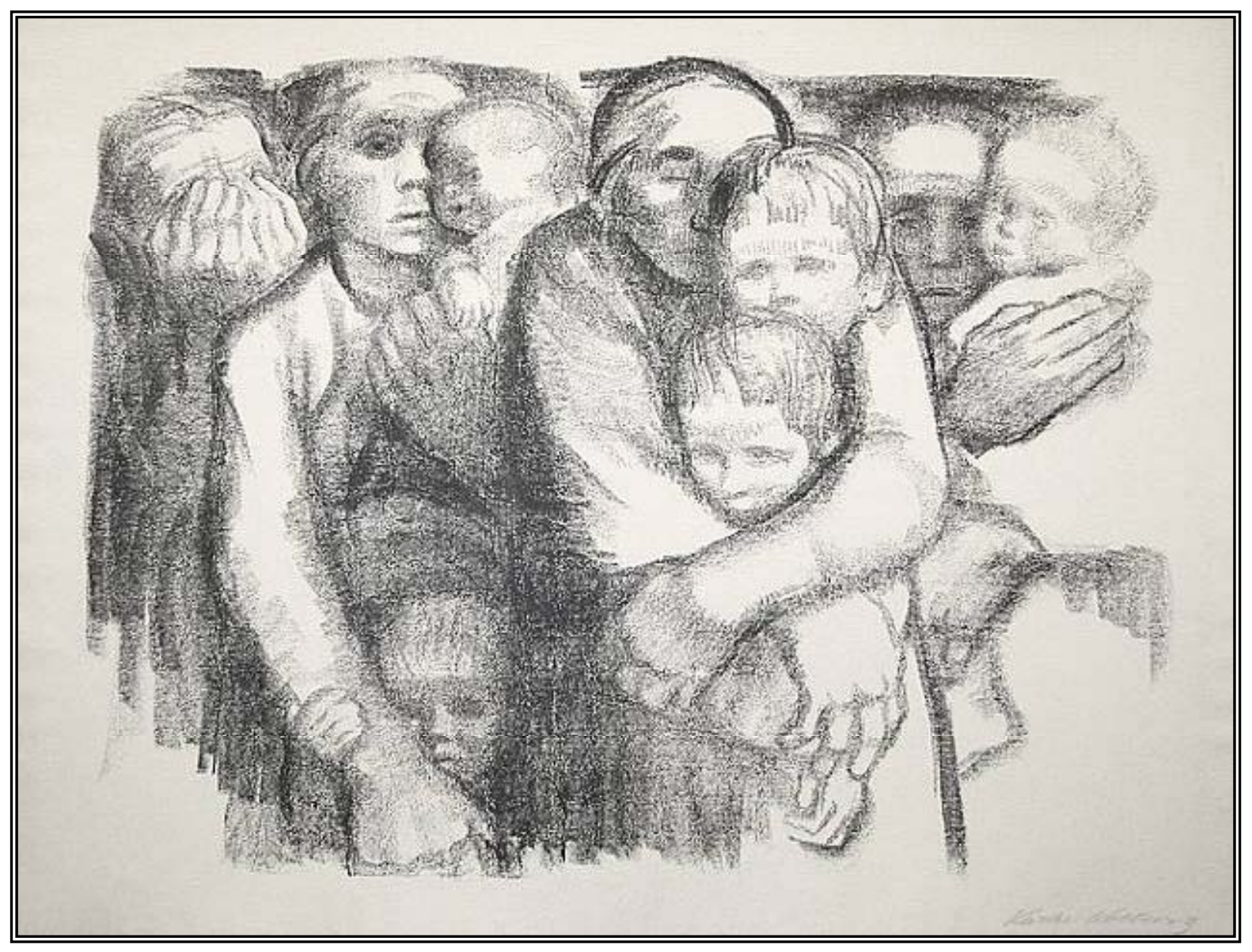

Tesis doctoral presentada para optar al grado de doctor por:

\section{PAMELA YANINA ZAPATA SEPÚLVEDA}

Dirigida por: Dr. Félix López Sánchez

Co-dirigida por: Dra. María Cruz Sánchez Gómez

Salamanca - España, 2008 
En portada:

Käthe Kollwitz

“Madre”, segunda versión, 1919.

Litografía. 


\section{(6) \\ VNiVERSIDAD \\ BSALAMANCA}

FACULTAD DE PSICOLOGÍA

DEPARTAMENTO DE PERSONALIDAD, EVALUACIÓN Y

TRATAMIENTO PSICOLÓGICOS

Doctorado en Psicología Clínica y de la Salud

\section{EFECTOS EMOCIONALES, AFECTIVOS Y SOCIALES DE LA PRIVACIÓN DE LIBERTAD Y TORTURA POR MOTIVOS POLÍTICOS EN CHILE DE 1973 A 1990}

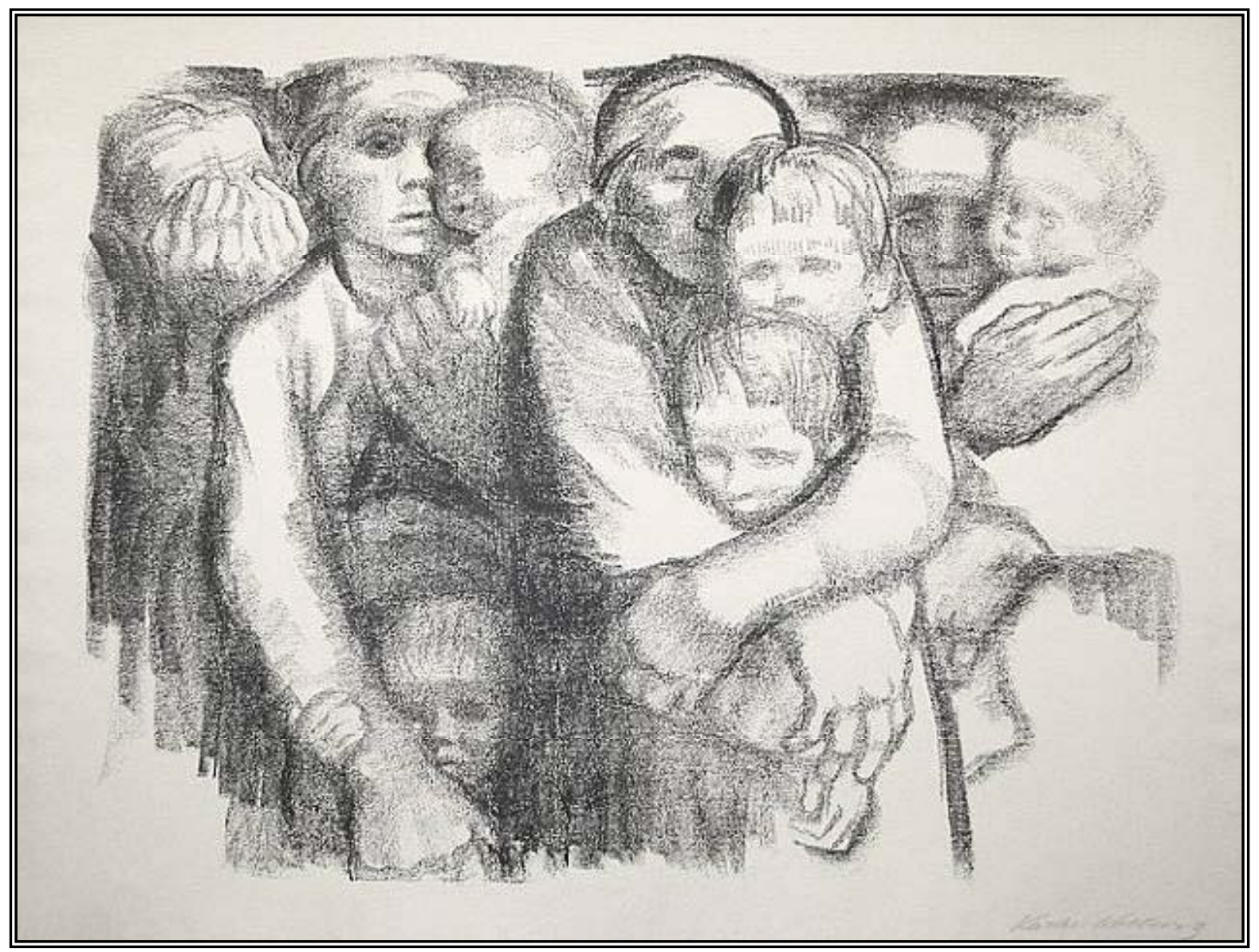

Tesis doctoral presentada para optar al grado de doctor por:

\section{PAMELA YANINA ZAPATA SEPÚLVEDA}

Dirigida por: Dr. Félix López Sánchez

Co-dirigida por: Dra. María Cruz Sánchez Gómez

Salamanca - España, 2008 

A mis padres, con amor e infinita gratitud 



\section{AGRADECIMIENTOS}

Quisiera agradecer a todos quienes me acompañaron en esta etapa de mi vida que recordaré siempre con mucho cariño.

En primer lugar, a mis padres por haberme apoyado tanto durante estos años. Por la preocupación, el aliento y todo el cariño que siempre me dieron y que traspasó todas las fronteras físicas existentes cuando eran miles los kilómetros que nos distanciaban. Llegar hasta aquí, hubiera sido imposible sin ustedes. Gracias papá por tu inagotable paciencia, tu gran corazón y tu generosidad, y gracias mamá por tus múltiples muestras de afecto, tus sabios consejos y tu presencia.

Al Dr. Félix López Sánchez, director del proyecto, por su dedicación y compromiso presentes desde el día que aceptó dirigir esta tesis doctoral. Muchas gracias querido Félix, por el tiempo que has dedicado a este proyecto, por tus inestimables aportaciones y correcciones, por enseñarme una teoría maravillosa de las relaciones humanas, y por el apoyo y afecto que me has dado durante este tiempo.

A la Dra. María Cruz Sánchez Gómez, co-directora del proyecto, por sus valiosos aportes principalmente en la parte empírica, por los conocimientos y la dedicación depositados en esta tesis doctoral, y en especial, por enseñarme el manejo del programa informático Nud*ist 4 y Nvivo6. Gracias Maricruz por mostrarme un mundo nuevo en metodología cualitativa.

A todas las personas que colaboraron en este estudio, pertenecientes a la directiva de la Agrupación Nacional de Ex - presos y Ex - presas políticas de Chile (ANEXPP CHILE), al Comité de Derechos Humanos de la Cisterna (Santiago de Chile), a la Agrupación de Ex - presos políticos de Arica, y en especial a cada una de las personas que conformaron la muestra de este estudio, de las ciudades de Arica, Santiago, Linares, Valdivia, Puerto Montt, y la isla de Chiloé. A todos ustedes que voluntariamente compartieron sus vivencias entregando el valioso testimonio de sus vidas. Gracias por permitirme conocerles y acceder a un mundo que era desconocido para mi, y por la lección de vida que sus relatos me han significado. Conocerles ha sido uno de los motores que ha impulsado el desarrollo de esta investigación.

Al Ministerio de Planificación y Cooperación del Gobierno de Chile, por haberme concedido la Beca Presidente de la República para estudios de post - grado en el extranjero y que financió los primeros tres años y medio de mi estancia en España para cursar el programa de doctorado en Psicología clínica y de la salud.

Al Sr. Howard Steele, director del Journal “Attachment and Human Development”, por sus aportes en la fase inicial del proyecto, principalmente en la formulación del objeto de estudio. 
Al Dr. José David Urchaga, profesor de la Facultad de Comunicación de la Universidad Pontificia de Salamanca, por su buena disposición y valioso aporte constructivo en la parte metodológica de este proyecto.

A mi hermano Sergio y al pequeño Benjita, por el cariño, ánimos y alegrías entregados durante todos estos años. Los quiero mucho.

A mi familia en Chile, y a todos mis amigos que se encuentran en distintos lugares del mundo y que forman parte de mi familia también.

Y a Él, por haberme dado la vida y estar conmigo durante todos estos años.

A todos ustedes dedico esta tesis doctoral, gracias.

Pamela 


\section{ÍNDICE}

Agradecimientos $\mathrm{v}$

Índice vii

Listas de tablas xiv

Listas de figuras xix

Introducción 1

\section{DESARROLLO TEÓRICO}

\section{Capítulo 1. CONCEPTOS Y TEORÍAS DE REFERENCIA: TEORÍAS SOBRE LAS} NECESIDADES EMOCIONALES, AFECTIVAS Y SOCIALES ……………...................................... 7

1.1. Teoría de la soledad social y emocional de Weiss, como marco de referencia general .................................... 9

1.1.1. Definición y tipología de la soledad ......................................................................................................... 9

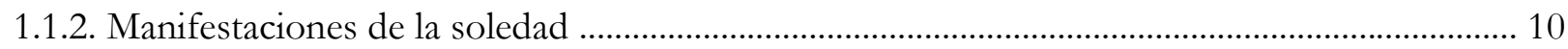

1.1.3. Causas de la soledad ....................................................................................................................................... 11

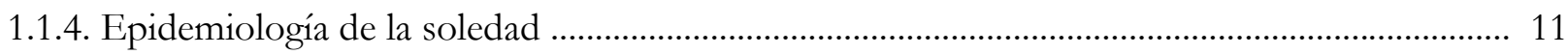

1.1.5. Aplicabilidad del modelo a la muestra ………....................................................................................... 12

1.2. Teorías de las necesidades humanas de Doyal y Gough ................................................................................ 14

1.2.1. Bases epistemológicas del modelo .......................................................................................................... 14

1.2.1.1. Definición de ser humano y las necesidades humanas básicas ....................................................... 14

1.2.1.2. Las necesidades planteadas por Doyal y Gaugh .............................................................................. 15

1.2.1.3. Necesidades de salud física y autonomía …………………………………………............................ 15

1.2.1.4. Satisfacción de necesidades básicas y necesidades intermedias ....................................................... 18

1.2.1.5. Indicadores para la satisfacción de las necesidades básicas ............................................................ 18

1.2.1.6. Necesidades humanas universales vs. relativismo cultural .......................................................... 19

1.2.2. Necesidades humanas básicas de grupos particulares concretos: El caso de los expresos políticos .. 20

1.3. Teoría de las necesidades interpersonales básicas de López .............................................................................. 22

1.3.1. Necesidades emocionales y sociales ................................................................................................. 24

1.3.1.1. Necesidad de vinculación afectiva y teoría del apego .................................................................. 24

1.3.1.1.1. La familia y su rol en el sistema de vinculación afectiva ................................... 26

1.3.1.1.2. El apego en la adolescencia y etapa adulta ....................................................... 27

1.3.1.1.3. Teoría del apego como referencia específica para entender los efectos de la tortura y prisión en las relaciones familiares ....................................................................... 31

1.3.1.1.4. Necesidad de vinculación afectiva y teoría de la soledad de Weiss .............................. 32 
1.3.1.2. Necesidades sociales

1.3.1.3. Concepción de ser humano individual y social y su relación con la satisfacción de necesidades interpersonales 34

1.3.1.4. El ser humano, su bienestar personal y social y calidad de vida 36

1.3.1.5. Dos propuestas actuales de teorías de las necesidades que contribuyen al modelo de López (2008)

\section{Capítulo 2. CARACTERÍSTICAS PSICOLÓGICAS DE SUPERVIVIENTES DE VIOLENCIA} POLÍTICA Y TORTURA: UNA REVISIÓN BIBLIOGRÁFICA DE INVESTIGACIONES RELACIONADAS

2.1. Violencia, prisión, tortura y trauma por motivos políticos 44

2.1.1. Definición de conceptos y aspectos relacionados 44

2.1.1.1. Violencia política 44

2.1.1.2. Preso político y prisión política 45

2.1.1.3. Definición de tortura 45

2.1.1.3.1. Modalidades (Física, psicológica, sexual) 47

2.1.1.3.2. Objetivos de la tortura 49

2.1.1.4. Trauma 50

2.1.1.4.1. Trauma y estrés post-traumático (DSM-IV-R) 51

2.1.1.4.2. El trauma visto desde los mecanismos intrapsíquicos asociados 56

2.1.1.4.3. El trauma desde un enfoque sociopolítico 57

2.1.1.4.4. Fases del proceso de trauma 59

2.1.2. Factores contextuales de la violencia política y tortura 62

2.1.2.1. Gobierno y sociedad 62

2.1.2.2. Familia 63

2.1.2.3. Represión política, estigmatización de las víctimas y generalización del miedo 64

2.1.2.3.1. Silencio, la negación de lo que sigue haciéndose presente 65

2.1.2.3.2. Temor 66

2.1.2.4. Exilio 67

2.1.3. Efectos psicológicos en supervivientes de violencia política y tortura 68

2.1.3.1. A nivel individual, social y familiar 69

2.1.3.1.1. Impacto específico de la violencia sexual en mujeres 77

2.1.3.2. Etapa evolutiva actual y secuelas: adultez vs vejez 81

2.1.3.3. Vinculación con la imagen del torturador 81

2.1.3.4. La experiencia de prisión política y tortura: necesidad de criterios diagnósticos específicos 
2.1.3.4.1. Criterio de estrés post traumático (DSM-IV) y tortura .................................... 83

2.1.3.4.2. Sintomatología de supervivientes ................................................................ 88

2.1.3.4.3 Secuelas neurológicas de la tortura .............................................................. 92

2.1.3.4.4. El síndrome del sobreviviente al holocausto (The Holocaust

Survivor Síndrome) …………………………………............................................... 92

2.1.3.5. La influencia de la reparación en los efectos psicológicos .................................................. 93

2.1.3.5.1. Medidas gubernamentales ......................................................................... 93

2.1.3.5.2. Víctimas y agrupaciones de DDHH: el rol del trabajo en DDHH y

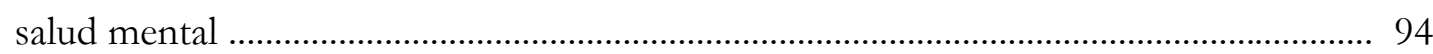

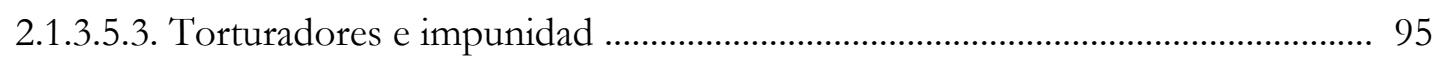

2.1.3.5.4. Reconciliación y "olvido"................................................................................ 96

2.1.4. Problemas pendientes y limitaciones de los estudios ............................................................. 97

Capítulo 3. ESCENARIO HISTÓRICO-POLÍTICO Y SOCIAL DE LA PRISIÓN POLÍTICA EN CHILE Y LA RESPUESTA GUBERNAMENTAL, SOCIAL Y FAMILIAR A MÁS DE TRES DÉCADAS DESPUÉS. UNA REVISIÓN A LA BIBLIOGRAFÍA LATINOAMERICANA ......... 99

3.1. La prisión política y tortura en Chile desde 1973 a 1990 .................................................................... 102

3.1.1. Escenario histórico-político y social de los sucesos ........................................................................ 102

3.1.1.1. El contexto social cuando ocurrieron los hechos ............................................................... 106

3.1.1.2. Situaciones represivas acontecidas en Chile entre 1973 y 1990 .................................... 108

3.1.2. Contexto político y social chileno en la transición de la dictadura a la democracia ................ 108

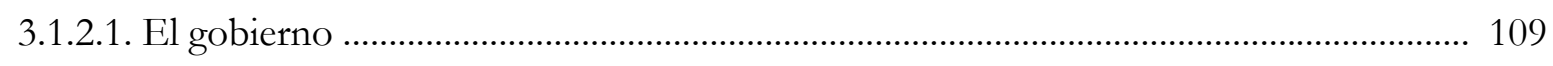

3.1.2.2. Apelación al olvido ....................................................................................................... 110

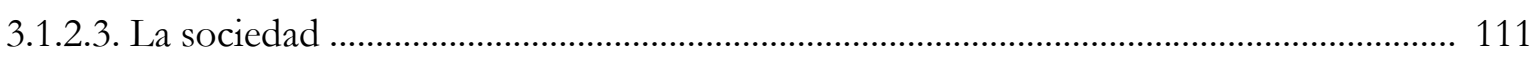

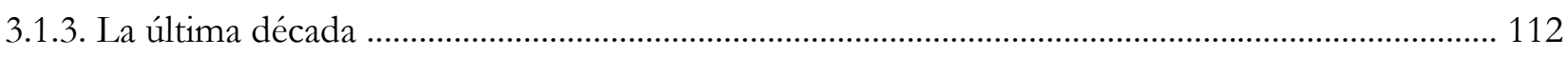

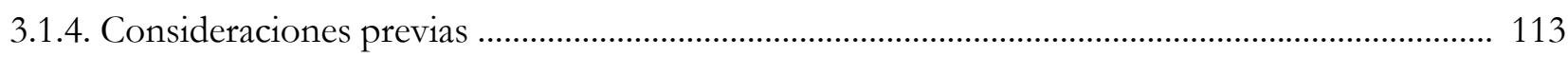

3.2. Respuesta gubernamental a supervivientes de prisión política y tortura: el informe Valech ......... 114

3.2.1. Antecedentes legales y funcionamiento de la Comisión Valech ................................................. 114

3.2.2. Características de períodos de prisión establecidos por la comisión Valech ................................ 116

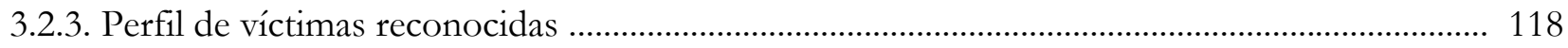

3.2.4. Clasificación de ex - preso político según la comisión Valech .................................................... 119

3.2.5. Métodos de tortura oficialmente reconocidos ........................................................................ 120

3.2.6. Consecuencias de prisión política y tortura en la vida de los EXPPS ....................................... 127

3.2.7. Propuestas de reparación gubernamental y respuesta de víctimas ............................................. 130

3.3. Contexto social y familiar para quienes vivieron el exilio ............................................................ 132 


\section{DESARROLLO EMPÍRICO}

\section{Capítulo 4. DISEÑO METODOLÓGICO, PLANTEAMIENTO DEL PROBLEMA E HIPÓTESIS}

4.1. Tendencias actuales de la investigación cualitativa en las ciencias humanas

4.2. Justificación, diseño y planteamiento del problema de investigación cualitativa empleado en el estudio. 139

4.2.1. Justificación

4.2.2. Diseño 141

4.2.3. Objetivos e hipótesis 142

4.3. Instrumento empleado: la entrevista en profundidad 144

4.4. Pasos metodológicos 147

4.4.1. Fase preparatoria 147

4.4.2. El acceso al campo 148

4.4.3. La muestra 149

4.4.4. La recogida de datos 150

4.4.5. El análisis de contenido 151

4.4.6. Transformación de datos 155

4.4.7. El proceso de codificación 156

4.4.8. Análisis de datos 156

4.5. Rigor científico: fiabilidad y validez del estudio 157

4.5.1. Test de fiabilidad 158

4.6. El programa QSR Nvivo 6 como herramienta informática de análisis de contenido ... 160

4.7. Áreas de interés investigativo 162

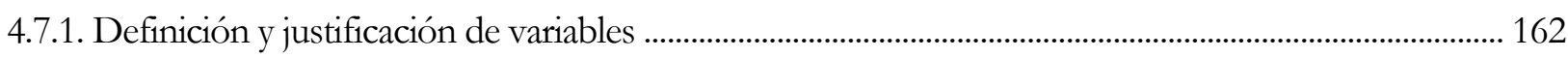

4.7.2. El mapa conceptual .................................................................................................................................. 162

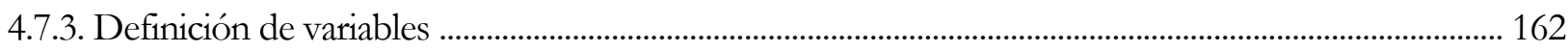

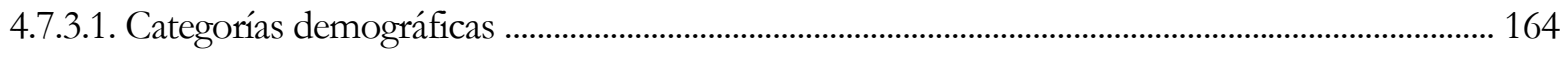

4.7.3.2. Categorías conceptuales .................................................................................................................. 178

5.2. Parte II. Frecuencias por sujeto y Unidades Textuales U.T.s de los grandes temas que conforman nuestro árbol de categorías y abarcan el total de los nudos hijos, abordados y codificados según su presencia en los discursos de los EXPPS entrevistados 
5.3. Parte III. Frecuencias de las sumatorias de nudos hijos (hojas del árbol de categorías) ...... 251

5.3.1. Antecedentes conceptuales del tiempo presente ...................................................................... 252

5.3.2. Antecedentes conceptuales del tiempo pasado ........................................................................ 268

5.3.3. Antecedentes conceptuales de la experiencia de prisión política y tortura ............................... 277

5.3.4. Antecedentes conceptuales de otras valoraciones ...................................................................... 289

5.3.5. Resumen de las tendencias presentadas según las modas obtenidas en los resultados demográficos y conceptuales 298

5.3.5.1. Tendencias en base a variables demográficas 298

5.3.5.2. Tendencias en base a variables conceptuales agrupadas según las necesidades interpersonales planteadas por López (2008) 300

5.4. Parte IV. Resultados del estudio sintáctico de palabras específicas y del cruce de éstas, asociadas al impacto en estudio

5.5. Parte V. Respuestas a preguntas de investigación que planteamos en base a la teoría que sustenta nuestro estudio 305

5.6. Parte VI. Análisis estadístico mediante la aplicación de la prueba de $\chi^{2}$ de Pearson para las variables demográficas sexo, edad y ubicación geográfica en relación a variables conceptuales seleccionadas

5.6.1. Variable sexo 333

5.6.2. Variable edad. 334

5.7. Parte VII. Análisis cluster de variables agrupadas y seleccionadas 337

Capítulo 6. DISCUSIÓN.

6.1 Omisiones.

6.1.1. Sufrimiento y dificultades producidos desde la experiencia de prisión y aludidos directamente, y su incidencia en el impacto estudiado

6.1.2. Tortura

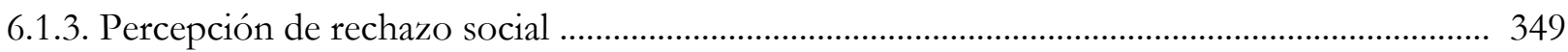

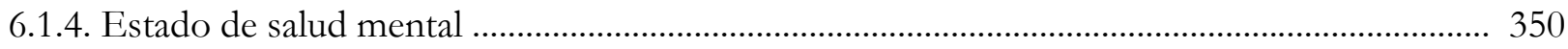

6.1.5. Silencio y violencia sexual en mujeres .................................................................................... 351

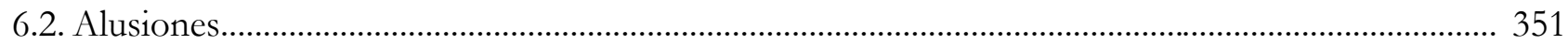

6.2.1. Aspectos contextuales y problemáticas posteriores a la experiencia de prisión y actuales, que inciden en el impacto emocional y social de la experiencia de prisión ....................................... 351

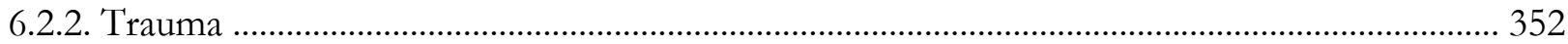

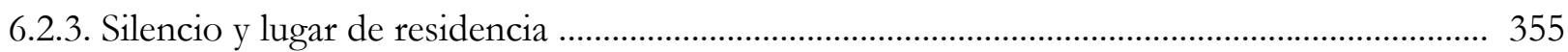

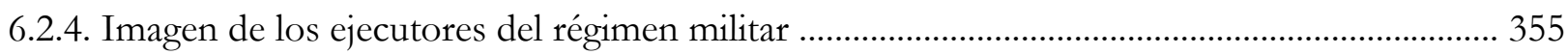

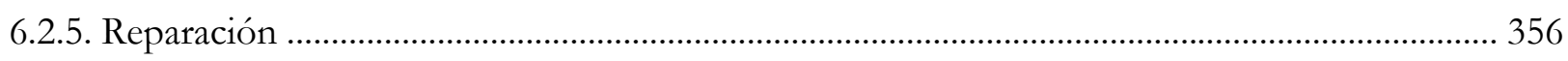

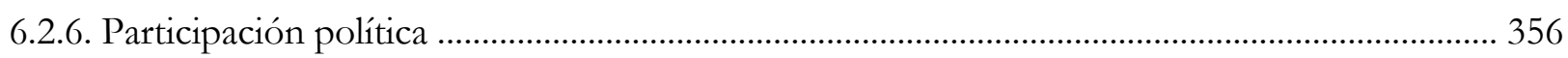




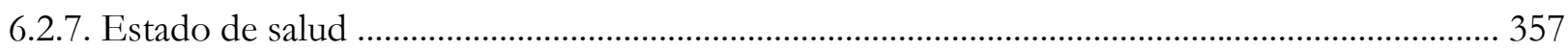

6.2.8. Concepción de mundo, seres humanos y sentido otorgado a la vida ...................................... 357

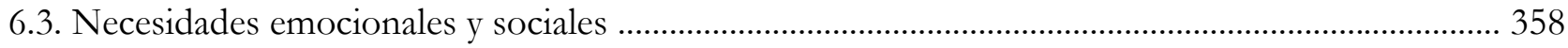

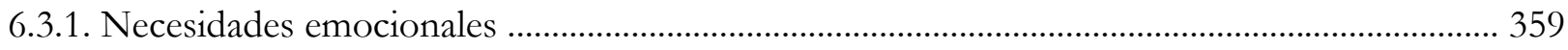

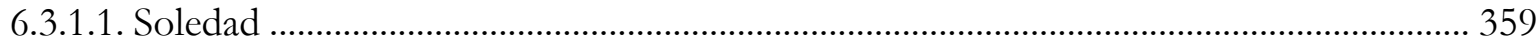

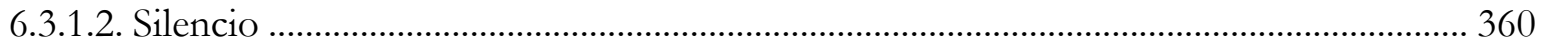

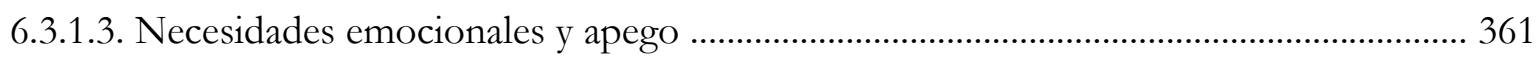

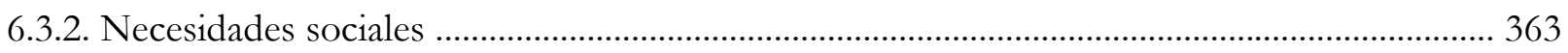

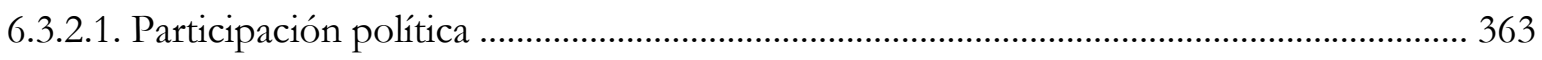

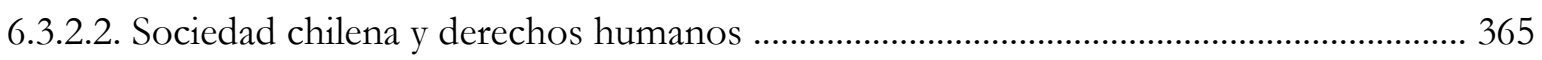

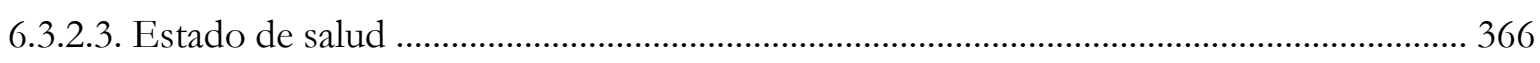

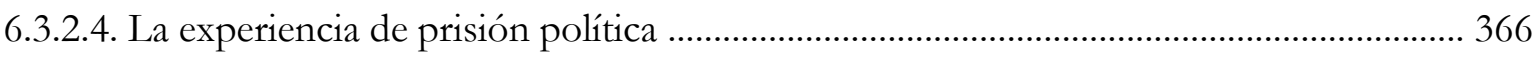

6.3.3. Dificultades posteriores a la experiencia de prisión y producto de su condición de

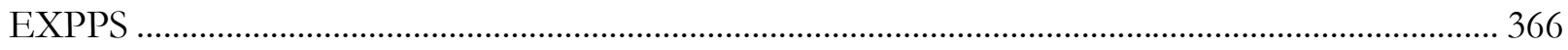

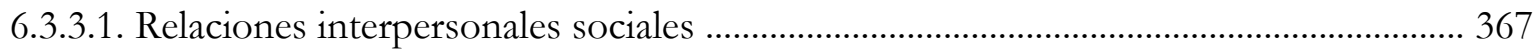

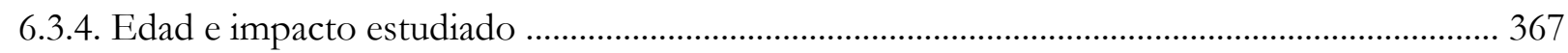

6.4. Análisis de conglomerados jerárquicos de variables: ¿de qué se quejan las víctimas? ..................... 368

6.5. El diseño metodológico empleado para estudiar el impacto emocional y social de la privación de libertad y tortura por motivos políticos en un grupo de chilenos ………………………………………………………….... 369

6.5.1. El marco referencial teórico ..................................................................................................................... 369

6.5.2. La metodología empleada ............................................................................................................... 370

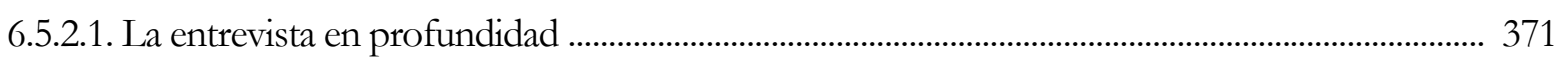

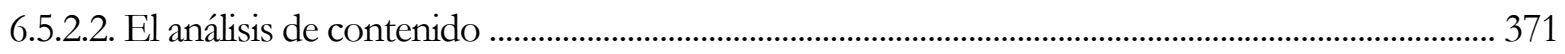

6.5.2.3. El mapa conceptual ...................................................................................................................... 371

6.5.2.4. El aporte del programa informático QSR Nvivo .............................................................................. 371

6.5.2.5. El aporte del programa informático SPSS ....................................................................................... 372

6.6. Limitaciones del estudio .................................................................................................................................... 372

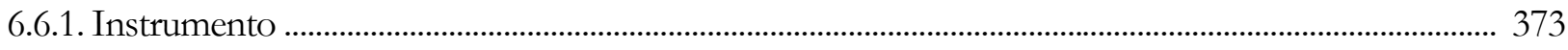

6.6.2. Factores contextuales ............................................................................................................................. 373

6.6.3. Síndrome de estrés postraumático ……………………………….......................................................... 374

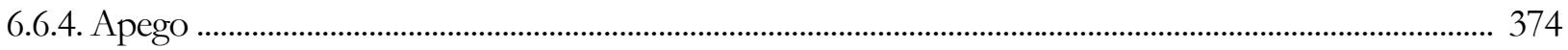

6.6.5. Dirigentes de agrupaciones de Derechos humanos y EXPPS ............................................................ 375

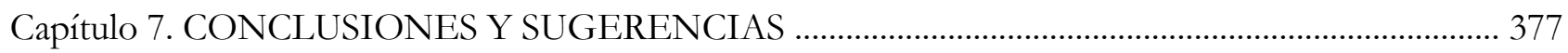

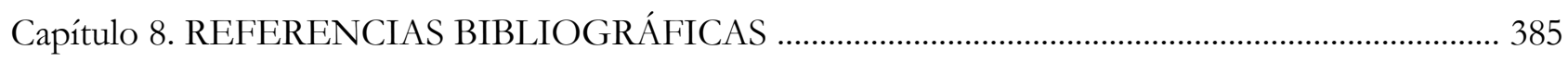

xii 
APÉNDICE A: ejemplo de la entrevista en profundidad empleada

APÉNDICE B: Reflexiones durante el trabajo de campo

APÉNDICE C: Test de fiabilidad

Tabla C 1. Categorías incluidas en el test de fiabilidad y su correspondencia con nuestro sistema de codificación 432

APÉNDICE D: Mapa conceptual jerárquico 433 


\section{ÍNDICE DE TABLAS Y FIGURAS}

Pág.

\section{LISTAS DE TABLAS}

Tabla 1. Necesidades humanas planteadas por Doyal y Gaugh ........................................................................... 23

Tabla 2. Operadores de búsqueda utilizados con el programa QSR Nvivo6 ....................................................... 161

Tabla 3. Antecedentes demográficos de sexo, edad y zona geográfica................................................................... 234

Tabla 4. Antecedentes demográficos de estado civil .................................................................................................... 236

Tabla 5. Antecedentes demográficos políticos de la pareja actual .............................................................................. 237

Tabla 6. Antecedentes demográficos educativos .............................................................................................. 237

Tabla 7. Antecedentes demográficos ocupacionales ................................................................................................ 238

Tabla 8. Antecedentes demográficos políticos ................................................................................................... 239

Tabla 9. Antecedentes demográficos de la experiencia de prisión ........................................................................ 239

Tabla 10. Antecedentes demográficos legales de la experiencia de prisión .............................................................. 240

Tabla 11. Antecedentes demográficos de la experiencia de tortura en prisión ....................................................... 240

Tabla 12. Antecedentes demográficos de tortura física en prisión .................................................................. 241

Tabla 13. Antecedentes demográficos de tortura psicológica en prisión ................................................................ 242

Tabla 14. Antecedentes demográficos de tortura sexual en prisión ........................................................................ 242

Tabla 15. Antecedentes demográficos familiares de pareja en la actualidad ...................................................... 243

Tabla 16. Antecedentes demográficos familiares de hijos ....................................................................................... 244

Tabla 17. Antecedentes demográficos familiares de nietos, ocio y salud de los participantes ............................ 245

Tabla 18. Collect de categorías demográficas y conceptuales .................................................................................... 246

Tabla 19. Collect de todas las variables de antecedentes conceptuales ................................................................... 247

Tabla 20. Collect de antecedentes conceptuales del presente ..................................................................................... 248

Tabla 21. Collect de antecedentes conceptuales de las relaciones interpersonales del presente ........................ 249

Tabla 22. Collect de antecedentes conceptuales del pasado ................................................................................. 249

Tabla 23. Collect de antecedentes conceptuales de prisión política............................................................................... 250

Tabla 24. Antecedentes conceptuales de otras valoraciones ................................................................................. 251

Tabla 25. Antecedentes conceptuales de la pareja actual .................................................................. 252

Tabla 26. Tema específico más aludido para la categoría pareja actual..................................................................... 252

Tabla 27. Antecedentes conceptuales de los hijos ........................................................................................... 253

Tabla 28. Tema específico más aludido para la categoría hijos ............................................................................ 253

Tabla 29. Antecedentes conceptuales de los nietos ....................................................................................................... 254

Tabla 30. Tema específico más aludido para la categoría nietos ........................................................................... 254

Tabla 31. Antecedentes conceptuales de la familia de origen en el presente ...................................................... 254

Tabla 32. Antecedentes conceptuales de la disposición de amigos en el presente ................................................ 255 
Tabla 33. Antecedentes conceptuales de la valoración de los amigos en el presente

Tabla 34. Tema específico más aludido para la categoría valoración de los amigos en el presente 255

Tabla 35. Antecedentes conceptuales de la disposición de compañeros en el presente 256

Tabla 36. Antecedentes conceptuales de la valoración de los compañeros en el presente . 256

Tabla 37. Tema específico más aludido para la categoría valoración de los compañeros en el presente . 256

Tabla 38. Antecedentes conceptuales de la disposición de apoyo incondicional en el presente 257

Tabla 39. Antecedentes conceptuales del tipo de vinculación de apoyo incondicional disponible en el presente

Tabla 40. Tema específico más aludido para la categoría tipo de vinculación de apoyo incondicional disponible en el presente 258

Tabla 41. Antecedentes conceptuales de la concepción del mundo en el presente 258

Tabla 42. Tema específico más aludido para la categoría concepción de mundo en el presente 258

Tabla 43. Antecedentes conceptuales de la concepción del mundo en el presente 259

Tabla 44. Antecedentes conceptuales de ideología en el presente de la valoración de creencias específicas .. 259

Tabla 45. Tema específico más aludido para la categoría valoración de creencias específicas 259

Tabla 46. Antecedentes conceptuales de ideología del sentido otorgado a las relaciones afectivas en el presente. 260

Tabla 47. Tema específico más aludido para la categoría sentido otorgado a las relaciones afectivas en el presente. 260

Tabla 48. Antecedentes conceptuales de la concepción de seres humanos en el presente 260

Tabla 49. Tema específico más aludido para la categoría concepción de seres humanos en el presente 261

Tabla 50. Antecedentes conceptuales de valoración personal 262

Tabla 51. Antecedentes conceptuales de valoración de ocupación actual 262

Tabla 52. Tema específico más aludido para la categoría valoración de ocupación actual 263

Tabla 53. Antecedentes conceptuales de valoración de la participación política 263

Tabla 54. Tema específico más aludido para la categoría participación política 263

Tabla 55. Antecedentes conceptuales de valoración de la motivación de participación política 264

Tabla 56. Tema específico más aludido para la categoría valoración de la motivación de participación política 264

Tabla 57. Antecedentes conceptuales del sentido de la vida 265

Tabla 58. Tema específico más aludido para la categoría valoración sentido de la vida 265

Tabla 59. Antecedentes conceptuales de valoración del Chile actual 266

Tabla 60. Antecedentes conceptuales de temores 267

Tabla 61. Tema específico más aludido para la categoría temores 268

Tabla 62. Antecedentes conceptuales de la familia de origen en el pasado 268

Tabla 63. Tema específico más aludido para la categoría familia de origen en el pasado 269 
Tabla 64. Antecedentes conceptuales del ambiente familiar de origen en el pasado 269

Tabla 65. Tema específico más aludido para la categoría ambiente familiar de origen en el pasado 269

Tabla 66. Antecedentes conceptuales de la disposición de amigos en el pasado 270

Tabla 67. Antecedentes conceptuales de la valoración de los amigos en el pasado 271

Tabla 68. Tema específico más aludido para la categoría valoración de amigos en el pasado 271

Tabla 69. Antecedentes conceptuales de la disposición de pareja en el pasado 272

Tabla 70. Antecedentes conceptuales de la valoración de la pareja en el pasado ...... 272

Tabla 71. Antecedentes conceptuales de la disposición de apoyo incondicional en el pasado 273

Tabla 72. Antecedentes conceptuales del tipo de vinculación de apoyo incondicional disponible en el pasado . 273

Tabla 73. Antecedentes conceptuales de la concepción del mundo en el pasado 274

Tabla 74. Antecedentes conceptuales de la visión de futuro en el pasado 275

Tabla 75. Antecedentes conceptuales de la valoración de su estar en el mundo en el pasado. 276

Tabla 76. Antecedentes conceptuales del sentido otorgado a la vida en el pasado 276

Tabla 77. Tema específico más aludido para la categoría sentido otorgado a la vida en el pasado 277

Tabla 78. Antecedentes conceptuales del sufrimiento vivido en prisión 277

Tabla 79. Tema específico más aludido para la categoría sufrimiento vivido en prisión 278

Tabla 80. Antecedentes conceptuales de la valoración del impacto de prisión en otros 278

Tabla 81. Antecedentes conceptuales de la actitud post-prisión 279

Tabla 82. Tema específico más aludido para la categoría actitud post-prisión 280

Tabla 83. Antecedentes conceptuales de la valoración del impacto de prisión en sus vidas ....... 280

Tabla 84. Tema específico más aludido para la categoría valoración del impacto de prisión en sus vidas ...... 280 Tabla 85. Antecedentes conceptuales de la valoración del impacto de prisión en relaciones interpersonales 281 Tabla 86. Antecedentes conceptuales de la valoración del impacto de prisión en relaciones interpersonales con la Familia 282

Tabla 87. Tema específico más aludido para la categoría valoración del impacto de prisión en relaciones interpersonales con la familia 282

Tabla 88. Antecedentes conceptuales de la valoración del impacto de prisión en relaciones interpersonales con los amigos 283

Tabla 89. Antecedentes conceptuales de la valoración del impacto de prisión en relaciones interpersonales con los compañeros 284

Tabla 90. Antecedentes conceptuales de la valoración de temores asociados a la experiencia de prisión 284

Tabla 91. Tema específico más aludido para la categoría valoración de temores asociados a la experiencia de prisión 284

Tabla 92. Antecedentes conceptuales del silencio personal 285 
Tabla 93. Tema específico más aludido para la categoría silencio personal ..... 286

Tabla 94. Antecedentes conceptuales del silencio con relaciones interpersonales 286

Tabla 95. Tema específico más aludido para la categoría silencio con relaciones interpersonales. 287

Tabla 96. Antecedentes conceptuales de la valoración de superación de la experiencia de prisión 287

Tabla 97. Antecedentes conceptuales de la percepción de apoyo recibido post-prisión 288

Tabla 98. Antecedentes conceptuales de la percepción del rechazo percibido post-prisión 289

Tabla 99. Antecedentes conceptuales de la experiencia de persecución política 289

Tabla 100. Antecedentes conceptuales del momento de ocurrencia de persecución política ........ 290

Tabla 101. Antecedentes conceptuales del afrontamiento realizado ante la persecución política 290

Tabla 102. Tema específico más aludido para la categoría afrontamiento realizado ante la persecución política 291

Tabla 103. Antecedentes conceptuales del régimen militar 291

Tabla 104. Tema específico más aludido para la categoría antecedentes conceptuales del régimen militar .... 292

Tabla 105. Antecedentes conceptuales de valoración de las etapas del Informe Valech ... 292

Tabla 106. Tema específico más aludido para la categoría valoración de las etapas del Informe Valech 292

Tabla 107. Antecedentes conceptuales de valoración de las medidas del Informe Valech 293

Tabla 108. Tema específico más aludido para la categoría valoración de las medidas del Informe Valech .... 293

Tabla 109. Antecedentes conceptuales de la concepción de reparación 294

Tabla 110. Antecedentes conceptuales de la valoración de políticos de izquierda y reparación 295

Tabla 111. Antecedentes conceptuales de reparación y justicia 295

Tabla 112. Antecedentes conceptuales de la valoración de sociedad chilena y Derechos Humanos 296

Tabla 113. Tema específico más aludido para la categoría valoración de sociedad chilena y Derechos Humanos

Tabla 114. Antecedentes conceptuales de la opinión del exilio 297

Tabla 115. Tema específico más aludido para la categoría opinión del exilio 297

Tabla 116. Resumen de antecedentes demográficos de sexo, edad, estado civil y lugar de residencia 298

Tabla 117. Resumen de antecedentes demográficos de ocupación 298

Tabla 118. Resumen de antecedentes demográficos de prisión 299

Tabla 119. Resumen de antecedentes demográficos de tortura 299

Tabla 120. Resumen de antecedentes demográficos de experiencia de exilio 299

Tabla 121. Resumen de antecedentes demográficos de familia actual 299

Tabla 122. Resumen de antecedentes demográficos de salud, ocio e uniformados 300

Tabla 123. Resumen de aspectos asociados a las necesidades emocionales 300

Tabla 124. Resumen de otros aspectos asociados a las necesidades emocionales 300

Tabla 125. Resumen de aspectos asociados a las necesidades sociales 300

Tabla 126. Resumen de aspectos asociados a las necesidades mentales y culturales 301 
Tabla 127. Resumen de aspectos asociados a la valoración personal 301

Tabla 128. Resumen de antecedentes de prisión 302

Tabla 129. Resumen de valoración de aspectos de reparación gubernamental 302

Tabla 130. Frecuencias obtenidos del análisis sintáctico de palabras específicas 304

Tabla 131. Frecuencias obtenidas por la intersección de palabras específicas 305

Tabla 132. Resultados de sujetos que afirmaron haber sufrido tortura sexual en prisión 306

Tabla 133. Prueba $\chi^{2}$ de Pearson para las variables"sexo" y "tortura sexual" 307

Tabla 134. Medidas de asociación simétricas para las variables "sexo" y "tortura sexual" 307

Tabla 135. Resultados para pregunta 3 ........................................................................................................................ 308

Tabla 136. Resultados para pregunta 4 ........................................................................................................... 309

Tabla 137. Resultados para pregunta 5 ............................................................................................................ 310

Tabla 138. Resultados para pregunta 6 ........................................................................................................ 311

Tabla 139. Resultados para pregunta 7 ................................................................................................................. 311

Tabla 140. Resultados para la respuesta 9 .................................................................................................................. 313

Tabla 141. Resultados para la respuesta 10 .................................................................................................. 314

Tabla 142. Resultados para la pregunta 11 ........................................................................................................ 315

Tabla 143. Resultados para la pregunta 12 ………………............................................................................... 316

Tabla 144. Resultados para la pregunta 13 .................................................................................................... 317

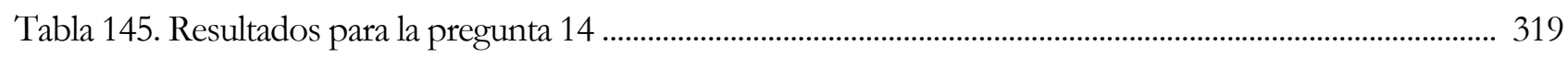

Tabla 146. Resultados para la respuesta 15 .......................................................................................................... 321

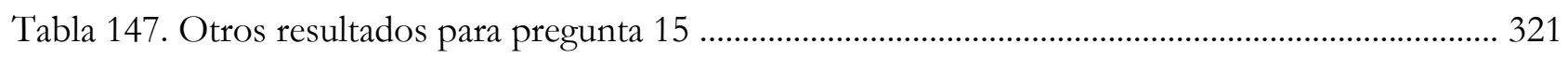

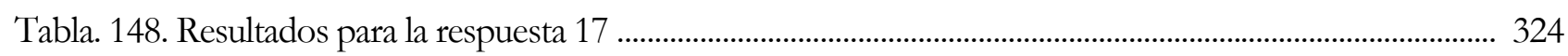

Tabla 149. Resultados para la respuesta 19 ................................................................................................... 326

Tabla 150. Resultados para la respuesta 21 ............................................................................................................. 328

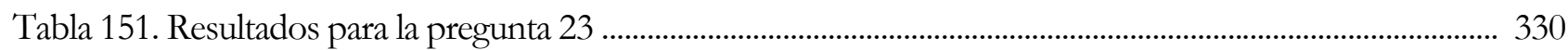

Tabla 152. Prueba de $\chi^{2}$ cuadrado para las variables 9 y 11 que presentan diferencias de género ....... 333

Tabla 153. Contingencia para la variable sexo y la variable 9 .................................................................. 333

Tabla 154. Contingencia para la variable sexo y la variable 11 ................................................................. 333

Tabla 155. Prueba de $\chi^{2}$ cuadrado para las variables que presentan diferencias por edad para

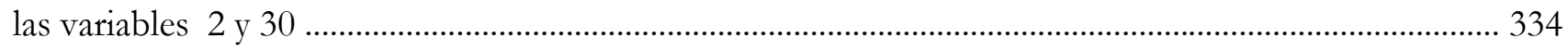

Tabla 156. Contingencia para la variable edad y la variable 2 …............................................................. 334

Tabla 157. Contingencia para la variable edad y la variable 30 ................................................................ 335

Tabla 158. Prueba de $\chi^{2}$ cuadrado para las variables que presentan diferencias por zona

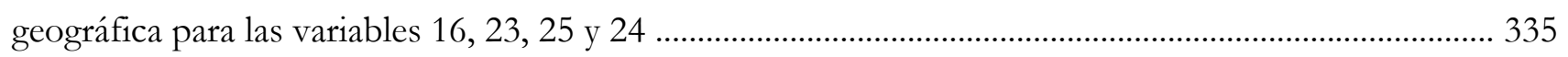

Tabla 159. Contingencia para la variable zona geográfica y la variable 16 .............................................. 335 
Tabla 160. Contingencia para la variable zona geográfica y la variable 23

Tabla 161. Contingencia para la variable zona geográfica y la variable 25

Tabla 162. Contingencia para la variable zona geográfica y la variable 30 337

Tabla 163. Casos por variables para análisis de conglomerados jerárquicos 338

Tabla 164. Variables para análisis de conglomerados jerárquicos 340

\section{LISTAS DE FIGURAS}

Figura 1. Esquema del modelo teórico de López (2008) 23

Figura 2. Resultados del test de fiabilidad de categorías de análisis 159

Figura 3. Variables demográficas sexo 164

Figura 4. Variables demográficas edad 164

Figura 5. Variables demográficas lugar de residencia 165

Figura 6. Antecedentes demográficos de sexo, edad y zona geográfica de la muestra 235

Figura 7. Estado civil de los participantes 236

Figura 8. Dendograma 339 


\section{INTRODUCCIÓN}

La violencia y la tortura por motivos políticos son hechos que desafortunadamente se han ejercido en el mundo entero durante siglos. Experiencias de este tipo, además de transgredir derechos humanos básicos y fundamentales como el derecho a la vida y a la libertad, producen una quiebra total en las vidas de sus víctimas directas, que afecta además a sociedades enteras que han presenciado estos sucesos.

El tema de la violencia política y de la tortura generalmente no es ajeno a ninguna persona, y durante años ha generado interés en distintos sectores políticos y sociales de todo el mundo. En la actualidad, sus prácticas son prohibidas por la legislatura internacional y nacional a nivel mundial, pero lamentablemente todavía se siguen presentando en algunos países.

En el ámbito científico, destacan los estudios en derecho penal e internacional y principalmente derechos humanos, que estudian leyes asociadas a estas prácticas y problemas pendientes como la impunidad y la reparación. En el área de la salud, las tendencias en investigación a población superviviente a experiencias de violencia política y tortura, se centran en el estudio de las secuelas físicas y neurológicas de la tortura, y el síndrome de estrés post-traumático.

En cuanto a las poblaciones de supervivientes más estudiadas, predominan las víctimas del Holocausto y de refugiados políticos en países europeos, y en general, los temas investigados en los países donde han ocurrido hechos de violencia política y tortura, suelen ser sensibles al tiempo en que estos hechos sucedieron. Así, hemos constatado para el caso de Israel, el predominio de estudios orientados al impacto de experiencias de violencia política y tortura en la descendencia de sus víctimas directas, a diferencia de países latinoamericanos que han estudiado a los supervivientes a estas experiencias en el período post-prisión inmediato a la liberación.

Consideramos que para el caso de Chile, en que el régimen militar gobernó hasta el año 1990, no han transcurrido muchos años desde que sucedieron los hechos, y una gran parte de la población superviviente aún está viva y sigue afectada, pero no disponemos de evidencia científica que revele las problemáticas actuales de estas personas.

Por su parte, en noviembre del año 2004 ocurre en Chile un hecho sin precedentes en el mundo entero: el Gobierno de Chile hace un primer reconocimiento a las víctimas supervivientes chilenas, que fueron privadas de su libertad por motivos políticos, entre septiembre de 1973 y diciembre de 1990. 
Con ello, se da a conocer a este país, mediante el Informe de la Comisión Nacional sobre Prisión Política y Tortura, conocido popularmente como Informe Valech (Gobierno de Chile, 2004), un listado de más de treinta mil personas que fueron clasificadas por un equipo multidisciplinario de profesionales, y del cual extrajimos a los participantes de nuestro estudio. No hay trabajos científicos realizados a victimas chilenas con esta parte de la población chilena reconocida gubernamentalmente.

Hemos elegido el modelo teórico de López (2008), para estudiar a un grupo de víctimas de experiencias de prisión y tortura por motivos políticos, por la universalidad de sus postulados, que hacen que el modelo en cuestión, sea de gran utilidad para conocer los problemas actuales de estas personas en relación a la satisfacción de sus necesidades interpersonales básicas. Por este motivo, nuestro interés se ha centrado en conocer y describir aquellos aspectos emocionales y sociales de los vínculos de apego, la red social y las relaciones de pareja que presenta un grupo de EXPPS chilenos, y su relación con la experiencia de la prisión y la tortura por motivos políticos.

La importancia de factores contextuales históricos que incluyen el momento en que ocurrieron los hechos, los actores implicados, el tipo de violencia política y tortura padecida, factores culturales posteriores y actuales, los regímenes políticos, la respuesta social y la reparación, son aspectos que desde el enfoque teórico de nuestro estudio, tienen gran relevancia en el entendimiento del impacto de las experiencias de prisión y tortura por causas políticas en las vidas de sus supervivientes.

La inexistencia en Chile del estudio de las secuelas a largo plazo en esta población y los objetivos que planteamos en nuestra investigación, hizo que formuláramos un diseño metodológico exploratorio de tipo ex-post-facto en base a metodología cualitativa de análisis de contenido. Para el tratamiento de los datos, empleamos el programa informático Nud*ist 4 y QSR Nvivo 6, y para algunas aplicaciones el programa SPSS en su versión No 15.

El objetivo principal del estudio, fue conocer y describir los efectos emocionales, afectivos y sociales a largo plazo de experiencias de prisión y tortura por motivos políticos, ocurridas en Chile entre 1973 y 1990, sobre la satisfacción de las necesidades interpersonales básicas con los vínculos de apego, la red social y las relaciones de pareja en un grupo de supervivientes chilenos.

Para conseguir nuestros objetivos, comparamos la valoración que los participantes hicieron de sus relaciones interpersonales previas a la experiencia de prisión y en la actualidad, y sus problemáticas actuales en torno a temas asociados a la experiencia de prisión, como la reparación y la percepción de la respuesta social chilena ante el tema de violación de derechos humanos en Chile. 
Para conocer el impacto emocional y social de la privación de libertad y tortura por motivos políticos en un grupo de chilenos supervivientes a estas experiencias, desarrollamos un estudio cualitativo que incluyó la administración de una entrevista en profundidad que creamos a partir de la teoría de las necesidades interpersonales básicas planteada por López y hallazgos científicos de secuelas psicológicas a largo plazo en población superviviente a estas experiencias.

Entrevistamos a un grupo de 60 ex - presos políticos (EXPPS) chilenos residentes en distintas ciudades de Chile, e indagamos temas asociados a la satisfacción de sus necesidades interpersonales emocionales y sociales desde una perspectiva histórica, además del impacto percibido de la experiencia de prisión y tortura en sus vidas, y la valoración en torno a sus problemáticas actuales, que incluyen los temas de reparación y justicia.

Los hallazgos de nuestra investigación nos permiten conocer el impacto a más de tres décadas de ocurridos los hechos de prisión política y tortura en un grupo de supervivientes chilenos, y establecer relaciones entre factores demográficos de la experiencia de prisión y la satisfacción de necesidades emocionales y sociales de las víctimas.

Creemos que este estudio aporta información acerca de aspectos emocionales y sociales de un grupo de chilenos supervivientes a la prisión y la tortura por motivos políticos, que puede ser de utilidad en la atención clínica de estas personas y favorecer el entendimiento de las problemáticas que presentan en la actualidad.

Esperamos además, que los hallazgos de este estudio validen a un grupo de personas que han tendido a vivir en silencio los efectos psicológicos de la prisión política y tortura en sus vidas. Esperamos que este trabajo contribuya a su comprensión y reconocimiento.

La parte teórica de esta investigación doctoral está organizada en tres capítulos. El primero de ellos, se centra en los conceptos y teorías de las necesidades interpersonales que hemos considerado imprescindibles para entender el impacto emocional y social que estudiamos. Comprende la revisión bibliográfica de la teoría de la soledad social y emocional de Weiss, la teoría de las necesidades humanas de Doyal y Gaugh, y la teoría de las necesidades interpersonales básicas de López.

El segundo capítulo, se formuló en base a la revisión bibliográfica que hicimos de la literatura científica relacionada al estudio de supervivientes a experiencias de prisión y tortura políticas de distintos países. Con esto, intentamos aproximarnos al impacto emocional y social de la experiencia de 
prisión en sus supervivientes chilenos, a partir de la aplicabilidad de estos hallazgos al grupo de personas que estudiamos, pese a las diferencias contextuales y culturales que encontramos en los distintos grupos de personas estudiadas. La revisión teórica que realizamos en este capítulo y que nos permitió conocer aspectos del impacto de la experiencia de prisión y tortura que presentan personas de distintos países, nos aportó información relevante acerca de las secuelas psicológicas que presentan estas personas a largo plazo.

En el tercer capítulo, describimos el escenario social y político de Chile desde el año 1973 al año 1990, y aspectos sociopolíticos relacionados que se presentaron con posterioridad a este período hasta los años 2005 y 2006. En este capítulo hicimos una revisión a la bibliografía latinoamericana elaborada principalmente por agrupaciones de derechos humanos y profesionales del área de salud mental, que desarrollaron documentos e investigaciones en base al trabajo de atención a supervivientes de experiencias de prisión y tortura en el tiempo posterior a su liberación. En este capítulo, incluimos además un apartado dedicado al Informe Gubernamental sobre Prisión Política y Tortura, en el cual detallaremos el proceso de reconocimiento de las víctimas, los períodos de represión política durante el régimen militar, las técnicas de tortura empleadas y las consecuencias de la prisión y tortura reconocidas por el gobierno de Chile en este informe.

La parte empírica de esta tesis, ha sido desarrollada en el capítulo cuarto, en el cual presentamos el diseño, la justificación y el planteamiento metodológicos de nuestro estudio; describimos los pasos que seguimos para la obtención y el tratamiento que realizamos a los datos; presentamos la fiabilidad y validez de nuestras categorías de análisis; y exponemos la definición de todas las categorías que fueron estudiadas.

En el capítulo quinto, presentamos los principales resultados a nivel inter-sujeto y desarrollamos las interrogantes de investigación que nos planteamos en el capítulo precedente, empleando funciones específicas de los programas informáticos que nos permitieron establecer relaciones entre variables y contrastar nuestras hipótesis de investigación.

En el capítulo sexto, exponemos la discusión de los hallazgos encontrados con la metodología empleada y la aplicabilidad del modelo teórico al estudio del impacto emocional y social de la experiencia de prisión política y tortura en sus supervivientes chilenos. Las principales omisiones y alusiones, nos revelaron información importante acerca de los objetivos de nuestra investigación, así como la agrupación de variables específicas contrastadas estadísticamente. 
En el último capítulo, presentamos las conclusiones de nuestra investigación.

Finalmente, hemos incluido una sección de apéndices que incluyen el instrumento cualitativo que elaboramos y un ejemplo de transcripción de entrevista, el mapa conceptual, el test de fiabilidad que administramos a jueces expertos para la validación de nuestras categorías de análisis, y algunas reflexiones que realizamos durante el trabajo de campo. 
CAPÍTULO I.

CONCEPTOS Y TEORÍAS DE REFERENCIA: TEORÍAS SOBRE LAS NECESIDADES EMOCIONALES, AFECTIVAS Y SOCIALES. 
Privación de libertad y tortura política en Chile (1973-1990) 
En este primer capítulo estudiaremos algunas de las teorías de las necesidades humanas que seleccionamos como canales para explicar el impacto emocional y social de la privación de libertad y tortura por motivos políticos, en una muestra de supervivientes chilenos. Creemos que los modelos teóricos que hemos escogido, nos proporcionarán una visión amplia del ser humano, sus necesidades y su bienestar psicológico. Excluimos otras teorías de las necesidades humanas como la de Maslow, Max-Neef, Elizalde y Hopenhayn y Schultz, entre otros, aunque las consideramos importantes, porque ya han sido revisadas por otros autores (e.g. Carcedo, 2005).

A continuación describiremos los principales postulados de tres modelos teóricos, que desarrollaremos en una secuencia que finalizará con la descripción del modelo teórico central de esta tesis doctoral: la teoría de las necesidades interpersonales básicas de López (2008).

\subsection{TEORÍA DE LA SOLEDAD SOCIAL Y EMOCIONAL DE WEISS, COMO MARCO DE REFERENCIA GENERAL}

\subsubsection{Definición y tipología de la soledad}

Weiss (1973) estudia los vínculos afectivos especialmente el apego y la amistad, y propone una tipología de soledad muy útil para nuestro estudio. En efecto, afirma que la soledad es multidimensional y debe entenderse como un fenómeno multifacético que considera las distintas tipologías que la conforman.

La soledad para Weiss, es la experiencia de estar físicamente solo y aislado, en un entorno social nuevo, sentirse diferente entre otros, en que la carencia de vínculos afectivos es el factor más decisivo e importante en el desencadenamiento de la experiencia de soledad (Weiss, 1973).

El modelo de soledad planteado por Weiss propone una tipología de soledades específicas, que distingue la soledad por aislamiento social (soledad social), de la soledad emocional. La primera de ellas, se presenta en personas que no tienen una adecuada red social, y puede ser subsanada mediante el acceso a redes sociales satisfactorias. La segunda en cambio, se experimenta por la ausencia de relaciones con figuras de apego emocionalmente cercanas, y podrá remediarse con la obtención de relaciones de apego satisfactorias o la reparación de una relación previamente perdida. Este tipo de soledad a su vez, se compone de dos dimensiones: la soledad romántica y la soledad familiar (Weiss, 1973). 
La tipología de la soledad planteada por Weiss (1973) que entiende la soledad como estados diferentes, ha sido apoyada por estudios en población adulta (Rubenstein y Shaver, 1982; Russell, Cutrona, Rose y Yurko, 1984).

Russell et al. (1984), encontraron que la soledad emocional y social estaban asociadas a diferentes experiencias subjetivas, así como a diferentes antecedentes de estrategias de conducta. DíTommaso y Spinner (1993), afirman que las dos formas de soledad planteadas por Weiss (1973), conllevan diferentes estados de sentimiento asociados a ellas, con sus consecuentes diferencias conductuales.

Weiss (1982) plantea que la soledad correlaciona con la introversión, el pasar tiempo en solitario, el descuido de sucesos que se relacionan con la soledad y la aflicción que se pueda experimentar por una pareja sentimental. Relacionado a estos factores, Weiss (1973) sostiene que la soledad no es causada por el hecho en sí de estar solo, sino por no disponer de una relación que se necesita y define un conjunto de relaciones. La soledad aparecerá siempre como una respuesta a la ausencia de algún tipo particular de relación, o específicamente como la ausencia de algunas provisiones de relaciones particulares.

Weiss $(1973,1974)$ identificó seis provisiones sociales: la integración social, las alianzas de confianza, el apego, el consejo, la reafirmación de la valía personal y la oportunidad de ser cuidado. El autor sostiene que en una relación interpersonal se debe satisfacer inherentemente un conjunto de necesidades sociales para que el individuo no experimente soledad.

Russell (1982), basándose en el modelo de soledad de Weiss, plantea que la soledad concierne la forma en que las personas perciben, experimentan y evalúan su aislamiento y la falta de comunicación con otros.

\subsubsection{Manifestaciones de la soledad}

De las manifestaciones de los distintos tipos de soledad planteados por Weiss (1982), las personas que presentan soledad emocional, tienen sentimientos de soledad total y perciben al mundo como desolador, aburrido o deficiente en relación a otros. Esta experiencia puede también ser vivida como un mundo interno vacío, y sensaciones de vacío o muerte.

La soledad por aislamiento social en cambio, refiere la ausencia de una red social atractiva, y sólo puede ser remediada por el acceso a este tipo de redes. Los síntomas predominantes son el sentimiento de aburrimiento, la ausencia de metas y de sentido de vida, sentimientos de marginación y el deseo de búsqueda de compañía de otros (Weiss, 1973). 
Weiss (1973), postula que la persona que padece soledad presenta dos manifestaciones: una de tipo afectiva sentida como dolor, y otra de tipo motivacional que le impulsa a encontrar a otros. A nivel cognitivo, el autor plantea que las personas que están solas, permanecen constantemente en estado de alerta en sus relaciones interpersonales. Lo que les permite evaluar el potencial de los otros para satisfacer la necesidad de relación no resuelta, atendiendo en las diferentes situaciones sociales al potencial de los otros para satisfacer esta necesidad. El autor sostiene además, que la soledad produce una hipersensibilidad al mínimo indicador y la tendencia a malinterpretar o exagerar la hostilidad o el intento de cariño de otros.

\subsubsection{Causas de la soledad}

Weiss (1973), plantea que la experiencia de soledad se atribuye a características de personalidad, pero también a factores relacionados a situaciones específicas de la vida de una persona. Refiere con ello, la existencia de factores situacionales y caracterológicos que interactúan entre sí, fomentando la soledad.

En este sentido, Weiss (1973), desarrolló dos líneas de investigación en base a estos factores. Una de ellas, considera la situación en que se presenta la experiencia de soledad, como por ejemplo situaciones de vida específicas de divorcio y viudez, y situaciones sociales como hospitalizaciones individuales y cambios de vecindad. La otra línea de investigación, considera características de personalidad como la introversión, la timidez y la baja autoestima, que inciden también en la presencia de soledad.

\subsubsection{Epidemiología de la soledad}

A nivel epidemiológico, Weiss (1982) sostiene que es más probable que las personas solteras manifiesten mayor grado de soledad que las personas casadas, cuya probabilidad aumenta cuando han estado casadas en el pasado. El autor sostiene además que es determinante la ausencia de una figura de apego en la manifestación de la soledad. Por otra parte, estudios de género revelan diferencias significativas entre hombres y mujeres, siendo estas últimas, quienes presentan más soledad que los hombres. En cuanto a la etapa del desarrollo, la soledad es más frecuente y posiblemente más intensa en la adolescencia que en períodos posteriores de vida.

A lo recientemente expuesto, se añade que personas mayores viudas y divorciadas, tienden menos a considerarse a sí mismas como solas, que viudos y divorciados en edades más jóvenes (Maisel citado en Weiss, 1973; Rubenstein y Shaver, 1982). 
Estudios realizados por Weiss (1982) a personas divorciadas, concluyeron que la soledad conduce a estas personas a buscar algo más que compañía o un compañero sexual, y dejará de vivenciarse cuando estas personas dispongan de una relación en la que tengan confianza de su continuidad y se base en algo verdadero. Las personas solas buscarán a menudo primero a alguien con quien pasar el tiempo, pero muchas de estas personas aprenderán que las relaciones transitorias pueden aumentar el grado de soledad.

Una función de la soledad en quienes la vivencian, está en que promueve un estado constante de alerta a relaciones en las cuales puede darse un compromiso mutuo (Weiss, 1982).

El modelo de Weiss (1973, 1974), visto desde las necesidades humanas, sostiene que el grado de salud de cada persona dependerá de la satisfacción de diferentes necesidades que podrán ser resueltas mediante la interacción social.

\subsubsection{Aplicabilidad del modelo a la muestra}

Nosotros esperamos encontrar en los supervivientes a experiencias de prisión política y tortura, y producto de experiencias de este tipo, un elevado nivel de soledad social y emocional. Esto en base al contexto en que sucedieron los hechos de represión política que creemos produjo temor y desconfianza en la sociedad chilena en general hacia los demás.

Los hechos que acontecieron el 11 de septiembre de 1973 en Chile, recordados mundialmente por el bombardeo a la Moneda y muerte de quien fuera en aquel entonces el ex - pdte. Salvador Allende, generó un temor social que se vio reflejado en un rechazo y desconfianza por parte de los chilenos a expresarse políticamente. Esto, por la posibilidad de verse afectados por represalias propias del sistema político militar. Nosotros creemos que este aspecto afectó en la forma de los chilenos de relacionarse a nivel interpersonal, y especialmente a los EXPPS.

Este cambio en las relaciones interpersonales de los chilenos y especialmente en las relaciones de los EXPPS, creemos que fue propiciado por la incertidumbre que generaba el desconocimiento y la dificultad a la hora de diferenciar la opción política entre chilenos. Pues en el caso de Chile, los opositores pertenecían al mismo país, y cualquier persona podía ser enemigo. De acuerdo a esto, la prisión era un riesgo vital inminente y constante, que podía ser inducido por cualquier persona.

Sumado a lo anterior, creemos que para quienes militaban en partidos de izquierda del país durante el régimen militar, el hecho de verse limitados en expresarse libremente en el ámbito político, produjo cambios 
en sus relaciones interpersonales, existiendo con ello mayor propensión a la soledad social. Al respecto, y a modo de anécdota, suele decirse en Chile que en reuniones sociales no se debe hablar de fútbol, religión y política, pues este tipo de intercambios suelen tener un mal final.

Nosotros esperamos que los EXPPS presenten un bajo nivel de implicancia en sus relaciones interpersonales y consecuentemente soledad social. Lo que creemos podrá contrastarse mediante la técnica de evaluación cualitativa que emplearemos en este estudio.

Creemos además, que experimentar hechos de violencia por motivos políticos y tortura, produjo variaciones en la valoración que los EXPPS hacen de los seres humanos de manera negativa. Esto consecuentemente pudo haber generado en ellos soledad social por ausencia de interés a la hora de relacionarse socialmente. Por otro lado, pensamos que este desinterés podría deberse además a las construcciones sociales de los EXPPS, que se sienten abandonados y perciben a la sociedad chilena como desinteresada en el tema de los derechos humanos.

No obstante lo anterior, podríamos pensar que quienes están actualmente inscritos en partidos políticos o en agrupaciones de derechos humanos, no presentan este tipo de soledad, pues encontrarían en su grupo de pares, apoyo a su experiencia de prisión y un espacio para el intercambio y sustento de la ideología política de cada uno de ellos.

En relación a la soledad emocional que esperamos encontrar en los EXPPS, podríamos pensar que ésta fue provocada por los hechos de violencia vividos en prisión, el silencio social y político que ha caracterizado a Chile desde 1973, y reacciones individuales esperables como la vergüenza y el deseo de olvidar la experiencia.

Nosotros mediante la entrevista en profundidad que hemos elaborado, indagaremos las relaciones interpersonales actuales y del pasado previo a la experiencia de prisión, a la vez que el impacto percibido por cada EXPP de la propia experiencia en sus vidas, en su posible soledad emocional y social, por lo que consideramos la teoría e investigaciones de Weiss una referencia muy útil. 


\subsection{TEORÍAS DE LAS NECESIDADES HUMANAS DE DOYAL Y GOUGH}

Doyal y Gough (1992/1994) desarrollaron una propuesta de las necesidades humanas que además de entender este tipo de necesidades desde una perspectiva particular que incluye elementos políticos, sociales y de derechos humanos, coincide en buena parte con el modelo teórico de las necesidades interpersonales básicas planteado por López (1995a, 1995b, 2008), eje central de nuestra investigación.

A continuación presentaremos algunos de los postulados esenciales de este modelo teórico, y su relación con los objetivos de nuestra investigación.

\subsubsection{Bases epistemológicas del modelo}

El modelo teórico de las necesidades humanas de Doyal y Gaugh (1992/1994), parte de una crítica a diferentes posturas teóricas existentes de este tipo de necesidades, y aunque surge de la confluencia de distintas teorías, les considera incompatibles con las necesidades básicas entendidas como objetivo de desarrollo de los seres humanos. Surge así, una postura relativista propia de enfoques constructivistas, contextuales y culturales (Ochaita y Espinoza, 2004).

\subsubsection{Definición de ser humano y las necesidades humanas básicas}

El modelo en estudio, considera al ser humano como un ente activo y con propósitos, con capacidad para iniciar acciones con objetivos y estrategias en función de intereses determinados. Es decir, un ser para el que la autonomía comprende una necesidad humana básica.

El modelo de Doyal y Gaugh reconoce la naturaleza mamífera animal de los seres humanos, no negando el trasfondo biológico de las necesidades humanas, y con ello las similitudes que tenemos con otras especies animales como la necesidad de alimentos o calor. Sin embargo, reconoce aquellas capacidades que nos diferencian de estas especies, como el intelecto, además de la prolongada dependencia que nos caracteriza como especie y que se presenta desde la infancia. Para los autores, son precisamente estas diferencias, las que hacen que nuestras capacidades intelectuales y afectivas configuren otras necesidades, como la de mantener relaciones con otros.

Las necesidades planteadas en este apartado, aluden al concepto de salud por ausencia de enfermedad. En el caso de los EXPPS chilenos, existe evidencia epidemiológica de altos índices de enfermedades 
provocadas durante el período de prisión y en los años posteriores ${ }^{1}$, que sin duda limitaron el desarrollo de un nivel de autonomía óptimo y afectaron negativamente en la calidad de vida de estas personas, y con ello en la satisfacción de las necesidades humanas básicas que nos ocupan en este apartado. Esto pudo verse reflejado en una participación limitada o inadecuada de estas personas en la sociedad.

Suponemos además que para los EXPPS que permanecieron viviendo durante años bajo el mismo gobierno que les privó de su libertad, la vida después de la prisión gira en torno a la subsistencia. Lo que impide la evolución de capacidades intelectuales y afectivas.

\subsubsection{Las necesidades planteadas por Doyal y Gaugh}

Las necesidades planteadas por Doyal y Gaugh son conceptualizadas como estrategias y objetivos universales. Para su entendimiento, los autores diferencian entre necesidades y aspiraciones o deseos. En efecto, señalan la importancia de diferenciar entre las necesidades básicas de aquellas que no lo son, y entre las necesidades y los deseos. Incluyen el concepto de mediación para referirse a que en el trasfondo de un objetivo, siempre debe haber otro. Lo que adquiere relevancia si consideramos que se puede obtener la razón por la que el objetivo se identifica con la necesidad y con ello se crea la justificación para su obtención con el fin de evitar un daño. Estas razones son en esencia de conocimiento público, ya que refieren un conocimiento compartido acerca del tipo de estrategia necesaria para evitar el daño. De igual forma, las aspiraciones o deseos son de conocimiento público, pero las personas pueden estar o no de acuerdo con las razones subyacentes (Ochaita y Espinoza, 2004).

Nosotros pensamos que los EXPPS han sobrevivido a experiencias de prisión política y tortura mediante una elevada capacidad de resiliencia. Suponemos que sus aspiraciones y deseos se relacionan con sus ideales políticos y han sido impactados por la experiencia de prisión. Creemos además, que tanto sus deseos como aspiraciones dependerán de su experiencia del mundo que estará marcada por la historia política en sus vidas.

\subsubsection{Necesidades de salud física y autonomía}

La insatisfacción de las necesidades humanas planteadas por Doyal y Gaugh (1992/2004), producirá un grave perjuicio en contra de la integración de las personas en su grupo social. Son necesidades básicas la salud física y autonomía, y los autores afirman que éstas deben ser cubiertas en todos los seres humanos con independencia de la cultura y las diferencias individuales, lo que permitirá una participación social activa.

\footnotetext{
${ }^{1}$ Datos presentados por el Ministerio de Salud del Gobierno de Chile mediante el PRAIS.
} 
En relación a la necesidad de autonomía, Doyal y Gaugh plantean tres aspectos que afectan a esta necesidad. Estos son el grado de comprensión que tienen las personas de sí, el bagaje cultural que poseen y lo que esperan como individuo dentro de ellos mismos, que permiten que una persona se desarrolle con autonomía.

El segundo aspecto, es la capacidad psicológica que tienen las personas para formular opciones para sí mismas, siendo esto indispensable para la autonomía dentro de cualquier grupo social; y el tercer aspecto, se asocia a todas aquellas oportunidades objetivas que la sociedad ofrece de acciones nuevas y significativas para que puedan actuar en consecuencia. Esto último, se asocia a la justicia y diversas prácticas en el ámbito político compatibles con un sistema que reparta con equidad los bienes, o que por lo menos disponga de otros sistemas que den garantía a todas las personas para la satisfacción de todas sus necesidades básicas, permitiendo la participación a todo nivel político (Ochaita y Espinoza, 2004).

Doyal y Gaugh (1992/1994), plantean la existencia de dos tipos de autonomía: de libertad de agencia y de libertad política. La primera de ellas es la más básica de las dos, e implica los niveles de comprensión, salud y oportunidades de participación a nivel político. Las que llevadas al contexto político de regímenes totalitarios, podrían darse a pesar que cada persona no tenga la posibilidad de participar de las decisiones políticas que les afectan.

Existe además un nivel más elevado de autonomía, que los autores denominan autonomía crítica, y que implica los niveles más elevados que puedan alcanzarse de desarrollo moral y libertad política. Este tipo de autonomía tiene relación con la oportunidad de las personas para cuestionar y participar en el ámbito política, aceptando o transformando las normas de la cultura, propio de regímenes democráticos. Para que este tipo de autonomía pueda darse, Doyal y Gaugh (1992/1994) afirman que las personas deben disponer de oportunidades para expresar sus libertades de agencia y política. De ocurrir lo contrario, y con independencia de los niveles cognitivos y emocionales de cada individuo, se provocarían discapacidades.

Doyal y Gaugh (1992/1994) proponen también la idea de igualdad material en la satisfacción de necesidades básicas, que implica disponer de la garantía de satisfacción de necesidades materiales, educativas y emocionales. Imprescindibles para conseguir autonomía y salud.

La Tabla 1, plantea de manera negativa las necesidades de Doyal y Gaugh, en que la autonomía se corresponde a la reducción al mínimo de la discapacidad, enfermedad, muerte y desórdenes mentales en el caso de la salud. Los indicadores de la tabla marcados con un asterisco, pueden obtenerse en casi todos los 
países. No ocurre lo mismo con aquellos marcados con doble asterisco, que no están disponibles siempre y sólo se usan en países que tienen claras ideas de cómo emplearlos.

Tabla 1. Necesidades humanas planteadas por Doyal y Gaugh ${ }^{2}$

\begin{tabular}{|c|c|c|}
\hline & $\begin{array}{l}\text { COMPONENTES } \\
\text { (POSITIVOS O } \\
\text { NEGATIVOS) } \\
\end{array}$ & INDICADORES SUGERIDOS \\
\hline \multirow{2}{*}{ Salud física } & $\begin{array}{l}\text { Posibilidad de } \\
\text { supervivencia }\end{array}$ & $\begin{array}{l}\text { - Esperanza de vida a varias edades*, } \\
\text { - Tasa de mortalidad por edades específicas, especialmente infantil } \\
\text { y por debajo de los } 5 \text { años*. }\end{array}$ \\
\hline & Mala salud física & $\begin{array}{l}\text { - Incidencia de discapacitaciones y desglose según gravedad**. } \\
\text { - Incidencia de desarrollo infantil insuficiente y desglose según } \\
\text { gravedad** } \\
\text { - } \quad \text { Porcentaje de personas que sufren dolencias graves** } \\
\text { - Tasas de morbilidad por varias clases de enfermedades** }\end{array}$ \\
\hline \multirow{3}{*}{ Autonomía } & Mala salud mental & $\begin{array}{l}\text { - Incidencia de trastornos psíquicos, depresivos y otros pro- } \\
\text { blemas**. }\end{array}$ \\
\hline & Privación cognitiva & 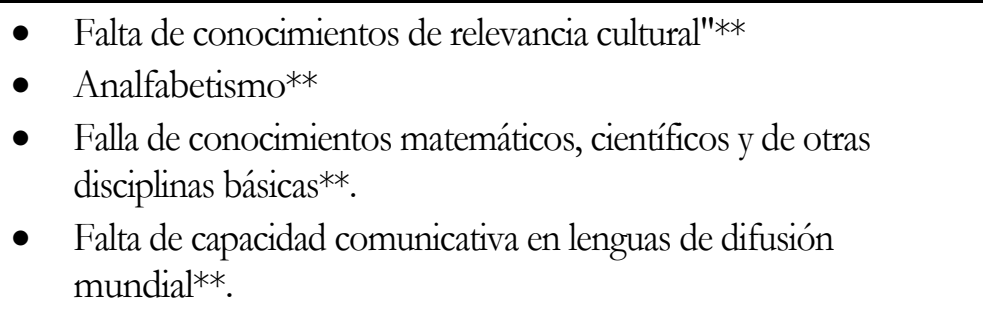 \\
\hline & $\begin{array}{c}\text { Posibilidades de } \\
\text { actividad económica }\end{array}$ & $\begin{array}{l}\text { - Desempleo y otras evaluaciones de la marginación de tareas sociales } \\
\text { significativas**. } \\
\text { - Falta de «tiempo libre», una vez realizadas las actividades } \\
\text { productivas y' reproductivas**. }\end{array}$ \\
\hline
\end{tabular}

${ }^{2}$ Los datos de la tabla 1., corresponden a la adaptación de Doyal y Gaugh (1992, pp. 240-241) de la edición castellana. 
1.2.1.4. Satisfacción de necesidades básicas y necesidades intermedias

El modelo que estudiamos en este apartado, postula la existencia de satisfactores universales o necesidades intermedias, definidos como cualidades de bienes, servicios, actividades y relaciones que favorecen la salud física, y la autonomía humana en las diferentes culturas existentes. Todas las que permiten relacionar las necesidades básicas universales y los satisfactores relacionados a lo social.

La universalidad que caracteriza a estas necesidades humanas, las concibe como objetivos que pueden actuar como medio, a la vez que comprender diferentes factores específicos. Por esto, Doyal y Gaugh (1992/1994) refieren las características de los satisfactores universales como necesidades intermedias o de segundo orden, que son una base segura para el establecimiento de una serie de objetivos que derivan de ellas, considerados de segundo orden y son necesarios para tener salud y autonomía.

Los dos niveles de necesidades propuestos por Doyal y Gaugh (1992/1994), sólo pueden conseguirse si se dan determinadas condiciones sociales. Igualmente proponen los autores una serie de indicadores para valorar el grado de bienestar de las diferentes sociedades.

Las necesidades intermedias a las que hemos hecho referencia, son universalmente necesarias para satisfacer las necesidades básicas. Los primeros cinco satisfactores, corresponden a satisfactores de la necesidad de salud física, y los seis siguientes, a satisfactores de la autonomía. Estos son:

1. Alimentos nutritivos y agua limpia.

2. Alojamientos adecuados a la protección.

3. Ambiente laboral desprovisto de riesgos.

4. Medio físico desprovisto de riesgos.

5. Atención sanitaria apropiada.

6. Seguridad de la infancia.

7. Relaciones primarias significativas.

8. Seguridad física.

9. Seguridad económica.

10. Enseñanza adecuada.

11. Seguridad en el control de nacimientos y el embarazo y parto.

1.2.1.5. Indicadores para la satisfacción de las necesidades básicas

Parece una tarea difícil establecer indicadores para la satisfacción de necesidades básicas universales, si consideramos la diversidad cultural presente en el mundo. Surgen en esta labor, tres problemas que comprenden encontrar patrones normativos, establecer mediciones y quién o quiénes son las personas indicadas para decidir acerca de las necesidades básicas y sus prioridades de satisfacción. Al respecto, Doyal y 
Gaugh (1992/1994) plantean un enfoque alternativo que difiere de otras formas de evaluar los niveles de satisfacción de necesidades. Ellos se enfocan en buscar un indicador único del desarrollo humano que permita dar cuenta de la satisfacción general de las necesidades humanas, y que denominan "la esperanza media de vida". Que se relaciona a nutrición, sanidad y alfabetización y considera diferencias culturales a la hora de estudiar las necesidades humanas (Ochaita y Espinoza, 2004, p. 106).

Las mediciones realizadas por los autores referentes al tema salud física, se basan en mediciones directas de la supervivencia y la discapacitación, y mediciones transculturales de las dolencias físicas según el modelo biomédico. Por otro lado, en lo referente a la autonomía, la evaluación se centra en la ausencia de enfermedad mental, la privación cognitiva y la participación de actividades sociales significativas.

Además Ochaita y Espinoza diferencian el indicador "falta de capacidad comunicativa en lenguas de difusión mundial", del componente "privación cognitiva" (Doyal y Gaugh, citado en Ochaita y Espinoza, 2004, p. 108), que ellos consideran a un nivel superior de los referentes a la autonomía. Para Doyal y Gaugh la “autonomía crítica” (Doyal y Gaugh, citado en Ochaita y Espinoza, 2004, p. 108), requiere que las personas tengan un conocimiento de otras modalidades de vida y en consecuencia de otras lenguas.

\subsubsection{Necesidades humanas universales vs. relativismo cultural}

Doyal y Gaugh (1992/1994) sostienen que los seres humanos tenemos la necesidad de participación social que sumada a la necesidad de salud física y autonomía, son extensivas a todas las culturas. Para satisfacer estas necesidades, requerimos de capacidades físicas, intelectuales y emocionales. Con ello la salud física y la autonomía, conformarían los criterios para diferenciar entre necesidades y aspiraciones o deseos.

Para Ochaita y Espinoza (2004), medir el progreso de una sociedad en base a los criterios consensuados de salud física y autonomía, refiere ciertas dificultades. Pues se encuentra por un lado el nivel básico de satisfacción de una necesidad y por otro, las diferentes formas de satisfacción de necesidades básicas según la cultura. Al respecto, Doyal y Gaugh (1992/1994) afirman que al momento de comparar, deben considerarse los niveles óptimos de satisfacción de necesidades que son independientes de la cultura; y en relación al segundo problema, que los satisfactores de las necesidades pueden estar determinados culturalmente. 
1.2.2. Necesidades humanas básicas de grupos particulares concretos: El caso de los expresos políticos

Para Doyal y Gaugh (1992/1994), todos los seres humanos independientemente de la raza, el sexo, la clase social y la cultura, somos iguales y tenemos las mismas necesidades. No obstante, los autores reconocen la existencia de grupos particulares específicos que requieren de satisfactores especiales adicionales para satisfacer todas sus necesidades.

En relación a esta última idea, creemos que la experiencia de prisión les otorga un carácter específico a los EXPPS, quienes en la actualidad alzan sus voces en pro de mejoras en las medidas gubernamentales de reparación, lo que nos indicaría la presencia de insatisfacción en sus necesidades.

Por otro lado, la exclusión social que caracteriza a víctimas de hechos de represión política en el mundo, podría influir en estas personas, quienes al percibir sentimientos de rechazo por parte de la sociedad chilena en general, entre otros sentimientos adversos, se verían impedidos para integrarse socialmente a sus realidades sociales. Todo lo que incidiría negativamente en la satisfacción de sus necesidades humanas básicas.

No obstante lo anterior, creemos que los EXPPS han logrado en gran medida integrarse a grupos sociales cuyo denominador común es la experiencia de prisión en sus integrantes o ideologías políticas similares. De presentarse esta integración a grupos selectivos de pares, creemos que podrían gozar de cierto grado de bienestar psicológico.

Suponemos que la experiencia de prisión política afectó de manera global en la vida de los EXPPS, produciendo un severo impacto desde la ocurrencia de la experiencia de prisión que provocó el cese de todo crecimiento personal. No obstante, gracias al factor de resiliencia que creemos está presente en cada EXPP sobreviviente, entendiendo este concepto como la resistencia de algunas personas a los avatares de la vida, la adversidad y la enfermedad (Barudy, 2005), creemos que ellos han podido emplear estrategias que les han permitido sobreponerse al suceso específico de violencia política, viéndose fortalecidos de la experiencia.

Creemos además que cada caso es único, no obstante hemos conseguido el permiso para evaluar a EXPPS que están relacionados de alguna manera a agrupaciones de derechos humanos y partidos políticos, por lo que creemos que todos ellos participan activamente en agrupaciones políticas que a la vez son sociales. Lo que indicaría que en alguna medida se han sobrepuesto a la experiencia en cuestión. A la vez, es fácil pensar que quienes no han resuelto en sus vidas esta experiencia, evitarían participar de una evaluación psicológica. Lamentablemente, no hemos podido acceder a estas personas. 
En cuanto a los tres aspectos que comprenden la necesidad de autonomía propuesta por Doyal y Gaugh, nosotros desconocemos en los EXPPS el grado de comprensión que ellos tienen de sí mismos y que han alcanzado en el transcurso de sus vidas. De igual modo desconocemos la capacidad psicológica que disponen para formular opciones para sí. Pero podríamos aventurarnos a pensar que ellos se sienten excluidos socialmente en Chile, lo que según los postulados de Doyal y Gaugh, dificultaría la satisfacción de esta necesidad. Esto último se fundamenta además en el slogan oficial de las agrupaciones de EXPPS chilenos cuyo lema de trabajo dice "Verdad, justicia y reparación", con lo que podemos inferir que perciben la ausencia de estos tres elementos en sus vidas.

Sumado a lo anterior, durante el régimen militar chileno, los EXPPS que estudiamos en este proyecto se vieron impedidos de participar a nivel político en el propio país, y privados de su derecho a la libertad de expresión en el mismo ámbito. Lo que creemos afectó negativamente en la satisfacción de la necesidad de autonomía planteada por Doyal y Gaugh.

En cuanto al nivel de autonomía crítica, esperamos encontrar que algunos de los EXPPS gocen en la actualidad de libertad política. Suponemos que sobretodo quienes pertenecían a partidos políticos como el partido comunista y el partido socialista de la época (más del 70\% de las personas clasificadas en el Informe Valech militaba en los partidos socialista, comunista y otros de extrema izquierda al momento de la detención $^{3}$ ), presentarán un elevado nivel crítico, manifestado en la insatisfacción ante los sistemas políticos que imperan a nivel mundial en la actualidad. Esto, debido a la naturaleza ideológica que caracteriza a los partidos referidos, que se oponen a la globalización y el sistema capitalista predominante en nuestros tiempos.

\footnotetext{
${ }^{3}$ Fuente: Informe Valech. Capítulo VII. Perfil de las víctimas.
} 


\subsection{TEORÍA DE LAS NECESIDADES INTERPERSONALES BÁSICAS DE LÓPEZ}

En esta sección desarrollaremos aquellas necesidades de la teoría de las necesidades interpersonales básicas de López (2008), con las que estudiaremos el impacto emocional y social de la privación de libertad y tortura por motivos políticos en Chile. Esta teoría es una ampliación de la teoría de Weiss.

Hemos elegido el modelo de López (2008), como marco referencial teórico de nuestro estudio, porque consideramos que el impacto causado por experiencias de privación de libertad y tortura por motivos políticos, afecta a todas las áreas de la vida de sus supervivientes, y creemos que podemos verlo reflejado en aspectos interpersonales y consecuentemente en el grado de bienestar presente de los EXPPS chilenos que estudiamos en esta investigación.

La teoría que plantea López (2008), a diferencia de otras teorías sobre las necesidades humanas, sitúa las necesidades mentales, emocionales, afectivas y sociales en el mismo nivel que aquellas de salud y autonomía. Esto en base a la concepción del ser humano como un ente cultural y filosófico que necesita aprender e interpretar la realidad, y como un ser para el contacto y la vinculación, que necesita vincularse a los demás. Desde esta perspectiva, los vínculos afectivos se corresponden a una necesidad inherente de la especie humana y son tan necesarios para el bienestar del individuo como la satisfacción de sus necesidades fisiológicas.

A continuación presentamos la clasificación de las necesidades interpersonales básicas que López reformuló en 2008.

A.- Necesidades de carácter físico-biológico.

-Ser planificado y nacer en un momento biológico y social adecuado de la madre y del padre.

-Alimentación

-Temperatura.

-Higiene.

-Sueño

-Actividad física: ejercicio y juego.

-Integridad física y protección de riesgos reales.

-Ambiente ecológico saludable.

-Salud.

B.- Necesidades mentales y culturales.

-Estimulación sensorial.

-Exploración física y social.

-Conocimiento de la realidad física y social.

-Adquisición de un sistema de valores y normas.

-Adquisición de saberes escolares y profesionales. 
-Interpretación positiva del mundo, el ser humano y el sentido de la vida.

\section{C- Necesidades emocionales y afectivas.}

-Necesidad de seguridad emocional, protección y base de exploración, afecto, estima y cuidados eficaces: El vínculo del apego.

-Necesidad de una red de relaciones sociales: el vínculo de amistad y el sentido de comunidad.

-Necesidad de interacción sexual placentera e intimidad: los afectos sexuales del deseo, la atracción, el enamoramiento, la intimidad, el apego y los cuidados entre iguales.

D.- Necesidad de participación. Los menores como protagonistas de su vida. La autonomía y la disciplina.

El siguiente esquema, nos indica los planteamientos de López (2008) desde la presencia de las necesidades que plantea, seguido de lo que debe presentarse para la satisfacción de éstas, y finalmente lo que ocurre en caso contrario. Promover la satisfacción de estas necesidades, evitará que el individuo sufra alguno de los tres tipos de soledad, o los tres que se plantean.

Figura 1. Esquema de necesidades interpersonales de López (2008).

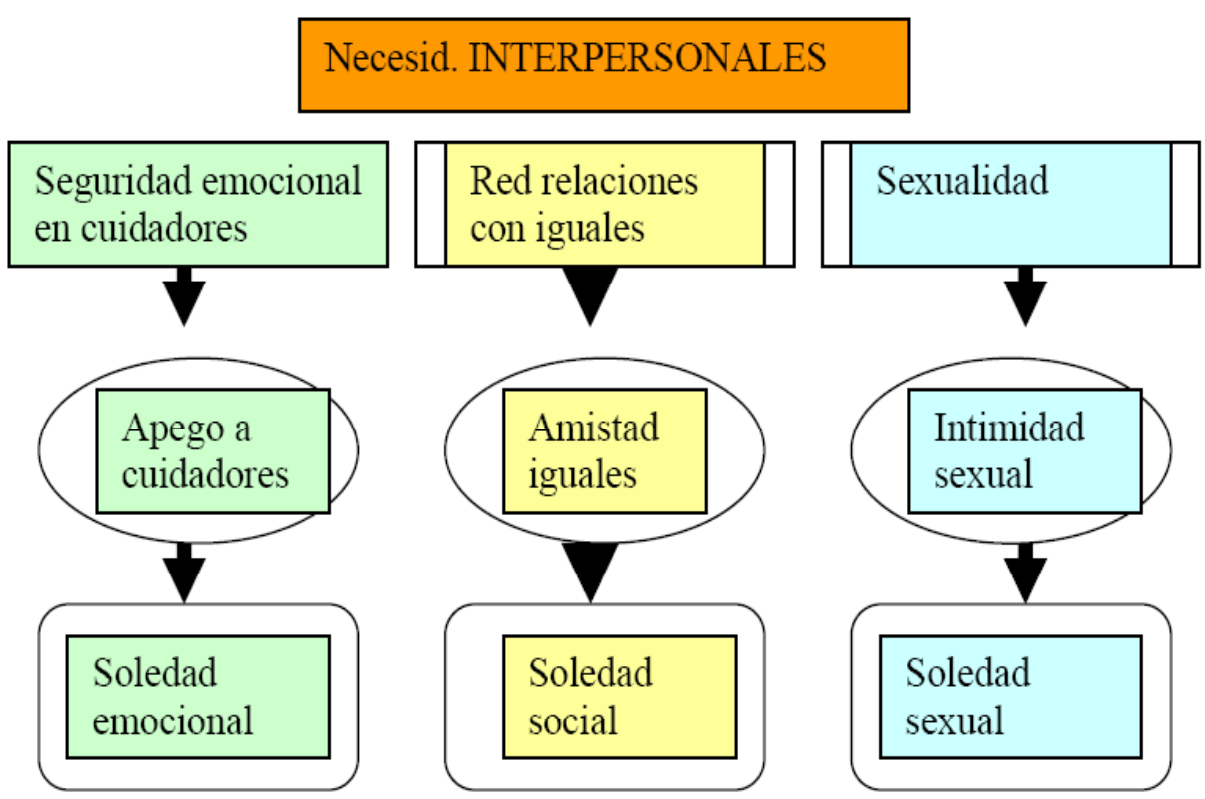

El modelo teórico de las necesidades interpersonales básicas de López, es un modelo explicativo interactivo que busca explicar el desarrollo emocional, afectivo y social del ser humano. En este modelo los factores biológicos y culturales, son considerados factores necesarios para entender la evolución del ser humano, siendo siempre el resultante una versión individual y distinta de cada ser humano (López, 1995a).

Las necesidades interpersonales básicas planteadas en el modelo teórico de López, tienen un carácter universal que es inherente a la especie humana. Se presentan en cada sujeto de manera interrelacionada entre sí, 
aunque de diferentes maneras a lo largo de todo el ciclo vital, y la satisfacción de cada una de ellas estará condicionada a la dependencia a las primeras figuras de apego en la infancia y a la pareja sexual en la vida adulta.

A continuación haremos una descripción más detallada de las necesidades interpersonales que vamos a estudiar.

\subsubsection{Necesidades emocionales y sociales}

López (2008), diferencia una amplia variedad de este tipo de necesidades. Todas ellas indican lo que como seres humanos necesitamos a un nivel emocional y social para desarrollarnos y sentirnos bien, tener bienestar y relacionarnos de manera adecuada con las demás personas.

Estas necesidades sólo pueden satisfacerse desde la infancia, por quienes ejercen la función de padres, familiares, otros adultos, pares o compañeros, asociaciones, comunidad y educadores, entre otros (López, 1995a). En la adultez en cambio, el individuo requiere salir de la propia soledad, así como dejar de lado los pensamientos egoístas, para abrirse al encuentro con los demás.

Nosotros esperamos encontrar en las personas que conforman nuestra muestra, insatisfacción asociada a las necesidades emocionales y sociales, producto de la experiencia de prisión política y tortura en sus vidas. A continuación estudiaremos las necesidades emocionales y su relación con la teoría del apego.

\subsubsection{Necesidad de vinculación afectiva y teoría del apego}

El ser humano es un proyecto que para realizarse como tal, necesita de óptimas condiciones ambientales, cuidados afectivos y sociales que en interacción con factores biológicos como el genoma, el cerebro, la anatomía y la fisiología de cada persona, permiten la satisfacción de sus necesidades básicas.

Desde la concepción del ser humano como un ser para el contacto y la vinculación, López plantea como necesidades interpersonales básicas: la necesidad de seguridad emocional, de pertenencia a una comunidad y de satisfacción sexual. La primera, asociada a la necesidad de resolver la soledad y el desamparo mediante la consecución de fuertes vínculos de apego a figuras incondicionales. La segunda, asociada a vínculos de amistad; y la tercera, a vínculos de enamoramiento (López, 2008).

Las tres necesidades planteadas por López, corresponden a las necesidades básicas que favorecen la supervivencia de la especie humana, y la satisfacción de cada una de ellas, mediará y dará sentido a las 
relaciones interpersonales íntimas. De ocurrir lo contrario, es decir, si una persona permanece tiempo desvinculada emocional, social o sexualmente, sufrirá sentimientos de soledad emocional y social (Weiss, 1982), presentando mayor vulnerabilidad a nivel biológico, psicológico o social.

Para López (2008), la necesidad de contacto y vinculación afectiva, tiene su origen en la filogénesis de los afectos. Se entiende así, que el proyecto de vida humano sólo puede desarrollarse en la vinculación afectiva con otros.

De acuerdo a lo anterior y a las hipótesis de nuestra investigación para la muestra en estudio, creemos que los EXPPS presentarán dificultades para resolver sus necesidades emocionales, familiares e íntimas, lo que se traducirá en dificultades en la resolución de sus problemas con la pareja, la familia y los amigos, pues lo que estamos probando es que la experiencia de prisión está asociada a grandes problemas a la hora de vivir las relaciones interpersonales.

A continuación, estudiaremos la necesidad del ser humano de contacto y vinculación afectiva en relación a algunas teorías que consideramos nos aportarán al entendimiento de esta necesidad en la muestra que estudiamos. Esta necesidad conforma el núcleo teórico de la teoría de las necesidades del autor y se fundamenta en la psicología evolutiva y la teoría del apego.

La teoría del apego desde sus orígenes (Bowlby, 1969, 1973, 1980), hasta la actualidad, ha planteado que el individuo tiene desde su nacimiento una pre-orientación hacia los miembros de su misma especie, en base a la necesidad primigenia de establecer vínculos afectivos con los demás. Lo que se inicia desde la búsqueda de contacto con la madre, que parte de la esencia de la naturaleza humana y es una necesidad tan primaria como la alimentación (López, 1995a, 2008).

Desde esta perspectiva, López concibe el apego como una conducta para la que el individuo está altamente programado, siendo mucho más universal durante los primeros años de vida que en la vida adulta (López, 1995a).

Entendiendo el apego como un sistema que se forma a partir de la interacción que un individuo tiene desde su nacimiento y que goza de cierta estabilidad en el tiempo, no está exenta de cambios durante el ciclo vital, nos permite plantear que una situación tan extrema como la experiencia de violencia política y tortura, pudo haber afectado este sistema. 
Para la teoría del apego, es fundamental el rol que juega la familia en el establecimiento del sistema de vinculación, siendo ésta, la que cumple el principal rol en la organización social básica de cada individuo. Además, es la encargada de satisfacer las necesidades fundamentales de protección ante peligros reales e incluso imaginarios en cada individuo, mediatizando sus relaciones con las distintas instituciones, sus pares y la sociedad en general (López, 2008).

\subsection{La familia y su rol en el sistema de vinculación afectiva}

López (2008) afirma que tanto las religiones como los estados, se han esforzado por sacralizar un concepto de familia universal y único, olvidando con ello que la organización social de las relaciones admite variantes compatibles con la satisfacción de las necesidades de la infancia.

López define la familia como un sistema de relaciones de parentesco verticales y horizontales que son reguladas de formas muy diferentes por las distintas culturas, siendo el elemento común a la mayoría de ellas, las relaciones de parentesco biológico o político entre los integrantes de cada grupo y el núcleo que les sustenta, el compromiso entre los cónyuges, el vínculo de apego entre hijos y padres, los vínculos paterno-materno filiales, y el vínculo fraterno. En base a estas consideraciones, las relaciones de parentesco subyacentes a los vínculos entre padres e hijos y el apego a los padres, son la esencia de la familia (e.g. López, 2008).

Dentro del contexto familiar, los componentes del apego variarán según el rol de cada uno. Los vínculos simétricos como el de la pareja, implicarán diferentes grados de pasión sexual, intimidad y compromiso, a diferencia de los vínculos asimétricos entre padres e hijos o el vínculo simétrico entre hermanos, que se caracterizarán por la ausencia de contenidos sexuales. Sin embargo, la evolución de las familias ha hecho que actualmente existan tantas tipos diferentes, que es imposible delimitar su definición.

Considerando todas las variantes de una familia u otra, López (2008) afirma que desde el punto de vista emocional y social, la familia ha sido, es y será siendo, el sistema básico del individuo.

El apego definido como un patrón relacional más o menos estable en el tiempo, se diferencia en tres estilos, estos son apego seguro, ansioso y evitatito (Hazan y Shaver, 1987). A los que han añadido algunos autores el desorganizado (Main y Cassidy, 1988). 
López define el apego como aquella especial relación, o lazo afectivo ( López, 2008) que el niño establece con un número reducido de personas y que le impulsa a buscar proximidad y contacto con ellas a lo largo del tiempo.

Para López (2008), la historia familiar y el tipo de apego, tienen influencia en la vida adulta por tres razones: la primera, debido a que es en la familia donde el individuo aprende el patrón básico relacional seguro, ansioso, evitativo o desorganizado, que mediatiza especialmente las relaciones íntimas. La segunda, por mantener que es en esta relación donde el individuo aprende las formas de comunicación que son útiles y necesarias en sus relaciones íntimas a lo largo de toda su vida; y la tercera, por considerar que en la historia de vida familiar es donde hay un aprendizaje vicario que condiciona las relaciones posteriores del individuo, a partir de los modelos de padres y de marido y esposa que el individuo observa y adquiere desde muy temprana edad.

Esto último, definido como "modelos operativos internos", es central para entender la teoría del apego y los estilos que se plantean, y refiere que todas las representaciones del mundo y los seres humanos construidas a lo largo de la vida, que incluyen a personas, ideas, lugares, cultura, y estructuras sociales, entre otras. Estos modelos que tenemos de nosotros mismos y de las demás personas, se establecen en el transcurso de sucesos importantes a lo largo de la vida, y están siendo constantemente interpretados y remodelados. Su importancia, radica en que determinan la forma en que desde la infancia interpretamos el mundo (Carreras, Brizzio, Casullo y Saavedra, 2006, p.93).

\subsection{El apego en la adolescencia y etapa adulta}

Consideramos relevante en nuestro estudio, referirnos a algunos postulados esenciales de la teoría del apego durante la adolescencia y la etapa adulta, porque precisamente en estas etapas evolutivas se encontraban mayoritariamente los EXPPS al momento de su detención (Informe Valech).

Hay evidencia científica que indica que las personas con apego seguro en la adultez, tienen una visión positiva del yo y del mundo social, y buscan afiliación y apoyo sin presentar la preocupación de ser abandonados. Estas personas además, presentan bajos niveles de ansiedad ante la posible pérdida de apego y a la escasa evitación de aproximación a las demás personas. Por su parte, las personas con apego inseguro presentan una visión negativa de sí y de los demás, y el deseo de intimidad y afiliación a otras personas, esto les genera desconfianza y temor ante las otras personas y eviten la cercanía. Todo lo que les genera ansiedad elevada por la escasa disponibilidad a figuras de apego (Casullo y Fernández Liporace, 2005). 
Las personas con apego seguro en la adultez, refieren que en su infancia dispusieron de la calidez de sus padres, y ambientes familiares en que predominan la fuerza de los lazos emocionales entre sus integrantes, es decir, con una alta cohesión familiar. También presentan la capacidad para adaptarse y cambiar sus estructuras, o flexibilidad en el funcionamiento familiar (Mikulincer y Florian, citado en Mikulincer y Shaver, 2003).

El apego inseguro en la adultez, se asocia a la experiencia de situaciones estresantes y traumáticas a nivel interpersonal en la infancia, como la negligencia, el maltrato físico, la conducta antisocial de los padres, la violencia marital, el divorcio, o el abandono severo, entre otras (Mickelson, Kessler y Shaver, 1997). Además, se asocia a personas cuyas relaciones interpersonales presentan bajos niveles de expresividad de afectos y de calidez emocional, y provenientes de familias frías y poco expresivas (Kennedy-Moore y Watson, 1999).

Las personas que tengan un apego seguro podrán regular sus afectos, siendo capaces de evaluar situaciones que les generen estrés como menos amenazantes y emplear formas de afrontamiento adaptativas como la búsqueda de apoyo instrumental e informativo, la solución directa y planificación, y el reconocimiento y expresión emocional. Siendo más probable en ellos el empleo de estrategias adaptativas como la reconstrucción o reelaboración positiva de los estresores (Mikulincer y Shaver, 2003).

El apego inseguro en tanto, se asocia a la inhibición de la expresión de emociones negativas. Sin embargo, personas con este tipo de apego, experimentan intensamente malestar aunque eviten manifestarlo por temor a alienarse ante las demás. Además presentan una auto-imagen negativa y un quiebre en las formas de afrontamiento directo a nivel adaptativo (Mikulincer y Shaver, 2003).

En cuanto a indicadores de salud mental, hay evidencia empírica que refiere que las personas con apego seguro presentan menos síntomas de ansiedad, depresión y hostilidad. Lo que refiere mayor bienestar en comparación a quienes presentan apego inseguro (Mikulinces y Shaver, 2003).

El rol de los amigos es importante en estas etapas de la vida, pues otorga al adolescente la posibilidad de pertenecer a una red de relaciones sociales con independencia del grupo familiar, que permite la identificación con los pares y tener la posibilidad de diálogo de temáticas que tratadas dentro de la familia, podrían dar lugar a conflictos a nivel intra-familiar. 
La amistad a diferencia del apego, tiene un carácter voluntario, simétrico, exigente, condicional y con cierta inestabilidad. Según estas características, las relaciones de amistad son complementarias a aquellas relaciones de apego incondicional, debido a las exigencias propias de la amistad, que implican el tener que ganarse a los amigos y mantenerles por méritos propios.

La pareja en la adolescencia, puede convertirse con el tiempo en figura de apego, incluso de manera preferente en relación a los padres, pudiendo reemplazarles en sus funciones. Para que esto ocurra, deben cumplirse ciertos requisitos, como por ejemplo que el compañero elegido manifieste un alto grado de interés por el compromiso entre ambos, seguridad y la decisión de querer que la relación funcione, disponibilidad en caso de ser requerido y eficacia en la ayuda. Estas características suelen darse de manera parcial en relaciones de pareja adolescente e incluso en parejas adultas (López, 2008). Hazan y Shaver (1987), entienden el proceso amoroso desde los patrones de apego que el individuo forma en la infancia y que mantiene a lo largo de su ciclo vital.

El modelo mental que cada individuo tiene de sí y de los otros, y las relaciones amorosas, se asocian a la historia del mismo y el estilo de apego. Tendrán entonces una experiencia amorosa positiva, aquellas personas que tienen una historia de apego igualmente positiva y un estilo de apego más seguro. Quienes tengan un modelo mental positivo, lo tendrán también de aquellas personas que tengan una historia de apego positiva y un estilo de apego seguro.

Según esta idea, el estilo de apego seguro se asociará a relaciones amorosas positivas donde predomine la confianza. Quienes dispongan de este patrón de apego, dispondrán de ventajas durante el proceso amoroso que se traducirán en la sólida construcción de su autonomía, la mejor capacidad de seducción, la capacidad de decidir con firmeza y mejores fundamentos para formar pareja y cuando vivan procesos de posible separación, mayor capacidad para la intimidad con sus parejas y para afrontar los conflictos. Serán entonces, quienes saldrán menos dañados de un quiebre de relación de pareja y la elaboración de la pérdida será mejor (López, 2008).

Quienes tengan un estilo de apego ansioso, tenderán a presentar en sus relaciones amorosas una marcada dependencia al otro, la necesidad de confirmación de ser amado, además de dificultades para la autonomía, la tendencia a hacer búsquedas y selecciones precipitadas, miedo a no ser amado, miedo a la pérdida y celos más frecuentes, ideas contrapuestas acerca del amor, dificultades para romper, inestabilidad e inseguridad emocional (López, 2008). 
Aquellas personas que tengan un estilo de apego evitativo, tenderán a establecer relaciones desconfiadas y distantes, además de miedo a la intimidad. Estas personas tendrán una pseudoautonomía emocional y relaciones en que predominará la dependencia a otros. (López, 2008).

Nosotros esperaríamos encontrar indicadores de apego ansioso y evitativo en los vínculos de pareja de los EXPPS, producto de hechos como la separación de la familia por períodos prolongados, la experiencia de vida en clandestinidad y persecución política durante el período del gobierno militar, entre otros motivos. Todo lo que generó temor en las familias de los EXPPS por la vida y el paradero de las víctimas.

La estabilidad en los vínculos de pareja, tiene funciones adaptativas para la especie humana, pues desde un aspecto social, favorece la crianza de los hijos. Lo que nos indica que los seres humanos tenemos la capacidad de establecer compromisos y alianzas que pueden ser muy estables, en base a capacidades de reconocimiento de la individualidad de los otros, el recuerdo de la experiencia y la posibilidad de hacer proyectos de futuro. Estos compromisos facilitan la estabilidad familiar y de la sociedad con independencia de la cultura.

El apego visto como necesidad de afecto, ha sido demostrado científicamente en numerosos estudios. Éstos plantean que para lograr un patrón de apego seguro, deben presentarse ciertas condiciones en los cuidados que deben darse al individuo desde su nacimiento, como la aceptación incondicional, la estima, el afecto y la eficacia en la protección de estos cuidados (Hazan y Shaver, 1987; López, Gómez, Apodaca, Delgado y Marcos, 1994). La historia familiar general y el tipo de patrón de apego se relacionará así en gran medida al grado de satisfacción afectiva que el individuo tendrá en sus relaciones interpersonales íntimas en su vida adulta.

De acuerdo a lo anterior, el grado de felicidad o infelicidad vivido en la infancia asociado a las relaciones con la familia, afectará en el grado de satisfacción que se pueda alcanzar en las relaciones de pareja en la adultez (Sneyder, citado en López, 2008). Según este planteamiento, presentarán mayor grado de insatisfacción en estas relaciones, aquellos individuos que vivieron situaciones de disfunción familiar en su infancia. Al respecto, intentaremos diferenciar variables del entorno familiar de la infancia de los EXPPS que podrían darnos indicadores de sus relaciones de apego, para comparar con los mismos indicadores en sus relaciones de apego actuales, que podrían estar influenciadas por la experiencia de violencia política y tortura. 
1.3.1.1.3. Teoría del apego como referencia específica para entender los efectos de la tortura y prisión en las relaciones familiares

Creemos que el elevado compromiso político que caracterizó a los EXPPS, reflejado posiblemente en el grado de identificación, pertenencia, y tiempo dedicado al desarrollo de funciones dentro de los grupos políticos, promovió el establecimiento de fuertes vínculos sociales de amistad y/ o de pareja. Los que se vieron amenazados con la experiencia personal y concreta de represión política en sus vidas, que buscaba quebrantar todo movimiento político. Así, la delación entre compañeros, el desaparecimiento, la tortura y otras amenazas, pudieron haber quebrantado estas relaciones interpersonales de apego fundadas en las agrupaciones políticas.

La función del apego a nivel subjetivo comprende buscar la seguridad en el contacto y la presencia de las figuras de apego. Si esto se cumple, la persona se sentirá protegido y sabrá que cuenta con el apoyo incondicional de otros, caracterizadas por la disponibilidad y eficacia. Si esto no se cumple, la persona sentirá insatisfacción en momentos de aflicción.

Otras funciones del apego, son las de ofrecer y regular la cantidad y calidad de información que el individuo intercambia desde su nacimiento con su entorno, fomentar su salud física y psíquica en relaciones de apego estables y satisfactorias, y favorecer su desarrollo social, todo lo que afectará en el desenvolvimiento de las personas en sus relaciones sexuales y afectivas en la adultez (e.g. López, 2008).

Los efectos de separaciones prolongadas de figuras de apego en las relaciones interpersonales, son un aspecto difícil de precisar en nuestro estudio. Esta dificultad se debe principalmente a la heterogeneidad de aspectos en que acontecen estas separaciones, a las modificaciones que se generan y a características de la personalidad de las personas previas a experiencias de este tipo. Lamentablemente no tenemos información de los EXPPS antes de la experiencia de prisión, sin embargo, creemos que los efectos aludidos afectaron de manera bi-direccional en sus relaciones interpersonales cercanas afectivamente.

No obstante lo anterior, hemos considerado necesario precisar en nuestro estudio, aquellos aspectos de la historia de vida familiar previa a la experiencia de prisión de los individuos que entrevistaremos, para compararlo sus equivalentes en el presente. Lo que evaluaremos en términos del grado de satisfacción de estas relaciones. 
Sin duda, creemos que la experiencia de prisión vulneró la satisfacción de las necesidades de vinculación afectiva y apego de manera extrema, en un período extremo de vida, en que las víctimas vieron reiteradamente amenazadas sus vidas y las de sus familias.

\subsection{Necesidad de vinculación afectiva y teoría de la soledad de Weiss.}

Ya desde mediados del siglo pasado, Fromm (citado en López 1995a, 2008) describía la importancia de la necesidad de vinculación afectiva, refiriendo que esta necesidad está mediatizada por los instintos, y que de su satisfacción depende el estado de salud mental del individuo. La insatisfacción de esta necesidad, sitúa al individuo en una posición de soledad e individuación que le significará un estado de encarcelamiento que atenta contra su equilibrio mental, y será experimentado aunque estén cubiertas todas las necesidades fisiológicas.

De acuerdo a lo anterior, y a pesar de la diversidad teórica de trabajos realizados sobre la soledad humana, todas las teorías que le estudian, coinciden en describirla como una experiencia psicológica dolorosa y profundamente significativa que refiere deficiencias en las relaciones interpersonales (Peplau y Perlman, citados en López, 1995a, 2008).

La relación existente entre la necesidad de vinculación afectiva planteada por López y la teoría de soledad de Weiss, radica en que la soledad emocional descrita por este último autor, se entiende como una experiencia psicológica de no estar vinculado afectivamente a nadie, manifestándose por ejemplo en depresión, aburrimiento, autodevaluación, irritación, desesperación y hasta suicidio (López 1995a, 2008).

Lo anterior en la infancia, se entiende que si la necesidad de seguridad emocional no se satisface por la ausencia de figuras de apego desde la infancia, y las propias deficiencias de estas ausencias, esto se traducirá en soledad emocional, un sentimiento de no tener a otro incondicional con el que poder contar, sentirse querido, valorado y cuidado (López, 2008).

Nosotros pensamos encontrar insatisfacción de la necesidad de vinculación afectiva en los EXPPS que estudiamos. Lo que se manifestaría en la tendencia a la desvinculación afectiva y soledad sentida en muchas de las relaciones interpersonales de ellos, principalmente aquellas de tipo social. Sin embargo, como esta es una necesidad tan fundamental para la vida de todo ser humano, esperamos encontrar en este grupo de personas la existencia de algunos vínculos significativos en sus relaciones más próximas, que pudieran encontrarse principalmente dentro del grupo familiar. 


\subsubsection{Necesidades sociales}

Para López (2008), el ser humano es un ser para el contacto y la vinculación, resultante de su historia filogenética y con una tendencia a mantener relaciones interpersonales íntimas como una conducta ambientalmente estable, que está presente en todas las sociedades conocidas. Esta conducta social, apareció y se desarrolló de manera muy relacionada con la aparición de la sexualidad y la prohibición del incesto (Lucas; Levi-Strauss, citados en López, 2008).

Además de la necesidad que tenemos los seres humanos de disponer de una o varias figuras de apego, tenemos la necesidad de ampliar nuestro mundo de relaciones con pares y la comunidad en que estamos insertos (López, 2008).

El individuo y su grupo familiar, no pueden vivir aislados del mundo y necesitan disponer de una amplia red de relaciones sociales para no sentirse marginados socialmente. Esta red social cumple la función de satisfacer la necesidad del individuo, de sentir pertenencia a un grupo y una comunidad, favoreciendo la amistad, la formación de grupos y el asociacionismo (López, 2008).

Las relaciones de amistad y con compañeros, permiten al individuo saber quién es, conocer su identidad, comunicarse con alguien que podrá darle apoyo y comprensión, divertirse de diferentes maneras, explorar la realidad más allá de la familia, defender derechos y ensayar conductas. Siendo una característica principal de estas relaciones, el carácter voluntario y la exigencia de reciprocidad que obliga al individuo a salirse de sí, considerando a los otros (López, 2008).

Nosotros creemos que la experiencia de violencia política afectó en las relaciones sociales de los EXPPS de Chile, porque ellos en sí, se volvieron una amenaza tanto para compañeros políticos, como para la sociedad chilena en general. Esto, debido a que cualquier contacto con ellos, podía entenderse como intercambio de información política, lo cual era sancionado con prisión. Esta situación pudo haber producido una respuesta social caracterizada por temor, silencio y actitudes de evitación, entre otras. Actualmente el dicho “dime con quien andas y te diré quien eres", suele usarse en Chile y puede tener relación con nuestro planteamiento.

Lo anterior, visto desde el lado de los EXPPS, pudo producir el quiebre de sus relaciones sociales con compañeros políticos y demás personas, y suponemos que afectó negativamente en la percepción que ellos tenían de estas relaciones en sus vidas. 
En conclusión, pensamos que en la época de la dictadura del régimen militar chileno, y en los años posteriores, los EXPPS no podían satisfacer la necesidad de ampliar su mundo de relaciones con sus pares y la comunidad, pues les significaba exponerse y exponer a sus familiares, compañeros y amigos a los peligros recién mencionados, lo que creemos trajo en sus vidas marginación social que podría presentarse en la actualidad y ser parte del impacto social que estudiamos en este estudio.

En congruencia a lo anterior, podríamos pensar que los EXPPS no disponen de relaciones de amistad satisfactorias, o que sus relaciones de este tipo, comprenden un bajo grado de compromiso e intimidad. Sin embargo, pensamos que con la resiliencia que les caracterizaría por haber supervivido a experiencias de prisión y/ o tortura, estas personas podrían haber resuelto sus necesidades sociales, y por ende, disponer en la actualidad de relaciones de amistad satisfactorias. Indagaremos acerca de sus relaciones interpersonales actuales y el grado de satisfacción o insatisfacción con que éstas son valoradas por los EXPPS.

A continuación, nos referiremos a dos temas que hemos decidido incluir en esta sección porque aunque no formen parte de las necesidades emocionales y sociales que indagaremos en la muestra, comprendan dos necesidades que si están relacionadas a las anteriores y creemos que nos darán indicadores del impacto que estudiamos.

1.3.1.3. Concepción de ser humano individual y social y su relación con la satisfacción de necesidades interpersonales

A nivel biológico, el autor reconoce en la especie humana, un genoma que nos determina como especie, y que define como la “...cristalización actual de una historia muy larga, una organización anatómica y fisiológica y unos programas sobre nuestra manera de desarrollarnos y de afrontar la vida" (López, 2008, p. 20). A nivel animal, el autor refiere el concepto de "información sentida" (López, 2008, p. 22, 23), para explicar la capacidad del ser humano de ser sensible a sentir placer y dolor, tener instintos y emociones, manejar e interpretar información, además de la necesidad de contacto y vinculación.

Dentro del mundo animal los seres humanos somos mamíferos sexuales, afectivos, sociales y culturales; y la complejidad de la naturaleza humana reflejada en la ocurrencia de experiencias de violencia política y tortura entre personas, como las experiencias vividas por la muestra de nuestro estudio, nos permitirá comprender el impacto de esta experiencia en sus vidas desde la vulnerabilidad propia de la naturaleza animal humana y las capacidades de adaptación y supervivencia que poseen. 
$\mathrm{El}$ autor reconoce la naturaleza diversa del ser humano y refiere los polos de lo peor y mejor que podemos llegar a ser. Lo peor, ser el animal más peligroso de todos, con un primitivismo animal tal que sólo podrán resolver conflictos mediante el uso de la violencia; o por el contrario, tener un nivel muy evolucionado, característico en individuos constructivos, creativos, cultos, dignos y bondadosos, con capacidad para resolver conflictos sin necesidad de recurrir a la violencia: el "ser cultural” (López, 2008, p. 26, 111) descrito por López. Ambos casos encontramos al estudiar los torturadores y las víctimas.

En efecto, podríamos situar a los torturadores en el primer extremo mencionado, explicando con ello, el cómo una persona puede ejercer violencia política y tortura a otro ser humano. Podríamos a la vez pensar que muchos de los supervivientes se aproximan más al otro extremo, al de seres culturales, pues creemos que para sobrevivir a estas experiencias se requiere disponer de este tipo de capacidades, para dar una lectura a la experiencia que permita superarla y optar por la vida.

Desde nuestro punto de vista, la experiencia de prisión y/ o tortura por motivos políticos repercutió en las relaciones interpersonales de cada EXPP, dependiendo de variables individuales, la experiencia de prisión, la resolución o no de la experiencia y la lectura realizada de la experiencia. Creemos que este impacto se verá acentuado en aquellas personas que sufrieron la experiencia de tortura sexual, y en estos casos podría verse reflejado en la insatisfacción de las necesidades emocionales y afectivas, específicamente la necesidad de interacción sexual placentera e intimidad.

La sociedad por su parte, vista como el otro polo de la interacción, la podemos entender como una compleja realidad conformada por muchos agentes sociales y socializadores, existiendo en ella una diversidad de sistemas que influyen desde la ecología en que se desarrolla el individuo, como por ejemplo, la tensión existente en el ambiente físico, la ausencia o presencia de redes locales de apoyo social, etc. (Bronfenbrenner, 1979).

Individuo y sociedad interactúan recíprocamente, siendo esta última, la combinación de todo el sistema familiar y social. Lo que desde las necesidades, implica concebir al ser humano como un agente o actor activo, que participa de la satisfacción de sus necesidades y de las necesidades de los demás (López, 2008).

Indagar en las valoraciones que los EXPPS hacen de los distintos agentes sociales implicados en los casos de prisión política y tortura ocurridos durante el gobierno militar en Chile, y la respuesta de la sociedad no implicada directamente a estos hechos; conforma uno de los objetivos de nuestra investigación. Suponemos que existe en ellos un sentimiento de exclusión social que dificultará la satisfacción de sus 
necesidades y su bienestar psicológico. Esto en base al silencio político y social que ha caracterizado al tema en Chile, y al posible rechazo y olvido de la sociedad chilena en general, posiblemente percibido por los EXPPS.

\subsubsection{El ser humano, su bienestar personal y social y calidad de vida}

Para López, el bienestar emocional y social es el "termómetro de la felicidad y la infelicidad" (López, 2008, p. 94), e implica una realidad muy compleja y difícil de delimitar que depende de factores personales, familiares, escolares y culturales. Estos son características de personalidad como la autoestima, la visión del mundo, la concepción de los seres humanos y un juicio moral determinado que sea convencional y de manera ideal post-convencional; valores como la tolerancia, la igualdad y la fraternidad; factores afectivos como la capacidad empática, el autocontrol emocional y la historia afectiva con los padres; y por último habilidades instrumentales como habilidades sociales de comunicación, afrontamiento y resolución de conflictos, además de habilidades profesionales de colaboración, entusiasmo y trabajo.

En síntesis, nuestro estudio pretende desde una visión evolutiva, contextual y particular, establecer relaciones globales entre las necesidades estudiadas de López (2008), y los temas abordados en el instrumento que hemos elaborado para entrevistar a una muestra de EXPPS.

Creemos que el modelo teórico que empleamos, nos permitirá indagar en los distintos temas que apuntan a áreas de la vida actual y pasada de los EXPPS, además de la valoración que ellos hacen de la experiencia de prisión y las problemáticas actuales en relación a la reparación y otros temas. La indagación de la historia familiar previa a la experiencia de prisión, nos permitirá establecer paralelismos entre la satisfacción de las necesidades antes y después de la experiencia y con ello, la influencia de esta misma, en las valoraciones.

En cuanto a la historia de vida pasada de los EXPPS, nos referimos específicamente a la infancia y adolescencia de ellos, creemos que situaciones de pobreza, hambruna, enfermedad, desempleo, vivir en hacinamiento familiar y no disponer de una vivienda digna, la no escolarización y las guerras, entre otras; son todas problemáticas que de haberse presentado en las etapas evolutivas aludidas en los EXPPS, han impedido la satisfacción de sus necesidades interpersonales en el pasado. Por ello hemos incluido estas valoraciones en las preguntas del instrumento que emplearemos para entrevistar a la muestra de nuestro estudio.

De acuerdo a lo anterior, López (2008) plantea que la satisfacción de las necesidades humanas desde la infancia requiere por una parte del respeto de los derechos del niño que le permitan vivir en condiciones que satisfagan todas sus necesidades básicas y el desarrollo de sus mejores posibilidades, y por otra, de la 
satisfacción de todas las necesidades fisiológicas, cognitivas, emocionales y sociales, y dar el derecho y lugar al individuo desde su infancia de ser un participante activo de acuerdo a su edad en su familia, la escuela y la sociedad en general.

Lamentablemente, durante el gobierno militar, la diversidad de ideología y valores fue censurada y duramente castigada, viéndose imposibilitados los individuos de analizar de manera crítica las distintas ideologías.

1.3.1.5. Dos propuestas actuales de teorías de necesidades que contribuyen al modelo de López (2008)

Dentro de las teorías de las necesidades humanas existentes, la "Self-Determination Theory" (SDT) de Deci y Ryan (1985, 2000), y la SPF: Social Production Function, de Steverink y Linderberg (2006), sirven de referencia y aportan nuevos elementos al modelo teórico planteado por López (2008).

La "Self Determination Theory" , enfatiza las necesidades psicológicas de las personas, reconociendo tres necesidades como imprescindibles para su óptimo desarrollo, y que se relacionan con la salud, la calidad de vida y el bienestar (Patrick y cols., 2007).

Estas necesidades son: Competencia, Pertenencia/ Relación próxima e íntima, y Autonomía. La primera de ellas, comprende la necesidad de sentir que los esfuerzos que realizamos son efectivos y que disponemos de la capacidad para conseguir lo que se nos plantee en la vida. La segunda, refiere la necesidad de sentirse vinculados afectivamente, en conexión y comprendida por otros, y la tercera, refiere la necesidad de sentirnos capaces de decidir y realizar conductas por nosotros mismos.

Las necesidades planteadas por Steverink y Lindenberg (2006) comprenden necesidades sociales de las personas, que son entendidas como lo que éstas necesitan tanto física como socialmente para desarrollarse y sentirse bien consigo mismas. Este grupo de necesidades, está compuesto por tres: Afecto, Confirmación de la conducta, y Estatus social. Estas necesidades, son consideradas inherentes, universales y permanentes durante la vida humana, donde los instrumentos necesarios para su satisfacción son los propósitos y los recursos de las personas.

La primera necesidad de este grupo, se satisface cuando la persona se siente aceptada, amada, querida, comprendida, "empatizada", y sabe que sus sentimientos son recíprocos, y que tiene a otras personas que están dispuestas a ayudarla de manera desinteresada, sabe además que su bienestar está 
relacionado al bienestar de otras personas, y siente que otras personas quieren estar física y emocionalmente cerca de ella.

La necesidad de confirmación conductual por su parte, se satisface cuando la persona siente que está actuando bien, según su propio criterio y ante la mirada de personas que le son relevantes. Esta necesidad incluye hacer bien las cosas, sentirse una buena persona, sentirse útil, contribuir al bien común y pertenecer a un grupo.

Por último, la necesidad de estatus se satisface cuando la persona siente que es tratado con respeto, es tomado en serio, independiente y autónomo, rinde más que otros, tiene influencia, se hace a sí mismo y es reconocido tanto por sus logros, como por sus habilidades y recursos.

La satisfacción de todas estas necesidades, se dará en diferentes grados, y pueden compensarse o reemplazarse entre sí. Pero se requiere de un cierto grado de satisfacción de ellas para lograr bienestar subjetivo.

Este modelo ha sido contrastado empíricamente por sus autores y tiene una extensión que permite entender los cambios evolutivos que ocurren con el envejecimiento de las personas (SPFSuccessful Aging Theory). Dentro de esta parte del modelo, las oportunidades y necesidades van cambiando con la edad, al igual que los recursos físicos y sociales disponibles. Estos cambios hacen que las personas precisen adaptarse a ellos, y presenten dos procesos de cambios asociados. El primero, comprende un patrón de cambio que tiende a mantener los recursos y las posibilidades para la satisfacción de las necesidades afectivas, en relación al patrón de las necesidades de estatus. Los recursos y posibilidades para satisfacer la necesidad de confirmación, se mantienen en un punto intermedio.

Un segundo patrón de cambio planteado por los autores, refiere la tendencia a sustituir y compensar la pérdida de satisfacción con el estatus, mediante el intento por satisfacer las necesidades de confirmación y afecto. La disminución de la confirmación, provocará un mayor esfuerzo por reemplazarla y compensarla con la satisfacción de la necesidad de afecto.

Los planteamientos de la SPF-Successful Aging Theory, otorgan importancia a la necesidad de pertenencia, lo que asociado a la necesidad de afecto de López (2008), fundamentan la importancia de la satisfacción de la necesidad de vinculación afectiva planteada por este último, siendo una de sus aportaciones principales al modelo de las necesidades interpersonales básicas, la distinción antes 
referida de los tres tipos de relaciones íntimas con la familia de origen, familia nueva creada en torno a la pareja, con la pareja, y las relaciones de amistad. De la calidad de estos vínculos, dependerá el desarrollo emocional y el bienestar de las personas.

Creemos que para las personas que estudiamos en esta tesis doctoral, la satisfacción de las necesidades referidas en este apartado dependerán de las limitaciones físicas y psicológicas que presenten y que han sido producidas por la experiencia de la prisión política y tortura en sus vidas. 
Privación de libertad y tortura política en Chile (1973-1990) 
CAPÍTULO II.

CARACTERÍSTICAS PSICOLÓGICAS DE SUPERVIVIENTES DE VIOLENCIA POLÍTICA Y TORTURA: UNA REVISIÓN BIBLIOGRÁFICA DE INVESTIGACIONES RELACIONADAS. 
Privación de libertad y tortura política en Chile (1973-1990) 
En el presente capítulo, desarrollaremos aquellas características biopsicosociales asociadas a supervivientes de experiencias de represión política. Para ello, hemos seleccionado estudios aplicados a supervivientes de distintos países del mundo, incluyendo Chile, que han vivido experiencias de este tipo. Aunque cada caso tiene características específicas, no es menos cierto que las situaciones de violencia, prisión y tortura política, tienen elementos comunes y consecuencias comunes. En todo caso, revisaremos las situaciones que más se asemejan a las de Chile (las ejercidas por gobiernos no democráticos sobre ciudadanos que supuestamente se oponen), dejando de lado otras muchas.

Las investigaciones que incluimos en este apartado, tienen principalmente un enfoque psicológico, pero entendiendo éste, como el estudio de los procesos mentales y emocionales, así como las conductas personales y sociales. En menor medida incluimos algunos estudios fundamentados en la medicina y los derechos humanos, porque consideramos que el impacto que estudiamos tiene un origen político que involucra aspectos que están fuera del ámbito psicológico.

Debido a las amplias diferencias culturales, contextuales, sociales, ideológicas, cronológicas y situacionales que encontramos en investigaciones relacionadas a experiencias de prisión por motivos políticos, hemos seleccionado principalmente aquellos estudios que consideramos que tienen factores en común con los hechos acontecidos en Chile.

Cuando hicimos búsquedas en las bases de datos científicas de áreas de investigación relacionadas, constatamos que el enfoque del objeto de estudio, depende del momento en que ocurrieron los hechos. Por citar algunos ejemplos, hemos observado que estudios realizados en Alemania, Israel o Turquía, en que los hechos de violación a los derechos humanos anteceden en décadas al caso de Chile, el enfoque se sitúa en torno a las secuelas de la experiencia de prisión en la descendencia, procesos de psicoterapia a las víctimas directas, y procesos de adaptación en refugiados en países de acogida, entre otros.

Específicamente en el caso de Chile, son escasos los estudios con corte científico realizados a población chilena víctima de la represión política en el período 1973-1990, y son aún más escasos estos estudios en chilenos residentes en Chile. Esto puede deberse a la vigencia de la problemática de violación a los derechos humanos en el país, que nos indica que es una problemática no resuelta aún.

De acuerdo a lo anterior, la bibliografía existente del impacto de la violencia política en Chile se caracteriza por el estudio del miedo, la impunidad y la reparación, además del impacto en chilenos en exilio. Información que proviene principalmente de organizaciones de derechos humanos que han 
emitido documentos en base a la experiencia de profesionales de salud mental que han participado en la atención de EXPPS desde el inicio de la dictadura y disponen de un amplio bagaje del conocimiento de la problemática.

\subsection{VIOLENCIA, PRISIÓN, TORTURA Y TRAUMA POR MOTIVOS POLÍTICOS}

En esta sección, definiremos aquellos conceptos que consideramos esenciales para entender la violencia, el cautiverio y la tortura por motivos políticos, además del trauma que estas acciones generan en el ser humano que las experimenta. Para ello, haremos una revisión crítica de los conceptos que estudiaremos en esta sección, según la aplicabilidad de las definiciones reconocidas mundialmente a nuestra muestra, prestando especial énfasis a los enfoques que más se adapten al caso de Chile.

\subsubsection{Definición de conceptos}

Los conceptos de violencia, prisión y tortura, tienen desde la universalidad que les caracteriza, un origen político y legal. A continuación aludiremos los referentes históricos de estos conceptos, para luego desarrollar sus definiciones psico-sociales. Para ello, hemos tomado elementos de la sociología, la medicina forense y principalmente la psicología, además de otras ciencias afines que nos ayudarán a entender y situar estos conceptos en el contexto chileno.

\subsubsection{Violencia política}

Creemos que de existir una distinción, hay una delgada línea divisoria entre la violencia política y la tortura. Al respecto podemos preguntarnos ¿qué es violencia política? y ¿qué es tortura?, o ¿todos los hechos de violencia política implican tortura?. Considerando el contexto en que se presentó la violencia política en Chile, muchos de estos hechos pueden ser considerados tortura, y la delimitación entre uno y otro, creemos que dependerá de la valoración subjetiva que realicen las víctimas de tales experiencias en base a criterios externos e internos.

Por empezar por lo que puede entenderse más claramente por violencia política, los estados disponen de medios para imponer cambios políticos en grupos de personas o incluso en comunidades enteras. El concepto de violencia organizada de estado, se ha introducido en las últimas décadas para incluir otras formas de persecución en adición a la tortura (Turner y Gorst-Unworst, 1993). Estas modalidades, en concordancia con la declaración universal de derechos humanos de 1948, incluyen 
encarcelamiento sin juicio, burlas, toma de rehenes, o cualquier tipo de privación violenta de libertad por motivos políticos o represivos (Van Geuns, 1987).

Pero pronto empiezan las dificultades. Por ejemplo, el Comité de derechos humanos consideró tortura el cautiverio en solitario por períodos prolongados, haciendo la distinción entre tortura y tratos por penas crueles, según la naturaleza, finalidad y severidad con que éstos ocurran. No obstante, se sostiene que la prueba de la gravedad puede dificultarse en aquellos casos que involucren sufrimientos mentales (Garretón, 2004).

Por eso, consideramos que la violencia física o psicológica no sistematizada, puede ser un tipo de tortura que posiblemente no se identifica por sus víctimas como tal. Pondremos especial atención a esta ambigüedad a la hora de evaluar la temática en los EXPPS que conformarán la muestra de nuestro estudio.

\subsubsection{Preso político y prisión política}

A continuación presentaremos la definición que Amnistía internacional hace de preso político Lo define como:

“... todo preso cuya causa contenga un elemento político significativo, ya sea la motivación de sus actos, los actos en si mismos o la motivación de las autoridades para detenerle" (Amnesty International [AI], 1979).

De acuerdo a esta definición, podemos entender por prisión política la acción de encarcelamiento o cautiverio de un preso político variable en tiempo y espacio. En el capítulo III haremos las especificaciones necesarias para delimitar estos conceptos en la realidad del caso de Chile durante el período 1973-1990.

Por ahora sabemos que los EXPPS chilenos, fueron privados de su libertad por tener una ideología política y / o accionar político de izquierda durante el régimen militar en Chile, fuera este motivo real o atribuido de forma arbitraria.

\subsubsection{Definición de tortura}

El ejercicio de la tortura está prohibido en el mundo entero desde la declaración universal de derechos humanos de las Naciones Unidas de 1948. Sin embargo, lamentablemente estas prácticas se han usado desde la antigua Grecia y Roma hasta nuestros días en distintos lugares del mundo, y han 
sido empleadas por estados autoritarios, como un instrumento de interrogación y represión sistemática (British Medical Association [BMA], 1986).

Siguiendo con una visión histórica de la tortura, ya en el siglo trece era definida como la pregunta en búsqueda de la verdad, mediante medios de tormento. En que las confesiones significan las pruebas de delito más importantes en presencia de otros indicadores, y la tortura, un trato legítimo para obtener confesiones (Peters, 1985). Amnistía Internacional por su parte, ha reportado el uso de ésta, en más de 90 países en los años 80 (AI, 1987); en más de 150 países en 1997, y en 149 países en el año 2000 (AI, 2001).

Actualmente, el uso de la tortura parece ser parte de un proceso de represión sistemática de oposición, realizado por un régimen que actúa dentro de su propio país (Martín-Baro, 1988).

A nivel epidemiológico, se estima que entre el 5 y el 35\% de todos los refugiados políticos en Europa, han sufrido tortura en sus países de origen (Barker, 1992); no existiendo diferencias entre hombres y mujeres (Allotey, 1998; Fornazzari y Freire, 1990); aunque son las mujeres quienes han sufrido más tortura sexual que los hombres (Allodi y Stiasny, 1990).

Weinstein, Dansky e Iacopino (1996), establecieron un listado de factores de riesgo para la tortura, que contempla el ser refugiado, líder de una organización de oposición, pariente de alguien que sufrió tortura, historia de arresto y detención, residencia en el país del conflicto, prisioneros de guerra, inmigrantes de países con regímenes totalitarios o militares, miembros de grupos minoritarios y guerra civil en el país de origen.

Consideramos una definición atingente a nuestro estudio, la clásica definición realizada por la Asociación Médica Mundial de la declaración de Tokio (World Medical Associstion [WMA], 1975), que definió la tortura como la deliberada, sistemática o insensible inflexión de sufrimiento físico o mental por una o más personas, actuando solas o en orden de cualquier autoridad, forzando a otra persona para dar información, hacer una confesión o cualquier otro motivo.

Autores como Bettelheim (1981), subrayan el factor muerte en la definición de tortura, afirmando que ésta comprende situaciones límites en que las personas se ven enfrentadas a la posibilidad de muerte en un contexto amenazante e inevitable. Últimamente, existe una clara posición establecida desde la convención de las Naciones Unidas (Naciones Unidas [ONU], 1984), que sostiene que la tortura es siempre realizada por la instigación o con el consentimiento o el acuerdo de un 
funcionario público u otra persona que actúa desde una posición oficial. Lo que significa una acción de un estado en contra de un individuo; y más aún, una acción usualmente fuera del proceso normal de investigación criminal y castigo.

Para nuestro estudio, emplearemos la definición que adoptó la Convención contra la tortura y otras penas o tratos crueles, inhumanos o degradantes de 1984, que define la tortura como:

Todo acto por el cual se inflijan intencionadamente a una persona dolores o sufrimientos graves, ya sean físicos o mentales, con el fin de obtener de ella o de un tercero información o una confesión, de castigarla por un acto que haya cometido o se sospeche que ha cometido, o de intimidar o coaccionara a esa persona o a otras, o por cualquier razón basada en cualquier tipo de discriminación, cuando dichos dolores o sufrimientos sean infligidos por un funcionario público, u otra persona en el ejercicio de funciones públicas, a instigación suya, o con su consentimiento o aquiescencia. No se considerarán torturas los dolores o sufrimientos que sean consecuencia únicamente de sanciones legitimas, o que sean inherentes o incidentales a ésta. El presente artículo se entenderá sin perjuicio de cualquier instrumento internacional o legislación nacional que contenga o pueda contener disposiciones de mayor alcance.

De esta definición, ha sido especialmente criticada la exclusión del sufrimiento y dolor mental (e.g. Basoglu, Livanou, y Crnobaric; 2007). Por su parte, Roberto Garretón (2004), desde el derecho internacional refiere que la definición de tortura contempla un acto, que puede ser una omisión además de una acción. Como por ejemplo, presenciar hechos de tortura sin ser parte de ella. El acto debe tener una intención y debe producir dolor o sufrimiento grave, siendo éste, el elemento material de la tortura, lo cual ha sido ampliamente criticado por la subjetividad que involucra (e.g. Villán, citado en Garretón, 2004).

Por último, es lamentable afirmar que la tortura y los abusos a los derechos humanos relacionados, continúan siendo la mayor amenaza al bienestar psicológico de los individuos y comunidades en el mundo entero (Silove, 1999).

\subsection{Modalidades (física, psicológica, sexual)}

La tortura suele clasificarse en tortura física, psicológica y sexual. Sin embargo, coincidiendo con Moreno y Grodin (2002), esta diferenciación puede volverse muy limitada y servirnos sólo para explicar su naturaleza y magnitud. 
Es muy extensa la variedad de técnicas de tortura que se han empleado en el mundo a lo largo de la historia, volviéndose una tarea imposible e inapropiada el hacer alusión a cada una de sus modalidades. Sin embargo, en el capítulo III, detallaremos las técnicas que el informe Valech reconoció oficialmente como las prácticas que fueron empleadas a los EXPPS en Chile entre los años 1973 y 1990.

Por otro lado, como es fácil de imaginar, la práctica de la tortura incluye métodos físicos y psicológicos que varían de un país a otro, e incluso de una región a otra dentro de un mismo país (Moisander y Edston, 2003). Lo que es un área de relevante interés principalmente para la medicina forense.

A nosotros nos interesa definir según los criterios del Informe Valech (Gobierno de Chile, 2004), lo que se entiende por cada uno de los tipos de tortura más comúnmente conocidos que fueron empleados en Chile.

En términos generales estos tipos de tortura se definen de la siguiente forma:

Por tortura física entendemos aquellos actos que cumplen con la definición de tortura que utilizamos en nuestro estudio, y que incluyen golpizas reiteradas, lesiones corporales deliberadas, colgamientos, posiciones forzadas, aplicación de electricidad, vejámenes y cualquier otro acto que produzca sufrimiento físico en la víctima.

Por tortura psicológica entendemos aquellos actos que cumplen con la definición de tortura que empleamos en nuestro estudio, y que incluyan amenazas, simulacro de fusilamiento, humillaciones, desnudamiento y cualquier otro acto que produzca sufrimiento psicológico en la víctima.

Por tortura sexual entendemos aquellos actos que cumplen con la definición de tortura que empleamos en nuestro estudio, y que incluyen todos los hechos de agresiones y violencia sexual, y todos aquellos actos con carácter sexual realizados a los EXPPS cuando estuvieron en cautiverio.

Creemos que los distintos tipos de tortura, se presentaron en muchos casos de manera simultánea. Así, el ejercicio de la tortura física incluyó implícitamente algún tipo de tortura psicológica; y por ejemplo, en el caso de la tortura sexual, el desnudamiento clasificado como tortura psicológica tiene componentes de tortura sexual (por la violencia sexual que implica la exposición del cuerpo desnudo ante otras personas, sin el propio consentimiento y en condición de cautiverio). 


\subsection{Objetivos de la tortura}

Los motivos por los que se emplea la tortura, se relacionan a la cultura, los regímenes y procesos políticos, y al momento histórico, entre otros. No obstante, pese a la diversidad de motivos y fenómenos políticos subyacentes, hay objetivos comunes en estas acciones y que guardan estrecha relación a los sucesos acontecidos en Chile durante el período de tiempo comprendido en nuestro estudio.

La variación en los objetivos de la tortura depende del impacto que se pretenda alcanzar con estas prácticas. De acuerdo a esta idea, se postula que a nivel individual, la tortura busca extraer información, castigar, exigir recompensa, deshonrar o inhabilitar al opositor político (Silove, 1996); y/o dañar física y mentalmente a la víctima (Piwowarczyk, Moreno y Grodin, 2000).

A nivel social, la tortura se emplea como estrategia general de limpieza étnica o genocidio (Silove, 1996), y/ o para extender el miedo a lo largo de la comunidad en la cual reside el individuo (Piwowarczyk, Moreno y Grodin, 2000). También para castigar y aterrorizar a disidentes políticos, religiosos o minorías étnicas (Moisander y Edston, 2003).

A nivel psicológico, la tortura busca destruir al individuo como opositor a un régimen político determinado, destruir además su voluntad, sus vínculos afectivos, creencias y lealtades, y en definitiva su integridad psíquica y física. De acuerdo a esto, rompe con el sentido de existencia del ser humano que la padece, mediante su destrucción física y psíquica.

El torturador por su parte, como representante de un régimen opositor represivo, impone al torturado un dilema extremo: el de dejarse maltratar hasta sentir un dolor intolerable, o dar información que perjudicará a sus compañeros (Lira y Castillo, 1991).

Para Silove, la tortura representa además de la amenaza a la vida y la seguridad, un ejemplo extremo de violación a los derechos humanos, en que el perpetrador de manera activa no solo busca amenazar a la víctima, sino también deshumanizarla, humillarla y degradarla (Silove, 1996). Esto se vuelve más complejo cuando los eventos que siguen a estas experiencias se asocian a la injusticia por la impunidad de los torturadores, viéndose las víctimas en la situación de tener que lidiar a diario con el recuerdo de las profundas injusticias que han sufrido (Silove, 1999). 
En general, el castigo y la represión sistematizada de comunidades enteras son algunas de los motivos de la tortura; y la pertenencia a un grupo político, social o natural de un lugar, una razón suficiente para ser torturado (Stover y Nightingale, 1985). Por último, la tortura fue el principal dispositivo de la dictadura para destruir a los detenidos de manera permanente y sistemática, con la finalidad que éstos renunciaran a sus ideales y proyectos comunes, se enfermaran, enloquecieran (Robaina, 2002).

\subsubsection{Trauma}

La palabra "trauma", viene del griego y significa herida. Para la Real Academia Española, comprende una "lesión duradera producida por un agente mecánico generalmente externo", un "choque emocional que produce un daño duradero en el inconsciente", y una "emoción o impresión negativa, fuerte y duradera" (Real Academia Española [RAE], 2001). Estas definiciones tienen en común, la alusión al impacto negativo y la elevada intensidad en la vida psicológica para quien padece un trauma. Consideramos que todas las situaciones represivas por motivos políticos como la tortura, los secuestros y las desapariciones, implican de alguna manera una amenaza vital, lo que las convierte en experiencias traumáticas en sí.

La prisión en tiempos de guerra, ha sido reconocida como una experiencia traumática extrema (e.g. Hunter, 1991, 1993), que puede vincularse a numerosos estresores crueles que se orientan a destruir la identidad de supervivientes a la prisión en guerra. Esto incluye tortura y terror, aislamiento carcelario y deprivación sistemática de necesidades básicas como comida, sueño, abrigo, actividad física y privacidad, todas bajo condiciones antihigiénicas.

Encontramos en la literatura científica la falta de consenso a la hora de conceptualizar el trauma producto de experiencias de violencia política y tortura. Lo que se debe en parte, a que para algunos esta noción se asocia al modelo médico que lo conceptualiza como estrés post-traumático; mientras para otros, refiere complejos procesos intra-psíquicos; y para otros la combinación de procesos psicológicos y sociales. No obstante esta falta de consenso, la mayoría de las definiciones de trauma generalmente incluyen los mismos elementos.

Nosotros haremos referencia a los tres enfoques del trauma, por considerar que todos aportan conocimientos a su entendimiento. El orden de presentación que seguiremos, se relaciona a la aplicabilidad de cada enfoque a nuestro estudio. Finalizaremos desarrollando el enfoque contextual del 
trauma, que considera la presencia de situaciones sociales específicas que aparentemente estarían caracterizadas por terror y destrucción (Becker, 2003).

\subsection{Trauma y estrés post-traumático (DSM-IV-R)}

El trauma, entendido como SEPT, ha sido estudiado de manera detallada en distintos contextos (e.g. Wilson, 1989; Horowitz, 1976; Raphael y Middleton, 1988), y se plantea que existen respuestas similares de síndromes de estrés como secuelas de un amplio rango de eventos traumáticos (Turner y Gorst-Unworst, 1993), asociadas a la personalidad pre-mórbida de la persona que lo padece (McFarlane, 1987). Son reacciones que pueden presentarse en cualquier persona que ha sido expuesta a elevados niveles de estrés (Wilson, 1988).

Introducimos con esta idea, un factor acerca del estrés: la necesidad de precisar la dosis necesaria para que una situación pueda provocar efectos traumáticos en una persona. Algunos autores han reportado dosis relacionadas a tales efectos, como por ejemplo Shore, Tatum y Vollmer (1986). Horowitz (1976), en base a estudios realizados a excombatientes, sostiene que cada persona tiene su punto de quiebre.

Por otro lado, la vulnerabilidad y los factores protectores de cada persona pueden influir en la respuesta individual al trauma (Silove, 1999). Siendo factores de riesgo de aparición del SEPT -como consecuencias psicológicas adversas de la tortura- variables tales como el sexo femenino (Beiser, Cargo y Woodbury, 1994; Chung y Kagawa-Singer, 1993; Hauff y Vaglum, 1993), y la historia psiquiátrica previa (Hauff y Vaglum, 1993). Por el contrario, son considerados factores protectores, las creencias religiosas, el sentido de compromiso con una causa política, y la preparación psicológica previa a la tortura (Allden, Poole, Chantavanich, Ohmar, Aung, Mollica, 1996; Basoglu, Ozmen, Sahin, Paker, Tasdemir, Ceyhanli, Incesu, Sarimurat, 1996; Basoglu, Mineka, Paker, Aker, Livanou, Gok, 1997; Holtz, 1998; Shrestha et al., 1998).

A lo anterior, se suman estudios realizados en población de supervivientes de tortura, que demostraron que la percepción de amenaza está altamente relacionada con el riesgo de estrés post traumático (Basoglu y Paker, 1995); y la reacción post traumática inicial, está condicionada a la presencia o ausencia de amenazas en el contexto del sobreviviente. Desde esta perspectiva, son importantes los estudios que se orientan a evaluar los efectos de las amenazas prolongadas en la perpetuación y exacerbación del SEPT (Silove, 1999). 
El enfoque médico del trauma, es quizás el modelo más utilizado o el más comúnmente asociado al concepto. Éste enfoque define al trauma con una serie de síntomas asociados a una enfermedad mental específica.

El trauma conceptualizado como síndrome de estrés post - traumático (SEPT), es la forma probablemente más conocida en el mundo, y la más usada desde que el año 1980 fuera incluido en el DSM III (American Psychiatric Association, 1980). Pese a todas las limitaciones asignadas a este enfoque, en la literatura científica existe la fuerte tendencia a conceptualizar el trauma como SEPT. Dentro de las investigaciones relacionadas, se encuentran las que estudian la relación entre los objetivos específicos de los eventos de trauma y los resultados en psicopatología (Silove, 1999). Dada la presencia de este enfoque en estudios relacionados al nuestro, estudiaremos a continuación el trauma como SEPT.

El trauma, según la clasificación internacional del desorden de estrés postraumático, consiste en una experiencia que está fuera del rango habitual de las experiencias humanas (American Psychiatric Association, 1987).

Woodcock (2000), define el trauma como un evento extremo; y alude a la de-construcción del trauma, distinguiendo entre el trauma como un evento y el trauma como un conjunto de secuelas psicológicas. Estas últimas, refieren un rango de respuestas psicológicas que pueden seguir a un evento extremo, en vez de una respuesta traumática única. Por otra parte, refiere que la persona puede responder con temor intenso, impotencia u horror. Respuestas que aunque limitan el rango de respuestas posibles, pueden ayudar a identificar estos rasgos particulares.

En adición a lo anterior, el criterio diagnóstico abarca tres elementos importantes que ocurren en quienes están traumatizados: la reexperiencia del evento extremo, estímulos evitativos asociados con este evento, y síntomas persistentes de excitación presentados con posterioridad inmediata al evento. La presencia de estos elementos por más de un mes, como causa de aflicción clínicamente significativa, o deterioro social u ocupacional, o en otras áreas importantes de funcionamiento, indican que una persona tiene SEPT (Woodcock, 2000).

Según el DSM-IV-R, el trastorno de SEPT es un trastorno que se presenta cuando:

a) la persona ha estado expuesta a un suceso traumático en el que se ha presentado una de las dos condiciones que presentamos a continuación: 
1. la persona haya experimentado, presenciado o le han explicado uno o más acontecimientos caracterizados por amenazas a su integridad física o la de los demás, o muertes;

2. la persona ha respondido con temor, desesperanza u horror intensos.

b) el acontecimiento traumático es reexperimentado de manera persistente, mediante una o más de las formas siguientes:

1. recuerdos recurrentes e intrusos del acontecimiento, que provocan malestar, y contienen imágenes, percepciones o pensamientos.

2. sueños recurrentes acerca del acontecimiento que producen malestar.

3. la persona actúa o tiene la sensación de que el acontecimiento traumático está ocurriendo. Esto incluye la sensación de estar reviviendo la experiencia traumática, alucinaciones, ilusiones y episodios disociativos de flashback, que pueden aparecer al despertarse o intoxicarse.

4. malestar psicológico intenso ante la exposición a estímulos externos o externos que recuerdan o simbolizan un aspecto del acontecimiento traumático.

5. respuestas de tipo fisiológicas ante la exposición a estímulos internos o externos que simbolizan o recuerdan un aspecto del acontecimiento que ha generado el trauma.

c) hay evitación persistente de estímulos asociados al trauma y el embotamiento de la reactividad general del individuo, ausentes antes del trauma, como indican tres o más de los siguientes síntomas:

1. la persona presenta esfuerzos para evitar sentimientos, pensamientos o conversaciones acerca del suceso traumático;

2. hace esfuerzos para evitar lugares, actividades o personas que motivan recuerdos del episodio traumático;

3. tiene incapacidad para recordar algún aspecto importante del trauma;

4. presenta una reducción acusada del interés o la participación en actividades significativas;

5. tiene la sensación de desapego o enajenación frente a otras personas;

6. manifiesta restricción en su vida afectiva ; y

7. tiene la sensación de un futuro desolador. 
d) hay síntomas persistentes de aumento de la activación o arousal, que no se presentaban antes del trauma, como indican dos o más de los siguientes síntomas:

1. dificultades para conciliar o mantener el sueño;

2. irritabilidad o ataques de ira;

3. dificultades de concentración;

4. hipervigilancia; $y$

5. exageradas respuestas de sobresalto.

e) todas las alteraciones presentes, que se detallan en los síntomas de los criterios b, c y d, se presentan con un periodo que supera el mes.

f) las alteraciones enumeradas provocan un significativo malestar clínico o deterioro social, laboral o de otras áreas que son importantes en la vida de quien las padece.

El DSM-IV-R, además permite hacer un diagnóstico diferencial de SEPT en función del tiempo de presentación de los síntomas. Un tiempo inferior de tres meses se clasifica de agudo, y un tiempo superior, se clasifica de crónico. También diferencia entre el tiempo de ocurrencia del evento hasta la aparición de los síntomas, clasificando de inicio moderado, cuando se presenta como mínimo a los seis meses de transcurrido el evento.

De acuerdo a este enfoque, el trauma es un acontecimiento en la vida de un sujeto que se caracteriza por la intensidad, la incapacidad de respuesta adecuada, y la presencia de un trastorno provocador de efectos patógenos en la organización mental del individuo (Laplanche y Pontalis, 1981).

Como podemos observar, la clasificación de SEPT del manual DSM-IV-R, tiene un carácter operativo para diagnosticar su presencia en personas que han vivido situaciones estresantes que puedan significar un trauma en sus vidas. Pero creemos que para estudios como el nuestro, es un diagnóstico limitado y poco aplicable, pues aunque los sucesos de violencia política y tortura son traumáticos para sus víctimas, la naturaleza cualitativa, los objetivos de nuestro estudio, y el tiempo transcurrido de los hechos superior a 30 años, la incidencia del diagnóstico de SEPT del DSM-IV-R en nuestra muestra, será muy baja y nos basaremos en criterios sociales y emocionales para estudiar el impacto de la prisión política. 
Una limitación de este enfoque a nuestro estudio, refiere la irrelevancia que se otorga a las causas y el entorno social en que acontece el trauma. Entonces, el trauma es entendido como consecuencia de un evento pasado, que dificulta la comprensión de situaciones traumáticas crónicas cuando el momento de aparición de síntomas antecede en muchos años su manifestación (Becker, 2003). En adición a esta idea, Bracken, Giller, Summerfield (1995), afirman que desde la inclusión de la categoría de SEPT al DSM III, el foco de interés científico ha estado en torno a la etiología de la personalidad pre-mórbida y al evento traumático. Sin embargo, han sido variables estudiadas de manera aislada, con exclusión del contexto social, político y cultural.

Una limitación más de esta visión de trauma, refiere la necesidad de consideración de postulados éticos en su definición y estudio, específicamente en el caso del trauma de supervivientes de guerra o de violencia política. Esto, fundamentado en la necesidad de un análisis conceptual que permita una interpretación particular, según Bracken et al. (1995). Nuestro estudio, pretende aportar en esta materia.

Nosotros entendemos que el SEPT captura la perturbación psicológica fundamental después de cualquier tipo particular de trauma, además de los conceptos previos del Síndrome de post-tortura (Allodi y Cowgill, 1982), el Síndrome del campo de concentración (Thygesen, 1980), y el Síndrome del trauma de violación (Burgess y Holmstrom, 1974).

Todo lo anterior, difiere de nuestro interés por estudiar el fenómeno, pues creemos que las causas del trauma en este caso son específicas y adquieren relevancia especial cuando éste es causado por un humano con premeditación, como es el caso de la violencia política y tortura ejercida por agentes del estado. Esta especificidad atenta en contra de todo el sistema cognitivo de las concepciones vitales de quien lo padece.

Añadimos finalmente, aquellos hallazgos en que hay investigaciones con supervivientes de traumas que indican que el SEPT ha sido reconocido como un diagnóstico insuficiente para explicar todas las reacciones de trauma reportadas (Turner y Gorst-Unworst, 1993; Herman, 1993; Silove, 1996; Silove, 1999). 
2.1.1.4.2. El trauma visto desde los mecanismos intra-psíquicos asociados.

Entender el trauma como un proceso dinámico en que el contexto social es relevante, pero el foco principal está en los complejos procesosmentales asociados, puede aportarnos información importante para entender el impacto que estudiamos en nuestro estudio.

Son muchos los modelos de SEPT que al igual que el modelo de Horowitz (1986), se enfocan en el factor intra-psíquico del proceso de trauma (e.g. Brett y Ostroff, citados en Bracken et al., 1995).

Becker (2003) por su parte, hace referencia a la dimensión individual del trauma, sosteniendo que los elevados niveles de terror, miedo y destrucción son parte de la estructura psicológica en el contexto del trauma. Desde este enfoque, el trauma implica una completa quiebra de cada individuo que sólo es comparable a la muerte, y que puede ocurrir en un momento terrible difícil de precisar con exactitud, o en un largo proceso, pero que siempre tiene el mismo efecto: en alguna parte a lo largo del camino, la estructura psíquica, el Yo, deja de existir. Y esto ocurre sin anestesia.

Desde este enfoque podemos ver que el trauma comprende un colapso en la estructura del sí mismo, que afecta todos los planos referenciales a nivel estructural y funcional del individuo, ocasionado por una amenaza catastrófica que genera una respuesta caótica, con la consecuente pérdida de la autonomía.

Desde esta perspectiva, se vuelve difícil la tarea de integración de la experiencia que lo ocasiona, y por ello, la persona no puede darle significado, lo que limita sus funciones autónomas (Benyakar, Kutz, Dasberg y Stern, 1989).

Bracken et al. por su parte, afirman que las conceptualizaciones actuales de la respuesta al trauma, se centran en los eventos intrapsíquicos, y en la quiebra de los procesos psicológicos o neurológicos por las experiencias traumáticas.

Horowitz (1986), plantea que el trauma afecta al ego del individuo que lo sufre, y sostiene que hay aspectos sociales, culturales y somáticos que están involucrados en el proceso de trauma. Por otro lado, valora de modo diferencial el fenómeno cognitivo del emocional que le subyace, centrándose en este último. Pero para Bracken et al., estas distinciones son comúnmente hechas en el mundo occidental, pero no son avaladas en muchas de las sociedades no occidentales. 
Para Becker, el concepto de trauma explica ciertos desórdenes mentales o perturbaciones psíquicas, causadas por eventos externos que exceden la capacidad de respuesta adecuada de la estructura psíquica. Visto así, el trauma es una reacción normal a una situación anormal, provocado por una situación que causa un sufrimiento psicológico extremo, pero cuya anormalidad es básicamente parte del entorno externo (Becker, 2003).

Para otros autores (Benyakar, Kutz, Dasberg y Stern, 1989), el trauma implica experimentar la muerte, siendo ésta, una connotación metafórica central de disrupción y discontinuidad, un sentido percibido de una quiebra irreparable de la estructura de personalidad de las personas y la realidad. Becker (2003), sostiene que la consecuencia del trauma es siempre una contradicción, pues por un lado el trauma equivale a la muerte, pero por otro, quien lo sufre continúa viviendo con el rencor de su experiencia. A nivel de la estructura psíquica, es como si se cayera a un lado de la experiencia traumática, y donde no hay psiquis, no hay memoria.

\subsection{El trauma desde un enfoque sociopolítico}

Creemos que el enfoque que concibe el trauma como un proceso social y político, es el enfoque que más aplicabilidad tiene a nuestro objeto de investigación. Este enfoque fundamenta sus postulados en estudios en países llamados del tercer mundo, que han demostrado que el efecto traumático no es sólo un proceso individual, sino que implica además un proceso social que impacta a la sociedad entera en que se presenta.

Para Becker (2003), el trauma debe entenderse en referencia al contexto específico social, cultural y político en que se genera, y su estudio en distintas realidades puede enseñarnos acerca del fenómeno. Se plantea así, la necesidad de formulación en cada país y contexto específico, de una definición local que dé sentido al trauma que se vive en ese contexto.

Para el caso de Chile, Becker define el término de "extrema traumatización", como un proceso individual y colectivo que refiere y depende de un contexto social determinado, marcado por la intensidad, duración prolongada e interdependencia entre las dimensiones sociales y psicológicas. Todo lo que excede la capacidad individual y social del individuo que lo sufre, para responder de manera adecuada a este proceso (e.g. Becker, 2003).

De acuerdo a lo anterior, Bracken et al., sostienen que el contexto tiende a ser visto de manera secundaria y como un factor que meramente choca en el progreso de los procesos psicológicos y 
biológicos del individuo. Por contra, autores sostienen que la realidad social, política y cultural en que suceden los hechos traumáticos, deben considerarse temas centrales, al igual que la realidad social comprendida por las circunstancias familiares, el acceso a las redes sociales, la posición económica y el estatus laboral.

Además, Bracken et al., afirman que en adición a lo anterior, deben valorarse las diferenciaciones entre factores como el compromiso político individual o la participación a un movimiento político, la posición social determinada por factores como el género, la clase y la etnia, y la condición de víctimas de represión de Estado o de otras formas de violencia organizada. Además de la realidad cultural de la posición lingüística, la implicación religiosa o espiritual, las creencias ontológicas básicas, el concepto del sí mismo, la comunidad y la enfermedad.

Desde esta perspectiva, las realidades sociales, políticas y culturales estructuran el contexto en que la violencia es experimentada, y determinan el sentido subjetivo de la violencia o el trauma, el modo como se experimenta el dolor asociado con la violencia, el tipo y la magnitud de apoyo general disponible para el individuo, además de las terapias disponibles y más apropiadas.

También Keilson, propone una valoración de trauma que realza el factor cultural en el concepto, instando a la formulación de una definición local. Plantea así, el concepto de proceso traumático secuencial cuyo origen se remonta al seguimiento de judíos huérfanos refugiados en Holanda como consecuencia de períodos de guerra (Keilson, 1992).

Desde el planteamiento de Keilson, las consecuencias del trauma involucran procesos cambiantes de la situación que lo ocasiona. Además plantea que los períodos por los que pasa la persona que padece un trauma, no necesariamente son negativos para su salud. De acuerdo a esta última idea, y concordando con Becker (2003), el impacto producto del trauma y el trauma en sí mismo, refiere la continuidad de un proceso traumático con posterioridad a la experiencia.

Creemos que esta definición de trauma es apropiada para nuestro estudio, a la vez que aplicable al caso de Chile. Adquiere así, relevancia el cambio secuencial ocurrido desde el 11 de septiembre de 1973 en Chile, con etapas que se fueron sucediendo y que podemos diferenciar desde el momento del golpe de Estado, el período de persecución, el de prisión, y el tiempo posterior a la dictadura militar, que involucra también un período de persecución, y que actualmente parece estar marcado por la lucha a favor del respeto de los derechos humanos, el cese de la impunidad y mejoras en la reparación gubernamental. 
Este planteamiento hace entender mejor otro aspecto señalado por diferentes autores referidos a los efectos sobre la memoria. Por ejemplo, Becker (2003), sostiene que el trauma a nivel individual y social como el producido por experiencias como las que estudiamos en nuestra investigación, producen la destrucción o fragmentación de la memoria. El autor considera que tanto las personas traumatizadas como las sociedades en las cuales ha ocurrido un trauma masivo, tienen memoria de ello, pero es una memoria fragmentada. Existe a lo mejor, solo el recuerdo de lo que ocurrió justo antes y después de lo que ocasionó el trauma, lo que muchas veces, puede ser una fantasía de la memoria. Cualquiera sea el caso, siempre implica la muerte y el letargo en vida.

Considerando los tres enfoques expuestos en esta sección, definir una noción de trauma es una tarea difícil y no es el objeto de esta investigación. Sin embargo, consideramos necesario especificar que para nosotros una definición operativa del trauma de la experiencia de prisión política y tortura, comprende elementos de los tres enfoques, aunque nos centraremos principalmente en el último de los presentados, por considerarlo más significativo y apropiado para los objetivos de la investigación en curso.

Por otro lado, creemos que no necesariamente quienes vivieron experiencias de prisión política y tortura han reaccionado mediante una respuesta traumática. Suponemos que dependiendo de la crueldad de los hechos, sufrieron o no un trauma con posterioridad a dichas experiencias. Por otra parte, en quienes presentaron esta reacción, creemos que después de 30 años posiblemente no presentarán el SEPT del DSM-IV-R. No obstante, consideramos oportuno incluir la noción de trauma propuesta, para considerar el sufrimiento inmediato de la prisión política y los procesos posteriores, como elementos que pueden presentarse dentro del impacto de la experiencia que estudiamos.

\subsection{Fases del proceso de trauma}

Aunque no estudiamos aquellas reacciones a corto plazo posteriores a la experiencia de prisión política, consideramos relevante presentar la descripción de las fases del trauma de los autores que hemos citado en este apartado, porque nos darán luces acerca del origen del impacto que estudiamos.

Creemos que las personas que viven el trauma de la violencia política y tortura pese a que presentan sufrimiento, pueden aprender a no sentirse perseguidas por sus experiencias, mantener relaciones interpersonales, y formar parte de uno o varios grupos, sin curarse. 
Dentro de las fases del proceso de trauma, Simon y Blum (1987), plantea un modelo compuesto de cuatro fases de respuestas de las víctimas: una primera reacción de shock, escepticismo y rechazo, seguido de una segunda fase que comienza cuando la víctima comienza a tener conocimiento de la magnitud de la amenaza violenta, caracterizada por un estado de miedo congelado, o seudo-calma, además de conductas de aislamiento. Las fases tercera y cuarta, incluyen la demora de respuestas y ocurre con posterioridad al evento: en la tercera fase, la víctima experimenta depresión traumática que es combinada con sentimientos de recriminación hacia su persona. En la cuarta fase y final, las víctimas pueden resolver la experiencia traumática y continuar un estilo de vida normal.

El modelo de Simon y Blum (1987) ha sido ampliado por Flynn (1987), quien modificó el segundo estado de miedo congelado, sosteniendo que en este período hay una breve etapa de suspensión temporal, en que las víctimas esperan de manera no realista que las autoridades les rescaten pronto. En esta fase, tienden a aceptar una posición sumisa y vulnerable. En la fase final, que coincide con la fase tres del modelo de Simon y Blum, las víctimas se resignan cada vez más y emplean una variedad de estrategias para sobrellevar la experiencia, realizando actividades como leer, escribir, contar lo sucedido y reflexionar.

Corrado y Tompkins (1989), afirman que a pesar de las estrategias recientemente mencionadas para sobrellevar la experiencia, personas expuestas a prolongados períodos de detención pueden llegar a vivir un estado de desesperación que les sobrepase, y experimentar un "traumático infantilismo psicológico" (Corrado y Tompkins, 1989, p. 284), que se expresará en actos de apaciguamiento, obediencia y sumisión. Todo lo que nos revela posibles secuelas a largo plazo.

Además, Corrado y Tompkins (1989) sostienen que puede ocurrir una transferencia negativa en el caso de la exposición prolongada de supervivientes a períodos de terror, en que las víctimas creen que el terrorista les ha permitido vivir. Symonds por su parte, plantea que el fenómeno planteado por Corrado y Tompkins, se basa en profundos y persistentes cambios de actitud y de conducta, que se basan en el alivio que siente la víctima al ver al terrorista como un "tipo bueno" (Symonds, citado en Corrado y Tompkins, 1989, p. 284).

Hatcher (1987) postula un quinto estado. Para este autor, existe un primer estado que involucra la negación de la realidad de las víctimas y la manifestación de respuestas asociadas a una de tres alternativas, consistentes en inmovilidad, huida o miedo; un segundo estado, en que la víctima comienza a aceptar lo ocurrido, aumentando su obediencia y sumisión; un tercer estado, en que 
aumenta la interacción cooperadora entre la víctima y el perpetrador. En el cuarto estado, hay miedo e incertidumbre asociado con la desintegración del control del perpetrador; y finalmente, en el quinto estado, la seguridad se reestablece y a menudo incluye una segunda oleada de miedo y ansiedad, que Symonds (1980) asocia a ansiedad, fobias, insomnio y depresión.

El modelo propuesto por Corrado y Tompkins (1989), es una extrapolación de cinco estados generales elaborados desde el trabajo de Symonds (1980), Flynn (1987) y Hatcher (1987), quienes fueron definiendo y modificando algunos de sus estados. Este modelo, plantea un primer estado en el que ocurre un período de trauma intenso asociado con el choque inicial desde donde es abducido; un segundo estado, en el que ocurre la resignación y la aceptación; un tercer estado que se caracteriza porque la víctima usa varios mecanismos que le permiten sobrellevar la experiencia; un cuarto estado caracterizado por una ansiedad renovada, asociada con la desintegración del control del aprehensor; y por último, un quinto estado, que incluye varias secuelas que se desarrollan después del término de la experiencia aterrorizadora (Corrado y Tompkins, 1989).

Corrado y Tompkins (1989), sostienen que la mayor evidencia sistemática y concluyente del impacto más frecuente y profundo del terrorismo de estado, se encuentra en la documentación y los casos de estudios de víctimas de campos de concentración. Para cuyas víctimas, tiene una importancia crucial la primera fase de la experiencia para la supervivencia (desPres, citado en Corrado y Tompkins, 1989). Pues los supervivientes reportan que una menor adaptación rápida a la vida del campo de concentración de opresiva brutalidad, se asocia a la muerte inmediata (e.g. Smith, citados en Corrado y Tompkins, 1989). Bettelheim (1979) por su parte, afirma que las víctimas que son incapaces de adaptarse durante las tres primeras semanas, a menudo se vuelven severamente deprimidas, retraídas y apáticas.

Bettelheim (1979) identifica tres amplias categorías de reacción durante el período posterior al campo de concentración. La primera de ellas, incluye individuos con desórdenes mentales persistentes, que les impiden un funcionamiento eficaz a nivel social y laboral. La segunda, incluye personas que no han experimentado prolongados efectos psicológicos, y la tercera, considera a personas que comprometieron toda su vida en el esfuerzo por tratar los efectos emocionales.

En conclusión, pese a la diversidad de factores que diferencian una situación traumática de otra, todos los autores citados hasta aquí, concuerdan en la idea de la presencia de un impacto psicológico en los supervivientes a experiencias de prisión política. 
Dentro de los efectos a largo plazo, creemos que el miedo, el sufrimiento y la pérdida, tenderán a presentarse a lo largo de la vida de los supervivientes, y las experiencias traumáticas generarán cambios de actitudes y de conducta en ellos hacia el mundo, y los seres humanos. Incluso pareciera que se establece un vínculo con la figura del opresor que también se mantiene durante sus vidas. Otras secuelas psicológicas que pueden presentar los supervivientes a largo plazo, pueden ser trastornos ansiosos relacionados a la experiencia. Estos efectos, varían en cuanto a la capacidad adaptativa de cada persona, aunque de una u otra forma cabe esperar que todos los que han sufrido experiencias traumáticas por motivos políticos, sufrirán algún tipo de consecuencia.

\subsubsection{Factores contextuales de la violencia política y tortura}

A continuación estudiaremos algunos factores contextuales que debemos atender para entender el impacto emocional y social de la privación de libertad y tortura por motivos políticos en Chile, en el período que comprende nuestro estudio. En este apartado estudiaremos la influencia del contexto según estudios realizados en distintos países del mundo y que nos guiarán para establecer aquellos factores contextuales que hacen único el caso de Chile. Esto último, será estudiado en el capítulo III.

\subsubsection{Gobierno y sociedad}

La intencionalidad política asociada a la experiencia traumática, producirá significaciones en la persona afectada que atribuirá a tal experiencia, dentro del contexto histórico en que sucedió. De acuerdo a esto, la reestructuración posterior a la experiencia traumática, dependerá de las reacciones de las personas en base a un conjunto de recursos afectivos e ideológicos, entre otros (Lira, Becker y Castillo, 1989).

El contexto socio-político en que acontecen sucesos de violencia política, condicionará los efectos traumáticos de los supervivientes a estas experiencias. La dureza de estos efectos y la actitud de indiferencia o rechazo -entre otras- por parte de la sociedad en que se presentan los hechos, impiden la manifestación del dolor propio de haber sido víctima de este tipo de violencia, quedando ese dolor reducido al plano individual y privado de la persona que lo vive (Lira, Becker y Castillo, 1989).

La disrupción del orden civil que a menudo se propicia en el contexto de la tortura y los abusos relacionados, conducen a quebrantar las redes sociales, los sistemas de justicia, los servicios de salud y otras estructuras de apoyo, que en otras circunstancias, constituyen importantes elementos en el reestablecimiento del entorno para el sobreviviente del trauma (Silove, 1999). 
Becker (2003) afirma que existe la tendencia mundial frente a hechos desastrosos como la violencia política y tortura en masas, en que los espectadores que forman parte de la sociedad donde acontecen estos hechos, tienden a percibir a las víctimas como una amenaza, y suelen ser los principales constructores de la "conspiración del silencio" (Becker 2003, p. 8).

En un contexto de guerra y persecución, la sociedad por su parte suele ver a quienes están directamente involucrados dentro de un continuo de poder y lucha. Ellos también han sufrido desde la pasividad y la ansiedad, las situaciones del conflicto y posiblemente esperan poder hacer algo al respecto, pero suelen mantenerse al margen. Lo que les situará en una posición de apolíticos y visualizarán el problema con lejanía (Becker, 2003).

De acuerdo a lo anterior, la tortura no sólo tiene efectos importantes en las víctimas directas, sino que también en la sociedad en general. Este impacto puede asociarse a cambios existenciales profundos, que han sido descritos por niños supervivientes al Holocausto y por muchas que se relacionaron con víctimas de tortura y persecución (Turner y Gorst-Unworst, 1993). Es así como en países que viven represión y tortura a gran escala, todas sus comunidades pueden verse afectadas a nivel social y político (Martín-Baró, 1988). Lo que, por cierto, también es un objetivo para los regímenes represores.

Considerando el impacto social de hechos de violencia política y tortura en la sociedad no afectada directamente, y creyendo que afecta a todos quienes conforman una sociedad, podemos pensar que esto produjo cambios de actitudes y de comportamiento en la sociedad chilena que influyeron negativamente en las relaciones sociales establecidas con los EXPPS. Esto podría incidir en la insatisfacción de las necesidades sociales básicas de las víctimas, según la teoría de López (2008).

\subsubsection{Familia}

La familia vista como contexto, es uno de los factores más relevantes en el estudio del impacto emocional y social de la privación de libertad y tortura por motivos políticos. Hay evidencia científica que nos indica que la familia tiende a crear una conspiración del silencio en torno al EXPP que promueve, entre otros efectos, el ocultamiento de la experiencia de prisión a los ojos de los hijos (e.g. Johnston, 1995; Myers, Smarsh, Amlund-Hagen y Kennon, 1999).

Muchos estudios realizados a supervivientes del Holocausto, han revelado la existencia de fuertes posibilidades de transmisión del trauma producto de experiencias de guerra a las generaciones 
siguientes, y han observado problemas en salud mental en la segunda y tercera generación de las víctimas a tales hechos (e.g. Bar-On et al, 1998). Otra importante línea de investigación ha relacionado los patrones de apego (Bowlby, 1984), con características emocionales resultantes de trauma o pérdida en padres EXPPS y sus hijos (Crittenden, 1992; Main y Hesse, 1990). Estos estudios han observado que la presencia de un duelo irresuelto en los padres producto de experiencias de guerra y prisión, puede afectar negativamente el bienestar de sus hijos (Igrega, 2003).

Nosotros creemos que ocultar la experiencia de prisión y todo lo que ello implica como la lucha por una ideología política y las experiencias vividas en cautiverio a los hijos, define un tipo de relación particular con ellos basada en el secreto, un secreto que, por otra parte, está presente bajo múltiples formas. En efecto, consideramos que experiencias como las vividas en prisión, son trascendentales en la vida de quien las padece y el ocultamiento de éstas, marca cierta distancia con los hijos que impide una verdadera comunicación. Por otro lado, este ocultamiento no suele ser exitoso ya que los efectos siempre presentes de una u otra forma del trauma producto de la experiencia de prisión, en los EXPPS que lo han experimentado, pueden transmitirse a los hijos y futuras generaciones, como lo han comprobado otros estudios a los que nos hemos referido con anterioridad en este mismo apartado.

En el caso de Chile, después de más de 30 años de ocurridos los hechos, podemos pensar que las familias de los EXPPS han sufrido más que el resto de la población, distintas variaciones como la separación, la formación de nuevos núcleos familiares, etc.. Nosotros estudiaremos las relaciones de los EXPPS con sus familias de origen antes del período comprendido entre 1973 y 1990, y lo compararemos con las relaciones con sus familias actuales, para con ello establecer algunas asociaciones que puedan mostrar indicadores del impacto de la experiencia de prisión en sus relaciones interpersonales familiares, y con ello evaluar el tipo de satisfacción de este tipo de necesidades.

Por otra parte, a pesar del impacto sobre la familia, esperamos que el núcleo familiar haya sido el apoyo fundamental para estas víctimas.

2.1.2.3. Represión política, estigmatización de las víctimas y generalización del miedo.

La represión política se justifica en la construcción psicológica e ideológica de la categoría de enemigo. Cuya construcción comprende en sí misma un elemento aterrador y siniestro, ya que el otro es también un ser humano (Lira, 1991). 
El concepto de identidad negativa planteada por Erikson (1968), nos permite entender desde un enfoque psico-social, aspectos subyacentes a la prisión política. El autor plantea que en tiempos de crisis colectivas, como el período de represión política al que hacemos referencia en nuestro estudio, los líderes políticos tienden a depositar sus rabias y frustraciones en el opositor, justificando así su proceder asociado a la violación de los derechos humanos. Su concepto nos permite explicar el porqué han sido perseguidos grupos específicos de personas.

El concepto de identidad negativa de Erikson, para Goffman es análogo a la estigmatización de personas (Goffmann, citado en Lira, 1991). Entendiéndose el concepto de estigma, como la situación de descalificación de un individuo. Es en esta formulación ideológica donde la represión encuentra su justificación, al incorporar en sus dominios, la categoría de enemigo: los EXPPS. En este contexto, la tortura es vista como un recurso legal, contra esas personas a las que se le da una identidad negativa, son estigmatizadas, para el ejercicio del control político de una sociedad (Lira, 1991).

Por su parte las víctimas, corren el riesgo de tender a la autodestrucción por ver negado el carácter social de su sufrimiento o por sobre-politizar este sentimiento, justificando al haber sido declaradas enemigos. De este modo, la persecución durante toda la vida, tiende a mediar la vida de quien la sufre, haciendo que la posición de víctima sea muy difícil de llevar, pues ellos no pueden olvidar, pero si continúan viviendo (Becker, 2003).

Todo ello parece aplicarse claramente al caso de Chile porque, como señala Elizabeth Lira (1991) en su trabajo titulado "Psicología de la amenaza política y el miedo", el miedo en toda la sociedad chilena fue una de las consecuencias de la represión política en Chile, cuyos integrantes percibieron una amenaza vital por años. Lo que se vio acrecentado por el asesinato de algunas personas que no eran políticas, reforzando la percepción de que toda la sociedad estaba amenazada.

\subsection{Silencio, la negación de lo que sigue haciéndose presente}

En un régimen político represivo como el de Chile entre 1973 y 1990, el silencio cumple el rol de la negación de los hechos que acontecen, haciéndonos creer que lo que no se ve, no existe (Lira, Becker y Castillo, 1989); pero que contradictoriamente nos remiten a temores, sufrimiento e incertidumbre, difíciles de enfrentar como sociedad.

El silencio actúa en contra de los intereses de la sociedad, perpetuando el conflicto en la vida de quienes la conforman. Lo que sumado a un régimen dictatorial que precisa de la sociedad para que 
ocurra una dictadura, hace que sus integrantes tiendan a ocupar un rol que se considera enfermo, dentro de este proceso, en que no solo no se preocupan por los que sufren, sino que además suelen estar asustados de lo que ocurre, sin que se puedan denunciar sus causas ni sus efectos. Reforzando con esta dinámica al poder político dominante, que se hace indiscutible, puesto que no se le puede criticar, sino limitarse a obedecerlo (Becker, 2003).

El silencio visto así, cumple el rol de proteger del pesar y el miedo, reducidos a una experiencia privada de la que no se puede hablar, que se produce en sociedades donde ocurren hechos de terrorismo de Estado. Pero dicho silencio tiene efectos dramáticos para las víctimas, puesto que limita la elaboración de los sucesos acontecidos en la vida de quienes padecen estos hechos, negando el espacio necesario para superar lo vivido, analizando y denunciando las causas, elaborando el propio sufrimiento y logrando la necesaria reparación. En efecto, estas personas no pueden hablar acerca de sus experiencias, porque la sociedad no está preparada para escucharles. En este sentido, una sociedad que tiende a mantener en silencio los hechos que acontecen dentro de su realidad sociopolítica, es seguro que es muy negativa para la resolución de traumas y conflictos personales y sociales, asociados a la represión política.

\subsection{Temor}

El temor que contextualiza los hechos está asociado a la amenaza social de la represión política. Ambos, temor y amenaza, configuran un tipo de relación social específica, que está definida por el contexto político en que estas relaciones suceden (Lira, 1991). Temores y amenazas que, por cierto, se basan en razones objetivas cuando la represión se sostiene en el tiempo, pero que se acrecientan subjetivamente en las víctimas.

Para Lira (1991) el miedo se genera en la subjetividad de las personas y por ello es una experiencia privada que no se ve socialmente, pero que incide en la conciencia y la conducta de las personas. Este miedo afecta la cotidianidad y las condiciones de la supervivencia material, aumenta la sensación de vulnerabilidad propia y a la posibilidad de pérdida de seres queridos. Este temor, sumado a la posibilidad de muerte física y al conflicto con las lealtades políticas, generan una contradicción en los EXPPS que emerge desde la misma represión política. Todo ello hace que estos factores contextuales provoquen conflictos internos entre la lealtad a valores políticos y los valores de la vida y el bienestar que se desea. Por ello pensamos que quienes dieron información mientras fueron interrogados en cautiverio sintieron, además de terror por la amenaza latente de muerte, culpa por 
haber traicionado a sus compañeros y al movimiento partidista en el que participaban activamente. Lo que pudo afectar en su ideología y actitudes y comportamientos hacia sus pares, y que actualmente nos remite a un impacto emocional y social producto de tales experiencias en el pasado y que de alguna forma pudo mantenerse durante muchos años, los años que duró la represión posterior, en los que estuvieron condenados a vivir la contradicción entre la fidelidad a las ideas políticas y las ganas de vivir sin sufrir las consecuencias de la represión.

Por otra parte, creemos que es muy difícil evaluar estos aspectos en los EXPPS, porque suponemos que no será fácil para ellos -en el caso de haber dado información en los interrogatoriosreconocer que delataron a sus compañeros. Por ello no indagaremos de forma explícita estos hechos, ni su conducta en prisión, sino que nos centraremos en cómo han vivido las relaciones con los compañeros ideológicos o de partido.

\subsubsection{Exilio}

Un apartado aparte requiere el estudio del impacto emocional y social de EXPPS que vivieron el exilio. Esto, porque puede que algunos de los sujetos que acepten participar en nuestro estudio, cumplen con la condición de residir en Chile en el momento de la evaluación, aunque hayan vivido el exilio en el pasado. No obstante, no es objeto de nuestro estudio estudiar exclusivamente estas variables, que ya han sido estudiadas en muchos contextos y países; pero creemos necesario hacer algunos señalamientos que consideramos importantes de considerar y que podrían incidir en el impacto que estudiamos en esta investigación.

Mucho se especula acerca de quienes parten al exilio. Estas especulaciones son formuladas sobretodo por aquellos EXPPS que no optaron por ese camino y por diversos motivos permanecieron en su país de origen. Podríamos pensar que quienes se quedaron en Chile, pueden tender a pensar que quienes partieron al exterior tuvieron mejores posibilidades de vida y más oportunidades. Basándonos en la lógica de que lo que no se vive, se idealiza; y de que muchos EXPPS llegaron al país en el período de la democracia y ocupan altos cargos gubernamentales después de haber tenido la posibilidad de estudiar en prestigiosas universidades extranjeras en su condición de asilados políticos.

Por el contrario, otros ponen el acento en que quienes se trasladaron a otros países por motivos políticos en calidad de refugiados, generalmente se ven expuestos a la continuidad de prolongados sufrimientos por inseguridad y deprivación, siendo muchas veces confinados a campos de concentración (Mollica et al., 1993); otros viven en un continuo estado de inseguridad en centros de 
detención (Human Rights and Equal Opportunity Report, 1998); o en condición de asilados sin estado (Silove, McIntosh y Becker, 1993; Silove, Sinnerbrink, Field, Manicavasagar y Steel, 1997; Silove, 1999).

A lo anterior, se añade el quiebre de la continuidad cultural que amenaza la identidad de estas personas, produciendo cambios que producen sentimientos de impotencia y pasividad, además del moldeo de psicopatología de acuerdo a población traumatizada (Silove, 1999).

En relación a los estudios realizados a víctimas de prisión política y tortura, hemos constatado en la bibliografía científica, la tendencia en investigación de estudios realizados en países de acogida, o en campos de refugiados o en comunidades que se han formado con este denominador común (Silove, 1999). Nuestro estudio no sigue esta tendencia, lo que le otorga un carácter novedoso por formar parte de un pequeño grupo de investigaciones que se han realizado y se realizan en el presente, a supervivientes de experiencias de prisión política y tortura in situ.

\subsubsection{Efectos psicológicos en supervivientes de violencia política y tortura}

Los efectos de la violencia política y la tortura son muy variables y van desde una repuesta que debe considerase normal por la gravedad de los hechos sufridos, hasta secuelas que pueden llegar a ser clasificadas de psicopatológicas. Estos efectos dependen de muchos factores como la naturaleza de los hechos que sucedieron, las características de las víctimas, como su resiliencia ${ }^{1}$, por ejemplo, y los apoyos recibidos.

Pese a que no todos los EXPPS chilenos sufrieron experiencias de tortura, con independencia de lo que definimos por tortura en una sección anterior de este mismo apartado, creemos que la mayoría de ellos vivieron experiencias similares cuando permanecieron en prisión. En cuanto a los efectos de la tortura en quienes vivieron estas experiencias, autores como Baker (1992) definen factores de riesgo: el sexo femenino, el tiempo y las condiciones de encarcelamiento, traumas psicológicos previos, preparación mental previa, nivel de educación, historia de tortura y edad de los supervivientes a estas experiencias.

\footnotetext{
${ }^{1}$ Entendemos por resiliencia aquella capacidad del ser humano que le permite resistir a condiciones adversas y recuperarse mediante el desarrollo paulatino de respuestas que se orientan a la construcción de un ajuste psicosocial positivo al medio, a pesar de la existencia simultánea de dolor y de conflicto intrapsíquico (Silva, citado en Arregui, 2002).
} 
Seleccionamos la información que presentaremos en este apartado, en base a la aplicabilidad que consideramos tienen estos estudios en la presente tesis doctoral. En esta selección no olvidamos la amplia gama de matices que diferencian el contexto y la realidad de cada país, pero debido a la escasa investigación realizada en población chilena, nos vimos obligados a enfocarnos en poblaciones distintas a la población chilena, motivados en la creencia en la universalidad de la temática: la violación a los derechos humanos.

Incluiremos además, un apartado que hace referencia al impacto de la violencia sexual en mujeres, cuya especificidad se justifica por la alta incidencia en mujeres según la información presentada en el Informe Valech, al que haremos referencia en el capítulo III.

\subsubsection{A nivel individual, social y familiar}

Turner y Gorst-Unworst (1993), resaltan que la tortura y muchas otras formas de violencia organizada, comprenden una actividad con una compleja parowticularidad social, psicológica y secuelas físicas. En efecto, adaptarse a la cotidianidad de una persona que ha vivido situaciones de violencia política, es tarea difícil, pues los mecanismos de adaptación y los valores que le sostenían se vuelven insuficientes, pudiendo tener efectos catastróficos en su vida (Lira, Becker y Castillo, 1989).

La reacción post-traumática de experiencias de violencia política, conforma un proceso individual en cada persona, familia o grupo que vive estas experiencias. Este proceso evoluciona con el tiempo, y parte de una situación específica que es común a muchas personas, pero que sin embargo tiene la particularidad de los recursos y carencias que existen y reaccionan en cada sujeto ante la situación.

A nivel sintomatológico, el impacto individual dependerá de aquellos aspectos generales y compartidos del contexto social y de la situación de represión vivida (Lira, Becker y Castillo, 1989). En este nivel, el sobreviviente de tortura no sólo ha sufrido agravios físicos y ha visto amenazada su vida de muerte, como ocurre también en el caso de desastres naturales. Además ha tenido que lidiar con un adversario que buscó causar un cambio psicológico máximo.

Para Lira Becker y Castillo (1989), las personas que han sufrido traumas extremos, presentan daños o conflictos a nivel psicológico que les imposibilitan integrar la experiencia a su personalidad consciente, causando en ellos una des-estructuración en la personalidad, en que el daño y las defensas 
que se desarrollan a partir de la experiencia, se incorporan inicialmente en la reorganización frente al trauma.

Para muchos supervivientes, el momento del trauma significó la pérdida de ellos mismos, que fue experimentado en un pre-lenguaje, como un conjunto de íconos y sensaciones corporales. Se postula que ellos tienen la sensación de haber tenido una experiencia espantosa única y alienada a otros, como si las conexiones con los demás se hubieran separado y ellos estuvieran perturbados. En el plano existencial, se sienten totalmente solos, lo que es como si el padre interno que está presente en cada persona, encargado de nutrir, proteger, mediar las experiencias primitivas y proveer el establecimiento de verdades básicas, se ha destrozado en el sobreviviente (Woodcock, 2000).

En el mismo plano existencial, Turner y Gorst-Unworst (1993) sostienen que los supervivientes a eventos traumáticos de tortura, presentan un dilema existencial que es inducido por quienes emplean técnicas de este tipo. Para entender este dilema, deben considerarse las dimensiones políticas y sociales en que estos hechos ocurren, debido a que las personas son torturadas por un propósito que no necesariamente se asocia a la obtención de información relevante.

El sobreviviente torturado por su parte, presenta un doble dilema, asociado a la realidad de la tortura en el mundo del torturado y su supervivencia inalterada, y a la insidiosa presión del torturador por cambiar sus ideas. Visto así, la tortura puede definirse como un evento catastrófico existencial (Bendfeldt-Zachrisson, 1985).

Silove (1999) refiere que la maldad y crueldad de la tortura, pueden alterar las creencias de los supervivientes en cuanto a la bondad de la vida y la humanidad; y llevar a los supervivientes a tener preocupaciones existenciales asociadas a encontrar una razón coherente que les permita entender los abusos sufridos, muchas veces sin lograrlo. Afectando así, su sistema de significado existencial.

De acuerdo a lo anterior, la necesidad de vivir en un mundo de tal crueldad, afecta significativamente el propósito de la propia existencia. Desde esta perspectiva, es muy probable que experiencias tempranas y culturas políticas o religiosas determinadas, produzcan fuertes efectos en su gente (Levi, 1987). Mayor es el impacto en quienes han dado información delatando a sus compañeros y a su grupo político, lo que muchas veces implica la destrucción de sus vidas, y el cambio radical de sus mundos (Turner y Gorst-Unworst, 1993). 
Desde este enfoque existencialista, se postula que los supervivientes a experiencias de tortura enfrentarán una crisis de confianza, fe y sentido, que puede intensificar los sentimientos de alineación y aislamiento emocional (Gorst-Unsworth, Van Velsen y Turner; 1993).

Las diferencias individuales asociadas a la predisposición psicológica a eventos traumáticos de cada persona y a la amplia variación en los tipos de incidentes de terrorismo de estado, hacen que sea difícil precisar consideraciones generales (Corrado y Tompkins, 1989). Por su parte, Silove (1999), sostiene que la tortura produce cambios en la identidad de las personas, específicamente en el sí mismo, como distorsiones en el concepto del sí mismo y el sentido de identidad.

A nivel inconsciente, se cree que el trauma de la tortura puede tener importantes significados. En algunos casos, antes de que ocurran estos eventos, los individuos pueden mantener frágiles fantasías narcisistas de omnipotencia que serán completamente destrozadas por la experiencia en sí, viéndose fragmentado y desintegrado el sí mismo de las personas afectadas (Ullman y Brothers, 1988). Al respecto, Turner y Gorst-Unworst (1993), afirman que esto coincide con los supervivientes atendidos en la Medical Foundation for the Care of Victims of Torture de Reino Unido, quienes reportaron como una de las tareas más difíciles en el proceso de recuperación, la reconstrucción de su fraccionado sentido del sí mismo.

Otra reacción que suelen presentar los supervivientes a experiencias traumáticas como la tortura, es la culpa interna por el hecho de haber sobrevivido y de ver que sus compañeros, familiares y/ o amigos murieron en la misma situación. Para estas personas, tener suficiente apoyo de pares o poder retornar de manera activa a su religión o a sus agrupaciones políticas, favorecerá la posibilidad de sobreponerse o suprimir en sus vidas algunos de los aspectos de la tortura. El mundo para estas personas, se vuelve un mundo sin amor, en el que los supervivientes pueden encontrar un pequeño sentido personal, pues hasta cierto punto pueden reconciliar al nuevo sí mismo con la nueva realidad del mundo externo actual (Turner y Gorst-Unworst, 1993).

Turner y Gorst-Unworst (1993) refieren una fase de victimización que pueden tener los EXPPS que han sufrido tortura. Es una fase en que ellos pueden culparse por su propia condición de supervivientes.

De acuerdo a West, Livesley, Reiffer y Sheldon (1986), la exposición a eventos de vida adversos, activa los sistemas de apego previos, dando lugar a modos característicos de relación con el entorno social. Para individuos seguros, esto promueve el uso del apoyo social en el servicio de necesidades 
emocionales e instrumentales. La importancia de la expresión de emociones negativas en un entorno de apoyo y la importancia de apoyo social en situaciones estresantes, han sido ampliamente documentados en la literatura (e.g. Hobfoll, 1985). Al respecto, hay evidencia empírica de la importancia que tienen los estilos de apego en la adaptación que sigue al estrés traumático. Lo que puede deberse a que el estilo de apego, influye directamente en ambas reacciones inmediatas de adaptación a largo plazo.

Para Woodcock (2000) la teoría del apego ofrece un marco conceptual de trabajo, que apunta a los procesos de internalización de eventos extremos y la movilidad de los síntomas traumáticos provocados por la tortura. Sostiene que quienes resisten eventos extremos, posteriormente a menudo reportan sentirse perdidos en el momento y tener la sensación de incapacidad para procesar lo que les está ocurriendo a nivel cognitivo y emocional. Las experiencias extremas producen marcas en los supervivientes como pérdidas y que experimentan como una terrorífica soledad existencial.

Desde la teoría del apego, se plantea que en las personas que vivencian experiencias de prisión política y tortura, se produce un apego perturbado de una representación interna del sí mismo. Volviéndose difícil la tarea de socializar, lo que motiva un retraimiento en ellos y ansiedad social, y les impide tener la capacidad de mantener relaciones estables con otros. La concretización de procesos psíquicos y sociales causados por eventos extremos, son lo opuesto a la experiencia de simbolización creativa, que surge en el espacio de transición, en que la capacidad para ser reflexivo disminuye (Woodcock, 2000).

Woodcock (2000) hace alusión a los efectos de eventos extremos en las representaciones internas de las figuras paternas en personas que padecen estos eventos. El autor plantea, que estas representaciones se pueden destruir por la exposición a estos eventos, en relación al tipo apego que se tiene con los propios padres. Esto podría influir, según Woodcock, de manera negativa en la parentalidad de los EXPPS con sus hijos, quienes pueden experimentar con padres que sólo son la sombra del pasado del sí mismo.

Un estudio comparativo realizado por Solomon, Ginzburg, Mikulincer, Neria y Ohry (1998) evaluó las experiencias subjetivas del cautiverio, el estado de salud mental actual y características del estilo de apego, a ex - prisioneros de guerra de Yom Kippur, 18 años después del llamado conflicto árabe - israelí. Este estudio, concluyó que aquellos individuos que presentaron un estilo de apego seguro, presentaron bajos niveles de sufrimiento y de impotencia, elevada capacidad para adaptarse al cautiverio, y mejor adaptación a largo plazo. Creemos que pese a las diferencias contextuales y 
culturales de la población aludida y la cultura chilena, estos hallazgos nos orientan acerca de la presencia de un impacto post - prisión con muchos años de posterioridad.

Kobak y Sceery (1988) sostienen que personas con apego seguro cuando se enfrentan a situaciones adversas, tienen la capacidad de modular los afectos negativos de manera constructiva, y presentar menor ansiedad. Esto demuestra, que tempranas experiencias positivas con la responsabilidad de otros en situaciones de aflicción, fueron internalizadas de una manera que les permitió contener afectos negativos, reconociendo el sufrimiento y activando la búsqueda de otros por confort y apoyo. Lo que es particularmente significativo durante la prisión, que se caracteriza por la completa impotencia donde los EXPPS no pueden hacer mucho por cambiar el entorno.

En el caso de las personas evitativas, los autores plantean que éstas tienden a adoptar una estrategia de des-apego y de dar término a relaciones cuando están con ira o en situaciones de estrés. Tienen además, mayor probabilidad de auto-restringir el reconocimiento de dolor y emociones negativas asociadas a la importancia percibida de relaciones interpersonales y apoyo social. Ellos pueden incluso, llegar a expresar emociones de hostilidad de manera inapropiada en sus relaciones sociales.

Por último, las personas ambivalentes, se caracterizan por sufrir desde bajos umbrales de activación de dolor y en general, tendencias destructivas que interfieran con la habilidad de mantener la confianza en sí mismo, en un entorno diferente (Ainsworth, Blehar, Waters y Wall, 1978).

Askevold (1980), descubrió que supervivientes de guerra que no estuvieron en campos de concentración, pero que estuvieron expuestos a la amenaza constante de muerte, presentaron secuelas orgánicas de deterioro de la memoria y pérdida de concentración, que definió como el síndrome del “marino de guerra". Esto demuestra que el impacto psicológico no se debe solo a la opresión física de vivir en campos de concentración, sino que al hecho de vivir bajo continuas amenazas de muerte y desastres personales.

De acuerdo a lo anterior, Turner y Gorst-Unworst (1993) sostienen que el deterioro cognitivo asociado al SEPT, probablemente es consecuencia de dos procesos: cambios en el estado emocional que afectan la concentración y el procesamiento de información de los supervivientes; y un daño orgánico cerebral desde el daño directo, la tortura eléctrica, la malnutrición, o la enfermedad física producida en prisión. 
Schlapobersky y Bamber (1988) sostienen que existen aspectos existenciales de la condición de post-tortura que implican una forma de esclavitud en que el torturador asegura que su intervención persistirá.

A nivel social, las consecuencias de la tortura no afectan sólo al individuo que la sufre, sino que además a sus familiares y amigos, que esperaron con incertidumbre y miedo durante el tiempo en que sucedieron estos hechos (Cohn et al., 1985).

Para autores como Turner y Gorst-Unworst (1993), las secuelas de la tortura deben diferenciarse entre los distintos tipos de traumas y sus distintas acepciones. Una de estas acepciones, entiende la tortura desde el efecto de cambios psicológicos específicos en cada persona. Efectos que variarán dependiendo de las diferencias entre personas y situaciones. Además los mismos autores, sostienen que aunque la opresión de la voluntad de las víctimas por el torturador sea un tema común, para algunos será una interrogante, para otros será un castigo y para muchos formará parte de un proceso de represión política y religiosa.

Becker (2003) afirma que la experiencia de trauma no sólo daña la capacidad de trabajo y de amar de una persona, sino también, la capacidad de tratar con las agresiones de manera saludable. Para el autor, las víctimas tienden a evadir el tema de las agresiones vividas, pues han sufrido bastante por ello y sólo quieren olvidar lo más rápido posible estos hechos, y con ello reconciliarse. Las agresiones no son percibidas como destructivas, sino como algo que las víctimas necesitan para seguir sus intereses de vida, que necesitan expresar, comunicar, y que les permitirán defenderse en situaciones similares.

No obstante lo anterior, en base a su experiencia de trabajo terapéutico con supervivientes de prisión política y tortura, Becker (2003) sostiene que muchas veces las víctimas vuelcan su potencial agresividad hacia ellos mismos, más que hacia los torturadores, lo que hace que se sientan enfadados por la pérdida y vergüenza asociadas a este sentimiento. Esto implica que los torturadores no solamente representan un peligro para las víctimas, sino que además ocupan todo el terreno de los sentimientos agresivos en ellos. De acuerdo a esta idea, el daño en las personas traumatizadas se encuentra, en la pérdida de la propia capacidad de salud por la presencia de rabia.

El número de situaciones como las que estudiamos en la presente tesis doctoral, pueden ser vividas una sola vez, o por el contrario, formar parte de una serie de sucesos que se fueron repitiendo. En este último caso, cada experiencia no significaría un trauma en sí, pero la sumatoria de sus efectos, conformaría una experiencia traumática (Lira, Becker y Castillo, 1989). 
Nosotros en concordancia con otros autores, desechamos la noción de un síndrome de tortura individual (Allodi y Cowgill, 1982; Basoglu y Marks, 1988; Turner y Gorst-Unworst, 1993), postulando que el impacto de la tortura, no solo implica reacciones individuales muy complejas, sino que tiene efectos en la comunidad y la sociedad.

Desde hace tiempo, estudios han demostrado que son comunes los síntomas que presentan los refugiados después de la tortura, consistentes en una mezcla de secuelas entre daños físicos permanentes y afecciones psicosomáticas, pero que no pueden diferenciarse claramente (Moisander y Edston, 2003).

En comparación con otros grupos de emigrantes, tanto refugiados como quienes buscan asilo político, presentan elevadas tasas de morbilidad y mortalidad. La enfermedad que prevalece, incluye condiciones tales como hepatitis B, tuberculosis, parásitos intestinales, SEPT, depresión y ansiedad (Ackerman, 1997). Esta prevalencia es mayor en refugiados torturados que en los mismos no torturados.

Un estudio realizado en refugiados judíos de Kibbutz, concluyó que no está claro en qué grado la depresión, el estrés y la ansiedad, afectan la salud mental de estas personas, pero si está claro que son las enfermedades que generalmente se observan en ellos (Abbott, citado en Reynolds y Shackman, 1993). Sin embargo, resulta paradójica la poca demanda de atención en salud mental en centros de atención para refugiados (e.g. Bernier, citado en Reynolds y Shackman, 1993). Esto último, se asocia a que puede que tanto diagnósticos como tratamientos, sean inapropiados para algunas culturas, o que estas personas opten por resolver sus propios problemas sin ayuda externa (Reynolds y Shackman, 1993).

Un estudio estadístico realizado en la University Institute of Forensic Medicine en Copenhague, evaluó las secuelas de la tortura en víctimas procedentes de Turquía exiliadas en Dinamarca, que habían padecido golpes y electricidad. Este estudio, comparó el estado de salud, el consumo de alcohol, la edad y el sexo en estos supervivientes. Se concluyó que durante el proceso evaluativo, los sujetos presentaron perturbación del sueño con pesadillas, deterioro de la memoria, labilidad emocional, capacidad de concentración alterada, jaquecas, aflicción cardio-pulmonar y muscular, dispepsia y problemas de lectura. Todos reportaron haber tenido buena salud antes de la tortura. El examen clínico por su parte, reveló pocos signos relacionados a la tortura, aunque se observaron casos de cicatrices pequeñas, fracturas o pérdida dental, desórdenes neurológicos moderados y depresión. Con lo que se concluye 
que la tortura tiene efectos traumáticos en sus supervivientes (Hougen, Kelstrup, Petersen y Rasmussen, 1988).

Los hallazgos encontrados en la investigación a la que acabamos de hacer referencia, coinciden con resultados de estudios previos realizados a víctimas de tortura, que revelan un pobre estado de salud en supervivientes a estas experiencias. A su vez, estos síntomas no son específicos y los supervivientes presentan pocos signos físicos que pueden atribuirse a la tortura. Por otro lado, la comparación realizada con el grupo control, reveló que éstos últimos presentan una notable acumulación de síntomas mentales no específicos, atribuibles al efecto de la expatriación (Hougen, et al., 1988).

No obstante lo anterior y en concordancia con la evidencia científica, quienes han vivido tortura en prisión, presentan mayores secuelas psicológicas que quienes estuvieron en prisión, pero no sufrieron este tipo de hechos (Thorvaldsen, citado en Hougen, et al., 1988)

El consumo de sustancias como drogas o alcohol fue mínimo en el grupo estudiado, y se confirma que la tortura y la inmigración, no inciden en este tipo de conductas (Hougen, et al.). Todos los sujetos estudiados, reportaron haber estado en malas condiciones de prisión, y el examen físico reveló pocos signos de tortura, siendo los más comunes, pequeñas cicatrices inespecíficas.

Hougen, et al. sostienen que se han realizado numerosos estudios comparativos del estado de salud de las víctimas de tortura, en relación a otros grupos de personas expuestos a situaciones de estrés extremo. Ellos consideran que la condición de víctimas de tortura no sólo es el resultado de la tortura y el encarcelamiento, sino también de vivir con un constante miedo por la posibilidad de volver a ser encarcelados y torturados. Esto en sí mismo, genera niveles de estrés comparables a otras condiciones que pueden causar el aumento de morbilidad (Hoching, citado en Hougen, et al.). Lo mismo puede ocurrir en quienes viven en exilio (Eitinger, citado en Hougen, et al.).

Hougen, et al. afirman que el primer estudio controlado que se realizó acerca de las consecuencias de la tortura en la salud, fue publicado por Petersen y Jacobsen (1985). Este estudio comenzó en el país de origen de las víctimas, quienes eran conscientes de la posibilidad de futuros encarcelamientos y torturas.

Moisander y Edston (2003), evaluaron las secuelas de la tortura, comparando a víctimas de seis países: Bangladesh, Siria, Turquía, Uganda y Perú. El estudio concluyó que los sujetos presentaron un 
alto porcentaje de SEPT (entre el 69 y el 92\%), y diferencias significativas entre países, con independencia de circunstancias, métodos y secuelas de tortura. La secuela más presente en los participantes del estudio, fue la jaqueca crónica, y penas asociadas. En la población peruana, en relación a los otros grupos, presentó un menor promedio de síntomas psicosomáticos físicos, un porcentaje más alto de SEPT que la media, pero asociado a un bajo riesgo de suicidio (Moisander y Edston, 2003).

Dor-Shav (1978) por su parte, investigó los efectos a largo plazo de la reclusión en campos de concentración nazis a 25 años después. Los sujetos mostraron evidencia de empobrecimiento y opresión. Con lo que el autor concluye que “iel precio sigue siendo pagado!” (Dor-Shav, 1978, pp. 1, 11).

Por último, un estudio realizado a población chilena, observó que la manifestación de conflictos producidos por la experiencia de prisión, se mantuvo en comportamientos psico-sociales y/ o enfermedades orgánicas. Todo lo que refleja una elevada dificultad para mantener un curso de vida integrado y normal, en los supervivientes chilenos víctimas directas de la represión política en el país (Martín, 2002).

\subsection{Impacto específico de la violencia sexual en mujeres}

Mención aparte merece el impacto causado por la violencia sexual a mujeres. Pues como ya hemos mencionado anteriormente, según el Informe Valech, casi el total de la población femenina reconocida como EXPP chilena, fue víctima de este tipo de violencia.

El estudio del silencio por su parte, ha sido especialmente enfocado a las víctimas de violencia sexual. En esta línea de investigación, un estudio cualitativo realizado en la Universidad de Leiden (Tanking, 2006) a mujeres que emigraron desde Afganistán, Bosnia y Sudán del sur a Holanda, por la guerra y en condición de víctimas de violencia sexual durante la huída, revelaron que la principal estrategia que emplearon fue guardar la experiencia de abuso sexual en secreto. Pero aunque ésta, parecía ser la actitud general de la mayoría de las mujeres en cuanto a sus experiencias sexuales, la investigación concluyó que en el caso de las mujeres estudiadas, su silencio se debe además de al tabú cultural de la violencia sexual, al resultado de una realidad compleja y dinámica en su diario vivir, en que a menudo se enfrentan a normas culturales confusas y contradictorias, y a la expectativa entre la cultura de origen y la cultura de refugiados. 
Tanking (2006) postula que mantener en silencio la experiencia de violencia sexual, es la mejor manera que una persona tiene, para enfrentar la experiencia. El impacto de estas experiencias, afecta a nivel individual, relacional, comunitario y social; y en el caso de mujeres refugiadas en otros países, se debe considerar además que los mecanismos de apoyo tradicionales se rompen cuando éstas emigran.

A nivel individual, la misma autora afirma, que muchas de las mujeres que vivieron violencia sexual, presentaron sintomatología de SEPT, ansiedad y depresión, pero que no siempre revelaron a otros estos síntomas. Ellas presentaron culpa asociada a ideas de no ser una buena mujer a los ojos de Dios, o a haber estado en el lugar y en el momento equivocados.

Considerar la cultura en países como África y Asia, es necesario a la hora de estudiar el fenómeno de la violencia política en países con ideologías diferentes a la población chilena. Esto, debido a la diversidad humana existente en base al factor cultural, que podría incidir en los resultados obtenidos en las distintas investigaciones que hemos seleccionado para esta sección.

$\mathrm{Al}$ respecto, se postula la existencia de un vínculo muy estrecho entre la identidad personal y la identidad sexual. Por este motivo, la violencia sexual en sí, es una agresión al centro del sí mismo de una persona, que además afecta la identidad relacional. Esto, debido a que en muchas de estas comunidades, la identidad de las personas no es vivida como un sí mismo individual, sino como un sí mismo familiar, que se experimenta como el producto de una intensa relación familiar (Roland, citado en Ramanujam, 1992). De este modo, la experiencia de violencia sexual, es sentida y expresada en el contexto familiar de estas mujeres y el contexto de su grupo social, sintiendo una gran cuota de responsabilidad acerca de lo que les ocurrió, intentando no hablar de ello para protegerse y proteger la posición social de su gente.

Otro aspecto a nivel individual, es la incorporación de la experiencia que afectó además de sus mentes a sus cuerpos. Al respecto, Schreuder (Schreuder, citado en Tankink, 2006), afirma que muchas personas que han sufrido violencia sexual, no tienen palabras para describir la experiencia, o no recuerdan, o sólo recuerdan partes de ella. No obstante, estas experiencias, quedan guardadas en la memoria corporal. Se refieren con ello a lo implícito, a una parte inconsciente de la memoria, que no siempre está abierta a una reflexión consciente. El silencio asociado a la experiencia, puede producir desordenes mentales, pero los recuerdos del cuerpo, pueden también expresarse en afecciones físicas. Muchas de las mujeres estudiadas en Afganistán afirman que el suicidio es una mejor opción ante la 
violencia sexual. Lo que actualmente para muchas de ellas, hace que no contemplen esta posibilidad, la responsabilidad que sienten hacia sus niños. Pero esto no quita que la vida para ellas haya terminado.

A nivel relacional, Tankink (2006) afirma que en muchas culturas, la violación a las mujeres afecta además de a la dignidad individual, a la dignidad de sus familias, siendo el esposo el que se siente más afectado, pues ha perdido su honor y respeto. Por ello, en muchos casos, la mujer siente que debe proteger a su esposo, siendo éste su motivo para guardar silencio, pues significa salvarle de la humillación y respetar sus sentimientos. Por otro lado, estas mujeres suelen sentir temor de ser abandonadas por sus esposos si ellas revelan su experiencia de violencia sexual. De hecho, muchas mujeres corren el riesgo de ser separadas de sus familias, o en casos más extremos, y como forma de recuperar el honor familiar, en Afganistán pueden ser obligadas a casarse con quien las ha violado. Una situación que puede ser desencadenante de violencia doméstica. A lo que se añade la influencia de la experiencia de violación sexual en la vida sexual marital.

No obstante lo anterior, también hay esposos que tras conocer la historia de violencia sexual de sus mujeres, las cuidan y apoyan. Sin embargo, Tankink (2006) señala, que como aquellos esposos que tienen conocimientos de violencia sexual cometida a sus parejas, no hablan acerca de ello, ésta es una conducta invisible para otras mujeres. Por ello, ellas sólo conocen las narrativas de sus culturas acerca de mujeres que se han divorciado de sus esposos por esta causa.

El silencio a nivel comunitario, está asociado a que los esposos piden a sus parejas que no hablen de la experiencia. Existe además miedo a que los miembros de la misma comunidad hablen en forma de chisme del tema.

En relación a las similitudes de los efectos de la violencia sexual a otros tipos de violencia, el silencio de la experiencia, produce miedo, aislamiento y exclusión social.

A lo anterior, se suma el preciado valor que tiene la virginidad en algunas sociedades, que hace que en muchos casos, el encontrar esposo sea algo imposible si en el entorno social se conoce el caso de violencia sexual, volviéndose algo muy vergonzoso para la mujer y su familia. Lo que empeora con la ocurrencia de embarazos causados por violaciones, pues el hecho del embarazo, evidencia en estas mujeres la violación, y el hijo producto de estos hechos, es más vulnerable a ser juzgado de portarse mal. Una vez más, el silencio es la única forma de protección de estos niños (Tankink, 2006). 
Tankink (2006) afirma que todas las mujeres consideran que el silencio es el mejor mecanismo para cubrir sus experiencias pasadas y para prevenir cualquier tipo de humillación o manipulación por parte de miembros de sus grupos de refugiados.

A nivel social, el silencio dependerá del contexto en el que las víctimas de violencia sexual se desenvuelvan con posterioridad a la experiencia. En el caso de prisioneros de guerra, variará si deben abandonar el país en calidad de refugiados políticos o si permanecerán en el mismo, pues creemos que permanecer en el mismo sitio, evidenciará la experiencia. Por otro lado, el contexto al que se inserten quienes han sufrido este tipo de violencia y el apoyo profesional que puedan recibir, influirá en la forma en que enfrenten la experiencia.

En conclusión, se afirma que la violación sexual en situaciones de conflicto, es un arma en contra de una comunidad entera; y su impacto, es equiparable a la explosión de una bomba. En la violación sexual, este hecho no va hacia fuera, sino hacia adentro de la víctima, que además explota cuando habla de ello, afectando sus relaciones y la comunidad en que forma parte. Visto así, el silencio por el que optan la mayoría de las mujeres, les permite protegerse de sus familias de una continua violación (Tanking, 2006).

Desde el modelo planteado por Silove (1999), al que hemos hecho referencia anteriormente, la violencia sexual en mujeres puede implicar una amenaza mortal en ellas, pues atenta en contra de su concepto personal y su sentido de integridad, además de hacer un quiebre en el funcionamiento marital, como una consecuencia de la injuria, el estigma de los embarazos no deseados, y como un instrumento de limpieza étnica, constituyendo una amenaza masiva a la identidad, la cultura y la religión de la comunidad entera.

En cuanto a investigaciones realizadas en población chilena, existe un estudio realizado por dos organizaciones chilenas no gubernamentales (Gutiérrez, 2005), que estudiaron esta temática en la población femenina que nos ocupa en nuestra investigación. Los hallazgos concluyen que para muchas mujeres detenidas que fueron víctimas de violencia sexual, les fue difícil indentificar este tipo de agresiones como una forma de tortura, principalmente por asociar la tortura a aquellas técnicas sistemáticas empleadas como electricidad, colgamientos, etc. Estos hechos fueron realizados por funcionarios de las fuerzas armadas en más de 100 lugares que incluyeron cuarteles, comisarías, campos de concentración, casas de tortura, estadios, entre otros. Y dentro de las técnicas usadas, se encuentran el empleo de perros para violación y vejaciones, y de ratas que se introducieron en la vagina de sus 
víctimas. Fueron además, objeto de este tipo de tortura, mujeres embarazadas, menores de edad y ancianas que fueron violadas en presencia de sus hijos.

\subsubsection{Etapa evolutiva actual y secuelas: adultez vs vejez}

A la hora de revisar los estudios científicos enfocados a los efectos del trauma de la tortura, nos encontramos con la predominancia de estudios longitudinales realizados a población sobreviviente al Holocausto y a su descendencia (e.g. Kellerman, 1999; Sagi-Schwartz et al., 2003).

Kellermann (1999), postula que después de más de medio siglo de post-guerra, sus supervivientes siguen siendo perseguidos por sus experiencias pasadas y sufren períodos de depresión, ansiedad y síntomas psicosomáticos, que perjudican su funcionamiento cotidiano. Lo que sumado a procesos evolutivos propios de la vejez, hacen que deban vivir constantes retos a diario, como crisis mentales, penas asociadas al envejecimiento, jubilación y enfermedades que pueden parecer insuperables cuando son vistas desde la sombra del pasado. A lo que se suma la tendencia en una amplia proporción de supervivientes de presentar angustia asociada al conocimiento que disponen del Holocausto, a no buscar ayuda profesional en varias fases de sus vidas, o a negar los sentimientos de tristeza, o a vivir con un sufrimiento mental crónico sin buscar ayuda.

Nosotros creemos que la etapa evolutiva es importante a la hora de estudiar el impacto de la experiencia de prisión, pero no hemos encontrado información relevante de estudios a poblaciones similares que se centren en este aspecto. Sin embargo, creemos que la muestra que conformará nuestro estudio, puede incluir a personas mayores de 65 años por los años transcurridos del período de represión política en Chile que comprende nuestro estudio.

\subsubsection{Presencia de la imagen del torturador}

Hay algunos estudios que se han centrado en aquellos factores asociados a la relación entre el torturador y el torturado, con posteridad a los hechos. Nosotros creemos que en el imaginario de las víctimas de experiencias de tortura, sobretodo en quienes estuvieron imposibilitados de ver a quienes ejercían estos hechos, se establece una relación con la figura del torturador que se mantiene a lo largo de sus vidas. Esto, por desconocimiento de quien realizó los hechos, y puede acabar estando representado por figuras del gobierno u otras personas. 
Volviendo al modelo planteado por Corrado y Tompkins (1989) y de acuerdo a lo anterior, se plantea que las víctimas de violencia política y tortura, tienen diferentes maneras de procesar su experiencia. Dentro de estas modalidades, una estrategia importante de sobrellevar lo sucedido, es la transferencia que se establece desde la víctima al torturador, que para estos autores incluye un vínculo emocional entre ambos, que puede ser muy cercano. Todo lo que está condicionado por el tipo de la experiencia.

Sin embargo, esta transferencia a la que hacemos referencia, resulta de las condiciones compartidas de estrés y supervivencia, sobretodo en detenciones prolongadas; y por ejemplo, tanto la víctima como el perpetrador, realizan una supervivencia compartida, que depende de la decisión de las autoridades de cómo se resolverá el alejamiento. Lo que sumado a la emergencia de otras dinámicas tales como el agotamiento, el hambre, el aburrimiento y a lo mejor lo más importante, la discusión de información personal u otra de tipo relevante, hacen que sea favorable el desarrollo de la transferencia (Corrado y Tompkins, 1989).

Bettelheim (1979), observó que algunas víctimas desarrollaron una estrategia de supervivencia que incluyó la identificación con los valores y conductas del agresor. Lo que en casos extremos llevó a que las víctimas se volvieran informantes, y fueran más crueles que sus represores con sus compañeros (Corrado, 1988). Para Simon y Blum, el proceso de transferencia puede servir "como una función defensiva que mitiga el miedo y la impotencia” (Simon y Blum, 1987, p. 194). Siendo la culpa, la consecuencia más seria en víctimas que han experimentado esta transferencia (Corrado y Tompkins, 1989).

Nosotros indagaremos la posible existencia de estas relaciones y su presencia en la actualidad con los sucesos de vida de los EXPPS que entrevistaremos. Pues creemos que quienes refieran información acerca de la presencia de este tipo de relaciones en su vida, refleja un impacto emocional de la experiencia de prisión en el presente.

2.1.3.4. La experiencia de prisión política y tortura: necesidad de criterios diagnósticos específicos.

Consideramos que pese a las distintas clasificaciones diagnósticas que se emplean para clasificar el impacto de la prisión política y tortura, no existe una categorización específica para el caso de Chile, y dadas las especificidades que caracterizaron a los hechos en cuestión, creemos necesario disponer de una clasificación particular. Al respecto, esperamos que los hallazgos de nuestro estudio aporten información para el establecimiento de una clasificación específica para el caso de Chile. 
Kellermann (1999), plantea que aunque exista la necesidad de tratamiento psiquiátrico y de realizar una descripción de los supervivientes de guerras en términos de desórdenes psiquiátricos, los profesionales en salud mental que tratan a estos pacientes y a sus familiares, no han logrado un consenso en cuanto a definir las problemáticas que presentan estas personas según estos criterios diagnósticos.

Otro motivo por el que se precisa de criterios diagnósticos específicos para el trauma provocado por experiencias de tortura, refiere la particularidad de éste tipo de eventos en la vida de una persona. Se postula que quien padece experiencias de tortura, configura una situación de doble vínculo frente a una situación límite de extrema indefensión, sometiéndose a violencia extrema, en que para salvaguardar su vida, debe renunciar a sus creencias, valores, y todo lo que le identifica como persona. Lo que puede significar una forma subjetiva de morir.

Otra especificidad del trauma provocado por la tortura, es el contexto interpersonal en que acontece, pues estos hechos se caracterizan por la degradación y deshumanización máxima de una relación entre el torturado y el torturador. Quizás este aspecto sea el que vuelve este tipo de experiencias, más abrumadora que cualquier otra (Lira, Becker y Castillo, 1989). Este factor específico, hace que la experiencia además de ser la más abrumadora para el individuo, tienda a debilitar sus mecanismos defensivos, recursos y posibles respuestas (Fundación de Ayuda Social de las Iglesias Cristianas [FASIC], 1987). Siendo este otro motivo para especificar los aspectos que caracterizan el impacto de experiencias de este tipo.

\subsection{Criterio de estrés post traumático (DSM-IV) y tortura}

Pese a las limitaciones que se han hecho al concepto de SEPT previamente citadas, el establecimiento de éste, como resultado final común de diversos traumas, ha ayudado a unificar las diferencias presentadas en la investigación del trauma (Mollica y Caspi-Yavin, 1992). A continuación presentaremos la utilidad de este modelo.

Podemos observar una evolución a través del tiempo, del criterio de SEPT, que ha sido modificado con las nuevas versiones del DSM, basándose en la actualidad en un modelo más etiológico que en sus orígenes. Actualmente, son elementos centrales de este síndrome, la intrusión, la evitación y el fenómeno de sobre-excitación que indudablemente ocurren en personas que han sufrido tortura (Mollica, Wyshak y Lavelle, 1987). 
Se ha demostrado empíricamente que en general todos los terapeutas dedicados al tratamiento de las víctimas del Holocausto, utilizan valoraciones clínicas de sus pacientes. Se plantean entonces, beneficios para el uso del diagnóstico en supervivientes al Holocausto y que en definitiva son los que en parte fundamentan la fuerte tendencia actual a usarlos con personas que han sufrido sucesos similares. Es así, como dentro de los beneficios que posee este uso, para autores como Kellermann (1999), la no consideración de la clásica nosología psiquiátrica en el diagnóstico y tratamiento con víctimas supervivientes al Holocausto y sus hijos, puede ser negativo por la imposibilidad de realizar una evaluación preliminar de los efectos terapéuticos que puedan compararse con resultados de otras investigaciones, y con ello, verse estancado el progreso científico en esta área. Se plantea así, la necesidad de realizar valoraciones diagnósticas y/ o psicosociales para el tratamiento de estas víctimas.

Además, el criterio diagnóstico del SEPT del DSM-IV, se considera el más adecuado para el diagnóstico de las víctimas, por sus características ampliamente reconocidas en la literatura científica en salud mental, además de su estandarización, y sobretodo, la delimitación del diagnóstico que sigue siendo imperativo a la hora de describir la manifestación de síntomas en la población clínica sobreviviente del Holocausto y su descendencia. Además, como sistema diagnóstico multi-axial, atiende no solo a una amplia variedad de personalidades mentales comunes y desórdenes físicos, sino también aspectos del entorno y del funcionamiento que se pueden descuidar si el foco se centra en valorar sólo la manifestación conductual de su psicopatología.

A lo anterior, se suma la importancia de traumatización prolongada en supervivientes del Holocausto, que hace que el eje IV del criterio diagnóstico del DSM-IV referido a la severidad del estresor psicológico, y el eje $\mathrm{V}$ de valoración global del funcionamiento actual, sean especialmente relevantes.

Debido a la creciente evidencia en cuanto a la relación entre características, intensidad y naturaleza del acto de exposición al trauma, y factores postraumáticos como determinantes de la vulnerabilidad individual al estrés postraumático, los hallazgos no superan la actual evidencia epidemiológica que indica que los valores de estrés postraumático, son relativamente bajos en población que ha sufrido exposiciones prolongadas al trauma de guerra y desplazamientos (Mollica et al., 1993; Shrestha et al., 1998), especialmente cuando las comparaciones se han realizado con medidas de estrés postraumático en poblaciones que han sido expuestas a un amplio rango de desastres naturales y a eventos únicos de traumas civiles (Blaszczynski et al., 1998; y Green, 1996). 
Sin embargo, otros factores relacionados a las guerras y las condiciones en que ocurre la prisión política y el exilio, pueden provocar más traumas en quienes viven estas experiencias, que la experiencia de violencia en sí (Silove, 1999). Estos indicadores se elevan, cuando se trata de estudios en población de países en guerra, perseguida por motivos políticos, y que fue posteriormente atendida en clínicas y hospitales. Pues estos grupos de supervivientes, presentan elevados niveles de SEPT (Kozaric-Kovacic, Folnegovic, Skrinjaric, Szajnberg y Marusic, 1995; Ekblad y Roth, 1997; Weine, Becker, McGlashan, Laub, Lazrove, Vojvoda y Hyman, 1995; Lavik et al., 1996). En concordancia a lo anterior, se presentan generalmente mayores niveles de somatización (Somasundaram y Sivayokan; 1994) y depresión, que de SEPT en supervivientes a experiencias de tortura (Hinton et al., 1993; Mollica et al., 1993).

La prevalencia de SEPT en población general, es de alrededor del 1\%; en refugiados no torturados que estuvieron en campos de batalla del 20\%; y en refugiados torturados del $67 \%$ (Westermeyer y Williams, 1998; McNally, 1992). Con ello, podemos ver que la incidencia de SEPT varía según el estudio y la población evaluada.

La baja prevalencia de SEPT en supervivientes de tortura, se basa en sólidas valoraciones epidemiológicas realizadas en poblaciones de refugiados, que sostienen que esta valoración se mantiene incluso ante la exposición a múltiples eventos traumáticos (Silove, 1999). Por otra parte, se ha contrastado empíricamente que el trauma general de guerra y las experiencias de pérdida, ejercen efectos indirectamente en síntomas de SEPT, combinados con el impacto de la tortura y la detención (Steel, Silove, Bird, McGorry y Mohan, 1999).

Enfocarse en la adaptación de los supervivientes a experiencias de tortura durante el Holocausto, sugiere que la tortura y otras violaciones a los derechos humanos pueden ejercer profundos efectos en quienes sufren experiencias de este tipo, que son abarcados por los síntomas incluidos en el criterio de SEPT (e.g. Bergmann y Jucovy, 1982). Estas reacciones psíquicas, incluyen el síndrome del sobreviviente o de campo de concentración "KZ" (Thygeson, 1980), y el síndrome de tortura (Allodi, 1991). En la década pasada, se han referido al término como "complejo estrés traumático", "caracterología postraumática o variación de la personalidad", y "síndrome de victimización” (Silove, 1996). En término de rasgos, se asocia a falta de motivación, inestabilidad afectiva, deterioro cognitivo, cambios de personalidad, somatización, formas extremas de ira, culpa y vergüenza, además de amplias fluctuaciones de dificultades interpersonales y tendencia a la revictimización. 
Los síntomas más comunes encontrados del SEPT en víctimas de terrorismo de estado, son la re-experimentación del trauma, memorias recurrentes intrusivas, sueños repetitivos y pesadillas, conductas del tipo “acting out”, o sentimientos similares a si el evento traumático estuviera repitiéndose, adormecimiento o retraimiento, hipervigilancia o reacción de susto hiperactivo, trastorno del sueño, culpa, deterioro de la memoria, evitación de actividades que despierten asociaciones al evento, y la intensificación de los síntomas por la exposición a eventos similares (Andreason, 1980; Kinzie, Frederickson, Fleck y Karls, 1984). Todo lo que se desarrolla como el resultado de eventos psicológicos traumáticos, fuera del rango de experiencias humanas "normales" (Corrado y Tompkins, 1989, p. 286).

A lo anterior, se añade el número de eventos estresantes, duración y contexto, que deben considerarse, incluyendo el grado de deseabilidad del evento y el control individual (Spitzer, Williams y Skodol, 1980). Así parece que no solamente el estrés en si mismo es el que causa daño, sino también la incapacidad del individuo para resistir (Corrado y Tompkins, 1989).

Turner y Gorst-Unworst (1993) sostienen la existencia de dos características centrales del SEPT. Una de estas características se corresponde a la tendencia de repetición compulsiva de algunos aspectos de la experiencia perturbadora, tales como pensamientos acerca del evento original, sentimientos asociados a la experiencia o la repetición de conductas y evasión de representaciones internas y externas que revocan o se asemejan al episodio traumático (Horowitz, 1976). Existen diferentes explicaciones para este fenómeno (Basoglu y Marks, 1988; Brett y Ostroff, 1985; Wilson, 1989; Wirtz y Harrell, 1987).

Horowitz en 1976 plantea un modelo del procesamiento cognitivo y emocional, que sugiere que las experiencias dolorosas necesitan ser procesadas en la mente del mismo modo que cualquier otra experiencia formativa. Él, apoyado por Rachman (1980), afirman que el procesamiento emocional, es una modalidad normal para tratar con el material afectivo, y sostienen que algunas veces este procesamiento puede ser detenido o incompleto, lo que significa una fuente de continuo dolor para el individuo.

Volviendo a Horowitz (1976), hay limites naturales de protección en proporción al procesamiento cognitivo y emocional. Él explica que la presencia de la denegación ideacional masiva y el entorpecimiento emocional, son fenómenos opuestos a las repeticiones intrusivas. Situaciones, sucesos o cualquier tipo de material que amenace con agobiar a la persona, le llevará a ésta, a la invocación de mecanismos defensivos. En su trabajo teórico y descriptivo, Horowitz refiere un proceso 
cíclico en el cual los individuos cambian entre la evitación y el estado de dolor emocional, en función de estas intrusiones en la conciencia. En casos extremos, el estado de rechazo y de amnesia irregular por eventos traumáticos, puede ser inducido. Desde esta concepción, los procesamientos exitosos están acompañados de una fase de proceso de intrusión que se alterna con rechazo. Cabe destacar que los eventos traumáticos pueden hacerse conscientes, no solo mediante mecanismos internos, sino también por estímulos externos que se parezcan a las circunstancias del episodio traumático y que pueden a la vez, ser una verdadera forma de evitación de tales estímulos.

Existe otro modelo que sugiere que la tortura y otros abusos, pueden desafiar cinco sistemas adaptativos centrales de las personas, que ayudan al estado de equilibrio psicosocial en cada una y sus comunidades. Estos sistemas se plantean como el subconjunto de la función de seguridad, apego, justicia, identidad de rol y sentido existencial. Todos los que en conjunto y en circunstancias normales, aseguran que la interacción entre el individuo y su sociedad ocurra en una forma que promueva la homeostasis personal y social (Silove, 1999).

El modelo al que hacemos referencia, explica que los eventos de trauma a nivel individual, son organizados de acuerdo a los propios significados psicosociales de las víctimas, con el consecuente impacto en adaptación (Silove, 1999). Esta idea es apoyada por Eisenbruch, quien además plantea que las nociones de adaptación que hemos mencionado, pueden tener una relevancia más directa a las experiencias subjetivas de los supervivientes y sus comunidades, que las categorías diagnósticas en uso actualmente (Eisenbruch, 1991).

El sistema de seguridad asociado al SEPT, ha llamado la atención de investigadores en la actualidad. Se cree que una clara delineación de tales sistemas adaptativos puede proveer un punto de convergencia, que se relacione al esfuerzo investigador más cercano a la experiencia subjetiva de los supervivientes y a los tipos de intervenciones clínicas ofrecidas en los servicios de tratamiento del trauma. Cabe precisar, que las amenazas realizadas con posterioridad a la experiencia, a lo largo del continuo de estrés que enfrentan los refugiados y otros supervivientes a violaciones a los derechos humanos, pueden significar el desafío a estos sistemas, a nivel individual y comunitario (Silove, 1999). 


\subsection{Sintomatología de supervivientes}

Las respuestas psicológicas descritas en supervivientes de tortura, han sido amplia y diversamente clasificadas en investigaciones disponibles en revistas científicas, de las cuales, muchas son citadas en este estudio. De cualquier modo, todas ellas suelen ser respuestas de protección.

Estas respuestas, incluyen daños a nivel de memoria y concentración, jaquecas, ansiedad, depresión, insomnio, pesadillas, embotamiento emocional, perturbaciones sexuales, ira, retraimiento social, falta de energía, apatía e impotencia (e.g. Abildgaard et al., 1984; Allodi y Cowgill, 1982; Cathcart, Berger y Knazan, 1979; Rasmussen y Lunde, 1980).

Goldfeld, Mollica, Pesavento y Faraone (1988) por su parte, categorizaron estos síntomas en cognitivos (desorientación, alteración de la memoria, deterioro en la capacidad lectora y de concentración), psicológicos (ansiedad, depresión, irritabilidad, labilidad emocional, retraimiento social), y neurovegetativos (falta de energía, insomnio, pesadillas y disfunción sexual).

Turner y Gorst-Unworst (1993) hacen una crítica a la categorización planteada en el párrafo anterior, sosteniendo que aunque esta valoración es usada para describir elementos comunes de las reacciones de tortura, carece de bases teóricas, tiene un valor heurístico reducido, el rango de síntomas enumerados es muy amplio e incluye rasgos de muchas condiciones psiquiátricas comunes, siendo difícil de interpretar como representando un desorden particular.

El modelo de los efectos psicológicos en víctimas de terrorismo de Estado planteado por Corrado y Tompkins (1989), sostiene que las principales secuelas son ansiedad, depresión, jaqueca crónica y SEPT. Los autores distinguen además la presencia de la culpa del sobreviviente, depresión crónica, retraimiento, apatía, meditación melancólica, miedo constante de nuevas persecuciones y el suicidio.

Muchas víctimas de tortura, siguen teniendo síntomas físicos y psicológicos por mucho tiempo (Petersen et al., 1985). Algunos desarrollan modalidades de respuesta a la tortura, como por ejemplo, la inducción de estados alterados de conciencia durante la tortura por hiperventilación. Conductas mal adaptadas que persisten, con posterioridad a la liberación y que pueden dominar el perfil de síntomas de un superviviente y pueden influir en la capacidad de resistencia de las víctimas al torturador. En esto, influyen variables tales como el grado de compromiso activo de los prisioneros en la resistencia previa a la tortura, la elección al azar o por error, o las diferentes culturas (Kinzie, 1985). 
Rachman en el año 1980, describió los factores que impiden el procesamiento emocional y que son comunes a la tortura: inducción de elevados niveles de excitación, fatiga, insomnio e irregularidad en la exposición al peligro. Todos los cuales, van en contra del éxito de este tipo de procesamiento y pueden ser manipulados por los torturadores con estos fines.

Otro impacto de la tortura, es la ansiedad crónica que se puede provocar durante la detención, por la exposición prolongada a estímulos dolorosos y el constante ataque reiterativo. Por otro lado, los supervivientes a estas experiencias, con posterioridad a la prisión, son vulnerables a nuevas detenciones o a la repatriación forzada, en el caso de haber huido a países en los que también se practica la tortura, lo que causa temor en ellos (Turner y Gorst-Unworst, 1993).

En relación a los síntomas de ansiedad crónica, se cree que los supervivientes pueden vivir con éstos, usando respuestas que tienden a ser mal adaptadas del tipo evitativas, y que fueron aprendidas durante la tortura. Un ejemplo de estas conductas, es el abuso de substancias psicotrópicas (Yager, Laufer y Gallops, 1984).

Otra reacción a eventos traumáticos como la tortura, refiere síntomas depresivos asociados al contexto postraumático (Turner y Gorst-Unworst, 1993; Silove, 1999). Lo que se fundamenta en que la experiencia de tortura está íntimamente ligada a procesos cargados emocionalmente y relacionados a la pérdida tanto física como psicológica (e.g. Turner y Gorst-Unworst, 1993). Esto se acentúa en personas que con posterioridad a experiencias de tortura, buscan asilo o refugio político en otros países (Kinzie, Fredrickson, Ben, Fleck y Karls, 1984), viviendo separaciones prolongadas de sus familia y deficiencias en el apoyo social en los países de reagrupación (Gorst-Unsworth y Goldenberg, 1998).

Las pérdidas que referimos recientemente, pueden ser físicas (parte del cuerpo y/ o el normal funcionamiento físico y salud corporal), o de distinto orden (trabajo, estatus, familia y credibilidad previos a la experiencia). Desde esta perspectiva, la tortura es vista como un evento importante de vida y como la causa de muchos otros eventos (Turner y Gorst-Unworst, 1993).

Otros factores que se presentan con posterioridad a experiencias de tortura, son los síntomas psiquiátricos, particularmente de depresión y de estrés postraumático (Gorst-Unsworth y Goldenberg, 1998; Hauff y Vaglum, 1995). Siendo factores de riesgo, la edad, la habilidad en el lenguaje, la adversidad económica y social, el miedo a la repatriación, a la vez que factores que pueden favorecer la recuperación de SEPT y otras formas de dolor psicosocial en refugiados y asilados políticos (Beiser et al., 1993; Chung y Kagawa-Singer, 1993; Gorst-Unsworth y Goldenberg, 1998; Hinton, Tiet, Tran y 
Chesney, 1997; Lavik, Hauff, Skrondal y Solberg, 1996; Silove, Sinnerbrink, Field, Manicavasagar y Steel, 1997).

Lo anterior concuerda con un estudio realizado por Mollica y sus colaboradores, que evaluaron a un grupo de mujeres viudas camboyanas del sudeste de Asia en calidad de refugiadas, que experimentaron al menos dos de los tres sucesos de trauma: violación, pérdida del esposo y pérdida de los hijos. La mayoría de ellas, presentó depresión mayor de acuerdo al criterio diagnóstico de occidente, y se auto-percibieron socialmente aisladas y viviendo en un mundo social hostil (Mollica, Wyshak y Lavelle, 1987; Mollica et al., 1993).

Enfermedades físicas y signos de deterioro cognitivo, comúnmente se presentan con posterioridad a la experiencia de tortura (Cathcart, Berger y Knazan, 1979, Ramussen y Lunde, 1980; Rasmussen y Marcussen, 1982), siendo secuelas físicas generalmente obvias y directas como consecuencias de la tortura (Goldfeld et al., 1988).

Turner y Gorst-Unworst (1993), afirman que aquellas personas que han sido torturadas físicamente, como una forma de ganar control sobre su mente, presentan síntomas somáticos que pueden tener muchos significados y que con frecuencia presentan una estrecha relación con disturbios emocionales. La hiperventilación, que puede ser un mecanismo relacionado a la producción de síntomas físicos relacionados a condiciones emocionales personales o ser parte de fenómenos disociativos; las disfunciones sexuales que suelen presentar los supervivientes de tortura, cuyos mecanismos etiológicos son inciertos (Lunde, Ramussen, Lindholm y Wagner, 1980), y que involucran procesos psicológicos que tienen más peso que los factores orgánicos, presentándose en víctimas de tortura que no han sufrido tortura sexual (Turner y Gorst-Unworst, 1993).

Horowitz por su parte, ya en el año 1976 describió síntomas de aturdimiento, miedo, temblor, pesadillas e inhabilidad para funcionar normalmente en supervivientes de la primera guerra mundial que fueron asociados a mecanismos psicológicos de debilidad y cobardía. También se desconoce la etiología del deterioro cognitivo posterior a la experiencia de tortura (Turner y Gorst-Unworst, 1993).

Thygeson (1980) realizó un listado con los principales indicadores del Síndrome de campos de concentración, que diferenció entre físicos y mentales. Dentro del primer grupo se encuentran: pérdida de peso, fatiga patológica, diarrea periódica o constante, sofocación, sudor nocturno, perturbaciones nocturnas y disminución de la potencia sexual. Dentro del segundo grupo: depresión, cambios de humor, labilidad, pesadillas, miedos, pérdida de memoria y/ o habilidad de concentración. 
Krystal y Niederland (1968) plantean que los EXPPS que fueron torturados, pueden presentar a consecuencia de estas acciones, ira persistente y agresividad hacia los demás. Al mismo tiempo que verse dentro de un espiral vicioso en el que la pérdida de control de la rabia les lleve a manifestar agresividad y estar en contra de lo que ellos deseen. Lo que tendería a intensificar sentimientos de vergüenza, culpa, soledad y desesperación. Al respecto, (Silove, 1999) critica que en la clasificación psiquiátrica convencional no se incluya una tipología específica para la ira y los problemas de control de impulsos, como consecuencia de violaciones a los derechos humanos.

El estudio de Krystal y Niederland (1968), revisa la evolución de los patrones de las secuelas psicológicas en supervivientes de campos de concentración. Ellos descubrieron que en el momento de la liberación, la víctima a menudo experimenta un sentimiento de triunfo, mezclado con optimismo hacia el futuro. Un período que dura desde pocos meses hasta años y se asocia a la idea de volver a ver a la familia. Posteriormente, se desarrolla el síndrome post-campo de concentración.

Un estudio realizado por Krystal y Niederland (1968), reveló que del 97\% de las personas que presentaron el síndrome post-campo de concentración, sufrieron ansiedad y depresión crónica, que fue precipitada por situaciones que revocaron la experiencia traumática y renovaron el miedo de persecución. Todas estas víctimas reportaron perturbación del sueño, mientras que un tercio desarrolló perturbación de memoria y capacidades cognitivas. Dos de los más importantes desórdenes involucraron rasgos de carácter masoquista (79\%) y culpa por sobrevivir (92\%). Al respecto, la culpa por sobrevivir, fue esencial a la hora de entender la depresión.

Un estudio que consideramos relevante para nuestra investigación, fue el que realizó la Amnesty International Danish Medical Group (1979), que evaluó los patrones de respuesta al terrorismo de estado en víctimas de tortura de Grecia y Chile, reportando que el 78\% de los grupos presentaron serias perturbaciones mentales. Cabe destacar que los investigadores encontraron que el método de tortura empleado, se relacionó a menudo con el tipo de secuela posteriormente desarrollada; y que los síntomas más comunes fueron ansiedad, irritabilidad y depresión. 
2.1.3.4.3. Secuelas neurológicas de la tortura

No es parte de esta investigación estudiar las secuelas neurológicas de la violencia política y específicamente la tortura en sus supervivientes, pero es un factor que no puede dejarse de lado, por el compromiso de este tipo de secuelas en la salud general de los supervivientes.

Hay evidencia empírica que demuestra que síntomas neurológicos son experimentados con frecuencia entre supervivientes de tortura (Moreno y Grodin, 2002), y síntomas tales como jaquecas, mareos, embotamiento y deterioro de la memoria, se encuentran tanto en condiciones neurológicas como psicológicas, dificultando el diagnóstico diferencial (Goldfeld et al.; MacDonald, Mummery, Heaney, 2001).

Por su parte, una revisión clínica realizada por investigadores de la Boston University School of Public Health y la Boston University Schools of Medicine and Public Health, refiere que hay formas de tortura que pueden afectar el sistema nervioso, como golpes, heridas a bala o por puñaladas, asfixia, suspensión prolongada y electricidad. Los autores plantean que es común que las víctimas de tortura presenten secuelas neurológicas de estas experiencias, con síntomas como jaquecas, vértigo, pérdida de conciencia y mareos, durante y después de la tortura. Sostienen además, que las secuelas de la tortura pueden ser devastadoras a nivel neurológico y psicológico (Moreno y Grodin, 2002). El estudio fue realizado por Rasmussen (1990), y evaluó de manera retrospectiva la presencia de síntomas neurológicos en al menos el 75\% de pacientes, reportando tener al menos uno de los síntomas de éstos durante la tortura, y el 64\% de los pacientes presentaron al menos un síntoma crónico. Las jaquecas fueron el síntoma más comúnmente reportado por los supervivientes de tortura (Moreno y Grodin, 2002).

\subsection{El síndrome del sobreviviente al holocausto (The Holocaust Survivor Síndrome)}

Algunas características de los supervivientes al Holocausto que les diferencian de cualquier otro grupo humano, se basan por ejemplo, en la relación entre la personalidad previa a la experiencia de guerra y la adaptación post-guerra. Fuera de estas diferencias, la variable vulnerabilidad y resiliencia al estrés, pueden ser las más importantes características de ellos, que les hacen más o menos susceptibles a enfermedades mentales. Existen además, diferencias significativas en cuanto a género, edad durante la guerra, diferencias en ocupación, antecedentes culturales y religiosos, efectos de la inmigración y rasgos de personalidad previos al Holocausto (Kellermann, 1999). 
El síndrome post-campo de concentración, está asociado a síntomas que incluyen un marcado humor depresivo, comportamiento malhumorado, tendencia al aislamiento y apatía. Todos los cuales se presentan de manera severa y persistente (Krystal y Niederland, 1968).

\subsubsection{La influencia de la reparación en los efectos psicológicos}

Conscientes de que experiencias de violencia política y tortura no se borran de la mente de quienes las han vivido, influenciando posiblemente muchas áreas de sus vidas a lo largo de los años, creemos que la reparación gubernamental es el medio más importante para la elaboración del daño producido en cautiverio.

Si pensamos que fue el estado de Chile el que causó el daño, y es el mismo el que repara estos daños, de acuerdo a lo que representa como institución, implica el reconocimiento oficial de un error y la valoración de este grupo de personas. Por otro lado, si pensamos en los daños causados, es muy difícil encontrar medidas que realmente logren el cometido de reparar a los EXPPS y muy probablemente nunca ellos se sientan satisfechos con estas medidas. Pues se trata de reparar lo irreparable. Creemos que esta valoración dependerá del daño sufrido.

En el capítulo III, estudiaremos aquellos aspectos de la reparación que el gobierno de Chile realizó a los EXPPS, cuya valoración indagaremos en la entrevista en profundidad que elaboramos.

A continuación nos referiremos a aspectos que hemos considerado importantes de incluir en nuestro marco teórico, y que podrían influir negativa o positivamente en sus vidas, dependiendo de la valoración que los EXPPS hagan de la reparación obtenida.

\subsection{Medidas gubernamentales}

Becker (2003) afirma que los políticos tratan el problema de los derechos humanos como un problema individual de víctimas, y sostiene que para el caso de Chile, la lucha de las víctimas por el respeto de los derechos humanos fue muy importante durante el período de la dictadura. Sin embargo, en el inicio de la fase de transición hacia la democracia, los políticos chilenos intentaron cesar con esta lucha, pues temieron que con su continuidad, la reconciliación sería imposible de lograr. Todo lo que nos indica que independientemente de la presencia del problema en las sociedades, los políticos y las personas traumatizadas, difieren en puntos de vista y acciones. 
Estudios en supervivientes de tortura, han demostrado que en la mayoría de los casos, se esconde la verdad de lo que ocurrió; y los reclamos de tortura, solo pueden ser valorados en base a la razonable creencia de la probabilidad estadística (Garbolino y Taroni, 2002). Nosotros prestaremos especial atención a la valoración subjetiva que estas personas hagan de estas medidas en la entrevista en profundidad que les administraremos.

2.1.3.5.2. Víctimas y agrupaciones de DDHH: el rol del trabajo en DDHH y salud mental

Becker (2003) afirma que los activistas que defienden los derechos humanos, tienden a creer que todas las heridas pueden curarse a través del cambio político. De acuerdo a las dimensiones sociales e individuales del trauma a las que hemos hecho referencia anteriormente, y dependiendo de la perspectiva que se tenga, se puede sobre-enfatizar una dimensión u otra, y en el caso de los activistas políticos, éstos tienden a subestimar la dimensión individual del trauma, negando el olvido de las necesidades individuales y las situaciones de las otras víctimas, por el proceso social.

El mismo autor, sostiene además que es importante entender que durante el período de lucha por el cambio y la democracia, quienes lo realizan, esperan un cambio total, pero que cuando estos ocurren, resulta que la democracia no suele cubrir sus expectativas. Esto no cura las heridas sufridas por los activistas, pues la muerte sigue siendo la muerte y lo que se perdió, no regresará jamás.

Nosotros hemos contactado oficialmente con agrupaciones de derechos humanos que han accedido a participar del estudio. La elección de estas agrupaciones, se basa en la formalidad que implica tratar con instituciones reconocidas por el gobierno de Chile y creemos que la mayoría de los participantes participan activamente en estas agrupaciones. Por todo ello y considerando lo anterior, indagaremos aspectos relevantes en relación a la participación política actual de los EXPPS, que relacionaremos con el impacto emocional y social de la privación de libertad y tortura por motivos políticos en Chile.

Por último, creemos que la lucha por los derechos humanos es una vía hacia la vida y libertad subjetiva de quienes abanderan la causa, y por ende, posiblemente una manera favorable para reparar los daños causados en períodos de cautiverio. 


\subsection{Torturadores e impunidad}

Los ejecutores de hechos de violencia política y tortura, tienden a negar el daño que causaron a sus víctimas y suelen temer a la venganza. Reacciones que se acrecientan bajo poderes gubernamentales de cambio (Becker, 2003).

Becker (2003) además sostiene, que en una sociedad en que han acontecido hechos de tortura, la solución no es negar a los ejecutores de tales acciones, tampoco insistir en un proceso de justicia ojo por ojo y diente por diente. Para él, el problema debe enfocarse en cómo superar una situación en la que los asuntos sólo dependen del poder político, mientras que la moral básica no se toma en cuenta.

Por otra parte, las víctimas tienen derecho a la verdad y la justicia. Sin embargo, la justicia puede superar la lógica de los torturadores, lo que facilita que los perpetradores asuman la responsabilidad de sus actos (Becker, 2003).

En el caso de Chile, la impunidad que caracteriza al caso Pinochet, mundialmente conocida y en proceso después de más de 30 años del golpe de Estado, y lo que la figura del expdte. en cuestión significa en los chilenos y sobretodo en los EXPPS, como representante de un régimen político y principalmente de la represión política acontecida en Chile entre los años 1973 y 1989, creemos que afecta negativamente en los EXPPS, pudiendo sentirse burlados por las sanciones judiciales en torno al caso.

Vera, Marty, Muñoz y Madariaga (2002) sostienen que la impunidad existente en Chile frente a la problemática de los derechos humanos, se ha convertido en la causa más perversa de daño en la salud mental de los chilenos. Ellos afirman la ausencia de verdad y justicia asociada que ha producido por más de treinta años en las víctimas sufrimiento y dolor crónico.

La impunidad a la que hacemos referencia en el caso de Chile, se cree que incide potenciando el sufrimiento de las víctimas que viven buscando la verdad y la justicia (Madariaga, 2000). Para Madariaga (2002), la impunidad es el mecanismo principal de recurrencia al trauma. Visto así, cada circunstancia nueva o suceso que evidencia la impunidad en la conciencia de quienes fueron víctimas a violaciones a los derechos humanos, además de sus familiares, funciona como gatillante del sufrimiento psíquico. 


\subsection{Reconciliación y "olvido"}

Madariaga $(2002,2006)$ introduce el concepto de retraumatización, que asegura, es empleado principalmente en el Cono Sur de América Latina, para definir un mecanismo de reactivación casi automática de síntomas de tipo psiquiátricos, conflictos intrapsíquicos y disfunciones familiares. Todos los que se presentan en las víctimas de violaciones a los derechos humanos, como una condición traumática individual, familiar y social, o más bien, como un estado de daño crónico con variaciones entre cierto equilibrio inestable y períodos de intensa sintomatología y disfuncionalidad. Esto nos remite a la continuidad del trauma referida anteriormente, y nos hace pensar en lo difícil que debe ser para las víctimas que estudiamos, pensar en la posibilidad de reconciliarse y más aún, olvidar los daños sufridos.

Silove (1999) plantea que los mecanismos sociales para la reconciliación y el olvido, pueden servir para reparar los sistemas de justicia y existencial, asegurando públicamente el conocimiento de las violaciones a los derechos humanos en el pasado y proporcionando un ritual de curación que otorgue algunos cierres contrapuestos a los eventos inadmisibles.

La impunidad mundialmente conocida para el caso de Chile, y sus efectos en el impacto de experiencias de violación a los derechos humanos en población chilena, para Madariaga (2002) indica que la mejor opción para las víctimas en cuanto a la superación de las experiencias de violencia política y tortura, requiere de un desafío moral que implique aplacar el sufrimiento provocado por estas experiencias y encontrar un estado de sosiego espiritual como actitud ante las señales de los militares, lo que involucra la renuncia a las propias aspiraciones legítimas y la interpelación a la autocontención del dolor, lo que consideramos una tarea muy difícil si consideramos la impunidad existente en el país con los victimarios.

Creemos que el gobierno debe reparar a sus víctimas y familiares, de modo que ellos sientan satisfacción con las medidas obtenidas. Para ello, la erradicación de la impunidad, debe ser uno de los objetivos centrales de la reparación, pues de lo contrario, pensamos que el trauma psicosocial de las víctimas se mantendrá indefinidamente. Por ello el tema de la valoración que los EXPPS hagan de la reparación, será un área que indagaremos con el instrumento que elaboramos para entrevistar a la muestra, por su importancia en el impacto emocional y social de estas personas en la actualidad.

Por otro lado, dudamos de la posibilidad de reparación para quienes hacen una lectura de la experiencia de prisión en sus vidas como un quiebre homologable a la muerte. Creemos que del grado 
de sufrimiento experimentado y vivido durante y posterior a la experiencia de prisión, dependerá la reparación que ellos estimen adecuada. Creemos además que es difícil que llegue un punto en que ellos consideren que han sido reparados, pues a nivel existencial, no existe tal reparación.

Por último, creemos que la reconciliación debe ser un proceso interno que requiere de elementos como el perdón y la aceptación de los hechos. De cualquier forma, hechos tan duros como los vividos bajo el régimen militar en Chile serán inolvidables, más para quienes vivieron en el propio cuerpo los sucesos de represión política. Sin embargo, y a pesar de la postura negativa que adoptamos en cuanto al olvido, creemos que los EXPPS dependiendo de su ideología, sus redes de apoyo social, y otros aspectos, pueden haber logrado seguir viviendo sin que el tema de la experiencia de prisión sea un eje central de sus vidas. Lo que en cierta forma, referiría un tipo de "olvido".

\subsubsection{Problemas pendientes y limitaciones de los estudios}

Debería terminar estableciéndose una valoración desde las necesidades de los afectados. A nivel forense, se precisa de más reportes de la valoración a las experiencias de tortura, y de un sistema apropiado para clasificar las secuelas somáticas e agravios provocados por la tortura (Moisander y Edston, 2003).

La mayoría de estudios que evalúan las secuelas psicológicas de la tortura son realizados en países distintos al país de origen de los supervivientes que nos ocupan en este estudio, lo que es una limitante, y puede afectar en las conclusiones de tales estudios. Creemos que las estrategias de supervivencia en países distintos en cultura, ideología e idioma, hizo posiblemente que los esfuerzos vitales se centraran en el proceso de adaptación, lo que fue distinto en los chilenos EXPPS que mantuvieron su residencia en Chile.

No hay estudios sobre efectos a largo plazo de victimas que se quedaron en su propio país, lo que implica que los hallazgos encontrados en estudios realizados a supervivientes de población trasladada a otros países, que tuvieron que lidiar con aspectos como la adaptación a nuevos entornos, la inclusión a grupos de refugiados, y la separación de la familia, afectan de manera distinta en el impacto que estudiamos. Por su parte, el contexto sociopolítico de Chile desarrollado con posterioridad a la experiencia de prisión, caracterizado por la manutención del régimen militar en el gobierno, entre otros aspectos, hacen que la presente investigación sea un aporte al conocimiento de los procesos psicológicos de la población estudiada. 
Por otro lado, no hay estudios cualitativos con entrevistas en profundidad que indaguen acerca de las experiencias de vida de los afectados, lo que nos permitirá acceder a un conocimiento único del tema, desde el carácter experto de los EXPPS, pero dificultó la fase de establecimiento de temáticas relevantes para el entendimiento del impacto que estudiamos.

Todo lo anterior, produjo limitaciones en nuestro estudio en cuanto a la selección de áreas relevantes a considerar para el entendimiento del impacto que estudiamos. Por nuestra parte, nuestro trabajo será de tipo descriptivo y centramos los objetivos de nuestra investigación principalmente en el estudio de las necesidades emocionales y sociales de las personas que estudiamos, y su vinculación con aspectos específicos de la experiencia de prisión política y tortura. 
CAPÍTULO III.

ESCENARIO HISTÓRICO-POLÍTICO Y SOCIAL DE LA PRISIÓN POLÍTICA EN CHILE Y LA RESPUESTA GUBERNAMENTAL, SOCIAL Y FAMILIAR A MÁS DE TRES DÉCADAS DESPUÉS. UNA REVISIÓN A LA BIBLIOGRAFÍA LATINOAMERICANA. 
Privación de libertad y tortura política en Chile (1973-1990) 
Cuando sucedieron esos hechos, Chile llevaba muchos años de vida democrática. Eso sí, se trataba de una democracia política pero con grandes diferencias sociales entre la población. En este contexto democrático pero de gran desigualdad social en el año 1970, una organización política de izquierdas llegó al poder, precedida por Salvador Allende. Las medidas de este gobierno parecieron intolerables a la derecha chilena, que apoyada por algunos países extranjeros, creó primero tensiones sociales graves para acabar dando un golpe de estado.

La represión política que comienza en Chile en 1973, se desarrolla en respuesta al proyecto social y político que se buscaba proteger. También al régimen económico que se quería implantar y las consiguientes regulaciones de control y legitimación. Desde estos aspectos, la represión política ocurrida en Chile entre 1973 y 1990, buscó destruir las bases del modelo de desarrollo económico y social presente en aquel período (Lira, 1989).

Lira (1989) sostiene que quienes fueron beneficiarios de los cambios políticos y sociales que la U.P. luchaban por conseguir la posibilidad de una existencia digna y participativa. Todo ello provocó un período de fuerte implicación emocional en la vida social y política de Chile.

Conscientes de la influencia de los acontecimientos políticos pasados y presentes en las vidas de los EXPPS y otras víctimas de violación a los derechos humanos, en esta sección hemos querido describir aspectos asociados a tales procesos, a través de los años, hasta el momento en que accedimos a la muestra. Lo que creemos que además de situarnos en el contexto en que ocurrieron los sucesos de represión política en Chile, nos permitirá ampliar nuestro entendimiento del impacto de la prisión política en la vida de los EXPPS que estudiamos en nuestra investigación.

De acuerdo a lo anterior y a nuestro objeto de estudio, creemos que el fallecimiento del expdte. Pinochet a finales del año 2007 y las condiciones sociopolíticas que caracterizaron este hecho histórico, han influido en el impacto que nosotros estudiamos en esta tesis. Sin embargo, nos limitaremos al estudio de tal impacto, dentro del contexto político y temporal en que accedimos a la muestra, caracterizado por el período electoral presidencial entre un candidato representante de derecha y una candidata de izquierda.

Por nuestra parte, lejos de tener una intención de manifestar juicios arbitrarios en cuanto a tendencias políticas, y de relatar la historia de Chile en el período que nos ocupa en este capítulo, nos centraremos en aquellos aspectos psicológicos asociados a los acontecimientos políticos que afectaron directamente a la sociedad chilena en el tema de los derechos humanos. 
En este capítulo también nos referiremos a la situación actual a nivel político y social, a más de 30 años de acontecidos los hechos de violencia política y tortura en Chile, con el objeto de relacionar estos factores contextuales presentes al momento de la fase de recolección de datos. Para ello, nos hemos visto en la necesidad de considerar además de artículos de corte científico y el informe gubernamental Valech, libros y documentos editados principalmente por ONGs e instituciones gubernamentales que fueron elaborados por profesionales principalmente chilenos, en base a la propia experiencia en atención psico-social de víctimas de la represión política en Chile.

Conscientes del sesgo político que los estudios aludidos en el párrafo anterior pueden comprender implícita y explícitamente, intentaremos excluir o explicitar estos elementos porque nuestro estudio pretende tratar el tema en cuestión mediante una descripción lo más objetiva posible.

\subsection{LA PRISIÓN POLÍTICA Y TORTURA EN CHILE DESDE 1973 A 1990}

\subsubsection{Escenario histórico-político de los sucesos}

El golpe de Estado acontecido en Chile el 11 de septiembre de 1973, tuvo como objetivo derrocar al gobierno constitucional de la Unidad Popular presidido por el expdte. Salvador Allende. Las imágenes que los medios de comunicación mostraron aquel día, han quedado grabadas en las retinas de todos los chilenos que vieron el bombardeo al Palacio de la Moneda, mientras el presidente Allende emitía comunicados al país pidiendo a los chilenos que mantuvieran la calma y resistieran como él al golpe de estado.

Ante estos hechos del 11 de septiembre de 1973 en Chile, la incertidumbre y el temor se propagó entre los chilenos, lo que se vio acrecentado con la noticia de la muerte del expdte. Allende, ese mismo día, dentro del palacio.

Los hechos del día 11 de septiembre de 1973 en Chile, sin duda dieron inicio a un período represivo, que desde aquel día logró sus principales cometidos de asumir el poder político de Chile y sembrar temor e incertidumbre en todo un país. Se dio inicio así, al régimen militar del expdte. Augusto Pinochet Ugarte, y con ello a un estado de guerra.

Posteriormente, la represión política buscaba derrocar a los partidarios del gobierno de la Unidad Popular, lo que como es obvio, abarcaba a la mayoría de sectores del país, pues Salvador 
Allende había sido elegido por votación popular y su gobierno socialista entre otras tendencias, se caracterizó por dar un rol importante a nivel político y público al pueblo chileno.

El período que se inicia el 11 de septiembre de 1973, como es sabido mundialmente, se caracterizó por la violación a los derechos humanos de muchos chilenos. Estas acciones buscaban reprimir a los líderes de la Unidad Popular y otros líderes de izquierda. Dentro de este capítulo, en una sección posterior trataremos las etapas en que fue ejercida la represión política según el Informe Valech y especificaremos las condiciones en que se sucedieron los hechos. Esta represión afecto no solo a quienes habían tenido cargos o eran lideres conocidos, sino a otras muchas personas con grados de implicación muy diferentes, en una forma de proceder que incluso, desde el punto de vista del represor, habría que calificar con frecuencia de indiscriminada.

En este primer período, la junta de gobierno de Chile asumió el poder ejecutivo, anuló el poder legislativo, y mediante la creación de decretos de ley, declaró el estado de sitio como "estado de tiempo de guerra" (Brinkmann, 2002, p. 47). Muchos chilenos fueron tomados prisioneros y vivieron períodos de cautiverio en cárceles, recintos militares y campos de concentración que se crearon para ello. Muchos de ellos, también sufrieron tortura y malos tratos en la vía pública y recintos que se crearon específicamente para realizar estos procedimientos.

Todo lo anterior, en base a una política institucional represiva, sistemática y masiva, que buscaba exterminar a quienes formaban parte de la izquierda chilena de aquel entonces: nos referimos a quienes eran vistos como los enemigos internos.

En este escenario, la crisis se ve agravada porque desaparece las nociones de sujeto de derecho y de pueblo, que son remplazadas por la de soberanía nacional (Domínguez, citado en Brinkmann, 2002). Esto favoreció y justificó la violación de los derechos humanos, pues con la eliminación selectiva de quienes se convirtieron con el golpe de estado en opositores al régimen, atentan contra la ideología y el accionar que se impuso a la sociedad chilena.

Desde el año 1975 en Chile, el organismo policial secreto de Pinochet llamado DINA, amplió sus operativos de represión política hacia el Cono Sur. Este organismo cesó sus funciones al verse Pinochet presionado por la crítica internacional, en 1977. No obstante, fue reemplazada por la CNI que realizó las mismas prácticas que su predecesora. Lo que fue amparado por la promulgación en 1978 del decreto ley 2.191 de Amnistía, que aseguraba la impunidad de los autores de hechos de represión (Brinkmann, citado en Brinkmann, 2002). 
Por la contraparte, fueron las instituciones religiosas cristianas las que intervinieron ante los hechos de violación a los derechos humanos en Chile. Estas instituciones se caracterizaron desde el año 1973, por responder y amparar a las víctimas de la represión política en Chile. También se establecieron agrupaciones de familiares de víctimas siguiendo esta misma tendencia, y organizaciones internacionales como Amnistía y la Cruz Roja, entre otros, que realizaron denuncias que permitieron que los hechos se dieran a conocer en el mundo entero.

El sociólogo Tomás Moulian (1998), sostiene que la dictadura militar en Chile se hizo así misma hacedora de la salvación de Chile ante las amenazas en su identidad por la U.P. Sus representantes gubernamentales, vieron en la U.P. el mal, refiriendo que quienes conformaban este sector de oposición, atentaban contra la vida asocial ordenada por ley natural y la fe, por lo que debía ser extirpada.

Todo lo anterior, produjo grandes cambios sociales en Chile, que sobrepasaron el marco de experiencias tanto individuales como sociales de los chilenos (Lira, Becker y Castillo, 1989).

Para Lira, Becker y Castillo (1989), el proceso inicial de represión política en Chile, fue masivo e invisible, y a medida que pasaban los años se fue volviendo más selectivo. Sin embargo, se postula que la mayoría de la sociedad chilena pudo vivir los años de la dictadura ignorando los hechos represivos, que hasta el año 1983, con ayuda de la censura en los medios de comunicación, fue más o menos encubierta. Esta manera de proceder intentaba hacer pensar que en Chile, todo transcurría normalmente.

Desde una perspectiva psicológica, Lira, Becker y Castillo (1989) describen esta primera etapa, correspondiente al período acontecido post-golpe militar, caracterizada por la formación de una escisión en la realidad social de los chilenos. Dentro de este panorama, la represión y la muerte que acontecían a algunas personas, ocurría sin testigos y eran fenómenos invisibles para todos los demás. Hechos que sólo se podían constatar en las secuelas físicas de las víctimas a la tortura, siendo los familiares posiblemente los que podían darse cuenta de lo que ocurría en el país.

Lira, Becker y Castillo (1989) además sostienen que en cuanto a la economía que caracterizó este período, el régimen militar mostró en Chile la cara de un país que se encontraba en orden y en progreso, aunque el fondo más bien estaba caracterizado por dos grupos sociales muy dispares entre sí, conformados por ricos y pobres. 
Surgen en este período la categoría amigo-enemigo, dentro de cuya acepción la muerte refiere una posibilidad asociada al quehacer político. La posibilidad de muerte vista así, implica una experiencia traumática (Lira, Becker y Castillo, 1989).

La violencia represiva ejercida en Chile por motivos políticos, no diferenció razas, clases sociales, nivel educativo, ni grupos sociales. Se emplearon métodos de represión sistemática invisibles y silenciosos para la mayoría de chilenos. Todo en busca de un objetivo: derrocar a los opositores al régimen. Es decir, entre otros, a los EXPPS que estudiamos en esta tesis doctoral.

La arbitrariedad aparente con que se ejerció violencia política en Chile, extendió la amenaza política a toda la sociedad chilena. Al respecto, Lira (1991) afirma que el asesinato a personas que no tenían vinculación política, realizado mayoritariamente en la primera década del período en cuestión, reforzó estos sentimientos de vulnerabilidad.

La imposición del régimen militar de la violación sistemática de los derechos humanos, fundamentado en la idea de ser un recurso importante para el orden social y político, caracterizó el período al que nos referimos en este apartado. Lo que afectó a toda la sociedad chilena, siendo este, un hecho innegable que ha generado divisiones a nivel nacional e internacional (Becker, Castillo, Gómez, Kovalskys y Lira, 1989).

Por otra parte, Chile ha sido el único país de Latinoamérica que desde el año 1973 puso a disposición de sus compatriotas víctimas de represión política, servicios sociales, legales, médicos y psicológicos para las víctimas de la dictadura. Estos servicios surgieron institucionalmente como respuesta de emergencia, originalmente desde las iglesias (Becker et al., 1989).

La denuncia, fue el instrumento, que dentro y fuera de Chile, permitió conocer los hechos de violación a los derechos humanos, a la vez que defenderlos. Habiendo sido utilizada desde el inicio de la dictadura militar en Chile, permitió en muchas ocasiones y durante muchos años, romper la barrera de silencio respecto a la situación real los hechos (Becker et al., 1989).

El gobierno militar sostuvo en su discurso que los hechos de represión política eran "acciones necesarias en estado de guerra" (Becker et al., 1989, p. 16)

En los primeros años del régimen militar, la metodología empleada fue la ejemplificación mediante la demostración de acciones represivas. Estas eran informadas detalladamente a la sociedad 
chilena, como parte de las acciones de la guerra, lo que produjo reacciones sociales esperadas como el miedo, la paralización y el aislamiento.

Una segunda etapa, se caracterizó por el silencio, cuya lógica refería que lo que no se sabe, no existe. En esta fase, la idea ficticia de bienestar económico para todos los chilenos, era la idea preferida defendida por el gobierno de la dictadura.

Por último, una tercera etapa surge cuando el silencio es insostenible, debido a la emergencia de respuestas sociales organizadas ante la cronificación de los hechos represivos. En este momento, el régimen político imperante, responde con violencia y terrorismo con un carácter generalizado e indiscriminado para frenar cualquier tipo de respuesta social y política en contra del régimen.

Las tres fases descritas por Becker et al. (1989), responden a la doctrina de seguridad nacional de un gobierno específico, cuyo objetivo buscó generar confusión deliberada en la sociedad, de forma que fuera una tarea difícil para sus integrantes el detectar las causas, los objetivos, sus protagonistas y ejecutores, lo que en definitiva genera más temor e incertidumbre. Para el autor además, algunos elementos de estas tres fases se mantuvieron presentes en las campañas de propaganda electoral del plebiscito de 1988.

Todo lo anterior, se fundamentó en la doctrina de seguridad nacional que perseguía a quienes fueran considerados los enemigos internos. Esta lógica hace que los hechos de represión política que atentaron contra los derechos humanos se justifique en una lógica de guerra. Así es como pudo instaurarse todo un largo período de terrorismo del estado chileno (Lira, Becker y Kovalskys, Gómez y Castillo, 1989).

\subsubsection{El contexto social cuando transcurrieron los hechos.}

A nivel social, el ejercicio del poder autoritario del régimen militar, hizo una quiebra en todas las formas de relaciones existentes en Chile, lo que tendió a generar además de confusión, angustia, inseguridad, temor y en distintos grados, desintegración personal y social. Con ello, también significó la ruptura de sueños, ideales, proyectos de vida, y participación política y social, que se convirtieron en experiencias castigadas y censuradas. Todo lo que creemos incidió en una severa perturbación en la salud mental de la sociedad chilena y más específicamente de las víctimas directas como los EXPPS que estudiamos en nuestro proyecto de investigación. 
Por su parte, la Constitución de 1980 fue promulgada tras el plebiscito realizado por el régimen militar. Este precedente, intentó además de legalizar tal régimen, asegurar la posesión del poder por un mínimo de ocho años y mantener su influencia con posterioridad a este período. Con la Constitución de 1980, Pinochet dejó claro que no tenía intenciones de dejar la presidencia de la república de Chile, y que para él y su gobierno, la Constitución significaba el comienzo de la transición hacia una democracia "protegida" contra la oposición (Brinkmann, 2002, p. 48). Todo lo que motivó que la oposición se organizara para intentar finalizar con la dictadura militar.

En este contexto, en que las organizaciones sociales se movilizan, como hemos referido, la preocupación por el tema de violación a los derechos humanos, se vuelve una prioridad. Así, se pasó de un enfoque de acción orientado a las ejecuciones, detenciones, desapariciones, tortura y exilio de sus víctimas, a otros temas como los derechos humanos de la libertad de expresión, la organización política, la participación ciudadana. E incluso se empezó a luchar también por los derechos de tipo sociales y económicos que se vieron afectados por el modelo neoliberal que caracterizó al régimen militar (Brinkmann, 2002, p. 48).

Ante las movilizaciones sociales de la oposición política en Chile después del año 1980, la represión política intensificó la represión. Lo que se vio concretizado en el año 1984 con la promulgación de la ley antiterrorista que avalaba principios ideológicos de la dictadura, asociados a la restricción de libertades fundamentales del ser humano provocando acciones como la persecución, las detenciones arbitrarias y la limitación del acceso a la justicia (Brinkmann, 2002, p. 48).

La CNI, por su parte, empleaba métodos de tortura cada vez más sofisticados que buscaban además de dañar físicamente a las víctimas, destruirles psíquicamente.

Desde 1983, las posturas de la resistencia fueron distintas. Por un lado, el partido demócratacristiano de aquella época, en Chile, se esforzaba por llegar a acuerdos con los gobernantes del régimen militar y los partidos de derecha. Por otro lado, otros partidos de izquierda, presididos por el partido comunista, buscaban directamente el derrocamiento del régimen gobernante, mediante la rebelión popular (Brinkmann, 2002, p. 48).

En el año 1986 se logra la unión de todos aquellos sectores opositores de la dictadura. Lo que duró hasta el año siguiente. Posteriormente, se creó la Concertación de Partidos por la Democracia, quedando el partido comunista de Chile, excluido de este nuevo pacto. La Concertación promueve el 
plebiscito de 1988 con el fin de dirimir acerca de la permanencia de Pinochet en la presidencia de la república; plebiscito en que, como es bien sabido, gana el "no".

Por su parte, hacia 1980, las agrupaciones de derechos humanos, orientaban sus esfuerzos por la consecución de la democracia, teniendo un rol importante dentro del plebiscito de 1988.

A finales de 1989, Patricio Aylwin fue elegido democráticamente como presidente de la República de Chile, asumiendo su mandato el 11 de marzo de 1990, dando término oficialmente al régimen militar.

\subsubsection{Situaciones represivas acontecidas en Chile entre 1973 y 1990}

El régimen represivo en Chile, incluyó principalmente la aplicación sistemática de tortura, detenciones en recintos oficiales del estado chileno y recintos no oficiales, secuestros, desapariciones, condenas de relegación, asesinatos, exilio, allanamientos en domicilios y lugares de trabajo, y amenazas. Todas, situaciones extremas muy traumáticas para quien las padeció.

\subsubsection{Contexto político y social chileno en la transición de la dictadura a la democracia}

Independientemente de la intencionalidad de los hechos de violación a los derechos humanos ocurridos en Chile, la verdad implica la aceptación de una realidad muy dura para cualquier ser humano. Escuchar frente a frente a un sobreviviente sus relatos acerca de las experiencias de tortura vividas en prisión, intentando imaginar los hechos, es además de doloroso, una experiencia desconcertante que puede despertar hasta los miedos más primitivos del ser humano. Por ello, el olvido suele ser una respuesta esperable ante los hechos. No por ello la más adecuada.

Pensar en el daño que un ser humano es capaz de causarle a otro semejante, no es fácil de asimilar. Por otro lado, a la vez, ver a las víctimas sonreír, comprobar su generosidad a la hora de querer participar voluntariamente y gratuitamente en un estudio como esta tesis doctoral, verles actuar en sus roles de padres de familia, aun convencidos y firmes en sus ideales políticos, y aceptando lo que les tocó vivir, con una elevada capacidad de resiliencia en el caso de algunos, ha sido sin duda, una lección de vida y de humanidad para nosotros.

Sabemos que, después de 30 años de los hechos, esto no ha sido una tarea fácil, pues además de los sufrimientos iniciales, con posterioridad a la experiencia de prisión, los EXPPS han tenido que 
sobrellevar muchas situaciones en que han visto perjudicadas sus expectativas de vida, sueños e ideales, teniendo que aceptar los cambios políticos y las decisiones gubernamentales del país al que pertenecen, sin sentirse tenidos en cuenta de una manera apropiada.

A continuación desarrollaremos algunos aspectos con los que los EXPPS tuvieron que lidiar después del año 1990, referidos al período de transición de la dictadura militar a la democracia en Chile. Nosotros creemos que estos aspectos pueden ayudarnos a entender el impacto emocional y social que estudiamos en esta investigación.

\subsubsection{El gobierno}

Esta fase se caracterizó por un prolongado proceso de negociación política entre represores y reprimidos políticos, en que la transición a la democracia y la democracia en sí, fueron vividas de forma muy conflictiva (Calderón, 1989).

Surge un nuevo sistema político y con ello nuevas situaciones que se fueron generando en el período de transición al que hacemos referencia. Son objetivos esenciales en este período eran razonables e inevitables: la reconstrucción del pasado desde los derechos humanos, con su inminentes connotaciones morales, políticas y sociales, por un lado, y la integración de los grupos excluidos como aquellos que se vieron más afectados en la dictadura, por otro.

En la fase de transición, la reforma constitucional chilena de 1980 determina el campo de acción tanto de las fuerzas políticas como sociales, en un contexto en que las fuerzas armadas mantienen el poder central.

Por ello, uno de los objetivos del proceso de transición, a nivel gubernamental, consistió en ir modificando de manera gradual la estructura legal apoyada por la Constitución de 1980, en una Constitución más democrática, disminuyendo la intervención militar que había caracterizado al período previo.

El gobierno de Patricio Aylwin Azócar, no ajeno a conflictos y discordancias por parte de los partidos de la Concertación, que vieron frustradas muchas de sus expectativas, en cuanto al tema de los derechos humanos en Chile, incluyó desde abril del año 1990, la creación de la Comisión Nacional de Verdad y Reconciliación, que buscaba lograr la reconciliación en el país, mediante el esclarecimiento de la verdad, sin tener en cuenta la intervención de la justicia (Brinkmann, 2002). 
El informe Rettig (citado en Gobierno de Chile, 2004), creado por la comisión a la que hacemos referencia en el párrafo anterior, y que se dio a conocer al país el año 1991, fue positivo en el sentido que implicó un primer intento por reconocer oficialmente los hechos de violación a los derechos humanos ocurridos en Chile entre los años 1973 y 1990; pero también fue negativo por distintas razones, entre las que destaca la exclusión de los casos de supervivientes a hechos de prisión política y tortura. Esto generó descontento en las víctimas directas y las organizaciones de derechos humanos.

Pero a pesar de las limitaciones, lo cierto es que el informe Rettig, reconoce que entre 1973 y 1990 no hubo una guerra pero sí una política de Estado que tenía el cometido de exterminar a los opositores al régimen político que imperaba. Además señala irregularidades por parte del poder judicial en torno al tema de los derechos humanos en Chile.

\subsubsection{Apelación al olvido}

Tal y como plantea Martín-Baró (1989) uno de los problemas más difíciles que tienen los gobiernos en sus procesos de transición pacífica de dictadura a democracia, es la necesidad con la que se encuentran, de resolver las secuelas producidas en la sociedad por la represión política ejercida con anterioridad. Lo que es aún más difícil en ausencia de guerras que definan la situación entre vencedores y perdedores.

En relación al período de transición que estudiamos en este apartado, Martín-Baró (1989) subraya la magnitud que alcanzan las campañas de contrainsurgencia o de represión estatal, produciendo daños en la sociedad que intentan hacer borrón y cuenta nueva de la historia represiva de un país; lo que en sí, genera más daños aún.

Nosotros creemos que, especialmente para los EXPPS, olvidar lo sucedido es imposible. Al respecto Martín-Baró (1989) sostiene que el daño causado, por este intento de hacer olvidar o justificar la represión, al implicar a la sociedad entera, comprende áreas sociales vitales que aumentaron el dolor de los EXPPS. En efecto, este intento de olvido, abarcó las estructuras sociales donde los EXPPS estaban insertos, las normas de su convivencia, las instituciones reguladoras de sus vidas, los valores y principios con los que fueron educados; y todo ello para justificar la represión.

Martín-Baró (1989, p. 10) plantea que dentro de los argumentos que justifican la opción de intentar olvidar los daños causados en regímenes políticos represivos y que apelan por un perdón incondicional de sus ejecutores, se encuentran: 
a) el argumento de la "debida obediencia", que deja como responsables únicos a algunos jefes de altos rangos dentro de las fuerzas armadas, quienes se conciben como individuos y no como representantes del gobierno.

b) El argumento de la necesidad política de superar el pasado para superar el conflicto, para lo que se precisa del perdón y la reconciliación de la sociedad en que acontecieron los hechos. Lo que muchas veces se apoya en un argumento cristiano.

c) El argumento "de fuerza mayor", que plantea que de no producirse el perdón y el olvido por parte de la sociedad, existe la amenaza por parte de los militares de rebelarse contra el sistema democrático y vuelva la dictadura.

Martín-Baró (1989) sostiene que es lógico para el progreso de una sociedad la resolución de los conflictos que presenta. El punto para él está, en que ese perdón y esa renuncia por la que apela esta razón, se tienen que establecer sobre los cimientos de la verdad y la justicia, y no de la mentira y la injusticia. La reparación gubernamental debe devolver públicamente el nombre y la dignidad a los EXPPS, y reconocer pública y oficialmente que lo que se cometió en contra de sus vidas fue injusto.

\subsubsection{La sociedad}

Becker et al. (1989) sostienen que existe la tendencia colectiva a creer que revivir la crueldad de los hechos de violación a los derechos humanos para los chilenos en Chile, y todo lo que ello implica, produce reacciones de rechazo en la sociedad que es contraproducente con la movilización social a favor del respeto de los derechos humanos.

Por otro lado, los mismos autores a los que hacemos referencia en el párrafo anterior, sostienen que hay evidencia empírica de estudios que afirman que el reconocer el daño sufrido por los chilenos, no debería dejar indiferente a la sociedad en general, quienes tenderían a reaccionar con sentimientos confusos de temor, culpa y desconcierto. Todo lo que tendría efectos paralizantes en la sociedad. Dentro de estas respuestas, se entiende que ante realidades tan duras, la sociedad prefiera "olvidar" lo sucedido. Lo que obviamente es imposible y perjudicial para la mayoría de los integrantes que la componen, principalmente para las víctimas directas por la limitación a la reparación social que esta actitud conlleva, pero que se convierte en un mecanismo adaptativo ante los sucesos.

Por último, según Becker et al. (1989), el sector que representa a la oposición, compuesto por quienes son más afectados por la represión política, se abanderan con la causa de los derechos humanos mediante la denuncia permanente. Pero sus esfuerzos impactan levemente a la sociedad, pues los 
hechos denunciables se han vuelto cotidianos. Todo lo que hace que la sociedad en su afán de restituir la armonía, tienda a negar lo sucedido, para así lograr la calma sin la emergencia de nuevos conflictos ni contradicciones.

\subsubsection{La última década}

En marzo del año 1994, asume la presidencia de la República de Chile, Eduardo Frei RuizTagle, en cuyo período se vio enfrentado a procesos judiciales internacionales en torno a quienes habían presidido la DINA.

Durante el mandato de Frei, específicamente el día 10 de marzo de 1998, Pinochet deja de ser comandante y jefe del ejército y asume al siguiente día como senador vitalicio, con la respectiva inmunidad que el cargo le otorgaba (Brinkmann, 2002).

En octubre de 1998, Pinochet es detenido en Londres por orden del juez español Baltasar Garzón, quien le seguía desde España por crímenes de lesa humanidad que se le imputaban al exmandatario chileno. Se inicia posteriormente, un proceso de extradición de Pinochet a España para ser juzgado por la violación a los derechos humanos, petición que tras la creación de la mesa de diálogo sobre derechos humanos creada por Eduardo Frei, fue denegada para ser juzgado en Chile.

El interés político internacional por sancionar a Pinochet por los motivos que exponemos en este apartado, se cree que influye positivamente en la percepción de la sociedad chilena, y también impactó en los tribunales de justicia chilenos. Como resultado, obtuvo el desaforo y el sometimiento a proceso como autor de secuestros reiterados y homicidios. Pero, posteriormente, el diagnóstico de demencia hizo que el ex-gobernante, fuera sobreseído del proceso en cuestión (Brinkmann, 2002).

El 11 de marzo de 2000 la presidencia de la República de Chile, es asumida por Don Ricardo Lagos Escobar, quien mantuvo la mesa de diálogo creada por Eduardo Frei y tras la presentación en junio del año 2000, presentó un informe final que fue criticado por los distintos sectores defensores de los derechos humanos en Chile, porque se consideró que eludía la responsabilidad institucional en los hechos durante el régimen militar de Pinochet (Brinkmann, 2002).

Posteriormente en el año 2003, el ex-presidente Lagos crea la Comisión Nacional sobre Prisión Política y Tortura, que clasificó los casos de víctimas supervivientes de experiencias de prisión política y tortura en Chile entre los años 1973 y 1990, como hemos mencionado reiteradamente en los capítulos 
que conforman esta tesis doctoral. En este informe nos hemos basado para hacer este estudio en cuanto a las víctimas que ha clasificado y que son nuestro objeto de estudio. En un apartado posterior, haremos referencia a especificaciones de este informe.

\subsubsection{Consideraciones previas}

Lira, Becker y Kovalskys, Gómez y Castillo (1989) sostienen que creemos que la sintomatología, o lo que en este estudio llamamos impacto de la experiencia de prisión en la vida de los EXPPS, implica un impacto individual sobre las personas que las sufrieron en el contexto de un impacto colectivo sobre toda la sociedad chilena. De acuerdo a este planteamiento, creemos que experiencias traumáticas como la violencia política y la tortura, pueden generar un impacto en sus víctimas que a más de treinta años estará condicionado por las particularidades de los EXPPS, sus capacidades y limitaciones para enfrentar y dar lectura a los hechos, así como por los procesos políticos y sociales que ha vivido la sociedad chilena; y muy especialmente por la forma en que se ha afrontado este problema.

Para la realidad represiva en Latinoamérica, el concepto de Bettelheim (1981) al que hemos hecho mención en el capítulo II, que él definió como situaciones límites, para referirse a las situaciones que atentan en contra de la vida de las personas o implican una amenaza. Para el autor, estas situaciones se corresponden a experiencias traumáticas que pueden ser producto de un hecho puntual y específico o de la suma de hechos sucesivos.

Lo anterior, aplicado al caso de Chile, el mayor número de detenciones y acciones represivas ocurrieron en el primer año de gobierno militar, y la posibilidad de nuevas detenciones fue una amenaza presente durante más de una década. Creemos que este aspecto incidió en la presencia de traumatizaciones en los EXPPS que estuvieron privados de su libertad en más de una oportunidad.

Mención aparte merecen quienes fueron exiliados y retornaron al país después de años de vivir en el extranjero. Quienes en algunos casos partieron solos, en familia, o hicieron familia estando en sus países de acogida. Creemos que estas personas al residir en otros países, no vivieron la amenaza constante de volver a ser privados de su libertad, como sus compañeros chilenos que mantuvieron su residencia en Chile, pero suponemos que si experimentaron temor por sus vínculos emocionales y sociales que dejaron en el país y los sucesos políticos de los años de dictadura militar. Por supuesto, tampoco podemos olvidar lo que supone tener que emigrar y hacerlo por estas razones concretas, 
además de los esfuerzos de adaptación a un nuevo país. A ellos dedicaremos un apartado dentro de este capítulo.

\subsection{RESPUESTA GUBERNAMENTAL A SUPERVIVIENTES DE PRISIÓN POLÍTICA Y TORTURA: EL INFORME VALECH}

Como hemos aludido en reiteradas oportunidades durante el desarrollo de la presente tesis doctoral, el Informe sobre prisión política y tortura, conocido popularmente como Informe Valech, significó el fin del silencio político mantenido a lo largo de la historia por el Gobierno de Chile, de los hechos de prisión política y tortura acontecidos en Chile entre los años 1973 y 1990, y realizados por los representantes del gobierno durante el régimen militar. Se reconoce con este documento por primera vez, a un grupo de chilenos supervivientes a estas experiencias.

Para nuestra investigación, el Informe Valech, nos ha otorgado una serie de conocimientos específicos de la población que estudiamos, sin precedentes en la materia. Ha sido para nosotros, el punto de origen de la formulación de nuestro objeto de estudio, y la fuente inspiradora de este proyecto. Además, nos ha permitido contactar con personas que fueron reconocidas por un equipo multidisciplinario de profesionales (abogados, psicólogos, asistentes sociales, etc.) en su condición de ex - presos políticos chilenos. Esto facilitó nuestro encuentro con estas personas, a quienes pudimos contactar mediante agrupaciones oficiales de EXPPS, y permitió la homogenización de la muestra en base a este criterio. Nuestro estudio, es pionero en investigar a personas que disponen de este reconocimiento oficial.

Por otro lado, las medidas gubernamentales de reparación que han sido otorgadas a los EXPPS reconocidos oficialmente, nos remiten a otros aspectos actuales de sus vidas, que se asocian al impacto que estudiamos. Por ello, dedicaremos esta sección, a desarrollar aspectos esenciales de este informe en función de nuestra investigación.

\subsubsection{Antecedentes legales y funcionamiento de la comisión Valech.}

La Comisión nacional sobre prisión política y tortura (Comisión Valech), fue un organismo que se estableció mediante el Decreto Supremo No 1040, a petición del expdte. Ricardo Lagos en septiembre de 2003, bajo su propuesta gubernamental denominada "no hay mañana sin ayer" (Gobierno de Chile, 2004, p. 21), cuyas funciones fueron dos: esclarecer la identidad de quienes fueron víctimas de privación de su libertad y tortura por motivos políticos en Chile, durante el régimen militar 
(entre el 11 de septiembre de 1973 y el 10 de marzo de 1990); y proponer al presidente Lagos, condiciones, características, modos y formas de medidas de reparación para estas personas.

Dicho en otras palabras, la comisión Valech se encargó de recopilar antecedentes de las violaciones a los derechos a la libertad personal y la integridad y seguridad que se hubieran cometido a personas por motivos políticos.

El funcionamiento de la comisión Valech, consistió en: recibir los antecedentes que presentaran de manera voluntaria todas aquellas personas que consideraban que habían sufrido la experiencia de prisión y/ o tortura por motivos políticos en el período antes citado; analizar los casos, mediante el examen del conjunto de antecedentes entregados por las personas mediante los procedimientos de validar la información en fuentes valoradas por la comisión como confiables, realizar investigación documental, solicitar información a organismos de derechos humanos y/ u organizaciones de víctimas, y/ u organismos públicos, investigar las referencias y los testigos, validar a través de la investigación en bases de datos disponibles, y llevar a cabo una segunda entrevista si los pasos recién referidos no fueron suficientes.

De acuerdo a los criterios reseñados en el párrafo anterior, los profesionales de la comisión Valech que se dedicaron a calificar a las personas que referían ser víctimas de privación de libertad y tortura por motivos políticos en Chile, establecieron mediante tres categorías, la precalificación de estas personas. Estas fueron: precalifica (para los casos que presentaron suficientes antecedentes para proceder a su precalificación), no califica (para los casos cuyos antecedentes no aplicaron a los tres criterios evaluativos), y con antecedentes por definir conforme a mandato (para los casos que contaban con suficientes antecedentes coherentes pero presentaban dudas respecto de su inclusión en el mandato).

Posteriormente, las personas que precalificaron fueron procesadas con la calificación o no de sus antecedentes. Esta acción consistió en el proceso colegiado de evaluación de todos aquellos antecedentes que la persona evaluada disponía y permitían identificar en ellos elementos objetivos de juicio que permitieran adquirir convicción moral de la calidad del preso y/ o torturado por motivos políticos.

Una vez finalizado el proceso de calificación de las víctimas, la comisión Valech estableció el Informe de la comisión nacional sobre prisión política y tortura, Informe Valech. 


\subsubsection{Características de períodos de prisión establecidos por la Comisión Valech}

Según el total de personas que el Informe Valech considerara en el informe emitido en noviembre del año 2004, el total de víctimas de privación de libertad y/ o tortura por motivos políticos alcanza a 33221 personas. De las cuales, según el estudio que la comisión Valech hiciera del número de detenciones realizadas por años durante el régimen militar, más del 94\% de las víctimas de prisión política y tortura, afirmaron haber sufrido tortura por parte de agentes del estado chileno o personas a su servicio, a lo largo de todo el país.

Otro indicador relevante, es aquel que refiere que la mayoría de las víctimas de prisión política (61\% de 33221 personas), estuvieron recluidas durante el inicio del régimen militar, calificado como el primer período. Estas detenciones, fueron realizadas principalmente por carabineros de Chile (43\%), y personal del ejército de Chile (30\%).

Durante el segundo período comprendido entre 1974 y 1977, fueron privados de su libertad el 18,33\% de las personas, equivalente a 6089; y durante el tercer período comprendido entre 1978 y 1990 , el 12,97\%, equivalente a 4308 personas.

Los lugares de reclusión durante el año 1973, fueron prefecturas, comisarías, sub-comisarías, retenes, cuarteles, tenencias, regimientos, estadios deportivos y otros recintos de deporte, escuelas matrices, casas patronales, fábricas, edificios de entidades públicas, hospitales, maestranzas, bases aéreas y navales, cárceles, estaciones ferroviarias, embarcaciones de la armada y la marina mercante, campos de prisioneros, fiscalías militares, gobernaciones, intendencias, y establecimientos educacionales.

Del total de detenciones reconocidas por el informe Valech emitido el año 2004, la mayoría de éstas $(38,88 \%)$ fueron realizadas por carabineros. En segundo lugar, estas acciones fueron realizadas por militares $(24,44 \%)$.

Según la distribución que el informe Valech presenta de las detenciones según región de aprehensión, la zona geográfica con más detenciones fue la perteneciente a la Región Metropolitana, alcanzando en 35,23\% (11705 personas). le sigue la VII región, con el 14,98\% (4976 personas).

Además de la Región Metropolitana, los participantes de nuestro estudio fueron detenidos en la I región que obtuvo el 3,69\% (1226 personas), la VI región, con el 4,24\% (1407 personas), la X región con $8,19 \%$ (2720 personas), y la XI región, con 1,03\% (342 personas). 
Entre septiembre y octubre del año 1973, se llevó a cabo la caravana de la muerte. Esta operación, fue encargada por el presidente de la junta militar de aquel año, a oficiales del ejército, que de norte a sur del país, aleccionaron con brutales ejemplificaciones, a personas que estaban privadas de su libertad por motivos políticos durante ese año. Con esta operación, se da inicio a todo tipo de abusos.

De lo anterior, la comisión Valech concluye que tanto la prisión política como la tortura, constituyeron una política de estado del régimen militar, que para llevarse a cabo, movilizó personal y recursos de diferentes entidades públicas, y dictó decretos leyes y leyes que ampararon tales acciones represivas. Se reconoce además, que con posterioridad al año 1973, y durante el régimen militar, la represión fue aplicada en casi todas las localidades del país, por personeros de las fuerzas armadas y de orden, y en ocasiones por civiles.

Hacia finales del año 1973, y tras la etapa de represión masiva, la represión política comienza a volverse más selectiva en sus técnicas de tortura. Afectando a menos personas que durante el primer año, y que predominantemente disponían de una participación política-partidista.

Desde este período surgen organismos de inteligencia como la DINA y el Comando conjunto, que estuvieron controlados por personeros de las fuerzas armadas y de carabineros.

Próximos al año 1976, comienzan a ocurrir cambios en las tendencias de represión. Disminuyen las detenciones por períodos prolongados, y se hacen frecuentes las aprehensiones por horas con la aplicación de tortura, principalmente electricidad. Además, se hacen más frecuentes los allanamientos en los hogares de las personas perseguidas, y la vigilancia y persecución a éstas. De igual modo, son comunes los interrogatorios sin detención, a la vez que la aplicación de tortura. La disminución de detenciones se mantuvo durante el período restante.

Durante el año 1979, se articuló el MIR (Movimiento de izquierda revolucionaria), para hacer frente mediante el uso de las armas al régimen militar, para lo que dispuso del ingreso clandestino de militantes poseedores de entrenamiento militar específico. Que ingresaron al país mediante la Operación retorno. En los ochentas, y siguiendo la tendencia del MIR, surge el Frente patriótico Manuel Rodríguez (FPMP), que era un grupo armado vinculado al partido comunista, y el MAPU Lautaro. Estas agrupaciones, comienzan a movilizar a un sector de chilenos, para reaccionar contra el régimen. 
En la década de los ochenta, parte de la oposición que vivía en clandestinidad, se hizo visible en espacios públicos, sobretodo en calles de Santiago de Chile, y la represión comenzó a emplear acciones como el uso del carro lanza agua, bombas lacrimógenas, arrestos y golpes. Todo lo que era común en ambientes de protestas.

Otra modalidad de represión en los ochenta, de carácter más selectivo, fue la relegación administrativa, que también fue empleada para aislar a torturados mientras se recuperaban físicamente.

Por su parte, y con el interés de lograr la interrupción de la tortura, agrupaciones religiosas se manifiestan públicamente para lograr su objetivo. Se crea así, en el año 1983, la Comisión nacional contra la tortura. Organismo que fue integrado por representantes de la iglesia católica, científicos de renombre y artistas, profesionales del área de la salud, y otras personas que luchaban en aquel entonces por la preservación de los derechos humanos en Chile.

\subsubsection{Perfil de víctimas reconocidas}

El informe gubernamental realizado por la comisión Valech, realizó un perfil general y una descripción específica por períodos, de la totalidad de las personas que clasificó.

Esta comisión, sostiene que los EXPPS no sólo fueron perseguidos por poseer cargos de responsabilidad en el gobierno de Salvador Allende, o ser figuras vinculadas a la izquierda chilena y a sus militantes comunes, durante el régimen militar, sino que también lo fueron, por ser representantes de organizaciones de base, con participación en movimientos de reivindicaciones de índole social, dirigentes de partidos, trabajadores sindicalizados, campesinos partícipes de la reforma agraria, estudiantes universitarios y de secundaria, además de dirigentes de juntas de vecinos.

A continuación, presentaremos las variables que estableció la comisión Valech, y la tendencia predominante por categorías según el perfil general.

El perfil general de víctimas, considera información acerca de su identidad, su lugar en la sociedad, y lo que son en la actualidad.

Sexo: la mayoría de los EXPPS calificados por la comisión Valech, son hombres. El porcentaje equivale al $87,53 \%$. 
Edad al momento de la detención: según este indicador, la moda la obtienen las personas que tenían desde 21 a 30 años al momento de su detención (44,25\%).

Edad actual: la mayoría de EXPPS tiene al momento de realización del informe Valech, más de 60 años (42,92\%). En segundo lugar, y con un 40,13\%, tiene una edad entre 51 y 60 años. Hemos referido este segundo resultado, por considerarlo relevante para nuestro estudio.

Actividad laboral al momento de la detención: la moda para la categoría, la obtiene ocupaciones laborales de tipo calificadas, con un 30,11\% de los EXPPS.

Actividad laboral actual: la moda la obtiene la ocupación laboral denominada sector pasivo, que refiere la jubilación o cesantía, y que alcanza al 27,66\% de los EXPPS.

Filiación política al momento de la detención: la mayoría de EXPPS (69\%), refirió mantener una adhesión a partidos políticos y los cargos que desempeñaba al momento de la detención. La mayoría de estas personas militaban en el partido socialista y comunista.

En cuanto al número de detenciones, la mayoría de las víctimas estuvo detenida en una oportunidad $(83,6 \%)$, en promedio permanecieron en tres recintos de detención cuando estuvieron en prisión (29\%), y permanecieron en prisión más de una semana y menos de un mes $(18,48 \%)$.

Por último, la violencia ejercida contra menores de edad, se presentó en el 4\% de los EXPPS clasificados, de los cuales el 70,93\% tenía entre 16 y 17 años al momento de su detención.

\subsubsection{Clasificación de ex - preso político según la comisión Valech}

El artículo $1^{\circ}$, inc. $1^{\circ}$, del Decreto Supremo $N^{o} 1040$, refiere las tres condiciones que deben cumplir quienes las personas para ser reconocidas por la Comisión Valech como EXPPS:

a) la privación de libertad o tortura, o ambas, deben haber sido perpetradas por motivos políticos;

b) estas acciones deben haber sido llevadas a efecto por agentes del estado chileno, o personas que en su servicio, actuaban con conocimiento, tolerancia, connivencia o aquiescencia con éstos, sin precisar una relación formal o contractual;

c) la fecha de ocurrencia de estas experiencias debe haber ocurrido entre el 11 de septiembre del año 1973 y el 10 de marzo del año 1990. 
El decreto en cuestión, también establece que quedan excluidas de esta calificación, las personas que fueron privadas de su libertad en manifestaciones públicas, que fueron puestas a disposición de tribunales por delitos comunes y posteriormente condenadas por estos delitos, y aquellas personas que fueron retenidas temporalmente durante la realización de allanamientos masivos, u otra forma que se le parezca de control colectivo o indiscriminado a sectores de la población chilena.

\subsubsection{Métodos de tortura oficialmente reconocidos}

La comisión Valech determinó las técnicas de tortura que experimentaron los EXPPS chilenos cuando fueron privados de su libertad por motivos políticos. Por nuestra parte, no fue objeto de nuestra investigación, estudiar los tipos de tortura específicos padecidos en prisión por los participantes de nuestro estudio. Pero creemos que conocer los tipos de tortura empleados en Chile durante el régimen militar, nos permite dimensionar los hechos a los que estas personas estuvieron expuestas durante su permanencia en prisión, y con ello entender con mayor conocimiento de causas, el impacto que estudiamos. A continuación, presentaremos las distintas modalidades de tortura que fueron clasificadas por la comisión Valech.

Golpizas reiteradas: constituyó el método de tortura más empleado durante el régimen militar, y el precursor en su aplicación a las víctimas chilenas. Comprende golpes en todo el cuerpo, la reiteración de éstos, la realización por varias personas, y durante tiempo prolongado. También comprende golpes en partes específicas del cuerpo de las personas, como en partes sensibles, que en ocasiones causaron hasta sangrado. Estas acciones muchas veces se realizaron tras el desnudamiento de la víctima, y con vendas en los ojos que les impidieron advertir los golpes. Se emplearon antes, durante y después de los interrogatorios.

Entre algunas de las consecuencias de estas acciones, la comisión Valech constató la pérdida total y parcial de la visión o la audición, la pérdida de piezas dentales, afecciones renales, esterilidad y lesiones en la columna.

Dentro de los golpes más aludidos por las víctimas calificadas por la comisión Valech, se encuentran los golpes de pies y puños, golpes con objetos contundentes, golpes con objetos flexibles o no contundentes, el teléfono (golpes con mano abierta en ambos oídos, cuya ejecución puede provocar lesiones auditivas permanentes), golpes reiterados en partes de la cara, genitales, cuello, rodillas y otras partes sensibles a nivel corporal. También dejar caer el cuerpo de los detenidos por escaleras, 
arrastrarles por el suelo, tomados del pelo, amarrados del cuello, u otra parte del cuerpo, pisar o saltar sobre las víctimas cuando están tendidos en el suelo.

Lesiones corporales deliberadas: refiere daños o detrimentos a nivel corporal en las víctimas, que es causado por una herida de corte o desgarro, o por un golpe, de manera intencional por agentes de estado, o particulares, con el consentimiento de aquel, que realiza la acción con una intención específica de causar lesión. Ejemplos de estas lesiones, son los golpes, los colgamientos, la aplicación de electricidad, heridas causadas por el contacto con el fuego, objetos calientes u sustancias corrosivas o cáusticas, que en su mayoría fueron aplicados cuando los detenidos se encontraban en estado inerme, maniatados y con la vista vendada o con capuchas.

Dentro de este tipo de tortura, las quemaduras más usadas, fueron aquellas realizadas con el uso de cigarrillos. Por su parte, las lesiones corporales clasificadas por la comisión Valech, comprendieron la extracción de partes menores del cuerpo, como uñas, dientes, etc.; cortes realizados con arma blanca, fracturas deliberadas, heridas a bala, lesiones auditivas deliberadas, producto de disparos de fusil desde una posición cercana a los oídos de las víctimas, o por la exposición de éstas a sonidos agudos por un período de tiempo prolongado, que llegaron a causar sangrado de boca, oídos y nariz y hasta la pérdida de conciencia de algunas de las personas que sufrieron este tipo de tortura. Se incluyen además dentro de esta modalidad de tortura, todas aquellas lesiones en las uñas u otras partes del cuerpo, causadas por la introducción de objetos punzantes, y las lesiones producidas por el hecho de hacer pasar un vehículo sobre partes del cuerpo de las víctimas.

Colgamientos: este tipo de tortura consistió en la inmovilización y el mantenimiento de posiciones forzadas, que tienden a tensar las articulaciones hasta provocar la dislocación de las víctimas.

Específicamente, estas prácticas comprendieron el colgamiento de las personas de una o ambas muñecas, o de uno o ambos pies en posición invertida, de pies y manos amarrados a un palo colocado en posición horizontal, o con los brazos atados por detrás de la espalda. Estas acciones provocan dolores que van aumentando a medida que pasa el tiempo en que son mantenidas, y que podía ir desde minutos a días. Todo lo que era acompañado de amenazas, humillaciones, golpes, y electricidad, mientras las víctimas de estos hechos permanecían sin vestimenta y podían ser sometidas a algún tipo de violencia sexual.

Dentro de esta modalidad de tortura, destaca aquella llamada "pihuelo" o "pau de arará", que en portugués significa "palo volador" (Gobierno de Chile, 2004, p. 231). Esta técnica consiste en amarrar 
las manos y luego éstas a los pies, cruzando una barra o palo en posición horizontal por el espacio que se forma entremedio de manos y pies. Posteriormente, la barra es colgada en forma horizontal, quedando la víctima en posición invertida. De este modo, quedaba colgando de manos y pies. Ocasionalmente la barra se giraba, aumentando los dolores.

Generalmente las personas que padecieron estas prácticas a corto y largo plazo, presentaron lesiones a la columna, y a nivel psicológico, el informe Valech considera que este tipo de tortura, principalmente realizada por períodos prolongados, genera sensaciones de indefensión, abandono y humillación.

Posiciones forzadas: esta modalidad de tortura, comprende la obligación de las víctimas para que mantenga una posición determinada por un período de tiempo prolongado que desde horas a días y semanas, produciendo un agotamiento físico extremo. Esta posición no necesariamente es incómoda, pero se vuelve intolerable por el tiempo que debe ser mantenida.

Generalmente, la coacción de este tipo de tortura, comprendía golpes propiciados ante cualquier movimiento realizado por las víctimas, amenazas, amarras de pies y manos, y la privación de la visión por períodos de tiempo limitados.

Dentro de las posiciones más empleadas, destacan el permanecer de pie, tendido en el suelo boca abajo, amarrado y sentado en una silla, de pie y en dirección a la pared, con las manos en alto, y de rodillas con las manos detrás de la nuca.

Aplicación de electricidad: esta modalidad de tortura comprende la aplicación de descargas eléctricas en partes del cuerpo o en su totalidad. De cualquier forma, provoca dolores físicos intensos y un agudo sufrimiento a nivel psíquico, y puede producir secuelas físicas permanentes.

Más de un tercio de las víctimas calificadas por la comisión Valech en su calidad de EXPPS, refirió haber sufrido, entre otras formas de tortura, la aplicación de electricidad en su cuerpo. Además, esta técnica fue empleada durante todo el régimen militar, de manera masiva y a escala nacional.

Los implementos utilizados para el ejercicio de esta técnica, consistían en magnetos que disponían de cables que eran adheridos a puntos sensibles del cuerpo de las víctimas. Generalmente, la intensidad de la descarga podía ser graduada, cuya variación dependía de los torturadores. En algunos casos, estos implementos eran más rudimentarios. 
Estas técnicas se realizaban previo desnudamiento de las víctimas, que eran sentadas en una silla preferentemente de metal, o tendidos en una cama o catre del mismo material. Se les maniataba e inmovilizaba, privándoles de la visión mediante vendas o capuchas. Todo lo que aumentaba la sensación de indefensión en quienes padecieron estos hechos.

Destacan como técnicas específicas, "la parrilla" (Gobierno de Chile, 2004, p. 233), que consistía en desnudar y encapuchar a la víctima, postrándole sobre un catre metálico al que era amarrado de manos y pies. Posteriormente, se aplicaba la descarga eléctrica utilizando la colocación de electrodos en distintas partes del cuerpo, principalmente en axilas, plantas de los pies, sienes, oídos, ojos, boca, encía, lengua, senos, pene o vagina, testículos, ano, y heridas abiertas.

La modalidad llamada "picana eléctrica" (Gobierno de Chile, 2004, p. 233), consistente en la aplicación de electricidad en una parte del cuerpo mediante una especie de bastón que producía la descarga, y la aplicación de descargas eléctricas a víctimas colocadas previamente en una bañera con agua fría.

Amenazas: consisten en la intimidación a través de advertencias acerca de los males o peligros que se ciernen sobre una persona afectada, o terceros relacionados con la misma, recibidas en situación de radical vulnerabilidad y en caso de no cumplir con las peticiones de los torturadores. Esta técnica causa un sufrimiento psicológico agudo en sus víctimas.

Estas técnicas refieren la amenaza de muerte, de desaparición forzada y de aplicación de otra modalidad de tortura en el detenido o sus familiares. Fueron empleadas durante todo el régimen militar, y llegaron al extremo de detener al cónyuge e hijos menores de edad, o tras allanar sus viviendas, obtener fotografías de los familiares para mostrarlos a la víctima durante la advertencia realizada por los torturadores de ser torturados, muertos o desaparecidos. Todo para conseguir información.

Simulacro de fusilamiento: esta técnica consiste en la imitación o fingimiento de la ejecución de una persona, para lo que se usa la descarga de fusiles u otras armas, de un pelotón comisionado para ello. Esta modalidad de tortura produce que la víctima experimente la inminencia de su muerte como real.

Esta técnica, al igual que otras referidas anteriormente, se empleó de manera masiva y sistemática durante todo el régimen militar. Generalmente, se efectuaba acompañada de una puesta en escena que hacía creer a las víctimas que iban a perder sus vidas. 
A las víctimas usualmente se les llevaba a lugares apartados, donde eran maniatados y vendados o encapuchados. Posteriormente, escuchaban las instrucciones dadas a un pelotón que disparaba al aire, a los costados o la cabeza de estas personas.

La comisión Valech, reconoce además como daño colateral de esta práctica, aquel causado a compañeros políticos de las víctimas de simulacro de fusilamiento, que desde sus lugares de reclusión, escuchaban los disparos, y pensaban que las personas habían muerto por esta causa. Lo que era promovido por la no reintegración de los presuntos fusilados a sus lugares de detención.

Las víctimas de este tipo de tortura registradas por la comisión Valech, sostuvieron que siempre creyeron que con estas prácticas sus vidas acabarían.

Humillaciones y vejámenes: esta modalidad de tortura que busca causar daño psíquico o mental grave en sus víctimas, comprende todos aquellos tratos y coacciones realizados a estas personas, con la intención de menoscabar la dignidad humana, el honor, la honra y el orgullo personal.

Esta técnica generalmente se asoció directa o indirectamente a otros tipos de tortura. Ejemplo de estas prácticas, se encuentra la ingestión forzada de desechos, que además de causar un sufrimiento mental grave por el trato indigno en contra de la condición de ser humano de las víctimas, también generó en muchos casos, daños físicos producto de las infecciones y enfermedades provocadas por este tipo de tortura.

En adición a la modalidad referida en el párrafo anterior, la comisión Valech considera acciones de esta modalidad de tortura: el arrojar excrementos e inmundicias al detenido, obligarle a besar la bota de un militar o policía, a arrastrarse por el suelo en medio de burlas y golpes, a pedir perdón renegando de sus ideas políticas y manifestando lealtad o reconocimiento a la superioridad a los militares o policías, a entonar himnos en medio de burlas, a insultarse a sí mismo o a los compañeros, y a hacerle correr privado de su visión mediante vendas o capuchas por lugares con obstáculos para que se caiga. Además de ser sometido a injurias, y raparle para luego ser mostrado en lugares públicos.

Desnudamiento: obligar a la víctima a quitarse la ropa y permanecer desnudo en presencia de otras personas con intenciones hostiles, mediante la coacción, o la fuerza, mientras es sometido a interrogatorios. Estos hechos, en ocasiones eran acompañados con golpes y electricidad. 
Agresión y violencia sexual: consistente en coaccionar física o psicológicamente a una persona por medio de la fuerza, a realizar o padecer actos sexuales. Estas acciones además de atentar contra la libertad de las personas, produce daños al desarrollo sexual y de la personalidad de éstas.

La comisión Valech concluyó que tanto hombres como mujeres sufrieron este tipo de tortura, pero fueron las mujeres principalmente quienes padecieron en mayor medida este tipo de agresión. También la comisión estimó que este tipo de tortura fue aplicado a menores de edad.

Dentro de las modalidades de tortura sexual que clasificó la comisión Valech, fueron comunes la agresión verbal con contenido sexual, las amenazas de violación hacia la víctima y sus familiares, la obligación por medio de la violencia para desnudarse con el objetivo de excitar al agente del estado, el simulacro de violación, la obligación de oír y presenciar la tortura sexual de compañeros o familiares, haber sido fotografiados en posiciones obscenas, la introducción de objetos en ano o vagina, la violación en distintas modalidades, e individuales, colectivas, o sodomíticas, la obligación de realizar actos sexuales con compañeros, familiares, incluso animales. La introducción de ratas u otros organismos vivos en boca, ano, o vagina.

Un dato relevante para nuestra investigación, es la afirmación que sostiene la comisión Valech acerca de que una gran mayoría de víctimas de esta modalidad de tortura, refirió haber carecido de apoyo especializado para tratar los efectos de estas experiencias en sus vidas, principalmente durante los primeros años del régimen militar, y muchas de estas personas, refirieron que nunca se habían atrevido a contar estas experiencias.

Presenciar torturas de otros: consiste en ser obligado a presenciar u oír hechos de tortura aplicados a compañeros, familia, etc., que busca que el prisionero pueda antecederse a lo que le puede ocurrir si desobedece a la autoridad. En cuanto a los familiares, los métodos de tortura más utilizados fueron las agresiones sexuales, la electricidad y los golpes.

Ruleta rusa: método que mediante un juego de azar consistente en dispararse en la sien con un revólver con una sola bala (o que simula estar cargado), con el desconocimiento del lugar del tambor donde ésta se encuentra. La tortura está, en la eventualidad de morir. Esta técnica no fue usada de manera masiva. 
Presenciar fusilamientos de otros detenidos: obligación de presenciar el fusilamiento de compañeros o amigos. Esta técnica promovía que la víctima vivenciara la inseguridad de su vida. En casos más crueles aún, los cuerpos fusilados eran arrojados sobre los espectadores.

Confinamiento en condiciones infrahumanas: refiere el confinamiento de un prisionero en una celda, bodegas de barcos o jaulas, construidas o ambientadas para provocar dolor físico o psíquico. Este confinamiento pudo haberse caracterizado por el aislamiento de la víctima por períodos prolongados de hasta meses. El confinamiento también pudo haberse realizado en celdas pequeñas que por su reducido espacio, no permitía que la víctima pudiera sentarse o permanecer de pie, sin luz, ventanas, ventilación, servicios higiénicos, agua, ni comida.

Privaciones deliberadas de medios de vida: privación de recursos materiales necesarios para la subsistencia, como el abrigo mínimo, el agua y los alimentos. Además de la ausencia de servicios higiénicos. Todo lo que atentaba en contra de la salud de las víctimas.

Privación o interrupción del sueño: impedimento a la víctima de conciliar el sueño, o interrupción deliberada y reiterada durante uno o más días, causando un daño físico y psíquico.

Dentro de esta modalidad de tortura, la comisión Valech reconoce como aquella más usada, la manutención de iluminación del recinto de detención con fotos potentes, ruidos molestos, y golpes reiterados al detenido.

Asfixias: consiste en impedir o dificultar la respiración de las víctimas, causante de sufrimiento físico y psicológico por la eventualidad de morir asfixiado. Dentro de las modalidades más recurrentes, la comisión Valech destaca el "submarino" (Gobierno de Chile, 2004, p. 249), consistente en el sumergimiento reiterado de la cabeza de la víctima en agua, hasta provocar su asfixia por falta de aire. Otras técnicas consistieron en poner a la víctima en posición invertida en un tambor con agua, poner la cabeza de la víctima en una bolsa plástica amarrada al cuello impidiendo con ello, el ingreso de aire, y la ingesta excesiva de agua por la vía oral o nasal, hasta llenar el estómago, logrando la asfixia.

Exposición a temperaturas extremas: consiste en exponer a una persona a temperaturas muy bajas o muy elevadas, con la finalidad de causarle daño físico o mental. 


\subsubsection{Consecuencias de prisión política y tortura en la vida de los EXPPS}

Para la comisión Valech, los EXPPS clasificados mantenían al momento de la evaluación, efectos de la experiencia de prisión tales como el dolor, la humillación y el miedo por los hechos de violencia que padecieron durante la experiencia de cautiverio. Esto hizo que para muchos de ellos, el tener que dar testimonio de sus experiencias, fuera una tarea difícil.

La comisión Valech refiere además, que la mayoría de EXPPS calificados, refirió que la experiencia de prisión política y tortura, tuvo efectos devastadores en sus vidas. Éstos, sumaban además de las enfermedades de salud física y mental, la perturbación de sus relaciones afectivas, sociales y sexuales, que deterioraron sus vínculos familiares y de pareja.

A nivel laboral, el informe en cuestión, refiere que la mayoría de EXPPS perdió su trabajo, y con ello, sus medios de subsistencia para vivir en condiciones mínimas. En algunos casos, hasta perdieron la propia vivienda.

A nivel social, el informe Valech refiere que muchas de las víctimas se sintieron acosados, denigrados y excluidos, lo que motivó que estas personas partieran al exilio. Para quienes permanecieron en el país, vivieron la estigmatización y la persecución en sus hogares, que en ocasiones llegó a la reiteración de la experiencia de privación de libertad, lo que motivó que decidieran cambiar de ciudad de residencia. Por su parte, quienes permanecieron en sus lugares de residencia previos a la experiencia de prisión y en localidades pequeñas como pueblos, se vieron en la obligación de tener que convivir con quienes fueron sus torturadores, que en muchos casos, mantuvieron sus funciones públicas.

Las redes de apoyo se debilitaron, lo que hizo que las posibilidades de inserción social y laboral de los EXPPS en el período post-prisión, desaparecieran. Afectando en sus expectativas de futuro.

De acuerdo a los antecedentes adversos referidos recientemente, la comisión Valech refiere que fue muy difícil para los supervivientes que estudiamos, el retomar un curso normal en sus vidas. De quienes considera que algunos lograron reponerse, pero no todos.

Una de las pérdidas más significativas en las vidas de los EXPPS, refiere la pérdida irrecuperable de las posibilidades de progreso y bienestar que muchos supervivientes disponían en el período previo a la experiencia de prisión. Los sueños y aspiraciones se perdieron., especialmente para familias de 
trabajadores y campesinos que depositaron todas sus esperanzas de mejorar sus vidas, en la Unidad Popular.

A nivel político, con el régimen militar, quienes integraban organizaciones sindicales y sociales, perdieron sus referentes ideológicos, en los que habían comprometido el sentido de sus vidas.

A modo general, la comisión Valech según los aspectos referidos recientemente, refiere que la experiencia de prisión política causó una quiebra vital que afectó a todas las dimensiones de la existencia de víctimas directas y sus familiares, que en muchos casos, se mantienen en el presente.

La comisión Valech plantea la importancia que tiene la identificación de elementos del contexto político en que sucedieron los hechos, en el significado emocional de las experiencias de prisión para sus supervivientes. Dentro de las que destaca como primer impacto, el descubrir que los hechos de violencia política y tortura, provenían de agentes de estado. Otros aspectos refieren la indefensión y el desamparo ante el poder armado y coactivo del gobierno de Chile, el apoyo recibido por instituciones religiosas, la no oficialidad del contexto de aplicabilidad de la tortura, que se caracterizó por el noreconocimiento de las autoridades que realizaban o amparaban estas prácticas, la negación de la detención del prisionero, que impedía que se pudiera intervenir a su favor, y por último, la inminencia de muerte.

Además de las consecuencias de la tortura en la vida de víctimas supervivientes a estas prácticas, las consecuencias psicológicas detectadas por la comisión Valech, aluden a aspectos conductuales, emocionales y psicosociales que afectaron a corto y largo plazo en la vida de los EXPPS.

Dentro de estas consecuencias, la comisión Valech destaca la inseguridad, el temor, el sentirse humillados, avergonzados y culpables, además de deprimidos, desesperanzados y angustiados. Se suman alteraciones a la memoria, problemas familiares y de pareja, la pérdida de grupos de referencia y redes de apoyo social, trastornos del sueño e insomnio crónico, inhibiciones de conductas y fobias; además de emociones como la tristeza y síntomas depresivos que se reactivan con fechas relacionadas a los hechos.

En relación a la tortura, el informe Valech reconoce que estas prácticas constituyeron una agresión masiva que estuvo destinada a quebrar las resistencias físicas, emocionales y morales de sus víctimas, en condiciones de total desamparo. Esto provocó que para estas personas, fuera difícil 
expresar en palabras la experiencia límite de la tortura, causado por un desencuentro entre palabras y emociones. Todo lo que dejó en evidencia, la experiencia traumática de la tortura.

El recuerdo de la tortura, fue asociado por la comisión Valech a reacciones de horror, tristeza y miedo, que han sido preservadas en silencio, perpetuando el trauma. Esta comisión considera que la tortura es experimentada como amenaza de muerte, pero estas experiencias sumadas a otras propias de la prisión, comprenden diferentes experiencias traumáticas, que adquieren este carácter, precisamente por la incapacidad de las víctimas para asimilarlas dentro de sus convicciones y marco conceptual.

A nivel de relaciones familiares, la comisión Valech sostiene que la experiencia de agresión deliberada por agentes del estado, produce el rompimiento en la confianza que las víctimas habían depositado en las instituciones y otros seres humanos. Lo que en consecuencia, afectó en la confianza establecida en términos de relaciones interpersonales, produciendo un retraimiento defensivo y aislamiento en las víctimas, traducido a soledad social, que afectó negativamente en sus posibilidad de establecer nuevas relaciones amistosas o amorosas. También considera que a algunas personas les llevó a reconfirmar sus convicciones políticas, hasta disociar el dolor personal y actuar como si no existiera.

El cambio político de partidos de izquierda, para quienes un EXPP significaba una amenaza por su reconocimiento oficial de izquierdista, además de otros motivos, hizo que organizaciones políticas cesaran su funcionamiento. En cuanto a los amigos, muchos de ellos también vivieron la experiencia de prisión, o partieron al exilio, o permanecieron recluidos en sus casas, y algunas víctimas se sintieron ellos mismos, un factor de riesgo para sus seres queridos, todo lo que fomentaba el aislamiento intrafamiliar.

El deterioro de las relaciones afectivas, era causado por la angustia y la desconfianza que unidas a la desesperanza y la auto desvalorización, empobrecieron y deterioraron estas relaciones. Se modificaron además las cogniciones de las víctimas en torno a la propia identidad, además de sus intereses y actitudes en la vida. Muchos de ellos, reconocen haberse vuelto irritables y presentar rabia que expresaron hacia ellos mismos y otras personas, comprendiendo así, una nueva tendencia autodestructiva en sus vidas.

A nivel sexual, la comisión Valech, detectó la presencia de un marcado silencio personal y social de las experiencias de violencia sexual en la vida de las víctimas de tales hechos. Esto, se entiende como una respuesta al fuerte impacto emocional que esta modalidad de tortura produce en las personas, y que se asocia al temor a ser denigradas y se cuestione su identidad sexual por este motivo. Todo lo que 
provocó efectos nefastos en las víctimas, dada la significación de la sexualidad tanto en la vida psíquica como relacional de las personas.

La tortura sexual, afectó en la autoestima, la dignidad, la integridad moral y emocional, la identidad, la capacidad de intimidad sexual y las relaciones de pareja de sus víctimas. Lo que a su vez, produjo un impacto en sus relaciones afectivas.

En relación a los hijos, la comisión Valech, destaca como consecuencia en éstos, efectos emocionales por la sensación de desamparo al percibir temor en sus padres, quienes sentían desolación por no proteger a sus hijos.

Las consecuencias psicosociales que el informe Valech detectó, consistieron en la repercusión social de los hechos de violación a los derechos humanos en Chile. En que la política se asocia a muerte. Emerge el silencio social, basado en la incredulidad y la negación de la ocurrencia de hechos de violación a los derechos humanos.

\subsubsection{Propuestas de reparación gubernamental y respuesta de víctimas}

El informe Valech sostiene que la primera propuesta de reparación gubernamental consistió en determinar quiénes fueron las víctimas de experiencias de prisión política y tortura acontecidas durante el régimen militar en Chile.

Por su parte, las medidas de reparación buscaban reparar el daño causado en las experiencias de prisión política y tortura en sus supervivientes. Dentro de las que estableció la comisión Valech, se encuentran las medidas individuales, las colectivas, y las institucionales. A continuación nos referiremos a cada una de ellas.

Dentro de las propuestas individuales, se incluyen medidas jurídicas, económicas, de salud, educación y vivienda.

Medidas judiciales: estas medidas en general apuntan a eliminar los antecedentes penales de las personas calificadas que hayan sido producidas por motivos políticos durante el régimen militar. Otra medida consiste en apoyar las iniciativas para el reconocimiento de la nacionalidad chilena a hijos de EXPPS nacidos en el exilio. Finalmente, dar la oportunidad a hijos y nietos de EXPPS, de ser eximidos del servicio militar si así lo requieren. 
Medidas económicas: la comisión sugiere una pensión económica no inferior a los beneficios económicos otorgados a otras víctimas de violaciones a los derechos humanos por la ley No 19123 y sus modificaciones posteriores, y que comprendan una pensión vitalicia para los EXPPS, heredable a hijos y cónyuge por fallecimiento previo o posterior a la evaluación de la comisión Valech. También se establecen indemnizaciones a los hijos que nacieron en cautiverio.

Medidas de salud: otorgar la garantía de atención integral de salud a las víctimas mediante el Programa de atención integral en salud (PRAIS).

Medidas educativas: estas medidas comprenden el desarrollo de un programa que permita a las víctimas terminar sus estudios básicos, medios o universitarios que cursaban al momento de su detención, para quienes acrediten que se vieron en la obligación de interrumpirlos. También conforma esta medida, el otorgamiento de becas de estudio para los hijos de las víctimas directas.

Medidas de vivienda: consisten en el otorgamiento de una bonificación especial a las víctimas que no hayan accedido a una vivienda mediante el subsidio del estado, no dispongan de una, y se encuentren en situación de precariedad habitacional.

A modo general, y en cuando a las medidas de reparación simbólicas y colectivas, éstas están dirigidas al reconocimiento de las víctimas por la sociedad, en un afán de respeto e intangibilidad de los derechos humanos. Buscan que los hechos de violaciones a los derechos humanos ocurridos durante el régimen militar en Chile no ocurran nunca más, y lograr una convivencia con respeto y dignidad entre los chilenos.

Estas medidas incluyen garantías de no repetición y medidas preventivas, que comprenden modificaciones en la legislación del país, mediante la inclusión de normas de derecho internacional de derechos humanos que garanticen que vuelvan a ocurrir hechos de violación a los derechos humanos, entre otras.

Un segundo grupo de medidas colectivas, comprenden gestos simbólicos de reconocimiento y encuentro, que incluyen el reconocimiento público por el estado chileno y sus instituciones, además de toda persona que es responsable de violaciones a los derechos humanos, de comprometerse a que estos hecho no vuelvan a ocurrir y a promover respeto de los derechos implicados. Este tipo de medida, incluye además el establecimiento de una fecha conmemorativa al compromiso con el respeto de los derechos humanos, y la entrega de un ejemplar del informe Valech a sus víctimas reconocidas en él. 
Por su parte, las medidas de reconocimiento de la memoria, consisten en declarar monumentos nacionales a todos los principales centros que se emplearon para ejercer tortura en Chile. Además de la creación de memoriales y sitios recordatorios de las víctimas de violaciones a los derechos humanos. Se propone además, la creación de un fondo en concurso permanente para proyectos de investigación en materia de derechos humanos, y la creación de un fondo editorial para la publicación de testimonios, obras literarias, obras de arte, que aporten en el reconocimiento de los hechos, por un período de tiempo limitado.

Una última medida colectiva propuesta por la comisión, comprende la difusión, promoción y educación en derechos humanos, que debe aplicarse a todo nivel educativo en Chile.

Dentro de las medidas institucionales, la comisión Valech propone la creación del instituto nacional de derechos humanos, y el resguardo y la confidencialidad de la información recopilada en el proceso evaluativo que realizó la misma.

\subsection{CONTEXTO SOCIAL Y FAMILIAR PARA QUIENES VIVIERON EL EXILIO}

Concordando con el planteamiento de Castillo y Gómez (1989), concebimos el exilio como otra forma de represión política para un grupo de chilenos, que conllevó en sus vidas, complejos procesos de rupturas y adaptaciones sucesivas que no finalizaron con el retorno al país.

El contexto para quienes fueron exiliados de Chile, como es obvio pensar, fue muy distinto de aquel de quienes mantuvieron su residencia en el mismo país, y nos hemos referido a ello en el capítulo II. A continuación haremos mención a algunas especificaciones del exilio en la vida de los EXPPS, que puedan incidir en la vida de los EXPPS diferencialmente en comparación a quienes no vivieron este cambio en sus vidas.

Para quienes vivieron el exilio, estuvieron distanciados de la cotidianidad chilena en época de dictadura, pero por otra parte, se postula que tenían la necesidad de mantener vínculos con quienes permanecieron en Chile. Todo lo que se cree, dificulta la elaboración de las experiencias vividas en el exilio, adquiriendo este último, un carácter traumático en sí (Castillo y Gómez, 1989). Comenzaron una nueva vida en un país extranjero, desde un punto de partida doloroso.

Uno de los principales motivos por los que se demanda atención en el centro ILAS en Chile, es a causa de dificultades en el proceso de reinserción a Chile por parte de hijos adolescentes de exiliados que partieron de Chile en sus primeros años de vida. Quienes presentan síntomas tales como angustia, 
labilidad emocional, síntomas depresivos y dificultad en sus relaciones interpersonales. No obstante lo anterior, las problemáticas que aparecieron en terapia fueron las mismas de aquellos jóvenes que no vivieron el exilio. Éstas incluyeron depresión, conflictos familiares y temores (Castillo y Gómez, 1989).

Para quienes regresan a Chile después del exilio, víctimas directas como EXPPS y en muchos casos víctimas también como sus familias, dependiendo entre otros factores, del tiempo de permanencia en el extranjero, nuevamente se ven enfrentados a un proceso de adaptación en un país que se vuelve extranjero para ellos. Ellos mismos han cambiado, por la experiencia de represión política que vivieron, por la etapa evolutiva en que se encuentran y por los cambios personales que han experimentado al vivir en el extranjero, además de otros motivos. Esto podría favorecer o dificultar la nueva etapa de reinserción social de los EXPPS, lo que dependerá de sus características personales y sus recursos disponibles. 
Privación de libertad y tortura política en Chile (1973-1990) 
CAPÍTULO IV.

DISEÑO METODOLÓGICO, PLANTEAMIENTO DEL PROBLEMA E HIPÓTESIS. 
Privación de libertad y tortura política en Chile (1973-1990) 
En cada una de las páginas de este capítulo, pretendemos plasmar todos los pasos metodológicos que hemos considerado necesarios para estudiar el impacto emocional y social de la privación de libertad y tortura por motivos políticos en una muestra de chilenos reconocidos oficialmente por el gobierno de Chile como EXPPS.

Iniciaremos la presentación de los contenidos de este capítulo, refiriéndonos a las tendencias actuales en este tipo de investigaciones y la aplicabilidad de la metodología cualitativa para nuestra investigación.

En una segunda fase, presentaremos la justificación, el diseño y los problemas de investigación de nuestro estudio. Además de las hipótesis que nos planteamos.

Posteriormente, desarrollaremos los temas que hemos agrupado y jerarquizado en nuestro mapa conceptual para entender el impacto que estudiamos, tanto a nivel demográfico como conceptual y que serán indagados con la técnica de recogida de datos que desarrollamos.

En la fase siguiente, haremos alusión a las estrategias que empleamos para acceder al campo, los pasos metodológicos que empleamos una vez en él, y el material obtenido. Todo relativo al trabajo que realizamos previo al traslado a Chile, período que finalizó después de cinco meses que duró la estancia en este país, período que empleamos para contactar con la muestra y realizar las entrevistas. Lo que fue realizado en distintas localidades del norte, centro y sur de Chile .

Una fase posterior, refiere información que consideramos relevante acerca del tratamiento que hicimos de los datos, y la utilidad que nos brinda el uso del programa QSR Nvivo 6 para la consecución de nuestros objetivos de investigación. Definiremos además los operadores de este programa informático que emplearemos en este estudio.

Finalmente, nos referiremos a la fiabilidad y validez de nuestro estudio y presentaremos el cronograma que hemos seguido para el desarrollo de la investigación.

Dada la naturaleza cualitativa de nuestro estudio, el desarrollo de las fases de investigación no se caracterizó por la exclusión entre sí. En efecto, durante el transcurso de la investigación nos vimos en la necesidad de reformular de manera constante los temas que incluimos en nuestro mapa conceptual, lo que en parte consideramos que se debió a que no dispusimos de estudios previos realizados a largo plazo en la población estudiada, que nos remitiera principalmente a las problemáticas actuales de los EXPPS chilenos y a la influencia de estos factores contextuales en el impacto que estudiamos. 
Muchos de los registros y anotaciones que hicimos durante las distintas fases, han guiado el desarrollo de este capítulo. Creemos que ello nos permitió recoger información adicional que nos entregó nuevos indicadores relevantes para incorporar y desechar principalmente en nuestro mapa conceptual.

Antes de continuar describiendo el procedimiento de nuestro estudio, consideramos imprescindible describir lo que nosotros entendemos como metodología cualitativa y que coincide con algunas definiciones, como aquella que entiende este tipo de metodología como “...una estrategia de investigación fundamentada en una depurada y rigurosa descripción contextual del evento, conducta o situación que garantice la máxima objetividad en la captación de la realidad, siempre compleja, y preserve la espontánea continuidad temporal que le es inherente, con el fin de que la correspondiente recogida sistemática de datos, categóricos por naturaleza, y con independencia de su orientación preferentemente ideográfica y procesual, posibilite un análisis que dé lugar a la obtención de conocimiento válido con suficiente potencia explicativa" (Anguera , 1986).

Una de las principales razones por las que hemos elegido la metodología cualitativa como perspectiva central de esta investigación, se debe a que nos interesa estudiar los aspectos intrínsecos del impacto de la privación de libertad y tortura por motivos políticos, desde la teoría que enmarca nuestro estudio, lo que sumado a la inexistencia de estudios relacionados en la población que estudiamos, nos permitirá lograr una visión amplia del fenómeno, situando nuestros objetivos de investigación, lejos del estudio de relaciones meramente numéricas. Sin embargo, la técnica de análisis de datos que emplearemos, nos permitió de igual modo hacer un contraste numérico que realizamos con las relaciones porcentuales y frecuencias que el programa informático QSR Nvivo6 efectuó de los datos, y los análisis que realizamos con la prueba de $\chi^{2}$ de Pearson y el análisis de conglomerados jerárquicos que realizamos a variables seleccionadas, con el programa cuantitativo de tratamiento de datos SPSS en su versión 15.

\subsection{TENDENCIAS ACTUALES DE LA INVESTIGACIÓN CUALITATIVA EN LAS CIENCIAS HUMANAS}

Encontramos en la literatura científica, múltiples corrientes dentro de la investigación cualitativa a nivel epistemológico y práctico, que han sido desarrolladas durante las últimos décadas. Destacan entre ellas, la investigación-acción, la investigación etnográfica, el estudio de casos, la observación participante, los grupos de discusión, y la entrevista en profundidad. 
A nivel empírico-analítico, se observa durante las últimas décadas una tendencia al empleo de diseños correlacionales predictivos, con el apoyo de herramientas informáticas. Estas herramientas, facilitan el procesamiento de datos y se vuelven cada vez más accesibles para la comunidad científica, permitiendo lograr una elevada precisión y constatación de resultados a la hora de desarrollar investigaciones cualitativas (Rey, 2005).

Nuestra investigación, sigue la tendencia de emplear herramientas informáticas, porque creemos que nos permitirá tratar la complejidad de tópicos y aspectos que estudiaremos, y propicia el estudio exploratorio de temas y relaciones entre ellos.

De acuerdo a lo anterior, y para estudiar el impacto emocional y social de la experiencia de prisión y tortura en sus supervivientes chilenos, hemos considerado aspectos demográficos y conceptuales de las personas que participarán del estudio, en términos personales, interpersonales y cognitivos en tres períodos (pre-prisión, post-prisión y actualidad), cuya exploración fue posible con el uso del programa informático Nvivo6.

\subsection{JUSTIFICACIÓN, DISEÑO Y PLANTEAMIENTO DEL PROBLEMA DE INVESTIGACIÓN CUALITATIVA EMPLEADO EN EL ESTUDIO}

\subsubsection{Justificación}

El silencio generalizado en torno a la violación a los derechos humanos ocurrida en Chile entre 1973 y 1990, que ha abarcado los sectores políticos, sociales y personales en la vida de sus víctimas y en la vida de los chilenos durante 31 años (Lagos, 2004), y que cesó, al menos gubernamentalmente con la publicación del Informe sobre prisión política y tortura que emitiera el gobierno de Chile en noviembre del año 2004, ha incidido en la ausencia de estudios realizados a las víctimas directas de estos hechos y refiere una situación actual inconclusa en torno a la reparación para sus víctimas.

Si consideramos que son más de treinta y cinco mil chilenos las víctimas directas de los hechos de violencia política y tortura acontecida en Chile en el período antes citado, no es una cifra menor para un país que para el año 1973 alcanzaba los diez millones de habitantes (Instituto Nacional de Estadísticas [INE], 2004), cuyo impacto aumenta, si consideramos que el sufrimiento vivido en prisión fue compartido con las familias de origen y/ o extendidas de los EXPPS, impactando además de en estos vínculos, en la descendencia en la actualidad. 
El quebrantamiento de las vidas de las víctimas, la destrucción de sus familias, los sueños frustrados, la imposibilidad de dar a los hijos una vida mejor, son algunas de las consecuencias que reconociera el mismo expdte. Lagos tras conocer los resultados del Informe Valech (Gobierno de Chile, 2004). Esto, sumado a la inexistencia de estudios previos a largo plazo en la población estudiada, nos motivaron para realizar este proyecto de tesis doctoral, que creemos aportará en el entendimiento de un fenómeno político y social que permanece en el tiempo y que afectará a nuevas generaciones.

A lo anterior, se suman sucesos políticos que han caracterizado el caso de Chile, como la impunidad en torno a la figura del expdte. Augusto Pinochet, el término del régimen militar sólo hace 15 años del momento que realizamos el trabajo de campo, entre otras características contextuales de la sociedad chilena y su evolución socio-política, hacen que el estudio del cautiverio por motivos políticos, sea necesario para las víctimas, la sociedad chilena en general, siendo un aporte al estudio del tema en víctimas pertenecientes a otros contextos.

La elección de la metodología cualitativa para llevar a efecto nuestra investigación, se basó en la naturaleza exploratoria de nuestro estudio, en la ausencia de indicadores del impacto en cuestión obtenidos en investigaciones científicas previas, en nuestro interés por conocer desde los expertos en el tema y mediante sus discursos, el énfasis que otorgan a temas específicos y la valoración que hacen de distintos aspectos interpersonales que nos ocupan en este estudio. Cuya riqueza de información no puede obtenerse por medio de técnicas cuantitativas.

En adición a lo anterior, la dificultad para conseguir la muestra y más aún para respetar ciertos criterios de heterogeneidad en su selección, según antecedentes demográficos personales, familiares, sociales y de prisión, hizo que en un período superior a los cinco meses, no lográramos entrevistar a más de 60 EXPPS, lo que nos impidió llevar a efecto la parte cuantitativa programada inicialmente para este estudio. La posibilidad de hacer un estudio cuantitativo que comparara los hallazgos obtenido en la muestra con un grupo control, era muy difícil, por la precisión de este último grupo y la heterogeneidad de la muestra.

Como hemos referido principalmente en el capítulo II, existen diversos estudios realizados a víctimas de experiencias de prisión política y tortura a nivel mundial, destacando aquellos realizados a víctimas del Holocausto, y de emigrantes de distintas procedencias asilados en países de Europa que han enfocado sus objetivos al estudio del Síndrome de estrés post-traumático y la trascendencia del trauma a la descendencia. Pero estos estudios no se han enfocado en la satisfacción de las necesidades interpersonales básicas que enmarcan nuestro estudio. Lo que hace novedoso nuestro trabajo. 
Por último, con la emisión del informe Valech el año 2004, fueron entregadas las primeras medidas de reparación del gobierno a las víctimas chilenas de privación de libertad y tortura por motivos políticos, no existiendo precedentes de la valoración que los EXPPS hicieran de estas medidas. Lo que es altamente trascendente si consideramos la influencia de los factores contextuales en la perpetuidad del trauma de experiencias como las que estudiamos en este proyecto (estudiada en el capítulo II). Nuestro estudio aporta en esta área del conocimiento.

\subsubsection{Diseño}

Nuestra investigación es un estudio exploratorio de tipo ex post facto en base a metodología cualitativa de análisis de contenido.

Para llevarlo a cabo, nos hemos basado en un enfoque interpretativo y crítico a la vez. Dentro de este enfoque, el lenguaje adquiere gran relevancia, pues implica una acción y una construcción social, constitutivas de objetos, mundos, mentes y relaciones sociales de las personas que estudiamos.

De acuerdo a todos los aspectos precedentes que justifican nuestro estudio, creemos que el diseño de nuestra investigación, empleando metodología cualitativa, nos permite considerar el denominado "tercer entorno" que afecta a la dinámica cultural, la socialización, la afiliación ideológica y el compromiso ciudadano, vistos como campos de significado característicos dentro de los objetivos de la investigación cualitativa y de nuestro estudio (Revuelta y Sánchez, 2003); además de conseguir una visión clara y descriptiva de una situación específica.

Basamos nuestra elección de metodología cualitativa para este proyecto, en el interés que tenemos por obtener un considerable volumen de información acerca de cómo los sujetos que estudiamos construyen sus significados, considerando sus valoraciones sociales y políticas en sus discursos.

Pretendíamos agotar el tema en estudio, realizando la mayor cantidad de entrevistas que el tiempo y los recursos disponibles nos permitieran, en un período de cuatro meses y medio, a EXPPS residentes en distintas ciudades a lo largo de Chile (se obtuvieron finalmente más de 10 mil párrafos que fueron nuestras unidades de análisis). 


\subsubsection{Objetivos e hipótesis}

\section{Objetivo general}

Conocer y describir los efectos emocionales, afectivos y sociales a largo plazo de experiencias de prisión y tortura por motivos políticos ocurridas en Chile entre 1973 y 1990, sobre la satisfacción de las necesidades interpersonales básicas: los vínculos de apego, la red social y las relaciones de pareja en un grupo de supervivientes chilenos.

\section{Objetivos específicos}

Establecer relaciones entre todas las variables de satisfacción de las necesidades emocionales con las variables de satisfacción de las necesidades sociales de los supervivientes a experiencias de prisión y tortura por motivos políticos, durante los períodos pre-prisión, post-prisión y actualidad.

Relacionar las concepciones del mundo, la vida y los seres humanos de los EXPPS, con la experiencia de prisión política y tortura por motivos políticos y la satisfacción de las necesidades interpersonales.

Describir los factores contextuales actuales que inciden en los efectos traumáticos de la experiencia de prisión y tortura por motivos políticos.

Establecer relaciones entre aspectos demográficos personales de la experiencia de prisión política y tortura, y aspectos conceptuales acerca de la satisfacción de necesidades interpersonales.

Conocer las dificultades posteriores con las que tuvieron que lidiar los EXPPS y que fueron causadas por la experiencia de prisión por motivos políticos en sus vidas, y su relación con las relaciones interpersonales, en especial con los hijos.

Estudiar el silencio de la experiencia de prisión por motivos políticos mantenido por los EXPPS, y sus efectos en la soledad emocional y social presente en sus vidas.

Relacionar las valoraciones que los EXPPS hacen de los distintos agentes sociales implicados en los casos de prisión política y tortura ocurridos durante el gobierno militar en Chile, y la respuesta de la sociedad no implicada directamente a estos hechos, con la experiencia de prisión por motivos políticos. 
Conocer la valoración que los EXPPS hacen directamente del impacto que perciben de la experiencia de prisión política y tortura en sus relaciones interpersonales y concepción de mundo.

Estudiar el sufrimiento experimentado durante la experiencia de prisión política y tortura, en supervivientes a estas experiencias.

\section{Hipótesis}

A más de 30 años de ocurridos los hechos de prisión política y tortura, sus supervivientes chilenos presentarán en la actualidad secuelas de estas experiencias manifestadas en mayor insatisfacción de sus necesidades emocionales (con la familia), y sociales (con los amigos y compañeros políticos), con respecto a la satisfacción de estas necesidades en el pasado previo a la experiencia de prisión.

Antecedentes demográficos de prisión como la experiencia de tortura, el tiempo prolongado de permanencia en prisión superior a horas, el reingreso en prisión, entre otros, incidirán negativamente en el impacto percibido de la experiencia de prisión.

En el estudio histórico de la satisfacción de necesidades emocionales y sociales de los EXPPS, éstos presentarán el aumento de insatisfacción en el período posterior a la experiencia de prisión política y tortura en sus vidas.

Los EXPPS sufrieron experiencias traumáticas producto del sufrimiento padecido cuando fueron privados de su libertad por motivos políticos, que pueden mantenerse de presentar en la actualidad problemas pendientes, como la insatisfacción con las medidas gubernamentales de reparación recibidas.

Experiencias de vida como la prisión política y tortura, afectan negativamente en las concepciones de mundo, vida y seres humanos de sus supervivientes, y en la insatisfacción de las necesidades interpersonales de éstos.

La experiencia de prisión política y tortura en sus supervivientes, afectará negativamente en la satisfacción de las necesidades emocionales y sociales de los EXPPS, indistintamente de las características demográficas de prisión. 
Los supervivientes de experiencias de prisión política y tortura, mostrarán una tendencia a la exclusión social producto de una valoración negativa de la respuesta social chilena percibida en torno a la violación a los derechos humanos en Chile.

Los supervivientes de experiencias de prisión política y tortura, presentarán la predominancia de indicadores de apego inseguro en sus relaciones interpersonales actuales.

\subsection{INSTRUMENTO EMPLEADO: LA ENTREVISTA EN PROFUNDIDAD}

La entrevista en profundidad que diseñamos (ver Apéndice A), fue elaborada a partir de dimensiones que establecimos inicialmente desde las necesidades interpersonales básicas humanas planteadas por López (2008) y Weiss (1973), y dimensiones demográficas de la vida personal, relacional y laboral de los participantes, que fueron indagadas desde una perspectiva histórica y contextual fundamentadas en el Informe Valech.

La elección de esta técnica, se basó en que comprende un modelo conversacional generado en un espacio compartido entre el investigador (con un aprendizaje teórico en psicología), y un experto en su experiencia específica (personas que vivieron en primera persona la experiencia de prisión política y tortura en Chile durante el régimen militar).

Tanto el investigador como el entrevistado, mediante la creación de espacios en que se generó un lenguaje en común, que en metodología cualitativa recibe el nombre de doxa, y que incluye el lenguaje experto proveniente de los paradigmas que enmarcan nuestro estudio: la teoría de las relaciones interpersonales de López (2008), y el lenguaje experto del entrevistado, obtenido tanto por su experiencia, su propia interacción con el lenguaje, y sus propios paradigmas (Murillo, 2004), se logró obtener el material de análisis de nuestro estudio.

Elegimos la entrevista en profundidad como instrumento para obtener los datos, porque consideramos que sus objetivos permiten cumplir los objetivos de nuestra investigación. Debido a que esta técnica busca que los entrevistados transmitan verbalmente su definición personal de un acontecimiento o suceso específico, en base a un esfuerzo de inmersión y de unión entre la memoria y la narración. Pues los contenidos son expresados verbalmente por las personas desde la propia experiencia con sus palabras (Murillo, 2004), lo que es muy de nuestro interés como material de análisis y es un valor de la metodología cualitativa al estudio de personas. 
Definimos la entrevista en profundidad, como una técnica en que un entrevistador solicita información a otra persona, un informante o entrevistado, con el fin de obtener datos de un problema determinado. Esta técnica requiere de un mínimo de dos personas y la posibilidad de interacción verbal. Su objetivo es acercarse a ideas, creencias, experiencias y supuestos mantenidos por los entrevistados. Siendo más importante la explicación que le dieron a la experiencia vivida de prisión en sus vidas que el conocimiento o explicación de los hechos. Así como los significados atribuidos y las personas que les rodean y experiencias vividas.

En la entrevista en profundidad que formulamos, establecimos preguntas en base a los objetivos de la investigación, mediante el empleo de un lenguaje que consideramos apropiado para el entrevistado. Para ello, intentamos preguntar por ejemplo acerca de los vínculos afectivos actuales con preguntas tales como “¿cuáles son las personas que se encuentran más cercanas a usted en la actualidad?”.

De acuerdo a los tipos de preguntas que conformaron la entrevista en profundidad, éstas fueron de tipo demográficas o biográficas, elaboradas con el fin de conocer antecedentes personales e interpersonales, además de antecedentes de prisión de los entrevistados, considerados relevantes para el estudio; preguntas sobre experiencias, conductas, acciones y actividades de sucesos específicos; preguntas acerca de sentimientos que buscaban respuestas emotivas de los entrevistados en relación a las experiencias que fueron evaluadas de prisión; preguntas de conocimiento con el fin de averiguar información acerca de cuánto sabe el entrevistado de los hechos que se estudian con la entrevista; preguntas de opinión/ valor que buscaban conocer el modo en que el entrevistado valora distintas situaciones asociadas a la experiencia de prisión. Estas últimas, además nos permitieron conocer información acerca de las intenciones, metas, deseos, valores, y percepción del mundo y el entorno en un antes y un después de la experiencia de prisión.

Simultáneamente, las preguntas fueron de tres tipos: descriptivas, estructurales y de contraste (Spradley, 1979), empleando tres momentos distintos en el proceso de aproximación al problema: el conocimiento, la comprobación y la relación.

Con las preguntas de tipo descriptivas se buscó aproximarse al contexto en que el informante desarrolla su vida cotidiana. Para esto las preguntas fueron del tipo "preguntas gran recorrido", con el fin de obtener material verbal de características significativas de una actividad o escenario sociales (espacios, tiempos, hechos, personas, acciones y objetos); del tipo "mini recorrido" que tienen el mismo formato que las anteriores, pero son más limitadas en cuanto a espacios, hechos, lugares, personas, actividades y objetos; preguntas "de experiencia", cuyo objetivo fue aproximarse a las circunstancias y prácticas que afectan a las 
personas, actividades, lugares, etc. (buscan resaltar sucesos atípicos e incidentes críticos como la experiencia de prisión).

El orden de presentación de las preguntas que conformaron la entrevista en profundidad, siguió un orden que en un principio evitó las temáticas alusivas al impacto de la experiencia de prisión. Fue así como comenzamos indagando aspectos del presente de los EXPPS, seguido de los mismos en el pasado correspondiente a la infancia y adolescencia de los EXPPS previo a la experiencia de prisión, seguido de aspectos alusivos a la experiencia de prisión en sus vidas, y finalizamos abordando aspectos contextuales desde una perspectiva histórica de las problemáticas que presentan y han presentado acerca de la reparación y la justicia percibida en torno al tema de los derechos humanos en Chile y su situación específica.

Prestamos especial atención y cuidado a cualquier posibilidad de inducción de algún tipo de retraumatización de la experiencia ${ }^{1}$. Lo que además de fundamentarse en causas éticas, fue posible porque no indagamos antecedentes históricos específicos de la experiencia en sí, siendo de nuestro interés el cómo esta experiencia afectó a distintos ámbitos de sus vidas y a su cosmovisión del mundo y los seres humanos.

No obstante lo anterior, el criterio de selección de la muestra fue el disponer del reconocimiento del Gobierno de Chile como EXPPS chilenos, y las temáticas abordadas de una u otra manera están entrelazadas con los hechos de prisión política y tortura, siendo difícil separarlos. Por ello intentamos "darles un rodeo" (Murillo, 2004), para también investigar indirectamente algunas temáticas que nos interesaba luego comparar entre los niveles de categorización demográficos y conceptuales del estudio.

La entrevista diseñada fue de tipo semi-estructurada, y esto permitió dar libertad a los entrevistados para que seleccionaran y ordenaran los contenidos que les interesaba expresar, muchos de ellos, con un elevado matiz histórico-político, lo que es congruente con el origen de la temática y en muchos casos, con la motivación principal de sus vidas.

En definitiva, la técnica es conversacional y no del tipo pregunta/ respuesta. Aunque en preguntas centrales de la entrevista, cerramos sus respectivas áreas con preguntas cerradas, para luego comparar a nivel intra e inter-sujeto (ejemplo de ello, preguntas acerca de la concepción del mundo: "en el mundo Ud. se siente: a gusto - a disgusto).

\footnotetext{
${ }^{1}$ Entendemos por retraumatización aquel impacto psicoemocional que se concibe como un fenómeno particular de la sociedad chilena y que es producto de la indagación profunda de antecedentes asociados a la experiencia de prisión u otros sucesos, y que se refleja generalmente en síntomas tales como el insomnio, fallos cognitivos, cefaleas, entre otras somatizaciones (Madariaga, 2002).
} 


\subsection{PASOS METODOLÓGICOS}

En este apartado, describiremos brevemente cada una de las fases que desarrollamos para obtener los resultados de nuestro estudio, el motivo de su realización y los cuestionamientos que fueron surgiendo en el camino. Consideramos que no es una tarea fácil resumir las etapas que presentaremos a continuación, principalmente, por la cantidad de información que obtuvimos en cada una de ellas, y que recibimos en la interacción verbal y no verbal con la muestra, su entorno próximo, la sociedad chilena, las agrupaciones de derechos humanos y partidos políticos que accedieron a colaborar con nuestra investigación, entre otras.

Hubieron momentos en que el caudal de información recibido fue muy grande, generando emociones y sentimientos en la investigadora que hizo este trabajo, quien accedía al conocimiento de un fenómeno tan doloroso como es la experiencia de prisión política y tortura en la vida de sus supervivientes. En ello, fue esencial el apoyo de los directores del proyecto, y como forma de controlar la objetividad del estudio y llevarlo a cabo conociendo lo que las personas estudiadas causaban en la investigadora que hizo el trabajo de campo, fuimos haciendo reflexiones y relatando lo que observábamos anexo a la aplicación del instrumento cualitativo que empleamos (ver Apéndice B).

En cada una de las fases que efectuamos, tuvimos que ir tomando decisiones entre las diferentes opciones que se nos fueron presentando durante el transcurso de cada una de ellas, las que se fueron sucediendo una tras otra de manera lineal, y en ocasiones simultánea. Lo que concuerda con el planteamiento de Pitman y Maxwell (1992, p. 753), que afirman que "toda la investigación cualitativa, incluyendo la evaluación cualitativa, es y debe ser guiada por un proceso continuo de decisiones y elecciones del investigador".

\subsubsection{Fase preparatoria}

En la fase preparatoria se diferencian dos grandes etapas: la etapa reflexiva y la etapa de diseño. Ambas culminaron con la elaboración del proyecto de tesis.

Durante la etapa reflexiva de nuestra investigación, se consideraron variables demográficas como por ejemplo: edad, género, nacionalidad, ciudad de residencia, nivel educativo. Esto, con la finalidad de determinar el tópico de interés del estudio.

Posteriormente, se realizó una búsqueda exhaustiva de investigaciones previas relacionadas y nos encontramos con un vacío de conocimientos para la población que estudiamos dentro del contexto chileno, 
viéndonos en la necesidad de basarnos en estudios realizados en otras poblaciones del mundo, como los estudios realizados a supervivientes del Holocausto de Israel (e.g. Sagi, Van-Ijzendoorn, Joels y Scharf, 2002).

La elección de la teoría y el diseño de nuestra investigación, se fundamenta en que consideramos que era lo más adecuado en base a la formación, experiencia y opción ética-política de la investigadora y los directores: el director del proyecto es quien ha desarrollado la teoría que encuadra nuestro estudio, la codirectora es experta en la metodología con la que lo llevaremos a efecto, y la doctoranda, ha tenido acceso a la realidad estudiada desde la perspectiva de una observadora pasiva y no implicada directamente a los hechos por residir en Chile durante el desarrollo de los hechos de represión política.

\subsubsection{El acceso al campo}

En la fase del trabajo de campo, la investigadora que se trasladó a Chile, contactó personalmente con las personas que aceptaron participar del estudio. Averiguamos los lugares oficiales en que los EXPPS se reunían y cuáles eran las agrupaciones reconocidas oficialmente por el gobierno de Chile (2004), y previo establecimiento de cita vía telefónica con presidentes de dos de estas agrupaciones, al momento de llegar a Chile, ya disponíamos de una entrevista para presentar nuestro proyecto.

Entendemos por campo, el contexto físico y social en el que han ocurrido y siguen ocurriendo los fenómenos que son objeto de nuestra investigación. Generalmente, está por definir y supera los límites de lo previsto inicialmente por los investigadores.

Por su parte, entendemos por acceso al campo, el proceso por el que los investigadores acceden de manera gradual a la información que requieren para desarrollar su trabajo. Este acceso se origina con el permiso obtenido en nuestro caso por dirigentes de agrupaciones oficiales de EXPPS que nos hizo posible entrar a estas agrupaciones, y posteriormente, nos permitió recoger un tipo de información que los participantes sólo proporcionan a quienes confían. Esta fase terminó cuando finalizamos la administración de las entrevistas.

El rol que jugaron las representaciones sociales de los actores en juego, fue una compleja e intangible influencia que ponía en riesgo el desarrollo esperado en esta fase de la investigación.

Por un lado, las ideas de quienes conformarían el grupo de entrevistados acerca del rol de los psicólogos, les predispuso positiva o negativamente a su decisión de participar del estudio y posteriormente a su actitud 
inicial durante la entrevista. A lo que se sumó el desconocimiento total de estas personas de la investigadora en el campo, generando desconfianza y dudas acerca de su motivo principal.

Uno de los objetivos centrales en esta etapa fue posicionarse desde una posición simétrica con ellos, aceptando asistir a un encuentro nacional de EXPPS, accediendo con ello a los "enchufes", entendiendo por este término, aquellas personas que nos permitirían más tarde el acceso a la muestra. Eran estas personas las que disponían del mayor número de EXPPS, por dirigir las distintas agrupaciones. Creemos que la posición simétrica horizontal, permitió que los participantes sintieran la confianza necesaria para el desarrollo de la entrevista.

Fue clave en esta etapa, lograr la confianza del grupo de dirigentes nacionales de la agrupación nacional de EXPPS, pues una vez establecida, se accedió a la muestra que participó de este proyecto. Esto fue posible con la ayuda de algunos dirigentes que contactaron vía correo electrónico con EXPPS de distintas ciudades, presentando a la investigadora encargada de realizar el trabajo de campo, y los motivos del estudio.

La investigación de campo hizo que la investigadora se integrara en la situación estudiada, permaneciendo con cierta prolongación en el contexto o escenario, conviviendo con los protagonistas del proceso, definiendo y adquiriendo un status propio desde el marco de relaciones sociales definidas dentro de la institución o comunidad que integra a los participantes (actuar como investigador, participante, o investigador-participante), poniéndose en el lugar de las personas cuyas ideas, métodos y herramientas de trabajo o producciones se trató de comprender.

Para esto, una estrategia fue el "vagabundeo" q supone un acercamiento informal incluso antes del primer contacto. Incluye información acerca de qué caracteriza al escenario, el aspecto exterior, opiniones, características de la zona, entorno, etc.

La segunda estrategia supone un acercamiento formal a partir del cual se construyeron esquemas sociales, espaciales y temporales de las interacciones entre individuos e instituciones: características personales y profesionales, competencias, organigramas de funcionamiento, horarios, utilización de espacios, tipología de actividades, etc.

\subsubsection{La muestra}

El criterio de selección de la muestra fue el empleado por la Comisión sobre prisión política y tortura establecida por el Gobierno de Chile (ver capítulo III). La elección de este criterio, se debió a que disponíamos 
del listado oficial gubernamental de los EXPPS reconocidos por el gobierno, y este reconocimiento oficial que marca un precedente a nivel mundial de un gobierno que evalúa la condición de víctimas a hechos de violación a los derechos humanos, es un valor añadido a nuestra investigación. Pues las personas que estudiamos oficialmente son EXPPS. Lo que hace que nuestro estudio sea único en este aspecto.

La selección del muestreo además fue según el criterio de disponibilidad e interés de los participantes para ser entrevistados. Básicamente nos interesaba que los EXPPS que participaran de nuestro estudio, fueran de ambos sexos, reconocidos oficialmente como EXPPS por el gobierno de Chile, residieran en Chile, y tuvieran hijos mayores de edad que pudieran responder a una selección de test psicométricos que inicialmente formaban parte del proyecto, y que han sido descartados por la dificultad que se nos presentó para obtener la participación de los hijos. Lo anterior, siguió la selección de informantes según un carácter intencional, dinámico y secuencial. En base a los criterios a los que hemos hecho mención recientemente.

La selección de la muestra estuvo condicionado por la situación frente al tema de los derechos humanos, presente en el país al momento de acceder al campo. Nos referimos a la incertidumbre en torno a las elecciones presidenciales, que dificultó nuestro acceso a ella. Sin embargo, creemos haber respetado los principios planteados por Bardín (1986) de exhaustividad (el material obtenido se obtuvo en base al criterio de selección preestablecido), representatividad (la muestra fue representativa del universo del que fue extraída), homogeneidad (el material respondió a criterios precisos de evaluación); pertinencia (sentido de la información en relación a los objetivos que se persiguen en el análisis).

Una de las dificultades con la que nos encontramos al definir la selección del material a estudiar (entrevistas realizadas a personas que tienen en común haber sobrevivido a experiencias de prisión política y tortura), fue el momento político en que la doctoranda se trasladó a Chile a realizar el trabajo de campo, pues coincidió con las elecciones presidenciales y las negociaciones del partido comunista con la candidata de izquierda, lo que dificultó el estudio durante los meses de estas elecciones, pues el objetivo de las reuniones de las agrupaciones de EXPPS era estudiar las negociaciones con la actual presidenta en período electoral.

\subsubsection{La recogida de datos}

Para recoger y registrar la información, los sistemas de observación utilizados en esta investigación fueron la grabación en formato digital, la entrevista en profundidad, y documentos de distinto tipo como el informe Valech y otros textos relacionados al tópico estudiado. 
El rigor de nuestra investigación se basó en el criterio de suficiencia que refiere la cantidad de datos recogidos, antes que al número de sujetos, y se consiguió cuando obtuvimos la saturación de la información, y adecuación de los datos. Estos aspectos significan que el término del trabajo de campo terminó cuando los discursos dejaron de presentar antecedentes novedosos para el estudio, y la información cubrió las necesidades teóricas del estudio y el modelo emergente.

\subsubsection{El análisis de contenido}

Se inicia tras el abandono del escenario, e incluyó las siguientes fases: reducción de datos, disposición y transformación de datos, y obtención de resultados y verificación de conclusiones.

Hemos optado por el análisis de contenido como metodología de nuestra investigación, porque además de ser una de las técnicas más utilizada tradicionalmente para el análisis de la comunicación humana (en términos de decodificación de mensajes manifiestos, latentes y ocultos, presentes en diferentes documentos), asume como técnica, que los documentos de análisis disponen de las actitudes y creencias de las personas que los producen, así como de las actitudes y creencias de los receptores de tales documentos (Cabero y Loscertales, 1996).

Nos parece interesante la analogía que hacen Igartua y Humanes (2004), quienes sostienen que la técnica del análisis de contenido permite reconstruir la arquitectura de los mensajes mediáticos, conocer su estructura, sus componentes básicos y su funcionamiento. Todo lo que en palabras de estos autores, refiere el descubrimiento del ADN de estos mensajes.

La presentación de los resultados será cuantitativa y refiere la tendencia a resumir aquellas características básicas de los documentos analizados. El objetivo principal de la técnica de análisis de contenido, es determinar las connotaciones de los mensajes, permitiendo realizar con los datos cuantitativos obtenidos, inferencias y extrapolaciones que pueden referirse al transmisor del mensaje, al receptor, o al mensaje en sí. Por último, cabe destacar que la técnica no limita sus objetivos al recuento exclusivo de frecuencias y datos hallados en el texto, en efecto, la obtención de estos valores cuantitativos, permite a los investigadores que emplean la técnica, validar y constatar hipótesis previamente formuladas, y realizar generalizaciones a partir de los datos encontrados (Cabero y Loscertales, 1996).

Bardín (1986) sostiene que la técnica de análisis de contenido es un conjunto de técnicas de análisis comunicacionales con el que se pueden obtener indicadores cuantitativos y cualitativos, mediante procedimientos sistemáticos y objetivos de descripción referidos al contenido de los mensajes, todo lo que 
permite realizar inferencias de conocimientos relativos a variables propias de las condiciones de producción y recepción de los mensajes. Al respecto, Krippendorf (1990) hace un aporte a la hora de introducir el contexto en la definición de análisis de contenido, sosteniendo que esta técnica está destinada a formular, desde datos específicos, inferencias válidas y reproducibles aplicables a un contexto particular. Por ello, hemos prestado especial atención al desarrollo del capítulo III, en que hemos desarrollado el escenario socio-político en que acontecieron los hechos, y algunos antecedentes del acontecer actual chileno que nos remiten a la situación actual de los EXPPS en torno a la reparación y otros asuntos pendientes en sus vidas y originados con la experiencia de prisión. Esta información, nos permitió situarnos en el escenario socio-político en que se formuló el discurso y darle sentido a través de él.

Nuestro propósito fue evaluar las secuelas psicológicas de la experiencia de prisión política y tortura de Chile, mediante la elaboración de esquemas y modelos de comunicación, que consideraban la politización en el discurso de las personas estudiadas.

La calidad de la investigación estará dada por la capacidad de los investigadores de adaptar los objetivos del estudio a las capacidades operativas de ellos, evitando cometer el error de querer abarcarlo todo. Sin duda esta fue una de las principales problemáticas con las que nos enfrentamos a la hora de hacer las entrevistas y de analizarlas, pues nos parecía que todo el material que obtuvimos era relevante para el estudio. Para acotar los temas, una buena técnica fue la realización de más de un ejercicio de contención académica entre la doctoranda y los directores de la presente tesis doctoral, de reformular el diseño de la investigación, en función de lo que pretendimos abarcar.

Dentro de las limitaciones de la técnica de análisis de contenido, a la hora de proceder con el tratamiento de la información, se encuentra el sesgo de los investigadores de imponer en el sistema de categorización establecido, los posibles significados que se buscan en el material. Para contrarrestar este asunto, hicimos un test de fiabilidad (que presentaremos posteriormente en este mismo capítulo), que entregamos a un grupo de psicólogos alumnos de doctorado y un doctor del programa de doctorado de Sexualidad y relaciones interpersonales de la Universidad de Salamanca, conocedores de la teoría de López (2008) que sustenta nuestra investigación. Estos investigadores participaron en calidad de jueces expertos, valorando una selección al azar de unidades textuales y sus posibles categorías. 
Las fases del proceso de elaboración del sistema de categorización de análisis de contenido fueron las siguientes:

1. Fase de preanálisis.

2. Formación del sistema categorial.

3. Codificación.

4. Análisis e interpretación.

5. Presentación del informe.

1. Fase de preanálisis. Esta fue la primera fase del estudio y consistió en la organización de la investigación. Para ello, hicimos un estudio exhaustivo del Informe Valech, con lo que pudimos investigar la población afectada, las medidas de reparación y acceder a información relativa a los supervivientes reconocidos por la Comisión Valech.

En esta fase, se establecieron los objetivos concretos de la investigación, la selección de la muestra, la revisión de la literatura e investigaciones afines acerca de la temática en estudio. Los objetivos en esta fase, se relacionaron con el nivel de análisis que empleamos posteriormente con el material textual, que en la codificación intentamos que sea lo más manifiesto posible, limitándonos a la hora de codificar, a las alusiones explícitas del entrevistado, no interpretando entre líneas. Esto, porque consideramos conveniente seguir el criterio de limitarnos a lo manifiesto como una forma de obtener resultados más confiables que aquellos que se obtienen profundizando en los contenidos latentes en la codificación.

2. Formación del sistema de categorías. Esta es la fase más significativa de la técnica de análisis de contenido, pues debe reflejar el propósito de la investigación y la teoría que la subyace.

Las categorías iniciales se establecieron en base a la revisión teórica de la teoría de las necesidades interpersonales básicas de López (2008), y estudios relacionados. Fue así como seguimos los criterios de exclusión mutua en la mayoría de las variables, homogeneidad, pertinencia, objetividad, fidelidad y productividad.

3. Codificación. A nivel general esta fase implica la elección de las unidades que analizamos o registramos, además de la determinación de los indicadores de codificación que empleamos para estos fines. La unidad de análisis que hemos elegido en nuestra investigación, es el párrafo (el fundamento de esta elección se encuentra en el apartado de este capítulo referido al programa QSR Nvivo6).

El criterio que empleamos para la codificación, fue la presencia o ausencia en el texto de las categorías y el sentido positivo, negativo con que se trata determinado tema, entre otros. 
Especial cuidado tuvimos a la hora de establecer los contenidos de cada categoría, intentando en todo momento superar la subjetividad de la interpretación. Por este motivo es que hemos codificado en base al contenido manifiesto de los documentos.

4. Análisis e interpretación. Esta etapa la organizamos en función de las preguntas de investigación siguientes:

- ¿cuál es el resultado principal?

- ¿son interpretaciones competentes?

- cla interpretación de los datos toma sentido con la teoría?

- ¿cómo decidir si la interpretación es correcta?

Durante todo el transcurso de la investigación, hemos establecido estructuras manifiestas e implícitas textuales y del habla. No nos hemos limitado a la hora de hacer nuestro análisis de contenido, al mero estudio cuantitativo de palabras, considerando aspectos que para nosotros son importantes de atender en esta investigación, como aquellos tópicos o temas específicos aludidos por el emisor de sus modelos de coherencia local, sus implicaciones y presuposiciones, sus aspectos retóricos, y a nivel general, las estructuras y las estrategias del discurso, más abstractas que en el caso de esta investigación, que hemos considerado cruciales para la interpretación y el uso social de los datos obtenidos; y es todo lo que dará sentido a la evaluación de las secuelas emocionales y sociales de la experiencia de prisión política por motivos políticos en Chile. Este proceso duró varios meses y creemos haber logrado una sistematización adecuada para un proyecto de tesis doctoral, lo que podrá verse reflejado en los pasos que hemos seguido y en el mapa conceptual que hemos definido para categorizar nuestros datos, compuesto de más de 1000 categorías de análisis.

También fuimos cautelosos a la hora de establecer los niveles de análisis de las estructuras discursivas, pues se considera que estas estructuras juegan un ron esencial en la producción, comprensión y almacenamiento de los textos y la información, y específicamente en nuestro estudio, en el análisis de los datos para determinar el impacto que estudiamos.

La consideración del contexto social, local y global, en un estudio como el nuestro, nos otorgó información valiosa a la hora de entender el impacto emocional y social de los EXPPS en términos de la influencia que tiene en la satisfacción de sus necesidades interpersonales básicas actuales, la situación por ejemplo en términos de reparación o la respuesta percibida de la sociedad chilena en general de la violación a los derechos humanos ocurrida en Chile. De acuerdo a esta idea, los modelos referidos a los sucesos específicos de privación de libertad y tortura por motivos políticos, conforman la base del significado o 
contenido del texto, mientras que los modelos de contexto al proporcionarnos información relevante acerca de las influencias a las formas variables del material textual, constituyendo una fase intermedia entre las situaciones sociales y las estructuras sociales por una parte, y las estructuras discursivas por otra.

\subsubsection{Transformación de datos}

En el trabajo de campo, la información que se recopiló fue almacenada en archivos de sonido con formato digital, cuya transformación conseguimos al transformar los datos en documentos textuales en formato "txt" mediante la fase de transcripción. Cuando finalizamos la transcripción del material de sonido, estuvimos en posesión de dar inicio a las operaciones analíticas y documentales de nuestro estudio. Este proceso de transcripción duró aproximadamente cinco meses, en que dedicamos 10 horas diarias aproximadamente a esta tarea. Período de tiempo que consideramos excesivo para esta labor, y que se vio lentificado por las dificultades en el entendimiento de las unidades de información verbales, que alargaron el período de tiempo programado para este trabajo.

Siguiendo a Pinto y Gálvez (1999), a modo global hicimos un análisis semántico (lo que los entrevistados han dicho), sintáctico (cómo lo han dicho), y pragmático (qué han querido decir).

El texto en este estudio será definido como una construcción teórica abstracta con autonomía comunicativa, que conforma una unidad de información compuesta por frases que están conectadas temáticamente y que transmiten significado mediante claves sintácticas, semánticas y pragmáticas (Pinto y Gálvez, 1999).

Los textos que hemos analizado han tenido diferentes tipologías, encontrando textos descriptivos, narrativos y expositivos. Los primeros referidos a descripciones de situaciones estáticas en cuanto a características físicas y perceptibles que realizaron los EXPPS durante la entrevista en profundidad, por ejemplo, referidos a la situación específica de violencia política o tortura en prisión; los textos narrativos, caracterizados por la presencia de personas en acción, cuando por ejemplo los EXPPS relataban anécdotas con compañeros en prisión; y los textos expositivos, caracterizados por la presencia de relaciones lógicas, conceptos abstractos entre acontecimientos y objetos en orden de informar, explicar y persuadir, que estuvieron presentes en los documentos cuando por ejemplo los EXPPS asociaban su experiencia de prisión en tiempo y espacio con otros acontecimientos o sucesos relevantes en sus vidas. 


\subsubsection{El proceso de codificación}

El procedimiento que utilizamos para la generación de los sistemas de categorías se realizó mediante el proceso de codificación en dos pasos. Para esto se imprimieron los textos de las entrevistas y se procedió a codificar los textos marcando a lápiz el comienzo y el final de los segmentos de texto relevantes para luego escribir el código apropiado al margen del papel. Una vez finalizada esta etapa se transfirió el trabajo realizado al ordenador. Con esto, se intenta reducir los datos mediante la codificación. Este proceso, duró aproximadamente tres meses, con una dedicación de ocho a diez horas diarias.

Los niveles de codificación que empleamos, fueron el reconocimiento, decodificación y codificación de signos, y el reconocimiento del léxico e identificación del significado de las palabras según la representación almacenada en la memoria del sujeto, además del reconocimiento de las estructuras sintácticas de oraciones y proposiciones, y la interpretación semántica de los conceptos presentes en cada texto. Un nivel superior, fue utilizado cuando todo el material de análisis documental fue codificado en el programa Nud*ist 4, lo que nos permitió elaborar la representación global del texto y obtener información referida al conocimiento del mundo del sujeto, sus proyecciones a futuro, sus esquemas e inferencias, entre otros, situadas en su memoria (Pinto y Gálvez, 1999).

\subsubsection{Análisis de datos}

El análisis de los datos resultó ser la tarea más fecunda en el proceso investigativo, en la medida que a través de esta fase se obtuvieron resultados y conclusiones y la profundización del conocimiento de la realidad. No obstante, fue una de las fases más complejas por la amplitud de información que obtuvimos.

Dentro de las fases que seguimos para hacer el análisis documental de contenido, se encuentran la selección, compuesta por señalizaciones o memos que hicimos durante la codificación y que nos ayudaron una vez finalizada esta fase, analizar el material codificado. La organización, de las categorías en redes o mapas conceptuales, y que supone la manera de representar de manera gráfica o explícita, los conceptos y sus relaciones dentro de las unidades textuales, constituyendo en sí, una guía que nos permitió determinar los contenidos de los documentos, facilitándonos el proceso de codificación.

Para su elaboración, nosotros identificamos y seleccionamos los conceptos del texto, seleccionamos el concepto más importante, hicimos un ordenamiento jerárquico a partir del concepto seleccionado, y creamos el mapa conceptual empleando la lista en cuestión. 
El orden que seguimos para la presentación de los resultados, siguió el esquema planteado por Pinto y Gálvez (1999), para la elaboración del resumen científico consistente en:

1.- Representación proposicional de las ideas más importantes, de las conexiones lógicas entre tales proposiciones, y de la jerarquía proposicional.

2.- Conceptualización en la confección del mapa cognitivo y la determinación de los esquemas que elaboramos.

3.- Valoración en la determinación de la información principal.

4.- Redacción del contenido empleando las macro estrategias de omisión-selección y generalización-integración.

5.- Esquematización realizando la adaptación a la estructura esquemática original y del contenido reducido mediante la formulación de nuevas categorías dicotómicas.

6.- Producción en la redacción del resumen.

\subsection{RIGOR CIENTÍFICO: FIABILIDAD Y VALIDEZ DEL ESTUDIO}

Debido a que las tareas de administración de las entrevistas y la codificación de éstas, fueron realizadas solamente por la doctoranda, no tuvimos que establecer previamente acuerdos entre codificadores ni entrevistadores. Por lo que el tipo de fiabilidad en base al acuerdo de criterios, no fue requerido para esta parte de la investigación.

Sin embargo, durante todo el proceso, los directores del proyecto emitieron sus valoraciones acerca de cómo se estaban llevando a cabo estas tareas, y en cuanto a la fiabilidad de las codificaciones, una vez finalizada esta fase, hicimos una selección al azar de unidades textuales con las que conformamos un test de fiabilidad para nuestras categorías.

De acuerdo a lo anterior, entendemos la fiabilidad del sistema de categorías, como aquella dada por el grado de exactitud y constancia del instrumento cuando es administrado en diversas ocasiones y por diferentes codificadores o analistas.

Por su parte, la validez del sistema de categorías, que refiere al grado en que el instrumento mide lo que realmente desea medir, creemos que después de analizar la primera entrevista con el director del proyecto, constatamos que ésta cumplía con nuestros objetivos de investigación. 


\subsubsection{Test de fiabilidad}

Para medir la fiabilidad del proceso, realizamos un test de las categorías de análisis, que estuvo conformado por una selección aleatoria de unidades textuales y sus respectivas categorías codificadas, más algunas erradas, que un grupo de jueces expertos, conformado por 10 profesionales psicólogos vinculados a la investigación de temáticas asociadas a las necesidades interpersonales básicas planteadas por López (2008), valoraran la presencia o ausencia cada categoría presentada por unidad textual (ver Apéndice C).

En el Apéndice C, presentamos además, la tabla que contiene el listado de variables que fueron codificadas por los jueces en el test de fiabilidad y las respuestas "correctas" e "incorrectas" . Estas últimas aparecen indicadas con un "si" y un "no", respectivamente.

El test en cuestión, estuvo compuesto de 15 párrafos con un total de 37 categorías asociadas, de las cuales 25 codificaciones eran correctas según nuestro criterio para codificar, y 12 incorrectas según el mismo criterio. Estas últimas, fueron incluidas en el test para evaluar la discriminación de los jueces en la categorización. Como podemos ver en la figura 1., aquellas categorías que correspondían a las categorías correctas según nuestra codificación, fueron identificadas por la mayoría de los jueces participantes. Mientras que aquellas categorías incorrectas, fueron identificadas por algunos jueces o por ninguno, no superando ninguna de ellas, el 50\% de coincidencia con las unidades textuales presentadas. Vemos así, que de las categorías que estaban correctamente codificadas según nuestro criterio, estas coincidieron con la categoría de los jueces en un porcentaje entre el 70 y el $100 \%$. 
Figura 2. Resultados del test de fiabilidad de categorías de análisis

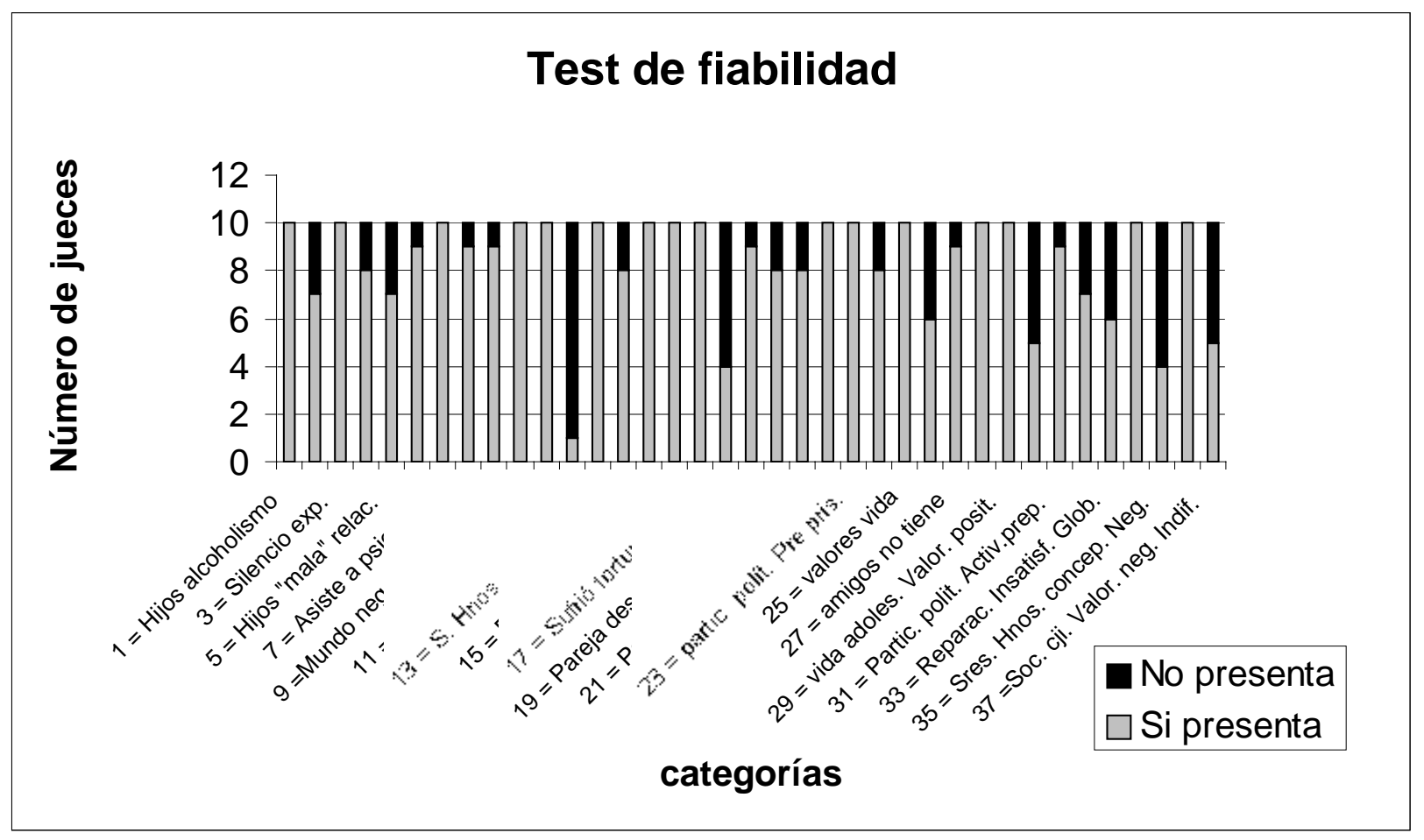

Según los resultados obtenidos, constatamos la correspondencia de nuestro criterio de codificación con el de los jueces expertos, y en cuanto a las diferencias obtenidas, observamos por ejemplo, en aquella unidad textual no codificada por nosotros y codificada por el 50\% de los jueces (la mayor puntuación obtenida de diferencia de criterios), que ésta correspondió a una inferencia a partir de la información contenida en la unidad en cuestión. Por ello, y según el criterio que empleamos para codificar, ésta unidad no fue codificada con la categoría. Nos referimos específicamente a la primera unidad textual presentada en el test de fiabilidad y a la segunda categoría presentada.

El objetivo del test de fiabilidad en cuestión, fue el de controlar otras de las limitaciones de este tipo de metodologías, consistente en que toda la validez de la técnica se asienta sobre la calidad del sistema de categorías previamente establecido, la dificultad que implica reducir un texto y sus connotaciones a un sistema de categorías previamente establecido, y el peligro que ello significa en cuanto a perder información relevante. Siendo difícil demostrar que las inferencias que se realizan de los textos son correctas.

Atendiendo a las dificultades que acabamos de mencionar, intentamos contrarrestarlas reestructurando las categorías de manera reiterada, a medida que iba aumentando nuestro conocimiento de la temática en estudio mediante la codificación de las entrevistas. Este proceso fue esencial para las fases sucesivas de la 
investigación, y tras codificar las entrevistas de la $\mathrm{N}^{0} 1$ a la $\mathrm{N}^{\circ}$, volvimos nuevamente a la $\mathrm{N}^{\mathrm{o}} 1$, y la misma acción repetimos al llegar a la entrevista $\mathrm{N}^{\circ} 10$. Siendo la entrevista $\mathrm{N}^{\circ} 10$, la última de la que se extrajeron nuevos nudos hijos. Posteriormente, codificamos todas las entrevistas (desde la $\mathrm{N}^{\circ} 1$ ) sin añadir más nudos al mapa conceptual. De este modo, logramos una homogeneidad en cuando a posibles codificaciones por unidad textual, y no perdimos información codificable en entrevistas previas a la $\mathrm{N}^{\circ} 10$. Elegimos hacer el corte en la entrevista $\mathrm{N}^{\mathrm{o}} 10$, como la última de la cual extrajimos nuevos nudos, porque consideramos que una vez terminada su codificación, habíamos logrado obtener todos los temas que requeríamos para estudiar el impacto emocional y social de la prisión política y tortura en sus supervivientes.

De acuerdo a lo anterior, la naturaleza de nuestras categorías fue flexible en la primera fase del proceso de análisis de contenido, aunque mantuvimos las categorías centrales que formulamos al inicio de la investigación, las que transformadas a preguntas, conformaron las áreas centrales de indagación en la entrevista en profundidad. Asumimos además, que la presencia de un tema, no es el único recurso para determinar su significación.

Para lograr la validez y fiabilidad de nuestro estudio, además aplicamos distintas metodologías en el análisis que efectuamos: con los datos, realizamos un total de 60 entrevistas en profundidad para obtener la información que necesitábamos procedente de varias fuentes acerca del mismo fenómeno; con los investigadores, el proyecto fue dirigido por una experta en metodología cualitativa y un experto en la teoría psicológica que sustenta el estudio y en metodología cualitativa, y cuyo trabajo de campo fue realizado por una investigadora chilena, conocedora de los códigos sociales y culturales de las personas en estudio. Con la teoría, se analizaron varias perspectivas de investigación de las secuelas que estudiamos en este proyecto doctoral; y a nivel metodológico, realizamos una combinación de métodos de investigación, tanto cualitativos como cuantitativos.

\subsection{EL PROGRAMA QSR NVIVO 6 COMO HERRAMIENTA INFORMÁTICA DE ANÁLISIS DE CONTENIDO}

Para efectuar un tratamiento eficaz de los datos obtenidos mediante las entrevistas en profundidad realizadas, hicimos el uso de CAQDAS (Computer Assisted Qualitative Data Análisis Software), que son herramientas informáticas que incluyen el análisis de datos textuales, y que se caracterizan por facilitar el proceso de síntesis, ordenamiento y organización de toda la información recogida para la presentación de los resultados del proyecto de tesis doctoral. El tratamiento informático que dimos a los datos, nos permitió hacer una visión de conjunto del objeto de estudio, a la vez que realizar un aprovechamiento exhaustivo de éstos 
(Revuelta y Sánchez, 2003). La elección de este soporte informático, se basa en su utilidad reconocida en investigaciones científicas previas (e.g. Lasaga, 2004).

El programa que empleamos, está especialmente diseñado para trabajar con sistemas jerárquicos de categorías. De acuerdo a la terminología del programa, las categorías reciben el nombre de nudos (nodes) y nos referiremos a nudos padres y nudos hijos para significar las relaciones jerárquicas dentro del sistema de nudos. Nosotros a partir de estas relaciones jerárquicas fuimos conformando diagramas en forma de árbol invertido. Este árbol, parte de dos raíces, una de ellas conformada por los antecedentes conceptuales, y la otra, por las categorías conceptuales de nuestro estudio. Fuimos progresivamente extendiendo ambas ramas mediante la colocación de distintas categorías que conformaron los niveles dentro del sistema, hasta descender en las categorías finales o nudos hijos, que han sido los que finalmente hemos codificado.

La unidad de análisis que consideramos más apropiada para nuestro estudio, es el párrafo. Entendemos por párrafo a todo texto comprendido entre dos saltos de párrafo. Puede estar compuesto por una o más líneas y por una o más frases. Es lo que QSR-NUD*IST 4 toma por omisión como Unidad Textual.

El árbol de nodos (Index System), fue el instrumento que nos permitió organizar los datos con el QSR NUD*IST 4. Para ello, creamos una primera rama para almacenar aquellas categorías o variables de tipo demográficas, seguido de otra rama para las categorías conceptuales o teóricas. Las primeras nos permitirán organizar la variabilidad del fenómeno en estudio, mediante el hábeas de datos, y las últimas serán aquellas que nos permitirán constituir el modelo explicativo de las primeras. La versión QSR Nvivo6, es una actualización del NUD*IST 4, y presenta mejoras en el sistema de documentos, codificación, exportación y manejo de datos en general.

Tabla 2. Operadores de búsqueda utilizados con el programa QSR Nvivo6.

\begin{tabular}{||l|l||}
\hline OPERADOR & FUNCIÓN \\
\hline Intersect & $\begin{array}{l}\text { Encuentra todas las U.T.s indexadas en dos o más nudos especificados. Se accede a todas } \\
\text { las unidades de texto que se refieren simultáneamente a dos o más temas. }\end{array}$ \\
\hline Union & $\begin{array}{l}\text { Encuentra todas las U.T.s codificadas bajo cualquiera de los códigos dados. Es una } \\
\text { búsqueda simultánea de más de un código que nos interesa revisar de manera conjunta. }\end{array}$ \\
\hline Collect & $\begin{array}{l}\text { Equivale a efectuar una “unión" de todos los nodos hijos de un nodo dado. } \\
\text { Es decir que equivale a unir todas las U.T.s indexadas en todos los nodos de } \\
\text { la rama del árbol que comienza con el nodo indicado. }\end{array}$ \\
\hline $\begin{array}{l}\text { Whole word } \\
\text { or phrase only }\end{array}$ & $\begin{array}{l}\text { Permite buscar palabras sin caracteres añadidos dentro de todas las U.T.s que hayan } \\
\text { o no hayan sido codificadas. }\end{array}$ \\
\hline
\end{tabular}




\section{7. ÁREAS DE INTERÉS INVESTIGATIVO}

\subsubsection{Definición y justificación de variables}

Las categorías que conforman nuestro estudio, son variables que generan datos expresados con palabras y que denotan cualidades o atributos. Como tales, los datos de nuestras variables no implican un orden a la hora de enunciarlos, y por este motivo los hemos reagrupado en categorías.

Algunas de los atributos de nuestras variables son:

- Variables cualitativas no ordenables, ya que los sucesos elementales que comprenden cada una de éstas, no requieren un orden determinado pero si un límite definido excluyente entre sí.

- Variables cualitativas ordinales, aquellas cuyos datos se agrupan en rangos, estando definidos por atributos o cualidades.

- Variables cuantitativas ordinales, que toman un valor entre dos valores dados consecutivos.

\subsubsection{El mapa conceptual}

Finalmente, modificamos la distribución jerárquica que establecimos para nuestro estudio en nuestro mapa conceptual, para con ello, establecer los resultados que consideramos más significativos para entender el impacto emocional y social, de la privación de libertad y tortura por motivos políticos. Esto, motivados por nuestro interés de sintetizar o reducir la información que obtuvimos a aquellos aspectos más esenciales según las frecuencias presentadas por los participantes del estudio. Lo que hicimos mediante el establecimiento de categorías dicotómicas referidas a valoraciones positivas o negativas, satisfactorias o insatisfactorias.

\subsubsection{Definición de variables}

A continuación presentamos las variables demográficas que conforman el mapa conceptual que elaboramos y que incluye todos los temas que consideramos relevantes para estudiar el impacto emocional y social de la privación de libertad y tortura por motivos políticos, víctimas de la represión política acontecida en Chile entre 1973 y 1990. 
Debido a la gran cantidad de temas que conforman este mapa conceptual, nos vimos en la necesidad de hacer el agrupamiento de las variables por áreas.

Este procedimiento lo realizamos también con las variables conceptuales una vez que finalizamos la fase de codificación, y para ello, establecimos variables más generales que incluyeron los nudos hijos codificados por tendencias que valoramos de manera dicotómicas. De esta forma, pudimos sintetizar los resultados de una manera que nos permitió entender las tendencias obtenidas según las sumatorias entre sujetos.

En el Apéndice D, hemos incluido el mapa conceptual jerárquico con el que codificamos las categorías de nuestro estudio. Este sistema de categorías fue posteriormente agrupado según categorías más generales que fueron establecidas con el fin de resumir los resultados para su presentación en esta tesis.

A continuación presentaremos todas las variables que conformaron nuestro mapa conceptual. Las que a nivel demográfico, mantendrán el orden de presentación inicial, pero en algunos casos han sido agrupadas en categorías más generales. No ocurrirá lo mismo con este mismo orden en aquellas variables conceptuales, que seguirán el orden según las agrupaciones a las que correspondan. De este modo, las variables serán definidas en su totalidad, pero estarán agrupadas en categorías más generales que les incluyen según la tendencia antagónica correspondiente. Esto, porque ésta será la manera en que presentaremos los resultados.

Hemos omitido algunos nudos hijos de esta sección, porque no presentaron frecuencias significativas, cuyas puntuaciones fueron omitidas de los resultados del estudio.

Hay categorías que hemos marcado con el signo “**”, y esto nos indica en el caso de sólo aparecer el signo en cuestión, que la variable ya ha sido definida anteriormente, difiriendo en la categoría previa (ejemplo: presente/ relaciones interpersonales/ familia/ pareja y pasado/ relaciones interpersonales/ familia/ pareja**), o la palabra que antecede al signo, ya forma parte de otra categoría.

Precisamos que cada vez que hablemos de "presente", éste se relaciona al momento de vida actual aludido por el entrevistado al momento de realización de la entrevista. 
Por último, hemos decidido no diferenciar la posición jerárquica de cada variable, y por ello se presentarán de manera indiscriminada aunque por categorías generales. El orden jerárquico de éstas, se encuentra en el mapa conceptual que presentamos en la sección de apéndices (ver apéndice D).

Para las variables conceptuales, hemos decidido modificar el orden de presentación de éstas. Lo que haremos en función de la forma en que presentamos los resultados conceptuales en el capítulo siguiente.

\subsubsection{Categorías demográficas}

Todas las categorías que definiremos a continuación, comprenden aquellas U.T.s que refieren antecedentes personales biográficos al momento de la entrevista de cada EXPP referida a:

\section{Sexo}

Figura 3. Variables demográficas sexo

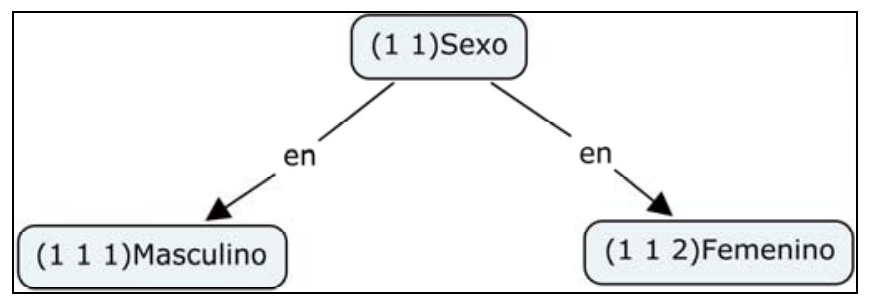

Sexo: naturaleza sexual del emisor.

Masculino: género masculino del emisor.

Femenino: género femenino del emisor.

\section{Edad}

Figura 4. Variables demográficas edad

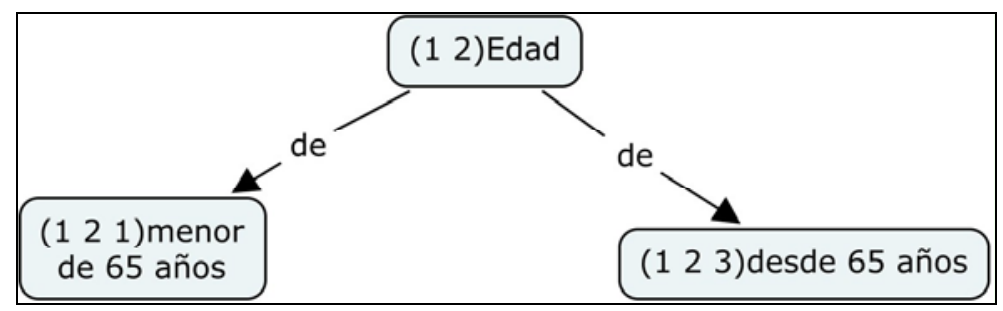

Edad: número de años, meses y días cumplidos por el emisor.

Menor de 65 años: la suma de años, meses y días del emisor es inferior a los 65 años. 
Desde 65 años: la suma de años, meses y días del emisor es de 65 años 0 superior.

\section{Zona geográfica}

Figura 5. Variables demográficas lugar de residencia

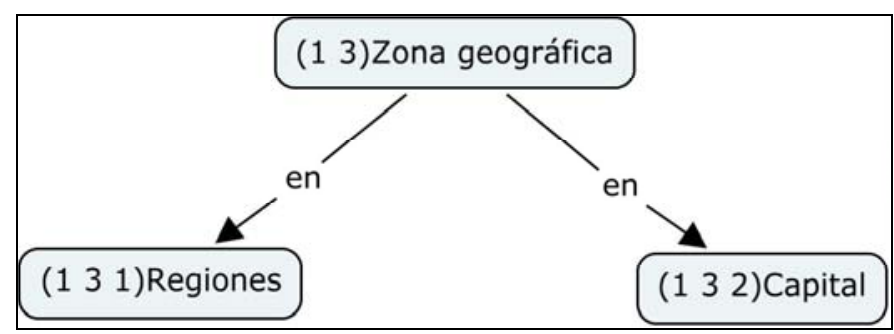

Zona geográfica: antecedentes acerca del lugar de residencia según regiones o capital del emisor al momento de la entrevista.

Regiones: residencia en localidades situadas en regiones del norte, centro y sur de Chile, a excepción de la región metropolitana.

Capital: residencia en la ciudad de Santiago de Chile situada dentro del perímetro de la región metropolitana.

\section{Estado civil}

Estado civil: situación del emisor determinada por sus relaciones familiares de matrimonio o parentesco que le confiere o impone determinados derechos $y$ obligaciones civiles.

Soltero: estado del emisor sin la disposición de una pareja con la que mantenga una convivencia al momento de la entrevista.

Casado o en convivencia: estado del emisor con la disposición de una pareja con la que mantenga una convivencia al momento de la entrevista.

Divorciado o separado de hecho: estado del emisor que refiera la disolución en el pasado de matrimonio u otra relación de pareja con convivencia.

Viudo: estado del emisor que refiera haber perdido en el pasado a uno o más cónyuges por muerte.

\section{Nivel educativo}

Nivel educativo: tipo de educación que posee el emisor.

Estudios primarios: el emisor posee estudios de enseñanza básica.

Estudios secundarios: el emisor ha completado sus estudios de enseñanza básica y posee estudios de enseñanza media.

Estudios técnicos: el emisor ha completado sus estudios de enseñanza básica y media y posee estudios que comprenden un período de dos a tres años de duración y que le han otorgado la capacidad y los conocimientos para realizar un trabajo específico de apoyo a un profesional.

Estudios universitarios: el emisor ha completado sus estudios de enseñanza básica y media y/ o técnicos, y posee estudios de enseñanza superior a nivel profesional. 


\section{Antecedentes ocupacionales}

Antecedentes ocupacionales: actividad laboral que el emisor realizaba antes de la experiencia de prisión, después de esta experiencia y en la actualidad.

ocupación pre-prisión: actividad laboral que el emisor realizaba al momento de ser privado de su libertad por motivos políticos.

Ninguna: el emisor no se encontraba realizando actividad laboral alguna para la fecha en que fue privado de su libertad por motivos políticos.

Trabajador no calificado: el emisor realizaba actividad laboral no especializada o que no requería de dominio teórico y práctico específico para la fecha en que fue privado de su libertad por motivos políticos.

Trabajador calificado: el emisor realizaba actividad laboral especializada o que requería de dominio teórico y práctico específico para la fecha en que fue privado de su libertad por motivos políticos.

Estudiante: el emisor se encontraba cursando estudios al momento de haber sido privado de su libertad por motivos políticos.

No especifica trabajo: el emisor realizaba actividad laboral al momento de haber sido privado de su libertad, pero no da antecedentes que especifiquen el tipo de ésta.

Dueña de casa: el emisor realizaba exclusivamente labores domésticas en el propio hogar al momento de la privación de su libertad por motivos políticos.

Trabajador independiente: el emisor realizaba actividad laboral de tipo independiente, no especificando si ésta requería de su dominio específico a nivel teórico y práctico o no.

ocupación post-prisión: actividad laboral que el emisor realizó desde que fue liberado de la reclusión por motivos políticos hasta los años siguientes que duró el régimen militar.

Ninguna: el emisor no realizó actividad laboral alguna en el período postprisión.

Trabajador no calificado: el emisor realizó actividad laboral no especializada o que no requería de dominio teórico y práctico específico en el período postprisión.

Trabajador calificado: el emisor realizó actividad laboral especializada o que requería de dominio teórico y práctico específico en el período post-prisión.

Estudiante: el emisor cursó estudios en el momento post-prisión.

Trabajador independiente: el emisor realizó actividad laboral de tipo independiente, no especificando si ésta requería de su dominio específico a nivel teórico y práctico o no.

Trabajo no especificado: el emisor realizó actividad laboral en el momento postprisión, pero no dio antecedentes que especifiquen el tipo de ésta.

Dueña de casa: el emisor realizó exclusivamente labores domésticas en el propio hogar en el período post-prisión.

ocupación actual: actividad laboral que el emisor refirió realizar al momento de la entrevista (actualidad).

Ninguna: el emisor refirió no realizar en la actualidad actividad laboral alguna por cesantía, jubilación o su condición de pensionado.

Trabajador no calificado: el emisor realiza en la actualidad actividad laboral que no requiere de su dominio teórico y práctico específico.

Trabajador calificado: el emisor realiza en la actualidad actividad laboral que requiere de su dominio teórico y práctico específico.

Trabajador independiente: el emisor realiza en la actualidad actividad laboral de tipo independiente, no especificando si ésta requería de su dominio específico a nivel teórico y práctico o no.

Estudiante: el emisor cursa estudios en la actualidad. 
Trabajador no especificado: el emisor realiza en la actualidad actividad laboral, pero no dio antecedentes que especifiquen el tipo de ésta.

\section{Antecedentes políticos (y de prisión)}

Antecedentes políticos: el emisor refiere antecedentes de su militancia política previa a la experiencia de prisión, en los años posteriores durante el régimen militar y en la actualidad.

Filiación política pre-prisión: el emisor refiere que militó o no en política al momento en que fue privado de su reclusión por motivos políticos.

Ninguna: el emisor niega haber militado en política al momento en que fue privado de su reclusión por motivos políticos.

Activista político: el emisor refiere que militaba en política al momento en que fue privado de su reclusión por motivos políticos.

Filiación política post-prisión: el emisor refiere que militó o no en política en el período posterior a su reclusión por motivos políticos, acontecido durante el régimen militar.

Ninguna: el emisor niega haber militado en política en el período posterior a su reclusión por motivos políticos, acontecido durante el régimen militar.

Activista político: el emisor refiere que militaba en política en el período posterior a su reclusión por motivos políticos, acontecido durante el régimen militar.

Filiación política actual: el emisor refiere militar en política en la actualidad (al momento de realización de la entrevista).

Ninguna: el emisor niega militar en política en la actualidad.

Activista político: el emisor refiere militar en política en la actualidad.

Clandestinidad: el emisor refiere haber permanecido un período de tiempo en situación o estado de manera secreta por motivos políticos, previo o posterior a la experiencia de reclusión por motivos políticos.

No vivió: el emisor refiere no haber permanecido un período de tiempo en situación o estado de manera secreta por motivos políticos, previo o posterior a la experiencia de reclusión por motivos políticos.

Si vivió: el emisor refiere haber permanecido un período de tiempo en situación o estado de manera secreta por motivos políticos, previo o posterior a la experiencia de reclusión por motivos políticos.

Exoneración: el emisor refiere haber sido obligado por motivos políticos a cesar sus servicios ocupacionales que realizaba en organismos de la administración pública del gobierno de Chile, de empresas en las que este gobierno tenía más del 50\% de participación, o empresas intervenidas por la autoridad civil o militar, o a organizaciones a las que les puso término durante el régimen militar.

No: el emisor niega haber sido obligado por motivos políticos a cesar sus servicios ocupacionales que realizó en organismos de la administración pública del gobierno de chile, de empresas en las que este gobierno tenía más del $50 \%$ de participación, empresas intervenidas por la autoridad civil o militar, o a organizaciones a las que les puso término durante el régimen militar.

Si: el emisor refiere haber sido obligado por motivos políticos a cesar sus servicios ocupacionales que realizó en organismos de la administración pública del gobierno de Chile, de empresas en las que este gobierno tenía más del $50 \%$ de participación, empresas intervenidas por la autoridad civil o militar, o a organizaciones a las que les puso término durante el régimen militar.

Antecedentes de prisión: alusión del emisor referida a los años de vida al momento de la reclusión por motivos políticos, la fecha, el recinto, la duración temporal, y el número de ocasiones de la misma. 
Edad: alusión del emisor referida a los años de vida al momento de la reclusión por motivos políticos

Menor de 21 años: afirmación del emisor de tener una edad inferior a los 21 años al momento de su reclusión por motivos políticos.

Mayor de 21 y menor de 40: afirmación del emisor de superar los 21 años de edad y no superar los 40 años al momento de su reclusión por motivos políticos.

Mayor de 40: afirmación del emisor de superar los 4๑ años de edad al momento de su reclusión por motivos políticos.

Período: alusión del emisor referida al período que comprende la fecha de su reclusión por motivos políticos.

Sept-Dic 1973: fecha de reclusión por motivos políticos del emisor entre los meses de septiembre y diciembre del año 1973, correspondiente al primer período del régimen militar reconocido por la Comisión Valech.

Ene 1974-Ago 1977: fecha de reclusión por motivos políticos del emisor entre el mes de enero del año 1974 y el mes de agosto de 1977, correspondiente al segundo período del régimen militar reconocido por la Comisión Valech.

Ago 1977-Mar 1990: fecha de reclusión por motivos políticos del emisor entre el mes de agosto del año 1977 y el mes de marzo del año 1990, correspondiente al tercer período del régimen militar reconocido por la Comisión Valech.

Post-marzo 1990: fecha de reclusión por motivos políticos del emisor posterior al mes de marzo del año 1990, correspondiente al período al régimen militar.

Lugar: alusión del emisor referida al recinto donde estuvo privado de su libertad por motivos políticos.

Recinto oficial FFAA: reclusión en recinto reconocidos oficialmente por el gobierno de chile mediante el Informe Valech, como regimientos, cárceles, comisarías y otros recintos.

Recinto no oficial FFAA: reclusión en un recinto reconocido como no oficiales por el gobierno de Chile mediante el Informe Valech, como casas clandestinas, gimnasios, u otro recinto que se utilizó para estos fines.

Lugar de relegación: reclusión en un recinto

Tiempo: alusión del emisor referida a la duración temporal que estuvo privado de su libertad por motivos políticos.

Menor de un mes: privación de libertad por motivos políticos durante menos de un mes.

Mayor de un mes: privación de libertad por motivos políticos por más de un mes.

Años: privación de libertad por motivos políticos por más de un año.

$\mathbf{N}^{\circ}$ de veces: alusión del emisor referida al número de ocasiones en que fue recluido por motivos políticos.

1 vez: privación de libertad por motivos políticos sólo en una ocasión.

Más de una vez: privación de libertad por motivos políticos en más de una ocasión.

Aspectos legales: el emisor alude antecedentes legislativos del período en que estuvo privado de su libertad por motivos políticos.

Procesamiento: alusión a antecedentes legislativos del período en que el emisor estuvo privado de su libertad por motivos políticos.

Detención sin juicio: negación de haber sido sometido a juicio durante o después de la permanencia en cautiverio por motivos políticos.

Sometido a juicio: afirmación de haber sido sometido a juicio durante o después de la permanencia en cautiverio por motivos políticos.

Resolución: alusión a antecedentes del fallo del procesamiento judicial realizado al propio caso de privación de libertad por motivos políticos.

Condena de presidio: afirmación de haber sido sentenciado cuando fue privado de su libertad por motivos políticos a un período de reclusión carcelario. 
Sobreseimiento temporal: afirmación de haber sido sometido a juicio cuando fue privado de su libertad por motivos políticos y cuya resolución judicial refiere un proceso de suspensión o paralización por causas legales.

Condena de relegación: traslado obligado del emisor a un lugar diferente de su residencia habitual, por un período de tiempo determinado y por motivos administrativos o judiciales.

Exilio: expulsión del país por motivos políticos por parte de representantes del gobierno durante el régimen militar.

No: niega haber sido expulsado del país por motivos políticos, por parte de representantes del gobierno durante el régimen militar.

Si: afirma haber sido expulsado del país por motivos políticos, por parte de representantes del gobierno durante el régimen militar.

Libertad por falta mérito: el o los representante(s) del poder judicial que llevan a efecto el juicio del emisor, hacen abandono de éste, por considerar que las pruebas disponibles para su procesamiento son insuficientes y por ello se deja en libertad.

Valor. exp. Tortura: apreciación objetiva y/ o subjetiva del emisor de haber padecido el ejercicio de hechos de tortura física, psicológica y sexual, cuando estuvo privado de su libertad por motivos políticos y ejercida por personeros del gobierno del régimen militar.

Refiere no tortura: negación de haber padecido hechos de tortura física y/ o psicológica y/ o sexual, por parte de personeros del gobierno del régimen militar, en el período que fue recluido por motivos políticos.

Ningún mal trato: niega haber padecido hechos de maltrato físico y/ 0 psicológico y/ o sexual, no valorados como tortura por parte de personeros del gobierno del régimen militar, en el período que fue recluido por motivos políticos.

Mal trato no tortura: afirma haber padecido hechos de maltrato físico y/ o psicológico y/ o sexual, no valorados como tortura por el emisor y realizados por personeros del gobierno del régimen militar, en el período que fue recluido por motivos políticos.

Físico: padecimiento de hechos de maltrato físico, no valorados como tortura por el emisor y realizados por personeros del gobierno del régimen militar, en el período que fue recluido por motivos políticos. Ej.: golpes.

Psicológico: padecimiento de hechos de maltrato psicológico, no valorados como tortura por el emisor y realizados por personeros del gobierno del régimen militar, en el período que fue recluido por motivos políticos. Ej.: amenazas verbales.

Sexual: padecimiento de hechos de maltrato sexual, no valorados como tortura por el emisor y realizados por personeros del gobierno del régimen militar, en el período que fue recluido por motivos políticos. Ej.: vejaciones o desnudamiento.

Refiere tortura: refiere haber padecido hechos de tortura física y/ 0 psicológica y/ o sexual, por parte de personeros del gobierno del régimen militar, en el período que fue recluido por motivos políticos. Con el objetivo de causar sufrimiento y deterioro de las víctimas, además de extraer información.

Física: refiere haber padecido hechos que buscaban causar sufrimiento psicológico y físico por medio de la confrontación a la eventualidad de morir, mediante tortura física por parte de personeros del gobierno del régimen militar, en el período que fue recluido por motivos políticos.

Modalidad: refiere el tipo de tortura física al que fue expuesto por parte de personeros del gobierno del régimen militar, en el período que fue recluido por motivos políticos. Estos hechos comprenden por ejemplo golpes de pies y puños, con objetos contundentes, objetos flexibles y/ o no contundentes en partes del cuerpo. 
Electricidad: afirmación de haber sido víctima de la aplicación de descargas eléctricas en el cuerpo por parte de personeros del gobierno del régimen militar, en el período que fue recluido por motivos políticos.

Submarino: afirmación de haber sido víctima de intento de asfixia con la posible eventualidad de morir por causa de estas acciones de tortura. Implica sumergir de modo reiterado la cabeza del emisor en agua, o privarlo de aire con otros elementos como bolsas plásticas, hasta causar su inminente asfixia por la falta de aire. Ocurridas en cautiverio efectuada por personeros del gobierno durante el régimen militar.

Teléfono: afirmación de haber sufrido golpes con las manos abiertas en ambos oídos de manera simultánea. Ocurridas en cautiverio efectuada por personeros del gobierno durante el régimen militar.

Golpes: valoración de padecimiento de tortura física por haber sido golpeado reiteradamente y de manera intencional por personeros del gobierno del régimen militar, durante la reclusión por motivos políticos.

Quemaduras: afirmación de haber sido víctima de lesiones corporales deliberadas mediante la aplicación de objetos como cigarrillos, fierros calientes, u otros elementos que quemaban partes del cuerpo del emisor. Ocurridas en cautiverio efectuada por personeros del gobierno durante el régimen militar.

otras: ejemplo colgamientos que implican la mantención de la víctima en posiciones forzadas que pueden tensionar partes de su cuerpo produciendo lesiones y dolores que van en aumento, posiciones forzadas por períodos prolongados, etc. Ocurridas en cautiverio efectuada por personeros del gobierno durante el régimen militar.

Secuelas: afirmación de haber presentado con posterioridad a la experiencia de privación de libertad o en la actualidad enfermedades, otras afecciones o cambios físicos producto de la experiencia de tortura física en cautiverio efectuada por personeros del gobierno durante el régimen militar.

No: negación de haber presentado con posterioridad a la experiencia de privación de libertad o en la actualidad enfermedades, otras afecciones o cambios físicos producto de la experiencia de tortura física en cautiverio efectuada por personeros del gobierno durante el régimen militar.

Si: afirma haber presentado con posterioridad a la experiencia de privación de libertad o en la actualidad enfermedades, otras afecciones o cambios físicos producto de la experiencia de tortura física en cautiverio efectuada por personeros del gobierno durante el régimen militar.

Momento: alusión al momento de presentación posterior a la experiencia de privación de libertad o en la actualidad de enfermedades, otras afecciones o cambios físicos producto de la experiencia de tortura física en cautiverio efectuada por personeros del gobierno durante el régimen militar.

Post prisión: alusión de presentación posterior a la experiencia de privación de libertad o en la actualidad de enfermedades, otras afecciones o cambios físicos producto de la experiencia de tortura física en cautiverio efectuada por personeros del gobierno durante el régimen militar.

Pre o post I.V.: alusión de presentación previa o posterior al Informe valech de enfermedades, otras afecciones o cambios físicos producto de la experiencia de tortura física en cautiverio efectuada por personeros del gobierno durante el régimen militar.

Presente: alusión de presentación en la actualidad de enfermedades, otras afecciones o cambios físicos producto de la experiencia de tortura física en cautiverio efectuada por personeros del gobierno durante el régimen militar.

Síntomas: afirma presentar señales físicas producto de la experiencia de tortura física en cautiverio efectuada por personeros del gobierno durante el régimen militar. Esto, con posterioridad a la experiencia de privación y/o hasta la actualidad. 
Discapacidad: afirma presentar inhabilidad física producto de la experiencia de tortura física en cautiverio efectuada por personeros del gobierno durante el régimen militar. Esto, con posterioridad a la experiencia de privación y/o hasta la actualidad.

otros signos físicos: afirma presentar señales físicas, como marcas corporales o ausencia de partes del cuerpo, etc., que no producen discapacidad en el emisor y que son producto de la experiencia de tortura física en cautiverio efectuada por personeros del gobierno durante el régimen militar. Esto, con posterioridad a la experiencia de privación y/o hasta la actualidad.

Signos "no relevantes": valoración del emisor de la presencia de marcas que no considera secuelas importantes en su vida, y que son producto de la experiencia de tortura física en cautiverio efectuada por personeros del gobierno durante el régimen militar. Esto, con posterioridad a la experiencia de privación y/ o hasta la actualidad.

Enf. Asociada/ otras: valoración del emisor de presentar patología producto de la experiencia de tortura física en cautiverio efectuada por personeros del gobierno durante el régimen militar. Esto, con posterioridad a la experiencia de privación y/ o hasta la actualidad.

Atte. en salud: alusión a haber recibido o no atención médica por presentar secuelas de la experiencia de tortura física vivida en cautiverio y efectuada por personeros del gobierno durante el régimen militar. Esto, con posterioridad a la experiencia de privación y/ o hasta la actualidad.

No: negación de haber recibido atención médica por presentar secuelas de la experiencia de tortura física vivida en cautiverio y efectuada por personeros del gobierno durante el régimen militar. Esto, con posterioridad a la experiencia de privación y/ o hasta la actualidad.

Si: afirmación de haber recibido atención médica por presentar secuelas de la experiencia de tortura física vivida en cautiverio y efectuada por personeros del gobierno durante el régimen militar. Esto, con posterioridad a la experiencia de privación y/ o hasta la actualidad.

En pasado: afirmación de haber recibido atención médica por presentar secuelas de la experiencia de tortura física vivida en cautiverio y efectuada por personeros del gobierno durante el régimen militar. Esto, con posterioridad a la experiencia de privación pero no en la actualidad.

En presente: afirmación de haber recibido atención médica por presentar secuelas de la experiencia de tortura física vivida en cautiverio y efectuada por personeros del gobierno durante el régimen militar. Esto, en la actualidad.

Sexual: refiere haber padecido hechos que buscaban causar sufrimiento psicológico, físico y sexual por medio de la confrontación a la eventualidad de morir, mediante tortura sexual por parte de personeros del gobierno del régimen militar, en el período que fue recluido por motivos políticos.

Psicológica: refiere haber padecido hechos que buscaban causar sufrimiento psicológico por medio de la confrontación a la eventualidad de morir, mediante tortura psicológica por parte de personeros del gobierno del régimen militar, en el período que fue recluido por motivos políticos.

Modalidad: refiere el tipo de tortura psicológica al que fue expuesto por parte de personeros del gobierno del régimen militar, en el período que fue recluido por motivos políticos. Estas acciones comprenden por ejemplo amenazas de muerte, presenciar tortura ejercida a compañeros, etc.

Amenazas: intimidación durante la permanencia en prisión por motivos políticos, por medio de la advertencia de los graves males o peligros que se depositan en el emisor y/ o sus relaciones, si éste no responde según lo requerido por personeros del gobierno militar.

Simulacro de fusilamiento: imitación o disimulo de su ejecución realizado por personeros del gobierno militar mientras el emisor permaneció en cautiverio, para lo que se emplea la descarga de fusiles o metralletas, u otra arma empleada 
para este fin, por parte de un grupo de militares u otro pelotón de uniformados de las fuerzas armadas. Todo lo que busca causar en la víctima la vivencia de muerte.

Humillación pública: tratos violentos que buscan menoscabar su dignidad como persona, su honor, honra y orgullo personal. Incluyen acciones como la ingesta forzada de desechos orgánicos, obligación a arrastrarse por el suelo mientras se hacen burlas y golpea al emisor, insultos, etc.

"Lavado de cerebro": técnica de tortura psicológica que buscaba debilitar las ideas del emisor y cambiarlas mediante la aplicación de estrategias sistematizadas como por ejemplo, la privación o interrupción del sueño.

Insultos: verbalizaciones peyorativas valoradas por el emisor como tortura psicológica y que atentaban en contra de su integridad como ser humano.

Secuelas/ No/ $\mathrm{Si}^{* *}$

Momento/ Post prisión/ Pre o post I.V./ Presente**

Síntomas**

Alteraciones sueño: el emisor refiere presentar alteraciones del sueño como por ejemplo insomnio, y pesadillas, que valora como producto de la tortura psicológica a la que fue expuesto por parte de personeros del gobierno del régimen militar, en el período que fue recluido por motivos políticos.

Labilidad emocional: el emisor refiere presentar cambios bruscos de humor que pueden presentarse y desaparecer de manera rápida e inesperada, que valora como producto de la tortura psicológica a la que fue expuesto por parte de personeros del gobierno del régimen militar, en el período que fue recluido por motivos políticos.

Retraimiento: el emisor refiere presentar la tendencia a aislarse socialmente, que valora como producto de la tortura psicológica a la que fue expuesto por parte de personeros del gobierno del régimen militar, en el período que fue recluido por motivos políticos.

Agresividad: el emisor refiere presentar la tendencia a aislarse socialmente, que valora como producto de la tortura psicológica a la que fue expuesto por parte de personeros del gobierno del régimen militar, en el período que fue recluido por motivos políticos.

Ansiedad: el emisor refiere presentar sensaciones de angustia y desesperación permanentes, que valora como producto de la tortura psicológica a la que fue expuesto por parte de personeros del gobierno del régimen militar, en el período que fue recluido por motivos políticos.

otros o no especifica: el emisor refiere presentar síntomas que no especifica o diferentes a los anteriores, que valora como producto de la tortura psicológica a la que fue expuesto por parte de personeros del gobierno del régimen militar, en el período que fue recluido por motivos políticos.

Enfermedad asociada: el emisor refiere presentar afecciones a su salud, que valora como producto de la tortura psicológica a la que fue expuesto por parte de personeros del gobierno del régimen militar, en el período que fue recluido por motivos políticos.

S.E.P.T. el emisor refiere presentar el síndrome de estrés postraumático (DSMIV), que valora como producto de la tortura psicológica a la que fue expuesto por parte de personeros del gobierno del régimen militar, en el período que fue recluido por motivos políticos.

Depresión: el emisor refiere presentar el trastorno del estado de ánimo denominado depresión (DSM-IV), que valora como producto de la tortura psicológica a la que fue expuesto por parte de personeros del gobierno del régimen militar, en el período que fue recluido por motivos políticos.

Trastorno del sueño: el emisor refiere presentar un trastorno del sueño (DSMIV), que valora como producto de la tortura psicológica a la que fue expuesto 
por parte de personeros del gobierno del régimen militar, en el período que fue recluido por motivos políticos.

Síndrome ansioso: el emisor refiere presentar un trastorno de ansiedad (DSM-IV), que valora como producto de la tortura psicológica a la que fue expuesto por parte de personeros del gobierno del régimen militar, en el período que fue recluido por motivos políticos.

Disfunción sexual: el emisor refiere presentar trastornos sexuales (DSM-IV), que valora como producto de la tortura psicológica a la que fue expuesto por parte de personeros del gobierno del régimen militar, en el período que fue recluido por motivos políticos.

otra o no especifica: el emisor refiere presentar secuelas que no especifica o diferentes a las anteriores, que valora como producto de la tortura psicológica a la que fue expuesto por parte de personeros del gobierno del régimen militar, en el período que fue recluido por motivos políticos.

Atte. en Salud Mental: alusión a haber recibido o no atención psiquiátrica y/ o psicológica, o de otro tipo en salud mental, por presentar secuelas de la experiencia de tortura psicológica vivida en cautiverio y efectuada por personeros del gobierno durante el régimen militar. Esto, con posterioridad a la experiencia de privación y/ o hasta la actualidad.

No: negación de haber recibido o no atención psiquiátrica y/ o psicológica, o de otro tipo en salud mental, por presentar secuelas de la experiencia de tortura psicológica vivida en cautiverio y efectuada por personeros del gobierno durante el régimen militar. Esto, con posterioridad a la experiencia de privación y/ o hasta la actualidad.

Si: afirmación de haber recibido o no atención psiquiátrica y/ o psicológica, o de otro tipo en salud mental, por presentar secuelas de la experiencia de tortura psicológica vivida en cautiverio y efectuada por personeros del gobierno durante el régimen militar. Esto, con posterioridad a la experiencia de privación y/ o hasta la actualidad.

En pasado: afirmación de haber recibido atención psiquiátrica y/ o psicológica, o de otro tipo en salud mental, por presentar secuelas de la experiencia de tortura psicológica vivida en cautiverio y efectuada por personeros del gobierno durante el régimen militar. Esto, con posterioridad a la experiencia de privación pero no en la actualidad.

En presente: afirmación de haber recibido atención psiquiátrica y/ 0 psicológica, o de otro tipo en salud mental, por presentar secuelas de la experiencia de tortura psicológica vivida en cautiverio y efectuada por personeros del gobierno durante el régimen militar. Esto, en la actualidad.

Sexual: refiere haber padecido hechos de tortura sexual por parte de personeros del gobierno del régimen militar, en el período que fue recluido por motivos políticos.

Modalidad: refiere haber padecido de acciones forzadas que especifica y que incluyen agresiones mediante conductas violentas para que realizara o sufriera actos sexuales. Ejercido por personeros del gobierno del régimen militar, en el período que fue recluido por motivos políticos.

Vejaciones: refiere haber padecido de humillaciones o maltrato de índole sexual, ejercido por personeros del gobierno del régimen militar, en el período que fue recluido por motivos políticos.

Violación: refiere haber padecido de relación sexual forzada, ejercida por personeros del gobierno del régimen militar, en el período que fue recluido por motivos políticos.

Ab. Animales: refiere haber padecido de acciones forzadas con animales, ejercidas por personeros del gobierno del régimen militar, en el período que fue recluido por motivos políticos.

Secuelas/ No/ Si **

Momento/ Post prisión/ Pre o post I.V./ Presente ** 


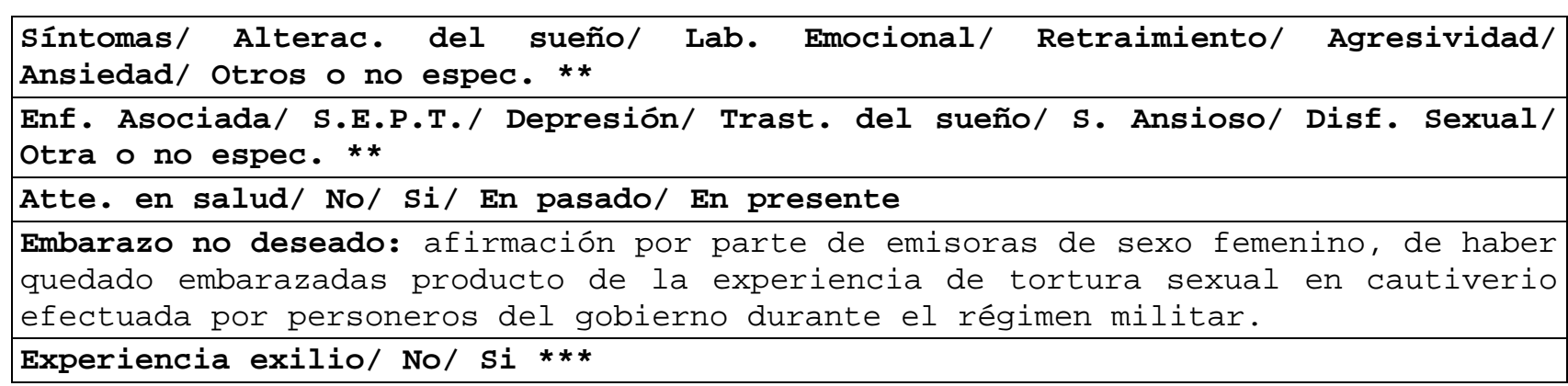

\section{Antecedentes familiares}

Antecedentes familiares: alusión emitida por el emisor de aquellas personas que conforman el grupo con quienes mantiene lazos de parentesco sanguíneos, por adopción o matrimonio, o afectivos, que viven o no juntos por un período indefinido de tiempo y que valoran como familia.

Pareja: alusión a disponer en la actualidad de una persona con la que el emisor ha establecido una relación bipersonal o subsistema conyugal dentro del sistema familiar.

No tiene: alusión a no disponer en la actualidad de una persona con la que el emisor ha establecido una relación bipersonal o subsistema conyugal dentro del sistema familiar.

Si tiene: alusión a disponer en la actualidad de una persona con la que el emisor ha establecido una relación bipersonal o subsistema conyugal dentro del sistema familiar.

Tiempo de relación: antecedentes históricos del período de duración de la relación de pareja que dispone en la actualidad, en función de la experiencia de prisión.

Desde antes de prisión: el emisor afirma que la relación de pareja que dispone en la actualidad se mantiene desde antes del momento en que fue privado de su libertad por motivos políticos.

Desde después de prisión: el emisor afirma que la relación de pareja que dispone en la actualidad se mantiene desde después del momento en que fue privado de su libertad por motivos políticos.

Antecedentes de prisión: información acerca de la relación de la pareja actual que dispone el emisor y su eventual participación política y experiencia de prisión producto de este tipo de participación.

No ex-pp: el emisor niega que la pareja que dispone en la actualidad fue privado de su libertad por motivos políticos.

Si ex-pp: el emisor afirma que la pareja que dispone en la actualidad fue privado de su libertad por motivos políticos.

Particip. política: el emisor afirma que la pareja que dispone en la actualidad participa o no en algún partido o agrupación de carácter político.

No: el emisor niega que la pareja que dispone en la actualidad participa en algún partido o agrupación de carácter político.

Si: el emisor afirma que la pareja que dispone en la actualidad participa en algún partido o agrupación de carácter político.

De derecha: el emisor afirma que la pareja que dispone en la actualidad participa en algún partido o agrupación de carácter político correspondiente a los partidos de la derecha chilena.

De izquierda: el emisor afirma que la pareja que dispone en la actualidad participa en algún partido o agrupación de carácter político correspondiente a los partidos de la izquierda chilena.

Hijos: alusión a disponer en la actualidad de uno o más vínculos filiales biológicos o no, valorados como tales, en su sistema familiar. 
No tiene: el emisor niega disponer en la actualidad de uno o más vínculos filiales biológicos o no, valorados como tales, en su sistema familiar.

Si tiene: el emisor afirma disponer en la actualidad de uno o más vínculos filiales biológicos o no, valorados como tales, en su sistema familiar.

No de hijos: especificación del emisor de la cantidad de vínculos filiales biológicos o no, valorados como tales, en su sistema familiar.

1 hijo: afirmación del emisor de disponer un vínculo filial biológico o no, valorados como tales, en su sistema familiar.

Más de 1 y menos de 5: afirmación del emisor de disponer más de uno y menos de cinco vínculos filiales biológicos o no, valorados como tales, en su sistema familiar.

5 o más: afirmación del emisor de disponer más de cinco vínculos filiales biológicos o no, valorados como tales, en su sistema familiar.

Media de edad: especificación del emisor del promedio de edad de su(s) vínculo(s) filial(es) biológico(s) o no, valorado(s) como tal(es), en su sistema familiar.

Menos de 12: especificación del emisor del promedio de edad inferior a los 12 años de su(s) vínculo(s) filial(es) biológico(s) o no, valorado(s) como tal(es), en su sistema familiar.

de 12 a 18: especificación del emisor del promedio de edad superior a los 12 años e inferior a los 18 años, de su(s) vínculo(s) filial(es) biológico(s) o no, valorado(s) como tal(es), en su sistema familiar.

Mayor de 18: especificación del emisor del promedio de edad superior a los 18 años de su(s) vínculo(s) filial(es) biológico(s) o no, valorado(s) como tal(es), en su sistema familiar.

Media de edad detención: especificación del emisor del promedio de edad de los vínculo(s) filial(es) biológico(s) o no, valorado(s) como tal(es), en su sistema familiar, al momento de la privación de libertad de éste.

No habían nacido: el emisor niega la disposición de vínculo(s) filial(es) biológico(s) o no, valorado(s) como tal(es), en su sistema familiar, al momento de su privación de libertad por motivos políticos.

Niños: el emisor afirma que disponía de vínculo(s) filial(es) biológico(s) o no, valorado(s) como tal(es), en su sistema familiar, cuya etapa evolutiva correspondía a la infancia al momento de su privación de libertad por motivos políticos.

Adolescentes: el emisor afirma que disponía de vínculo(s) filial(es) biológico(s) o no, valorado(s) como tal(es), en su sistema familiar, cuya etapa evolutiva correspondía a la adolescencia al momento de su privación de libertad por motivos políticos.

Adultos: el emisor afirma que disponía de vínculo(s) filial(es) biológico(s) o no, valorado(s) como tal(es), en su sistema familiar, cuya etapa evolutiva correspondía a la adultez al momento de su privación de libertad por motivos políticos.

Ocupación: especificación del emisor de la ocupación actual de su(s) vínculo(s) filial(es) biológico(s) o no, valorado(s) como tal(es) en su sistema familiar.

Ninguna: el emisor afirma que posee uno o más vínculo(s) filial(es) biológico(s) o no, valorado(s) como tal(es) en su sistema familiar, y que esta(s)persona(s) no realizan actividad ocupacional alguna.

Estudiante: el emisor afirma que posee uno o más vínculo(s) filial(es) biológico(s) o no, valorado(s) como tal(es) en su sistema familiar, y que esta(s)persona(s) se encuentra estudiando en el presente.

Trabajador: el emisor afirma que posee uno o más vínculo(s) filial(es) biológico(s) o no, valorado(s) como tal(es) en su sistema familiar, y que esta(s)persona(s) se encuentra estudiando en el presente. 
Estudiante y trabajador: el emisor afirma que posee uno o más vínculo(s) filial(es) biológico(s) o no, valorado(s) como tal(es) en su sistema familiar, y que esta(s)persona(s) se encuentra estudiando y trabajando en el presente.

Dueña de casa: el emisor afirma que posee uno o más vínculo(s) filial(es) biológico(s) o no, valorado(s) como tal(es) en su sistema familiar, y que esta(s)persona(s) se dedica a las labores domésticas de su propia casa en el presente.

Antecedentes políticos: el emisor alude antecedentes políticos de su(s) vínculo(s) filial(es) biológico(s) o no, valorados como tales en su sistema familiar.

Participación actual o pasada: el emisor alude antecedentes políticos de su(s) vínculo(s) filial(es) biológico(s) o no, valorados como tales en su sistema familiar.

Ninguna: el emisor afirma que su(s) vínculo(s) filial(es) biológico(s) o no, valorado(s) como tal(es) en su sistema familiar, no ha(n) realizado ni realiza(n) militancia política alguna, ni refiere su preferencia por alguna tendencia política.

Simpatizantes de izquierda: el emisor afirma que su(s) vínculo(s) filial(es) biológico(s) o no, valorado(s) como tal(es) en su sistema familiar, no ha(n) realizado ni realiza(n) militancia política alguna, pero presenta una preferencia asociada a la izquierda política.

Simpatizantes de derecha: el emisor afirma que su(s) vínculo(s) filial(es) biológico(s) o no, valorado(s) como tal(es) en su sistema familiar, no ha(n) realizado ni realiza $(\mathrm{n})$ militancia política alguna, pero presenta una preferencia asociada a la derecha política.

Apolíticos: el emisor afirma que su(s) vínculo(s) filial(es) biológico(s) o no, valorado(s) como tal(es) en su sistema familiar, no ha(n) realizado ni realiza(n) militancia política alguna, y afirma que no tiene(n) tendencia política.

Si participan o han participado: el emisor afirma que su(s) vínculo(s) filial(es) biológico(s) o no, valorado(s) como tal(es) en su sistema familiar, ha(n) realizado y/ o realiza(n) militancia política alguna.

Activistas de derecha: el emisor afirma que su(s) vínculo(s) filial(es) biológico(s) o no, valorado(s) como tal(es) en su sistema familiar, ha(n) realizado y/ o realiza(n) militancia política de derecha.

Activistas de izquierda: el emisor afirma que su(s) vínculo(s) filial(es) biológico(s) o no, valorado(s) como tal(es) en su sistema familiar, ha(n) realizado y/ o realiza(n) militancia política de izquierda.

Antecedentes de prisión: el emisor alude información de la experiencia o no de cautiverio por motivos políticos de su(s) vínculo(s) filial(es) biológico(s) o no, valorado(s) como tal(es) en su sistema familiar.

Ninguno es ex-pp: el emisor refiere que su(s) vínculo(s) filial(es) biológico(s) o no, valorado(s) como tal(es) en su sistema familiar, no fueron privados de su libertad por motivos políticos.

1 o más son ex-pps: el emisor refiere que su(s) vínculo(s) filial(es) biológico(s) o no, valorado(s) como tal(es) en su sistema familiar, fue(ron) privados de su libertad por motivos políticos.

Nietos: especificación del emisor de la cantidad de vínculos con hijos de sus hijos biológicos o no, valorados como tales, en su sistema familiar.

No tiene: el emisor niega tener vínculos con hijos de sus hijos biológicos o no, valorados como tales, en su sistema familiar.

Si tiene: el emisor afirma tener vínculos con hijos de sus hijos biológicos o no, valorados como tales, en su sistema familiar. 
Familia de origen: especificación del emisor de sus vínculos con sus padres y hermanos, u otro familiar perteneciente a la familia donde éste fue concebido, creció y se desarrolló antes de constituir su familia actual.

\section{Antecedentes de ocio}

\begin{tabular}{l} 
Antecedentes de ocio: el emisor realiza o no actividades recreativas en el \\
presente. \\
$\begin{array}{l}\text { No realiza actividades: el emisor niega realizar o no actividades recreativas en } \\
\text { el presente. }\end{array}$ \\
\hline $\begin{array}{l}\text { Si realiza actividades: el emisor afirma realizar o no actividades recreativas } \\
\text { en el presente. }\end{array}$
\end{tabular}

\section{Antecedentes de salud}

\begin{tabular}{l} 
Antecedentes de salud: el emisor alude la presencia o no de enfermedades. \\
\hline Refiere antecedentes mórbidos: el emisor afirma presentar enfermedad(es). \\
\hline No refiere antecedentes mórbidos: el emisor niega presentar enfermedad(es). \\
\hline $\begin{array}{l}\text { Antecedentes atención en salud: el emisor afirma haber recibido asistencia } \\
\text { médica y/ o psicológica por presentar enfermedad. }\end{array}$ \\
$\begin{array}{l}\text { Momento: el emisor afirma haber recibido asistencia médica y/ o psicológica por } \\
\text { presentar enfermedad. }\end{array}$
\end{tabular}

Pasado: el emisor afirma haber recibido asistencia médica y/ o psicológica por presentar enfermedad en el pasado.

Atte. médica: el emisor afirma haber recibido asistencia médica por presentar enfermedad en el pasado.

Atte. psicológica: el emisor afirma haber recibido asistencia psicológica por presentar enfermedad en el pasado.

Presente: el emisor afirma estar recibiendo asistencia médica y/ o psicológica por presentar enfermedad en el presente.

Atte. Médica: el emisor afirma estar recibiendo asistencia médica por presentar enfermedad en el presente.

Atte. psicológica: el emisor afirma estar recibiendo asistencia psicológica por presentar enfermedad en el presente.

Relación experiencia: el emisor refiere haber recibido o estar recibiendo asistencia médica y/ o psicológica por presentar enfermedad en el presente o el pasado, producto de la experiencia de privación de libertad por motivos políticos.

Ninguna: el emisor refiere no haber recibido nunca asistencia médica y/ 0 psicológica por presentar enfermedad en el presente o el pasado, producto de la experiencia de privación de libertad por motivos políticos.

Si: el emisor refiere haber recibido o estar recibiendo asistencia médica y/ 0 psicológica por presentar enfermedad en el presente o el pasado, producto de la experiencia de privación de libertad por motivos políticos.

\section{Vinculación con uniformados}

Vinculación uniformados: el emisor refiere presentar o no algún tipo de relación con personeros de las fuerzas armadas del gobierno de Chile.

No tiene: el emisor niega presentar algún tipo de relación con personeros de las fuerzas armadas del gobierno de chile.

Si tiene: el emisor refiere presentar algún tipo de relación con personeros de las fuerzas armadas del gobierno de chile.

Familia: el emisor afirma tener familiar(es) de las fuerzas armadas del gobierno de Chile. 
Pareja: el emisor afirma tener una pareja de las fuerzas armadas del gobierno de Chile.

Hijos: el emisor afirma tener hijo(s) de las fuerzas armadas del gobierno de Chile.

Nietos: el emisor afirma tener nieto(s) de las fuerzas armadas del gobierno de Chile.

Amigos: el emisor afirma tener amigo(s) de las fuerzas armadas del gobierno de Chile.

Familia de origen: el emisor afirma tener integrante(s) de su familia de origen perteneciente(s) a las fuerzas armadas del gobierno de chile.

\subsubsection{Categorías conceptuales}

\section{- PRESENTE}

\section{Relaciones interpersonales}

Presente: valoración de aspectos interpersonales e ideológicos de la vida actual del emisor que incluyen el grado de satisfacción en el ámbito familiar, social, laboral, y su valoración del mundo, los seres humanos, el sentido de la vida, su ocupación, su participación en política, su persona, el chile actual y sus temores.

Relaciones interpersonales actuales: alusión a aspectos y valoraciones de las relaciones interpersonales que dispone $y$ no dispone en el presente con la familia, los amigos y compañeros políticos.

Familia: alusión a aspectos y valoraciones de las relaciones interpersonales que dispone y no dispone en el presente con los integrantes de su núcleo familiar**.

\section{Pareja/ valoración positiva}

Pareja: alusión a aspectos y valoraciones de las relaciones interpersonales que dispone y no dispone en el presente con quien mantiene un vínculo definido en los antecedentes demográficos de pareja.

Valoración positiva: alusión a aspectos específicos de la relación valorados de manera satisfactoria por el emisor y en relación a la pareja, entendida según la definición de la variable demográfica "pareja".

Valoración tipo de relación: apreciación global positiva, negativa de la relación que se mantiene con la pareja.

"Buena": apreciación global positiva de la relación que se mantiene con la pareja.

Valoración satisfacción Sexual: apreciación global positiva, negativa 0 intermedia de la relación que se mantiene con la pareja en el plano sexual.

Satisfecho: apreciación global positiva de la relación que se mantiene con la pareja en el plano sexual.

Valoración aspectos de relación: apreciaciones específicas de la relación que el emisor mantiene con su pareja

Comprendido: apreciación del grado de la tolerancia/ entendimiento percibida por parte de la pareja.

Si: el emisor afirma sentirse tolerado/entendido por su pareja.

Solo: apreciación del grado de sensación de aislamiento emocional y afectivo percibido por parte de la pareja.

No: el emisor niega sentirse aislado emocional y afectivamente de su pareja. 


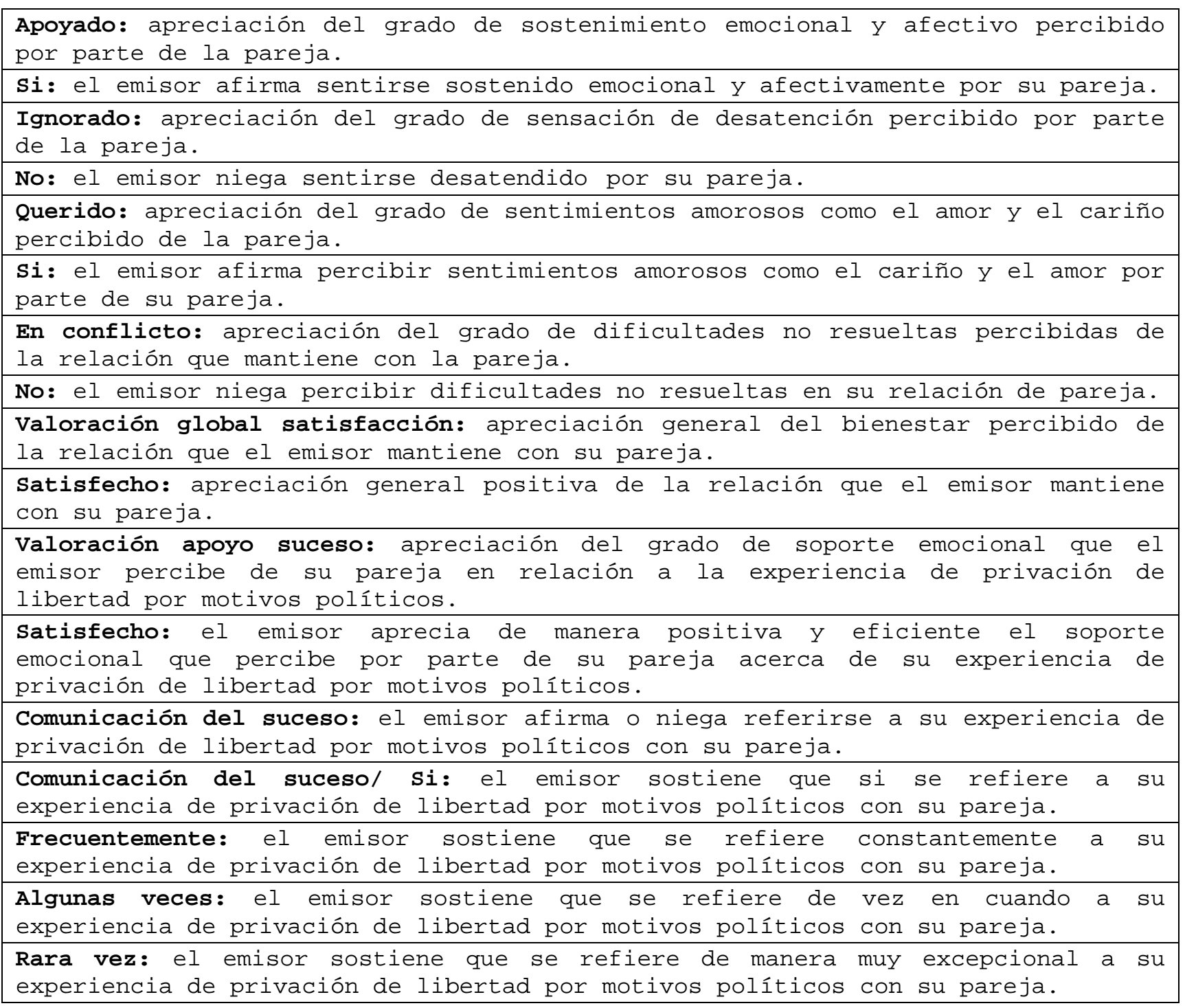

\section{Pareja/ valoración negativa.}

Pareja / Valoración negativa: alusión a aspectos específicos de la relación valorados de manera insatisfactoria por el emisor y en relación a la pareja, entendida según la definición de la variable demográfica "pareja".

Valoración tipo de relación/ "Mala": apreciación global negativa de la relación que se mantiene con la pareja.

Valoración satisfacción Sexual/ Insatisfecho: apreciación global negativa de la relación que se mantiene con la pareja en el plano sexual.

Valoración aspectos de relación: apreciaciones específicas de la relación que el emisor mantiene con su pareja

Comprendido/ No: el emisor niega sentirse tolerado/ entendido por su pareja.

Solo/ Si: el emisor afirma sentirse aislado emocional y afectivamente de su pareja.

Apoyado/ No: el emisor niega sentirse sostenido emocional y afectivamente por su pareja.

Ignorado/ Si: el emisor afirma sentirse desatendido por su pareja.

Querido/ No: el emisor niega percibir sentimientos amorosos como el cariño y el amor por parte de su pareja. 
En conflicto/ Si: el emisor afirma percibir dificultades no resueltas en su relación de pareja.

Valoración global satisfacción/ insatisfecho: apreciación general negativa de la relación que el emisor mantiene con su pareja.

Valoración apoyo suceso/ insatisfecho: el emisor aprecia de manera negativa y deficiente el soporte emocional que percibe por parte de su pareja acerca de su experiencia de privación de libertad por motivos políticos.

Comunicación del suceso/ No: el emisor sostiene que no se refiere a su experiencia de privación de libertad por motivos políticos con su pareja.

Pareja no desea recordar: el emisor sostiene que no hace referencias a su experiencia de privación de libertad por motivos políticos con su pareja, porque ésta, no tiene la voluntad para escuchar acerca del tema.

Ex-pp no desea recordar: el emisor sostiene que no hace referencias a su experiencia de privación de libertad por motivos políticos con su pareja, porque él mismo, no tiene la voluntad para hablar acerca del tema.

\section{Hijos/ Valoración positiva}

Hijos: alusión a aspectos y valoraciones de las relaciones interpersonales que dispone y no dispone en el presente con quien mantiene un vínculo definido en los antecedentes demográficos de hijos.

Valoración tipo de relación: apreciación global positiva, negativa de la relación que se mantiene con los hijos.

"Buena":apreciación global positiva de la relación que se mantiene con los hijos.

Valoración aspectos de relación: apreciaciones específicas de la relación que el emisor mantiene con los hijos.

Comprendido: apreciación del grado de la tolerancia/ entendimiento percibida por parte de los hijos.

Si: el emisor afirma sentirse tolerado/ entendido por sus hijos.

Solo: apreciación del grado de sensación de aislamiento emocional y afectivo percibido por parte de sus hijos.

No: el emisor niega sentirse aislado emocional y afectivamente de sus hijos.

Apoyado: apreciación del grado de sostenimiento emocional y afectivo percibido por parte de sus hijos.

Si: el emisor afirma sentirse sostenido emocional y afectivamente por sus hijos.

Ignorado: apreciación del grado de sensación de desatención percibido por parte de sus hijos.

No: el emisor niega sentirse desatendido por sus hijos.

Querido: apreciación del grado de sentimientos amorosos como el amor y el cariño percibido de los hijos.

Si: el emisor afirma percibir sentimientos amorosos como el cariño y el amor por parte de los hijos.

En conflicto: apreciación del grado de dificultades no resueltas percibidas de la relación que mantiene con los hijos.

No: el emisor niega percibir dificultades no resueltas en su relación los hijos. Valoración global satisfacción: apreciación general del bienestar percibido de la relación que el emisor mantiene con sus hijos.

Satisfecho: apreciación general positiva de la relación que el emisor mantiene con sus hijos.

Valoración apoyo en política: apreciación del grado de soporte emocional que el emisor percibe de sus hijos en relación a su participación política. 
Satisfecho: el emisor aprecia de manera positiva y eficiente el soporte emocional que percibe por parte de sus hijos acerca de su participación política.

Valoración apoyo suceso: apreciación del grado de soporte emocional que el emisor percibe de sus hijos en relación a su experiencia de privación de libertad por motivos políticos.

Aceptación: apreciación positiva del soporte emocional que el emisor percibe de sus hijos en relación a su experiencia de privación de libertad por motivos políticos, valorada como tolerancia.

Culpa: apreciación de la falta cometida o no a los hijos con la que el emisor valora su experiencia de privación de libertad por motivos políticos.

No: el emisor niega valorar su experiencia de privación de libertad por motivos políticos, como una falta cometida hacia sus hijos.

Responsabilidad de sus vidas: el emisor refiere o no sentirse y actuar denotando adeudo con sus hijos.

Si: el emisor afirma sentirse y actuar denotando adeudo con sus hijos.

\section{Hijos/ Valoración negativa}

Valoración tipo de relación/ "Mala": apreciación global negativa de la relación que se mantiene con los hijos.

Valoración aspectos de relación/ Comprendido/ No: el emisor niega sentirse tolerado/ entendido por sus hijos.

Solo/ Si: el emisor afirma sentirse aislado emocional y afectivamente por sus hijos.

Apoyado/ No: el emisor niega sentirse sostenido emocional y afectivamente por sus hijos.

Ignorado/ Si: el emisor afirma sentirse desatendido por sus hijos.

Querido/ No: el emisor niega percibir sentimientos amorosos como el cariño y el amor por parte de sus hijos.

En conflicto/ Si: el emisor afirma percibir dificultades no resueltas en su relación con sus hijos.

Valoración global satisfacción/ insatisfecho: apreciación general negativa de la relación que el emisor mantiene con sus hijos.

Valoración apoyo en política/ Insatisfecho: el emisor aprecia de manera negativa y deficiente el soporte emocional que percibe por parte de sus hijos acerca de su participación política.

Valoración apoyo suceso/ Rechazo: apreciación negativa del soporte emocional que el emisor percibe de sus hijos en relación a su experiencia de privación de libertad por motivos políticos, valorada como intolerancia.

Culpa/ Si: el emisor afirma valorar su experiencia de privación de libertad por motivos políticos, como una falta cometida hacia sus hijos.

Responsabilidad de sus vidas/ No: el emisor niega sentirse y actuar denotando adeudo con sus hijos.

\section{Nietos/ Valoración positiva}

Nietos: alusión a valoraciones específicas de las relaciones interpersonales que dispone el emisor en el presente con quien mantiene un vínculo definido en los antecedentes demográficos como nietos.

Valoración positiva: alusión a aspectos específicos de la relación valorados de manera satisfactoria por el emisor y en relación a los nietos, entendido según la definición de la variable demográfica nietos.

Presencia: el emisor afirma la presencia de apegos en sus relaciones con sus nietos. 
Valoración afectos: apreciación de la presencia o no de apegos establecidos con los nietos.

Valoración global satisfacción: apreciación general del bienestar percibido de la relación que el emisor mantiene con sus nietos.

Satisfecho: apreciación general positiva de la relación que el emisor mantiene con sus nietos.

\section{Nietos/ Valoración negativa}

Valoración negativa: alusión a aspectos específicos de la relación valorados de manera insatisfactoria por el emisor y en relación a los nietos, entendido según la definición de la variable demográfica nietos.

Valoración afectos/ Ausencia: el emisor niega la presencia de apegos en sus relaciones con sus nietos.

Valoración global satisfacción/ Insatisfecho: apreciación general negativa de la relación que el emisor mantiene con sus nietos.

\section{Familia de origen/ Valoración positiva}

Familia de origen en presente: alusión a aspectos y valoraciones de las relaciones interpersonales que dispone $y$ no dispone en el presente con quien mantiene un vínculo definido en los antecedentes demográficos de familia de origen.

Valoración positiva: alusión a aspectos específicos de la relación valorados de manera satisfactoria por el emisor y en relación a integrantes de su familia de origen, entendida según la definición de la variable demográfica familia de origen.

Valoración afectos: el emisor refiere presentar o no apegos en sus relaciones con integrantes de su familia de origen.

Presencia: el emisor afirma la presencia de apegos en sus relaciones con integrantes de su familia de origen.

Valoración apoyo en política: apreciación del grado de soporte emocional que el emisor percibe de integrantes de su familia de origen de su participación política.

Positiva: el emisor aprecia de manera positiva y eficiente el soporte emocional que percibe de su participación política, por parte de integrantes de su familia de origen.

Valoración global satisfacción: apreciación general del bienestar percibido de la relación que el emisor mantiene con integrantes de su familia de origen.

Satisfecho: apreciación general positiva de la relación que el emisor mantiene con integrantes de su familia de origen.

\section{Nietos/ Valoración negativa}

Valoración negativa: alusión a aspectos específicos de la relación valorados de manera insatisfactoria por el emisor y en relación a integrantes de su familia de origen, entendida según la definición de la variable demográfica familia de origen.

Valoración afectos/ Ausencia: el emisor niega la presencia de apegos en sus relaciones con integrantes de su familia de origen.

Valoración apoyo en política/ Negativa: el emisor aprecia de manera negativa y deficiente el soporte emocional que percibe de su participación política, por parte de integrantes de su familia de origen,.

Valoración global satisfacción/ Insatisfecho: apreciación general negativa de la relación que el emisor mantiene con integrantes de su familia de origen. 


\section{Amigos/ no tiene}

Amigos: alusión a aspectos y valoraciones de las relaciones interpersonales que dispone y no dispone el emisor en el presente con quien(es) mantiene un vínculo social caracterizado por la confianza y el afecto, que refiere amistad.

No tiene: el emisor niega disponer de vínculos sociales de confianza y afecto que valore como amistad y en relación a otras personas.

Ninguno: el emisor niega disponer de uno o más vínculos sociales de confianza y afecto que valore como amistad en relación a otras personas.

Amistades no amigos: el emisor niega disponer de uno o más vínculos sociales de confianza y afecto que valore como amistad en relación a otras personas. no obstante, refiere disponer de relaciones sociales impersonales y sin la presencia de confianza ni de afectos, que no valora como amigos, pero si como amistad.

\section{Amigos/ si tiene}

Si tiene: el emisor afirma disponer de vínculos sociales de confianza y afecto que valore como amistad y en relación a otras personas.

\section{Amigos/ si tiene/ valoración positiva}

Valoración positiva: alusión a aspectos específicos de la relación valorados de manera satisfactoria por el emisor y en relación a los amigos, entendidos según la definición de la variable demográfica amigos.

Valoración aspectos de relación: apreciaciones específicas de la relación que el emisor mantiene con sus amigos.

Comprendido: apreciación del grado de la tolerancia/ entendimiento percibida por parte de sus amigos.

Si: el emisor afirma sentirse tolerado/ entendido por sus amigos.

Solo: apreciación del grado de sensación de aislamiento emocional y afectivo percibido por parte de sus amigos.

No: el emisor afirma sentirse aislado emocional y afectivamente de sus amigos.

Apoyado: apreciación del grado de sostenimiento emocional y afectivo percibido por parte de sus amigos.

Si: el emisor afirma sentirse sostenido emocional y afectivamente por sus amigos.

Querido: apreciación del grado de sentimientos amorosos como el amor y el cariño percibido de sus amigos.

Si: el emisor afirma percibir sentimientos amorosos como el cariño y el amor por parte de sus amigos.

Ignorado: apreciación del grado de sensación de desatención percibido por parte de sus amigos.

No: el emisor niega sentirse desatendido por sus amigos.

En conflicto: apreciación del grado de dificultades no resueltas percibidas de la relación que mantiene con sus amigos.

No: el emisor niega percibir dificultades no resueltas con sus amigos.

Valoración global satisfacción: apreciación general del bienestar percibido de la relación que el emisor mantiene con sus amigos.

Satisfecho: apreciación general positiva de la relación que el emisor mantiene con sus amigos.

Concepción: cogniciones del emisor acerca de su ideología de la amistad en función de la posibilidad de existencia de estos vínculos o no.

Si existe: concepción del emisor acerca de su ideología de la amistad que refiere que es posible tener amigos. 


\section{Amigos/ si tiene/ valoración positiva}

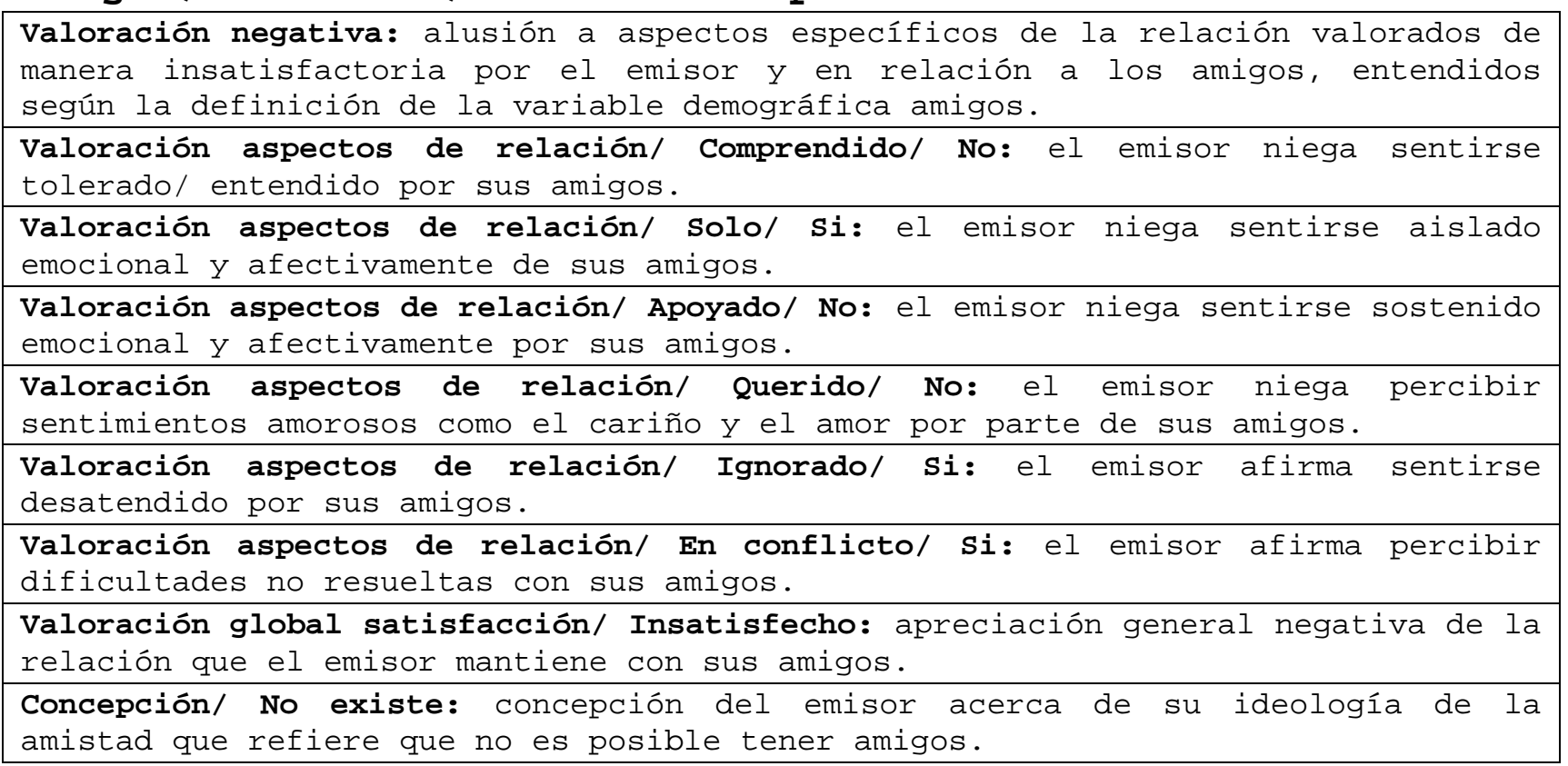

\section{Compañeros políticos/ Si tiene relación}

Compañeros: alusión a aspectos y valoraciones de las relaciones interpersonales que dispone y no dispone en el presente con quien mantiene en común un vínculo de participación política.

Si tiene relación: el emisor afirma relacionarse socialmente con otros partidarios políticos de la agrupación que participa u otros EXPPS.

\section{Compañeros políticos/Si tiene relación}

No tiene relación: el emisor niega relacionarse socialmente con otros partidarios políticos de la agrupación que participa u otros EXPPS.

\begin{tabular}{l} 
Compañeros políticos/ Si tiene relación/ Valoración \\
positiva \\
$\begin{array}{l}\text { Valoración positiva: alusión a aspectos específicos de la relación valorados de } \\
\text { manera satisfactoria por el emisor y en relación a los correligionarios. }\end{array}$ \\
\hline $\begin{array}{l}\text { Valoración global satisfacción: apreciación general del bienestar percibido de } \\
\text { la relación que el emisor mantiene con sus correligionarios. }\end{array}$ \\
\hline $\begin{array}{l}\text { Satisfecho: apreciación general positiva de la relación que el emisor mantiene } \\
\text { con sus correligionarios. }\end{array}$
\end{tabular}

\section{Compañeros políticos/ Si tiene relación/ Valoración} negativa

Valoración negativa: alusión a aspectos específicos de la relación valorados de manera insatisfactoria por el emisor y en relación a los compañeros políticos.

Valoración global satisfacción/ Insatisfecho: apreciación general negativa de la relación que el emisor mantiene con sus correligionarios. 


\section{Apoyo incondicional/ Si dispone}

Apoyo incondicional: disposición de relaciones interpersonales sin condiciones y de las que se cuenta de manera segura en caso de necesidad. Característico de apegos seguros.

Si dispone: el emisor afirma disponer de relaciones interpersonales sin condiciones con las que pueda contar de manera segura en caso de necesidad.

\section{Apoyo incondicional/ No dispone}

No dispone: el emisor niega disponer de relaciones interpersonales sin condiciones con las que pueda contar de manera segura en caso de necesidad.

\section{Apoyo incondicional/ Si dispone/ tipo de vinculación}

Familia: el emisor afirma disponer de relaciones interpersonales familiares sin condiciones con las que pueda contar de manera segura en caso de necesidad.

Pareja: el emisor afirma disponer de una relación interpersonal con su compañero(a) sentimental (definición de pareja en variables demográficas) sin condiciones con la que pueda contar de manera segura en caso de necesidad.

Hijos: el emisor afirma disponer de una(s) relación(es) interpersonal(es) filial(es), sin condiciones con la(s) que pueda contar de manera segura en caso de necesidad.

Hermanos: el emisor afirma disponer de relación(es) interpersonal(es) fraterna(s) sin condiciones con la(s) que pueda contar de manera segura en caso de necesidad

Padres: el emisor afirma disponer de relación(es) interpersonal(es) paterna(es) sin condiciones con la(s) que pueda contar de manera segura en caso de necesidad Nietos: el emisor afirma disponer de relación(es) interpersonal(es) con hijo(s) de sus hijo(s) sin condiciones con las que pueda contar de manera segura en caso de necesidad.

Amigos: el emisor afirma disponer de relación(es) interpersonal(es) social(es) con amigos (según definición demográfica del concepto) sin condiciones con las que pueda contar de manera segura en caso de necesidad.

Compañeros: el emisor afirma disponer de relación(es) interpersonal(es) social(es) con compañeros (según definición demográfica del concepto) sin condiciones con las que pueda contar de manera segura en caso de necesidad.

Conocidos: el emisor afirma disponer de relación(es) interpersonal(es) social(es) con personas no valoradas como amigos ni compañeros, pero que conoce, sin condiciones con las que pueda contar de manera segura en caso de necesidad.

Ex-pareja: el emisor afirma disponer de relación interpersonal con persona que en el pasado fue su pareja (según definición demográfica del concepto) sin condiciones con las que pueda contar de manera segura en caso de necesidad.

Dios: el emisor afirma disponer de relación interpersonal con quien corresponda a la deidad de una religión o secta mono o politeísta, sin condiciones con las que pueda contar de manera segura en caso de necesidad.

\section{Concepción de mundo/ Valoración positiva}

Concepción mundo: alusiones al conjunto de cogniciones que el emisor presenta en la actualidad de su ideología del cosmos y que incluyen apreciaciones de su entorno más cercano hasta el más lejano, y aspectos filosóficos, políticos, sociales, estéticos, éticos, científicos, naturales, temporales, etc.

Positiva: alusiones al conjunto de cogniciones que el emisor presenta en la actualidad de su ideología del cosmos y que incluyen apreciaciones de su entorno más cercano hasta el más lejano, y aspectos filosóficos, políticos, sociales, estéticos, éticos, científicos, naturales, temporales, etc., y que valora como buenas o favorables. 

Valoración global positiva: alusiones al conjunto de cogniciones que el emisor
presenta en la actualidad, acerca de su ideología del cosmos y que incluyen
apreciaciones de su entorno más cercano hasta el más lejano, y aspectos
filosóficos, políticos, sociales, estéticos, éticos, científicos, naturales,
temporales, etc., que valora como buenas o favorables.
Causa humana: alusiones al conjunto de cogniciones que el emisor presenta en la
actualidad, acerca de su ideología del cosmos y que incluyen apreciaciones de su
entorno más cercano hasta el más lejano, y aspectos filosóficos, políticos,
sociales, estéticos, éticos, científicos, naturales, temporales, etc., que
valora como buenas o favorables y que atribuye a la influencia del hombre.

Causa naturaleza: alusiones al conjunto de cogniciones que el emisor presenta en la actualidad, acerca de su ideología del cosmos y que incluyen apreciaciones de su entorno más cercano hasta el más lejano, y aspectos filosóficos, políticos, sociales, estéticos, éticos, científicos, naturales, temporales, etc., que valora como buenas o favorables y que atribuye a la influencia del medio ambiente.

Tendencias actuales: alusiones al conjunto de cogniciones que el emisor presenta en la actualidad, acerca de su ideología del cosmos y que incluyen apreciaciones de su entorno más cercano hasta el más lejano, y aspectos filosóficos, políticos, sociales, estéticos, éticos, científicos, naturales, temporales, etc., que valora como buenas o favorables y que atribuye a la influencia de factores temporales presentes que considera que son propios de los tiempos en que está viviendo.

Influencia dictadura: alusiones al conjunto de cogniciones que el emisor presenta en la actualidad, acerca de su ideología del cosmos y que incluyen apreciaciones de su entorno más cercano hasta el más lejano, y aspectos filosóficos, políticos, sociales, estéticos, éticos, científicos, naturales, temporales, etc., que relaciona o no al régimen militar y su impacto percibido.

No observa: alusiones al conjunto de cogniciones que el emisor presenta en la actualidad, acerca de su ideología del cosmos y que incluyen apreciaciones de su entorno más cercano hasta el más lejano, y aspectos filosóficos, políticos, sociales, estéticos, éticos, científicos, naturales, temporales, etc., que no relaciona al régimen militar y su impacto percibido.

Aspectos positivos: Valoraciones favorables que el emisor realiza del cosmos acerca de la naturaleza, procesos y cambios políticos ocurridos en América Latina en el año 2005, y los adelantos tecnológicos.

Naturaleza: el emisor alude a aspectos del medio ambiente que valora de manera favorable a la hora de referirse al cosmos.

Cambios políticos América Latina.: el emisor alude a aspectos políticos contextuales que valora de manera favorable.

Avances tecnológicos: el emisor alude a aspectos asociados a los adelantos de productos que refieren el aprovechamiento práctico del conocimiento científico.

Valoración aspectos: alusiones a aspectos específicos de cogniciones actuales que el emisor presenta de su ideología del cosmos.

Acogedor: el emisor refiere concebir o no al cosmos de su entorno más cercano, de manera agradable, cómoda, y tranquila.

Si: el emisor afirma percibir el entorno más cercano entendido como mundo, de manera agradable, cómoda, y tranquila.

Hostil: el emisor refiere concebir o no al cosmos de manera desagradable, incómoda, intranquila, peligrosa y amenazante.

No: el emisor niega concebir al cosmos de manera desagradable, incómoda, intranquila, peligrosa y amenazante.

Tiene sentido: el emisor refiere concebir o no al cosmos y su evolución, con una razón de ser.

Si: el emisor afirma concebir al cosmos y su evolución, con una razón de ser. 
Difícil: el emisor refiere concebir o no al cosmos de manera que le cuesta en gran medida supervivir en él.

No: el emisor niega concebir al cosmos de manera que le cueste en gran medida supervivir en él.

Agradable: el emisor refiere concebir o no al cosmos universal de manera placentera.

Si: el emisor concibe al cosmos universal de manera placentera.

Peligroso: el emisor refiere concebir o no al cosmos universal que presenta la amenaza constante contra su integridad y la de otras personas.

No: el emisor no concibe al cosmos universal de manera amenazante contra su integridad y la de otras personas.

Valoración de su estar: apreciación del emisor acerca de cómo refiere sentirse generalmente en el cosmos.

A gusto: el emisor refiere sentirse en general bien en el cosmos.

\section{Concepción de mundo/ Valoración negativa}

Negativa: alusiones al conjunto de cogniciones que el emisor presenta en la actualidad, acerca de su ideología del cosmos y que incluyen apreciaciones de su entorno más cercano hasta el más lejano, y aspectos filosóficos, políticos, sociales, estéticos, éticos, científicos, naturales, temporales, etc., que valora como malas o desfavorables.

Valoración global negativa: alusiones al conjunto de cogniciones que el emisor presenta en la actualidad, acerca de su ideología del cosmos y que incluyen apreciaciones de su entorno más cercano hasta el más lejano, y aspectos filosóficos, políticos, sociales, estéticos, éticos, científicos, naturales, temporales, etc., que valora como malas o desfavorables.

Causa humana: alusiones al conjunto de cogniciones que el emisor presenta en la actualidad, acerca de su ideología del cosmos y que incluyen apreciaciones de su entorno más cercano hasta el más lejano, y aspectos filosóficos, políticos, sociales, estéticos, éticos, científicos, naturales, temporales, etc., que valora como malas o desfavorables y que atribuye a la influencia del hombre.

Causa naturaleza: alusiones al conjunto de cogniciones que el emisor presenta en la actualidad, acerca de su ideología del cosmos y que incluyen apreciaciones de su entorno más cercano hasta el más lejano, y aspectos filosóficos, políticos, sociales, estéticos, éticos, científicos, naturales, temporales, etc., que valora como malas o desfavorables y que atribuye a la influencia del medio ambiente.

Tendencias actuales: alusiones al conjunto de cogniciones que el emisor presenta en la actualidad, acerca de su ideología del cosmos y que incluyen apreciaciones de su entorno más cercano hasta el más lejano, y aspectos filosóficos, políticos, sociales, estéticos, éticos, científicos, naturales, temporales, etc., que valora como malas o desfavorables y que atribuye a la influencia de factores temporales presentes que considera que son propios de los tiempos en que está viviendo.

Influencia dictadura/ Si observa: alusiones al conjunto de cogniciones que el emisor presenta en la actualidad, acerca de su ideología del cosmos y que incluyen apreciaciones de su entorno más cercano hasta el más lejano, y aspectos filosóficos, políticos, sociales, estéticos, éticos, científicos, naturales, temporales, etc., que relaciona al régimen militar y su impacto percibido.

Problemáticas: especificación de aspectos negativos del conjunto de cogniciones que el emisor presenta en la actualidad, acerca de su ideología del cosmos y que incluyen apreciaciones de su entorno más cercano hasta el más lejano de aspectos sociales, políticos, y personales.

Sociales: especificación de aspectos negativos del conjunto de cogniciones que el emisor presenta en la actualidad, acerca de su ideología del cosmos y que 
incluyen apreciaciones de su entorno más cercano hasta el más lejano de aspectos relativos a la sociedad.

Desigualdad: el emisor refiere como un aspecto negativo de sus cogniciones actuales del cosmos, la falta de igualdad de oportunidades para las personas.

Exclusión: el emisor refiere como un aspecto negativo de sus cogniciones actuales del cosmos, el rechazo que sufren las personas quedando fuera del lugar que ocupaban.

Pobreza: el emisor refiere como un aspecto negativo de sus cogniciones actuales del cosmos, la situación de no disposición de recursos económicos básicos para la subsistencia que sufren las personas.

Desunión: el emisor refiere como un aspecto negativo de sus cogniciones actuales del cosmos, la disgregación entre personas.

Violencia: el emisor refiere como un aspecto negativo de sus cogniciones actuales del cosmos, la coacción entre personas.

Delincuencia: el emisor refiere como un aspecto negativo de sus cogniciones actuales del cosmos, los delitos que cometen las personas.

Consumo drogas: el emisor refiere como un aspecto negativo de sus cogniciones actuales del cosmos, el empleo de sustancias psicotrópicas que se emplean para producir estados alterados de conciencia de manera ilegal.

Políticas: especificación de aspectos negativos del conjunto de cogniciones que el emisor presenta en la actualidad, acerca de su ideología del cosmos y que incluyen apreciaciones de su entorno más cercano hasta el más lejano de aspectos relativos al ámbito político.

Corrupción: el emisor refiere como un aspecto negativo de sus cogniciones actuales del cosmos, al cohecho ejercido por representantes de los gobiernos actuales.

Globalización: el emisor refiere como un aspecto negativo de sus cogniciones actuales del cosmos, a la tendencia de mercados y empresas a alcanzar una dimensión mundial.

Guerras: el emisor refiere como un aspecto negativo de sus cogniciones actuales del cosmos, a la presencia de lucha con armas entre dos o más naciones o bandos de una nación.

Consumismo: el emisor refiere como un aspecto negativo de sus cogniciones actuales del cosmos, a la tendencia desenfrenada a adquirir y consumir bienes que no considera necesarios.

Potencias mundiales: el emisor refiere como un aspecto negativo de sus cogniciones actuales del cosmos, a la influencia de naciones que presentan una marcada influencia política y social en el mundo (ej.: Estados Unidos de América).

Futuro incierto: el emisor refiere como un aspecto negativo de sus cogniciones actuales del cosmos, la incertidumbre que percibe en torno a las decisiones políticas posteriores.

Sobre-explotación recursos naturales: el emisor refiere como un aspecto negativo de sus cogniciones actuales del cosmos, las políticas de gobiernos que apuntan a la desprotección del medio ambiente.

Exclusión política: el emisor refiere como un aspecto negativo de sus cogniciones actuales del cosmos, al hecho de alejar a alguien del lugar que ocupaba en el ámbito político.

Condiciones desfavorables trabajo: el emisor refiere como un aspecto negativo de sus cogniciones actuales del cosmos, a la tendencia a estipulaciones laborales que percibe de manera insatisfactoria.

Terrorismo: el emisor refiere como un aspecto negativo de sus cogniciones actuales del cosmos, a hechos de dominación por medio del terror.

Regímenes políticos: el emisor refiere como un aspecto negativo de sus cogniciones actuales del cosmos, a sistemas de gobiernos. 
Personales: especificación de aspectos negativos del conjunto de cogniciones que el emisor presenta en la actualidad, acerca de su ideología del cosmos y que incluyen apreciaciones de su entorno más cercano hasta el más lejano de aspectos relativos a la influencia del hombre.

Individualismo: el emisor refiere como un aspecto negativo de sus cogniciones actuales del cosmos, características humanas como la tendencia a actuar de manera independiente.

No lucha: el emisor refiere como un aspecto negativo de sus cogniciones actuales del cosmos, a la ausencia de disputa por parte de las personas.

Pérdida de ideales: el emisor refiere como un aspecto negativo de sus cogniciones actuales del cosmos, a la ausencia de convicciones.

Ausencia de valores: el emisor refiere como un aspecto negativo de sus cogniciones actuales del cosmos, a la falta de importancia a aspectos que él otorga importancia.

Soledad: el emisor refiere como un aspecto negativo de sus cogniciones actuales del cosmos, a la tendencia al aislamiento emocional y afectivo en relación a otras personas.

Acogedor/ No: el emisor niega concebir al cosmos referido a su entorno más cercano de manera agradable, cómoda, y tranquila.

Hostil/ Si: el emisor afirma concebir al cosmos de manera desagradable, incómoda, intranquila, peligrosa y amenazante.

Tiene sentido/ No: el emisor concibe al cosmos y su evolución, sin una razón de ser.

Difícil/ Si: el emisor refiere concebir al cosmos de manera que le cuesta en gran medida supervivir en él.

Agradable/ No: el emisor no concibe al cosmos universal de manera placentera.

Peligroso/ Si: el emisor si concibe al cosmos universal de manera amenazante contra su integridad y la de otras personas.

Valoración de su estar/ A disgusto: el emisor refiere sentirse de mala gana o en general mal en el cosmos.

\section{Ideología}

Ideología: alusiones al conjunto de ideas fundamentales del emisor, y que incluyen sus valores, creencias y el sentido filosófico que otorga a sus relaciones afectivas que dispone.

\section{Ideología/ Valores}

Valores: alusiones a ideas y conceptos que el emisor otorga importancia.

Familia: alusión a la importancia que el emisor otorga al concepto genérico de familia. Entendiéndose ésta, como el grupo de personas emparentadas entre sí, con un vínculo consanguíneo y/ o afectivo.

Amistad: alusión a la importancia que el emisor otorga al concepto genérico de amistad. Entendiéndose éste, como el descrito en antecedentes conceptuales de amigos.

Solidaridad: alusión a la importancia que el emisor otorga a la adhesión circunstancial a la causa o empresa de otros.

Lealtad: alusión a la importancia que el emisor otorga a la lealtad entre personas.

Confidencialidad: alusión a la importancia que el emisor otorga a la confianza y seguridad recíproca entre personas.

Salud y vida: alusión a la importancia que el emisor otorga al buen estado físico-psíquico y social de todas las funciones del individuo y al estado óptimo 
que pueden alcanzar los seres vivos para desarrollarse, reproducirse y mantenerse.

Honestidad: alusión a la importancia que el emisor otorga a la rectitud de las personas.

Palabra: alusión a la importancia que el emisor otorga al empeño que hacen personas de su fe y probidad atestiguando lo que afirma.

Perdón: alusión a la importancia que el emisor otorga a la remisión de agravios que reciben las personas.

Educación: alusión a la importancia que el emisor otorga a la instrucción por medio de la acción docente.

Ideales Unidad Popular: alusión a la importancia que el emisor otorga a los planteamientos políticos del socialismo que caracterizaron el período del gobierno de Salvador Allende.

Cuidado medio ambiente: alusión a la importancia que el emisor otorga a la manutención que las personas hacen de la naturaleza.

Esfuerzo: alusión a la importancia que el emisor otorga al empleo de energía del vigor o actividad del ánimo para la consecución de algo superando dificultades.

Relaciones humanas: alusión a la importancia que el emisor otorga a las relaciones interpersonales.

Cultura: alusión a la importancia que el emisor otorga al conjunto de conocimientos que una persona puede llegar a adquirir y que valora de manera positiva para su desarrollo.

Trabajo: alusión a la importancia que el emisor otorga a la ocupación retribuida.

Buen pasar: alusión a la importancia que el emisor otorga a un estilo de vida satisfactorio en cuanto a un bienestar económico.

Libertad: alusión a la importancia que el emisor otorga a la facultad que tienen los seres humanos para actuar o no, según su inteligencia y antojo. Propio de personas no privadas de su libertad.

Dignidad: alusión a la importancia que el emisor otorga a las personas para comportarse con decoro y hacerse respetar.

\section{Ideología/ Creencias/Si cree}

Creencias: alusión a las convicciones religiosas y doctrinales del emisor.

Si cree: afirmaciones que revelan convicciones específicas del emisor.

Creencias/ Valoración específica: alusión a las convicciones específicas religiosas y doctrinales del emisor.

Religiosas o espirituales: alusión a las convicciones acerca de la divinidad o relativas al espíritu sostenidas por el emisor.

Si: el emisor afirma tener convicciones acerca de la divinidad y/ o relativas al espíritu.

Justicia: alusión a la convicción o no del emisor de la virtud de dar y respetar en cada persona lo que le corresponde o pertenece, y/ o el poder judicial.

Si: el emisor afirma tener la convicción en la virtud de dar y respetar en cada persona lo que le corresponde o pertenece y/ o el poder judicial.

Amor: alusión del emisor a su creencia o no en el sentimiento de afecto, inclinación y entrega a otra persona.

Si: el emisor afirma tener la convicción en el sentimiento de afecto, inclinación y entrega a otra persona.

Paz: alusión del emisor a su creencia o no en la concordia entre estados y gobernantes.

Si: el emisor afirma tener la convicción en la concordia entre estados y gobernantes. 
Personas: alusión del emisor a su creencia o no en los demás seres humanos.

Si: el emisor afirma tener la convicción en los demás seres humanos.

Felicidad: alusión del emisor a su convicción o no en la existencia de un estado de ánimo que se disfruta lo que se desea, proporcionando satisfacción, alegría y bienestar a quien la posee.

Si: el emisor afirma tener la convicción en la existencia de un estado de ánimo que se disfruta lo que se desea, proporcionando satisfacción, alegría y bienestar a quien la posee.

\section{Ideología/ Creencias/ No cree}

No cree: el emisor niega tener convicciones específicas.

Religiosas o espirituales/ No: el emisor niega tener convicciones acerca de la divinidad y/ o relativas al espíritu.

Justicia/ No: el emisor niega tener la convicción en la virtud de dar y respetar en cada persona lo que le corresponde o pertenece y/ o el poder judicial.

Amor/ No: el emisor niega tener la convicción en el sentimiento de afecto, inclinación y entrega a otra persona.

Paz/ No: el emisor niega tener la convicción en la concordia entre estados y gobernantes.

Personas/ No: el emisor niega tener la convicción en los demás seres humanos.

Felicidad/ No: el emisor niega tener la convicción en la existencia de un estado de ánimo que se disfruta lo que se desea, proporcionando satisfacción, alegría y bienestar a quien la posee.

\section{Ideología/ sentido de las relaciones afectivas que dispone/ valoración positiva}

Sentido relaciones afectivas que dispone: alusiones generales a ideas $y$ conceptos con las que el emisor entiende los vínculos que mantiene con figuras de apego.

Valoración positiva: alusiones generales a ideas y conceptos con las que el emisor entiende los vínculos que mantiene con figuras de apego y que valora favorablemente.

Características: aspectos específicos del sentido que el emisor otorga de manera general a sus vínculos de apego.

Sólidas: el emisor en general entiende sus vínculos de apego como estables y seguras.

Básicas: el emisor en general entiende sus vínculos de apego de modo fundamental.

Cercanas: el emisor en general entiende sus vínculos de apego próximas y tendientes a la intimidad.

Atribución: facultades que el emisor otorga de manera general a sus vínculos de apego, en base al entendimiento que hace de estas relaciones en su vida.

Indispensables: el emisor en general entiende sus vínculos de apego como imprescindibles para su vida.

Importantes: el emisor en general otorga a sus vínculos de apego relevancia y significación en su vida.

De ayuda: el emisor en general otorga a sus vínculos de apego la capacidad de auxiliarle.

Necesarias: el emisor en general otorga a sus vínculos de apego el carácter de inevitables para su bienestar.

Valoración global: apreciación global que el emisor hace de su entendimiento de los vínculos de apego que dispone. 
Satisfecho: el emisor entiende a modo general sus vínculos de apego de manera positiva o satisfactoria con las que se siente a gusto.

\section{Ideología/ sentido de las relaciones afectivas que} dispone/ valoración negativa

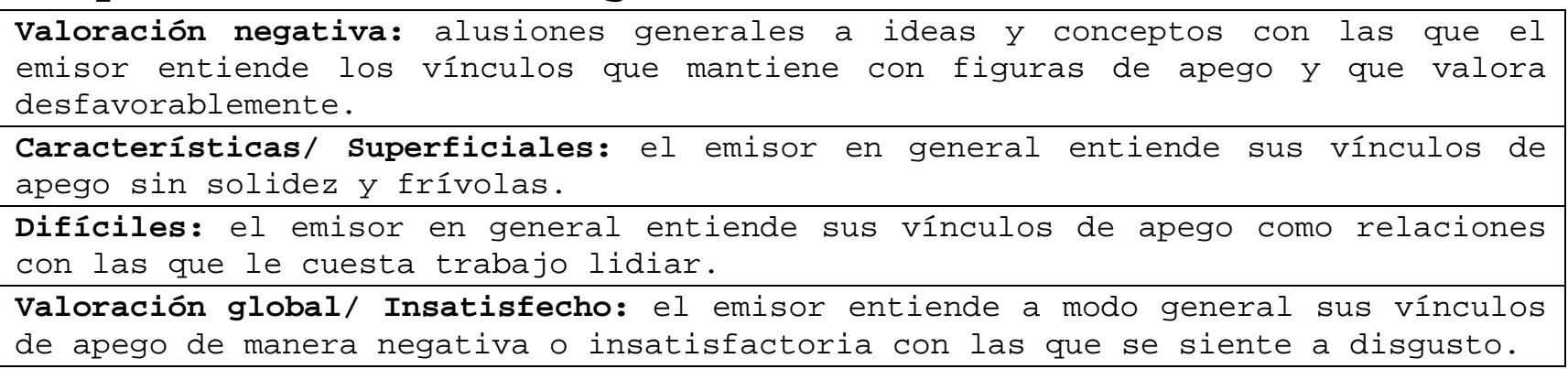

\section{Concepción de seres humanos/ Valoración positiva}

Concepción seres humanos: alusiones al conjunto de cogniciones que el emisor presenta de modo genérico en la actualidad del hombre.

Visión positiva: el emisor alude a aspectos de su ideología de los hombres concibiéndoles de manera favorable y/ o optimista.

Concepción de seres humanos/ Valoración negativa

Concepción seres humanos/ Visión negativa: el emisor alude a aspectos de su ideología de los hombres concibiéndoles de manera desfavorable y/ o pesimista.

Valoración personal/ positiva

Valoración personal: alusión a la apreciación que el emisor realiza en base a su persona.

Positiva: el emisor alude a apreciaciones favorables con las que se auto-

percibe.

\section{Valoración personal/ negativa}

Negativa: el emisor alude a apreciaciones desfavorables con las que se autopercibe.

\section{Valoración de ocupación actual/ Positiva}

Valoración ocupación actual: alusión a la apreciación que el emisor realiza de su actividad laboral si procede, en la actualidad.

Positiva: apreciaciones favorables de la motivación y a modo general de la ocupación actual que el emisor realiza.

Motivación: alusión al interés con que el emisor realiza su actividad laboral, si procede.

Alta: el emisor alude a su elevado interés por la actividad laboral que realiza en la actualidad, si procede.

Valoración global: apreciación global del emisor de su actividad laboral actual, si procede.

Satisfecho: el emisor valora globalmente de manera favorable su actividad laboral actual, si procede. 


\section{Valoración de ocupación actual/ Negativa}

\begin{tabular}{|l}
\hline $\begin{array}{l}\text { Valoración ocupación actual/ Negativa: apreciaciones desfavorables de la } \\
\text { motivación y a modo general de la ocupación actual que el emisor realiza. }\end{array}$ \\
\hline $\begin{array}{l}\text { Motivación/ Baja: el emisor alude a su escaso interés por la actividad laboral } \\
\text { que realiza en la actualidad, si procede. }\end{array}$ \\
\hline $\begin{array}{l}\text { Valoración global/ Insatisfecho: el emisor valora globalmente de } \\
\text { desfavorable su actividad laboral actual, si procede. }\end{array}$ \\
\hline
\end{tabular}

\section{Valoración de participación política/ Positiva}

\begin{tabular}{l} 
Valoración participación política: apreciación que el emisor hace de su rol \\
político en la actualidad. \\
\hline $\begin{array}{l}\text { Positiva: apreciaciones favorables que el emisor hace de su rol político actual } \\
\text { en base a la auto-crítica y a modo general. }\end{array}$ \\
\hline $\begin{array}{l}\text { Autocrítica asociada: alusiones favorables o desfavorables con las que el emisor } \\
\text { se auto-percibe en su trabajo político actual. }\end{array}$ \\
$\begin{array}{l}\text { Positiva: el emisor valora favorable y satisfactoriamente aspectos de su trabajo } \\
\text { político actual. }\end{array}$ \\
$\begin{array}{l}\text { Valoración global: apreciación general favorable o desfavorable de la } \\
\text { participación política que realiza en la actualidad. }\end{array}$ \\
$\begin{array}{l}\text { Satisfecho: el emisor valora a modo general de manera favorable su desempeño } \\
\text { actual en el ámbito político, refiriendo conformidad con su trabajo. }\end{array}$ \\
\hline
\end{tabular}

\section{Valoración de participación política/ Negativa}

Negativa: apreciaciones desfavorables que el emisor hace de su rol político actual en base a la auto-crítica y a modo general.

Autocrítica asociada/ Negativa: el emisor valora de manera desfavorable e insatisfactoria aspectos de su trabajo político actual.

Valoración global/ Insatisfecho: el emisor valora a modo general de manera desfavorable su desempeño actual en el ámbito político, refiriendo disconformidad con su trabajo.

Motivación principal: alusión a los motivos del interés por el que el emisor milita en política en el presente.

Defensa ideales Unidad Popular: el emisor alude como motivo de su militancia en política, su interés por mantener el pensamiento y los valores propios del gobierno de Salvador Allende.

Mejora reparación: el emisor alude como motivo de su militancia en política, el conseguir modificaciones que valora como favorables en reparos gubernamentales a su persona y la de otros de la experiencia de prisión.

Ayuda social: el emisor alude como motivo de su militancia en política, auxiliar a las personas más vulnerables socialmente.

\section{Sentido de la vida/ Valoración positiva}

Sentido de la vida: cogniciones que el emisor refiere acerca del entendimiento que le otorga a la existencia de los seres vivos en general.

Valoración disfrute de vida: apreciación de la propia existencia acerca del grado de gozo alcanzado en ésta.

Satisfecho: el emisor refiere sentir satisfacción o disfrute con su vida actual.

Valoración global: apreciación general del emisor de la propia existencia en favorable o desfavorable para su bienestar.

Positiva: apreciación general del emisor de la propia existencia en favorable para su bienestar. 
Sentido de la vida/ Valoración negativa

$\begin{aligned} & \text { Valoración disfrute de vida/ Insatisfecho: el emisor refiere } \\ & \text { satisfacción o disfrute con su vida actual. }\end{aligned}$
$\begin{aligned} & \text { Valoración global/ Negativa: apreciación general del emisor de la propia } \\ & \text { existencia en desfavorable para su bienestar. }\end{aligned}$

Valoración de Chile actual/ Positiva

Valoración Chile actual: apreciación del emisor de aspectos generales actuales de la situación del país al que pertenecen.

Positiva: apreciación desfavorable de la situación actual del país al que pertenecen.

\section{Valoración de chile actual/ Positiva}

Valoración Chile actual/ Negativa: apreciación desfavorable de la situación actual del país al que pertenecen.

\section{Temores/ No tiene}

Temores: alusión a miedos que presenta el emisor en su discurso, no asociados a la experiencia de prisión.

No tiene: el emisor niega tener miedos.

\section{Temores/Si tiene}

Si tiene: el emisor afirma tener miedos.

Enfermedad o daño a familiares: el emisor manifiesta miedos asociados a que se ocasione algún perjuicio o deterioro a los integrantes de su familia, y/ o a la presencia de enfermedad en éstos.

Enfermedad individual: el emisor manifiesta miedos asociados a presentar problemas de salud en su persona.

Muerte: el emisor manifiesta miedos asociados a la posibilidad de termino de su vida.

\section{- PASADO}

\section{Familia de origen en el pasado/ Valoración positiva}

Pasado: valoración de aspectos interpersonales e ideológicos de la infancia y adolescencia del emisor, previa a la experiencia de privación de libertad por motivos políticos. Estos aspectos incluyen el grado de satisfacción en el ámbito familiar y social y su visión del futuro, el estar en el mundo, y el sentido que otorga a la vida.

Relaciones interpersonales: **

Familia origen: *

Madre: alusión del emisor a su valoración que realiza, si procede, de la relación que mantuvo con su progenitora durante su infancia y adolescencia.

Si tuvo relación: el emisor afirma haber mantenido contacto alguno con su progenitora.

Valoración relación: apreciación global positiva, negativa de la relación que el emisor mantuvo con su progenitora durante su infancia y adolescencia. 


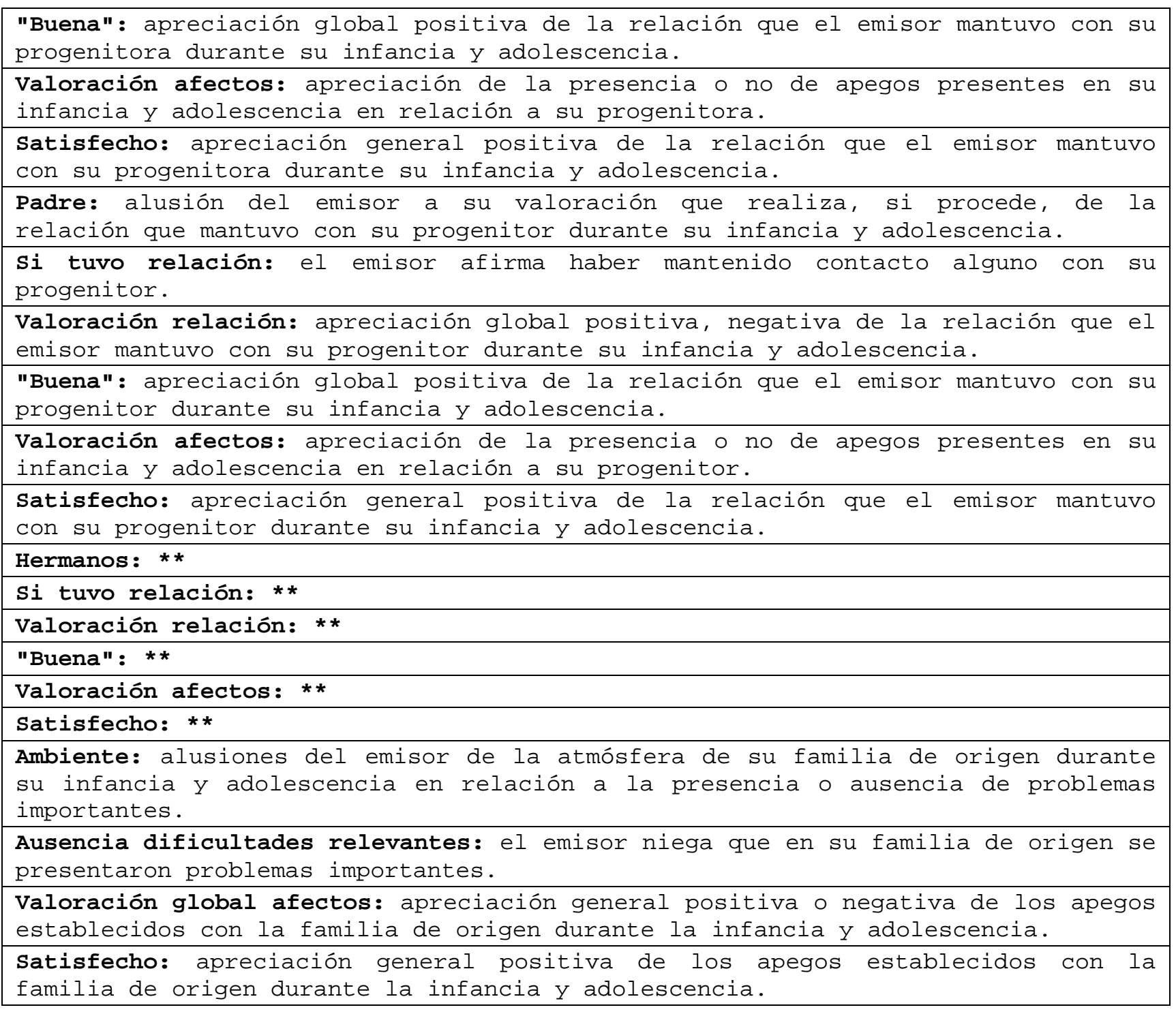

\section{Familia de origen en el pasado/ Valoración negativa}

Madre/ No tuvo relación: el emisor niega haber mantenido contacto alguno con su progenitora.

Si tuvo relación/ Valoración relación/ "Mala": apreciación global negativa de la relación que el emisor mantuvo con su progenitora durante su infancia y adolescencia.

Valoración afectos/ Insatisfecho: apreciación general negativa de la relación que el emisor mantuvo con su progenitora durante su infancia y adolescencia.

Padre/ No tuvo relación: el emisor niega haber mantenido contacto alguno con su progenitor.

Si tuvo relación/ Valoración relación/ "Mala": apreciación global negativa de la relación que el emisor mantuvo con su progenitor durante su infancia y adolescencia.

Valoración afectos/ Insatisfecho: apreciación general negativa de la relación que el emisor mantuvo con su progenitor durante su infancia y adolescencia.

Hermanos/ No tuvo relación:

Valoración relación/ "Mala": **

Valoración afectos/ Insatisfecho: 
Ambiente/ Presencia dificultades relevantes: el emisor afirma que en su familia de origen se presentaron problemas importantes.

Violencia: el emisor afirma que en su familia de origen se presentaron problemas de algún tipo de maltrato entre los integrantes del núcleo familiar y durante su infancia y adolescencia.

Alcoholismo: el emisor afirma que en su familia de origen se presentaron problemas de consumo excesivo de alcohol en uno o más integrantes del núcleo familiar y durante su infancia y adolescencia.

Drogadicción: el emisor afirma que en su familia de origen se presentaron problemas de consumo excesivo de drogas en uno o más integrantes del núcleo familiar y durante su infancia y adolescencia.

Pobreza extrema: el emisor afirma que en su familia de origen se presentaron problemas económicos importantes que afectaron negativamente en la satisfacción de sus necesidades biológicas durante su infancia y adolescencia.

Muerte: el emisor afirma que en su familia de origen aconteció uno o más sucesos de muerte de integrantes de su núcleo familiar, durante su infancia y adolescencia, y que valoró negativamente.

Trabajo infantil: el emisor afirma que en su familia de origen se presentaron problemas económicos por lo que tuvo que trabajar desde muy temprana edad, durante su infancia y adolescencia.

Crianza de hermanos: el emisor afirma que en su familia de origen se vio obligado a velar y hacerse responsable de el desarrollo y cuidados integrales de sus hermanos, durante su infancia y adolescencia.

Imposibilidad estudios: el emisor afirma que en su familia de origen no tuvo la oportunidad de estudiar durante su infancia y adolescencia.

Crianza cuidadores: el emisor afirma que en su familia de origen se vio bajo el cuidado de personas externas a su familia que se encargaron de su crianza durante su infancia y adolescencia.

Abuso sexual: el emisor afirma que en su familia de origen se presentaron problemas de violencia sexual en uno o más integrantes del núcleo familiar y durante su infancia y adolescencia.

Separación: el emisor afirma que en su familia de origen ocurrió el alejamiento de uno o más integrantes del núcleo familiar, durante su infancia y adolescencia.

Valoración global afectos/ Insatisfecho: apreciación general negativa de los apegos establecidos con la familia de origen durante la infancia y adolescencia.

\section{Ideología política}

Ideología política: alusión a la presencia o ausencia de la tendencia partidista de los integrantes de la familia de origen del emisor, cuando éste vivía su infancia y adolescencia.

Apolíticos: el emisor refiere la ausencia de una tendencia política en los integrantes de su familia de origen cuando éste vivía su infancia y adolescencia.

De derecha: el emisor afirma que su familia de origen tenía una tendencia política de uno o más partidos de la derecha chilena durante su infancia y adolescencia.

De izquierda: el emisor afirma que su familia de origen no tenía una tendencia política de uno o más partidos de la izquierda chilena durante su infancia y adolescencia.

*Nota: las variables referidas a la ideología política de la familia de origen en la infancia y adolescencia, no fueron incluidas en las dos categorías previas. 


\section{Amigos/ No tuvo}

Amigos de infancia y adolescencia: alusión del emisor a la presencia o ausencia de vínculos de amistad** durante su infancia y adolescencia.

No tuvo: **

\section{Amigos/ Si tuvo/ Valoración positiva}

\section{Amigos de infancia y adolescencia/ Si tuvo: **}

Satisfacción:

Se mantienen: el emisor afirma que sus amigos de infancia y adolescencia permanecen siendo sus amigos en la actualidad.

No se mantienen: el emisor afirma que sus amigos de infancia y adolescencia no permanecen siendo sus amigos en la actualidad.

\section{Amigos/Si tuvo/ Valoración negativa}

Insatisfacción: **

\section{Pareja de adolescencia/ No tuvo}

Pareja adolescencia: alusión del emisor a la presencia o ausencia de vínculos de pareja** durante su infancia y adolescencia.

No tuvo: *

\section{Pareja de adolescencia/ Si tuvo/ Valoración Positiva}

Pareja adolescencia/ Si tuvo: **

Satisfacción:

Pareja de adolescencia/ Si tuvo/ Valoración Positiva

Pareja adolescencia/ Si tuvo/ Insatisfacción: **

\section{Apoyo incondicional/ Si tuvo}

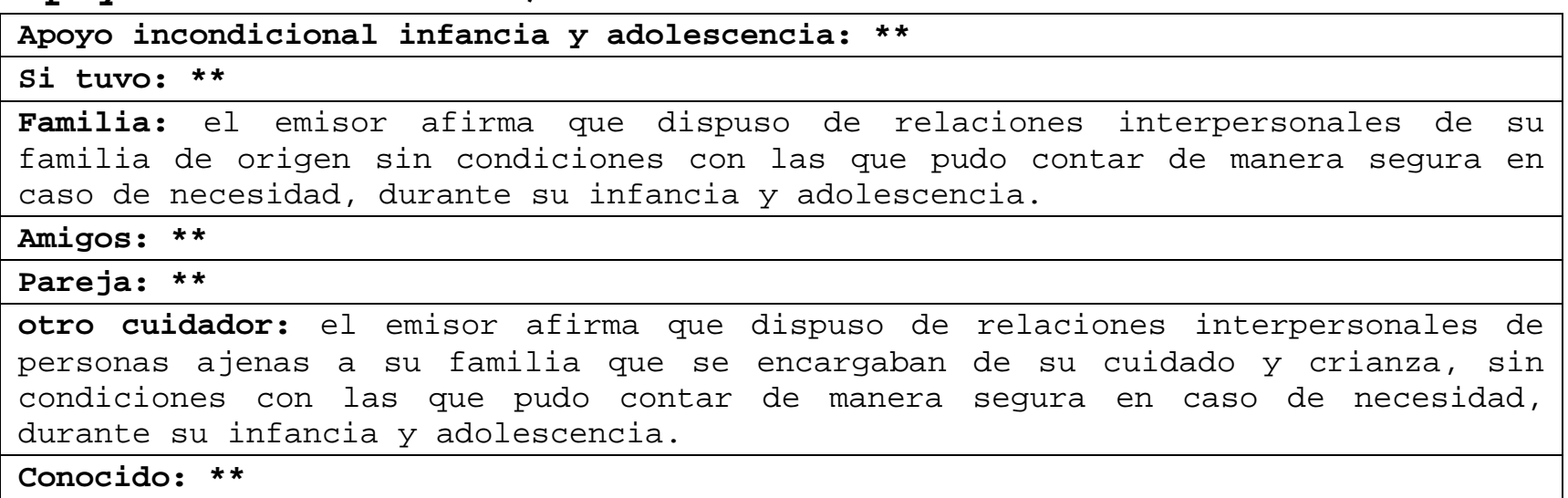

Apoyo incondicional/ No tuvo

Apoyo incondicional infancia y adolescencia/ No tuvo: **

\section{Concepción de mundo}

Concepción mundo:

No pensaba en ello: el emisor refiere no haber dedicado tiempo a darle sentido al entorno cuando vivía su infancia y adolescencia.

*Nota: la categoría precedente fue excluida de los resultados. 
Concepción de mundo positiva

Concepción mundo/ Si pensaba en ello: el emisor refiere haber dedicado tiempo a darle sentido al entorno cuando vivía su infancia y adolescencia.

Visión positiva:

Concepción de mundo negativa

Concepción mundo/ Si pensaba en ello/ Visión negativa: **

\section{Visión de futuro}

No pensaba en ello: el emisor refiere no haber dedicado tiempo a meditar acerca de un tiempo posterior al que vivió durante su infancia y adolescencia.

*Nota: la categoría precedente fue excluida de los resultados.

\section{Visión de futuro optimista}

Visión de futuro: alusión del emisor acerca de sus cogniciones durante su infancia y adolescencia, de lo que iba a suceder en un tiempo posterior.

Si pensaba en ello: el emisor refiere haber dedicado tiempo a meditar acerca de un tiempo posterior al que vivió durante su infancia y adolescencia.

Optimista: el emisor refiere haber mantenido cogniciones desfavorables de el tiempo posterior al que vivió durante su infancia y adolescencia.

\section{Visión de futuro pesimista}

Si pensaba en ello/ Pesimista: el emisor refiere haber mantenido cogniciones desfavorables de el tiempo posterior al que vivió durante su infancia y adolescencia.

\section{Valoración de su estar en el mundo/ Satisfecho}

Valoración de su estar: apreciación del emisor acerca de cómo recuerda haberse sentido a modo general en el cosmos durante su infancia y adolescencia.

Satisfecho: el emisor recuerda haberse sentido de buena gana o a gusto en el cosmos durante su infancia y adolescencia.

\section{Valoración de su estar en el mundo/ Insatisfecho}

Valoración de su estar/ Insatisfecho: el emisor recuerda haberse sentido de mala gana o a disgusto en el cosmos durante su infancia y adolescencia.

\section{Sentido de la vida}

Sentido de la vida: **

No pensaba en ello: **

*Nota: la categoría precedente fue excluida de los resultados.

\section{Sentido de la vida/ Positivo}

\begin{tabular}{|l|}
\hline Sentido de la vida/ Si pensaba en ello: ** \\
\hline Valoración disfrute de vida: ** \\
\hline Satisfecho: ** \\
\hline Valoración global: ** \\
\hline Positiva: **
\end{tabular}




\section{Sentido de la vida/ Negativo}

\begin{tabular}{|l|}
\hline Valoración disfrute de vida/ Insatisfecho: ${ }^{* *}$ \\
\hline Valoración global/ Negativa: ${ }^{* *}$ \\
\hline
\end{tabular}

\section{- PRISIÓN POLÍTICA Y TORTURA}

\section{Sufrimiento en prisión/ Refiere}

Prisión política y tortura: valoración de aspectos relacionados directamente a la experiencia de privación de libertad y tortura por motivos políticos tanto en la vida del emisor como en la vida de sus compañeros. Comprende la valoración que hacen de la propia experiencia de prisión y la de los compañeros, la actitud que mantuvo con posterioridad a la experiencia de prisión y en respuesta a ella, la valoración percibida del impacto de la experiencia en su vida, los miedos que presenta y que valora como producto de la experiencia, el mutismo mantenido de ésta consigo mismo, la valoración de re-traumatización de la experiencia, y la superación de ésta, el apoyo y rechazo percibidos de parte de la sociedad de ellos en su condición de EXPPS.

Valoración experiencia: juicios emitidos acerca de la apreciación que el emisor hace de aspectos asociados al acontecimiento de privación de libertad y/ o tortura ocurrida en su vida y en la de otros por motivos políticos.

En su vida: apreciación del emisor del sufrimiento padecido personalmente cuando fue privado de su libertad por motivos políticos.

Sufrimiento: el emisor alude al dolor físico y/ o psíquico experimentado cuando fue privado de su libertad por motivos políticos.

Mínimo: padecimiento de dolor físico y/ o psíquico valorado como ínfimo por el emisor y experimentado cuando fue privado de su libertad por motivos políticos.

Medio: padecimiento de dolor físico y/ o psíquico valorado como moderado por el emisor y experimentado cuando fue privado de su libertad por motivos políticos.

Extremo: padecimiento de dolor físico y/ o psíquico valorado como excesivo por el emisor y experimentado cuando fue privado de su libertad por motivos políticos.

\section{Menos que compañeros}

En su vida/ Sufrimiento/ Menos que compañeros: padecimiento de dolor físico y/ o psíquico valorado como inferior al padecido por otros EXPPS cuando fue privado de su libertad por motivos políticos.

\section{Valoración del impacto de prisión en compañeros}

Prisión política y tortura/ Valoración experiencia/ En otros ex-pps: apreciación del emisor de las consecuencias de la experiencia de privación de libertad por motivos políticos padecida por sus compañeros políticos en la vida de éstos.

En salud mental: el emisor alude como consecuencia de la experiencia de privación de libertad en otros compañeros políticos, alteraciones en la psiquis.

Debilidad: el emisor alude como consecuencia de la experiencia de privación de libertad en otros compañeros políticos, alteraciones no especificadas en la psiquis.

Depresión: el emisor alude como consecuencia de la experiencia de privación de libertad en otros compañeros políticos, síntomas del síndrome caracterizado por una profunda tristeza y la inhibición de las funciones vegetativas, en ocasiones con trastornos neurovegetativos.

Locura: el emisor alude como consecuencia de la experiencia de privación de libertad en otros compañeros políticos, alteraciones de falta de juicio de realidad. 


\begin{abstract}
Alcoholismo: el emisor alude como consecuencia de la experiencia de privación de libertad en otros compañeros políticos, el consumo excesivo de bebidas alcohólicas.

Drogadicción: el emisor alude como consecuencia de la experiencia de privación de libertad en otros compañeros políticos, el consumo excesivo de sustancias con efecto estimulante $y /$ o deprimente y/ o narcótico y/ o alucinógeno conocidas como drogas.

Deterioro general: el emisor alude como consecuencia de la experiencia de privación de libertad en otros compañeros políticos, daños a nivel global en la
\end{abstract} salud y vida.

Miedo: el emisor alude como consecuencia de la experiencia de privación de libertad en otros compañeros políticos, temor asociado a la experiencia.

En calidad de vida: el emisor alude como consecuencia de la experiencia de privación de libertad en otros compañeros políticos, cambios desfavorables en la satisfacción de las necesidades básicas y otras necesarias para vivir favorables para sus vidas.

Pobreza extrema: el emisor alude como consecuencia de la experiencia de privación de libertad en otros compañeros políticos, la no disposición de recursos económicos básicos para la subsistencia.

Imposibilidad de educación: el emisor alude como consecuencia de la experiencia de privación de libertad en otros compañeros políticos, el impedimento para continuar sus estudios.

Cesantía: el emisor alude como consecuencia de la experiencia de privación de libertad en otros compañeros políticos, el término de su actividad laboral y la imposibilidad de volver a trabajar.

Vivienda deficitaria: el emisor alude como consecuencia de la experiencia de privación de libertad en otros compañeros políticos, déficit en la calidad de vida asociado al lugar de residencia.

Exclusión social: el emisor alude como consecuencia de la experiencia de privación de libertad en otros compañeros políticos, daños a nivel global en la salud y vida.

Inseguridad: el emisor alude como consecuencia de la experiencia de privación de libertad en otros compañeros políticos, incertidumbre no especificada.

Insatisfacción necesidades básicas: el emisor alude como consecuencia de la experiencia de privación de libertad en otros compañeros políticos, dificultades para satisfacer lo que valora como los requerimientos elementales para la subsistencia favorable de los individuos.

En familia: el emisor alude como consecuencia de la experiencia de privación de libertad en otros compañeros políticos, daños especificados en la familia **.

Disfunción: alusión del emisor de alteraciones en el funcionamiento de la dinámica familiar de la vida de los compañeros políticos y producto de la experiencia de privación de libertad por motivos políticos.

Ruptura: alusión del emisor de quiebres en las relaciones familiares de la vida de los compañeros políticos y producto de la experiencia de privación de libertad por motivos políticos.

Prostitución: alusión del emisor de la venta de servicios sexuales de uno o más integrantes familiares de la vida de los compañeros políticos y producto de la experiencia de privación de libertad por motivos políticos.

En ideología y accionar político: alusión del emisor de cambios en la tendencia doctrinal en política de los compañeros políticos y producto de la experiencia de privación de libertad por motivos políticos.

Retracción: el emisor alude el alejamiento de agrupaciones políticas en que participaban los compañeros, producto del cambio en la tendencia doctrinal en política ocurrida tras la experiencia de privación de libertad por motivos políticos en ellos. 
Delatores: el emisor alude el apoyo al régimen militar mediante la entrega de información de compañeros políticos de los compañeros, producto del cambio en la tendencia doctrinal en política ocurrida tras la experiencia de privación de libertad por motivos políticos en ellos.

Muerte: alusión del emisor al cese de la vida de los compañeros políticos y producto de la experiencia de privación de libertad por motivos políticos.

En salud física: el emisor alude como consecuencia de la experiencia de privación de libertad en otros compañeros políticos, alteraciones o no en el estado de salud corporal.

Si: el emisor alude como consecuencia de la experiencia de privación de libertad en otros compañeros políticos, alteraciones en el estado de salud corporal.

En salud física/ No: el emisor niega como consecuencia de la experiencia de privación de libertad en otros compañeros políticos, alteraciones en el estado de salud corporal.

*Nota: la categoría precedente fue excluida de los resultados.

\section{Actitud Post-prisión/ Favorable}

Actitud post-prisión: alusión a la respuesta auto-percibida de la experiencia de privación de libertad por motivos políticos, en el período post-prisión**.

Reacción inmediata: alusión a la respuesta auto-percibida en el período inmediato inferior a un año y con posterioridad a la experiencia de privación de libertad por motivos políticos, en el período post-prisión**.

Sentimientos: alusión a los estados afectivos auto-percibidas en el período inmediato inferior a un año y con posterioridad a la experiencia de privación de libertad por motivos políticos, en el período post-prisión**.

odio: el emisor refiere haber o no sentido aversión y antipatía hacia todo lo relacionado al régimen militar, producto de la experiencia de privación de libertad por motivos políticos, en el período post-prisión**.

No: el emisor niega haber sentido aversión y antipatía hacia todo lo relacionado al régimen militar, producto de la experiencia de privación de libertad por motivos políticos, en el período post-prisión**.

Temor: el emisor refiere haber o no sentido miedo hacia todo lo relacionado al régimen militar, producto de la experiencia de privación de libertad por motivos políticos, en el período post-prisión**.

No: el emisor niega haber sentido miedo hacia todo lo relacionado al régimen militar, producto de la experiencia de privación de libertad por motivos políticos, en el período post-prisión**.

Aflicción: el emisor refiere haber o no sentido tristeza o angustia moral hacia todo lo relacionado al régimen militar, producto de la experiencia de privación de libertad por motivos políticos, en el período post-prisión**.

No: el emisor niega haber sentido tristeza o angustia moral hacia todo lo relacionado al régimen militar, producto de la experiencia de privación de libertad por motivos políticos, en el período post-prisión**.

Frustración: el emisor refiere haber o no sentido desilusión hacia todo lo relacionado al régimen militar, producto de la experiencia de privación de libertad por motivos políticos, en el período post-prisión**.

No: el emisor niega haber sentido desilusión hacia todo lo relacionado al régimen militar, producto de la experiencia de privación de libertad por motivos políticos, en el período post-prisión**.

Orgullo: el emisor refiere haber o no sentido valoración positiva hacia su persona, producto de la experiencia de privación de libertad por motivos políticos, en el período post-prisión**. 
Si: el emisor afirma haber sentido valoración propia positiva, producto de la experiencia de privación de libertad por motivos políticos, en el período postprisión**.

Sentimientos/ Vergüenza: el emisor refiere haberse o no sentido apocado, producto de la experiencia de privación de libertad por motivos políticos, en el período post-prisión**.

No: el emisor niega haberse sentido apocado, producto de la experiencia de privación de libertad por motivos políticos, en el período post-prisión**.

Sentimientos/ Culpa: el emisor refiere haberse o no sentido responsable de la experiencia de privación de libertad por motivos políticos, y a consecuencia de ella, en el período post-prisión**.

No: el emisor niega haberse sentido responsable de la experiencia de privación de libertad por motivos políticos, y a consecuencia de ella, en el período postprisión**.

Rabia: el emisor refiere haber o no sentido coraje de la experiencia de privación de libertad por motivos políticos, y a consecuencia de ella, en el período post-prisión**.

No: el emisor niega haber sentido coraje de la experiencia de privación de libertad por motivos políticos, y a consecuencia de ella, en el período postprisión**.

Soledad: el emisor refiere haberse no sentido aislado afectiva y socialmente de los demás, producto de la experiencia de privación de libertad por motivos políticos, en el período post-prisión**.

No: el emisor niega haberse sentido aislado afectiva y socialmente de los demás, producto de la experiencia de privación de libertad por motivos políticos, en el período post-prisión**.

Afrontamiento: alusión del emisor a su modo de hacer frente a la experiencia vivida de privación de libertad por motivos políticos, en el período postprisión**.

Estrategia superación: alusión del emisor de haberse propuesto y realizado acciones para vencer las dificultades posteriores causadas por la propia experiencia de privación de libertad por motivos políticos. Esto en el período post-prisión**.

Realización acciones legales: alusión del emisor de haber interpuesto querellas a los responsables de su experiencia de privación de libertad por motivos políticos. Esto en el período post-prisión**.

Lectura: alusión a la explicación que el emisor hace de la propia experiencia de privación de libertad por motivos políticos. Esto en el período post-prisión**.

Una valiosa experiencia: el emisor alude su valoración positiva de la propia experiencia de privación de libertad por motivos políticos. Esto en el período post-prisión**.

Una etapa más de vida: el emisor entiende su experiencia de privación de libertad por motivos políticos como un episodio anecdótico de su vida. Esto en el período post-prisión**.

Algo que tenía que suceder: el emisor entiende su experiencia de privación de libertad por motivos políticos como un episodio inevitable en su vida. Esto en el período post-prisión**.

Una nueva oportunidad de vida: el emisor entiende su experiencia de privación de libertad por motivos políticos como la oportunidad para vivir de nuevo. Esto en el período post-prisión**.

Acción política: alusión a la continuidad o no de la militancia en partidos y agrupaciones de izquierda en el período post-prisión producto de la experiencia de privación de libertad por motivos políticos como la oportunidad para vivir de nuevo. Esto en el período post-prisión**. 
Continúa militancia: alusión a la continuidad de la militancia en partidos y agrupaciones de izquierda en el período post-prisión producto de la experiencia de privación de libertad por motivos políticos como la oportunidad para vivir de nuevo. Esto en el período post-prisión**.

\section{Actitud Post-prisión/ desfavorable}

Actitud post-prisión/ Reacción inmediata/ Victimización: afirmación de autopercibir una respuesta de mostrarse ante los demás exponiendo el sufrimiento padecido cuando estuvo privado de su libertad por motivos políticos, como consecuencia de su privación de libertad por motivos políticos, en el período post-prisión**.

Actitud post-prisión/ Reacción inmediata/ Deseo de morir: afirmación de autopercibir una respuesta de querer terminar con su vida, como consecuencia de su privación de libertad por motivos políticos, en el período post-prisión**.

Actitud post-prisión/ Reacción inmediata/ Bloqueo: afirmación de auto-percibir una respuesta imposibilitada para funcionar como era usual en él, como consecuencia de su privación de libertad por motivos políticos, en el período post-prisión**.

Actitud post-prisión/ Reacción inmediata/ Evitación: afirmación de autopercibir una respuesta de apartarse de cualquier hecho, noticia, o cosa que le recordara la experiencia, como consecuencia de su privación de libertad por motivos políticos, en el período post-prisión**.

Sentimientos/ odio/ Si: el emisor afirma haber sentido aversión y antipatía hacia todo lo relacionado al régimen militar, producto de la experiencia de privación de libertad por motivos políticos, en el período post-prisión**.

Sentimientos/ Temor/ Si: el emisor afirma haber sentido miedo hacia todo lo relacionado al régimen militar, producto de la experiencia de privación de libertad por motivos políticos, en el período post-prisión**.

Sentimientos/ Aflicción/ Si: el emisor afirma haber sentido tristeza o angustia moral hacia todo lo relacionado al régimen militar, producto de la experiencia de privación de libertad por motivos políticos, en el período post-prisión**.

Sentimientos/ Frustración/ Si: el emisor afirma haber sentido desilusión hacia todo lo relacionado al régimen militar, producto de la experiencia de privación de libertad por motivos políticos, en el período post-prisión**.

Vergüenza/ Si: el emisor afirma haberse sentido apocado, producto de la experiencia de privación de libertad por motivos políticos, en el período postprisión**.

Culpa/ Si: el emisor afirma haberse sentido responsable de la experiencia de privación de libertad por motivos políticos, y a consecuencia de ella, en el período post-prisión**.

Rabia/ Si: el emisor afirma haber sentido coraje de la experiencia de privación de libertad por motivos políticos, y a consecuencia de ella, en el período postprisión**.

Soledad/ Si: el emisor afirma haberse sentido aislado afectiva y socialmente de los demás, producto de la experiencia de privación de libertad por motivos políticos, en el período post-prisión**.

Afrontamiento/ Evitación: alusión del emisor de haberse apartado de cualquier estímulo relacionado a la propia experiencia de privación de libertad por motivos políticos. Esto en el período post-prisión**.

Subversión: alusión del emisor de haber realizado acciones revolucionarias contra lo establecido, y como respuesta a la propia experiencia de privación de libertad por motivos políticos. Esto en el período post-prisión**.

Ironizar: alusión del emisor de haber tendido a burlarse de su experiencia vivida de privación de libertad por motivos políticos. Esto en el período postprisión**. 
Negación: alusión del emisor de haber tendido a no admitir la ocurrencia de su experiencia vivida de privación de libertad por motivos políticos. Esto en el período post-prisión**.

Lectura/ Una muy mala experiencia: el emisor alude su valoración negativa de la propia experiencia de privación de libertad por motivos políticos. Esto en el período post-prisión**.

Acción política/ Cese militancia: alusión a la discontinuidad de la militancia en partidos y agrupaciones de izquierda en el período post-prisión producto de la experiencia de privación de libertad por motivos políticos como la oportunidad para vivir de nuevo. Esto en el período post-prisión**.

Orgullo/ No: el emisor niega haber sentido valoración propia positiva, producto de la experiencia de privación de libertad por motivos políticos, en el período post-prisión**.

${ }^{*}$ Nota: la categoría precedente fue excluida de los resultados.

\section{Valoración del impacto de prisión en su vida/ No percibe}

Valoración impacto: alusión del emisor de la apreciación directa que hace de cómo percibe que la experiencia de privación de su libertad por motivos políticos afectó distintos ámbitos de su vida.

Trabajo o estudio: el emisor alude su percepción directa de los efectos de la experiencia de privación de su libertad por motivos políticos en el área laboral o estudiantil.

No impactó: el emisor niega que la experiencia de privación de su libertad por motivos políticos afectó en su ocupación laboral o estudiantil.

Economía: el emisor alude su percepción directa de los efectos de la experiencia de privación de su libertad por motivos políticos en sus bienes.

No: el emisor niega que la experiencia de privación de su libertad por motivos políticos haya afectado en sus bienes.

Salud: el emisor alude su valoración directa de los efectos percibidos o no de la experiencia de privación de su libertad por motivos políticos en sus condiciones físicas y psíquicas, en el período previo y posterior a la reclusión.

No refiere enfermedad asociada: el emisor alude su valoración directa de los efectos percibidos de la experiencia de privación de su libertad por motivos políticos, negando la alteración del funcionamiento de sus condiciones físicas y psíquicas, en el período previo y posterior a la reclusión.

Traspaso del trauma: el emisor alude su valoración directa de los efectos percibidos o no de la experiencia de privación de su libertad por motivos políticos en el traspaso de su afección o trauma causado en prisión, a su descendencia.

No percibe: el emisor alude su valoración directa de los efectos que no percibe de la experiencia de privación de su libertad por motivos políticos en el traspaso de su afección o trauma causado en prisión, a su descendencia.

Ilusión: el emisor alude su valoración directa de los efectos percibidos o no de la experiencia de privación de su libertad por motivos políticos en su capacidad de entusiasmo y alegría por su existencia.

No: el emisor niega que la experiencia de privación de su libertad por motivos políticos haya influido negativamente en su capacidad de entusiasmo y alegría por su existencia.

Calidad de vida: el emisor alude su valoración directa de los efectos percibidos o no de la experiencia de privación de su libertad por motivos políticos, cambios desfavorables en la satisfacción de las necesidades básicas y otras necesarias para vivir favorables para sus vidas. 
No: el emisor niega que la experiencia de privación de su libertad por motivos políticos, haya producido cambios desfavorables en la satisfacción de las necesidades básicas y otras necesarias para vivir favorables para sus vidas.

Características de personalidad: el emisor alude su valoración directa de los efectos percibidos o no de la experiencia de privación de su libertad por motivos políticos, cambios en aspectos de sus diferencias individuales.

No: el emisor niega que la experiencia de privación de su libertad por motivos políticos, haya producido cambios en aspectos de sus diferencias individuales.

\section{Valoración del impacto de prisión en su vida/ Si percibe} Valoración impacto/ Trabajo o estudio/ Si impactó: el emisor afirma que la experiencia de privación de su libertad por motivos políticos afectó en su ocupación laboral o estudiantil.

Cancelación: el emisor afirma que la experiencia de privación de su libertad por motivos políticos fue causa de su despido laboral o cancelación de matrícula estudiantil.

Condiciones desfavorables: el emisor afirma que la experiencia de privación de libertad por motivos políticos fue causa de cambios negativos en su actividad laboral o estudiantil.

Inestabilidad: el emisor afirma que la experiencia de privación de libertad por motivos políticos fue causa de un constante peligro de perder el trabajo o los estudios.

Imposibilidad trabajo por antecedentes penales: el emisor afirma que la experiencia de privación de libertad por motivos políticos le imposibilitó realizar actividad laboral alguna, porque la experiencia de prisión quedó marcado en su hoja de vida.

Economía/ Si: el emisor afirma que la experiencia de privación de su libertad por motivos políticos haya afectado en sus bienes.

Salud/ Refiere enfermedad asociada: el emisor valora de manera directa como uno de los efectos percibidos de la experiencia de privación de su libertad por motivos políticos, el funcionamiento anormal de sus condiciones físicas y psíquicas, en el período previo y posterior a la reclusión.

Traspaso del trauma/ Si percibe: el emisor alude su valoración directa de los efectos que percibe de la experiencia de privación de su libertad por motivos políticos en el traspaso de su afección o trauma causado en prisión, a su descendencia.

Vida: el emisor alude su valoración directa de los efectos percibidos de la experiencia de privación de su libertad por motivos políticos en aspectos de su existencia.

No disfrute de la vida: el emisor alude su valoración directa de los efectos percibidos de la experiencia de privación de su libertad por motivos políticos en la incapacidad para sentir satisfacción por su existencia.

Disfrute de la vida: el emisor alude su valoración directa de los efectos percibidos de la experiencia de privación de su libertad por motivos políticos en el aumento de su capacidad para sentir satisfacción por su existencia.

Ilusión/ Si: el emisor afirma que la experiencia de privación de su libertad por motivos políticos influyó negativamente en su capacidad de entusiasmo y alegría por su existencia.

Calidad de vida/ Si: el emisor afirma que la experiencia de privación de su libertad por motivos políticos, haya producido cambios desfavorables en la satisfacción de las necesidades básicas y otras necesarias para vivir favorables para sus vidas.

Características de personalidad/ Si: el emisor afirma que la experiencia de privación de su libertad por motivos políticos, produjo cambios en aspectos de sus diferencias individuales. 


\section{Valoración del impacto de prisión en relaciones interpersonales/ No percibe cambios (a)}

Relaciones interpersonales: el emisor alude su apreciación directa de los efectos de la experiencia de privación de su libertad por motivos políticos en su relación con las personas.

Familia: el emisor alude su valoración directa de los efectos que percibe o no de la experiencia de privación de su libertad por motivos políticos en su relación con la familia**.

Pareja: el emisor alude su valoración directa de los efectos que percibe o no de la experiencia de privación de su libertad por motivos políticos en su relación con la pareja**.

No percibe cambios: el emisor niega percibir efecto alguno de la experiencia de privación de libertad por motivos políticos en su relación con la pareja**.

Hijos: el emisor alude su valoración directa de los efectos percibidos o no de la experiencia de privación de su libertad por motivos políticos en su relación con los hijos**.

No percibe cambios: el emisor niega percibir efecto alguno de la experiencia de privación de libertad por motivos políticos en su relación con los hijos**.

Amigos: el emisor alude su valoración directa de los efectos percibidos o no de la experiencia de privación de su libertad por motivos políticos en su relación con los amigos**.

No percibe cambios: el emisor niega percibir efecto alguno de la experiencia de privación de libertad por motivos políticos en su relación con los amigos**.

Laborales o estudiantiles: el emisor alude su valoración directa de los efectos percibidos o no de la experiencia de privación de su libertad por motivos políticos en sus relaciones con quienes eran sus compañeros de trabajo o de estudio en el período previo y posterior a la reclusión.

Las mismas: el emisor afirma que sus relaciones interpersonales de trabajo o estudio previas a la experiencia de prisión, sufrieron o no cambios producto de ésta.

Si: el emisor afirma que sus relaciones interpersonales de trabajo o estudio previas a la experiencia de prisión, sufrieron cambios producto de ésta.

Más distantes: el emisor afirma o niega que sus relaciones interpersonales de trabajo o estudio previas a la experiencia de prisión, se volvieron producto de ésta, más alejadas.

No: el emisor niega que sus relaciones interpersonales de trabajo o estudio previas a la experiencia de prisión, se volvieron producto de ésta, más alejadas.

Se perdieron: el emisor afirma o niega que sus relaciones interpersonales de trabajo o estudio previas a la experiencia de prisión, cambiaron producto de ésta, con el cese de estas relaciones.

No: el emisor niega que sus relaciones interpersonales de trabajo o estudio previas a la experiencia de prisión, cambiaron producto de ésta, con el cese de estas relaciones.

Compañeros: el emisor alude su valoración directa de los efectos percibidos o no de la experiencia de privación de su libertad por motivos políticos en sus relaciones con sus compañeros**, en el período previo y posterior a la reclusión.

No percibe cambios: el emisor niega percibir efecto alguno de la experiencia de privación de libertad por motivos políticos en su relación con los compañeros**.

Fuente de protección: el emisor afirma o niega que sus relaciones interpersonales de trabajo o estudio previas a la experiencia de prisión, cambiaron producto de ésta, volviéndose un medio de resguardo. 
No: el emisor niega que sus relaciones interpersonales de trabajo o estudio previas a la experiencia de prisión, cambiaron producto de ésta, volviéndose un medio de resguardo.

Fuente de peligro: el emisor afirma o niega que sus relaciones interpersonales de trabajo o estudio previas a la experiencia de prisión, cambiaron producto de ésta, volviéndose un riesgo para su vida.

No: el emisor niega que sus relaciones interpersonales de trabajo o estudio previas a la experiencia de prisión, cambiaron producto de ésta, volviéndose un riesgo para su vida.

Fuente de apoyo: el emisor afirma o niega que sus relaciones interpersonales de trabajo o estudio previas a la experiencia de prisión, cambiaron producto de ésta, volviéndose una ayuda para él.

No: el emisor niega que sus relaciones interpersonales de trabajo o estudio previas a la experiencia de prisión, cambiaron producto de ésta, volviéndose una ayuda para él.

Identidad: el emisor alude su valoración directa de los efectos percibidos o no de la experiencia de privación de su libertad por motivos políticos en su relación consigo mismo, en el período previo y posterior a la reclusión.

No: el emisor niega percibir efectos de la experiencia de privación de su libertad por motivos políticos en su relación consigo mismo, en el período previo y posterior a la reclusión.

\section{Valoración del impacto de prisión en relaciones interpersonales/ Si percibe cambios (a)}

Relaciones interpersonales/ Familia/ Pareja/ Si percibe cambios: el emisor afirma percibir efectos de la experiencia de privación de libertad por motivos políticos en su relación con la pareja**.

Negativos: el emisor afirma percibir efectos negativos de la experiencia de privación de libertad por motivos políticos en su relación con la pareja**.

Positivos: el emisor afirma percibir efectos positivos de la experiencia de privación de libertad por motivos políticos en su relación con la pareja**.

Hijos/ Si percibe cambios: el emisor afirma percibir efectos de la experiencia de privación de libertad por motivos políticos en su relación con los hijos**.

Causas: el emisor alude los motivos que produjeron los efectos que percibió de la experiencia de privación de libertad por motivos políticos en su relación con los hijos**.

Ausencia: el emisor alude como motivo de los efectos que percibió de la experiencia de privación de libertad por motivos políticos en su relación con los hijos**, el período de abandono inevitable ocurrido durante la experiencia de cautiverio.

Precariedad: el emisor alude como motivo de los efectos que percibió de la experiencia de privación de libertad por motivos políticos en su relación con los hijos**, la carencia de recursos económicos a la que la familia se vio expuesta durante el período de cautiverio y/ o el período posterior.

Separación: el emisor alude como motivo de los efectos que percibió de la experiencia de privación de libertad por motivos políticos en su relación con los hijos**, la separación que vivieron éstos entre sí y el, por verse vistos en la necesidad de ser cuidados por otras personas durante el período de cautiverio del emisor.

Efectos: alusión al tipo de impacto específico percibido de la experiencia de prisión en la relación del emisor con sus hijos**.

Transmisión trauma: el emisor percibe como impacto de su experiencia de prisión en su relación con los hijos**, el traspaso del trauma que indirectamente afirma haber sufrido por la experiencia de prisión. 
Diferente ideología política: el emisor percibe como impacto de su experiencia de prisión en su relación con los hijos**, la preferencia política de éstos distinta a la suya.

Imposibilidad educación: el emisor percibe como impacto de su experiencia de prisión en su relación con los hijos**, el no haberles podido costear los estudios de éstos.

Valoración global: apreciación general del impacto percibido de su experiencia de prisión en su relación con los hijos**.

Negativa: el emisor aprecia a modo general de manera desfavorable el impacto que percibe de la experiencia de prisión en su relación con sus hijos**.

Positiva: el emisor aprecia a modo general de manera favorable el impacto que percibe de la experiencia de prisión en su relación con sus hijos**.

Amigos/ Si percibe cambios: el emisor afirma percibir efectos de la experiencia de privación de libertad por motivos políticos en su relación con los amigos**.

Negativos: el emisor aprecia a modo general de manera desfavorable el impacto que percibe de la experiencia de prisión en su relación con sus amigos**.

Positivos: el emisor aprecia a modo general de manera favorable el impacto que percibe de la experiencia de prisión en su relación con sus amigos**.

Laborales o estudiantiles/ Las mismas/ No: el emisor niega que sus relaciones interpersonales de trabajo o estudio previas a la experiencia de prisión, sufrieron cambios producto de ésta.

Laborales o estudiantiles/ Más distantes/ Si: el emisor afirma que sus relaciones interpersonales de trabajo o estudio previas a la experiencia de prisión, se volvieron producto de ésta, más alejadas.

Laborales o estudiantiles/ Se perdieron/ Si: el emisor afirma que sus relaciones interpersonales de trabajo o estudio previas a la experiencia de prisión, cambiaron producto de ésta, con el cese de estas relaciones.

Fuente de protección/ Si: el emisor afirma que sus relaciones interpersonales de trabajo o estudio previas a la experiencia de prisión, cambiaron producto de ésta, volviéndose un medio de resguardo.

Fuente de peligro/ Si: el emisor afirma que sus relaciones interpersonales de trabajo o estudio previas a la experiencia de prisión, cambiaron producto de ésta, volviéndose un riesgo para su vida.

Fuente de apoyo/ Si: el emisor afirma que sus relaciones interpersonales de trabajo o estudio previas a la experiencia de prisión, cambiaron producto de ésta, volviéndose una ayuda para él.

Compañeros/ Si percibe cambios: el emisor afirma percibir efectos de la experiencia de privación de libertad por motivos políticos en su relación con los compañeros**.

Negativos: el emisor aprecia a modo general de manera desfavorable el impacto que percibe de la experiencia de prisión en su relación con sus compañeros**.

Positivos: el emisor aprecia a modo general de manera favorable el impacto que percibe de la experiencia de prisión en su relación con sus compañeros**.

Identidad/ Si: el emisor afirma percibir efectos de la experiencia de privación de su libertad por motivos políticos en su relación consigo mismo, en el período previo y posterior a la reclusión.

*Nota: las variables que se presentan en la letra (b), (c) y (d), son extraídas de la tabla precedente. 


\section{Valoración del impacto de prisión en relaciones interpersonales/Si percibe cambios/ Familia (b)}

\section{Cambios Positivos}

Relaciones interpersonales/ Familia/ Pareja/ Si percibe cambios **.

Positivos**.

Hijos/ Valoración global **.

Positiva ${ }^{* *}$.

\section{Cambios negativos}

Relaciones interpersonales/ Familia/ Pareja/ Si percibe cambios Negativos **.

Hijos/ Si percibe cambios **.

Causas **.

Ausencia **.

Precariedad ${ }^{* *}$.

Separación ${ }^{* *}$.

Efectos **.

Transmisión trauma ${ }^{* *}$.

Diferente ideología política ${ }^{* *}$.

Imposibilidad educación **.

Valoración global/ Negativa **.

Valoración del impacto de prisión en relaciones interpersonales/Si percibe cambios/Amigos (c)

Cambios positivos

Amigos/ Si percibe cambios/ Negativos ${ }^{* *}$.

Cambios negativos

Amigos/ Si percibe cambios/ Negativos **.

Valoración del impacto de prisión en relaciones interpersonales/ $\mathrm{Si}$ percibe cambios/ Compañeros políticos (d)

Cambios positivos

Compañeros/Si percibe cambios/ Positivos **.

Cambios negativos

Compañeros/Si percibe cambios/ Negativos **.

Temores asociados/ No tiene

Temores asociados: el emisor alude su valoración directa de los efectos percibidos o no de la experiencia de privación de su libertad por motivos políticos, la presencia o ausencia de miedos actuales. 
No presenta: el emisor niega presentar miedos en el presente, asociados a la experiencia de privación de su libertad por motivos políticos.

\section{Temores asociados/ Si tiene}

Temores asociados/ Si presenta: el emisor afirma presentar miedos en el presente, asociados a la experiencia de privación de su libertad por motivos políticos.

A cambios políticos: el emisor afirma presentar producto de la experiencia de privación de su libertad por motivos políticos, miedos a modificaciones que puedan realizarse en el ámbito político.

Cese participación política: el emisor afirma presentar producto de la experiencia de privación de su libertad por motivos políticos, miedo a que por algún motivo deje de trabajar activamente en el ámbito político.

Nueva experiencia prisión: el emisor afirma presentar producto de la experiencia de privación de su libertad por motivos políticos, miedos a la reiteración de esta experiencia.

A uniformados: el emisor afirma presentar producto de la experiencia de privación de su libertad por motivos políticos, miedos a personeros de las fuerzas armadas del gobierno.

A daño familiar: el emisor afirma presentar producto de la experiencia de privación de su libertad por motivos políticos, miedos a que se cause sufrimiento alguno a uno o más integrantes de su familia**.

Muerte por motivos políticos: el emisor afirma presentar producto de la experiencia de privación de su libertad por motivos políticos, miedos a perder la vida por causa de su participación política.

\section{Silencio personal/ No hizo (a)}

Silencio personal: alusión del emisor a mantener en secreto en el presente y/ o pasado, su experiencia de privación de libertad por motivos políticos, aludiendo además en su respuesta al tiempo y con quienes se presentó.

No: el emisor niega haber guardado en secreto su experiencia de privación de libertad por motivos políticos, desde la ocurrencia de esta experiencia.

Relaciones interpersonales: el emisor afirma o niega haber guardado en secreto durante su vida su experiencia de privación de libertad por motivos políticos, con sus relaciones interpersonales**.

Consigo mismo: el emisor afirma o niega haber guardado en secreto durante su vida su experiencia de privación de libertad por motivos políticos, con él mismo. Ej.: evitando recordar, o haciendo "como si" no hubiera ocurrido la experiencia.

No: el emisor niega haber guardado en secreto durante su vida su experiencia de privación de libertad por motivos políticos, con él mismo.

Pareja: el emisor afirma o niega haber guardado en secreto durante su vida su experiencia de privación de libertad por motivos políticos, con su pareja**.

No: el emisor niega haber guardado en secreto durante su vida su experiencia de privación de libertad por motivos políticos, con su pareja**.

Hijos: el emisor afirma o niega haber guardado en secreto durante su vida su experiencia de privación de libertad por motivos políticos, con sus hijos**.

No: el emisor niega haber guardado en secreto durante su vida su experiencia de privación de libertad por motivos políticos, con sus hijos**.

Familia origen: el emisor afirma o niega haber guardado en secreto durante su vida su experiencia de privación de libertad por motivos políticos, con integrantes de su familia de origen**. 
No: el emisor niega haber guardado en secreto durante su vida su experiencia de privación de libertad por motivos políticos, con integrantes de su familia de origen**.

Amigos: el emisor afirma o niega haber guardado en secreto durante su vida su experiencia de privación de libertad por motivos políticos, con sus amigos**.

No: el emisor niega haber guardado en secreto durante su vida su experiencia de privación de libertad por motivos políticos, con sus amigos**.

Compañeros trabajo - estudio: el emisor afirma o niega haber guardado en secreto durante su vida su experiencia de privación de libertad por motivos políticos, con quienes han sido y/ o son sus compañeros de trabajo o estudio**.

No: el emisor niega haber guardado en secreto durante su vida su experiencia de privación de libertad por motivos políticos, con quienes han sido y/ o son sus compañeros de trabajo o estudio**.

Con sociedad: el emisor afirma o niega haber guardado en secreto durante su vida su experiencia de privación de libertad por motivos políticos, con el grupo de personas que conviven y se relacionan dentro del mismo espacio y ámbito cultural del territorio chileno.

No: el emisor niega haber guardado en secreto durante su vida su experiencia de privación de libertad por motivos políticos, con el grupo de personas que conviven y se relacionan dentro del mismo espacio y ámbito cultural del territorio chileno.

\section{Silencio personal/ Si hizo (a)}

Silencio personal/ Si: el emisor afirma haber guardado en secreto su experiencia de privación de libertad por motivos políticos, desde la ocurrencia de esta experiencia.

Tiempo: el emisor afirma haber guardado en secreto su experiencia de privación de libertad por motivos políticos, y alude el período de tiempo en función del Informe Valech**.

Desde prisión hasta presente: el emisor afirma haber guardado en secreto su experiencia de privación de libertad por motivos políticos, desde la ocurrencia de los hechos hasta la actualidad.

Desde prisión hasta antes I.V.: el emisor afirma haber guardado en secreto su experiencia de privación de libertad por motivos políticos, desde la ocurrencia de los hechos y hasta un momento anterior a la emisión del Informe valech**.

Desde prisión hasta I.V.: el emisor afirma haber guardado en secreto su experiencia de privación de libertad por motivos políticos, desde la ocurrencia de los hechos y hasta en momento de emisión del Informe Valech**.

Relaciones interpersonales/ Consigo mismo/ Si: el emisor afirma haber guardado en secreto durante su vida su experiencia de privación de libertad por motivos políticos, con él mismo.

Pareja/ Si: el emisor afirma haber guardado en secreto durante su vida su experiencia de privación de libertad por motivos políticos, con su pareja**.

Hijos/ Si: el emisor afirma haber guardado en secreto durante su vida su experiencia de privación de libertad por motivos políticos, con sus hijos**.

Familia origen/ Si: el emisor afirma haber guardado en secreto durante su vida su experiencia de privación de libertad por motivos políticos, con integrantes de su familia de origen**.

Amigos/ Si: el emisor afirma haber guardado en secreto durante su vida su experiencia de privación de libertad por motivos políticos, con sus amigos**.

Compañeros trabajo - estudio/ Si: el emisor afirma haber guardado en secreto durante su vida su experiencia de privación de libertad por motivos políticos, con quienes han sido y/ o son sus compañeros de trabajo o estudio**. 
Con sociedad/ Si: el emisor afirma haber guardado en secreto durante su vida su experiencia de privación de libertad por motivos políticos, con el grupo de personas que conviven y se relacionan dentro del mismo espacio y ámbito cultural del territorio chileno.

Causas: motivos por los que el emisor afirma haber mantenido en secreto su experiencia de privación de libertad por motivos políticos.

Temor: el emisor afirma que mantuvo en secreto la experiencia de privación de libertad por motivos políticos por el miedo que la experiencia le suscitaba y/ o suscita.

Protección: el emisor afirma que mantuvo en secreto la experiencia de privación de libertad por motivos políticos por considerar que esta opción permitía el resguardo de las personas.

Vergüenza: el emisor afirma que mantuvo en secreto la experiencia de privación de libertad por motivos políticos por el apocamiento sufrido.

Negación: el emisor afirma que mantuvo en secreto la experiencia de privación de libertad por su actitud de hacer como que no vivió la experiencia.

Miedo al rechazo: el emisor afirma que mantuvo en secreto la experiencia de privación de libertad por motivos políticos por su temor a ser despreciado.

Menoscabo: el emisor afirma que mantuvo en secreto la experiencia de privación de libertad por motivos políticos por el deterioro percibido de la experiencia.

Consecuencias: efectos percibidos por el emisor de el secreto que mantuvo y/ o mantiene de su experiencia de privación de libertad por motivos políticos.

No percibe: el emisor no considera que el secreto que mantuvo y/ o mantiene de la experiencia de privación de libertad por motivos políticos, produjo efectos en sus relaciones con otras personas y/ o su vida.

Si percibe: el emisor considera que el secreto que mantuvo y/ o mantiene de la experiencia de privación de libertad por motivos políticos, produjo efectos en sus relaciones con otras personas y/ o su vida.

Negativas: el emisor considera que el secreto que mantuvo y/ o mantiene de la experiencia de privación de libertad por motivos políticos, produjo efectos desfavorables en sus relaciones con otras personas y/ o su vida.

Positivas: el emisor considera que el secreto que mantuvo y/ o mantiene de la experiencia de privación de libertad por motivos políticos, produjo efectos favorables en sus relaciones con otras personas y/ o su vida.

Silencio personal/ Relaciones interpersonales (b)

*Nota: las variables que se presentan en la letra (b), son extraídas de la tabla precedente.

No hizo

\begin{tabular}{|l|}
\hline Pareja** \\
\hline Hijos** \\
\hline Familia origen** \\
\hline Amigos** \\
\hline Compañeros de trabajo** \\
\hline Con sociedad** \\
\hline
\end{tabular}

Si hizo

\begin{tabular}{|l|}
\hline Pareja $^{* *}$ \\
\hline Fijos** $^{* *}$ \\
\hline Amigos $^{* *}$ \\
\hline
\end{tabular}


Compañeros de trabajo**

Con sociedad**

\section{Valoración de superación de experiencia/ No}

Tortura y violencia: alusiones indirectas del emisor que refieren el haber o no padecido malos tratos y tortura en prisión.

Valoración superación experiencia: el emisor refiere haber o no vencido las dificultades producidas en su vida por la experiencia de hechos de tortura y malos tratos vividos cuando fue privado de su libertad por motivos políticos.

No: el emisor refiere no haber vencido las dificultades producidas en su vida por la experiencia de hechos de tortura y malos tratos vividos cuando fue privado de su libertad por motivos políticos.

\section{Valoración de superación de experiencia/ Si}

Tortura y violencia/ Valoración superación experiencia/ Si: el emisor refiere haber vencido las dificultades producidas en su vida por la experiencia de hechos de tortura y malos tratos vividos cuando fue privado de su libertad por motivos políticos.

\section{Apoyo recibido post-prisión/ No tuvo}

Apoyo post-prisión: alusión del emisor de haber contado o no con el soporte emocional y social de otras personas para superar la experiencia.

No tuvo: el emisor refiere no haber contado con persona alguna que le haya otorgado soporte emocional y social para superar la experiencia.

\section{Apoyo recibido post-prisión/ Si tuvo}

Apoyo post-prisión/ Si tuvo: el emisor refiere haber contado con persona alguna que le haya otorgado soporte emocional y social para superar la experiencia.

\section{Rechazo percibido post-prisión/ No percibe}

Rechazo post-prisión: alusión del emisor de haber percibido la no aceptación de una o más personas producto de la experiencia.

No percibe: el emisor niega haber percibido la no aceptación de una o más personas producto de la experiencia.

\section{Rechazo percibido post-prisión/ Si percibe}

Rechazo post-prisión/ Si percibe: el emisor afirma haber percibido la no aceptación de una o más personas producto de la experiencia.

\section{- OTRAS VALORACIONES}

\section{Persecución política/ No (a)}

otras valoraciones: valoración de factores contextuales acontecidos con posterioridad a la experiencia de prisión y asociados no a la experiencia de prisión en sí, pero si a la condición de EXPPS. Estos factores corresponden a la experiencia de acoso por personeros de gobierno, los juicios acerca del gobierno militar y sus ejecutores, las medidas gubernamentales de reparación, la percepción de la sociedad chilena y su respuesta ante las violaciones a los 
derechos humanos acontecidas en chile durante el régimen militar, y la opinión del hecho de expulsión del país de chilenos por motivos políticos.

Persecución política: alusiones del emisor que refieren o no haber sido víctima de acoso por motivos políticos por parte de personeros del gobierno militar.

No: el emisor niega haber sido víctima de acoso por motivos políticos por parte de personeros del gobierno militar.

\section{Persecución política/ Si (a)}

otras valoraciones/ Persecución política/ Si: el emisor afirma haber sido víctima de acoso por motivos políticos por parte de personeros del gobierno militar.

Momento: el emisor afirma haber sido víctima de acoso por motivos políticos por parte de personeros del gobierno militar y especifica el momento en que éste ocurrió en su vida.

Pre-prisión: el emisor afirma haber sido víctima de acoso por motivos políticos por parte de personeros del gobierno militar o a personas que asocia a éste, en el período que antecedió su privación de libertad por motivos políticos.

Post-prisión: el emisor afirma haber sido víctima de acoso por motivos políticos por parte de personeros del gobierno militar o personas que asocia a éste, en el período posterior a su privación de libertad por motivos políticos y durante el régimen militar.

Presente: el emisor afirma ser víctima de acoso por motivos políticos por parte de personeros del gobierno militar o a personas que asocia a éste, en la actualidad.

Área: el emisor alude al ámbito de su vida en que ha sido o es víctima de acoso por motivos políticos por parte de personeros del gobierno militar o personas que asocia a éste.

Laboral: el emisor afirma haber sido o ser víctima de acoso por motivos políticos por parte de personeros del gobierno militar o a personas que asocia a éste, y que afectaron directamente su actividad laboral.

Listas negras: el emisor afirma haber sido o ser víctima de acoso por motivos políticos por parte de personeros del gobierno militar o a personas que asocia a éste, en su lugar de trabajo, formando parte de nóminas que transitaban por las empresas gubernamentales y cuyos nombres estaban vetados por el gobierno para trabajar.

Amenazas anónimas: afirma haber sido o ser víctima de acoso por motivos políticos por parte de personeros del gobierno militar o a personas que asocia a éste, consistente en la recepción de mensajes sin autoría y que buscaban amedrentar y sembrar temor al emisor. Lo que involucraba su trabajo o eran recibidas en el lugar de éste.

Antecedentes legales: afirma haber sido o ser víctima de acoso por motivos políticos por parte de personeros del gobierno militar o a personas que asocia a éste, en su lugar de trabajo, recibiendo amonestaciones desfavorables para su desempeño y que asocia a la experiencia de prisión.

Familiar: el emisor afirma haber sido o ser víctima de acoso por motivos políticos por parte de personeros del gobierno militar o a personas que asocia a éste, y que afectaron directamente su vida familiar y/ o a integrantes de su núcleo familiar**.

Vigilancia permanente domicilio: el emisor afirma haber sido o ser víctima de acoso por motivos políticos por parte de personeros del gobierno militar o a personas que asocia a éste, cuyos hechos consistieron en la observación continua de su domicilio.

Allanamientos: el emisor afirma haber sido o ser víctima de acoso por motivos políticos por parte de personeros del gobierno militar o a personas que asocia a éste, y que consistió en el registro inesperado y oficial o no de su domicilio. 
Agresión física o verbal: el emisor afirma haber sido o ser víctima de acoso por motivos políticos por parte de personeros del gobierno militar o a personas que asocia a éste, y que consistió en malos tratos hacia su persona e integrantes familiares a nivel físico y verbal.

A familiares: el emisor afirma haber sido o ser víctima de acoso por motivos políticos por parte de personeros del gobierno militar o a personas que asocia a éste, y que afectó directamente a los integrantes de su familia**.

Personal: el emisor afirma haber sido o ser víctima de acoso por motivos políticos por parte de personeros del gobierno militar o a personas que asocia a éste, y que afectaron directamente a su integridad como persona.

Agresión física vía pública: el emisor afirma haber sido o ser víctima de acoso por motivos políticos por parte de personeros del gobierno militar o a personas que asocia a éste, y que consistieron en la recepción de malos tratos físicos en lugares públicos.

Agresión verbal vía pública: el emisor afirma haber sido o ser víctima de acoso por motivos políticos por parte de personeros del gobierno militar o a personas que asocia a éste, y que consistieron en la recepción de malos tratos verbales en lugares públicos.

Detenciones posteriores: el emisor afirma haber sido o ser víctima de acoso por motivos políticos por parte de personeros del gobierno militar o a personas que asocia a éste, y que consistieron en nuevas situaciones de privación de libertad.

Amenazas anónimas: el emisor afirma haber sido o ser víctima de acoso por motivos políticos por parte de personeros del gobierno militar o a personas que asocia a éste, y que consistieron en la recepción de mensajes sin autoría que buscaban amedrentar y sembrar temor al emisor.

Política: el emisor afirma haber sido o ser víctima de acoso por motivos políticos por parte de personeros del gobierno militar o a personas que asocia a éste, y que afectaron directamente su participación política.

Nueva detención: el emisor afirma haber sido o ser víctima de acoso por motivos políticos por parte de personeros del gobierno militar o a personas que asocia a éste, y que consistieron en nuevas situaciones de privación de libertad que le impidieron seguir participando en política.

Ejecutores: el emisor alude específicamente a la persona que le acosó por motivos políticos.

Uniformados: el emisor sostiene que fueron personeros del gobierno militar quienes le acosaron por motivos políticos.

Compañeros de trabajo: el emisor sostiene que fueron sus colegas de trabajo quienes le acosaron por motivos políticos.

Amistades: el emisor sostiene que fueron personas con quienes mantenía vínculos sociales de amistad** quienes le acosaron por motivos políticos.

Vecinos: el emisor sostiene que fue la gente que habitaba próxima a su domicilio quienes le acosaron por motivos políticos.

Afrontamiento: alusión del emisor de su respuesta efectuada ante el acoso político percibido por parte de personeros del gobierno militar o a personas que asocia a éste.

No realiza: el emisor niega haber realizado algún acto en respuesta al acoso político percibido por parte de personeros del gobierno militar o a personas que asocia a éste.

Si realiza: el emisor afirma haber realizado algún acto en respuesta al acoso político percibido por parte de personeros del gobierno militar o a personas que asocia a éste.

Enfrentamiento directo: el emisor afirma haber respondido de manera directa haciendo frente a la persona del gobierno militar o asociada a éste que le acosó por motivos políticos. 
Cambio de ciudad: el emisor afirma haber respondido cambiando su ciudad de residencia como respuesta a las personas del gobierno militar o asociadas a éste, que le acosaron por motivos políticos.

Medidas legales: el emisor afirma haber respondido interponiendo querellas a los responsables del acoso político recibido de personas del gobierno militar o asociadas a éste.

Renuncia: el emisor afirma haber respondido abandonando voluntariamente su ocupación laboral, como respuesta a las personas del gobierno militar o asociadas a éste, que le acosaron por motivos políticos.

\section{Persecución política/ Si/ Momento (b)}

*Nota: las variables que se presentan en la letra (b)y (c), son extraídas de la tabla precedente.

Pre-prisión ${ }^{* *}$.

Post-prisión**.

Presente $^{* *}$.

Persecución política/ Si/ Afrontamiento/ No realiza (c)

Afrontamiento**.

No realiza**.

Persecución política/ Si/ Afrontamiento/ Si realiza (c)

\begin{tabular}{|l|}
\hline Afrontamiento/ Si realiza** \\
\hline Enfrentamiento directo $^{* *}$. \\
\hline Cambio de ciudad $^{* *}$. \\
\hline Medidas legales $^{* *}$. \\
\hline Renuncia $^{* *}$. \\
\hline
\end{tabular}

Régimen militar/ Valoración negativa

Régimen militar: el emisor alude sus valoraciones acerca de los personeros del gobierno que ejecutaron las detenciones y su proceder durante este período gubernamental en Chile (1973-1990).

Valoración aspectos específicos: apreciaciones aludidas por el emisor de aspectos del gobierno militar y de las personas que lo llevaron a cabo.

Proceder régimen: el emisor alude su apreciación de aspectos de la modalidad ejercida por el gobierno militar para gobernar.

Ilegalidad: el emisor valora que las acciones realizadas bajo el régimen militar y como parte de sus estrategias de gobierno, fueron delictivas.

Injusticia: el emisor valora que las acciones realizadas bajo el régimen militar y como parte de sus estrategias de gobierno, fueron delictivas.

Caos: el emisor valora que las acciones realizadas bajo el régimen militar y como parte de sus estrategias de gobierno, fueron desorganizadas y desconcertantes.

Error: el emisor valora que las acciones realizadas bajo el régimen militar y como parte de sus estrategias de gobierno, fueron una equivocación.

Sistematización: el emisor valora que las acciones realizadas bajo el régimen militar y como parte de sus estrategias de gobierno, fueron planeadas. Ejecutores: alusión a la lectura que el emisor realiza de los personeros del gobierno del régimen militar que ejercieron violencia y tortura por motivos políticos. 
Desequilibrados: el emisor valora que los personeros de las fuerzas armadas del gobierno de chile que ejecutaron hechos de violencia y tortura eran personas que no estaban en su sano juicio.

Drogodependientes: el emisor valora que los personeros de las fuerzas armadas del gobierno de chile que ejecutaron hechos de violencia y tortura eran personas que padecían adicción a drogas.

Alcohólicos: el emisor valora que los personeros de las fuerzas armadas del gobierno de chile que ejecutaron hechos de violencia y tortura eran personas que padecían adicción a bebidas alcohólicas.

Perversos: el emisor valora que los personeros de las fuerzas armadas del gobierno de chile que ejecutaron hechos de violencia y tortura eran personas malignas.

Inexplicable: el emisor valora que no puede hacer una lectura razonable de las acciones que realizaron personeros de las fuerzas armadas del gobierno de chile en cuanto a la ejecución de hechos de violencia y tortura.

Enfermos: el emisor valora que los personeros de las fuerzas armadas del gobierno de chile que ejecutaron hechos de violencia y tortura eran personas que no funcionaban normalmente a nivel físico y psíquico.

objetivo percibido: lectura que el emisor otorga a los propósitos que el régimen militar buscaba conseguir con sus acciones políticas durante su mandato.

Anular: el emisor afirma que el régimen militar buscaba con su accionar conseguir incapacitar a los opositores.

Excluir: el emisor afirma que el régimen militar buscaba con su accionar conseguir descartar a los opositores de su rol en la sociedad.

Exterminar: el emisor afirma que el régimen militar buscaba con su accionar conseguir acabar con la vida de los opositores.

Represión: el emisor afirma que el régimen militar buscaba con su accionar conseguir contener, detener o castigar mediante el empleo de acciones violentas a los opositores.

Resultado percibido: lectura que el emisor otorga a los efectos alcanzados por el régimen militar mediante sus acciones políticas durante su mandato.

Anulación: el emisor percibe como efectos de las acciones políticas realizadas por el régimen militar durante su mandado, la incapacidad lograda en la vida de los opositores.

Exclusión: el emisor percibe como efectos de las acciones políticas realizadas por el régimen militar durante su mandado, la incapacidad lograda en la vida de opositores.

Exterminio: el emisor percibe como efectos de las acciones políticas realizadas por el régimen militar durante su mandado, el cese de la vida de opositores.

Temor sociedad: el emisor percibe como efectos de las acciones políticas realizadas por el régimen militar durante su mandado, una respuesta social en Chile caracterizada por el miedo hacia los representantes del régimen militar.

Represión: el emisor percibe como efectos de las acciones políticas realizadas por el régimen militar durante su mandado, la contención, detención y el castigo de los opositores.

Condiciones desfavorables de vida: el emisor percibe como efectos de las acciones políticas realizadas por el régimen militar durante su mandado, cambios negativos que afectaron en la calidad de vida y la satisfacción de las necesidades básicas** de los opositores.

Condiciones desfavorables de trabajo: el emisor percibe como efectos de las acciones políticas realizadas por el régimen militar durante su mandado, cambios negativos que afectaron en la situación laboral de los opositores. 


Daño familiar: el emisor percibe como efectos de las acciones políticas
realizadas por el régimen militar durante su mandado, el perjuicio a los
integrantes de su grupo familiar**.

Influencias: lectura que el emisor otorga a factores que sustentaron el poder del régimen militar y al poder percibido en el tiempo de este gobierno en el presente.

EEUU: el emisor sostiene que el régimen militar recibió apoyo de los Estados Unidos para su gobierno.

otros países: el emisor sostiene que el régimen militar recibió apoyo de países excluyendo los Estados Unidos para su gobierno.

Actualidad: lectura que el emisor otorga al poder que el accionar del régimen militar perdura o no en la actualidad chilena.

No presenta influencias: el emisor niega que el régimen militar ejerza poder alguno en la actualidad chilena.

Si presenta influencias: el emisor afirma que el régimen militar ejerce poder en la actualidad chilena. *Nota: las categorías "influencias" precedentes, fueron excluidas de los
resultados.

\section{Reparación/ Valoración de etapas de Informe Valech/ Satisfacción}

Reparación: valoraciones emitidas por el emisor de su satisfacción e insatisfacción con el proceder y las medidas que el gobierno de chile ha entregado a las víctimas de privación de libertad y tortura por motivos políticos mediante la ley Valech, para compensar los perjuicios causados durante el régimen militar.

Informe valech: valoraciones emitidas por el emisor de su satisfacción e insatisfacción con distintos aspectos del Informe sobre prisión política y tortura emitido por el gobierno de Chile para las víctimas de estos hechos.

Etapas: valoraciones emitidas por el emisor de su satisfacción e insatisfacción con las fases que la comisión que elaboró el Informe Valech realizó para establecer la nómina oficial de víctimas chilenas.

Convocatoria: valoraciones emitidas por el emisor de su satisfacción e insatisfacción con la fase de comunicación oficial del inicio del proceso evaluativo que realizaría la comisión valech para establecer la nómina oficial de víctimas chilenas

Satisfecho: el emisor valora positivamente la fase de comunicación oficial que realizó la comisión valech para dar a conocer el período de tiempo que duró el proceso de evaluación y establecimiento de la nómina oficial de víctimas chilenas. Esto por considerar que abarcó a todas las víctimas.

Evaluación: valoraciones emitidas por el emisor de su satisfacción e insatisfacción con la fase de estimación de las personas que la comisión Valech de la nómina oficial de víctimas chilenas.

Satisfecho: el emisor valora positivamente la fase de comunicación oficial que realizó la comisión valech para determinar la nómina oficial de víctimas chilenas.

Difusión: valoraciones emitidas por el emisor de su satisfacción e insatisfacción con la forma en que la comisión Valech puso en conocimiento a la luz pública, la nómina oficial de víctimas chilenas.

Satisfecho: el emisor valora positivamente la forma en que la comisión Valech puso en conocimiento a la luz pública, la nómina oficial de víctimas chilenas. 
Reconocimiento oficial: el emisor valora positivamente la forma en que la comisión valech puso en conocimiento a la luz pública, la nómina oficial de víctimas chilenas. Esto, por haber sido reconocidos por el gobierno de chile.

Conocimiento mundial: el emisor valora positivamente la forma en que la comisión Valech puso en conocimiento a la luz pública, la nómina oficial de víctimas chilenas. Esto, por considerar que permitió que personas de todo el mundo se enteraran de la prisión y tortura por motivos políticos ocurridas durante el régimen militar.

\section{Reparación/ Valoración de etapas de Informe Valech/ Insatisfacción}

Reparación/ Informe Valech/ Etapas/ Convocatoria/ Insatisfecho: el emisor valora negativamente la fase de comunicación oficial que realizó la comisión Valech para dar a conocer el inicio del proceso de evaluación y establecimiento de la nómina oficial de víctimas chilenas.

Tiempo reducido: el emisor valora negativamente el período de tiempo que se anunció públicamente el inicio del proceso de evaluación y establecimiento de la nómina oficial de víctimas chilenas. Esto, por considerarlo demasiado breve.

Difusión limitada: el emisor valora negativamente la fase de comunicación oficial que realizó la comisión valech para dar a conocer el período de tiempo que duró el proceso de evaluación y establecimiento de la nómina oficial de víctimas chilenas. Esto por considerar que no abarcó a todas las víctimas.

Evaluación/ Insatisfecho: el emisor valora negativamente la fase de comunicación oficial que realizó la comisión valech para determinar la nómina oficial de víctimas chilenas.

Difícil situación: el emisor valora negativamente la fase que la comisión Valech realizó para estimar la nómina oficial de víctimas chilenas. Esto, por considerar que esta fase, fue dificultosa para los EXPPS.

Sentirse juzgado: el emisor valora negativamente la fase que la comisión valech realizó para estimar la nómina oficial de víctimas chilenas. Esto, por considerar que los EXPPS se sintieron negativamente criticados y puestos en duda.

Errores en identificación: el emisor valora negativamente la fase que la comisión Valech realizó para estimar la nómina oficial de víctimas chilenas. Esto, por considerar que se cometieron fallos en la identificación.

Inapropiado: el emisor valora negativamente la fase que la comisión valech realizó para estimar la nómina oficial de víctimas chilenas. Esto, por considerarlo inadecuado.

Difusión/ Insatisfecho: el emisor valora negativamente la forma en que la comisión valech puso en conocimiento a la luz pública, la nómina oficial de víctimas chilenas.

Protección información torturador: el emisor valora negativamente la forma en que la comisión Valech puso en conocimiento a la luz pública, la nómina oficial de víctimas chilenas. Esto, por la confidencialidad de los datos obtenidos resguardado por ley u obtenidos en las entrevistas realizados a los EXPPS de los representantes del gobierno que ejercieron violencia y tortura a prisioneros políticos.

Publicación lista víctimas: el emisor valora negativamente la forma en que la comisión valech puso en conocimiento a la luz pública, la nómina oficial de víctimas chilenas. Esto, por poner en conocimiento público el listado oficial de EXPPS chilenos, según las víctimas, sin su consentimiento. 


\section{Reparación/ Valoración de medidas de Informe Valech/ Satisfacción}

Medidas: valoraciones emitidas por el emisor de su satisfacción e insatisfacción con la disposición de recursos que entregó el Informe Valech para compensar el daño causado a quienes sufrieron la privación de su libertad y/ o tortura por motivos políticos en Chile.

Tipos: alusión específica del emisor a la valoración que realiza en términos de satisfacción e insatisfacción según la naturaleza de los recursos que entregó el Informe valech para compensar el daño causado a quienes sufrieron la privación de su libertad y/ o tortura por motivos políticos en Chile.

Económicas: alusión específica del emisor a la valoración que realiza en términos de satisfacción e insatisfacción de los recursos monetarios que entregó el Informe valech para compensar el daño causado a quienes sufrieron la privación de su libertad y/ o tortura por motivos políticos en Chile.

Satisfecho: el emisor valora positivamente los recursos monetarios que entregó el Informe valech para compensar el daño causado a quienes sufrieron la privación de su libertad y/ o tortura por motivos políticos en Chile.

Estabilidad económica: el emisor valora positivamente los recursos monetarios que entregó el Informe Valech para compensar el daño causado a quienes sufrieron la privación de su libertad y/ o tortura por motivos políticos en Chile. Porque afirma que le han permitido gozar de tranquilidad para satisfacer sus necesidades básicas**.

Mejora condiciones vida: el emisor valora positivamente los recursos monetarios que entregó el Informe Valech para compensar el daño causado a quienes sufrieron la privación de su libertad y/ o tortura por motivos políticos en Chile. Porque considera que ha permitido un aumento de las condiciones favorables de su calidad de vida** y la satisfacción de sus necesidades básicas**.

Salud (PRAIS): alusión específica del emisor a la valoración que realiza en términos de satisfacción e insatisfacción acerca del programa de reparación y ayuda integral en salud y derechos, que entregó el Informe Valech para compensar el daño causado a quienes sufrieron la privación de su libertad y/ o tortura por motivos políticos en Chile.

Satisfecho: el emisor valora positivamente el programa de reparación y ayuda integral en salud $y$ derechos que entregó el Informe valech para compensar el daño causado a quienes sufrieron la privación de su libertad y/ o tortura por motivos políticos en chile.

Servicio salud general: el emisor valora positivamente a modo global toda la asistencia que recibe del programa de reparación y ayuda integral en salud y derechos que entregó el Informe Valech para compensar el daño causado a quienes sufrieron la privación de su libertad y/ o tortura por motivos políticos en chile.

Servicio salud mental: el emisor valora positivamente y de manera específica el la atención que recibe o ha recibido en psicología o psiquiatría del programa de reparación y ayuda integral en salud y derechos que entregó el Informe Valech para compensar el daño causado a quienes sufrieron la privación de su libertad y/ o tortura por motivos políticos en Chile.

Educación: alusión específica del emisor a la valoración que realiza en términos de satisfacción e insatisfacción acerca de las becas de estudio universitarios que entregó el Informe Valech para compensar el daño causado a quienes sufrieron la privación de su libertad y/ o tortura por motivos políticos en Chile.

Satisfecho: el emisor valora positivamente las becas de estudio universitarios que entregó el Informe Valech para compensar el daño causado a quienes sufrieron la privación de su libertad y/ o tortura por motivos políticos en Chile.

Desea estudiar: el emisor valora positivamente las becas de estudio universitarios que entregó el Informe Valech para compensar el daño causado a 
quienes sufrieron la privación de su libertad y/ o tortura por motivos políticos en Chile. Esto, porque tiene interés en iniciar o continuar estudios universitarios.

Vivienda: alusión específica del emisor a la valoración que realiza en términos de satisfacción e insatisfacción acerca de los recursos económicos para la vivienda que entregó el Informe Valech para compensar el daño causado a quienes sufrieron la privación de su libertad y/ o tortura por motivos políticos en Chile.

Satisfecho: el emisor valora positivamente los recursos económicos para la vivienda que entregó el Informe valech para compensar el daño causado a quienes sufrieron la privación de su libertad y/ o tortura por motivos políticos en Chile.

\section{Reparación/ Valoración de medidas de Informe Valech/ Insatisfacción}

Medidas/ Tipos/ Económicas/ Insatisfecho: el emisor valora negativamente los recursos monetarios que entregó el Informe Valech para compensar el daño causado a quienes sufrieron la privación de su libertad y/ o tortura por motivos políticos en chile.

Exclusión jubilación: el emisor valora negativamente los recursos monetarios que entregó el Informe Valech para compensar el daño causado a quienes sufrieron la privación de su libertad y/ o tortura por motivos políticos en Chile. Esto, porque el otorgamiento de la pensión Valech no es compatible con la pensión que recibe una persona cuando cesa su actividad laboral por vejez.

Exclusión beneficios: el emisor valora negativamente los recursos monetarios que entregó el Informe Valech para compensar el daño causado a quienes sufrieron la privación de su libertad y/ o tortura por motivos políticos en Chile. Esto, porque el otorgamiento de la pensión valech no es compatible con otros recursos monetarios que tiene derecho de recibir y que no especifica.

Insuficiente: el emisor valora negativamente los recursos monetarios que entregó el Informe valech para compensar el daño causado a quienes sufrieron la privación de su libertad y/ o tortura por motivos políticos en Chile. Esto, porque considera que no cubren sus gastos básicos de vida.

No heredable: el emisor valora negativamente los recursos monetarios que entregó el Informe Valech para compensar el daño causado a quienes sufrieron la privación de su libertad y/ o tortura por motivos políticos en Chile. Esto, porque al momento de su fallecimiento, no serán traspasadas a su pareja y/ o hijos.

Salud (PRAIS)/ Insatisfecho: el emisor valora negativamente el programa de reparación y ayuda integral en salud y derechos que entregó el Informe Valech para compensar el daño causado a quienes sufrieron la privación de su libertad y/ o tortura por motivos políticos en Chile.

Servicio salud general: el emisor valora negativamente a modo global toda la asistencia que recibe del programa de reparación y ayuda integral en salud y derechos que entregó el Informe valech para compensar el daño causado a quienes sufrieron la privación de su libertad y/ o tortura por motivos políticos en Chile.

Servicio salud mental: el emisor valora negativamente y de manera específica el la atención que recibe o ha recibido en psicología o psiquiatría del programa de reparación y ayuda integral en salud y derechos que entregó el Informe Valech para compensar el daño causado a quienes sufrieron la privación de su libertad y/ o tortura por motivos políticos en Chile.

Educación/ Insatisfecho: el emisor valora negativamente las becas de estudio universitarios que entregó el Informe valech para compensar el daño causado a 
quienes sufrieron la privación de su libertad y/ o tortura por motivos políticos en chile.

No heredable: el emisor valora negativamente las becas de estudio universitarios que entregó el Informe valech para compensar el daño causado a quienes sufrieron la privación de su libertad y/ o tortura por motivos políticos en Chile. Esto, porque no es transferible a los hijos**.

No desea estudiar: el emisor valora negativamente las becas de estudio universitarios que entregó el Informe Valech para compensar el daño causado a quienes sufrieron la privación de su libertad y/ o tortura por motivos políticos en Chile. Esto, porque las considera inapropiadas para él que no tiene interés en iniciar o continuar estudios universitarios.

Vivienda/ Insatisfecho: el emisor valora negativamente los recursos económicos para la vivienda que entregó el Informe Valech para compensar el daño causado a quienes sufrieron la privación de su libertad y/ o tortura por motivos políticos en Chile.

Valoración aspectos/ Subsanan/ No: el emisor niega que las medidas otorgadas con el Informe Valech hayan compensado el daño que la experiencia de privación de libertad por motivos políticos causó en su vida.

Valoración aspectos/ Tardías/ Si: el emisor considera que el tiempo transcurrido entre los hechos de prisión política y la entrega de las medidas otorgadas con el Informe valech aconteció después del tiempo que esperaba.

Valoración aspectos/ Lo posible/ No: el emisor considera que el gobierno no utilizó todos los medios disponibles para establecer las medidas otorgadas del Informe Valech.

Valoración aspectos/ No tienen relación/ Si: el emisor considera que las medidas otorgadas con el Informe valech no corresponden con los daños producidos con la experiencia de privación de libertad por motivos políticos.

Valoración aspectos/ Justas/ No: el emisor considera que las medidas otorgadas con el Informe valech no son equitativas con los daños producidos con la experiencia de privación de libertad por motivos políticos.

Valoración aspectos/ No tienen sentido/ Si: el emisor considera que las medidas otorgadas con el Informe Valech no tienen razón de ser en relación a los daños producidos con la experiencia de privación de libertad por motivos políticos.

Valoración global/ Insatisfecho: el emisor valora negativamente las medidas gubernamentales otorgadas por el gobierno de chile establecidas por la comisión sobre la prisión política y tortura.

\section{Reparación/ Valoración de medidas de Informe Valech/ Satisfacción}

Valoración aspectos: valoración específica aludida por el emisor de asuntos referentes a la reparación otorgada por la Comisión valech.

Subsanan: el emisor alude a la apreciación que hace de las medidas otorgadas con el Informe valech en cuanto a la compensación del daño que la experiencia de privación de libertad por motivos políticos causó en su vida.

Si: el emisor afirma que las medidas otorgadas con el Informe valech hayan compensado el daño que la experiencia de privación de libertad por motivos políticos causó en su vida.

Tardías: el emisor alude a la apreciación que hace de las medidas otorgadas con el Informe valech según el tiempo que tardaron en ser entregadas a sus víctimas.

No: el emisor no considera que el tiempo transcurrido entre los hechos de prisión política y la entrega de las medidas otorgadas con el Informe Valech haya hecho que estas medidas hayan ocurrido después del tiempo que esperaba.

Lo posible: el emisor alude a la apreciación que hace de las medidas otorgadas con el Informe Valech según los medios disponibles del gobierno. 
Si: el emisor considera que el gobierno utilizó todos los medios disponibles para establecer las medidas otorgadas del Informe valech.

No tienen relación: el emisor alude a la apreciación que hace de las medidas otorgadas con el Informe Valech según la correspondencia de éstas con los daños producidos con la experiencia de privación de libertad por motivos políticos.

No: el emisor considera que las medidas otorgadas con el Informe Valech si corresponden con los daños producidos con la experiencia de privación de libertad

Justas: el emisor alude a la apreciación que hace de las medidas otorgadas con el Informe Valech según la equidad que otorga a éstas con los daños producidos con la experiencia de privación de libertad por motivos políticos.

Si: el emisor considera que las medidas otorgadas con el Informe Valech son equitativas con los daños producidos con la experiencia de privación de libertad por motivos políticos.

No tienen sentido: el emisor alude a la apreciación que hace de las medidas otorgadas con el Informe Valech según la razón que les otorga en relación a los daños producidos con la experiencia de privación de libertad por motivos políticos.

No: el emisor considera que las medidas otorgadas con el Informe Valech si tienen razón de ser en relación a los daños producidos con la experiencia de privación de libertad por motivos políticos.

Valoración global: apreciación general del emisor de las medidas de reparación otorgadas por el gobierno de Chile establecidas por la comisión sobre la prisión política y tortura.

Satisfecho: el emisor valora positivamente las medidas gubernamentales otorgadas por el gobierno de Chile establecidas por la comisión sobre la prisión política y tortura, por motivos políticos.

\section{Concepción de reparación/ No existe}

Concepción: alusión al concepto de reparación según la apreciación del rol de las acciones de reparación en sanar los daños causados durante la experiencia de prisión por motivos políticos.

No es posible: el emisor considera que no existe medida de reparación alguna que pueda sanar los daños causados durante la experiencia de prisión por motivos políticos.

\section{Concepción de reparación/ Si existe}

Concepción/ Es posible: el emisor considera que existe una o más medidas de reparación que pueden sanar los daños causados durante la experiencia de prisión por motivos políticos.

\section{Reparación/ Valoración de políticos actuales de izquierda/ Insatisfacción}

Valoración políticos actuales: alusión a la apreciación que el emisor hace de los políticos actuales en chile y el aporte percibido en torno a las medidas gubernamentales de reparación.

De izquierda: alusión a la apreciación que el emisor hace de los políticos actuales de partidos de la izquierda de chile y su aporte percibido en torno a las medidas gubernamentales de reparación.

Insatisfecho: el emisor valora negativamente el aporte que los políticos pertenecientes a partidos de la izquierda chilena han hecho a favor de las medidas gubernamentales de reparación. 


Reparación/ Valoración de políticos actuales de
izquierda/ Satisfacción
$\begin{aligned} & \text { Valoración políticos actuales/ De izquierda/ Satisfecho: el emisor valora } \\ & \text { positivamente el aporte que los políticos pertenecientes a partidos de la } \\ & \text { izquierda chilena han hecho a favor de las medidas gubernamentales de } \\ & \text { reparación. }\end{aligned}$

\section{Reparación y justicia/ No}

Justicia: apreciación del emisor del derecho, razón y equidad con que percibe las medidas gubernamentales de la reparación que goza en la actualidad.

No: el emisor sostiene que no se cumple el derecho, la razón y equidad en las medidas gubernamentales de la reparación que goza en la actualidad.

\section{Reparación y justicia/ Si}

Justicia/ Si: el emisor sostiene que se cumplen el derecho, la razón y equidad en las medidas gubernamentales de la reparación que goza en la actualidad.

\section{Sociedad chilena y derechos humanos/ Insatisfacción}

Sociedad chilena
percepción de la respuesta social chilena en relación a la violación a los
derechos humanos en chile.

Valoración respuesta: apreciaciones del emisor de la percepción que tiene de la respuesta social chilena ante la violación a los derechos humanos ocurrida en Chile durante el régimen militar.

Valoración en tiempo: apreciación de los cambios en el tiempo que el emisor ha percibido en la respuesta social chilena ante la violación a los derechos humanos ocurrida en chile durante el régimen militar.

Cambios: percepción y alusión a cambios en el tiempo de la respuesta social chilena ante la violación a los derechos humanos ocurrida en chile durante el régimen militar.

Negativos: percepción y alusión a cambios en el tiempo, valorados como desfavorables por el emisor de la respuesta social chilena ante la violación a los derechos humanos ocurrida en chile durante el régimen militar.

Influencia Informe Valech: percepción y alusión a cambios en el tiempo, de la respuesta social chilena ante la violación a los derechos humanos ocurrida en chile durante el régimen militar, atribuidos a la presentación del Informe gubernamental sobre prisión política y tortura emitido por el gobierno de chile.

Negativa: el emisor percibe y alude cambios en el tiempo, que valora de manera desfavorable, de la respuesta social chilena ante la violación a los derechos humanos ocurrida en chile durante el régimen militar, atribuidos a la presentación del Informe gubernamental sobre prisión política y tortura emitido por el gobierno de chile.

Beneficios económicos: el emisor percibe y alude cambios en el tiempo, que valora de manera desfavorable, de la respuesta social chilena ante la violación a los derechos humanos ocurrida en chile durante el régimen militar, atribuidos a la presentación del Informe gubernamental sobre prisión política y tortura emitido por el gobierno de chile. Apreciación que fundamenta en la pensión económica vitalicia que reciben del gobierno.

Tendencias: apreciaciones del emisor de la orientación que percibe de la respuesta social chilena ante la violación a los derechos humanos ocurrida en chile durante el régimen militar. 
Desfavorables: apreciaciones negativas del emisor de la orientación que percibe de la respuesta social chilena ante la violación a los derechos humanos ocurrida en chile durante el régimen militar.

Negación: el emisor refiere la tendencia social de creer que no hubo violación a los derechos humanos en chile durante el régimen militar.

Indiferencia: el emisor refiere la tendencia social a presentar un estado de ánimo que refleja ni inclinación ni rechazo ante la violación a los derechos humanos en chile durante el régimen militar.

Olvido: el emisor refiere la tendencia social a dejar de sentir afecto o interés por la violación a los derechos humanos en chile durante el régimen militar.

Apoyo a régimen: el emisor refiere la tendencia social a fundamentar al gobierno militar en la violación a los derechos humanos en chile durante el régimen militar.

Estigmatización: el emisor refiere la tendencia social de marcar con deshonra o mala fama a las víctimas de violación a los derechos humanos en chile durante el régimen militar.

Exclusión social: el emisor refiere la tendencia social de aislar socialmente a las víctimas de violación a los derechos humanos en chile durante el régimen militar.

Desconocimiento: el emisor refiere la tendencia social de ignorar la violación a los derechos humanos en chile durante el régimen militar.

Silencio social: alusión del emisor a la presencia o ausencia por parte de la sociedad chilena a abstenerse de hablar de la violación a los derechos humanos en chile durante el régimen militar.

Presencia: el emisor refiere percibir por parte de la sociedad chilena la abstención de hablar de la violación a los derechos humanos en chile durante el régimen militar.

Valoración aspectos específicos: apreciaciones del emisor de la respuesta social chilena que percibe o no ante aspectos particulares de la violación a los derechos humanos ocurrida en chile durante el régimen militar.

Conoce: el emisor alude a la respuesta social chilena que percibe del conocimiento o desconocimiento de aspectos particulares de la violación a los derechos humanos ocurrida en chile durante el régimen militar.

No: el emisor percibe como respuesta social chilena el desconocimiento de aspectos particulares de la violación a los derechos humanos ocurrida en chile durante el régimen militar.

Ignora: el emisor alude a su percepción de la respuesta social chilena desinteresada o no de la violación a los derechos humanos ocurrida en chile durante el régimen militar.

Si: el emisor afirma percibir una respuesta social chilena desinteresada en la violación a los derechos humanos ocurrida en chile durante el régimen militar.

Sensibilizada: el emisor alude a su percepción de la respuesta social chilena que se conmueve o no, o es perceptible o no a sentimientos de tristeza o dolor por la violación a los derechos humanos ocurrida en chile durante el régimen militar.

No: el emisor alude a su percepción de la respuesta social chilena que no se conmueve, 0 no es perceptible a sentimientos de tristeza o dolor por la violación a los derechos humanos ocurrida en Chile durante el régimen militar.

Rechaza: el emisor alude a su percepción de la respuesta social chilena que acepta o no la violación a los derechos humanos ocurrida en chile durante el régimen militar.

Si: el emisor alude a su percepción de la respuesta social chilena que acepta la violación a los derechos humanos ocurrida en chile durante el régimen militar. 
Se responsabiliza: el emisor alude a su percepción de la respuesta social chilena que se siente o no en la obligación de responder ante la violación a los derechos humanos ocurrida en chile durante el régimen militar.

No: el emisor alude a su percepción de la respuesta social chilena que se siente o no en la obligación de responder ante la violación a los derechos humanos ocurrida en Chile durante el régimen militar.

Teme: el emisor alude a su percepción de la respuesta social chilena que siente o no inquietud y miedo ante las víctimas de violación a los derechos humanos ocurrida en chile durante el régimen militar.

Si: el emisor alude a su percepción de la respuesta social chilena que siente inquietud y miedo ante las víctimas de violación a los derechos humanos ocurrida en Chile durante el régimen militar.

Valoración global: apreciación global del emisor de la respuesta social chilena que percibe de manera favorable o desfavorable ante la violación a los derechos humanos ocurrida en chile durante el régimen militar.

Insatisfecho: apreciación global del emisor de la respuesta social chilena que percibe de manera desfavorable ante la violación a los derechos humanos ocurrida en Chile durante el régimen militar.

Justicia: apreciación del derecho, razón o equidad percibido o no en la respuesta de la sociedad chilena ante la violación a los derechos humanos ocurrida en chile durante el régimen militar.

No: apreciación del derecho, razón o equidad no percibido en la respuesta de la sociedad chilena ante la violación a los derechos humanos ocurrida en chile durante el régimen militar.

\section{Sociedad chilena y derechos humanos/ Satisfacción}

Sociedad chilena y DDHH/ Valoración respuesta/ Valoración en tiempo/ Cambios/ Positivos: percepción y alusión a cambios en el tiempo, valorados como favorables por el emisor de la respuesta social chilena ante la violación a los derechos humanos ocurrida en chile durante el régimen militar.

Influencia Informe Valech/ Positiva: el emisor percibe y alude cambios en el tiempo, que valora de manera desfavorable, de la respuesta social chilena ante la violación a los derechos humanos ocurrida en chile durante el régimen militar, atribuidos a la presentación del Informe gubernamental sobre prisión política y tortura emitido por el gobierno de chile.

Mayor conocimiento: el emisor percibe y alude cambios en el tiempo, que valora de manera favorable, de la respuesta social chilena ante la violación a los derechos humanos ocurrida en chile durante el régimen militar, atribuidos a la presentación del Informe gubernamental sobre prisión política y tortura emitido por el gobierno de Chile; refiriendo que este informe ha permitido que la sociedad chilena haya ampliado su entendimiento acerca del tema.

Tendencias/ Favorables: apreciaciones positivas del emisor de la orientación que percibe de la respuesta social chilena ante la violación a los derechos humanos ocurrida en chile durante el régimen militar.

Reconocimiento: el emisor refiere la tendencia social de valoración positiva a las víctimas de violación a los derechos humanos en chile durante el régimen militar.

Apoyo causa: el emisor refiere la tendencia social de fundamentar los motivos de la militancia política previa a la experiencia de prisión de las víctimas de violación a los derechos humanos en chile durante el régimen militar.

Interés en tema: el emisor refiere la tendencia social de atención e inclinación hacia el tema de la violación a los derechos humanos en chile durante el régimen militar.

Respeto: el emisor refiere la tendencia social de consideración a las víctimas de violación a los derechos humanos en Chile durante el régimen militar. 
Conciencia social: el emisor refiere la tendencia social a conocer y saber el alcance de la violación a los derechos humanos en chile durante el régimen militar.

Silencio social/ Ausencia: el emisor refiere no percibir por parte de la sociedad chilena la abstención de hablar de la violación a los derechos humanos en chile durante el régimen militar.

Valoración aspectos específicos/ Conoce/ Si: el emisor alude a la respuesta social chilena el conocimiento de aspectos particulares de la violación a los derechos humanos ocurrida en chile durante el régimen militar.

Ignora/ No: el emisor niega percibir una respuesta social chilena desinteresada en la violación a los derechos humanos ocurrida en chile durante el régimen militar.

Sensibilizada/ Si: el emisor alude a su percepción de la respuesta social chilena que se conmueve, o es perceptible a sentimientos de tristeza o dolor por la violación a los derechos humanos ocurrida en chile durante el régimen militar.

Rechaza/ No: el emisor alude a su percepción de la respuesta social chilena que no acepta la violación a los derechos humanos ocurrida en chile durante el régimen militar.

Se responsabiliza/ Si: el emisor alude a su percepción de la respuesta social chilena que se siente en la obligación de responder ante la violación a los derechos humanos ocurrida en chile durante el régimen militar.

Teme/ No: el emisor alude a su percepción de la respuesta social chilena que no siente inquietud y miedo ante las víctimas de violación a los derechos humanos ocurrida en chile durante el régimen militar.

Valoración global/ Satisfecho: apreciación global del emisor de la respuesta social chilena que percibe de manera favorable ante la violación a los derechos humanos ocurrida en Chile durante el régimen militar.

Justicia/ Si: apreciación del derecho, razón o equidad percibido en la respuesta de la sociedad chilena ante la violación a los derechos humanos ocurrida en Chile durante el régimen militar.

\section{Opinión de exilio/ Negativa}

Opinión exilio: valoración favorable o desfavorable del emisor de su expulsión del país por motivos políticos (si procede), y/ o de la de otros EXPPS.

De experiencia personal: valoración favorable o desfavorable del emisor de la propia experiencia de expulsión o no del país por motivos políticos.

Valoración negativa: el emisor valora desfavorablemente su experiencia o no de expulsión del país por motivos políticos en su vida.

De compañeros: valoración favorable o desfavorable del emisor de la experiencia de otros EXPPS que vivieron la expulsión o no del país por motivos políticos.

Valoración negativa: el emisor valora desfavorablemente la experiencia de otros EXPPS de expulsión del país por motivos políticos.

\section{Opinión de exilio/ Positiva}

\begin{tabular}{l}
$\begin{array}{l}\text { Opinión exilio/ De experiencia personal/ Valoración positiva: el emisor valora } \\
\text { favorablemente su experiencia o no de expulsión del país por motivos políticos } \\
\text { en su vida. }\end{array}$ \\
$\begin{array}{l}\text { De compañeros/ Valoración positiva: el emisor valora desfavorablemente la la } \\
\text { experiencia de otros EXPPS de expulsión del país por motivos políticos. }\end{array}$ \\
\hline
\end{tabular}


*Nota: Las variables que presentamos a continuación, no han sido agrupadas en ningún tema que presentaremos en el siguiente capítulo, pero algunas de ellas si serán estudiadas individualmente.

\section{Vinculación con imagen de torturador}

Relación torturador: el emisor alude tener o no vinculación alguna con personas que identifica como ejecutores de tortura y malos tratos.

Ninguna: el emisor niega tener vinculación alguna con personas que identifica como ejecutores de tortura y malos tratos.

Si tiene: el emisor afirma tener vinculación alguna con personas que identifica como ejecutores de tortura y malos tratos.

\section{Valoración de superación experiencia}

Valoración superación experiencia: el emisor refiere haber o no vencido las dificultades producidas en su vida por la experiencia de prisión política.

No: el emisor refiere no haber vencido las dificultades producidas en su vida por la experiencia de prisión política.

Si: el emisor refiere haber vencido las dificultades producidas en su vida por la experiencia de prisión política.

\section{Re-traumatización}

Re-traumatización: el emisor refiere presentar lo que en chile se entiende por re-traumatización y que se asocia a la reactivación de una respuesta de estrés post-traumático ocasionada por hechos o recuerdos que el emisor asocia a la experiencia.

No presenta: el emisor refiere no haber reactivado una respuesta de estrés posttraumático ocasionada por hechos o recuerdos que el emisor asocia a la experiencia.

Si presenta: el emisor refiere haber reactivado una respuesta de estrés posttraumático ocasionada por hechos o recuerdos que el emisor asocia a la experiencia.

Acontecer asociado: el emisor refiere haber reactivado una respuesta de estrés post-traumático ocasionada por sucesos políticos posteriores que el emisor asocia a la experiencia.

Informe Valech: el emisor refiere haber reactivado una respuesta de estrés posttraumático ocasionada por alguna de las etapas del Informe gubernamental sobre prisión política y tortura emitido por el gobierno de chile.

\section{Reparación/ Lectura}

Lectura: explicación que el emisor se da a modo general del concepto filosófico de la reparación.

Negativa: el emisor se explica de manera desfavorable y/ o pesimista el concepto de reparación.

Positiva: el emisor se explica de manera favorable y/ u optimista el concepto de reparación.

\section{Reparación/ Valoración políticos actuales de derecha}

\begin{tabular}{l} 
Valoración políticos actuales/ De derecha: alusión a la apreciación que el \\
emisor hace de los políticos actuales de partidos de la derecha de chile y su \\
aporte percibido en torno a las medidas gubernamentales de reparación. \\
\hline Insatisfecho: el emisor valora negativamente el aporte que los políticos \\
pertenecientes a partidos de la derecha chilena han hecho a favor de las medidas \\
gubernamentales de reparación.
\end{tabular}


Satisfecho: el emisor valora positivamente el aporte que los políticos pertenecientes a partidos de la derecha chilena han hecho a favor de las medidas gubernamentales de reparación.

Como podemos observar, todas las categorías demográficas apuntan a antecedentes biográficos de las personas que forman parte de la muestra de la presente investigación doctoral.

Por su parte, el segundo grupo de categorías, hace referencia a los temas que según el modelo teórico que empleamos en este estudio, creemos que nos revelará información acerca del impacto emocional y social de la privación de libertad y tortura por motivos políticos en la muestra estudiada.

Las tres primeras ramas del segundo grupo de categorías, se establecieron a priori. La cuarta la añadimos a medida que fuimos haciendo las entrevistas. Esta última rama, incluyó los siguientes temas que presentamos a continuación:

o Persecución política,

o Régimen militar

o Reparación,

o Sociedad chilena y DDHH, y

o Opinión de exilio

La decisión de añadir estas temáticas, se basó en que eran temas que aparecieron de manera recurrente y espontánea en las entrevistas, por parte de los entrevistados y que tenían relación directa con el tema en estudio. Todo lo que consideramos un aporte desde los propios EXPPS, en su condición de expertos de la temática de nuestra investigación. Fue así como nos fuimos dando cuenta, que las explicaciones ya sea políticas, personales, sociales, etc., que ellos dan a su experiencia, estaban fuertemente enlazadas a estas temáticas.

Consideramos necesario precisar, que a momentos nos pareció demasiado extensas las ramificaciones que se iban configurando del mapa conceptual, sin embargo, dado el carácter exploratorio de nuestro estudio, optamos por mantener aquellas ramificaciones que consideramos interesantes de incluir por estar directa e indirectamente relacionadas a nuestro objeto de estudio. 
Privación de libertad y tortura política en Chile (1973-1990) 


\section{CAPÍTULO V.}

RESULTADOS Y ANÁLISIS. 
Privación de libertad y tortura política en Chile (1973-1990) 
A continuación expondremos los resultados que obtuvimos mediante operaciones realizadas con el programa Nvivo6 (estudio de frecuencias y correlaciones presentadas por temas según sujeto y U.T.s y el cruce de temas), y el programa SPSS versión 15 en español (estudio de diferencias significativas entre variables demográficas y conceptuales aplicando la prueba $\chi^{2}$ de Pearson, y análisis cluster, para describir aquellas agrupaciones que subyacen a las variables que seleccionamos para este análisis).

Dada la magnitud de nuestras variables, nos vimos en la necesidad de reducirlas una vez terminado el proceso de codificación. Para ello, hicimos agrupaciones y que presentamos en el capítulo IV. Los criterios de agrupación, comprendieron el antagonismo de las valoraciones frente a un tema determinado, como satisfacción versus insatisfacción, y positivo versus negativo. La totalidad de variables se presentan en el apéndice D, y su justificación, en el capítulo IV).

Consideraciones previas:

- Todos los resultados que presentaremos a continuación corresponden a un nivel inter-sujeto.

- Analizaremos los datos de las tablas siguientes con el criterio de la moda y en algunos casos además la media.

- Los datos que resumimos en las tablas que presentamos a continuación, han sido obtenidos mediante la sumatoria de datos binarios en que $1=$ presente, $\mathrm{y} 0=$ ausente.

- Los porcentajes que presentaremos en las tablas, serán en relación al 100\% de la muestra, y en las variables demográficas cuando las frecuencias para una categoría sean inferiores al 100\%, incluiremos estos porcentajes en relación al 100\% del N de la categoría.

a Excluimos de los resultados que presentamos en esta sección, los valores obtenidos para las categorías no especificadas de los distintos temas.

- Referencias temporales como pasado o pre-prisión, indican el período previo a la experiencia de prisión que incluye las horas, días y semanas anteriores; post-prisión refiere el tiempo transcurrido desde que el EXPP fue puesto en libertad, hasta el término del régimen militar en marzo de 1990; y presente, indica el momento en que realizamos la entrevista en profundidad.

- Por último, el orden de presentación general del contenido de las tablas que presentamos a continuación, está conformado en la primera columna por los valores obtenidos, y en la primera fila, por las categorías de clasificación del estudio. 
El orden de presentación de los resultados será el siguiente:

Parte I. Antecedentes demográficos presentados en frecuencias y porcentajes.

Parte II. Frecuencias de los grandes temas que conforman el mapa conceptual y abarcan el total de los nudos hijos.

Parte III. Frecuencias de las sumatorias de nudos hijos (hojas del árbol de categorías, o categorías más específicas del mapa conceptual).

Parte IV. Resultados del estudio sintáctico de palabras y del cruce de éstas, asociadas al impacto en estudio.

Parte V. Respuestas a preguntas de investigación que planteamos en base a la teoría que sustenta nuestro estudio.

Parte VI. Análisis estadístico mediante la aplicación de la prueba de $\chi^{2}$ de Pearson para las variables demográficas sexo, edad y ubicación geográfica en relación a variables conceptuales seleccionadas.

Parte VII. Análisis cluster de variables agrupadas y seleccionadas.

Parte VIII. Análisis de la metodología empleada.

\subsection{PARTE I. ANTECEDENTES DEMOGRÁFICOS PRESENTADOS EN FRECUENCIAS Y PORCENTAJES.}

Tabla 3. Antecedentes demográficos de sexo, edad y zona geográfica

\begin{tabular}{||c|c|c|c|c|c||}
\hline \hline \multicolumn{2}{|c|}{ SEXO N $=60$} & \multicolumn{2}{c|}{ EDAD N =60 } & \multicolumn{2}{c|}{ ZONA GEOGRÁFICA } \\
& Femenino & $\begin{array}{c}\text { Menor de } \\
\text { 65años }\end{array}$ & Desde 65 años & Regiones & Capital \\
\hline Masculino & 19 & $\underline{\mathbf{9}}$ & 11 & $\underline{\mathbf{4 8}}$ & 12 \\
\hline$\underline{\mathbf{4 1}}$ & $32 \%$ & $82 \%$ & $18 \%$ & $80 \%$ & $20 \%$ \\
\hline $68 \%$ & $32 \%$ & \multicolumn{3}{|l}{} \\
\hline
\end{tabular}


Figura 6. Antecedentes demográficos de sexo, edad y zona geográfica de la muestra

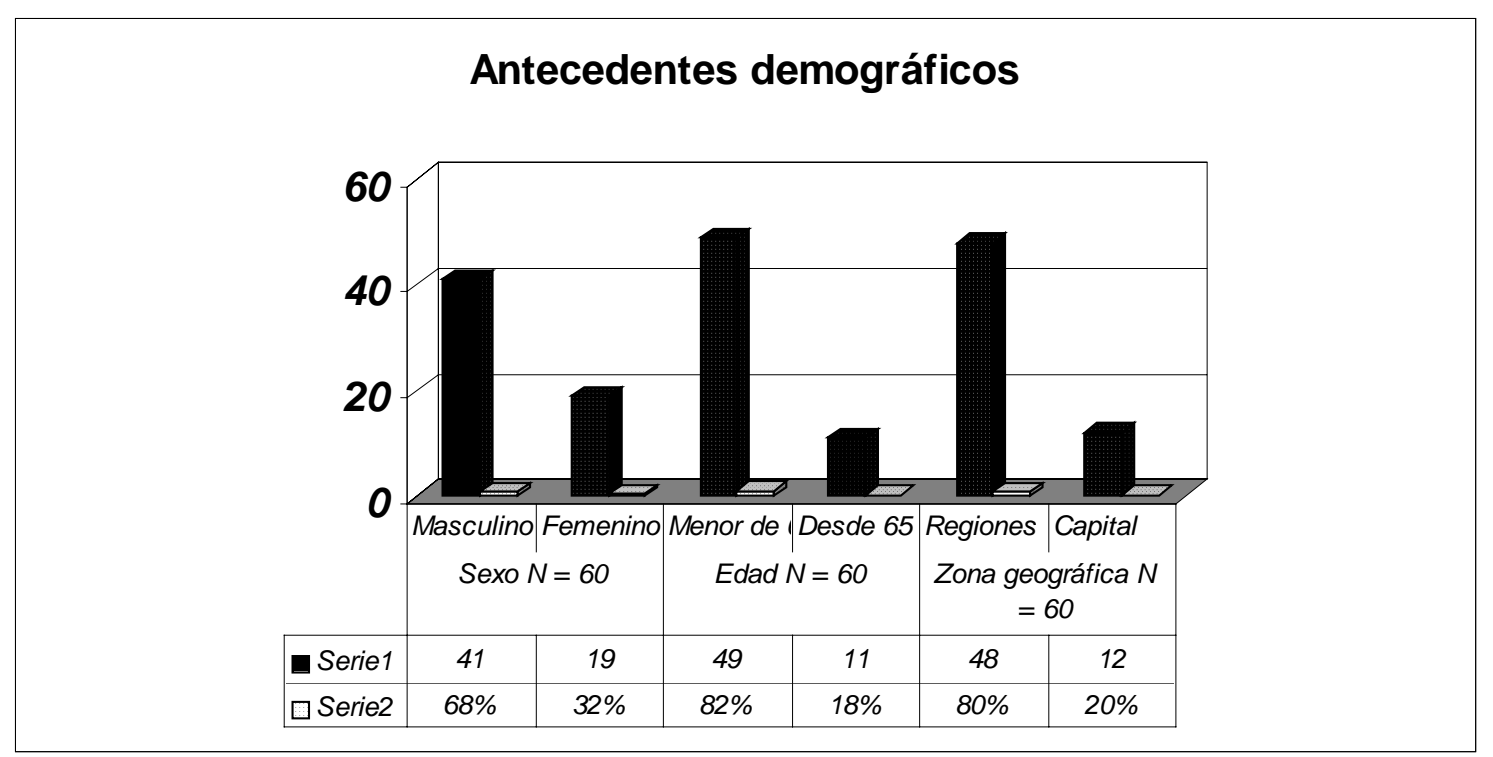

Como nos indica la Tabla 3 y la Figura 6, la mayoría de los participantes fueron varones (68\%), cuya tendencia corresponde a la tendencia de EXPPS reconocidos por el gobierno de Chile y que hemos presentado en el capítulo III. Coincide también, con la tendencia presente en las agrupaciones de derechos humanos y EXPPS a las que tuvimos acceso, en las que destaca la participación activa de varones.

Las tendencias por edad, nos indican que la mayoría de los EXPPS tenían menos de 65 años al momento de la entrevista (68\%),mientras que un grupo minoritario (18\%) eran adultos mayores.

En cuanto a la zona geográfica de residencia de los EXPPS al momento de la entrevista, la mayoría corresponde a las regiones situadas en el norte y sur del país (80\%). Por su parte, el $20 \%$ de la muestra se encontraba residiendo en Santiago de Chile a la hora de la administración de la entrevista.

Concretar entrevistas con EXPPS residentes en Santiago de Chile, se volvió una difícil tarea cuando realizamos el trabajo de campo. Esto, principalmente causado por las extensas distancias existentes entre los locales donde estas personas se reúnen, y un estilo de vida agitado, que caracteriza a las personas que residen en la capital, que influyó en que muchos de ellos no dispusieran de tiempo para participar del estudio.

En la Parte VI presentamos los resultados obtenidos del estudio estadístico mediante la prueba de $\chi^{2}$ de Pearson para las variables demográficas de la Tabla 3, cuyos valores hemos comparado con un grupo de variables previamente agrupadas, que resumen algunos de los resultados presentados en este capítulo. 
Tabla 4. Antecedentes demográficos de estado civil

\begin{tabular}{||c|c|c|c||}
\hline \hline \multicolumn{4}{|c||}{ ESTADO CIVIL $\mathrm{n}=58(97 \%)$} \\
\hline Soltero & $\begin{array}{c}\text { Casado o en } \\
\text { convivencia }\end{array}$ & $\begin{array}{c}\text { Divorciado o } \\
\text { separado de hecho }\end{array}$ & Viudo \\
\hline 4 & $\underline{\mathbf{4 8}}$ & 27 & 4 \\
\hline $7 \%$ & $80 \%$ & $45 \%$ & $7 \%$ \\
\hline
\end{tabular}

Figura 7. Estado civil de los participantes

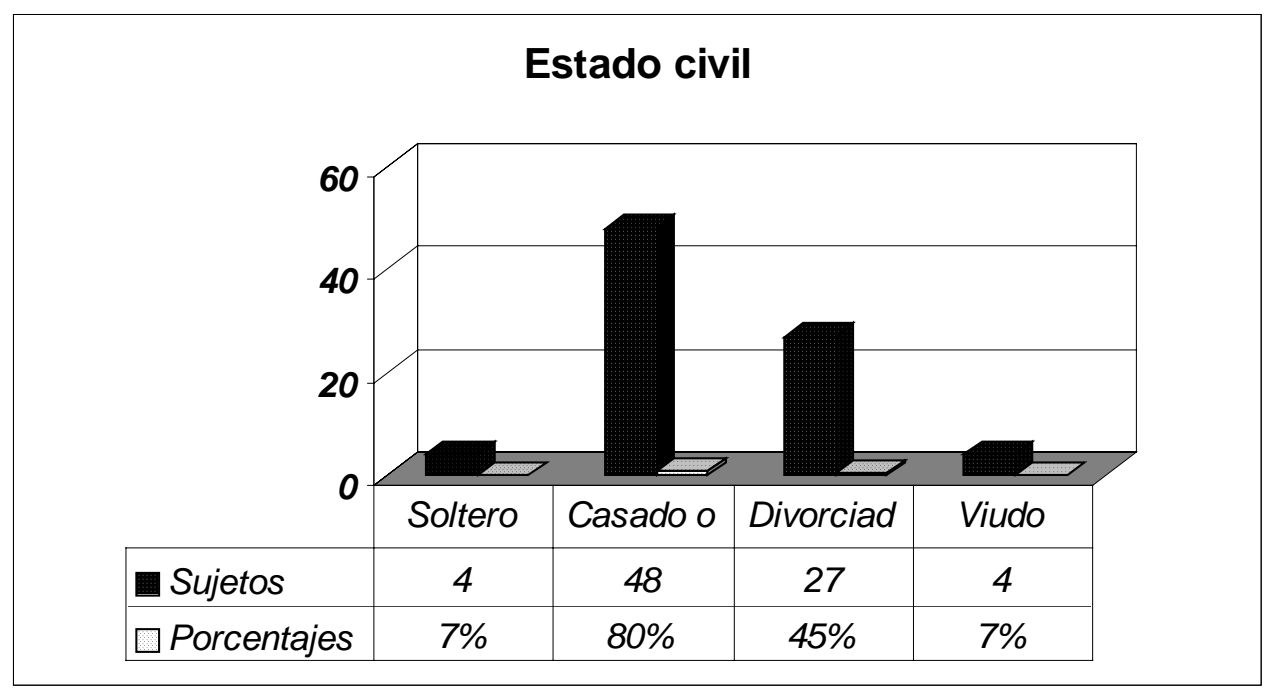

En cuanto al estado civil de la muestra, la mayoría refirió estar casado o en convivencia al momento de ser entrevistados. Se observa además que algunos EXPPS refirieron más de un estado civil a la vez, de lo que podemos deducir que un grupo de estas personas han formado pareja más de una vez, haciendo alusión a ello en distintos momentos durante la entrevista.

A continuación presentamos una tabla de antecedentes políticos referidos a las parejas de quienes afirmaron tener estas relaciones en sus vidas al momento de la entrevista. 
Tabla 5. Antecedentes demográficos políticos de la pareja actual

\begin{tabular}{|c|c|c|c|c|c|c|c|c|}
\hline \multirow{6}{*}{$\begin{array}{l}\mathrm{N} \\
\mathrm{U} \\
\mathrm{D} \\
\mathrm{O} \\
\mathrm{S}\end{array}$} & \multirow{2}{*}{\multicolumn{8}{|c|}{$\begin{array}{c}\text { ANTECEDENTES FAMILIARES } \\
\text { Pareja } \mathrm{n}=59\end{array}$}} \\
\hline & & & & & & & & \\
\hline & \multirow{4}{*}{$\begin{array}{c}\text { No } \\
\text { tien } \\
\mathrm{e}\end{array}$} & \multicolumn{7}{|c|}{ Si tiene $\mathrm{n}=42$} \\
\hline & & \multicolumn{2}{|c|}{$\begin{array}{l}\text { Tiempo de relación } \\
\mathrm{n}=41\end{array}$} & \multicolumn{2}{|c|}{$\begin{array}{l}\text { Antecedentes de } \\
\text { prisión } \mathrm{n}=16\end{array}$} & \multicolumn{3}{|c|}{$\begin{array}{l}\text { Participación política } \\
\mathrm{n}=16\end{array}$} \\
\hline & & \multirow{2}{*}{$\begin{array}{c}\text { Desde } \\
\text { antes de } \\
\text { prisión }\end{array}$} & \multirow{2}{*}{$\begin{array}{c}\text { Desde } \\
\text { después } \\
\text { de prisión }\end{array}$} & \multirow{2}{*}{$\begin{array}{l}\text { No } \\
\text { EXPP }\end{array}$} & \multirow[t]{2}{*}{ SI EXPP } & \multirow[t]{2}{*}{ No } & \multicolumn{2}{|c|}{$\mathrm{Si} N=14$} \\
\hline & & & & & & & $\begin{array}{c}\text { De } \\
\text { derecha }\end{array}$ & De izquierda \\
\hline $\mathrm{n}$ & 17 & $\underline{27}$ & 13 & 8 & 8 & 2 & 2 & $\underline{12}$ \\
\hline$\%$ & 28 & 45 & 22 & 13 & 13 & 3 & 3 & 20 \\
\hline
\end{tabular}

Como nos indica la Tabla 5, de quienes especificaron el tiempo de relación que mantienen con sus parejas, la mayoría refirió que este período se inicia antes de la experiencia de prisión, y en cuanto a la participación política, la mayoría de las parejas participan actualmente en política de izquierda en Chile. No hay diferencias entre quienes refirieron que sus parejas son EXPPS de quienes aludieron lo contrario. Por último, ningún puntaje alcanzó la media de la muestra.

Tabla 6. Antecedentes demográficos educativos

\begin{tabular}{|c|c|c|c|c|c|c|c|c|c|}
\hline \multicolumn{10}{|c|}{$\begin{array}{c}\text { NIVEL EDUCATIVO } \\
\mathrm{n}=33\left(55^{\circ} \%\right)\end{array}$} \\
\hline \multicolumn{2}{|c|}{$\begin{array}{l}\text { Estudios } \\
\text { primarios }\end{array}$} & \multicolumn{2}{|c|}{$\begin{array}{c}\text { Estudios } \\
\text { secundarios }\end{array}$} & \multicolumn{2}{|c|}{ Estudios técnicos } & \multicolumn{2}{|c|}{$\begin{array}{c}\text { Estudios } \\
\text { universitarios }\end{array}$} & \multicolumn{2}{|c|}{ Ninguno } \\
\hline Frec. & $\%$ & Frec. & $\%$ & Frec. & $\%$ & Frec. & $\%$ & Frec. & $\%$ \\
\hline 7 & 12 & 6 & 10 & 8 & 13 & $\underline{16}$ & 27 & 2 & 3 \\
\hline
\end{tabular}

Como nos indica la Tabla 6, más de la mitad de la muestra hizo alusión a su nivel educativo, de quienes la mayoría refirió disponer de estudios universitarios. No obstante, esta mayoría no supera la media de sujetos entrevistados. 
Tabla 7. Antecedentes demográficos ocupacionales

\begin{tabular}{|c|c|c|c|c|c|c|c|c|c|c|c|c|c|c|c|}
\hline \multicolumn{16}{|c|}{ ANTECEDENTES OCUPACIONALES n $=59(98 \%)$} \\
\hline \multirow{2}{*}{$\begin{array}{c}\text { Nud } \\
\text { os }\end{array}$} & \multicolumn{5}{|c|}{ Ocupación pre-prisión $\mathrm{n}=51$} & \multicolumn{5}{|c|}{ Ocupación post-prisión $\mathrm{n}=55$} & \multicolumn{5}{|c|}{ Ocupación actual $\mathrm{n}=51$} \\
\hline & $\begin{array}{l}\text { Nin } \\
\text { guna }\end{array}$ & $\begin{array}{c}\text { Trab } \\
\text { ajad } \\
\text { or } \\
\text { no } \\
\text { calif. } \\
\text { / no } \\
\text { espe } \\
\text { cif. }\end{array}$ & $\begin{array}{c}\text { Trab } \\
\text { ajad } \\
\text { or } \\
\text { califi } \\
\text { cado }\end{array}$ & $\begin{array}{c}\text { Estu } \\
\text { diant } \\
\mathrm{e}\end{array}$ & $\begin{array}{c}\text { Trabaj } \\
\text { ador } \\
\text { indepe } \\
\text { ndient } \\
\text { e }\end{array}$ & $\begin{array}{l}\text { Nin } \\
\text { guna }\end{array}$ & $\begin{array}{c}\text { Trab } \\
\text { ajad } \\
\text { or } \\
\text { no } \\
\text { calif. } \\
\text { / no } \\
\text { espe } \\
\text { cif. }\end{array}$ & $\begin{array}{c}\text { Trab } \\
\text { ajad } \\
\text { or } \\
\text { califi } \\
\text { cado }\end{array}$ & $\begin{array}{c}\text { Estu } \\
\text { diant } \\
\mathrm{e}\end{array}$ & $\begin{array}{l}\text { Trabaj } \\
\text { ador } \\
\text { indepe } \\
\text { ndient } \\
\text { e }\end{array}$ & $\begin{array}{l}\text { Nin } \\
\text { guna }\end{array}$ & $\begin{array}{c}\text { Trab } \\
\text { ajad } \\
\text { or } \\
\text { no } \\
\text { califi } \\
\text { cado } \\
\text { / no } \\
\text { espe } \\
\text { cif }\end{array}$ & $\begin{array}{c}\text { Trab } \\
\text { ajad } \\
\text { or } \\
\text { califi } \\
\text { cado }\end{array}$ & $\begin{array}{l}\text { Trab } \\
\text { ajad } \\
\text { or } \\
\text { inde } \\
\text { pend } \\
\text { iente }\end{array}$ & $\begin{array}{c}\text { Estu } \\
\text { diant } \\
\mathrm{e}\end{array}$ \\
\hline Sits & 5 & 37 & 12 & 11 & 2 & 15 & $\underline{45}$ & 9 & 9 & 14 & $\underline{24}$ & 13 & 13 & 20 & 3 \\
\hline$\%$ & 8 & 62 & 20 & 18 & 3 & 25 & 75 & 15 & 15 & 23 & 40 & 22 & 22 & 33 & 5 \\
\hline
\end{tabular}

En cuanto a los antecedentes ocupacionales de los EXPPS entrevistados, la Tabla 7, nos indica que casi la totalidad de la muestra hizo alusión a estos antecedentes en los tres períodos indagados de sus vidas. Observamos según las modas obtenidas por sujetos, que el trabajo no calificado y no especificado, fue la actividad laboral predominante en los EXPPS que conformaron la muestra antes y después de prisión, superando ambas frecuencias la media de sujetos entrevistados. Vemos además, que ocupaciones laborales clasificadas bajo esta categoría, aumentaron en el período post-prisión, lo que en el Chile de aquellos años, significó muy probablemente, una actividad laboral sin beneficio laboral alguno, a cambio de un salario inferior a lo que cualquier familia, incluso persona, requiere para cubrir de manera mínima sus necesidades básicas de comida, vivienda y abrigo. En cambio, observamos en el presente, que la moda para la categoría refiere que los EXPPS no realizan actividad laboral, lo que se presentó en menos de la media de sujetos.

A modo general observamos el aumento gradual de personas que refirieron no trabajar y trabajar de manera independiente, en el tiempo posterior a prisión y en la actualidad. Por el contrario, la proporción de estudiantes disminuye tras el episodio de prisión y en la actualidad.

Todo lo anterior, nos indica que los EXPPS estuvieron limitados por la experiencia de prisión en cuanto a oportunidades de estudio y trabajo, probablemente viéndose obligados a tener que trabajar de manera independiente. Esto refiere dificultades adicionales en las vidas de los EXPPS con posterioridad a la experiencia de prisión y producto de ésta, al proceso de reincorporación a la vida cotidiana y la superación de la experiencia de prisión política y tortura. 
Tabla 8. Antecedentes demográficos políticos

\begin{tabular}{|c|c|c|c|c|c|c|c|c|c|c|}
\hline \multirow[t]{3}{*}{ NUDOS } & \multicolumn{10}{|c|}{ ANTECEDENTES POLÍTICOS n $=58$} \\
\hline & \multicolumn{2}{|c|}{$\begin{array}{c}\text { Filiación política } \\
\text { pre-prisión }\end{array}$} & \multicolumn{2}{|c|}{$\begin{array}{l}\text { Filiación política } \\
\text { post-prisión }\end{array}$} & \multicolumn{2}{|c|}{$\begin{array}{c}\text { Filiación política } \\
\text { actual }\end{array}$} & \multicolumn{2}{|c|}{ clandestinidad } & \multicolumn{2}{|c|}{ Exoneración } \\
\hline & $\begin{array}{c}\text { Ningu } \\
\text { na }\end{array}$ & $\begin{array}{c}\text { Activist } \\
\text { a } \\
\text { político }\end{array}$ & $\begin{array}{c}\text { Ningu } \\
\text { na }\end{array}$ & $\begin{array}{c}\text { Activist } \\
\text { a } \\
\text { político }\end{array}$ & $\begin{array}{c}\text { Ningu } \\
\text { na }\end{array}$ & $\begin{array}{c}\text { Activist } \\
\text { a } \\
\text { político }\end{array}$ & $\begin{array}{l}\text { No } \\
\text { vivió }\end{array}$ & Si vivió & No & $\mathrm{Si}$ \\
\hline Sujetos & 5 & $\underline{51}$ & 7 & $\underline{34}$ & 13 & $\underline{41}$ & 0 & $\underline{21}$ & 2 & $\underline{18}$ \\
\hline$\%$ & 8 & 85 & 12 & 57 & 22 & 68 & 0 & 35 & 3 & 30 \\
\hline
\end{tabular}

En cuanto a los antecedentes políticos de los EXPPS entrevistados, la Tabla 8 nos indica que la mayoría de ellos hizo referencia a su participación en este ámbito. Las modas por momento indagado, nos indican que la mayoría de sujetos participantes ha mantenido desde antes de prisión y hasta la actualidad, una participación política activa. Sin embargo observamos una disminución de estas frecuencias en la etapa postprisión que creemos guarda relación con los objetivos de la represión política.

Un grupo inferior a la media de sujetos entrevistados, refirió haber vivido períodos de clandestinidad y de exoneración.

Los resultados que exponemos en la Tabla 8, nos señalan a modo global que la mayoría de EXPPS reconoce su implicación política, lo que nos confirma su condición de EXPPS.

Tabla 9. Antecedentes demográficos de la experiencia de prisión

\begin{tabular}{|c|c|c|c|c|c|c|c|c|c|c|c|c|c|c|c|}
\hline \multirow{3}{*}{$\begin{array}{l}\mathrm{N} \\
\mathrm{U} \\
\mathrm{D}\end{array}$} & \multicolumn{15}{|c|}{ ANTECEDENTES DE PRISIÓN (A) $n=60$} \\
\hline & \multicolumn{3}{|c|}{ Edad } & \multicolumn{4}{|c|}{ Período } & \multicolumn{3}{|c|}{ Lugar } & \multicolumn{3}{|c|}{ Tiempo } & \multicolumn{2}{|c|}{$\mathrm{N}^{\mathrm{o}}$ de veces } \\
\hline & - de & $+\mathrm{de}$ & $+\mathrm{de}$ & Sept & Ene & Ago & Post- & Reci & Reci & Lugar & Men & May & Años & 1 & + de 1 \\
\hline $\mathrm{O}$ & 21 & $21 \mathrm{y}$ & 40 & - dic & 197 & 197 & marzo & nto & nto & $\mathrm{de}$ & or & or & & vez & vez \\
\hline $\mathrm{S}$ & año & - de & & 197 & $4-$ & $7-$ & 1990 & ofici & no & relega & de & de & & & \\
\hline & $\mathrm{s}$ & 40 & & 3 & ago & Mar & & $\mathrm{al}$ & ofici & ción & un & un & & & \\
\hline & & & & & 197 & 199 & & FFA & al & & mes & mes & & & \\
\hline & & & & & 7 & 0 & & A & $\begin{array}{c}\text { FFA } \\
\text { A }\end{array}$ & & & & & & \\
\hline$S$ & 12 & $\underline{27}$ & 6 & $\underline{26}$ & 21 & 14 & 1 & $\underline{49}$ & 25 & 3 & 23 & $\underline{27}$ & 10 & 3 & $\underline{17}$ \\
\hline$\%$ & 20 & 45 & 10 & 43 & 35 & 23 & 2 & 82 & 42 & 5 & 38 & 45 & 17 & 5 & 28 \\
\hline
\end{tabular}

Como nos indica la Tabla 9, la totalidad de la muestra refirió aspectos de la propia experiencia de prisión. Las modas por grupos intermedios de categorías, nos muestran que la mayoría de personas que aludieron cada categoría intermedia, eran mayores de edad al momento de ingresar a prisión, no superaban los 40 años, estuvieron recluidos en el primer período del gobierno militar comprendido entre septiembre y diciembre de 1973, permanecieron en recintos oficiales para estos fines, un tiempo mayor de un mes, y fueron privados de su libertad en más de una ocasión. De todas estas tendencias, la única que superó la media de 
sujetos entrevistados, fue la que señala que la reclusión fue predominantemente en recintos oficiales como cárceles, comisarías o regimientos.

Un dato relevante de la Tabla 9, es la alusión del $42 \%$ de la muestra, que hace referencia a haber permanecido recluidos en recintos no oficiales. Esto nos indica, que es altamente probable que todos ellos hayan sido víctimas de hechos de tortura, pues como hemos descrito en el capítulo III, estos recintos fueron en su mayoría casas clandestinas acondicionadas para estos fines.

Tabla 10. Antecedentes demográficos legales de la experiencia de prisión

\begin{tabular}{|c|c|c|c|c|c|c|c|c|c|c|}
\hline \multirow{4}{*}{$\begin{array}{l}\mathrm{N} \\
\mathrm{U} \\
\mathrm{D} \\
\mathrm{O} \\
\mathrm{S}\end{array}$} & \multicolumn{10}{|c|}{ ANTECEDENTES DE PRISIÓN (B) } \\
\hline & \multicolumn{10}{|c|}{ Aspectos legales } \\
\hline & \multicolumn{2}{|c|}{ Procesamiento } & \multicolumn{6}{|c|}{ Resolución } & \multicolumn{2}{|c|}{$\begin{array}{l}\text { Experiencia de } \\
\text { exilio }\end{array}$} \\
\hline & $\begin{array}{c}\text { Detenc } \\
\text { ión sin } \\
\text { juicio }\end{array}$ & $\begin{array}{c}\text { Someti } \\
\text { do a } \\
\text { juicio }\end{array}$ & $\begin{array}{c}\text { Conde } \\
\text { na de } \\
\text { presidi } \\
\text { o }\end{array}$ & $\begin{array}{c}\text { Sobres } \\
\text { eimien } \\
\text { to } \\
\text { tempo } \\
\text { ral }\end{array}$ & $\begin{array}{l}\text { Conde } \\
\text { na de } \\
\text { relegac } \\
\text { ión }\end{array}$ & Exilio & $\begin{array}{l}\text { Liberta } \\
\mathrm{d} \text { por } \\
\text { falta de } \\
\text { mérito }\end{array}$ & $\begin{array}{l}\text { Otra o } \\
\text { no } \\
\text { especifi } \\
\text { ca }\end{array}$ & No & $\mathrm{Si}$ \\
\hline $\mathrm{S}$ & 1 & $\underline{24}$ & $\underline{8}$ & 3 & 4 & 1 & 4 & 3 & $\underline{17}$ & 12 \\
\hline$\%$ & 2 & 40 & 13 & 5 & 7 & 2 & 7 & 5 & 28 & 20 \\
\hline
\end{tabular}

Las frecuencias obtenidas para la Tabla 10, nos indican que la mayoría de sujetos que aludió aspectos legales de prisión (que no superaron la media de participantes), fueron sometidos a juicio, condenados oficialmente a presidio y vivieron el exilio. Lo que nos indica que los antecedentes legales de estas personas quedaron marcados con anotaciones penales que les impidieron o dificultaron por años su reinserción laboral. Lo que pudo afectar también en su reinserción social. Pues, sus antecedentes legales referían su condición de criminales.

Tabla 11. Antecedentes demográficos de la experiencia de tortura en prisión

\begin{tabular}{|c|c|c|c|c|c|c|c|}
\hline \multirow{5}{*}{$\begin{array}{l}\mathrm{N} \\
\mathrm{U} \\
\mathrm{D} \\
\mathrm{O} \\
\mathrm{S}\end{array}$} & \multicolumn{7}{|c|}{ ANTECEDENTES DE PRISIÓN (C) } \\
\hline & \multicolumn{7}{|c|}{ Valoración experiencia de tortura $\mathrm{n}=53$} \\
\hline & \multicolumn{4}{|c|}{ Refiere no tortura $\mathrm{n}=4$} & \multicolumn{3}{|c|}{ Refiere Tortura $\mathrm{n}=53$} \\
\hline & \multirow{2}{*}{$\begin{array}{l}\text { Ningún } \\
\text { mal trato }\end{array}$} & \multicolumn{3}{|c|}{ Maltrato no tortura } & \multirow[t]{2}{*}{ Física } & \multirow[t]{2}{*}{ Psicológica } & \multirow[t]{2}{*}{ Sexual } \\
\hline & & Físico & Psicológico & Sexual & & & \\
\hline $\mathrm{S}$ & 1 & $\underline{3}$ & 2 & 1 & $\underline{42}$ & 36 & 14 \\
\hline$\%$ & 2 & 5 & 3 & 2 & 70 & 60 & 23 \\
\hline
\end{tabular}

En cuanto a la valoración de experiencia de tortura, una persona de toda la muestra manifestó no haber recibido ningún maltrato durante su estancia en prisión, pero observamos que la totalidad de la muestra que valoró la experiencia de tortura, refirió haber recibido estas prácticas. Esta contradicción 
la podemos explicar de acuerdo a las amplias jerarquías de nudos que se desprenden de las modalidades y secuelas de tortura, en que posiblemente la persona que niega haber recibido estas acciones, pudo haber aludido a algún aspecto que indirectamente refirió haber sufrido estas prácticas.

A continuación, estudiaremos en detalle los resultados obtenidos en la parte de la tabla bajo el nudo "refiere tortura".

Tabla 12. Antecedentes demográficos de tortura física en prisión

\begin{tabular}{|c|c|c|c|c|c|c|c|c|c|c|c|c|c|c|c|c|c|c|}
\hline \multicolumn{19}{|c|}{ FÍSICA $\mathrm{n}=42$} \\
\hline \multicolumn{19}{|c|}{ Si especifica } \\
\hline \multicolumn{7}{|c|}{ Modalidad } & \multicolumn{12}{|c|}{ Secuelas } \\
\hline \multirow{4}{*}{$\begin{array}{l}\text { N } \\
\text { ud } \\
\text { os }\end{array}$} & \multirow{4}{*}{$\begin{array}{c}\text { Ele } \\
\text { ctri } \\
\text { cida } \\
\text { d }\end{array}$} & \multirow{4}{*}{$\begin{array}{c}\text { Sub } \\
\text { mari } \\
\text { no }\end{array}$} & \multirow{4}{*}{$\begin{array}{c}\text { Telé } \\
\text { fon } \\
\text { o }\end{array}$} & \multirow{4}{*}{$\begin{array}{l}\text { Gol } \\
\text { pes }\end{array}$} & \multirow{4}{*}{$\begin{array}{l}\text { Que } \\
\text { mad } \\
\text { uras }\end{array}$} & \multirow{4}{*}{$\begin{array}{r}\mathrm{Ot} \\
\mathrm{s}\end{array}$} & \multirow{5}{*}{\multicolumn{2}{|c|}{ No }} & \multicolumn{10}{|c|}{$\mathrm{Si}$} \\
\hline & & & & & & & & & \multicolumn{3}{|c|}{ Momento } & \multicolumn{3}{|c|}{ Síntomas } & $\begin{array}{l}\text { Enf. } \\
\text { asoc } \\
\text { iada }\end{array}$ & \multicolumn{3}{|c|}{ Atte. en salud } \\
\hline & & & & & & & & & \multirow{2}{*}{$\begin{array}{c}\text { Post } \\
\text { prisi } \\
\text { ón }\end{array}$} & \multirow{2}{*}{$\begin{array}{c}\text { Pre } \\
\text { o } \\
\text { post } \\
\text { I. V. }\end{array}$} & \multirow{2}{*}{$\begin{array}{l}\text { Pres } \\
\text { ente }\end{array}$} & \multirow{2}{*}{$\begin{array}{c}\text { Disc } \\
\text { apaci } \\
\text { dad }\end{array}$} & \multirow[b]{2}{*}{$\begin{array}{l}\text { Otr } \\
\text { Os } \\
\text { sign } \\
\text { os } \\
\text { físic } \\
\text { os }\end{array}$} & \multirow{2}{*}{$\begin{array}{l}\text { Signo } \\
\text { s "no } \\
\text { releva } \\
\text { ntes" }\end{array}$} & \multirow{2}{*}{$\begin{array}{c}\text { Otra } \\
\mathrm{s}\end{array}$} & \multirow{2}{*}{$\begin{array}{c}\mathrm{N} \\
\mathrm{O}\end{array}$} & \multicolumn{2}{|r|}{$\mathrm{Si}$} \\
\hline & & & & & & & & & & & & & & & & & $\begin{array}{c}\text { En } \\
\text { pasa } \\
\text { do }\end{array}$ & $\begin{array}{c}\text { En } \\
\text { present } \\
\mathrm{e}\end{array}$ \\
\hline $\mathrm{S}$ & 13 & 6 & 4 & 31 & 3 & & & 0 & 5 & 4 & $\underline{16}$ & 7 & $\underline{9}$ & 1 & 5 & 4 & 3 & 1 \\
\hline$\%$ & 22 & 10 & 7 & 52 & 5 & & & 0 & 8 & 7 & 27 & 12 & 15 & 2 & 8 & 4 & 5 & 2 \\
\hline
\end{tabular}

Como nos indica la Tabla 12, la mayoría de las personas entrevistadas (70\%) refirió haber sido víctima de algún tipo de violencia física que fue valorada como tortura física. La única moda que supera la media de la muestra, refiere los golpes como el tipo de tortura más ejercido en ellos.

En cuanto a las secuelas de la tortura física recibida en prisión, las modas obtenidas, que en ningún caso supera la media de sujetos entrevistados, nos indican que estas secuelas se mantienen en el presente, y comprenden afecciones físicas. 
Tabla 13. Antecedentes demográficos de tortura psicológica en prisión

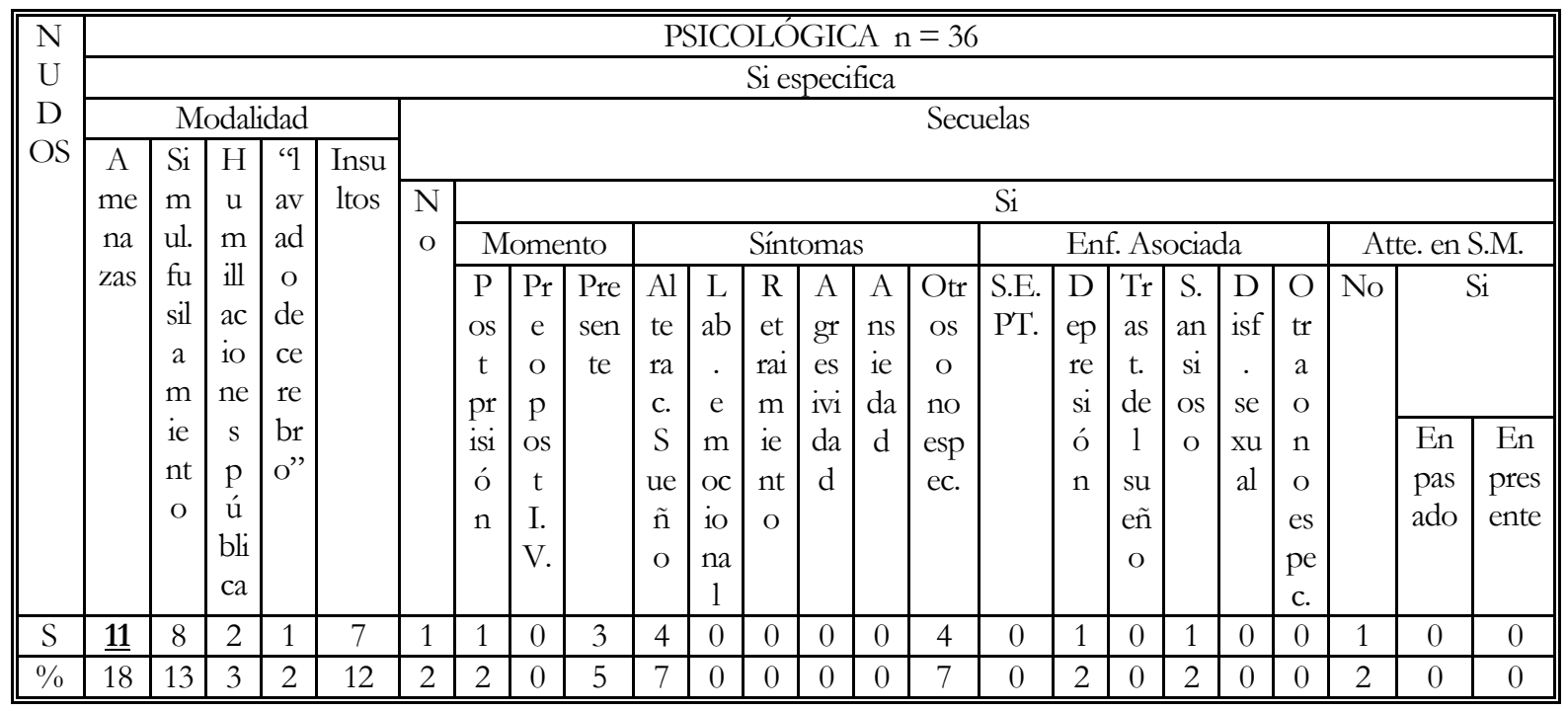

Como observamos en la Tabla 13, más de la mitad de la muestra refiere a haber sufrido tortura psicológica, y en cuanto a las especificaciones que estas personas hicieran de su experiencia, ninguna moda supera la media de sujetos. Considerando esto, son las amenazas las acciones más referidas, y la presencia de secuelas asociadas es muy baja.

A modo general, podemos decir que las escasas puntuaciones observadas en la Tabla 13, indican una tendencia por parte de los EXPPS a no hablar abiertamente de sus experiencias de tortura psicológica sufrida en prisión.

Tabla 14. Antecedentes demográficos de tortura sexual en prisión

\begin{tabular}{|c|c|c|c|c|c|c|c|c|c|c|c|c|c|c|c|c|c|c|c|c|c|c|c|}
\hline \multicolumn{24}{|c|}{ SEXUAL $\mathrm{n}=14$} \\
\hline $\mathrm{N}$ & \multicolumn{23}{|c|}{ Si especifica } \\
\hline ud & \multicolumn{3}{|c|}{ Modalidad } & \multicolumn{20}{|c|}{ Secuelas } \\
\hline \multirow[t]{11}{*}{ os } & \multirow{11}{*}{$\begin{array}{l}\mathrm{V} \\
\text { eja } \\
\mathrm{ci} \\
\text { on } \\
\text { es }\end{array}$} & \multirow{11}{*}{$\begin{array}{l}\mathrm{V} \\
\text { io } \\
\text { la } \\
\text { ci } \\
\text { ó } \\
\text { n }\end{array}$} & \multirow{11}{*}{$\begin{array}{l}\text { Ab } \\
\text { An } \\
\text { im } \\
\text { ale } \\
\text { s }\end{array}$} & \multirow{11}{*}{$\begin{array}{c}\mathrm{N} \\
\mathrm{O}\end{array}$} & \multicolumn{19}{|c|}{$\mathrm{Si}$} \\
\hline & & & & & \multicolumn{3}{|c|}{ Momento } & \multicolumn{6}{|c|}{ Síntomas } & \multicolumn{6}{|c|}{ Enf. Asociada } & \multicolumn{4}{|c|}{ Atte. en salud. } \\
\hline & & & & & $\mathrm{P}$ & & Pre & $\overline{\mathrm{Al}}$ & $\mathrm{L}$ & $\mathrm{R}$ & $\mathrm{A}$ & $\mathrm{A}$ & Otr & S. & & $\mathrm{T}$ & S. & $\mathrm{D}$ & Otra & $\mathrm{N}$ & $S$ & \begin{tabular}{|l|}
$\mathrm{si}$ \\
\end{tabular} & Emb. \\
\hline & & & & & & $\mathrm{e}$ & sen & te & $\mathrm{a}$ & et & gr & ns & os o & E. & e & $\mathrm{ra}$ & $\mathrm{a}$ & isf & o no & 0 & & & no \\
\hline & & & & & $\mathrm{s}$ & $\mathrm{o}$ & te & $\mathrm{ra}$ & b. & $\mathrm{ra}$ & es & ie & no & P. & pr & st. & $\mathrm{ns}$ & . & espe & & & & desead \\
\hline & & & & & $\mathrm{t}$ & $\mathrm{p}$ & & c. & e & $\mathrm{i}$ & ivi & $\mathrm{da}$ & esp & $\mathrm{T}$. & es & $\mathrm{d}$ & io & se & c. & & & & o \\
\hline & & & & & $\mathrm{p}$ & os & & S & $\mathrm{m}$ & $\mathrm{m}$ & $\mathrm{da}$ & $\mathrm{d}$ & ec. & & ió & el & so & $\mathrm{x}$ & & & & & \\
\hline & & & & & ri & $\mathrm{t}$ & & ue & o & ie & $\mathrm{d}$ & & & & $\mathrm{n}$ & $\mathrm{su}$ & & ua & & & $\mathrm{pa}$ & pre & \\
\hline & & & & & si & I. & & $\tilde{\mathrm{n}}$ & ci & $\mathrm{nt}$ & & & & & & $\mathrm{e}$ & & 1 & & & $\mathrm{sa}$ & sen & \\
\hline & & & & & ó & V. & & O & o & $\mathrm{O}$ & & & & & & $\tilde{\mathrm{n}}$ & & & & & do & te & \\
\hline & & & & & $\mathrm{n}$ & & & & $\begin{array}{l}\mathrm{n} \\
\mathrm{al}\end{array}$ & & & & & & & o & & & & & & & \\
\hline$S$ & $\underline{10}$ & 2 & 0 & 0 & 1 & 0 & 0 & 0 & 0 & 0 & 0 & 0 & 0 & 0 & 0 & 0 & 0 & 0 & 0 & 0 & 0 & 0 & 2 \\
\hline $\mathrm{X}$ & 20 & 3 & 0 & 0 & 2 & 0 & 0 & 0 & 0 & 0 & 0 & 0 & 0 & 0 & 0 & 0 & 0 & 0 & 0 & 0 & 0 & 0 & 3 \\
\hline
\end{tabular}


La Tabla 14, nos señala que un grupo menor a la media de sujetos entrevistados (23\%), refirió haber sido víctima de hechos que valoraron como tortura sexual, en que sobresalen las vejaciones como la modalidad más aludida, habiendo sido valorada por el $20 \%$ de la muestra.

A modo general, observamos que los EXPPS que refirieron haber sufrido situaciones de tortura sexual en prisión, no suelen especificar estas situaciones. Lo que mantiene la tendencia presentada en las tablas precedentes acerca de la omisión de información asociada a la experiencia de tortura.

Tabla 15. Antecedentes demográficos familiares de pareja en la actualidad

\begin{tabular}{|c|c|c|c|c|c|c|c|c|}
\hline \multicolumn{9}{|c|}{ ANTECEDENTES FAMILIARES } \\
\hline \multicolumn{9}{|c|}{ Pareja $\mathrm{n}=59$} \\
\hline \multirow{4}{*}{$\begin{array}{l}\text { No } \\
\text { tiene }\end{array}$} & \multicolumn{8}{|c|}{ Si tiene $\mathrm{n}=42$} \\
\hline & \multicolumn{3}{|c|}{ Tiempo de relación } & \multicolumn{2}{|c|}{$\begin{array}{c}\text { Antecedentes de } \\
\text { prisión }\end{array}$} & \multicolumn{3}{|c|}{ Participación política } \\
\hline & \multirow{2}{*}{$\begin{array}{c}\text { Desde } \\
\text { antes de } \\
\text { prisión }\end{array}$} & \multirow{2}{*}{$\begin{array}{c}\text { Desde } \\
\text { después } \\
\text { de prisión }\end{array}$} & \multirow{2}{*}{$\begin{array}{c}\text { No } \\
\text { especifica }\end{array}$} & \multirow{2}{*}{$\begin{array}{c}\text { No } \\
\text { EXPP }\end{array}$} & \multirow{2}{*}{$\begin{array}{c}\text { SI } \\
\text { EXPP }\end{array}$} & \multirow[t]{2}{*}{ No } & \multicolumn{2}{|r|}{$\mathrm{Si}$} \\
\hline & & & & & & & $\begin{array}{c}\text { De } \\
\text { derecha }\end{array}$ & De izquierda \\
\hline 17 & 27 & 13 & $\underline{36}$ & 8 & 8 & 2 & 2 & $\underline{12}$ \\
\hline
\end{tabular}

La Tabla 15, nos da información acerca de los antecedentes demográficos de las parejas de los EXPPS. Información que fue aludida por casi la totalidad de la muestra (98\%). Observamos que en la vida presente de los participantes del estudio y en relación a la pareja, predominan las siguientes tendencias: la mayoría de los EXPPS entrevistados, refiere disponer de relación de pareja, no especificando el tiempo que mantienen estas relaciones; un grupo inferior a la media de participantes, pero que obtiene la moda de la categoría, refiere la tendencia de sus parejas a participar en política de izquierda; por último, obtienen la misma frecuencia los que refieren que sus parejas son EXPPS y los que sostienen lo contrario.

A modo general, observamos que de los EXPPS que entregaron información de sus parejas actuales, tienden a compartir ideología y accionar político con estas personas, y en algunos casos la condición de EXPP. Lo que sin duda puede favorecer la superación de la experiencia de prisión política y tortura. 
Tabla 16. Antecedentes demográficos familiares de hijos

\begin{tabular}{|c|c|c|c|c|c|c|c|c|c|c|c|c|c|c|c|c|c|c|c|c|c|}
\hline \multirow{7}{*}{$\begin{array}{l}\mathrm{N} \\
\mathrm{U} \\
\mathrm{D} \\
\mathrm{O} \\
\mathrm{S}\end{array}$} & \multirow{2}{*}{\multicolumn{21}{|c|}{$\begin{array}{c}\text { ANTECEDENTES FAMILIARES } \\
\text { Hijos } \mathrm{n}=60\end{array}$}} \\
\hline & & & & & & & & & & & & & & & & & & & & & \\
\hline & \multirow{5}{*}{$\begin{array}{c}\mathrm{N} \\
\mathrm{o} \\
\text { tie } \\
\text { ne }\end{array}$} & \multicolumn{20}{|c|}{ Si tiene $\mathrm{n}=60$} \\
\hline & & \multicolumn{3}{|c|}{$\mathrm{N}^{\mathrm{o}}$ de hijos } & \multicolumn{4}{|c|}{ Media de edad } & \multicolumn{5}{|c|}{$\begin{array}{l}\text { Media de edad } \\
\text { detención }\end{array}$} & \multicolumn{6}{|c|}{ Antecedentes políticos } & \multicolumn{2}{|c|}{$\begin{array}{l}\text { Antec.de } \\
\text { prisión }\end{array}$} \\
\hline & & \multirow{3}{*}{$\begin{array}{c}1 \\
\text { hijo }\end{array}$} & \multirow{3}{*}{$\begin{array}{l}+ \text { de } \\
1 \text { y }- \\
\text { de } 5\end{array}$} & \multirow{3}{*}{$\begin{array}{l}5 \text { o } \\
\text { más }\end{array}$} & \multirow{3}{*}{\multicolumn{2}{|c|}{$\begin{array}{l}- \text { de } \\
12\end{array}$}} & \multirow{3}{*}{$\begin{array}{c}\text { De } \\
12 \mathrm{a} \\
18\end{array}$} & \multirow{3}{*}{$\begin{array}{c}+\mathrm{de} \\
18\end{array}$} & \multirow{3}{*}{$\begin{array}{l}\text { No } \\
\text { habí } \\
\text { an } \\
\text { naci } \\
\text { do }\end{array}$} & \multirow{3}{*}{\multicolumn{2}{|c|}{$\begin{array}{l}\text { Niñ } \\
\text { os }\end{array}$}} & \multirow{3}{*}{$\begin{array}{l}\text { A } \\
\text { d } \\
\text { ol } \\
\text { es } \\
\text { ce } \\
\text { nt } \\
\text { es }\end{array}$} & \multirow{3}{*}{$\begin{array}{c}\text { Ad } \\
\text { ulto } \\
\text { s }\end{array}$} & \multicolumn{6}{|c|}{ Participación actual o pasada } & \multirow{3}{*}{$\begin{array}{l}\mathrm{N} \\
\text { in } \\
\text { gu } \\
\mathrm{n} \\
\mathrm{O} \\
\mathrm{es} \\
\mathrm{E} \\
\mathrm{X} \\
\mathrm{P} \\
\mathrm{P}\end{array}$} & \multirow{3}{*}{$\begin{array}{c}1 \mathrm{o}+ \\
\text { son } \\
\text { EXPP }\end{array}$} \\
\hline & & & & & & & & & & & & & & \multicolumn{4}{|c|}{ ninguna } & \multicolumn{2}{|c|}{$\begin{array}{l}\text { Si partic. o } \\
\text { han p. }\end{array}$} & & \\
\hline & & & & & & & & & & & & & & & $\begin{array}{l}\text { Sim } \\
\text { patiz } \\
\text {. de } \\
\text { izqd } \\
\text { a. }\end{array}$ & $\begin{array}{l}\text { Sim } \\
\text { patiz } \\
\text {. de } \\
\text { dere } \\
\text { cha }\end{array}$ & $\begin{array}{l}\text { Apolí } \\
\text { ticos }\end{array}$ & $\begin{array}{c}\text { Acti } \\
\text { vista } \\
\text { s de } \\
\text { dere } \\
\text { cha }\end{array}$ & $\begin{array}{c}\text { Activ } \\
\text { istas } \\
\text { de } \\
\text { izqui } \\
\text { erda }\end{array}$ & & \\
\hline $\mathrm{S}$ & 0 & 5 & $\underline{43}$ & 9 & & 1 & 6 & $\underline{39}$ & 12 & & $\underline{40}$ & 3 & 0 & & 5 & 0 & $\underline{8}$ & 0 & $\underline{8}$ & 0 & $\underline{7}$ \\
\hline$\%$ & 0 & 8 & 72 & 1 & & 2 & 10 & 65 & 20 & & 67 & 5 & 0 & & 8 & 0 & 13 & 0 & 13 & 0 & 12 \\
\hline
\end{tabular}

La Tabla 16, nos indica que todos los EXPPS refirieron información demográfica de sus hijos y con ello, nos revela que todos los participantes del estudio son padres.

De acuerdo a las modas que superan la media de participantes, observamos que la mayoría de ellos tienen más de un hijo y menos de cinco, son mayores de edad, y al momento de la detención ya eran padres y sus hijos se encontraban en la etapa evolutiva de la infancia. Otras modas que se presentan en la Tabla 16, y que no superan la media de sujetos entrevistados, refiere la igualdad de un grupo de sujetos que afirmó que sus hijos son apolíticos, y otro grupo que sostuvo que éstos participaban activamente en partidos de izquierda. En cuanto a la condición de EXPPS de los hijos, un grupo minoritario equivalente al 12\% de la muestra, indicó que sus hijos tenían esta condición.

A modo general, podemos observar que los hijos de los EXPPS no han estado ajenos a las experiencias de prisión vividas por sus padres, que acontecieron mayoritariamente cuando ellos eran niños. Este indicador es relevante para entender el impacto familiar y el traspaso de experiencias como la prisión política y tortura a la generación de hijos. Pues estos hijos, probablemente vieron como sus padres fueron detenidos, y lo que este hecho implicó en sus vidas, caracterizado por un período de ausencia, el temor de sus familiares por conocer antecedentes del paradero del padre ausente, la inminente amenaza de muerte, y las dificultades económicas que ello conllevó. Esto último, por lo que significa tener un padre recluido en prisión, imposibilitado para trabajar y satisfacer las necesidades básicas de comida y abrigo de un grupo familiar, siendo esta última, una realidad que poco cambió una vez que fueron liberados, al verse imposibilitados para trabajar 
formalmente por antecedentes penales que permanecieron durante años en sus hojas de vida, limitando significativamente sus oportunidades en la vida para sobreponerse a la experiencia de prisión.

Por su parte, la abstención de participación política de los hijos, puede ser una respuesta ante los hechos ocurridos a sus padres, de igual modo que la participación en partidos de izquierda. Creemos que estudiar el impacto psicosocial en los hijos es un campo de investigación bastante relevante, y esperamos hacerlo en posteriores investigaciones. Por último, observamos que el tema "hijos", fue un tema muy aludido por los EXPPS, motivo por el que creemos que presentan facilidad para hablar de este tipo de relaciones interpersonales, a diferencia de otros temas que hemos presentado anteriormente.

Tabla 17. Antecedentes demográficos familiares de nietos, ocio y salud de los participantes

\begin{tabular}{|c|c|c|c|c|c|c|c|c|c|c|c|c|}
\hline \multirow{6}{*}{$\begin{array}{c}\mathrm{NU} \\
\mathrm{DO} \\
\mathrm{S}\end{array}$} & \multirow{3}{*}{\multicolumn{2}{|c|}{$\begin{array}{c}\text { ANTECED } \\
\text { ENTES } \\
\text { FAMILIAR } \\
\text { ES } \\
\end{array}$}} & \multirow{3}{*}{\multicolumn{2}{|c|}{$\begin{array}{c}\text { ANTECED } \\
\text { ENTES DE } \\
\text { OCIO }\end{array}$}} & \multirow{2}{*}{\multicolumn{2}{|c|}{$\begin{array}{c}\text { ANTEC. } \\
\text { DE SALUD }\end{array}$}} & \multirow{3}{*}{\multicolumn{6}{|c|}{ ANTEC. ATTE. EN SALUD }} \\
\hline & & & & & & & & & & & & \\
\hline & & & & & \multirow{2}{*}{$\begin{array}{c}\text { Refie } \\
\text { re } \\
\text { ante }\end{array}$} & \multirow{2}{*}{$\begin{array}{l}\text { No } \\
\text { refier } \\
\mathrm{e}\end{array}$} & & & & & & \\
\hline & \multicolumn{2}{|c|}{ Nietos } & \multirow{3}{*}{$\begin{array}{l}\text { No } \\
\text { realiz } \\
\text { a } \\
\text { activi } \\
\text { dad }\end{array}$} & \multirow{3}{*}{$\begin{array}{c}\mathrm{Si} \\
\text { realiz } \\
\text { a } \\
\text { activi } \\
\text { dad }\end{array}$} & & & \multicolumn{4}{|c|}{ Momento } & \multicolumn{2}{|c|}{ Relac. exp. } \\
\hline & No & $\mathrm{Si}$ & & & \multirow{2}{*}{$\begin{array}{l}\text { c. } \\
\text { mór } \\
\text { bido } \\
\mathrm{s}\end{array}$} & \multirow{2}{*}{$\begin{array}{c}\text { antec. } \\
\text { mórb } \\
\text { idos }\end{array}$} & \multicolumn{2}{|c|}{ Pasado } & \multicolumn{2}{|c|}{ Presente } & \multirow{2}{*}{$\begin{array}{l}\text { Ning } \\
\text { una }\end{array}$} & \multirow{2}{*}{$\mathrm{Si}$} \\
\hline & & & & & & & $\begin{array}{l}\text { Atte. } \\
\text { médi } \\
\text { ca }\end{array}$ & $\begin{array}{l}\text { Attc } \\
\text { Psic } \\
\text { lógic }\end{array}$ & $\begin{array}{l}\text { Atte. } \\
\text { Médi } \\
\text { ca }\end{array}$ & $\begin{array}{c}\text { Atte } \\
\text { Psicológi } \\
\text { ca }\end{array}$ & & \\
\hline $\mathrm{S}$ & 0 & 41 & 1 & 15 & 27 & 0 & 13 & 8 & 6 & 4 & 1 & 8 \\
\hline$\%$ & 0 & 68 & 2 & 25 & 45 & 0 & 22 & 13 & 10 & 7 & 2 & 13 \\
\hline
\end{tabular}

La Tabla 17, nos entrega información de distintos aspectos demográficos de la vida de los EXPPS que inicialmente consideramos que podrían aportarnos información relevante para nuestro objeto de estudio. En cuanto a las relaciones interpersonales, la alusión a los nietos se presentó en más de la mitad de la muestra (68\%), lo que nos indica que la mayoría de la muestra cuenta con estos vínculos familiares en su vida.

En lo que respecta a un tema que consideramos que nos remite a la calidad de vida de los EXPPS, observamos que la mayoría de las personas que mencionaron el tema de actividades de ocio, realiza algún tipo de actividad de este tipo. No obstante, estas frecuencias corresponden apenas al 20\% de la muestra.

En términos de salud, la mayoría de las personas que hicieron referencia a su estado de salud (que no supera la media de sujetos entrevistados), aludió la presencia de antecedentes mórbidos en la actualidad, haber recibido y estar recibiendo atención médica. Todo lo que asocian a la experiencia de prisión. No obstante, esta última tendencia se presentó en el 13\% de la muestra. 
5.2. PARTE II. FRECUENCIAS POR SUJETO Y UNIDADES TEXTUALES U.T.S. DE LOS GRANDES TEMAS QUE CONFORMAN NUESTRO ÁRBOL DE CATEGORÍAS Y ABARCAN EL TOTAL DE LOS NUDOS HIJOS, ABORDADOS Y CODIFICADOS SEGÚN SU PRESENCIA EN LOS DISCURSOS DE LOS EXPPS ENTREVISTADOS

A continuación presentaremos algunos valores que el programa QSR Nvivo 6 nos arrojó y que nos darán una visión global de los resultados obtenidos.

a Total de documentos: $6 \odot$.

- Total de categorías jerárquicas que conforman el mapa conceptual (nudos padres + nudos hijos): 1305.

- Total de categorías codificadas (sólo nudos hijos): 784.

- Total de unidades de texto codificadas: 9900.

- Total de codificaciones: 18026.

Mediante el operador collect obtuvimos sumatorias de frecuencias por sujeto y U.T.s de nudos padres y nudos intermedios, que abarcaron la totalidad de nudos hijos de nuestro árbol de categorías.

1. Tablas collect de nudos padres a nudos intermedios.

La Tabla 1, presenta las frecuencias obtenidas en las categorías demográficas y conceptuales que comprenden la totalidad de temas de nuestro mapa conceptual.

Tabla 18. Collect de categorías demográficas y conceptuales

\begin{tabular}{|c|c|c|c|c|}
\hline \multirow[t]{2}{*}{ CATEGORÍAS: } & \multicolumn{2}{|c|}{$\begin{array}{c}\text { POR DOCUMENTO } \\
\mathrm{N}=60\end{array}$} & \multicolumn{2}{|c|}{$\begin{array}{c}\text { POR UNIDAD DE } \\
\text { ANÁLISIS } \\
\mathrm{N}=9900\end{array}$} \\
\hline & Frecuencia & \% según UR & Frecuencia & \% según UR \\
\hline (1)Antecedentes demográficos & $\underline{60}$ & 100 & 2532 & 26 \\
\hline (2)Antecedentes conceptuales & $\underline{60}$ & 100 & 6123 & $\underline{62}$ \\
\hline Promedios & 60 & & 4327.5 & \\
\hline
\end{tabular}

La Tabla 18, nos indica que el 100\% de la muestra refirió temáticas incluidas en las dos grandes ramas del árbol de categorías y que incluyen todos los temas que incluimos en nuestro estudio. Además nos muestra que el $62 \%$ del total de U.T.s codificadas en el proyecto, refiere temas incluidos en el nudo (2), obteniendo la 
moda según frecuencias de U.T.s codificadas. Deducimos de estos resultados que 1245 U.T.s (12.5\%) quedaron vacías de contenido o sin codificar.

Tabla 19. Collect de todas las variables de antecedentes conceptuales

\begin{tabular}{|c|c|c|c|c||}
\hline \multirow{2}{*}{$\begin{array}{c}\text { (2)ANTECEDENTES } \\
\text { CONCEPTUALES }\end{array}$} & \multicolumn{2}{|c|}{$\begin{array}{c}\text { POR DOCUMENTO } \\
\mathrm{N}=60\end{array}$} & \multicolumn{2}{c|}{$\begin{array}{c}\text { POR UNIDAD DE } \\
\text { ANÁLISIS } \\
\mathrm{N}=9900\end{array}$} \\
\cline { 2 - 5 } & Frecuencia & $\%$ según UR & Frecuencia & $\%$ según UR \\
\hline (2.1.) Presente & $\underline{\mathbf{6 0}}$ & 100 & $\underline{\mathbf{3 4 2 4}}$ & 35 \\
\hline (2.2.) Pasado & $\underline{\mathbf{6 0}}$ & 100 & 991 & 10 \\
\hline (2.3.) Prisión política & 59 & 98 & 935 & 9.4 \\
\hline (2.4.) Otras valoraciones & $\underline{\mathbf{6 0}}$ & 100 & 2342 & 14 \\
\hline Promedio & 59.7 & & 1923 & \\
\hline
\end{tabular}

La Tabla 19, nos indica que a excepción de una persona participante del estudio que no aludió el tema "prisión política" en su discurso, la totalidad de la muestra hizo referencia a todos los temas conceptuales que conforman nuestro mapa conceptual.

De acuerdo a las frecuencias de U.T.s codificadas del total del proyecto, observamos que el tema (2.1), obtuvo la moda de los temas conceptuales codificados, con un 35\% del total de U.T.s del proyecto. El nudo (2.4.) por su parte, supera también la media por U.T.s codificadas, con un $14 \%$ del total de estas unidades codificadas en el proyecto.

De acuerdo a estos resultados, podemos decir que los temas conceptuales referidos al "presente" de la vida de los EXPPS, fueron los más aludidos de las categorías conceptuales del proyecto. Por su parte, las temáticas que agrupamos en el nudo "otras valoraciones" superan la media de U.T.s de las ramas comprendidas en la Tabla 19, lo que puede deberse a la diversidad de temas y categorías que se incluyen en esta rama del árbol, y que refieren temas como la "reparación", las valoraciones que hacen los EXPPS de la sociedad chilena y la respuesta percibida en el tema de los derechos humanos. Temas que creemos son de gran interés para los participantes, y se relacionan directamente a sus problemáticas actuales. 
Tabla 20. Collect de antecedentes conceptuales del presente

\begin{tabular}{|c|c|c|c|c|}
\hline \multirow[t]{2}{*}{ PRESENTE } & \multicolumn{2}{|c|}{$\begin{array}{c}\text { POR DOCUMENTO } \\
\mathrm{N}=60\end{array}$} & \multicolumn{2}{|c|}{$\begin{array}{c}\text { POR UNIDAD DE } \\
\text { ANÁLISIS } \\
\text { N }=9900\end{array}$} \\
\hline & Frecuencia & \% según UR & Frecuencia & \% según UR \\
\hline (2.1.1.) Relaciones interpersonales actuales & $\underline{60}$ & 100 & $\underline{1693}$ & 17 \\
\hline (2.1.2.) Concepción de mundo & $\underline{\underline{60}}$ & 100 & 888 & 9 \\
\hline (2.1.3.) Ideología & $\underline{\underline{60}}$ & 100 & 716 & 7.2 \\
\hline (2.1.4.) Concepción seres humanos & 42 & 70 & 68 & 0.69 \\
\hline (2.1.5.) Valoración personal & 28 & 60 & 54 & 0.55 \\
\hline (2.1.6.) valoración ocupación actual & 34 & 57 & 58 & 0.59 \\
\hline (2.1.7.) valoración participación política & 29 & 48 & 64 & 0.65 \\
\hline (2.1.8) Sentido vida & 33 & 55 & 41 & 0.41 \\
\hline (2.1.9.) Valoración Chile actual & 22 & 37 & 41 & 0.41 \\
\hline (2.1.10.) Temores & 55 & 92 & 67 & 0.68 \\
\hline Promedio & 42.3 & & 369 & \\
\hline
\end{tabular}

La Tabla 20, nos indica que las categorías incluidas en los primeros tres nodos (2.1.1.), (2.1.2.) y (2.1.3.), se presentaron en el 100\% de los documentos, y por tanto obtienen la moda por documentos de los temas incluidos en la categoría "presente". Además supera la media de frecuencias por sujeto para este grupo de categorías, el nodo (2.1.10.) que se presentó en el 92\% de los documentos y que refiere los “temores" aludidos por los EXPPS.

Según las frecuencias por U.T.s codificadas para la categoría "presente", la moda la obtuvo el tema “relaciones interpersonales actuales" (2.1.1.), con un 17\% del total de U.T.s del proyecto. Además, superan la media los nudos “concepción de mundo"(2.1.2.), e "ideología” de los EXPPS (2.1.3.), que se presentaron en un $9 \%$ y $7 \%$ de los discursos respectivamente. Estos temas fueron los más aludidos del nudo "presente", lo que puede indicarnos que son temas de importancia para los EXPPS en la actualidad.

A continuación, hemos querido especificar las frecuencias obtenidas para la primera categoría incluida en la tabla precedente, de los tipos de relaciones interpersonales aludidos por los EXPPS participantes del estudio. Fundamentamos la incorporación de esta tabla, en nuestro interés por conocer la importancia de las relaciones interpersonales para los EXPPS que estudiamos, y creemos que estas alusiones pueden darnos una idea del interés que implican estas relaciones para ellos. En la siguiente sección, las estudiaremos en detalle. 
Tabla 21. Collect de antecedentes conceptuales de las relaciones interpersonales del presente

\begin{tabular}{||c|c|c|c|c||}
\hline \multirow{2}{*}{$\begin{array}{c}\text { (2.1.1.) RELACIONES } \\
\text { INTERPERSONALES }\end{array}$} & \multicolumn{2}{|c||}{ POR DOCUMENTO N $=60$} & \multicolumn{2}{c||}{ POR UNIDAD DE ANÁLISIS N = } \\
\cline { 2 - 5 } ACTUALES & Frecuencia & $\%$ según UR & Frecuencia & \% según UR \\
\hline Pareja & $\mathbf{4 3}$ & 72 & $\mathbf{3 6 0}$ & 3.6 \\
\hline Hijos & $\underline{\mathbf{6 0}}$ & 100 & $\underline{\mathbf{0 0 7}}$ & 6.1 \\
\hline Nietos & 12 & 20 & 17 & 0.17 \\
\hline Familia origen & $\mathbf{4 2}$ & 70 & 123 & 1.2 \\
\hline Amigos & $\underline{\mathbf{6 0}}$ & 100 & $\mathbf{5 4 1}$ & 5.5 \\
\hline Compañeros & 25 & 42 & 50 & 0.51 \\
\hline $\mathrm{X}$ & $\mathbf{4 0 . 3}$ & & 283 & \\
\hline
\end{tabular}

La tabla 21, nos indica que de las relaciones interpersonales actuales de los EXPPS entrevistados, las relaciones con "hijos" y "amigos" fueron aludidas por la totalidad de la muestra. Las relaciones con la "pareja" y la "familia de origen" superan también la moda por sujetos. En cuanto a las frecuencias por U.T.s codificadas para el nudo (2.1.1.), el tema "hijos" obtiene la moda y los temas "amigos" y "pareja" superan la media de frecuencias para el nudo 2.1.1. Todo lo que nos informa el alto interés que tienen estas relaciones para ellos.

Cabe mencionar que la alusión realizada por todos los participantes al tema "amigos", no nos indica necesariamente que todos los entrevistados dispongan de estas relaciones. Pues dentro de este tema existen clasificaciones que refieren el no tener amigos.

La frecuencia alcanzada por el tema "compañeros" de partidos políticos o agrupaciones de EXPPS, que no superó la media de aparición por sujetos, puede remitirnos a información de aspectos del impacto emocional y social que nos ocupa en este estudio.

Tabla 22. Collect de antecedentes conceptuales del pasado

\begin{tabular}{|c|c|c|c|c||}
\hline \multirow{2}{*}{ PASADO } & \multicolumn{2}{|c|}{$\begin{array}{c}\text { POR DOCUMENTO } \\
\mathrm{N}=60\end{array}$} & \multicolumn{2}{c|}{$\begin{array}{c}\text { POR UNIDAD DE } \\
\text { ANÁLISIS } \\
\text { N = 9900 }\end{array}$} \\
\cline { 2 - 5 } & \multicolumn{2}{|c|}{} & & \multicolumn{2}{c||}{$\begin{array}{c}\text { \% según } \\
\text { UR }\end{array}$} \\
\cline { 2 - 5 } & Frecuencia & $\%$ según UR & Frecuencia & 7.8 \\
\hline (2.2.1.) Relaciones interpersonales & $\underline{\mathbf{6 0}}$ & 100 & 61 & 0.62 \\
\hline (2.2.2.) Concepción de mundo & 50 & 83 & 54 & 0.55 \\
\hline (2.2.3.) Visión futuro & 41 & 68 & 65 & 0.66 \\
\hline (2.2.4.) Valoración de estar en mundo & $\mathbf{5 6}$ & 93 & 91 & 0.92 \\
\hline (2.2.5.) Sentido de vida & $\mathbf{5 7}$ & 95 & 209 & \\
\hline Promedio & 53 & & & $\mathbf{7 7 2}$ \\
\hline
\end{tabular}

La Tabla 22, nos indica que de los temas alusivos a la vida pasada de los EXPPS (previa a la experiencia de prisión), el tema "relaciones interpersonales" fue el único que se presentó en la totalidad de la 
muestra, obteniendo la moda además por U.T.s codificadas $(7.8 \%)$ del total de nudos comprendidos en el nudo "pasado". Es además el único tema que supera la media por U.T.s.

Otros nudos que superaron la media por documentos del nudo "pasado", aludieron a la valoración del cómo los EXPPS recuerdan haberse sentido en el mundo durante su adolescencia, y al sentido que otorgaban a la vida.

Tabla 23. Collect de antecedentes conceptuales de prisión política

\begin{tabular}{|c|c|c|c|c|}
\hline \multirow[t]{2}{*}{ PRISIÓN POLÍTICA } & \multicolumn{2}{|c|}{$\begin{array}{c}\text { POR DOCUMENTO } \\
\mathrm{N}=60\end{array}$} & \multicolumn{2}{|c|}{$\begin{array}{c}\text { POR UNIDAD DE } \\
\text { ANÁLISIS } \\
\mathrm{N}=9900\end{array}$} \\
\hline & Frecuencia & \% según UR & Frecuencia & \% según UR \\
\hline (2.3.1.) Valoración experiencia & 45 & 75 & 251 & 2.5 \\
\hline (2.3.2.) Actitud post-prisión & 50 & 83 & 129 & 1.3 \\
\hline (2.3.3.) Valoración impacto & $\underline{\underline{59}}$ & 98 & $\underline{463}$ & 4.7 \\
\hline (2.3.4.) Temores asociados & 23 & 38 & 39 & 0.39 \\
\hline (2.3.5.) Silencio personal & 38 & 63 & 99 & 1 \\
\hline (2.3.6.) Tortura y violencia & 4 & 6.7 & 5 & 0.05 \\
\hline (2.3.7.) Re-traumatización & 5 & 8.3 & 7 & 0.07 \\
\hline (2.3.8.) Valorac. superación experiencia & 28 & 47 & 47 & 0.47 \\
\hline (2.3.9.) Apoyo post-prisión & 26 & 43 & 44 & 0.44 \\
\hline (2.3.10.) Rechazo post-prisión & 5 & 8.3 & 6 & 0.06 \\
\hline Promedio & 30.8 & & 109 & \\
\hline
\end{tabular}

La tabla 23, nos indica que el tema "valoración del impacto" de la experiencia de prisión política y tortura fue aludido por casi la totalidad de la muestra, obteniendo la moda de frecuencias por sujeto y por U.T.s para el nudo "prisión política". Además los nudos (2.3.2.), (2.3.1.) y (2.3.5.) superan la media de sujetos entrevistados, de los cuales, los dos primeros superan la media por U.T.s codificadas para el tema "prisión política".

Lo anterior nos indica que los EXPPS aludieron mayoritariamente temas relacionados a: el impacto de la experiencia de prisión en sus vidas, la valoración subjetiva que hicieron de estas experiencias, la actitud que asumieron con posterioridad a la experiencia de prisión, y el silencio que mantuvieron de la experiencia. Todo lo que refiere valoraciones personales de la influencia de la experiencia de prisión en sus vidas y actitudes posteriores asociadas.

Observamos además, que no fueron mayormente referidas aquellas temáticas asociadas a aspectos que podríamos considerar dificultades en sus vidas y que acontecieron con posterioridad a la experiencia de prisión y producto de ella. Lo que podría deberse a que corresponden difíciles de abordar para los EXPPS, pudiendo significar temas dolorosos de su experiencia. 
Tabla 24. Antecedentes conceptuales de otras valoraciones

\begin{tabular}{|c|c|c|c|c|}
\hline \multirow[t]{2}{*}{ OTRAS VALORACIONES } & \multicolumn{2}{|c|}{$\begin{array}{c}\text { POR DOCUMENTO } \\
\mathrm{N}=60\end{array}$} & \multicolumn{2}{|c|}{$\begin{array}{c}\text { POR UNIDAD DE } \\
\text { ANÁLISIS } \\
\mathrm{N}=9900\end{array}$} \\
\hline & Frecuencia & \% según UR & Frecuencia & \% según UR \\
\hline (2.4.1.)Persecución política & 35 & 58 & 79 & 0.80 \\
\hline (2.4.2.) Régimen militar & 38 & 63 & 85 & 0.86 \\
\hline (2.4.3.) Reparación & $\underline{60}$ & 100 & $\underline{651}$ & 6.6 \\
\hline (2.4.4.) Soc. chilena y DDHH & $\underline{60}$ & 100 & 564 & 5.7 \\
\hline (2.4.5.) Opinión exilio & 13 & 22 & 28 & 0.28 \\
\hline Promedio & 48.2 & & 281.4 & \\
\hline
\end{tabular}

La tabla 24, nos indica que los nudos "reparación" y "sociedad chilena y derechos humanos" obtuvieron la moda por sujetos para el nudo "otras valoraciones", habiendo además superado la media por U.T.s, cuya moda la obtuvo el primero de los dos temas. Con esta información, podemos deducir que ambos temas son de mucho interés para los EXPPS entrevistados.

\subsection{PARTE III. FRECUENCIAS DE LAS SUMATORIAS DE NUDOS HIJOS (HOJAS DEL ÁRBOL DE CATEGORÍAS).}

Los resultados que presentamos a continuación, han sido obtenidos con el programa nvivo6, mediante la sumatoria de las frecuencias de tablas coding de datos binarios, en que " 1 " corresponde a la presencia de un tema, y "O" a su ausencia. Hemos resumido los resultados según la presencia de los temas por sujeto (o documento), y por U.T.s que en nuestro proyecto ha sido el párrafo. Algunos de los nudos han sido agrupados con el empleo de las funciones "collect" y "union" del programa Nvivo6. (estas uniones corresponden al orden de presentación de las categorías definidas en nuestro estudio y agrupadas en el capítulo IV). Por último, algunas tablas contienen datos de tablas precedentes que hemos decidido presentar, porque consideramos que aportaban mayores antecedentes para el entendimiento del impacto que estudiamos. En cada caso, se harán las especificaciones correspondientes.

El orden que seguiremos para presentar los resultados de esta sección, será el siguiente:

a. Tablas por sujeto y U.T.s en frecuencias y porcentajes de nudos agrupados y en algunos casos, no agrupados.

b. Análisis de las modas obtenidas en cada tabla y posterior a cada una de ellas.

c. Tablas que presenta el nudo hijo que obtuvo la moda entre nudos hijos que fueron agrupados cuando la tabla presenta datos de nudos hijos agrupados. 
d. Una o más U.T.s que serán presentadas a modo de ejemplo de las codificaciones que realizamos y que ha sido extraído de los discursos de los EXPPS que corresponda al nudo referido en la parte c.

\subsubsection{Antecedentes conceptuales del presente}

\subsubsection{Valoración de relaciones interpersonales actuales específicas}

Tabla 25. Antecedentes conceptuales de la pareja actual

\begin{tabular}{||c|c|c|c|c|c||}
\hline \multirow{2}{*}{ PAREJA } & \multicolumn{3}{|c|}{ POR DOCUMENTO } & \multicolumn{2}{c||}{$\begin{array}{c}\text { POR UNIDAD DE } \\
\text { ANÁLISIS }\end{array}$} \\
\cline { 2 - 6 } & \multirow{2}{*}{ Frecuencia } & $\mathrm{N}=60$ & $\mathrm{n}=43$ & \multicolumn{2}{c||}{$\mathrm{N}=9900$} \\
\cline { 3 - 6 } & & $\%$ según UR & $\%$ según UR & Frecuencia & \% según UR \\
\hline Valoración positiva & $\underline{\mathbf{4 0}}$ & 67 & 93 & $\underline{\mathbf{2 0 5}}$ & 2.1 \\
\hline Valoración negativa & 18 & 30 & 42 & 69 & 0.7 \\
\hline
\end{tabular}

Como nos indica la tabla 25, de los 43 sujetos que hicieron alusión a su "pareja" actual, la mayoría de ellos (93\% de quienes aludieron la temática y $67 \%$ de la muestra) realizó una "valoración positiva" de estas relaciones. Esta valoración se presentó en alrededor de cinco U.T.s por discurso. Por su parte, el 30\% de participantes valoró negativamente estas relaciones. Además observamos que del total de personas que valoraron el tema "pareja" en su vida presente, un grupo de 15 personas hicieron alusiones negativas y positivas a la vez de estas relaciones.

Tabla 26. Tema específico más aludido para la categoría pareja actual

\begin{tabular}{|ll|}
\hline Por documentos & \multicolumn{1}{c|}{ Por U.T.s } \\
\hline $\begin{array}{l}\text { Valoración global satisfacción: } \\
\text { satisfecho }(55 \%)\end{array}$ & Valoración global satisfacción: \\
satisfecho $(0.44 \%)$
\end{tabular}

...eh, Lo conozco hace como un año y medio. Super buena [la relación], excelente todo, y, y lo más bonito, o sea, en la medida que, que van pasando los días, lo voy conociendo más... todo; y un día salió el tema de, de los derechos humanos, y resulta que él también estuvo detenido eh... 70 días, y no hizo los trámites.. (mujer, 35 años). 
Tabla 27. Antecedentes conceptuales de los hijos

\begin{tabular}{|c|c|c|c|c|}
\hline \multirow[t]{2}{*}{ HIJOS } & \multicolumn{2}{|c|}{$\begin{array}{c}\text { POR DOCUMENTO } \\
\mathrm{N}=60\end{array}$} & \multicolumn{2}{|c|}{$\begin{array}{c}\text { POR UNIDAD DE } \\
\text { ANÁLISIS } \\
\mathrm{N}=9900 \\
\end{array}$} \\
\hline & Frecuencia & \% según UR & Frecuencia & \% según UR \\
\hline Valoración positiva & $\underline{59}$ & 98 & $\underline{392}$ & 4 \\
\hline Valoración negativa & 43 & 72 & 182 & 1.8 \\
\hline
\end{tabular}

Como observamos en la tabla 27, la totalidad de la muestra habló de sus relaciones interpersonales actuales con los hijos, valorándolas mayoritariamente de manera positiva (98\%). La misma tendencia se presentó en cuanto a U.T.s codificadas que alcanza el $4 \%$ del total de las U.T.s codificadas del proyecto, equivalente aproximadamente a siete alusiones por discurso.

Por su parte, las valoraciones negativas que se hicieron de estas relaciones, estuvieron presentes en el $72 \%$ de los discursos, lo que nos indica que más de la mitad de la muestra se encuentra insatisfecho con sus hijos. Esta tendencia se presentó en alrededor de 4 U.T.s por sujeto.

Observamos además que de los sujetos que hicieron valoraciones positivas y negativas, un grupo hace referencia a ambas valoraciones de manera simultánea. Lo que nos indica que sus apreciaciones pueden ser en relación a distintos hijos o a distintos aspectos de sus relaciones con éstos.

Tabla 28. Tema específico más aludido para la categoría hijos

\begin{tabular}{|ll|}
\hline Por documentos & Por U.T.s \\
\hline $\begin{array}{l}\text { Valoración tipo de relación: } \\
\text { "buena" }(77 \%)\end{array}$ & $\begin{array}{l}\text { Valoración tipo de relación: } \\
\text { "buena" }(0.79 \%)\end{array}$ \\
\hline
\end{tabular}

Y la relación con mis hijos siempre ha sido muy buena. Eh... tengo muy buena relación con todos, porque en la práctica yo los crié sola. Para el golpe de estado yo era dirigente, mi esposo era dirigente, y ambos fuimos... yo quería. Como sabía que mi esposo tuvo que salir del país, y yo me quedé. Con mis hijos, claro. $\Upsilon$ a mi hijo el menor, el que va a contestar, él tenía tres años. $E l$ mayor tenía doce. Todos seguiditos, el único diferente era él que después de cinco años lo tuve a éh, al último. Y todos los demás fueron por un año. Cuando yo me quedé con mis hijos eh... empezó la tarea de ser papá y mamá poh (mujer, 64 años). 
Tabla 29. Antecedentes conceptuales de los nietos

\begin{tabular}{|c|c|c|c|c|c|}
\hline \multirow[t]{3}{*}{ NIETOS } & \multicolumn{3}{|c|}{ POR DOCUMENTO } & \multirow{2}{*}{\multicolumn{2}{|c|}{$\begin{array}{c}\text { POR UNIDAD DE } \\
\text { ANÁLISIS } \\
\mathrm{N}=9900\end{array}$}} \\
\hline & \multicolumn{2}{|c|}{$\mathrm{N}=60$} & \multirow{2}{*}{$\frac{\mathrm{n}=12}{\% \text { según UR }}$} & & \\
\hline & Frecuencia & \% según UR & & Frecuencia & \% según UR \\
\hline Valoración positiva & 9 & 15 & 75 & 11 & 0.11 \\
\hline Valoración negativa & 5 & 8.3 & 42 & 6 & 0.06 \\
\hline
\end{tabular}

En cuanto a la relación de los EXPPS con sus nietos, 12 personas valoraron estas relaciones en sus vidas, quienes hicieron mayoritariamente una valoración positiva (75\%). La misma tendencia se presenta en cuanto a U.T.s, no superando a 1 U.T.s por sujeto. Por último, dos personas refieren valoraciones negativas y positivas al respecto.

Tabla 30. Tema específico más aludido para la categoría nietos

\begin{tabular}{|ll|}
\hline Por documentos & \multicolumn{1}{c|}{ Por U.T.s } \\
\hline $\begin{array}{l}\text { Valoración de afectos: } \\
\text { "presencia" }(13 \%)\end{array}$ & Valoración de afectos: \\
\hline
\end{tabular}

"Bueno claro, Los más cercanos en éstos momentos son mis hijos y mi nieta. Los dos hijos mayores y mi nieta que tiene... 12 años" (varón, 62 años).

Tabla 31. Antecedentes conceptuales de la familia de origen en el presente

\begin{tabular}{||c|c|c|c|c|c||}
\hline \multirow{2}{*}{$\begin{array}{c}\text { FAMILIA DE } \\
\text { ORIGEN EN EL } \\
\text { PRESENTE }\end{array}$} & \multicolumn{3}{|c||}{ POR DOCUMENTO } & \multicolumn{2}{c||}{$\begin{array}{c}\text { POR UNIDAD DE } \\
\text { ANÁLISIS }\end{array}$} \\
\cline { 2 - 6 } & Frecuencia & $\mathrm{N}=60$ & $\mathrm{n}=42$ & \multicolumn{2}{c||}{ N = 9900 } \\
\cline { 2 - 6 } & \% según UR & $\%$ según UR & Frecuencia & $\%$ según UR \\
\hline Valoración positiva & $\underline{\mathbf{3 4}}$ & 57 & 80.9 & $\underline{\mathbf{8 1}}$ & 0.82 \\
\hline Valoración negativa & 17 & 28 & 40 & 40 & 0.40 \\
\hline \hline
\end{tabular}

La Tabla 31, nos indica que la mayoría de EXPPS hizo alusión a la valoración que hace de su familia de origen en la actualidad. A su vez, la mayoría de estas personas, hace una valoración positiva de estas relaciones, representadas por más de la mitad de la muestra participante del estudio. Las alusiones por sujeto fueron presentadas en alrededor de dos U.T.s por discurso. 
Tabla 32. Antecedentes conceptuales de la disposición de amigos en el presente

\begin{tabular}{|c|c|c|c|c|}
\hline \multirow[t]{2}{*}{ AMIGOS (A) } & \multicolumn{2}{|c|}{$\begin{array}{c}\text { POR DOCUMENTO } \\
\mathrm{N}=60\end{array}$} & \multicolumn{2}{|c|}{$\begin{array}{c}\text { POR UNIDAD DE } \\
\text { ANÁLISIS } \\
\mathrm{N}=9900\end{array}$} \\
\hline & Frecuencia & \% según UR & Frecuencia & \% según UR \\
\hline No tiene & 21 & 35 & 37 & 0.37 \\
\hline Si tiene & $\underline{52}$ & 87 & $\underline{506}$ & 5.1 \\
\hline
\end{tabular}

La Tabla 32, nos indica que todos los EXPPS participantes del estudio refirieron tener o no amigos en el presente. La mayoría de estas personas afirman tener amigos. Lo que fue manifestado aproximadamente en 9 U.T.s por discurso. Por el contrario, el 35\% de la muestra negó tener relaciones de amistad.

De todas las personas que aludieron tener y no tener amigos, deducimos de la tabla que un grupo de 13 personas refiere simultáneamente las dos apreciaciones.

Tabla 33. Antecedentes conceptuales de la valoración de los amigos en el presente

\begin{tabular}{||c|c|c|c|c||}
\hline \multirow{2}{*}{ AMIGOS (B) } & \multicolumn{2}{|c|}{$\begin{array}{c}\text { POR DOCUMENTO } \\
\mathrm{N}=60\end{array}$} & \multicolumn{2}{c|}{$\begin{array}{c}\text { POR UNIDAD DE } \\
\text { ANÁLISIS } \\
\text { N=9900 }\end{array}$} \\
\cline { 2 - 5 } & Frecuencia & \% según UR & Frecuencia & $\%$ según UR \\
\cline { 2 - 5 } & 17 & 28 & 38 & 0.38 \\
\hline Valoración negativa & $\underline{\mathbf{4 8}}$ & 80 & $\underline{\mathbf{3 0 7}}$ & 3.1 \\
\hline Valoración positiva & \multicolumn{3}{|c}{} \\
\hline
\end{tabular}

Los datos de la Tabla 33, se desprenden de las frecuencias agrupadas en la variable "si tiene" de la tabla 32. Así, observamos que la mayoría de sujetos que refirió tener amigos, hace una "valoración positiva" de estas relaciones. Lo que se presentó aproximadamente en 6 U.T.s por discurso. El resto de participantes, equivalente al 30\%, valoran negativamente estas relaciones. Un grupo menor incluido en la tabla (5 personas), refieren simultáneamente ambas valoraciones en sus discursos.

Tabla 34. Tema específico más aludido para la categoría valoración de los amigos en el presente

\begin{tabular}{|ll|}
\hline Por documentos & \multicolumn{1}{c|}{ Por U.T.s } \\
\hline $\begin{array}{l}\text { Valoración global satisfacción: } \\
\text { "satisfecho" }(63 \%)\end{array}$ & $\begin{array}{l}\text { Valoración global satisfacción: } \\
\text { "satisfecho" }(0.54 \%)\end{array}$ \\
\hline
\end{tabular}

Amigos tengo también, no muchos, pero tengo. En eso soy muy selectiva para mis amigos no me entrego asi tan fácilmente. Eh... amigas tengo por ejemplo de aquellas de que conserve de cuando era estudiante hace muchísimos años de la enseñanza básica; tengo mis colegas, que fueron colegas míos que nos mantenemos en un grupo que nos juntamos todas las semanas que tomamos un cafecito, que vamos a bailar, que nos vamos a tomar un traguito por ahí, pero son pocos pero muy buenos también y de mucha confianza, típico de los amigos que eh dependemos 
unos de otros en al... ayudar.... algunos sentidos cuando alguien tiene uno problema los demás están afí para apoyarla, así considero yo que mi relación es muy rica (mujer, 59 años).

Tabla 35. Antecedentes conceptuales de la disposición de compañeros en el presente

\begin{tabular}{||c|c|c|c|c|c||}
\hline \multirow{3}{*}{ COMPANEROS } & \multicolumn{3}{|c|}{ POR DOCUMENTO } & \multicolumn{2}{c|}{$\begin{array}{c}\text { POR UNIDAD DE } \\
\text { ANÁLISIS }\end{array}$} \\
\cline { 2 - 6 } & \multicolumn{2}{|c|}{$\mathrm{N}=60$} & $\mathrm{n}=25$ & \multicolumn{2}{c||}{$\mathrm{N}=9900$} \\
\cline { 2 - 6 } & Frecuencia & $\%$ según UR & $\%$ según UR & Frecuencia & $\%$ según UR \\
\hline No tiene relación & 0 & 0 & 0 & 0 & 0 \\
\hline Si tiene relación & $\underline{\mathbf{2 5}}$ & 42 & 100 & $\underline{\mathbf{5 0}}$ & 0.51 \\
\hline \hline
\end{tabular}

De acuerdo a los datos de la Tabla 35, podemos ver que menos de la mitad de sujetos entrevistados hizo referencia a las relaciones que mantienen en la actualidad con sus compañeros políticos. Sin embargo del $42 \%$ de la muestra que aludió la presencia o ausencia de estas relaciones en su vida, todos refirieron tener este tipo de relaciones. Lo que manifestaron en dos U.T.s promedio por discurso.

Tabla 36. Antecedentes conceptuales de la valoración de los compañeros en el presente

\begin{tabular}{||c|c|c|c|c|c||}
\hline \multirow{3}{*}{ COMPAÑEROS (B) } & \multicolumn{3}{|c||}{ POR DOCUMENTO } & \multicolumn{2}{c||}{$\begin{array}{c}\text { POR UNIDAD DE } \\
\text { ANÁLISIS }\end{array}$} \\
\cline { 2 - 6 } & \multicolumn{2}{|c|}{$\mathrm{N}=60$} & $\mathrm{~N}=25$ & \multicolumn{2}{c||}{ =9900 } \\
\cline { 2 - 6 } & Frecuencia & $\%$ según UR & $\%$ según UR & Frecuencia & $\%$ según UR \\
\hline Valoración negativa & 5 & 8.3 & 20 & 6 & 0.6 \\
\hline Valoración positiva & $\underline{\mathbf{1 6}}$ & 27 & 64 & $\underline{\mathbf{2 5}}$ & 0.25 \\
\hline \hline
\end{tabular}

De quienes refirieron mantener relaciones interpersonales actuales con sus compañeros, la mayoría hace una "valoración positiva" de estas relaciones en sus vidas. Cuya tendencia se mantiene en cuanto a U.T.s codificadas, que no superaron a dos párrafos por sujeto.

Tabla 37. Tema específico más aludido para la categoría valoración de los compañeros en el presente

\begin{tabular}{|ll|}
\hline \multicolumn{1}{|c|}{ Por documentos } & \multicolumn{1}{c|}{ Por U.T.s } \\
\hline $\begin{array}{l}\text { Valoración global satisfacción: } \\
\text { "satisfecho" }(27 \%)\end{array}$ & $\begin{array}{l}\text { Valoración global satisfacción: } \\
\text { "satisfecho" }(0.25 \%)\end{array}$ \\
\hline
\end{tabular}

“... mire, claro, claro, claro. Pero yo creo que el compañero es más, más amigo de uno que amigo. Claro" (varón, 77 años).

“...En realidad yo diría que mis hijas menores me apoyan más que los mayores que pasaron más peripecias conmigo. $\Upsilon$ también tengo mas apoyo de afuera. De mis amigas, de otros compañeros, pero mis hijas mayores y este tipo, no" (mujer, 63 años). 
Tabla 38. Antecedentes conceptuales de la disposición de apoyo incondicional en el presente

\begin{tabular}{||c|c|c|c|c||}
\hline \hline \multirow{3}{*}{$\begin{array}{c}\text { APOYO } \\
\text { INCONDICIONAL }\end{array}$} & \multicolumn{2}{|c|}{$\begin{array}{c}\text { POR DOCUMENTO } \\
\mathrm{N}=60\end{array}$} & \multicolumn{2}{c|}{$\begin{array}{c}\text { POR UNIDAD DE } \\
\text { ANÁLISIS } \\
\text { N=9900 }\end{array}$} \\
\cline { 2 - 5 } & \multicolumn{2}{|c||}{$\begin{array}{c}\% \text { según UR } \\
\text { Frecuencia }\end{array}$} & Frecuencia & $\%$ según UR \\
\hline No dispone & 4 & 6.7 & 4 & 0.04 \\
\hline Si dispone & $\underline{\mathbf{5 6}}$ & 93 & $\underline{\mathbf{6 8}}$ & 0.69 \\
\hline
\end{tabular}

Al ser consultados los EXPPS acerca de la disposición de apoyo incondicional en sus vidas, la totalidad de estas personas se manifestó al respecto. De ellos, la mayoría afirmó disponer de este tipo de apoyo. Lo que se presentó en un promedio de una U.T.s por discurso.

Tabla 39. Antecedentes conceptuales del tipo de vinculación de apoyo incondicional disponible en el presente

\begin{tabular}{||c|c|c|c|c|c||}
\hline \multirow{2}{*}{$\begin{array}{c}\text { APOYO } \\
\text { INCONDICIONAL } \\
\text { SI DISPONE (B) }\end{array}$} & \multicolumn{3}{|c|}{ POR DOCUMENTO } & \multicolumn{2}{c||}{$\begin{array}{c}\text { POR UNIDAD DE } \\
\text { ANÁLISIS }\end{array}$} \\
\cline { 2 - 6 } & \multicolumn{2}{|c|}{$\mathrm{N}=60$} & $\mathrm{n}=56$ & \multicolumn{2}{c||}{ N =9900 } \\
\cline { 2 - 6 } & Frecuencia & $\%$ según UR & $\%$ según UR & Frecuencia & $\%$ según UR \\
\hline Familia actual & $\underline{\mathbf{2 8}}$ & 47 & 50 & $\underline{\mathbf{2 9}}$ & 0.29 \\
\hline Familia de origen & $\mathbf{1 3}$ & 22 & 23 & $\mathbf{1 5}$ & 0.15 \\
\hline Otros familiares & 10 & 17 & 18 & 11 & 0.11 \\
\hline Amigos & $\mathbf{1 3}$ & 22 & 23 & $\mathbf{1 7}$ & 0.17 \\
\hline Compañeros & 3 & 5 & 5 & 4 & 0.04 \\
\hline Otros & 7 & 12 & 13 & 10 & 0.10 \\
\hline $\mathrm{X}$ & 12.33 & \multicolumn{5}{|l}{} \\
\hline
\end{tabular}

La Tabla 39, presenta el tipo de relación que tienen los EXPPS que afirmaron contar con apoyo incondicional en su vida presente, y vemos que ningún valor supera la media de sujetos entrevistados, pero la moda la obtienen integrantes de la "familia actual", que fue referida por un $47 \%$ de la muestra. El mismo grupo obtiene la moda por U.T.s, que en promedio fue aludido una vez por discurso.

Además, superan la media por sujetos y U.T.s, los “amigos” y la "familia de origen”. Ambas categorías están presentes en aproximadamente una U.T.s por discurso.

La Tabla 39, además nos indica que del grupo de EXPPS que refirió disponer de este tipo de apoyo en sus vidas, algunos manifiestan tener más de una relación interpersonal que valoran de manera incondicional, y de grupos diferentes de los presentados en la tabla. 
Tabla 40. Tema específico más aludido para la categoría tipo de vinculación de apoyo incondicional disponible en el presente

\begin{tabular}{|ll|}
\hline Por documentos & \multicolumn{1}{c|}{ Por U.T.s } \\
\hline Familia: “hijos” (28\%) & Familia: “hijos" $(0.17 \%)$ \\
& Familia: “amigos" $(0.17 \%)$ \\
\hline
\end{tabular}

Cualquiera de mis hijos, en ese aspecto. $\Upsilon$ mis amigas también. Yo se que en caso de... Bueno hay también compañeros también diría como institución que me apoyarían. Cómo no me van a apoyar los del comité. Si es mi partido. O sea en ese aspecto no me siento... (mujer, 63 años).

Tabla 41. Antecedentes conceptuales de la concepción del mundo en el presente

\begin{tabular}{||c|c|c|c|c||}
\hline \multirow{2}{*}{$\begin{array}{c}\text { CONCEPCIÓN DEL } \\
\text { MUNDO }\end{array}$} & \multicolumn{2}{|c|}{$\begin{array}{c}\text { POR DOCUMENTO } \\
\mathrm{N}=60\end{array}$} & \multicolumn{2}{c|}{$\begin{array}{c}\text { POR UNIDAD DE } \\
\text { ANÁLISIS } \\
\text { N =9900 }\end{array}$} \\
\cline { 2 - 5 } & Frecuencia & $\%$ según UR & Frecuencia & $\%$ según UR \\
\hline Valoración negativa & $\underline{\mathbf{6 0}}$ & 100 & $\mathbf{5 2 8}$ & 5.3 \\
\hline Valoración positiva & 51 & 85 & 150 & 1.5 \\
\hline \hline
\end{tabular}

Según la Tabla 41, la totalidad de sujetos se refirió a la temática "concepción del mundo" en el presente, valorándolo de manera negativa. Lo que estuvo presente en el 5\% del total de U.T.s codificadas en el proyecto (aproximadamente 9 unidades textuales por discurso). Sin embargo, el 85\% de sujetos, hizo valoraciones positivas del mundo, manifestado en alrededor de 3 U.T.s por discurso.

Lo anterior nos indica que aunque la totalidad de EXPPS valoran negativamente el mundo en general, también valoran aspectos positivos de éste.

Tabla 42. Tema específico más aludido para la categoría concepción de mundo en el presente

\begin{tabular}{|ll|}
\hline Por documentos & \multicolumn{1}{c|}{ Por U.T.s } \\
\hline $\begin{array}{l}\text { Valoración global / negativa: } \\
\text { "causa humana" }(63 \%)\end{array}$ & $\begin{array}{l}\text { Valoración global / negativa: } \\
\text { "causa humana" }(0.62)\end{array}$ \\
\hline
\end{tabular}

A ver con palabras mías. ¡Vy!, difícil, porque veo el mundo realmente en una escala valórica muy mala. Eh... una falta de solidaridad, un individualismo extremo, aqui cada uno se salva por si solo; eh... como que necesariamente entro a comparar lo que yo viví en mi infancia con lo que se vive hoy, en que el vecino no le interesa cómo está el de al lado, si está pasando hambre, qué se yo, cesante, o qué, no le interesa. Muy frí, muy impersonal veo este mundo. Creo que está, le está faltando el, el separarse un poco de las cosas materiales y dedicarse más a lo que uno siente como persona (varón 51 años). 
Tabla 43. Antecedentes conceptuales de ideología en el presente

\begin{tabular}{|c|c|c|c|c||}
\hline \multirow{2}{*}{\begin{tabular}{c} 
IDEOLOGÍA \\
\cline { 2 - 5 }
\end{tabular}} & \multicolumn{2}{|c|}{$\begin{array}{c}\text { POR DOCUMENTO } \\
\mathrm{N}=60\end{array}$} & \multicolumn{2}{c|}{$\begin{array}{c}\text { POR UNIDAD DE } \\
\text { ANÁLISIS N = 9900 }\end{array}$} \\
\cline { 2 - 5 } & Frecuencia & $\%$ según UR & Frecuencia & $\%$ según UR \\
\hline Valores & 56 & 93 & 82 & 0.83 \\
\hline Creencias & $\underline{\mathbf{6 0}}$ & 100 & $\underline{\mathbf{5 3 7}}$ & 5.4 \\
\hline Sentido relaciones afectivas que dispone & 57 & 95 & 108 & 1.1 \\
\hline
\end{tabular}

La Tabla 43, nos indica que todos los sujetos participantes de la muestra mencionaron aspectos de su ideología en sus discursos. En general, los tres temas que componen este tema, son referidos simultáneamente por la mayoría de sujetos entrevistados. De quienes la subcategoría "creencias" obtiene la moda por sujetos y U.T.s codificadas, presentándose en el $100 \%$ de los discursos (aproximadamente 9 unidades por cada documento).

Tabla 44. Antecedentes conceptuales de ideología en el presente de la valoración de creencias específicas

\begin{tabular}{|c|c|c|c|c|}
\hline \multirow{2}{*}{$\begin{array}{c}\text { VALORACIÓN } \\
\text { CREENCIAS } \\
\text { ESPECÍFICAS } \\
\text { (RELIGIOSAS, JUSTICIA, } \\
\text { AMOR, PAZ, PERSONAS, } \\
\text { FELICIDAD) }\end{array}$} & \multicolumn{2}{|c|}{$\begin{array}{c}\text { POR DOCUMENTO } \\
\mathrm{N}=60\end{array}$} & \multicolumn{2}{|c|}{$\begin{array}{c}\text { POR UNIDAD DE } \\
\text { ANÁLISIS } \\
\mathrm{N}=9900\end{array}$} \\
\hline & Frecuencia & \% según UR & Frecuencia & \% según UR \\
\hline No cree & 36 & 60 & 72 & 0.73 \\
\hline Si cree & $\underline{59}$ & 98 & $\underline{396}$ & 4 \\
\hline
\end{tabular}

Vemos en la Tabla 44, que las modas por categoría y U.T.s nos señalan que casi la totalidad de los EXPPS entrevistados (98\%), afirmaron creer en los aspectos consultados. Lo que expresaron en aproximadamente siete U.T.s cada uno.

No obstante lo anterior, más de la mitad de la muestra refirió no creer en algunos aspectos especificados que fueron consultados en la entrevista en profundidad administrada, lo que se presentó en un promedio de 2 U.T.s por discurso.

Tabla 45. Tema específico más aludido para la categoría valoración de creencias específicas

\begin{tabular}{|c|c|}
\hline Por documentos & Por U.T.s \\
\hline $\begin{array}{l}\text { Valoración específica: } \\
\text { “amor”/ “si” ( }(90 \%)\end{array}$ & $\begin{array}{l}\text { Valoración específica: } \\
\text { "religiosas o espirituales" } \\
\text { "si" }(1.6 \%)\end{array}$ \\
\hline
\end{tabular}

¿En qué creo? Creo en la justicia. Creo en la lealtad, creo en el amor creo mucho y producto de todas esas creencias creo también en el creer, en la existencia de algo más. Creo que uno no está en 
este planeta, o no está en la vida o en este plano de vida eh para no estar. Uno está para comprender a otros planos a otras cosas, y por eso acojo con mucha, con mucha alegría digamos la existencia de Dios (varón, 54 años).

Tabla 46. Antecedentes conceptuales de ideología del sentido otorgado a las relaciones afectivas en el presente

\begin{tabular}{|c|c|c|c|c|c|}
\hline \multirow{3}{*}{$\begin{array}{l}\text { SENTIDO } \\
\text { RELACIONES } \\
\text { AFECTIVAS QUE } \\
\text { DISPONE } \\
\end{array}$} & \multicolumn{3}{|c|}{ POR DOCUMENTO } & \multirow{2}{*}{\multicolumn{2}{|c|}{$\begin{array}{c}\text { POR UNIDAD DE } \\
\text { ANÁLISIS } \\
\mathrm{N}=9900\end{array}$}} \\
\hline & \multirow{2}{*}{ Frecuencia } & $\mathrm{N}=60$ & $\mathrm{~N}=57$ & & \\
\hline & & $\begin{array}{c}\text { \% según } \\
\text { UR }\end{array}$ & $\begin{array}{c}\text { \% según } \\
\text { UR }\end{array}$ & Frecuencia & \% según UR \\
\hline Valoración positiva & $\underline{52}$ & $\underline{87}$ & 91 & $\underline{93}$ & 0.94 \\
\hline Valoración negativa & 8 & 13.3 & 14 & 10 & 0.10 \\
\hline
\end{tabular}

Como observamos en la Tabla 46, la mayoría de las personas entrevistadas (87\%) refirió el sentido que otorgan a las relaciones afectivas que disponen, valorando positivamente este aspecto, en un promedio de una U.T.s. Además observamos, que un grupo menor (tres personas) que aludió la temática en cuestión, refiere simultáneamente ambos tipos de valoraciones.

Tabla 47. Tema específico más aludido para la categoría sentido otorgado a las relaciones afectivas en el presente

\begin{tabular}{|ll|}
\hline Por documentos & \multicolumn{1}{c|}{ Por U.T.s } \\
\hline $\begin{array}{l}\text { Valoración global: “satisfecho" } \\
(65 \%)\end{array}$ & $\begin{array}{l}\text { Valoración global: } \\
\text { "satisfecho" }(0.49)\end{array}$ \\
\hline
\end{tabular}

... a mi esposa, las relaciones claro las relaciones con mi esposa... también es importante, porque resulta de que... es importante porque con mi señora hemos pasado muchas cosas, ¿cierto?, como de juventud... a lo mejor ella estuvo afí... y aparte que tenemos nuestras hijas que, porque yo le doy un sentido a la vida porque yo pensé que ya desde el año 73 que ya no iba a existir. Entonces, ver que en estos momentos estoy vivo todavía, y veo a mis hijas y me satisface mucho. en ese sentido (varón, 58 años).

Tabla 48. Antecedentes conceptuales de la concepción de seres humanos en el presente

\begin{tabular}{|c|c|c|c|c|c|}
\hline \multirow{3}{*}{$\begin{array}{c}\text { CONCEPCIÓN SERES } \\
\text { HUMANOS }\end{array}$} & \multicolumn{3}{|c|}{ POR DOCUMENTO } & \multirow{2}{*}{\multicolumn{2}{|c|}{$\begin{array}{c}\text { POR UNIDAD DE } \\
\text { ANÁLISIS } \\
\mathrm{N}=9900\end{array}$}} \\
\hline & \multirow[t]{2}{*}{ Frecuencia } & $\mathrm{N}=60$ & $\mathrm{n}=42$ & & \\
\hline & & $\begin{array}{c}\text { \% según } \\
\text { UR }\end{array}$ & $\begin{array}{c}\text { \% según } \\
\text { UR }\end{array}$ & Frecuencia & $\begin{array}{c}\text { \% según } \\
\text { UR }\end{array}$ \\
\hline Valoración negativa & $\underline{25}$ & 60 & 42 & $\underline{40}$ & 0.40 \\
\hline Valoración positiva & 17 & 40 & 28 & 21 & 0.21 \\
\hline
\end{tabular}


Según la Tabla 48, más de la mitad de la muestra hizo referencia a la concepción que hacen de los seres humanos. De quienes la mayoría realiza exclusivamente una valoración global negativa. Lo que se presenta de una a dos U.T.s por sujeto.

Tabla 49. Tema específico más aludido para la categoría concepción de seres humanos en el presente

\begin{tabular}{|ll|}
\hline Por documentos & \multicolumn{1}{c|}{ Por U.T.s } \\
\hline $\begin{array}{l}\text { Concepción seres humanos: } \\
\text { "visión negativa" }(42 \%)\end{array}$ & $\begin{array}{l}\text { Concepción seres humanos: } \\
\text { "visión negativa" }(0.40)\end{array}$ \\
\hline
\end{tabular}

Los seres fumanos, el ser fumano es un, es un cómo se llama, es un, es un ente evolutivo, ¿ya?, y lamentablemente va cambiando de acuerdo a las circunstancias que les ponen las sociedades, los sistemas, prueba de eso yo lo tengo más claro que nunca, o sea, esta prueba, to que es Chile hoy día, Estados Unidos les está poniendo el modelo económico a Chile, y ahí usted va a ver a... porque aquí no hay, pero de Iquique pa' allá usted va a los Malls y la gente anda paseando en los malls y aunque no tenga ni un veinte pa' comer y están todos endeudados con tarjetas. Entonces creo, ¿ya?, en el ser humano, pero lamentablemente no creo en su capacidad de usar el cerebro, la cabeza pa poder estudiar y ver las realidades como son, se dejan muy fácil manipular (varón, 53 años).

Los seres humanos, egoístas, eh encuentro que los hombres a veces machistas, eh, ehm, personas, cómo se llama, no sinceras. Me ha tocado muchas, muchas personas que se acercan, se han acercado cuando yo tenía casa por mi plata, pero no por amistad, o por lo que yo valgo. Entonces, relativamente, o sea, estoy sola por eso. Porque no confío en las personas. Yo me encerré en mi, o sea, yo puedo decir, yo me encerré en mi mundo (mujer, 54 años).

Creo, creo, creo, no, hay eh, del punto de vista eh, estrictamente politico creo en el hombre, pese a que tengo una, eh, pésima imagen, una pésima impresión, creo en el ser humano, este, creo, creo en la fuerza espiritual que genera cada ser humano, ¿no?. To creo que en el fondo, dentro de cada ser humano hay un demonio y un Dios, hay fuerzas del bien y del mal, ¿entiendes?. Que están luchando pugnando, y, y, y creo en la gente, ¿no?, eh... creo en los cambios y creo que es posible que cuando el ser humano se descubra a sí mismo, ¿entiende?, en lo que vale, va a desaparecer la mitad de los males y los vicios que existen en este mundo. Por ejemplo el pelambre, La envidia, el cagüin, el enredo, la traición, eso va a desaparecer. Porque la gente es peladora, caguinera, pelambrera, ¿me entiende?, es traidora en sí, en la medida que no se soportan a sí mismos en su condición de hombres y mujeres. Nada más. Claro, yo estoy demasiado ocupado viviendo mi vida para preocuparme de vivir la vida de otro (varón, 52 años). 
Tabla 50. Antecedentes conceptuales de valoración personal

\begin{tabular}{|c|c|c|c|c|c|}
\hline \multirow{3}{*}{$\begin{array}{l}\text { VALORACIÓN } \\
\text { PERSONAL }\end{array}$} & \multicolumn{3}{|c|}{ POR DOCUMENTO } & \multirow{2}{*}{\multicolumn{2}{|c|}{$\begin{array}{c}\text { POR UNIDAD DE } \\
\text { ANÁLISIS } \\
\mathrm{N}=9900\end{array}$}} \\
\hline & \multirow{2}{*}{ Frecuencia } & $\mathrm{N}=60$ & $\mathrm{n}=28$ & & \\
\hline & & \% según UR & \% según UR & Frecuencia & \% según UR \\
\hline Negativa & 6 & 10 & 21 & 9 & 0.09 \\
\hline Positiva & 26 & 43 & 93 & 45 & 0.45 \\
\hline
\end{tabular}

La Tabla 50, nos indica que menos de la mitad de participantes del estudio hizo una valoración de su persona, de quienes la mayoría (equivalente al 43\% de la muestra del estudio), hizo una autovaloración "positiva" que fue manifestada en alrededor de 2 U.T.s por documento.

Deducimos de la tabla 50, que un grupo de 4 personas refirió en sus discursos de manera simultánea una valoración tanto positiva como negativa de su persona.

Entonces, Lo primero, usted prepárese una oración. Y la oración, yo preparé una que decía "yo, Manuel, soy un gallo encachado, tengo energía, tengo deseo de hacer cosas, aquí, allá, y por lo tanto voy a salir adelante, y como que no me ha pasado ninguna cosa nunca... (varón, 77 años).

¿De acuerdo a mis creencias con respecto a Dios? () A to mejor por eso tengo una sola amiga, porque he sido muy defraudada y me considero una persona buena. Yo me analizo a mi misma, soy muy crítica conmigo misma. Creo no cometer malos actos con nadie. Me considero una persona super solidaria. Si yo veo que alguien está mal trato en lo posible de ayudar. Obviamente la caridad empieza por casa. Si yo veo que algo me está sobrando, y yo veo a un sobrino que está mal le digo "tómalo, llévate esto"; entonces no concibo cuando alguien me hace daño (mujer, 50 años).

Tabla 51. Antecedentes conceptuales de valoración de ocupación actual

\begin{tabular}{||c|c|c|c|c|c||}
\hline \multirow{2}{*}{$\begin{array}{c}\text { VALORACIÓN } \\
\text { OCUPACIÓN } \\
\text { ACTUAL }\end{array}$} & \multirow{3}{*}{ Frecuencia } & $\mathrm{N}=60$ & $\mathrm{n}=34$ & \multicolumn{2}{|c|}{$\begin{array}{c}\text { POR UNIDAD DE } \\
\text { ANÁLISIS } \\
\mathrm{N}=9900\end{array}$} \\
\cline { 2 - 6 } & & $\%$ según UR & \% según UR & Frecuencia & $\%$ según UR \\
\hline Negativa & 9 & 15 & 26 & 11 & 0.11 \\
\hline Positiva & $\underline{\mathbf{2 8}}$ & 47 & 82 & $\underline{44}$ & 0.44 \\
\hline \hline
\end{tabular}

La Tabla 51 nos indica que más de la mitad de la muestra valoró su actividad laboral actual al momento de la entrevista. De quienes la mayoría (el 47\% de la muestra) lo hace de manera positiva. Lo que se manifestó en menos de dos U.T.s por documento. Deducimos de la tabla, que un grupo de tres personas realizan simultáneamente una valoración positiva y negativa. 
Tabla 52. Tema específico más aludido para la categoría valoración de ocupación actual

\begin{tabular}{|ll|}
\hline Por documentos & \multicolumn{1}{c|}{ Por U.T.s } \\
\hline $\begin{array}{l}\text { Valoración global: “satisfecho” } \\
(42 \%)\end{array}$ & $\begin{array}{l}\text { Valoración global: } \\
\text { "satisfecho" }(0.35 \%)\end{array}$ \\
\hline
\end{tabular}

"No, me siento satisfecho porque trabajo y todavía puedo desarrollarme. He visto compañeros que no, han quedado pal..." (varón,58 años).

Yo, mira yo aquí en estos momentos estoy, estoy muy satisfecho, estoy muy con... estoy muy contento, y satisfecho porque yo aquí realmente estoy haciendo to que me gusta, la cosa social, deportiva, y nunca he tenido problemas, me siento bien, bien satisfecho (varón, 55 años).

Tabla 53. Antecedentes conceptuales de valoración de la participación política

\begin{tabular}{||c|c|c|c|c|c||}
\hline \multirow{2}{*}{$\begin{array}{c}\text { VALORACIÓN } \\
\text { PARTICIPACIÓN } \\
\text { POLÍTICA }\end{array}$} & \multirow{3}{*}{ Frecuencia } & $\mathrm{N}=60$ & $\mathrm{n}=29$ & \multicolumn{2}{c|}{$\begin{array}{c}\text { POR UNIDAD DE } \\
\text { ANÁLISIS } \\
\text { N }=9900\end{array}$} \\
\cline { 3 - 6 } & & $\begin{array}{c}\text { \% según } \\
\text { UR }\end{array}$ & $\begin{array}{c}\text { \% según } \\
\text { UR }\end{array}$ & Frecuencia & $\%$ según UR \\
\hline Negativa & 7 & 12 & 24 & $\underline{\mathbf{1 2}}$ & 0.12 \\
\hline Positiva & $\underline{\mathbf{1 0}}$ & 17 & 34 & 11 & 0.11 \\
\hline
\end{tabular}

En cuanto a la valoración que los EXPPS hicieron de su participación política, observamos que menos de la mitad hizo alusión a esta área de sus vidas, de los cuales predomina una valoración positiva que se presentó en el 17\% de sujetos de la muestra (y el 24\% de quienes refirieron esta temática), y en una U.T.s aproximada por sujeto.

Por último, un grupo de 12 personas que no aparecen en las valoraciones presentes en la Tabla 53, aludieron la temática "valoración participación política", pero ésta no fue especificada. Lo que podemos explicar porque los EXPPS hacen mención constantemente de su participación política y pueden haberla valorado tanto implícita como explícitamente al referirse a otros temas o al mismo, sin definir claramente una valoración en términos positivos o negativos.

Tabla 54. Tema específico más aludido para la categoría participación política

\begin{tabular}{|lc|}
\hline Por documentos & \multicolumn{1}{c|}{ Por U.T.s } \\
\hline $\begin{array}{l}\text { Autocrítica asociada: “positiva” } \\
(13 \%)\end{array}$ & $\begin{array}{l}\text { Autocrítica asociada: } \\
\text { "negativa” }(0.10 \%)\end{array}$ \\
\hline
\end{tabular}


Positiva:

To pienso que yo me siento satisfecho, porque he tratado de ayudar al máximo a los compañeros, a los que trabajan conmigo, a educarlos, a siempre insistir en que se eduquen, y a apoyarlos pa' que se especialicen. Eh... a donde yo trabajo tengo la posibilidad de apoyarlos para que saquen alguna profesión, y así lo he hecho prácticamente en la empresa (varón, 62 años).

Negativa:

Entonces yo digo también, yo fui muy egoísta, yo debi habérmela jugado por mi familia, y me la jugué por otros; y no sé si uno lo hace con recompensa, yo creo que no, pero por lo menos, me digan "a ti no vamos a ayudarte, pero a tu hijo si", no se, a lo mejor algo pasó ahí, que nosotros cambiamos mucho y ellos no. O a lo mejor ellos están haciendo lo correcto y nosotros lo incorrecto (varón, 55 años).

Tabla 55. Antecedentes conceptuales de valoración de la motivación de participación política

\begin{tabular}{|c|c|c|c|c|c|}
\hline \multirow{3}{*}{$\begin{array}{c}\text { VALORACIÓN } \\
\text { PARTICIPACIÓN } \\
\text { POLÍTICA - } \\
\text { MOTIVACIÓN } \\
\text { PRINCIPAL }\end{array}$} & \multicolumn{3}{|c|}{ POR DOCUMENTO } & \multirow{2}{*}{\multicolumn{2}{|c|}{$\begin{array}{l}\text { POR UNIDAD DE } \\
\text { ANÁLISIS N = } 9900\end{array}$}} \\
\hline & \multirow[b]{2}{*}{ Frecuencia } & \multirow{2}{*}{$\frac{\mathrm{N}=60}{\% \text { según UR }}$} & \multirow{2}{*}{\begin{tabular}{|c|}
$\mathrm{n}=26$ \\
$\%$ según UR
\end{tabular}} & & \\
\hline & & & & Frecuencia & \% según UR \\
\hline Defensa ideales U.P. & 8 & 13 & 31 & 11 & 0.11 \\
\hline Mejora reparación & 8 & 13 & 31 & 15 & 0.15 \\
\hline Ayuda social & 14 & 23 & 54 & 19 & 0.19 \\
\hline Otro motivo & 2 & 3.3 & 8 & 2 & 0.02 \\
\hline Promedio & 8 & & & 11.75 & \\
\hline
\end{tabular}

Nos pareció interesante destacar lo que motiva a los EXPPS a participar en política actualmente (resultados extraídos de la Tabla 53), porque consideramos que nos puede entregar información de sus necesidades y sus posibles problemas políticos actuales. Encontramos que es la "ayuda social" la única motivación que supera la media de las motivaciones referidas por sujetos y U.T.s. Por último, deducimos a modo general, que las motivaciones aludidas incluyeron en algunos de ellos, más de un aspecto.

Tabla 56. Tema específico más aludido para la categoría valoración de la motivación de participación política

\begin{tabular}{|ll|}
\hline Por documentos & \multicolumn{1}{c|}{ Por U.T.s } \\
\hline $\begin{array}{l}\text { Motivación principal: “Ayuda } \\
\text { social” }(23 \%)\end{array}$ & $\begin{array}{l}\text { Motivación principal: “ayuda } \\
\text { social” }(0.19 \%)\end{array}$ \\
\hline
\end{tabular}

En un comienzo yo eh... era muy crítica, porque pensaba que por culpa de, de ellos, cómo ellos habían sido, teníamos que andar así. Claro, pero después cuando yo ya fui creciendo, fui una madre, eh... una mujer, me di cuenta de otras cosas que, que yo también lo llevaba muy dentro, como.. Luchar por las injusticias, todas esas cosas. Entonces eso fue lo que mi padre siempre hizo (mujer, 64 años). 
Ah, quisiera que cambiaran muchas cosas. He luchado digamos, para cambiar el sistema, me gustaría cambiar el sistema de globalización, del neoliberalismo. Para que haya más justicia, para que haya más compensación entre, entre los pobres, más igualdad, no las hay. Ese, ese ha sido, ha sido nuestra lucha toda la vida desde que... (varón, 62 años).

Tabla 57. Antecedentes conceptuales del sentido de la vida

\begin{tabular}{|c|c|c|c|c|c|}
\hline \multirow{3}{*}{$\begin{array}{l}\text { SENTIDO DE LA } \\
\text { VIDA }\end{array}$} & \multicolumn{3}{|c|}{ POR DOCUMENTO } & \multirow{2}{*}{\multicolumn{2}{|c|}{$\begin{array}{c}\text { POR UNIDAD DE } \\
\text { ANÁLISIS } \\
\mathrm{N}=9900\end{array}$}} \\
\hline & \multirow{2}{*}{ Frecuencia } & \multirow{2}{*}{$\begin{array}{c}\mathrm{N}=60 \\
\% \text { según } \\
\text { UR }\end{array}$} & \multirow{2}{*}{$\begin{array}{c}\mathrm{N}=33 \\
\text { \% según UR }\end{array}$} & & \\
\hline & & & & Frecuencia & \% según UR \\
\hline Valoración negativa & 9 & 15 & 27 & 10 & 0.10 \\
\hline Valoración positiva & $\underline{24}$ & 40 & 73 & $\underline{31}$ & 0.31 \\
\hline
\end{tabular}

La Tabla 57, nos indica que más del 50\% de la muestra hizo alusión al sentido que otorga a la vida, de cuya proporción, la mayoría hace una "valoración positiva" (73\%), equivalente al 40\% de la muestra. Lo que se manifestó en aproximadamente una U.T.s por sujeto.

La Tabla 57, además nos muestra que las respuestas de los participantes referidas a esta valoración específica, se presentan de manera excluyente en una de las dos categorías, lo que nos indica que los EXPPS presentan una valoración claramente definida al respecto.

Tabla 58. Tema específico más aludido para la categoría valoración sentido de la vida

\begin{tabular}{|ll|}
\hline Por documentos & \multicolumn{1}{c|}{ Por U.T.s } \\
\hline Valoración global: positiva (35\%) & $\begin{array}{l}\text { Valoración global: positiva } \\
(0.25 \%)\end{array}$ \\
\hline
\end{tabular}

La vida para mi el sentido que tiene es lo máximo, lo más bello porque Dios nos dio esta vida y, y nosotros tenemos que saber vivirla en las 6uenas y en las malas. No solamente en las buenas que porque, por eso que la gente se mata, o porque tiene problemas. Yo los problemas grandes, graves que tuve cuando fui preso politico, igual quiero la vida poh, yo no la he, no he subsanado todo eso, pero igual la quiero, la amo a la vida (varón, 58 años).

"Bueno la vida es lo principal para mi porque me dio, se me dio otra oportunidad. $\Upsilon$ sería malo si yo dijera "no, la vida para mi no tiene ningún incentivo", porque se me dio una oportunidad y por algo me la dieron" (varón, 62 años).

"Todo, todo, mi causa es la vida, mi causa es la vida, y una vida con caracteres bien especificos, una vida con dignidad. Eh, ese es mi norte" (varón, 54 años).

Entonces para mi la vida es como un regalo que te entregan pa' manifestarte en este mundo terrenal. Con todas tus cualidades, todas tus debilidades, ¿entiendes?. Yo no soy de esas personas que se levanta en la mañana y se pregunta ¿qué voy a hacer?", ¿ya?. Siempre tengo algo que hacer, y no que 
sea cuestión... una cuestión trabajólica, ni que vaya por interés digamos al dinero. To he hecho muchos trabajos y nunca me han pagado, digamos, y no por eso me siento menos triunfador o mas triunfador que otros (varón, 55 años).

Tabla 59. Antecedentes conceptuales de valoración del Chile actual

\begin{tabular}{||c|c|c|c|c|c||}
\hline \multirow{3}{*}{$\begin{array}{c}\text { VALORACIÓN } \\
\text { DEL CHILE } \\
\text { ACTUAL }\end{array}$} & \multirow{2}{*}{ Frecuencia } & $\mathrm{N}=60$ & $\mathrm{n}=22$ & \multicolumn{2}{c|}{$\begin{array}{c}\text { POR UNIDAD DE } \\
\text { ANÁLISIS } \\
\text { N }=9900\end{array}$} \\
\cline { 3 - 6 } & & \% según UR & $\%$ según UR & Frecuencia & $\%$ según UR \\
\hline Negativa & $\underline{\mathbf{2 1}}$ & 35 & 95 & $\underline{\mathbf{3 7}}$ & 0.37 \\
\hline Positiva & 2 & 3.3 & 9 & 3 & 0.04 \\
\hline
\end{tabular}

En cuanto a la valoración que los EXPPS hicieron en base a la percepción que tienen de aspectos generales de Chile en la actualidad, observamos en la Tabla 59, que menos de la mitad de ellos se expresaron al respecto. De aquellas personas que si se manifestaron, la mayoría refirió una valoración negativa del propio país, aludiendo a la misma, en una frecuencia aproximada de dos U.T.s por discurso. Una de estas personas, realiza simultáneamente una valoración positiva y negativa.

Negativa:

Chile no tiene capacidad para haber sensibilidad, pensar en el otro, no. Nosotros nos hemos transformado en una, esa sociedad construida, a transformar una sociedad individualista. Yo soy yo y mis circunstancias y chao. "Hasta cuándo se van a dejar de, de, de reclamar esos presos politicos, ¿ah?. Porqué esos viejos no se van a su casa". Si esas, esas frases son comunes, ¿ah?. El otro día iba en el taxi, iba en el taxi dijo, el chofer dijo, estábamos hablando del Evo Morales estuvo acá, y dijo "si el único problema yo no se porqué los comunistas dijo..." entonces, le dije "iqué tiene usted contra los comunistas?", "pero es que los comunistas son...", le dije "¿usted cree que los comunistas somos asesinos, son ladrones, son delincuentes, son terroristas?", "no, pero es que se meten en todo, si sabe que por culpa de ellos...", "mire - le dije yo - usted está hablando con una comunista, no he matado a nadie, no le he robado a nadie; soy una persona de bien. Soy trabajadora, soy inteligente, soy exitosa. $\mathcal{N}$ o le debo favores a nadie (mujer, 43 años).

Por ser esta politica aquí, que hay aquí en Chile este, este neoliberalismo nos ha llevado al abismo en muchos aspectos, tanto en Lo, en la cuestión social, como en la cuestión, en todo. Esto nos ha llevado pero, del, del tiempo que yo conozco, que yo era un hombre hecho y derecho cuando llego el gobierno popular, que yo lo apoyé mucho, y que yo lo apoyé mucho y que trabajé por él. Hay una diferencia y un cambio total en la, en la, en la cómo se llama, en la fisonomía, en la fisonomía social, económica y cultural de, de este país (varón, 69 años).

Digamos en Chile, se produjo después del año 73 una desintegración social tremendamente grande en que todos en alguna medida nos hemos transformado en individualistas, y yo to encuentro tremendamente malo para una sociedad. Y si tu miras y analizas las últimas elecciones, te das cuenta que la gente lo único que espera es que el gobierno le de. PerO no luchan para ganárselo. Entonces yo 
creo que en una sociedad, todos deberíamos estar incorporados, deberíamos trabajar, y deberíamos luchar para lograr algo, integrarnos a la sociedad. (varón, 58 años).

yo creo que hay una suerte de hipocresía más que silencio. Aquí se han trastocado los valores y no... a ver, lo que nosotros, yo cuando niño conocí que robar era malo, hoy día por ejemplo se, ya no es robar, es malversación de fondo, irregularidades, es decir, le han cambiado los nombres y esa es una suerte de hipocresía, entonces ya como que aparece que no es tan delito. Entonces, es una sociedad, una sociedad que va apuntando a lo que es meramente material, por lo tanto lo que pa nosotros era poco ético, era prácticamente delinquir, hoy día es normal, habitual en este mundo de hoy no importa a quien yo pise con tal de yo escalar. Yo tengo que ganar. Yo tengo que ganar por lo tanto ahora dentro de este mismo contexto, se da este, esta suerte de silencio. de decir, no revolquemos el pasado, no, no, no revolvamos más, para qué si qué sentido tiene, qué objetivo. $\Upsilon$ dar a entender al mundo entero que si yo por ejemplo presento una querella por mi tortura, es que yo me quedé en el pasado, que yo soy retrógrado, que yo sigo con odio; y no, no, nunca, nunca ni en el momento más duro yo he sentido odio. $\mathcal{N}$ o sé lo que es sentir odio, rabia si, pero no ese odio por castigar al otro. Pero si no venganza, pero si la verdad tiene que conocerse. Es decir, a partir de una cuestión tan simple como si tengo una herida, no saco nada con ponerle una, una pomadita por encima si no logro sacar todo lo que hay abajo y a partir de eso poder hacer la curación definitiva (varón, 51 años).

Positiva:

Si de hecho, tiene, tiene que haber porque... cómo se... siempre quedan cosas poh, así como yo le digo que hay un, que hay un temor oculto con mi señora por los hijos que algo pueda pasar mas adelante, ahora no poh. Ahora estamos bien, ta todo bien Chile, está marchando bien todo. NNo todo pero están funcionando las cosas. Pero los temores igual quedan (varón, 52 años).

....yo creo que... insisto Chile si, o sea, es, es, tu notai tranquilidad, notai paz, digamos. $\Upsilon$ no lo digo yo, tan solo yo, sino que gente bien instruida, gente de Europa; nosotros trabajamos con una ONGG europea y ellos nos planteaban, o sea, pasan la frontera de Chile y se sienten tranquilos, digamos. $\mathcal{A}$ diferencia digamos, del Perú que están medio esto que esto otro. En Chile si, como que se siente paz, o sea... (varón, 55 años).

Tabla 60. Antecedentes conceptuales de temores

\begin{tabular}{||c|c|c|c|c|c||}
\hline \multirow{3}{*}{ TEMORES } & \multicolumn{3}{|c|}{ POR DOCUMENTO } & \multicolumn{2}{c|}{$\begin{array}{c}\text { POR UNIDAD DE } \\
\text { ANÁLISIS } \\
\text { N }=9900\end{array}$} \\
\cline { 2 - 5 } & \multirow{2}{*}{ Frecuencia } & $\mathrm{N}=60$ & $\mathrm{n}=55$ & \multicolumn{2}{c||}{} \\
\cline { 3 - 6 } & & $\begin{array}{c}\text { \% según } \\
\text { UR }\end{array}$ & \% según UR & Frecuencia & $\%$ según UR \\
\hline No tiene & 21 & 35 & 38 & 24 & 0.24 \\
\hline Si tiene & $\underline{\mathbf{3 4}}$ & 57 & 62 & $\underline{43}$ & 0.43 \\
\hline
\end{tabular}

La Tabla 60, nos indica que la mayoría de sujetos entrevistados hizo alusión a la presencia o ausencia de temores en su vida. De todos los participantes, el 57\% afirmó tener temores en la actualidad. Lo que se manifestó en aproximadamente una unidad textual por documento. Todos quienes aludieron la temática “temores", presentaron respuestas excluyentes para cada categoría comprendida en la tabla en cuestión. 
Tabla 61. Tema específico más aludido para la categoría temores

\begin{tabular}{|lc|}
\hline Por documentos & Por U.T.s \\
\hline Si tiene: Otro $(37 \%)$ & Si tiene: Otro $(0.27 \%)$ \\
\hline
\end{tabular}

"Si tengo, si. $\mathcal{A}$ lo que no volvamos, no volvamos nunca a lo que fuimos antes. Al cambio que queríamos. Al cambio radical que queríamos plantear nosotros en tiempo de la época de la juventud mía, el tiempo de la, el tiempo de la Unidad Popular" (varón, 69 años).

(ríe) a ver, miedo a... a no tener. Ahora el miedo que yo siento que mis hijos no tengan pa sus hijos. Que les cueste tanto como nos costó a nosotros. eso es lo que yo no quiero. Porque ya nosotros estamos viejos. Uno ya pasó. y no se, a uno en realidad le da lo mismo, y no debiera ser así pero qué le vamos a hacer (mujer, 54 años).

Que le tenga miedo, eh, claro hay una cantidad de cosas que uno le tiene miedo, que son un poquito irracionales pero son miedos que uno tiene que trabajar. Miedo a la enfermedad, miedo a la muerte, miedo al sufrimiento, eh... a cosas que te causen dolor. Miedo a que, a no poder valerte por ti mismo. Que llegue un momento en que tengas que depender de los demás. $\mathcal{A}$ ir perdiendo habilidad, autonomía (varón, 53 años).

\subsubsection{Antecedentes conceptuales del tiempo pasado}

Tabla 62. Antecedentes conceptuales de la familia de origen en el pasado

\begin{tabular}{||c|c|c|c|c||}
\hline \multirow{2}{*}{$\begin{array}{c}\text { FAMILIA DE ORIGEN } \\
\text { EN PASADO }\end{array}$} & \multicolumn{2}{|c|}{$\begin{array}{c}\text { POR DOCUMENTO } \\
\mathrm{N}=60\end{array}$} & \multicolumn{2}{c|}{$\begin{array}{c}\text { POR UNIDAD DE } \\
\text { ANÁLISIS } \\
\text { N=9900 }\end{array}$} \\
\cline { 2 - 5 } & Frecuencia & \% según UR & Frecuencia & $\%$ según UR \\
\hline Valoración negativa & 35 & 58 & 84 & 0.85 \\
\hline Valoración positiva & $\underline{\mathbf{5 1}}$ & 85 & $\underline{\mathbf{1 6 7}}$ & 1.7 \\
\hline \hline
\end{tabular}

La Tabla 62, nos indica que la totalidad de la muestra valoró sus relaciones interpersonales con la familia de origen en la infancia y adolescencia, de quienes el $85 \%$ hizo una "valoración positiva". Esto fue aludido en un promedio de 3 U.T.s por documento. Por su parte, más de la mitad de sujetos entrevistados $(58 \%)$ realizó una "valoración negativa" de estas relaciones en su infancia y adolescencia.

Deducimos de la Tabla 62, que un grupo de 26 personas realizó una valoración negativa y positiva a la vez. Lo que podemos explicar por la diversidad de temáticas comprendidas en ambas valoraciones que fueron analizadas en función de distintas relaciones intra-familiares. 
Tabla 63. Tema específico más aludido para la categoría familia de origen en el pasado

\begin{tabular}{|ll|}
\hline Por documentos & \multicolumn{1}{c|}{ Por U.T.s } \\
\hline $\begin{array}{l}\text { Madre/ valoración: “buena” } \\
(55 \%)\end{array}$ & $\begin{array}{l}\text { Madre/ valoración: “buena” } \\
(0.40)\end{array}$ \\
\hline
\end{tabular}

Bueno eh... yo tuve... en cuanto a mis padres, por ejemplo, ellos tuvieron existencias bastante distintas, mi padre murió cuando yo era muy niñita, tenia 9 años cuando el murió, y mi mama tuvo una vida mucho más larga, ella murió hace 8 años. Entonces... eh... tuve dos visiones de los padres, eh... muy humildes, muy modestos, muy, muy, muy pobres diríamos... muy, muy pobres. Pero me enseñaron cosas que a mí nunca se me han olvidado; por ejemplo desde rezar, intentar ser justa, el educarme, porque para ellos lo mas importante era tener educación, ellos eran personas que apenas pasaron por la escuela segundo año básico de aquellos tiempos primarios, sin embargo tenían una cultura que ya me los quisiera ver a esos grandes pensadores que te... tuvieran la cultura que tenían ellos, que podían hablar de todo, que estaban muy informado, entonces, este... esta cosa fue una herencia que ellos me dejaron y que yo la he tratado de mantener por, por siempre, y sigo diciendo que mi núcleo familiar fue muy poquito, de hecho con respecto a mis padres (mujer, 59 años).

Tabla 64. Antecedentes conceptuales del ambiente familiar de origen en el pasado

\begin{tabular}{||c|c|c|c|c|c||}
\hline \multirow{2}{*}{ AMBIENTE FAMILIA ORIGEN } & \multicolumn{3}{|c|}{ POR DOCUMENTO } & \multicolumn{2}{c|}{ POR UNIDAD DE } \\
\cline { 2 - 5 } & \multirow{2}{*}{ Frecuencia } & $\mathrm{N}=60$ & $\mathrm{n}=49$ & \multicolumn{2}{c||}{ ANÁLISIS N =9900 } \\
\cline { 3 - 6 } & & $\begin{array}{c}\% \text { según } \\
\text { UR }\end{array}$ & $\begin{array}{c}\% \text { según } \\
\text { UR }\end{array}$ & Frecuencia & $\%$ según UR \\
\hline Ausencia dificultades relevantes & 3 & 5 & 6 & 3 & 0.03 \\
\hline Presencia dificultades relevantes & $\underline{\mathbf{4 6}}$ & 77 & 94 & $\underline{\mathbf{1 4 3}}$ & 1.4 \\
\hline
\end{tabular}

Según la Tabla 64, más de la mitad de EXPPS entrevistados aludió al ambiente familiar de sus hogares donde crecieron, de quienes el $94 \%$, equivalente al $77 \%$ de la muestra, afirmó la existencia de dificultades relevantes en estos ambientes. Esto se presentó en un promedio de 3 U.T.s por discurso.

La totalidad de sujetos que valoraron el ambiente familiar en que vivieron su infancia y adolescencia, hizo una valoración excluyente entre las dos categorías presentadas en la Tabla 64.

Tabla 65. Tema específico más aludido para la categoría ambiente familiar de origen en el pasado

\begin{tabular}{|ll|}
\hline Por documentos & \multicolumn{1}{c|}{ Por U.T.s } \\
\hline $\begin{array}{l}\text { Presencia de dificultades relevantes: } \\
\text { Pobreza extrema }(32 \%)\end{array}$ & Presencia de dificultades relevantes: \\
Pobreza extrema $(0.27 \%)$
\end{tabular}

Yo creo que me sentí satisfecha hasta como los 14 años. Cuando muere mi papá. De ahí pasamos por un periodo de mucho dolor, de mucha dificultad, de mucha pobreza también, material. Eh... de mucha violencia verbal y, y física, ¿ah?, esos fueron períodos negros. A mi, mi mamá me pegaba, 
pero me sacaba las medias tandas. A todos. Pero a mi, a mi y a mi hermano mayor fueron a los que más nos pegaron. Las tandas nos daba mi mamá. JNosotros llegamos a decirle después cuando grande que ella había entrenado a la CNI poh. Nos daba las medias tandas (mujer, 43 años).

Digamos que yo me siento insatisfecho de, de, de, de por ejemplo de los..., porque en primer lugar, yo no, no tuve la oportunidad de educarme, que eh... por ejemplo, yo me crié en un barrio totalmente pobre, mísero, donde, donde había que trabajar de temprana edad (varón, 69 años).

Eh me sentía a disgusto porque eh, por la necesidad de rebelarme contra el sistema que vivíamos pero además, por eh, las necesidades que yo vivía dentro de mi casa. fueron épocas de mucha, mucha, mucha, mucha pobreza. Mucha, mucha, mucha pobreza, entonces, claro eso te provoca frustraciones... o sea, ponte tu, te ibai al colegio y si podiai tomar desaynno, sabiai que no podiai almorzar. Era como, era un lujo tener dos comidas diarias, en esa época no. Fueron tiempos, y no fueron pocos años, en realidad fueron hartos años de, de, de hartas necesidades... eh que me hacían sentir claro, a disgusto, y con mucha rebeldía y no entender por qué. En mi adolescencia, desde los 13 hasta los... desde los 14 hasta los no se poh, 17-18 años. Fueron años 6astante duros, 6astante duros (mujer, 37 años).

Tabla 66. Antecedentes conceptuales de la disposición de amigos en el pasado

\begin{tabular}{|c|c|c|c|c|}
\hline \multirow[t]{2}{*}{ AMIGOS } & \multicolumn{2}{|c|}{$\begin{array}{c}\text { POR DOCUMENTO } \\
\mathrm{N}=60\end{array}$} & \multicolumn{2}{|c|}{$\begin{array}{c}\text { POR UNIDAD DE } \\
\text { ANÁLISIS } \\
\text { N }=9900\end{array}$} \\
\hline & Frecuencia & \% según UR & Frecuencia & \% según UR \\
\hline No tuvo & 8 & 13 & 11 & 0.11 \\
\hline Si tuvo & $\underline{54}$ & 90 & $\underline{172}$ & 1.7 \\
\hline
\end{tabular}

Según nos indica la Tabla 66, todos los participantes hablaron acerca de la presencia o ausencia de relaciones de amistad durante su infancia y adolescencia, de quienes la mayoría (90\%), refirió haber dispuesto de ese tipo de relaciones interpersonales. Esto fue referido en un promedio de tres unidades por documento.

Por último, dos personas refirieron simultáneamente que tuvieron y no tuvieron amigos en la infancia y adolescencia. De estas personas podemos inferir que al momento de referirse a estas apreciaciones, lo hacían pensando en personas específicas y no haciendo una valoración general del tema. 
Tabla 67. Antecedentes conceptuales de la valoración de los amigos en el pasado

\begin{tabular}{|c|c|c|c|c|c|}
\hline \multirow{3}{*}{ AMIGOS } & \multicolumn{3}{|c|}{ POR DOCUMENTO } & \multirow{2}{*}{\multicolumn{2}{|c|}{$\begin{array}{c}\text { POR UNIDAD DE } \\
\text { ANÁLISIS } \\
\mathrm{N}=9900\end{array}$}} \\
\hline & \multirow[t]{2}{*}{ Frecuencia } & $\mathrm{N}=60$ & $\mathrm{n}=54$ & & \\
\hline & & $\begin{array}{c}\text { \% según } \\
\text { UR }\end{array}$ & \% según UR & Frecuencia & \% según UR \\
\hline Valoración negativa & 2 & 3 & 4 & 2 & 0.02 \\
\hline Valoración positiva & $\underline{47}$ & 78 & 87 & $\underline{78}$ & 0.8 \\
\hline
\end{tabular}

Observamos en la Tabla 67, que la mayoría de quienes refirieron haber tenido amigos durante las etapas evolutivas de infancia y adolescencia de sus vidas (87\%), hacen una "valoración positiva" de este tipo de relaciones. Lo que se presentó en un promedio de 2 U.T.s por documento.

Tabla 68. Tema específico más aludido para la categoría valoración de amigos en el pasado

\begin{tabular}{|lc|}
\hline Por documentos & Por U.T.s \\
\hline Si tuvo: satisfacción $(78 \%)$ & Si tuvo: satisfacción $(0.79 \%)$ \\
\hline
\end{tabular}

"Completamente satisfecho. O sea, yo viví una infancia y una adolescencia, una preadolescencia hasta, hasta ahí hasta los 12 años muy linda" (varón, 60 años).

"No era... si amigos de mi, claro del colegio. Si. Eran buenas relaciones. Eran cercanas si, eran buenas" (varón, 55 años).

Si bien, bien, mis amigos porque de la infancia después ya todo cambió, del golpe de estado todo cambió, ya no son amigos. Hola y chao, eso. Antes no, estábamos tardes enteras conversando, estábamos en los mismos colegios acá en la teja (varón, 75 años).

Haber si me acuerdo de alguien, tendría que ser un amigo sí sí. Era mayor que mi, si, era mayor que mi pero, pero él, él cuánto se llama, me trataba como amigo, y me hacía reír, salíamos juntos, le gustaba cómo se llama, eh... divertirse, qué se yo, conmigo, todas esas cosas, entonces yo to, yo to estimé mucho porque lo veía como que una persona mayor, o sea, como, me sentía como cobijado, si protegido, claro (varón, 53 años).

En aquellos tiempos si poh, es que no sabíamos. NNo, no, no sabíamos de problemas en esos tiempos. O sea, y si lo sabíamos lo tapábamos con nuestros juegos, con nuestras fantasías, en estar jugando como cualquier niño a las reinas, éramos ingenieros, hacíamos bromas, jugábamos con la arena. Realmente si, la pasábamos muy bien, en un... tomando en cuenta nuestro clima (mujer, 59 años). 
Tabla 69. Antecedentes conceptuales de la disposición de pareja en el pasado

\begin{tabular}{||c|c|c|c|c|c||}
\hline \hline \multirow{3}{*}{ PAREJA } & \multicolumn{3}{|c||}{ POR DOCUMENTO } & \multicolumn{2}{c|}{$\begin{array}{c}\text { POR UNIDAD DE } \\
\text { ANÁLISIS } \\
\text { N }=9900\end{array}$} \\
\cline { 2 - 4 } & \multirow{2}{*}{ Frecuencia } & $\mathrm{N}=60$ & $\mathrm{n}=42$ & \multicolumn{2}{c||}{} \\
\cline { 3 - 6 } & & \% según UR & $\begin{array}{c}\text { \% según } \\
\text { UR }\end{array}$ & Frecuencia & \% según UR \\
\hline No tuvo & 15 & 25 & 36 & 16 & 0.16 \\
\hline Si tuvo & $\underline{\mathbf{2 9}}$ & 48 & 69 & $\underline{\mathbf{5 2}}$ & 0.53 \\
\hline
\end{tabular}

Como nos señala la Tabla 69, más de la mitad de personas entrevistadas refirieron el tema pareja en su adolescencia. De los cuales el 69\% afirma haber tenido este tipo de relaciones en esta etapa de sus vidas, equivalente al 48\% de sujetos de la muestra. Lo que fue manifestado en alrededor de 2 U.T.s por cada EXPP que realizó esta afirmación.

Dos personas refirieron simultáneamente la afirmación y negación que comprende la Tabla 69, lo que nos indica una contradicción al respecto.

Tabla 70. Antecedentes conceptuales de la valoración de la pareja en el pasado

\begin{tabular}{|c|c|c|c|c|c|}
\hline \multirow{3}{*}{ PAREJA } & \multicolumn{3}{|c|}{ POR DOCUMENTO } & \multirow{2}{*}{\multicolumn{2}{|c|}{$\begin{array}{c}\text { POR UNIDAD DE } \\
\text { ANÁLISIS } \\
\mathrm{N}=9900\end{array}$}} \\
\hline & \multirow[t]{2}{*}{ Frecuencia } & $\mathrm{N}=60$ & $\mathrm{n}=29$ & & \\
\hline & & $\begin{array}{c}\text { \% según } \\
\text { UR }\end{array}$ & $\begin{array}{c}\text { \% según } \\
\text { UR }\end{array}$ & Frecuencia & \% según UR \\
\hline Valoración negativa & 5 & 8.3 & 17 & 5 & 0.05 \\
\hline Valoración positiva & $\underline{17}$ & 28 & 59 & $\underline{22}$ & 0.22 \\
\hline
\end{tabular}

Los datos de la tabla en cuestión, están incluidos en las sumatorias que presenta la tabla precedente, y nos indica que de quienes afirmaron haber tenido pareja durante su adolescencia (48\% de la muestra), observamos que el 59\% valora positivamente este tipo de relaciones en el pasado, correspondiente al 28\% de la muestra. Esto fue aludido en promedio en una U.T.s por discurso.

Podemos observar además, que las valoraciones de un grupo de personas que refirieron haber tenido relaciones de pareja durante su adolescencia, no están incluidas en la tabla por haber referido una valoración no especificada o intermedia.

Yo como te decía entré a trabajar a Mellafe y Salas a los 14 años. Tenía. era un niño ya, pero no... como se llama en esa industria era una industria de cómo una familia; se hacían fiestas, se hacían paseos, y bueno uno ahí ya va conociendo niñas, yo conocí a una niña, y era bastante buena la relación porque los dos éramos compañeros de trabajo, así que no había ningún problema (varón, 55 años). 
"Si, ella cuando pololeamos, ella tenía 17 y nos casamos a los 20. Era buena, era Guena relación, era buena relación" (varón, 65 años).

Tabla 71. Antecedentes conceptuales de la disposición de apoyo incondicional en el pasado

\begin{tabular}{||c|c|c|c|c||}
\hline \multirow{3}{*}{$\begin{array}{c}\text { APOYO } \\
\text { INCONDICIONAL }\end{array}$} & \multicolumn{2}{|c|}{$\begin{array}{c}\text { POR DOCUMENTO } \\
\mathrm{N}=60\end{array}$} & \multicolumn{2}{c|}{$\begin{array}{c}\text { POR UNIDAD DE } \\
\text { ANÁLISIS } \\
\mathrm{N}=9900\end{array}$} \\
\cline { 2 - 5 } & Frecuencia & $\%$ según UR & Frecuencia & $\%$ según UR \\
\hline No tuvo & 15 & 25 & 15 & 0.15 \\
\hline Si tuvo & $\underline{\mathbf{4 5}}$ & 75 & $\underline{\mathbf{5 0}}$ & 0.51 \\
\hline
\end{tabular}

Acerca del apoyo incondicional que los EXPPS refirieron haber dispuesto en su infancia y adolescencia, observamos que la totalidad de la muestra hizo referencia a esta apreciación y que sus respuestas fueron excluyentes entre sí. La mayoría refirió haber contado con el apoyo incondicional de personas durante las etapas evolutivas comprendidas en la categoría (75\% de la muestra). Lo que fue aludido en una U.T.s de promedio por cada individuo.

Tabla 72. Antecedentes conceptuales del tipo de vinculación de apoyo incondicional disponible en el pasado

\begin{tabular}{|c|c|c|c|c|c|}
\hline \multirow{3}{*}{$\begin{array}{c}\text { APOYO } \\
\text { INCONDICIONAL }\end{array}$} & \multicolumn{3}{|c|}{$\begin{array}{l}\text { POR DOCUMENTO } \\
\end{array}$} & \multirow{2}{*}{\multicolumn{2}{|c|}{$\begin{array}{c}\text { POR UNIDAD DE } \\
\text { ANÁLISIS } \\
\text { N }=9900\end{array}$}} \\
\hline & \multirow[t]{2}{*}{ Frecuencia } & \multirow{2}{*}{$\begin{array}{c}\mathrm{N}=60 \\
\text { \% según } \\
\text { UR }\end{array}$} & \multirow{2}{*}{$\begin{array}{c}\mathrm{n}=45 \\
\text { \% según UR }\end{array}$} & & \\
\hline & & & & Frecuencia & \% según UR \\
\hline Familia & $\underline{22}$ & 37 & 49 & $\underline{23}$ & 0.23 \\
\hline Amigos & $\overline{18}$ & 30 & 40 & 20 & 0.20 \\
\hline Otro & 8 & 13 & 18 & 10 & 0.10 \\
\hline
\end{tabular}

La Tabla 72, ha sido extraída de los resultados presentados en la tabla que la antecede, y nos indica que de las 45 personas que refirieron haber dispuesto de apoyo incondicional en sus vidas en el pasado, equivalente al $75 \%$ de la muestra entrevistada, la mayoría de ellos y con un 49\% de presentación, refiere que este apoyo lo encontró en su familia. Es la familia entonces, el grupo de personas que obtiene la moda por la categoría, habiendo estado presente en el $37 \%$ de la muestra entrevistada.

En segundo lugar, y para el 30\% de la muestra, y el 40\% de quienes refirieron haber contado con este tipo de apoyo en el pasado, en las relaciones de amistad hallaron de apoyo incondicional en su infancia y adolescencia.

El 13\% de la muestra, y 18\% de quienes afirmaron la disposición de este tipo de soporte en las etapas evolutivas referidas, refirieron que este lo encontraron en otras personas que no estaban dentro de su familia o 
sus grupos de amigos. Por último, un grupo de 3 personas refirió haber contado con este tipo de apoyo por parte de más de una persona, clasificados en distintos grupos incluidos en la tabla.

En lo afectivo, en lo emocional... si poh, si. Eh... primero que nada la nana que nos, que nos crió a nosotros. O sea, siempre fue como, como una segunda mamá, ella, ella siempre. Pero a parte de eso había un, una abuela especial, muy especial. Mi abuela había dado, o sea, la mamá de mi padre, yo creo que habría dado su vida por nosotros (varón, 60 años).

Yo siempre eh, me... a mi hermana mayor que siempre yo contaba con ella porque incluso cuando yo entré a trabajar, entré a trabajar cuan.. Donde trabajaba ella. Entonces siempre estuvimos.. Un vínculo entre los dos que era como inseparable. Hasta el día de hoy (varón, 62 años).

"Se puede decir, no mi primera polola pero si mi primer amor. To la veo todavía, pero.. pero nos vemos como personas como amigos" (varón, 53 años).

Tabla 73. Antecedentes conceptuales de la concepción del mundo en el pasado

\begin{tabular}{|c|c|c|c|c|c|}
\hline \multirow{3}{*}{$\begin{array}{l}\text { CONCEPCIÓN } \\
\text { DE MUNDO }\end{array}$} & \multicolumn{3}{|c|}{ POR DOCUMENTO } & \multirow{2}{*}{\multicolumn{2}{|c|}{$\begin{array}{c}\text { POR UNIDAD DE } \\
\text { ANÁLISIS } \\
\mathrm{N}=9900\end{array}$}} \\
\hline & \multirow[t]{2}{*}{ Frecuencia } & \multirow{2}{*}{$\begin{array}{c}\mathrm{N}=60 \\
\text { \% según UR }\end{array}$} & \multirow{2}{*}{$\begin{array}{c}\mathrm{n}=49 \\
\text { \% según UR } \\
\end{array}$} & & \\
\hline & & & & Frecuencia & \% según UR \\
\hline Negativa & 15 & 25 & 31 & 22 & 0.22 \\
\hline Positiva & $\underline{\underline{34}}$ & 57 & 69 & $\underline{37}$ & 0.37 \\
\hline
\end{tabular}

Como nos señala la Tabla 73, Superan la media de entrevistados, los EXPPS que aludieron a la concepción del mundo que tenían en el pasado (82\%). De estas personas, la mayoría refirió una valoración positiva (57\% de la muestra y 69\% de quienes aludieron su valoración específica), y esto se manifestó en un promedio de 2 U.T.s por discurso.

Por último, observamos que todas las personas que refirieron esta valoración, lo hicieron de manera excluyente optando por una valoración positiva o negativa, y todas las alusiones tuvieron contenido codificable en las categorías presentadas en la Tabla 73.

"A gusto en ese mundo. Sabe que nosotros en ese tiempo no... Lo pasábamos tan bien que nos olvidábamos de tođo lo demás. SNo... no nos interesaba que, qué pasaba, que, que habían elecciones y todo..." (varón, 62 años).

Me sentía muy a gusto en aquellos tiempos poh, si el 73 nos hizo bajarnos de esa nube pero terrible, si yo viva en esa nube, yo era una niñita engreída, que se le cumplían los gustos, y a todo esto ya empezamos a progresar económicamente, mi madre una mujer de trabajo y lo que no tuvimos cuando éramos chicos to tuvimos cuando éramos de grande, tuvimos una gran prosperidad, trabajamos mucho todos juntos y tuvimos comodidades, entonces, eh... mi vida adolescente, mi vida hasta... hasta antes de, de esta tragedia, fue una vida de, de mucho gusto, de mucho gozar de 
cosas, de que no me falto nada, de que incluso era muy como... como sin pensar nada más que vivir el momento, que lo pasé muy fien (mujer, 59 años).

Tabla 74. Antecedentes conceptuales de la visión de futuro en el pasado

\begin{tabular}{|c|c|c|c|c|c|}
\hline \multirow{3}{*}{$\begin{array}{l}\text { VISIÓN DE } \\
\text { FUTURO }\end{array}$} & \multicolumn{3}{|c|}{ POR DOCUMENTO } & \multirow{2}{*}{\multicolumn{2}{|c|}{$\begin{array}{c}\text { POR UNIDAD DE } \\
\text { ANÁLISIS } \\
\mathrm{N}=9900 \\
\end{array}$}} \\
\hline & \multirow{2}{*}{ Frecuencia } & $\frac{N=60}{N=}$ & $\mathrm{n}=34$ & & \\
\hline & & $\begin{array}{c}\text { \% según } \\
\text { UR }\end{array}$ & \% según UR & Frecuencia & \% según UR \\
\hline Pesimista & 5 & 8.3 & 15 & 6 & 0.06 \\
\hline Optimista & $\underline{30}$ & 50 & 88 & $\underline{39}$ & 0.39 \\
\hline
\end{tabular}

Como nos indica la Tabla 74, un grupo mayor a la mitad de EXPPS entrevistados aludió a la visión de futuro que tenía en su infancia y adolescencia. De los cuales, la mayoría, equivalente al 88\% de quienes emitieron en sus discursos esta visión, y al 50\% del total de participantes del estudio, refirió haber tenido una visión positiva del futuro. Apreciación que se manifestó en alrededor de una U.T.s por sujeto.

Por último, cabe destacar que una persona refirió simultáneamente haber tenido una visión tanto positiva como negativa del futuro en el pasado.

Me vine a Arica buscando metas, con sueños de que me iba a ir bien. Me vine sola a trabajar. Estudiaba y trabajaba, salia del trabajo y me iba a estudiar, y me vine buscando metas y sueños que se interrumpieron el 72. Entonces fueron poquitos mis días bien (mujer, 52 años).

No me acuerdo. O sea, yo creo que tenía esperanza en algunas cosas. Era media soñadora, me evadía de los problemas de la casa. inventaba mis cuentos. Si, yo siempre los inventé. Y nunca me ha costado inventar mis cuentos. (por ejemplo) inventaba of cuando yo sea grande voy a vivir en una casa grande. Inventaba toda una historia y en eso yo estaba. Era buena pa leer además, muy buena pa leer (mujer, 60 años).

Chuta que dificil, eh pero yo fui siempre optimista, que es un pesimista desinformado, como decía alguien por ahí. To fui siempre optimista, siempre tuve la facilidad, y un poco se lo debo eso a la actitud de mi viejo también ah, eh de ver por encima de cualquier desgracia y cualquier situación penca, era capaz de mirar para allá y ver que era posible. Después cuando fui más activo laboralmente y todo eso, me fue bien, y muy bien, y ahí descubrí que había sido una estupidez haber dejado de estudiar, pero en fin ya estaba metido en una máquina. Asumí el compromiso de familia en esa misma política, claro, de sentirme capaz de... de ningún problema para mi cruzar el océano era como cruzar una acequia de un salto. Nunca topé en cosas... (varón, 56 años).

Eh, Gueno yo en ese tiempo veía la vida a pesar de todo la veía con hartas esperanzas. Pero resulta que después las cosas no me resultaron tampoco. () si, tenía sueños, tenía esperanzas. To creo que vivía en un mundo de sueños. Soñaba con todo lo que no tenía (mujer, 63 años). 
Tabla 75. Antecedentes conceptuales de la valoración de su estar en el mundo en el pasado

\begin{tabular}{|c|c|c|c|c|c|}
\hline \multirow{3}{*}{$\begin{array}{l}\text { VALORACIÓ } \\
\text { N DE SU } \\
\text { ESTAR EN EL } \\
\text { MUNDO }\end{array}$} & \multicolumn{3}{|c|}{ POR DOCUMENTO } & \multirow{2}{*}{\multicolumn{2}{|c|}{$\begin{array}{c}\text { POR UNIDAD DE } \\
\text { ANÁLISIS } \\
\mathrm{N}=9900 \\
\end{array}$}} \\
\hline & \multirow[t]{2}{*}{ Frecuencia } & $\mathrm{N}=60$ & $n=56$ & & \\
\hline & & \% según UR & \% según UR & Frecuencia & \% según UR \\
\hline Insatisfecho & 18 & 30 & 32 & 21 & 0.21 \\
\hline Satisfecho & $\underline{40}$ & 67 & 71 & $\underline{44}$ & 0.44 \\
\hline
\end{tabular}

Como nos señala la Tabla 75, casi la totalidad de la muestra valoró su estar en el mundo durante su infancia y/ o adolescencia (el 93\% de la muestra). De este grupo de personas y superó la media de sujetos del estudio ( $67 \%$ del total de participantes, y $71 \%$ de personas que aludieron la temática en cuestión), el número de personas que recordaron haberse sentido generalmente satisfechos durante su vida en el pasado.

Dos personas que hemos incluido en los análisis previos a la Tabla 75 , refirieron simultáneamente satisfacción e insatisfacción en cuanto a su estar en el pasado.

"Feliz. Sabía que se tenía un tubo de oxígeno dentro de mi cuerpo y eso se terminó el 73" (varón, 75 años).

"No, yo me sentía bien con lo que hacía, a pesar de las limitaciones de tiempo de que estaba estudiando me sentía bien. Siempre estaba ocupado pero tenía energía de sobra en ese tiempo" (varón, 58 años).

"Pienso que en la época que me tocó vivir a mi, dentro de las posibilidades que tenía, pienso que a gusto. Porque era feliz" (varón, 53 años).

Tabla 76. Antecedentes conceptuales del sentido otorgado a la vida en el pasado

\begin{tabular}{|c|c|c|c|c|c|}
\hline \multirow{3}{*}{$\begin{array}{l}\text { SENTIDO DE LA } \\
\text { VIDA }\end{array}$} & \multicolumn{3}{|c|}{ POR DOCUMENTO } & \multirow{2}{*}{\multicolumn{2}{|c|}{$\begin{array}{c}\text { POR UNIDAD DE } \\
\text { ANÁLISIS } \\
\mathrm{N}=9900\end{array}$}} \\
\hline & \multirow{2}{*}{ Frecuencia } & $\mathrm{N}=60$ & $\mathrm{n}=55$ & & \\
\hline & & $\begin{array}{c}\text { \% según } \\
\text { UR }\end{array}$ & $\begin{array}{c}\text { \% según } \\
\text { UR }\end{array}$ & Frecuencia & \% según UR \\
\hline Negativo & 13 & 22 & 24 & 18 & 0.18 \\
\hline Positivo & $\underline{50}$ & 83 & 91 & $\underline{65}$ & 0.66 \\
\hline
\end{tabular}

Como señala la Tabla 76, el 91\% de personas que aludieron al sentido que otorgaban a la vida en su adolescencia (equivalente al $83 \%$ de la muestra entrevistada), refirió un sentido de vida positivo, lo que manifestaron en alrededor de una U.T.s por persona.

Por su parte, un grupo de 8 personas (incluidas en los análisis del párrafo anterior), refirieron simultáneamente una valoración negativa y positiva en sus discursos, que podríamos considerar contradictorio 
en este grupo, en relación al tema específico o considerar que refiere una valoración de las dos apreciaciones en su vida pasada.

Tabla 77. Tema específico más aludido para la categoría sentido otorgado a la vida en el pasado

\begin{tabular}{|lc|}
\hline Por documentos & Por U.T.S \\
\hline Valoración global: positiva $(82 \%)$ & Valoración global: positiva $(0.59 \%)$ \\
\hline
\end{tabular}

En ese tiempo la vida se ve mas, mas linda en esa edad, ¿no?. Porque no tiene las complicaciones de, de, de, de, de tener obligaciones, de, de trabajo, de esto, el papá, o en ese tiempo mi mamá, mis hermanos se preocupaban de la comida, entonces por lo tanto no es, no es, no había una preocupación... que la vida era bonita. Salía a jugar a la pelota siempre... (varón, 67 años).

Muy buenos recuerdos, yo fui una adolescente... estamos hablando de los 17- 18 años yo fui un adolescente muy alegre, eh... muy amiguera, muy amante de las fiestas, muy amante de la moda, eh... fui de la minifanda, delépoca del rock, lo gocé pero a concho, viví una vida plena. Eh... no había malón que donde yo no estuviera invitada, fui súper popular. Era... ef... Lo pase muy pero muy bien, una época de adolescente, diría yo de, de, de poco cerebro y de mucho.. de mucho, mucho pasarlo bien. Eh... fui siempre muy buena alumna en el colegio, entonces no me preocupaba mucho en las notas pa pasarto bien, como yo fui a estudiar a La Serena, vivía en la playa y que se yo, y sin embargo mis notas eran buenas, entonces tuve muy buena... tengo muy buenos recuerdos de esa época de estar de cabra joven (mujer, 59 años).

\subsubsection{Antecedentes conceptuales de la experiencia de prisión política y tortura}

Tabla 78. Antecedentes conceptuales del sufrimiento vivido en prisión

\begin{tabular}{||c|c|c|c|c|c||}
\hline \multirow{3}{*}{ SUFRIMIENTO } & \multicolumn{3}{|c|}{ POR DOCUMENTO } & \multicolumn{2}{c|}{$\begin{array}{c}\text { POR UNIDAD DE } \\
\text { ANÁLISIS } \\
\text { N }=9900\end{array}$} \\
\cline { 2 - 4 } & \multirow{3}{*}{ Frecuencia } & $\mathrm{N}=60$ & $\mathrm{n}=24$ & \multicolumn{2}{c||}{} \\
\cline { 3 - 6 } & & $\begin{array}{c}\text { \% según } \\
\text { UR }\end{array}$ & $\begin{array}{c}\text { \% según } \\
\text { UR }\end{array}$ & Frecuencia & \% según UR \\
\hline Refiere & $\underline{\mathbf{1 7}}$ & 28 & 71 & $\underline{\mathbf{2 4}}$ & 0.24 \\
\hline Menos que compañeros & 11 & 18 & 46 & 14 & 0.14 \\
\hline
\end{tabular}

Sólo 24 personas equivalentes al 40\% de la muestra, refirieron haber sufrido en prisión. De estas personas, el $71 \%$, correspondiente al 28\% de la muestra, lo manifestó en alrededor de una vez por discurso. Por su parte, el $46 \%$ de quienes aludieron este sufrimiento específico, equivalentes al 18\% de la muestra, refirió que su sufrimiento fue inferior al de sus compañeros, manteniéndose la frecuencia de alusión por U.T.s.

Por último, cuatro personas hicieron alusión a las dos categorías comprendidas en la Tabla 78, y éstas están incluidas en los valores que entrega la tabla. Lo que nos indica que estas personas, refirieron haber 
sufrido en prisión basando su apreciación en la propia experiencia y en función de otras personas que vivieron situaciones de prisión política también.

Tabla 79. Tema específico más aludido para la categoría sufrimiento vivido en prisión

\begin{tabular}{|ll|}
\hline Por documentos & \multicolumn{1}{c|}{ Por U.T.s } \\
\hline $\begin{array}{l}\text { Sufrimiento: no especifica } \\
\text { cantidad }(18 \%)\end{array}$ & $\begin{array}{l}\text { Sufrimiento: no especifica } \\
\text { cantidad }(0.13 \%)\end{array}$ \\
\hline
\end{tabular}

Pero a ver, no le entiendo la pregunta. ¿De parte de quién?, ¿de las autoridades o de la ciudadanía?. Mira, si bien es cierto aquí algo se ha hecho, primero con el informe Rettig, después con el informe Valech, pero creo que no es suficiente, no es suficiente, falta mucho todavía, falta reconocer muchas cosas que... porque uno no puede andar contando, ni puede andar trayendo un cartel lo que a ti te ficieron, una que para una es doloroso y otra de que no puede tampoco andar en eso siempre, porque eh... se daña uno misma. debiera haber yo pienso más, más apertura, más, porque yo creo que también serviría como de terapia para las personas que de repente tienen más eh... conflictos que, que uno, traumas incluso. Bueno, a mi me tocó, me costó mucho superar muchas cosas, pero he superado mucho, pero todavía tengo mis cositas por afí (mujer, 64 años).

Ahora obviamente, a la familia le afecta montones poh. Yo creo que hay momentos que como familia, por eso, a lo mejor nos hemos mantenido un poco unida, por el dolor y el recuerdo yo creo. O por el recuerdo. Porque siempre, lo que siempre hemos dicho entre nosotros "¿qué hubiera pasado si hubiera faltado uno de los hermanos, hubiera desaparecido, cómo estaría? (varón, 51 años).

Tabla 80. Antecedentes conceptuales de la valoración del impacto de prisión en otros

\begin{tabular}{|c|c|c|c|c|c|}
\hline \multirow{3}{*}{$\begin{array}{c}\text { VALORACIÓN } \\
\text { IMPACTO } \\
\text { NEGATIVO EN } \\
\text { OTROS EXPPS }\end{array}$} & \multicolumn{3}{|c|}{ POR DOCUMENTO } & \multirow{2}{*}{\multicolumn{2}{|c|}{$\begin{array}{c}\text { POR UNIDAD DE } \\
\text { ANÁLISIS } \\
\mathrm{N}=9900\end{array}$}} \\
\hline & \multirow{2}{*}{ Frecuencia } & $\mathrm{N}=60$ & $\mathrm{n}=41$ & & \\
\hline & & \% según UR & \% según UR & Frecuencia & \% según UR \\
\hline Salud mental & 15 & 25 & 37 & 20 & 0.20 \\
\hline Calidad de vida & 8 & 13 & 20 & 12 & 0.12 \\
\hline Familia & 8 & 13 & 20 & 8 & 0.08 \\
\hline Ideología & 9 & 15 & 22 & 14 & 0.14 \\
\hline Salud física & 11 & 18 & 27 & 17 & 0.17 \\
\hline Muerte & $\underline{27}$ & 45 & 66 & $\underline{42}$ & 0.42 \\
\hline
\end{tabular}

Como indica la Tabla 80, más de la mitad de EXPPS entrevistados hizo referencia al impacto negativo percibido en otros EXPPS producto de la experiencia de cautiverio. Las 41 personas aludidas, refieren el impacto en 6 ámbitos, dentro de los cuales la moda la obtiene la "muerte" (con el 66\% de sujetos que aludieron esta temática y el 45\% del total de la muestra). Lo que se presentó en un promedio de 1,5 U.T.s por documento, obteniendo la moda por unidades codificadas. 
Cada uno de los cinco ámbitos restantes contemplados en la Tabla 80, se presentó en menos de la mitad de las personas que aludieron a este tema, y del total de la muestra que valoró el impacto negativo de la prisión en otros EXPPS, estas alusiones se presentaron en un promedio de dos ámbitos por persona.

Entendemos que la muerte de otros EXPPS, es la consecuencia más tangible y cruel de las experiencias de la violencia y tortura vivida en prisión. Por ello, creemos que ha sido la temática más aludida.

Ahí conocí como a siete personas que los mataron y no volvieron nunca más. Inclusive en la misma cárcel de Antofagasta hicieron fusilamiento, y eso yo no me voy a olvidar nunca porque mi compañero de celda se llamaba "apellido", dormía al lado mío y lo sacaron para matarlo. Yen un dos por tres el fiscal que estaba ahí dijo "no, este no hay que matarlo, es otro", entonces el, le dieron cómo se llama una imagen y el hombre como que se estaba volviendo Loco, y el recuerdo me cayó, a donde estaba, o fusilaban a la ida a los compañeros de Antofagasta, me regaló un Cristo que todavía lo tengo en mi casa, tallado, bien bonito me lo dedicó, todo. Yéé él fue un impacto psicológico muy malo que le hicieron, porque la verdad de las cosas es que se sufrió bastante (varón, 55 años).

Y, y hay gente.. Yo, yo sufrí mucho, aunque fueron solamente siete meses. Pero hay gente, hay gente que le falta el Grazo, que han, han muerto, le falta una pierna. Entonces por los.. Eh... fue muy, muy, unas injusticias muy grandes; e h... en ese tiempo y hasta ahora (varón, 58 años).

Tabla 81. Antecedentes conceptuales de la actitud post-prisión

\begin{tabular}{||c|c|c|c|c|c||}
\hline \multirow{2}{*}{\begin{tabular}{c} 
ACTITUD POST - $\begin{array}{c}|c| \mid \\
\text { PRISIÓN }\end{array}$ \\
\cline { 2 - 4 }
\end{tabular}} & \multirow{2}{*}{ Frecuencia } & $\mathrm{N}=60$ & $\mathrm{n}=50$ & \multicolumn{2}{|c|}{$\begin{array}{c}\text { POR UNIDAD DE } \\
\text { ANÁLISIS } \\
\text { N }=9900\end{array}$} \\
\cline { 3 - 6 } & $\begin{array}{c}\text { \% según } \\
\text { UR }\end{array}$ & \% según UR & Frecuencia & $\%$ según UR \\
\hline Desfavorables & 30 & 50 & 60 & 58 & 0.59 \\
\hline Favorables & $\underline{\mathbf{4 2}}$ & 70 & 84 & $\underline{\mathbf{5}}$ & 0.76 \\
\hline
\end{tabular}

La mayoría de los participantes del estudio aludió a la forma en que enfrentó la vida en el período posterior al episodio de prisión. De estas personas, la mayoría con un $84 \%$, equivalente al $70 \%$ de la muestra, refirió actitudes que hemos considerado favorables para sus vidas. Todas las cuales se presentaron en dos U.T.s por documento.

Por su parte, el 60\% de quienes aludieron estas actitudes, correspondiente al 50\% de la muestra entrevistada, refirió actitudes desfavorables relacionadas a la experiencia de prisión que hemos considerado negativas para sus vidas. Lo que se presentó en dos U.T.s aproximadas por documento.

Por último, deducimos de la Tabla 81, que un grupo de 22 personas, refirió simultáneamente actitudes que hemos considerado favorables y desfavorables para su vida posterior y para la superación de la experiencia de prisión. 
Tabla 82. Tema específico más aludido para la categoría actitud post-prisión

\begin{tabular}{|ll|}
\hline Por documentos & Por U.T.s \\
\hline $\begin{array}{l}\text { Lectura: “una valiosa } \\
\text { experiencia" }(25 \%)\end{array}$ & $\begin{array}{l}\text { Lectura: "una valiosa } \\
\text { experiencia" }(0.16 \%)\end{array}$ \\
\hline
\end{tabular}

$\mathcal{N}$ o, lo siento, me siento orgulloso de... esto es como, es como cualquier funcionario público, ¿ya?, pero en nuestra época, yo me siento orgulloso de haber podido que... querer cambiar la sociedad, ¿ya?, de haber sido partícipe, de haber querido cambiar una sociedad para no haber llegado a to que somos ahora, de eso me siento orgulloso (varón, 53 años).

Me siento orgullosa, me siento orgullosísima. Yo por mi, yo, yo digo y siempre, yo, yo siempre, nunca quisiera cambiar, y quisiera que Dios siempre me diera la fortaleza de no cambiar y ojalá hacer que más personas sean, sean también que luchen por, por, porque para mi la, el... cómo dijera yo, Ca... el haber sido torturada y todas esas cosas, para mi como que me enriqueció, me dio más ánimo para poder salir eh... adelante y ojalá que todo el mundo fuera de nuestra... de nuestro lado (mujer, 61 años).

Tabla 83. Antecedentes conceptuales de la valoración del impacto de prisión en sus vidas

\begin{tabular}{|c|c|c|c|c|c|}
\hline \multirow{3}{*}{$\begin{array}{c}\text { VALORACIÓN } \\
\text { IMPACTO } \\
\text { PRISIÓN EN } \\
\text { ÁMBITOS DE LA } \\
\text { VIDA }\end{array}$} & \multicolumn{3}{|c|}{ POR DOCUMENTO } & \multirow{2}{*}{\multicolumn{2}{|c|}{$\begin{array}{c}\text { POR UNIDAD DE } \\
\text { ANÁLISIS } \\
\mathrm{N}=9900\end{array}$}} \\
\hline & \multirow{2}{*}{ Frecuencia } & $\mathrm{N}=60$ & $\mathrm{n}=59$ & & \\
\hline & & \% según UR & \% según UR & Frecuencia & \% según UR \\
\hline No percibe & 12 & 20 & 20 & 13 & 0.13 \\
\hline Si percibe & $\underline{57}$ & 95 & 97 & $\underline{217}$ & 2.2 \\
\hline
\end{tabular}

Como nos indica la Tabla 83, casi la totalidad de EXPPS entrevistados realizó una valoración del impacto de la experiencia de prisión en sus vidas. De estas personas, la mayoría afirmó percibir tal impacto (el 97\%, correspondiente al 95\% de la muestra). Lo que se presentó en aproximadamente 4 U.T.s por sujeto.

Por último, un grupo de 10 personas incluidas en las dos valoraciones que muestra la Tabla 83, hizo alusión simultáneamente a ambas categorías. Lo que aparentemente es una contradicción, pero que puede deberse a valoraciones realizadas en función de distintos ámbitos de sus vidas que han sido indagados en la categoría (ver Apéndice D).

Tabla 84. Tema específico más aludido para la categoría valoración del impacto de prisión en sus vidas

\begin{tabular}{|ll|}
\hline Por documentos & \multicolumn{1}{c|}{ Por U.T.s } \\
\hline $\begin{array}{l}\text { Traspaso del trauma a hijos: } \mathbf{s i} \\
\text { percibe }(52 \%)\end{array}$ & $\begin{array}{l}\text { Traspaso del trauma a hijos: si } \\
\text { percibe }(0.61 \%)\end{array}$ \\
\hline
\end{tabular}

Eh... que la (bija) eh... con miedo, si. La (hija) tiene miedo, la (hija) tiene miedo a las aglomeraciones 
cuando hay mucha gente por ejemplo si va a una, a una marcha y cuestiones y ve a muchas... ve pacos, ipah!, se sale sola la (hija), se va pa' la casa (mujer, 62 años).

Endureció su carácter poh. ELllos tienen un carácter muy duro. Pero, yo creo que más que tienen que ver con su autoestima poh. O sea, el papá y la mamá separados primero separados porque no se llevaron bien y esa es una cuestión netamente personal, pero que el papá no la pueda venir a ver, porque el papá vive en otra parte, porque el papá no puede entrar a Chile, porque si viene a Chile se va a tener que mamar unos, unos días en la cárcel, y porque fue expulsado del país (mujer, 43 años).

Cómo defino yo, es parte de mi identidad. SNo, es par... por todo lo que yo te decía, lo que pasó con mis niños. Por todas las carencias, esos vacíos que... afectivos que se produjeron, ef... fue un daño muy grande; y eso no se supera nunca con nada (mujer, 64 años).

Tabla 85. Antecedentes conceptuales de la valoración del impacto de prisión en relaciones interpersonales

\begin{tabular}{|c|c|c|c|c|c|}
\hline \multirow{3}{*}{$\begin{array}{c}\text { VALORACIÓN } \\
\text { IMPACTO PRISIÓN } \\
\text { EN RELACIONES } \\
\text { INTERPERSONALES }\end{array}$} & \multicolumn{3}{|c|}{ POR DOCUMENTO } & \multirow{2}{*}{\multicolumn{2}{|c|}{$\begin{array}{c}\text { POR UNIDAD DE } \\
\text { ANÁLISIS } \\
\text { N }=9900\end{array}$}} \\
\hline & & $\mathrm{N}=60$ & $\mathrm{n}=52$ & & \\
\hline & Frecuencia & \% según UR & \% según UR & Frecuencia & \% según UR \\
\hline No percibe cambios & 24 & 40 & 46 & 42 & 0.42 \\
\hline Si percibe cambios & $\underline{43}$ & 72 & 83 & $\underline{142}$ & 1.4 \\
\hline
\end{tabular}

Observamos en la Tabla 85, que la mayoría de los EXPPS valoró el impacto de la experiencia de prisión en sus relaciones interpersonales. De estas personas, el 83\%, equivalente al $72 \%$ de la muestra, afirmó percibir cambios en sus relaciones interpersonales producto de la experiencia de prisión. Lo que manifestaron en un promedio de tres U.T.s por cada discurso.

Por último, cabe destacar que 15 personas refirieron simultáneamente las dos valoraciones que presenta la Tabla 85, lo que creemos que se debe a que ésta tabla agrupa valoraciones específicas de distintas relaciones interpersonales, pudiendo estas personas, haber percibido cambios en algunas relaciones y no en otras.

De acuerdo a lo anterior, hemos decidido extraer de la Tabla 85, los resultados referidos a relaciones específicas de los EXPPS (ver Tabla 86). 
Tabla 86. Antecedentes conceptuales de la valoración del impacto de prisión en relaciones interpersonales con la familia

\begin{tabular}{|c|c|c|c|c|c|}
\hline \multirow{3}{*}{$\begin{array}{c}\text { VALORACIÓN } \\
\text { IMPACTO PRISIÓN } \\
\text { EN RELACIONES } \\
\text { INTERPERSONALES } \\
\text { - FAMILIA }\end{array}$} & \multicolumn{3}{|c|}{ POR DOCUMENTO } & \multirow{2}{*}{\multicolumn{2}{|c|}{$\begin{array}{c}\text { POR UNIDAD DE } \\
\text { ANÁLISIS } \\
\mathrm{N}=9900\end{array}$}} \\
\hline & \multirow[t]{2}{*}{ Frecuencia } & $\mathrm{N}=60$ & $\mathrm{n}=24$ & & \\
\hline & & $\begin{array}{c}\text { \% según } \\
\text { UR }\end{array}$ & $\begin{array}{c}\text { \% según } \\
\text { UR }\end{array}$ & Frecuencia & \% según UR \\
\hline Cambios negativos & $\underline{22}$ & 37 & 92 & $\underline{44}$ & 0.44 \\
\hline Cambios positivos & 0 & 0 & 0 & 0 & 0 \\
\hline
\end{tabular}

Como nos indica la Tabla 86, menos de la mitad de la muestra valoró el impacto de la experiencia de prisión en sus relaciones familiares, de quienes el 92\%, correspondiente al 37\% de la muestra, refirió un impacto negativo en estas relaciones. Estas alusiones se presentaron en una frecuencia de dos U.T.s por documento.

Ningún EXPPS entrevistado que refiriera el impacto de la experiencia de prisión en sus relaciones familiares, manifestó cambios positivos, y dos personas hicieron referencia al impacto de la prisión en estas relaciones, pero no especificaron sus respuestas, quedando excluidos de las dos opciones presentes en la Tabla 86. Esto nos indica, que de los EXPPS que valoraron el impacto de la experiencia de prisión, la mayoría sostiene que este episodio en sus vidas afectó de manera negativa en sus relaciones familiares, y ninguno sostiene lo contrario.

Tabla 87. Tema específico más aludido para la categoría valoración del impacto de prisión en relaciones interpersonales con la familia

\begin{tabular}{|ll|}
\hline Por documentos & \multicolumn{1}{c|}{ Por U.T.s } \\
\hline $\begin{array}{ll}\text { Hijos/ valoración global: negativa } & \text { Hijos/ valoración global: negativa } \\
(22 \%) & (0.20 \%)\end{array}$ \\
\hline
\end{tabular}

Que... influyó en mi vida familiar... en mucho influyó. Ahí... con el tiempo me separé por cómo yo đlegué. Eh... Clegué muy, Clegué muy, muy enfermo, muy neurótico, muy.... ¿cómo se llama cuando uno es muy rabioso?, eh... muy agresivo, de cualquier cosa, me parecía mal. Todo eso. Eh... Los retaba, no les pegaba si ah, los retaba... todo, todo, todo después me parecía mal, todo (varón, 58 años).

Bien... es muy atrevida mi hija. ...yo diría que si ah, pero ahora es un poco peor, o sea, si, siempre ha sido un poco dificil, siempre despierta, muy altanera, muy, muy altanera. Entonces, es que ella, por ella pasaron muchas cosas en su vida también poh. El hecho de que ella se... el hecho de que ella se haya, ella es así también porque, el hecho estuvo, sufrió el abandono. El abandono de, cómo se llama, de, de nosotros, estuvo, estuvo con sus tías, con su abuela, un buen tiempo. Estuvo con ellos, porque nosotros estuvimos escondidos con mi marido estuvimos un 6uen tiempo (mujer, 53 años). 
A lo mejor influyó en la medida de que yo me puse como más huraño con ellos, como que no les di el tiempo que necesitaba darles, puede haber sido eso ah. No los traté como, como debía haber sido. De repente fui brusco. Mi hija mayor tenía tres años, después tenía otro que tenía un año el (hijo1), después nació (hijo2) que como le decía a los dos meses falleció; después nació (hijo3), después al último (hijo4). Pero yo igual me, mi espíritu huraño así igual de repente sigue. Me he calmado si, antes yo era muy irascible, flotaba" (varón, 58 años).

Tabla 88. Antecedentes conceptuales de la valoración del impacto de prisión en relaciones interpersonales con los amigos

\begin{tabular}{|c|c|c|c|c|c|}
\hline \multirow{3}{*}{$\begin{array}{c}\text { VALORACIÓN } \\
\text { IMPACTO PRISIÓN } \\
\text { EN RELACIONES } \\
\text { INTERPERSONALES - } \\
\text { AMIGOS }\end{array}$} & \multicolumn{3}{|c|}{ POR DOCUMENTO } & \multirow{2}{*}{\multicolumn{2}{|c|}{$\begin{array}{c}\text { POR UNIDAD DE } \\
\text { ANÁLISIS } \\
\mathrm{N}=9900\end{array}$}} \\
\hline & \multirow[t]{2}{*}{ Frecuencia } & $\mathrm{N}=60$ & $\mathrm{n}=21$ & & \\
\hline & & $\begin{array}{c}\text { \% según } \\
\text { UR }\end{array}$ & \% según UR & Frecuencia & \% según UR \\
\hline Cambios negativos & $\underline{16}$ & 27 & 76 & $\underline{27}$ & 0.27 \\
\hline Cambios positivos & 2 & 3.3 & 10 & 2 & 0.02 \\
\hline
\end{tabular}

Como nos indica la Tabla 88, menos de la mitad de EXPPS entrevistados valoró el impacto de la prisión en sus relaciones de amistad. De quienes la mayoría de ellos (76\%), equivalente al 27\% de la muestra, aluden cambios negativos en estas relaciones. Este aspecto fue expresado en un promedio de dos U.T.s por sujeto.

Por último, tres personas no fueron incluidas en la tabla debido a que aludieron la temática en estudio, pero no especificaron su valoración asociada a ésta.

Es que no se, uno pensaba que eran amigos y en un momento determinado cuando uno más los necesitaba nunca estuvieron con uno, entonces pero yo los respeto. Cuando tengo posibilidad de conversar con ellos converso, no dejo de tener relaciones con ellos pero afí no más (varón, 55 años).

Si tengo, claro, claro, claro, claro, nada que ver, es que los amigos de antes, hablemos, yo siempre digo, porque hay un disco que dice los amigos de antes usan gomina, esos ya no usan gomina, porque ellos nos aislaron a nosotros, como extremistas, como un peligro público, un peligro de la sociedad éramos nosotros. en cambio me he encontrado con gente nueva, gente que estuvo también detenida, exonerada politica, exonerada de sus trabajos. Afí conversamos bien, porque somos de la misma enfermedad. Todos mis amigos son del mismo caso del 73 (varón, 75 años). 
Tabla 89. Antecedentes conceptuales de la valoración del impacto de prisión en relaciones interpersonales con los compañeros

\begin{tabular}{||c|c|c|c|c|c||}
\hline VALORACIÓN & \multicolumn{3}{|c|}{ POR DOCUMENTO } & \multicolumn{2}{c|}{$\begin{array}{c}\text { POR UNIDAD DE } \\
\text { ANÁLISIS } \\
\text { IMPACTO PRISIÓN }\end{array}$} \\
\cline { 2 - 5 } $\begin{array}{c}\text { EN RELACIONES } \\
\text { INTERPERSONALES } \\
\text { - COMPAÑEROS (D) }\end{array}$ & & $\mathrm{N}=60$ & $\mathrm{n}=9$ & \multicolumn{2}{c||}{} \\
\cline { 2 - 6 } & Frecuencia & $\%$ según UR & $\%$ según UR & Frecuencia & $\%$ según UR \\
\hline Cambios negativos & $\underline{\mathbf{5}}$ & 8 & 56 & $\underline{\mathbf{9}}$ & 0.09 \\
\hline Cambios positivos & 0 & 0 & 0 & 0 & 0 \\
\hline
\end{tabular}

La Tabla 89 nos indica que menos de la mitad de la muestra (15\%) hizo alusión al impacto percibido en sus relaciones con los compañeros políticos, de quienes el 56\% correspondiente al 8\% de la muestra, refirió cambios negativos. Lo que se manifestó alrededor de dos U.T.s por discurso. Observamos además, que ningún EXPPS que refirió la temática en cuestión, aludió cambios positivos en estas relaciones, y cuatro personas refirieron esta temática pero no la especificaron.

\section{"Si nosotros, que más encima que todo, no sé si fue la coincidencia macabra... a todos nos trataron muy} mal dentro del partido" (varón, 40 años).

Tabla 90. Antecedentes conceptuales de la valoración de temores asociados a la experiencia de prisión

\begin{tabular}{||c|c|c|c|c|c||}
\hline \multirow{3}{*}{$\begin{array}{c}\text { TEMORES } \\
\text { ASOCIADOS }\end{array}$} & \multicolumn{3}{|c|}{ POR DOCUMENTO } & \multicolumn{2}{c|}{ POR UNIDAD DE } \\
\cline { 2 - 4 } & \multirow{2}{*}{ Frecuencia } & $\mathrm{N}=60$ & $\mathrm{n}=23$ & \multicolumn{2}{c||}{ ANÁLISIS N = 9900 } \\
\cline { 3 - 6 } & & $\begin{array}{c}\text { \% según } \\
\text { UR }\end{array}$ & \% según UR & Frecuencia & \% según UR \\
\hline No tiene & 3 & 5 & 13 & 4 & 0.04 \\
\hline Si tiene & $\underline{\mathbf{2 1}}$ & 35 & 91 & $\underline{\mathbf{3 5}}$ & 0.35 \\
\hline
\end{tabular}

Como nos indica la Tabla 90, menos de la mitad de personas entrevistadas aludió a sus temores asociados a la experiencia de prisión. De quienes el 91\% (35\% de la muestra), refirió en un promedio de dos U.T.s por documento, la presencia de éstos en su vida.

Por último, una persona refirió simultáneamente en su discurso, que tiene y no tiene temores asociados. La que se incluye en los valores que entrega la Tabla 90.

Tabla 91. Tema específico más aludido para la categoría valoración de temores asociados a la experiencia de prisión

\begin{tabular}{|lc|}
\hline Por documentos & Por U.T.s \\
\hline Si presenta: a cambios políticos $(15 \%)$ & Si presenta: no especifica $(0.12 \%)$ \\
\hline
\end{tabular}


A cambios políticos:

A mi lo que me tiene en este momento atormentada, son las elecciones. Como ha afectado. O sea, veo que se puede volver a tiempos... Mientras yo no saque eso de adentro, yo no sentía esto, estaba tan guardado, tan guardado... (mujer, 52 años).

¿Algo a que le tenga miedo?, en general yo hace mucho tiempo que vencí el miedo, pero que yo siento, el temor que siempre tengo yo, es de que estos hechos pudieran en alguna vez repetirse, y a la mejor nosotros no la vamos a vivir de nuevo, pero si las nuevas generaciones que vienen, y eso me dolería mucho a mi, porque fue una, una experiencia absolutamente espantosa, y cual más, cual menos, todos tenemos secuelas de ese, de esas torturas, todos las tenemos (mujer, 59 años).

No especifica:

Claro, por ejemplo yo estuve 3 años presos. La (esposa) estuvo más tiempo afuera, pero no se acercaron nunca a ella a preguntarle qué pasó. Además que yo también lo entiendo. El temor es una cosa que, no se, no todos to asumimos. O si lo asumimos lo asumimos de diferentes manera (varón, 55 años).

Tabla 92. Antecedentes conceptuales del silencio personal

\begin{tabular}{|c|c|c|c|c|c|}
\hline \multirow{3}{*}{$\begin{array}{l}\text { SILENCIO } \\
\text { PERSONAL }\end{array}$} & \multicolumn{3}{|c|}{ POR DOCUMENTO } & \multirow{2}{*}{\multicolumn{2}{|c|}{$\begin{array}{c}\text { POR UNIDAD DE } \\
\text { ANÁLISIS } \\
\mathrm{N}=9900\end{array}$}} \\
\hline & \multirow{2}{*}{ Frecuencia } & $\mathrm{N}=60$ & $\mathrm{~N}=38$ & & \\
\hline & & $\begin{array}{l}\text { \% según } \\
\text { UR }\end{array}$ & $\begin{array}{c}\text { \% según } \\
\text { UR }\end{array}$ & Frecuencia & \% según UR \\
\hline No hizo & 13 & 22 & 34 & 15 & 0.15 \\
\hline Si hizo & $\underline{34}$ & 57 & 89 & $\underline{75}$ & 0.72 \\
\hline
\end{tabular}

En cuanto a la alusión que los EXPPS hicieran del silencio que guardaron de su experiencia de prisión, la Tabla 92, comprende todas las respuestas asociadas a esta temática. Estas incluyen el silencio mantenido por cada EXPP de su propia experiencia, lo que podríamos entender como el "querer olvidar", y aquellas alusiones al silencio en función de las relaciones interpersonales. Por ello en la Tabla 94, presentaremos resultados que están incluidos dentro de la tabla que la precede, y que son específicos del silencio mantenido a nivel interpersonal. Creemos que la información que reporta esta tabla, es relevante para el entendimiento del impacto psico-social que estudiamos en esta tesis doctoral.

Según la Tabla 92, más de la mitad de la muestra participante del estudio manifestó haber mantenido en silencio su experiencia de prisión política. Lo que se presentó en el 89\% de las personas que aludieron esta temática, equivalente al 57\% de la muestra; y fue expresado en un promedio de dos U.T.s por documento. 
Nueve personas refirieron simultáneamente haber mantenido y no haber mantenido silencio de su experiencia de prisión. Esto, lo que podemos explicar porque los nudos hijos en que clasificamos estas respuestas, valoran de manera específica la presencia de este silencio en distintos tipos de relaciones interpersonales que aquí hemos agrupado. De acuerdo a esto, las personas que refieren las dos categorías de la Tabla 92, por ejemplo, pudieron haber mantenido en silencio su experiencia de prisión con los hijos pero no con la pareja.

Tabla 93. Tema específico más aludido para la categoría silencio personal

\begin{tabular}{|lc|}
\hline Por documentos & Por U.T.s \\
\hline Tiempo: desde prisión hasta presente $(18 \%)$ & Tiempo: no especifica $(0.16 \%)$ \\
\hline
\end{tabular}

Desde prisión hasta presente:

Yo he tratado de lo menos posible de tocar este tema en la familia. O sea, una sola vez lo toqué y

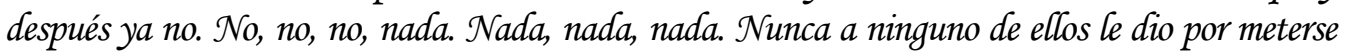
en, en las fuerzas armadas (varón, 55 años).

No especifica:

$\mathcal{N}$ o es que yo, yo eh... a ellos no pueden decir nada porque yo se los dije cuando grandes, porque no se los dije cuando chicos porque no quería traumatizarlos con lo que me había pasado, y no quería ha... hacerlos a ellos partícipes. Por decir, se los decía de chiquitos, ellos se iban a traumatizary me iban a mirar de otro modo. Por eso no lo hice. So se si a otras personas le habrá... les parecerá mal. Yo... creo que... (varón, 58 años).

Tabla 94. Antecedentes conceptuales del silencio con relaciones interpersonales

\begin{tabular}{|c|c|c|c|c|c|}
\hline \multirow{3}{*}{$\begin{array}{c}\text { SILENCIO } \\
\text { RELACIONES } \\
\text { INTERPERSONALES }\end{array}$} & \multicolumn{3}{|c|}{ POR DOCUMENTO } & \multirow{2}{*}{\multicolumn{2}{|c|}{$\begin{array}{l}\text { POR UNIDAD DE } \\
\text { ANÁLISIS N }=9900\end{array}$}} \\
\hline & \multirow[b]{2}{*}{ Frecuencia } & \multirow{2}{*}{$\frac{\mathrm{N}=60}{\% \text { según UR }}$} & \multirow{2}{*}{$\frac{\mathrm{n}=26}{\% \text { según UR }}$} & & \\
\hline & & & & Frecuencia & \% según UR \\
\hline No hizo & 7 & 12 & 27 & 11 & 0.11 \\
\hline Si hizo & $\underline{25}$ & 42 & 96 & $\underline{59}$ & 0.60 \\
\hline
\end{tabular}

La Tabla 94, nos indica que menos de la mitad de la muestra habló del silencio que mantuvo con sus relaciones interpersonales, quienes en su mayoría (correspondiente al 96\% de quienes aludieron la temática y al $42 \%$ de la muestra entrevistada), afirmaron la presencia de este aspecto en sus relaciones interpersonales. Lo que fue expresado aproximadamente en dos U.T.s por discurso.

Por último, seis personas refirieron simultáneamente las dos opciones comprendidas en la Tabla 94, lo que posiblemente se debe a que estas personas mantuvieron silencio con algunas personas en particular. 
Tabla 95. Tema específico más aludido para la categoría silencio con relaciones interpersonales

\begin{tabular}{|c|c|}
\hline Por documentos & Por U.T.s \\
\hline Hijos: si (27\%) & Hijos: si $(0.30 \%)$ \\
\hline
\end{tabular}

Es que ellos no sospechan. Eh a ver, yo tengo la siguiente formación, yo para las ideas que yo tengo, yo llegué solo, yo no les puedo imponer a ustedes mis ideas. En ese tiempo yo era soltero. Yo era solo. Ehm cuando yo estuve, caí a la cárcel, era solo, soltero, yo tenía mi mamá y mi hermana y mi familia conmigo. Cuando caí preso ellos me iban a ver a la cárcel, a ellos no le ficieron nada. Entonces, la cárcel como que para mi yo la enfrenté muy fácil porque no tenía responsabilidades más que la mamá y, y mi hermana. $Y$ cuando me llegó el aviso pa irme, no quise dejar sola a mi mamá, porque ella siempre estaba al pendiente de mi. Después cuando salí seguí con el mismo training, trabajaba y seguía y después me junté, me casé con Vilma. Pero en ese tiempo cuando estábamos con Vilma estaba la situación fuerte, fuerte, yo caía preso, ella se ponía a llorar, los niños chicos, era una situación más o menos complicada. Entonces yo nunca, uno trata de cuidar de no inmiscuirla a ella y a los $\mathcal{N}$ iños (varón, 62 años).

Eh, la verdad de las cosas que nunca he conversado con mis hijos eh, to que pasé. SNo to he conversado porque no los, los, no los quiero crear, eh, criar con una psicosis. Con una, una odiosidad. $Y$ eso no, no, porque... claro, a ver si de repente mis hijos van a, van a tener una odiosidad a lo que es militar. Entonces no, no me gustaría que mis hijos vivieran con ese rencor que mi papá fue detenido, que fue torturado (varón, 55años).

Tabla 96. Antecedentes conceptuales de la valoración de superación de la experiencia de prisión

\begin{tabular}{|c|c|c|c|c|c|}
\hline \multirow{3}{*}{$\begin{array}{l}\text { VALORACIÓN } \\
\text { SUPERACIÓN } \\
\text { EXPERIENCIA }\end{array}$} & \multicolumn{3}{|c|}{ POR DOCUMENTO } & \multirow{2}{*}{\multicolumn{2}{|c|}{$\begin{array}{c}\text { POR UNIDAD DE } \\
\text { ANÁLISIS } \\
\mathrm{N}=9900\end{array}$}} \\
\hline & \multirow{2}{*}{ Frecuencia } & $\mathrm{N}=60$ & $n=28$ & & \\
\hline & & \% según UR & \% según UR & Frecuencia & \% según UR \\
\hline $\mathrm{No}$ & $\underline{28}$ & 47 & 100 & $\underline{47}$ & 0.47 \\
\hline $\mathrm{Si}$ & $\overline{0}$ & 0 & 0 & $\overline{0}$ & 0 \\
\hline
\end{tabular}

Como nos indica la Tabla 96, menos de la mitad de la muestra valoró la superación de la propia experiencia de prisión, quienes en su totalidad y con una frecuencia cercana a las 2 U.T.s por discurso, negaron haberla superado.

Esta tabla nos da información relevante para entender el impacto de la prisión política en sus supervivientes, desde la apreciación de los afectados directos.

Cómo defino yo, es parte de mi identidad. $\mathcal{N}$ o, es par... por todo lo que yo te decía, lo que pasó con mis niños. Por todas las carencias, esos vacíos que... afectivos que se produjeron, eh... fue un daño muy grande; y eso no se supera nunca con nada (mujer, 64 años). 
Yo si tuviera que vivir de nuevo lo que pasé, no creo que yo hablaría. Porque en el fondo no es algo que digamos que joh!, que reparada estoy. Me gasto 70 mil pesos en remedios y me dan 112000. No subsanan los hechos, yo creo que nada me va a pagar todo to que yo viví. Lo que viví a lo mejor si yo no hubiera hablado, lo que estoy viviendo ahora es como lo más fuerte (mujer, 52 años).

"No, problemas no tengo. Real problema, este problema psicólogo... psicológico nomás que tengo respecto a eso, pero no se me va a olvidar nunca yo creo" (varón, 69 años).

Tabla 97. Antecedentes conceptuales de la percepción de apoyo recibido post-prisión

\begin{tabular}{|c|c|c|c|c|c|}
\hline \multirow{3}{*}{$\begin{array}{l}\text { APOYO RECIBIDO } \\
\text { POST - PRISIÓN }\end{array}$} & \multicolumn{3}{|c|}{ POR DOCUMENTO } & \multirow{2}{*}{\multicolumn{2}{|c|}{$\begin{array}{c}\text { POR UNIDAD DE } \\
\text { ANÁLISIS } \\
\text { N }=9900\end{array}$}} \\
\hline & \multirow[t]{2}{*}{ Frecuencia } & \multirow{2}{*}{$\begin{array}{c}\mathrm{N}=60 \\
\text { \% según } \\
\text { UR }\end{array}$} & \multirow{2}{*}{$\begin{array}{c}\mathrm{n}=26 \\
\text { \% según } \\
\text { UR }\end{array}$} & & \\
\hline & & & & Frecuencia & \% según UR \\
\hline No tuvo & 5 & 8 & 19 & 9 & 0.09 \\
\hline Si tuvo & $\underline{23}$ & 38 & 88 & $\underline{35}$ & 0.35 \\
\hline
\end{tabular}

La Tabla 97, nos indica que menos de la mitad de la muestra aludió en sus discursos el apoyo recibido con posterioridad al período de prisión. De este grupo de personas, la mayoría afirma haber recibido este tipo de soporte por parte de otras personas ( $88 \%$ de los sujetos que aludieron la temática, y 38\% de la muestra). Lo que se presentó en aproximadamente dos U.T.s por discurso.

Dos personas aludieron simultáneamente las dos categorías de la Tabla 97, lo que creemos que a pesar de ser contradictorio, nos indica que estas valoraciones se hicieron en base a distintos tipos de relaciones interpersonales específicas.

Yo ahí tengo muy buenas amistades mías, ahora me he apartado mucho de la iglesia. En la iglesia, me ayudaron mucho los curas, participé mucho con ellos, fice el primer acto el primero de mayo después que salí preso con los curas, nos llenaron la iglesia, la Santa Cruz con bombas lacrimógenas, los pacos, los milicos, pero hicimos el acto... con los curas, ellos me hicieron el documento, ellos redactaron el discurso, los curas, y así (varón, 62 años).

Cuando salí fue, afí quedé totalmente sola. Porque la familia no se apareció. Después me apoyaron dos primos, que eran más lejanos. Bueno que también toda mi familia estaba en Puerto Montt. Para qué hacernos tontos, pero igual, si quieren apoyar, de allá me pueden

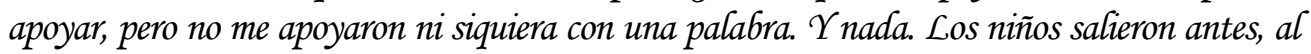
extremo que los niños salieron, cuando me los entregó la DINA no tenía dónde dejarlos. Y al final me los tuvo, me los cuidó unos compañeros, no parientes (mujer, 63 años). 
Tabla 98. Antecedentes conceptuales de la percepción del rechazo percibido post-prisión

\begin{tabular}{||c|c|c|c|c|c||}
\hline \multirow{2}{*}{$\begin{array}{c}\text { RECHAZO } \\
\text { PERCIBIDO POST- } \\
\text { PRISIÓN }\end{array}$} & \multicolumn{3}{|c|}{ POR DOCUMENTO } & \multicolumn{2}{c|}{$\begin{array}{c}\text { POR UNIDAD DE } \\
\text { ANÁLISIS } \\
\text { N = 9900 }\end{array}$} \\
\cline { 2 - 4 } & & $\mathrm{N}=60$ & $\mathrm{n}=5$ & \multicolumn{2}{c||}{} \\
\hline No percibe & Frecuencia & $\begin{array}{c}\text { \% según } \\
\text { UR }\end{array}$ & $\begin{array}{c}\text { \% según } \\
\text { UR }\end{array}$ & Frecuencia & $\%$ según UR \\
\hline Si percibe & $\underline{\mathbf{5}}$ & 0 & 0 & 0 & 0 \\
\hline
\end{tabular}

La Tabla 98, nos indica que sólo el 8\% de la muestra valora el rechazo percibido con posterioridad al período de prisión y a causa de éste. De estas personas, la totalidad afirmó haber sido rechazados por otras personas, lo que fue atribuido a causas políticas.

Pero claro. Claro, eso, eso ni, mira ni, ni, ni dudarlo porque es más, con el dedo te indicaban, por lo menos a mi me sucedió, "usted quédese calladito compañerito", el compañerito como diciendo... o... "el comunacho"..., así esas expresiones así(varón, 60 años).

...eh, pero libre no total porque tenía que haber sido por cárcel, eh fui marcado que no podía trabajar en ninguna parte apatronado, porque solamente o sea, uno iba a buscar trabajo y en Arica, claro, pedían el carnet, o el finiquito o algo, y tenían la lista de todos los que habian sido presos politicos o peligrosos según ellos pal régimen, o pa', o pa' no se que. Bueno me tocó duro y trabajé particular en diferentes pololos, sacando guano, a pesar de que tengo mi profesión yo, pero tampoco me daban trabajo, eh, iba a mariscar, vendía fierros, chatarra, pero la parte oscura o chueca de la vida nunca la hice, en el sentido de robar, de engañar, de mentir, no. Solamente si había que comer pan duro, comía pan duro; si había que ir a buscar grasa a los mataderos pa hacer chicharrones y vender grasa lo hacía, eh trabajo... Cimpiar baños, hacer cosas, a pesar de que había sido empleado yo en Citroen, pero de a poco a poco se fue olvidando la gente y fue creyendo de que... confiando en mi y dándome trabajo, esporádico hasta que logré salir un poquito adelante... (varón, 58 años).

\subsubsection{Antecedentes conceptuales de otras valoraciones}

Tabla 99. Antecedentes conceptuales de la experiencia de persecución política

\begin{tabular}{||c|c|c|c|c|c||}
\hline \multirow{3}{*}{$\begin{array}{c}\text { PERSECUCIÓN } \\
\text { POLÍTICA }\end{array}$} & \multirow{3}{*}{ Frecuencia } & $\mathrm{N}=60$ & $\mathrm{n}=35$ & \multicolumn{2}{c|}{$\begin{array}{c}\text { POR UNIDAD DE } \\
\text { ANÁLISIS } \\
\text { N }=9900\end{array}$} \\
\cline { 2 - 4 } & & $\begin{array}{c}\text { \% según } \\
\text { UR }\end{array}$ & $\%$ según UR & Frecuencia & $\%$ según UR \\
\hline $\mathrm{No}$ & 0 & 0 & 0 & 0 & 0 \\
\hline $\mathrm{Si}$ & $\underline{\mathbf{3 5}}$ & 58 & 100 & $\underline{\mathbf{9 9}}$ & 0.80 \\
\hline
\end{tabular}


En cuanto a la persecución política vivida por los EXPPS, más de la mitad de personas entrevistadas hizo alusión a estos hechos (58\%), quienes en su totalidad refirieron en un promedio de dos U.T.s cada una, haber sufrido este tipo de experiencia en sus vidas.

Tabla 100. Antecedentes conceptuales del momento de ocurrencia de persecución política

\begin{tabular}{|c|c|c|c|c|c|}
\hline \multirow{3}{*}{$\begin{array}{c}\text { PERSECUCIÓN } \\
\text { POLÍTICA } \\
\text { MOMENTO }\end{array}$} & \multicolumn{3}{|c|}{ POR DOCUMENTO } & \multirow{2}{*}{\multicolumn{2}{|c|}{$\begin{array}{c}\text { POR UNIDAD DE } \\
\text { ANÁLISIS } \\
\mathrm{N}=9900 \\
\end{array}$}} \\
\hline & \multirow{2}{*}{ Frecuencia } & \multirow{2}{*}{$\begin{array}{c}\mathrm{N}=60 \\
\% \text { según UR }\end{array}$} & \multirow{2}{*}{$\begin{array}{c}\mathrm{n}=30 \\
\text { \% según UR }\end{array}$} & & \\
\hline & & & & Frecuencia & \% según UR \\
\hline Pre-prisión & 5 & 8 & 17 & 5 & 0.05 \\
\hline Post-prisión & $\underline{26}$ & 43 & 87 & $\underline{47}$ & 0.47 \\
\hline Presente & 2 & 3 & 7 & 3 & 0.03 \\
\hline
\end{tabular}

Los datos que presenta la Tabla 100, fueron extraídos de la Tabla 99. Al comparar ambas tablas, observamos que la mayoría de personas que refirió la temática "persecución política", especificó el momento de ocurrencia de este episodio en sus vidas, siendo el período más aludido, el período posterior a la experiencia de prisión (aludido por el 43\% de la muestra). Esto se presentó en alrededor de dos U.T.s por sujeto.

Por último, un mínimo de alrededor de tres personas, refirió simultáneamente haber sido víctima de persecución política en más de uno de los momentos presentados en la tabla.

Eh, no, hartos poh. Hartos problemas. Si yo tuve que hacer como tres veces el quinto año porque la CNI me, me detenía o, o me, o me, me martirizaba poh. $\Upsilon$, y, y esta casa fue allanada como 5 - 6 veces después que quedé libre (varón, 52 años).

Si, yo cuando nació él me retiré. Afí ya estaba, trabajaba con él, le llevaba la documentación a él, todos sus trabajadores, pasaba más en casa, pero cuando salía a comprar era el problema que ahí estaba el seguimiento y todo. A ver nosotros, hasta el año 96 por ahí. (después de Pinochet) no, igual siguieron, ellos igual siguieron. Yo denuncié el caso antes de la Comisión Valech (mujer, 43 años).

Tabla 101. Antecedentes conceptuales del afrontamiento realizado ante la persecución política

\begin{tabular}{||c|c|c|c|c|c||}
\hline \multirow{2}{*}{$\begin{array}{c}\text { PERSECUCIÓN } \\
\begin{array}{c}\text { POLÍTICA } \\
\text { AFRONTAMIENTO }\end{array}\end{array}$} & \multirow{3}{*}{ Frecuencia } & $\mathrm{N}=60$ & $\mathrm{n}=14$ & \multicolumn{2}{c|}{$\begin{array}{c}\text { POR UNIDAD DE } \\
\text { ANÁLISIS } \\
\text { N }=9900\end{array}$} \\
\cline { 3 - 6 } & & $\begin{array}{c}\text { \% según } \\
\text { UR }\end{array}$ & \% según UR & Frecuencia & \% según UR \\
\hline No realiza & 5 & 8.3 & 36 & 6 & 0.06 \\
\hline Si realiza & $\underline{10}$ & 17 & 71 & $\underline{15}$ & 0.90 \\
\hline
\end{tabular}

Los datos presentados en la Tabla 101 (extraídos de la Tabla 99 y la Tabla 100), nos revelan que de menos de la mitad de personas entrevistadas que afirmaron haber sufrido persecución política en sus vidas, la 
mayoría refirió haber realizado algún tipo de afrontamiento ante tales situaciones represivas (71\%). Este porcentaje equivale al 17\% de la muestra entrevistada, y se presentó en un promedio de 1,5 U.T.s por sujeto.

Una persona incluida en las frecuencias presentadas en la Tabla 101, sostuvo las dos categorías antagónicas lo que puede deberse a que sufrió más de un hecho puntual de persecución política, habiendo afrontado los hechos sólo en una de las dos ocasiones.

Tabla 102. Tema específico más aludido para la categoría afrontamiento realizado ante la persecución política

\begin{tabular}{|ll|}
\hline Por documentos & Por U.T.s \\
\hline $\begin{array}{l}\text { Si realiza: enfrentamiento directo } \\
(8.3 \%)\end{array}$ & $\begin{array}{l}\text { Si realiza: enfrentamiento directo } \\
(0.08 \%)\end{array}$ \\
\hline
\end{tabular}

Cuando salí de la cárcel, Clegué afuera, el partido el partido comunista siempre fue clandestino, trabajó muy bien en la clandestinidad el partido comunista. Cuando yo llegué tomaron contacto conmigo y me dijeron cuál es mi función "ya, usted es público, usted es el hombre que va a dar la cara", yo di la cara, entonces yo iba... pasé a la parte pública, capacitando a los públicos, afí en las reuniones, tratar de organizarlos, formamos... más riesgo, claro, formamos los sindicatos, a formar la coordinadora, comando, todas esas cosas poh. Echamos los, los militares que estaban en algunos sindicatos, todo eso, público, éramos de público. Iba a ver los alegatos "¿que no tení miedo?", "no, ¿por qué iba a tener miedo?". Se juntaban todos los viejos, un grupo de hombres público, y yo como había estado preso no tenía temor. Me seguía la CNI, tenía una moto yo, me arrancaba de la CNI, entonces me seguía, y a veces me encontraba con la CNI, la enfrentaba. Ella se ponía a llorar. Ella se ponía a llorar (varón, 62 años).

Tabla 103. Antecedentes conceptuales del régimen militar

\begin{tabular}{||c|c|c|c|c|c||}
\hline \multirow{3}{*}{ RÉGIMEN MILITAR } & \multicolumn{3}{|c|}{ POR DOCUMENTO } & \multicolumn{2}{c|}{ POR UNIDAD DE } \\
\cline { 2 - 4 } & \multirow{2}{*}{ Frecuencia } & $\mathrm{N}=60$ & $\mathrm{n}=38$ & \multicolumn{2}{c||}{ ANÁLISIS N = 9900 } \\
\cline { 3 - 4 } & & $\begin{array}{c}\% \text { según } \\
\text { UR }\end{array}$ & $\begin{array}{c}\% \text { según } \\
\text { UR }\end{array}$ & Frecuencia & $\begin{array}{c}\text { \% según } \\
\text { UR }\end{array}$ \\
\hline Refiere valoración negativa & $\underline{\mathbf{3 8}}$ & 63 & 100 & $\underline{\mathbf{8 5}}$ & 0.86 \\
\hline \hline
\end{tabular}

La creación de las categorías que presentamos en la Tabla 103, fueron establecidas con posterioridad a la administración de la entrevista en profundidad, y el motivo de su consideración, se debe a la reiterada presencia de esta temática en los discursos de los EXPPS entrevistados y su relación con el tema que estudiamos en esta investigación.

Observamos en la Tabla 103, que más de la mitad de entrevistados emitió valoraciones acerca del régimen militar, y como era esperable, la totalidad de estas personas valoraron de manera negativa al gobierno militar chileno. Esta tendencia se presentó aproximadamente en dos U.T.s por discurso. 
Tabla 104. Tema específico más aludido para la categoría antecedentes conceptuales del régimen militar

\begin{tabular}{|ll|}
\hline Por documentos & \multicolumn{1}{c|}{ Por U.T.s } \\
\hline $\begin{array}{l}\text { Resultados percibidos: temor } \\
\text { sociedad }(35 \%)\end{array}$ & $\begin{array}{l}\text { Resultados percibidos: temor } \\
\text { sociedad }(0.27 \%)\end{array}$ \\
\hline
\end{tabular}

Mira, La sociedad chilena yo creo que es la misma sociedad de, de... si, frente a éstos hechos está teniendo una reacción, y que nos hace pensar de que vamos a salir. El conjunto de la sociedad está reaccionando, como te digo, muy lentamente, Lo que tuvo la eficacia del, del, del golpe que se dio, que fue para eso, para que la gente reaccionara; eh... e, e, e, e, la, la sobredosis de terror que se Clama. Eso fue lo que se hizo y, y vamos saliendo poh (varón, 73 años).

Tabla 105. Antecedentes conceptuales de valoración de las etapas del Informe Valech

\begin{tabular}{|c|c|c|c|c|c|}
\hline \multirow{3}{*}{$\begin{array}{c}\text { INFORME VALECH - } \\
\text { ETAPAS }\end{array}$} & \multicolumn{3}{|c|}{ POR DOCUMENTO } & \multirow{2}{*}{\multicolumn{2}{|c|}{$\begin{array}{c}\text { POR UNIDAD DE } \\
\text { ANÁLISIS } \\
\mathrm{N}=9900 \\
\end{array}$}} \\
\hline & \multirow[t]{2}{*}{ Frecuencia } & \multirow{2}{*}{$\begin{array}{c}\mathrm{N}=60 \\
\text { \% según UR }\end{array}$} & \multirow{2}{*}{$\begin{array}{c}\mathrm{n}=20 \\
\text { \% según UR }\end{array}$} & & \\
\hline & & & & Frecuencia & \% según UR \\
\hline Insatisfacción & $\underline{19}$ & 32 & 95 & $\underline{26}$ & 0.26 \\
\hline Satisfacción & 2 & 3.3 & 10 & 2 & 0.02 \\
\hline
\end{tabular}

La Tabla 105, nos indica que menos de la mitad de sujetos entrevistados valoró las etapas del informe gubernamental sobre prisión política y tortura con el que fueron evaluados y reconocidos oficialmente como EXPPS chilenos. El 95\% de las personas que valoraron las etapas en cuestión, y con una frecuencia aproximada de una U.T.s cada una, expresó insatisfacción asociada a éstas, y una de ellas, manifestó simultáneamente satisfacción e insatisfacción asociada a la temática.

Tabla 106. Tema específico más aludido para la categoría valoración de las etapas del Informe Valech

\begin{tabular}{|ll|}
\hline Por documentos & \multicolumn{1}{c|}{ Por U.T.S } \\
\hline $\begin{array}{l}\text { Evaluación/ insatisfecho: errores } \\
\text { en identificación }(12 \%)\end{array}$ & $\begin{array}{l}\text { Evaluación/ insatisfecho: errores } \\
\text { en identificación }(0.08 \%)\end{array}$ \\
\hline
\end{tabular}

"En la reparación hay mucha injusticia, gente que se quedó fuera, gente que también sufrió junto a sus familiares y de ninguna manera le llegan los beneficios a ellos" (varón, 53 años). 
Tabla 107. Antecedentes conceptuales de valoración de las medidas del Informe Valech

\begin{tabular}{||c|c|c|c|c||}
\hline \multirow{2}{*}{$\begin{array}{c}\text { INFORME VALECH - } \begin{array}{c}\text { POR DOCUMENTO } \\
\text { MEDIDAS }\end{array} \\
\mathrm{N}=60\end{array}$} & \multicolumn{2}{c|}{$\begin{array}{c}\text { POR UNIDAD DE } \\
\text { ANÁLISIS } \\
\text { N =9900 }\end{array}$} \\
\cline { 2 - 5 } & \multicolumn{2}{|c||}{$\begin{array}{c}\text { \% según UR } \\
\text { Frecuencia }\end{array}$} & Frecuencia & $\%$ según UR \\
\hline Insatisfacción & $\underline{\mathbf{6 0}}$ & 100 & $\underline{442}$ & 4.5 \\
\hline Satisfacción & 41 & 68 & 96 & 0.97 \\
\hline
\end{tabular}

La Tabla 107, nos indica que la totalidad de los participantes del estudio valoró con insatisfacción las medidas gubernamentales de reparación. Lo que fue expresado en un promedio de 4 U.T.s por discurso.

No obstante lo anterior, más de la mitad de sujetos entrevistados que refirieron una valoración negativa de los beneficios que reciben del gobierno por su condición de EXPPS, también refirieron satisfacción. Lo que se presentó en el 68\% de la muestra y en un promedio de 2 U.T.s por documento.

La tendencia a presentar ambas valoraciones consideradas antagónicas, se debe a que para la temática en cuestión, hemos incluido valoraciones específicas de las distintas medidas que hemos agrupado con el objeto de sintetizar la información obtenida. Por ello, pueden presentarse valoraciones negativas y positivas de diferentes medidas. Sin embargo, vemos según el número de sujetos y principalmente de U.T.s, la marcada alusión a valorar negativamente tales medidas.

Tabla 108. Tema específico más aludido para la categoría valoración de las medidas del Informe Valech

\begin{tabular}{|ll|}
\hline Por documentos & \multicolumn{1}{c|}{ Por U.T.s } \\
\hline Valoración global: insatisfecho & Valoración global: insatisfecho \\
$(77 \%)$ & $(0.79)$ \\
\hline
\end{tabular}

¿cómo dice usted?, no, de ninguna manera satisfecha porque a nosotros por ejemplo nos dieron el beneficio de, de la ley Valech, nos dieron una minoría, es algo como, como una aspirina y lárgate de aquí, no te quiero ver más, una onda así(mujer, 61 años).

Mire yo creo que eso es algo como querer tapar el sol con un dedo, porque usted la reparación tiene que ser con la verdad, y aparte con la verdad, los presos politicos que a la vez fuimos exonerados, no necesitamos limosna, necesitamos que nos reintegren a nuestro trabajo, porque nosotros tenemos fuerza, somos trabajadores, ¿entiende?. Entonces no necesitamos tener una pensión de 100 mil pesos, no. Nosotros queríamos que nos reintegraran a nuestro trabajo, nada más. $\mathcal{N}$ ole estamos pidiendo un favor a nadie (varón, 65 años).

'No se discutió, no escucharon a los afectados, acá se determinó como iba a ver, una verdadera dictadura porque dijeron "esto se hace así, se hace asi", y se hizo asi' (varón, 62 años). 
Son paliativas, son paliativas. Son este, lo que pasa es que particularmente este gobierno, sino no podría estar donde está, tiene que responder en ciertos porcentajes a los intereses del sistema neoliberal, del sistema opresivo así como en todas partes del mundo. Si no les da un buen gobierno a ellos, no podría estar en el gobierno. O lo derrocarían, o la oposición sería mayor, o no se qué pasaría, pero este gobierno to que ha sabido es reconciliar, y de alguna manera gobernar eh a poner un $70 \%$ para la gente rica y un 30\% para la gente pobre. Entonces, te puedo decir que hasta podría ser 6uenas intenciones, pero Camentablemente estas intenciones no llegan a la gente que tiene los problemas, por lo menos hasta ahora no llegan (varón, 53 años).

Tabla 109. Antecedentes conceptuales de la concepción de reparación

\begin{tabular}{|c|c|c|c|c|c|}
\hline \multirow{3}{*}{$\begin{array}{l}\text { REPARACIÓN - } \\
\text { CONCEPCIÓN }\end{array}$} & \multicolumn{3}{|c|}{ POR DOCUMENTO } & \multirow{2}{*}{\multicolumn{2}{|c|}{$\begin{array}{c}\text { POR UNIDAD DE } \\
\text { ANÁLISIS } \\
\mathrm{N}=9900 \\
\end{array}$}} \\
\hline & \multirow{2}{*}{ Frecuencia } & $\mathrm{N}=60$ & $\mathrm{n}=30$ & & \\
\hline & & $\begin{array}{c}\text { \% según } \\
\text { UR }\end{array}$ & $\begin{array}{c}\text { \% según } \\
\text { UR }\end{array}$ & Frecuencia & \% según UR \\
\hline No es posible & $\underline{25}$ & 42 & 83 & $\underline{32}$ & 0.32 \\
\hline Si es posible & 6 & 10 & 20 & 6 & 0.06 \\
\hline
\end{tabular}

La Tabla 109, nos indica que la mitad de EXPPS participantes del estudio se manifestó acerca de su concepción de reparación. De estas personas, el 83\% equivalente al 42\% de la muestra, refirió que las propias experiencias de prisión política y en algunos casos tortura, no son reparables. Lo que se presentó en alrededor de una U.T.s por sujeto que aludió la temática.

Por último, una persona incluida en los valores de la Tabla 109, presenta simultáneamente las dos valoraciones en su discurso. Lo que nos parece contradictorio pero podría ser interpretado en base al contexto en que estas apreciaciones fueron realizadas.

¡ah! no poh. $\mathcal{N}$, eso es irreparable, porque el daño que se produce es para toda la vida. Entonces, una pensión, yo tengo una hija separada producto de lo mismo, porque el chico es con daño, se... no está loco ni mucho menos pero tienen cosas dentro (mujer, 64 años).

$\mathcal{N}$ o, para nada. Porque a mi con 112 mil pesos que empezaron a darme, eh, no me reparan en nada el daño causado. O sea, no me lo van a reparar nunca. Yaunque me dieran 10 millones, o 20 millones jamás van a repararme el daño que a mi me causaron (mujer, 54 años).

Pésimas. Yo le digo, es que no es la plata. To siempre con varias personas, con él y con otras personas, señoras que están en esto que son directiva de los derechos humanos acá en Valdivia, yo digo que no es la plata, que a uno aunque le den toda la plata del mundo no le van a borrar el daño que le hicieron. Aqui lo que más hizo falta fue atención psicológica, porque quedamos todos enfermos. $\Upsilon$ si yo estoy enferma, ¿iré a pretender que mis hijos sean sanos? $\mathcal{N}$ o pueden ser sanos mis hijos (mujer, 43 años). 
Tabla 110. Antecedentes conceptuales de la valoración de políticos de izquierda y reparación

\begin{tabular}{|c|c|c|c|c|c|}
\hline \multirow{3}{*}{$\begin{array}{c}\text { REPARACIÓN - } \\
\text { OPINIÓN POLÍTICOS } \\
\text { ACTUALES } \\
\text { (IZQUIERDA) }\end{array}$} & \multicolumn{3}{|c|}{ POR DOCUMENTO } & \multirow{2}{*}{\multicolumn{2}{|c|}{$\begin{array}{c}\text { POR UNIDAD DE } \\
\text { ANÁLISIS } \\
\mathrm{N}=9900 \\
\end{array}$}} \\
\hline & \multirow[t]{2}{*}{ Frecuencia } & \multirow{2}{*}{$\begin{array}{c}\mathrm{N}=60 \\
\text { \% según UR }\end{array}$} & \multirow{2}{*}{$\begin{array}{c}\mathrm{n}=22 \\
\text { \% según UR }\end{array}$} & & \\
\hline & & & & Frecuencia & \% según UR \\
\hline Insatisfacción & $\underline{21}$ & 35 & 95 & $\underline{46}$ & 0.46 \\
\hline Satisfacción & 1 & 1.7 & 5 & 1 & 0.01 \\
\hline
\end{tabular}

La Tabla 110, hace alusión a la opinión manifestada por los EXPPS de los políticos actuales de izquierda en relación al tema de la reparación gubernamental. De acuerdo a lo cual, observamos que menos de la mitad de la muestra hizo alusión a esta temática, de quienes la mayoría (99\%) refirió insatisfacción en torno a estas personas (el 35\% de la muestra). Esta tendencia se presentó en un promedio de dos U.T.s por documento.

Consideramos necesario precisar como dato anexo, que las categorías presentadas en la Tabla 110, surgieron con posterioridad a la administración de la entrevista.

Yo creo que no es el gobierno, el gobierno no ha hecho ni una cosa. Yo creo que ha sido por exigencias de otra gente, por eso que ellos están, sino... (¿exigencias internas o externas?) no, aquí dentro del país. Ahora han tenido ellos... han tenido que enfrentar la presión internacional. Porque muchos casos chilenos están en las naciones unidas, están en España, están en un montón de partes. Entonces de una u otra forma hay presión internacional también (mujer, 60 años).

"...mire yo creo, yo pienso que por, por lo que yo me, me junto con la gente, está decepcionada. Decepcionada de, de, de, de estos gobiernos que ha habido. Decepcionada total" (varón, 69 años).

Tabla 111. Antecedentes conceptuales de reparación y justicia

\begin{tabular}{|c|c|c|c|c|c|}
\hline \multirow{3}{*}{$\begin{array}{c}\text { REPARACIÓN - } \\
\text { JUSTICIA }\end{array}$} & \multicolumn{3}{|c|}{ POR DOCUMENTO } & \multirow{2}{*}{\multicolumn{2}{|c|}{$\begin{array}{c}\text { POR UNIDAD DE } \\
\text { ANÁLISIS } \\
\mathrm{N}=9900\end{array}$}} \\
\hline & \multirow[t]{2}{*}{ Frecuencia } & $\mathrm{N}=60$ & $\mathrm{~N}=27$ & & \\
\hline & & \% según UR & \% según UR & Frecuencia & \% según UR \\
\hline No & $\underline{27}$ & 45 & 100 & $\underline{47}$ & 0.47 \\
\hline $\mathrm{Si}$ & 0 & 0 & 0 & 0 & 0 \\
\hline
\end{tabular}

Acerca de la apreciación que los EXPPS emitieron de la propia percepción de justicia en cuanto a la reparación recibida, observamos que menos de la mitad de estas personas valoró esta temática, y de quienes lo hicieron, la totalidad consideró que las medidas gubernamentales recibidas son injustas. Manifestado en aproximadamente dos U.T.s por discurso. 
Esta categoría se estableció a posteriori de la administración de la técnica aplicada, de acuerdo a lo cual consideramos que su incidencia fue elevada.

Mire, yo veo que la gente se compadece, pero dice "ya está bueno de esto". Claro, pero resulta que no, no han analizado de que todavía no ha habido una justicia. No han analizado de que no han aparecido muchos cadáveres, que hay mucha gente desaparecidos todavía, y resulta que ellos tienen familias, hay, hay hijos, hay señoras, hay viudas, hay abuelos (varón, 65 años).

"yo creo que para que haya reparación, tiene que haber verdad. Tiene que aflorar toda la verdad. Yo creo que para que haya reparación verdadera, tienen que haber juicios, juicios justos. Juicios justos, ¿ah?" (mujer, 43 años).

Y... y hay gente... yo, yo sufrí mucho, aunque fueron solamente siete meses. Pero hay gente, hay gente que le falta el brazo, que han, han muerto, le falta una pierna. Entonces por los.. Eh... fue muy, muy, unas injusticias muy grandes; eh... en ese tiempo y hasta ahora (varón, 58 años).

Tabla 112. Antecedentes conceptuales de valoración de sociedad chilena y Derechos Humanos

\begin{tabular}{||c|c|c|c|c||}
\hline \multirow{2}{*}{$\begin{array}{c}\text { SOCIEDAD CHILENA Y } \\
\text { DDHH }\end{array}$} & \multicolumn{2}{|c|}{$\begin{array}{c}\text { POR DOCUMENTO } \\
\mathrm{N}=60\end{array}$} & \multicolumn{2}{c|}{$\begin{array}{c}\text { POR UNIDAD DE } \\
\text { ANÁLISIS } \\
\text { N=9900 }\end{array}$} \\
\cline { 2 - 5 } & Frecuencia & $\begin{array}{c}\text { \% según } \\
\text { UR }\end{array}$ & Frecuencia & $\%$ según UR \\
\hline Insatisfacción & $\underline{\mathbf{5 9}}$ & 98 & $\underline{\mathbf{3 6 3}}$ & 3.7 \\
\hline Satisfacción & 55 & 92 & 178 & 1.8 \\
\hline
\end{tabular}

Como nos indica la Tabla 112, todos los participantes del estudio valoraron su percepción acerca de las reacciones de la sociedad chilena ante el tema de los derechos humanos en Chile; y vemos que refieren mayoritariamente insatisfacción ante estas respuestas, cuyas frecuencias por sujeto alcanzan el 98\% del total de la muestra, y se presentan en un promedio de seis U.T.s por documento. No obstante lo anterior, el 92\% de la muestra refirió satisfacción relacionada a la temática aludida, con un promedio de tres U.T.s por documento.

Creemos que esto se debe al grado de implicación en el tema de los Derechos humanos en Chile por parte de las personas que entrevistamos. Lo que hace difícil en ellos formular una opinión global de su percepción acerca de la respuesta social chilena ante los hechos de violación de derechos humanos en Chile que han experimentado personalmente. 
Tabla 113. Tema específico más aludido para la categoría valoración de sociedad chilena y Derechos Humanos

\begin{tabular}{|l|c|}
\hline Por documentos & Por U.T.s \\
\hline Soc. chilena/ se responsabiliza: no $(80 \%)$ & Soc. chilena/ se responsabiliza: no $(0.48 \%)$ \\
\hline
\end{tabular}

Nooo... para nada, "no si yo no tuve la culpa, no si a mi no me gusta la política, mire esto es cuestión de política, yo no me gusta, yo no me meto en política"; eso es lo que uno escucha cuando... "hay esto es que, es que el Pinochet salvó a Chile del marxismo, salvó de una guerra civil". o sea, 17 años que a ti te tuvieron, te tuvieron transmitiendo ese, ese mensaje jalo hondo en los chilenos, y eso se les quedo grabado en el subconsciente, entonces si los tuvieron presos, "ah... por algo habrá sido", era así nomás la cosa (mujer, 59 años).

Mira, si no saben, no se responsabilizan. Además que hay un sector que todavia habla. Que, que lo que se hizo el, el, fue salvar a Chile del comunismo. Eso fue lo que se, lo que se dice, y todavía se repite. Eh... y todavía hay gente que se lo cree (varón, 73 años).

Tabla 114. Antecedentes conceptuales de la opinión del exilio

\begin{tabular}{|c|c|c|c|c|c|}
\hline \multirow{3}{*}{ OPINIÓN EXILIO } & \multicolumn{3}{|c|}{ POR DOCUMENTO } & \multirow{2}{*}{\multicolumn{2}{|c|}{$\begin{array}{c}\text { POR UNIDAD DE } \\
\text { ANÁLISIS } \\
\text { N }=9900\end{array}$}} \\
\hline & \multirow[t]{2}{*}{ Frecuencia } & $\mathrm{N}=60$ & $\mathrm{n}=13$ & & \\
\hline & & $\begin{array}{c}\text { \% según } \\
\text { UR }\end{array}$ & \% según UR & Frecuencia & \% según UR \\
\hline Negativa & 9 & 15 & 69 & 16 & 0.16 \\
\hline Positiva & $\underline{10}$ & 17 & 77 & $\underline{18}$ & 0.18 \\
\hline
\end{tabular}

La Tabla 114, nos indica que menos de la mitad de la muestra emitió opiniones acerca del exilio, y las frecuencias obtenidas, no marcan tendencias mayormente diferenciadas. Así, observamos que la mayoría de quienes opinaron acerca del exilio, lo valoraron positivamente (el 77\% equivalente al 17\% de la muestra). Del total de sujetos que refirió la temática exilio, un grupo de 6 personas incluidas en los valores de la tabla en estudio, refiere ambas valoraciones.

Tabla 115. Tema específico más aludido para la categoría opinión del exilio

\begin{tabular}{|ll|}
\hline Por documentos & \multicolumn{1}{c|}{ Por U.T.s } \\
\hline $\begin{array}{l}\text { De experiencia personal: } \\
\text { valoración positiva }(12 \%)\end{array}$ & De experiencia personal: \\
valoración positiva $(0.11 \%)$
\end{tabular}

"Que fui consecuente. NNo me fui a Cuba cuando me, me dijeron que tenía que irme a Cuba. $\Upsilon$ podría haber vuelto como algunos que, que se fueron y ahora llegaron con plata. Están en el gobierno lucrando" (varón, 52 años).

...si, no, tremendamente satisfecho. Aparte después trabajé para la embajada cubana en Londres... no, no, muy... yo estoy muy... yo estoy tremendamente agradecido de Inglaterra, o 
sea, el hecho de que yo no quiera volver, es justamente por eso, digamos. Porque ya la situación cambió radicalmente, ¿te das cuenta?. Esa actividad que había antes, ya hoy día no existe, ya los chilenos no se juntan. Es muy difíill.. (antes) puff, todos los días, todos los días. Todos los días teniamos nuestras agrupaciones, el Chile democrático, el Chile Nation Group; teníamos un montón de, de actividades, y era todo el día. Todo el día digamos, o sea, nosotros terminábamos de trabajar y nos íbamos a trabajar digamos a las agrupaciones de derechos humanos, de, de partidos políticos, además el MIR todavía allá funcionaba (varón, 55 años).

\subsubsection{Resumen de las tendencias presentadas según las modas obtenidas en los resultados demográficos y conceptuales}

A continuación haremos un perfil de los resultados que hemos presentado en esta sección, y que corresponden al resumen de los hallazgos encontrados según las modas obtenidas por las categorías generales a nivel inter-sujeto de las variables estudiadas, y que nos entrega indicadores del impacto emocional y social de la experiencia de prisión política y tortura en un grupo de supervivientes chilenos.

\subsubsection{Tendencias en base a variables demográficas}

Tabla 116. Resumen de antecedentes demográficos de sexo, edad, estado civil y lugar de residencia

\begin{tabular}{|c|c|}
\hline \multicolumn{2}{|c|}{ ANTECEDENTES DEMOGRÁFICOS ACTUALES } \\
\hline Sexo & Varón \\
\hline Edad & Inferior a 65 años \\
\hline Estado civil & Casado o en convivencia \\
\hline Lugar de residencia & Norte de Chile \\
\hline
\end{tabular}

Tabla 117. Resumen de antecedentes demográficos de ocupación

\begin{tabular}{|c|c|}
\hline \multicolumn{2}{|c|}{$\begin{array}{c}\text { ANTECEDENTES DEMOGRÁFICOS LONGITUDINALES EN } \\
\text { CUANTO A OCUPACIÓN. }\end{array}$} \\
\hline \multirow{3}{*}{ Ocupación } & Pre-prisión: trabajador no calificado \\
\cline { 2 - 2 } & Post-prisión: trabajador no calificado \\
\cline { 2 - 2 } & Actual: ninguno \\
\hline \multirow{3}{*}{ Participación política } & Pre-prisión: activista político \\
\cline { 2 - 2 } & Post-prisión: activista político \\
\cline { 2 - 2 } & Actual: activista político \\
\hline
\end{tabular}


Tabla 118. Resumen de antecedentes demográficos de prisión

\begin{tabular}{|c|c|}
\hline \multicolumn{2}{|c|}{ ANTECEDENTES DEMOGRÁFICOS DE PRISIÓN. } \\
\hline Edad & Mayor de 21 años y menor de 40 años \\
\hline Período & Desde septiembre hasta diciembre de 1973 \\
\hline Lugar & Recinto oficial de las Fuerzas Armadas \\
\hline Tiempo & Meses \\
\hline Procesamiento judicial & Sometido a juicio \\
\hline Aspectos legales & Condena de presidio \\
\hline
\end{tabular}

Tabla 119. Resumen de antecedentes demográficos de tortura

\begin{tabular}{|c|c|}
\hline \multicolumn{2}{|c|}{ ANTECEDENTES DEMOGRÁFICOS DE TORTURA } \\
\hline Tortura física & $\begin{array}{c}\text { Golpes, refiriendo secuelas físicas en el } \\
\text { presente }\end{array}$ \\
\hline Tortura psicológica & no especificada y amenazas \\
\hline Tortura sexual & Vejaciones \\
\hline
\end{tabular}

Tabla 120. Resumen de antecedentes demográficos de experiencia de exilio

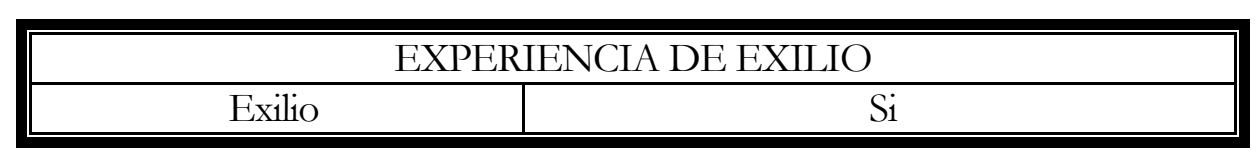

Tabla 121. Resumen de antecedentes demográficos de familia actual

\begin{tabular}{|c|c|}
\hline \multicolumn{2}{|c|}{ ANTECEDENTES FAMILIARES ACTUALES } \\
\hline Pareja & $\begin{array}{c}\text { si tienen, tiempo de relación no especificada, } \\
\text { participación política de izquierda }\end{array}$ \\
\hline Hijos & $\begin{array}{c}\text { si tienen, más de uno y menos de cinco, edad } \\
\text { actual mayor a los } 18 \text { años, niños al momento } \\
\text { de la detención de sus padres, trabajadores en } \\
\text { la actualidad }\end{array}$ \\
\hline Nietos & si tienen \\
\hline
\end{tabular}


Tabla 122. Resumen de antecedentes demográficos de salud, ocio e uniformados

\begin{tabular}{|c|c|}
\hline \multicolumn{2}{|c|}{ OTROS } \\
\hline & $\begin{array}{c}\text { refieren antecedentes mórbidos, atención } \\
\text { médica en el pasado, relación de } \\
\text { enfermedades con experiencia de prisión }\end{array}$ \\
\hline Antecedentes de salud & Si realizan actividad \\
\hline Antecedentes de ocio & si tiene, familia de origen \\
\hline Vinculación con uniformados & \\
\hline
\end{tabular}

5.3.5.2. Tendencias en base a variables conceptuales agrupadas según las necesidades interpersonales planteadas por López (2008)

Tabla 123. Resumen de aspectos asociados a las necesidades emocionales

\begin{tabular}{|c|c|c|c|}
\hline \multicolumn{2}{|c|}{ Presente } & \multicolumn{2}{|c|}{ Pasado } \\
\hline Pareja & Valoración positiva & Parejas & si tuvieron, valoración positiva \\
\cline { 3 - 4 } & & Familia de origen & Valoración positiva \\
\hline Hijos & Valoración positiva & Ambiente en familia & $\begin{array}{c}\text { presencia de dificultades } \\
\text { relevantes (negativo) }\end{array}$ \\
\hline Nietos & Valoración positiva & de origen & renten \\
\hline
\end{tabular}

Tabla 124. Resumen de otros aspectos asociados a las necesidades emocionales

\begin{tabular}{|c|c|c|}
\hline & Presente & Pasado \\
\hline $\begin{array}{c}\text { Sentido de relaciones } \\
\text { afectivas que disponen }\end{array}$ & Valoración positiva & \\
\hline $\begin{array}{c}\text { Apoyo } \\
\text { Incondicional }\end{array}$ & si disponen, familia actual & Si dispuso, familia de origen \\
\hline
\end{tabular}

Tabla 125. Resumen de aspectos asociados a las necesidades sociales

\begin{tabular}{|c|c|c|}
\hline & Presente & Pasado \\
\hline Amigos & Valoración positiva & si tuvieron, valoración positiva \\
\hline Compañeros & Valoración positiva & \\
\hline
\end{tabular}


Tabla 126. Resumen de aspectos asociados a las necesidades mentales y culturales

\begin{tabular}{|c|c|c|}
\hline & Presente & Pasado \\
\hline Concepción del mundo & valoración negativa & Valoración positiva \\
\hline Sentido de la vida & valoración positiva & Valoración positiva \\
\hline Concepción de seres humanos & valoración negativa & \\
\hline Ideología & (positivo) & \\
\hline Visión del futuro & valoran creencias específicas creyendo en ellas & \\
\hline Valoración de su estar en el mundo & ayuda social & optimista \\
\hline $\begin{array}{c}\text { Motivación principal de participación } \\
\text { política }\end{array}$ & Negativa & \\
\hline Valoración del Chile actual & Si tiene & \\
\hline Temores & no es posible la reparación & \\
\hline Concepción de reparación &
\end{tabular}

Tabla 127. Resumen de aspectos asociados a la valoración personal

\begin{tabular}{|c|c|}
\hline \multicolumn{2}{|c|}{ Valoración personal } \\
\hline Valoración personal & Positiva \\
\hline Valoración de ocupación actual & Positiva \\
\hline Valoración de participación política & Positiva \\
\hline
\end{tabular}


Tabla 128. Resumen de antecedentes de prisión

\begin{tabular}{|c|c|}
\hline \multicolumn{2}{|c|}{ Prisión política } \\
\hline $\begin{array}{c}\text { Sufrimiento asociado } \\
\text { compañeros }\end{array}$ & si refiere \\
\hline Actitud post-prisión & Favorable \\
\hline $\begin{array}{c}\text { Valoración del impacto de prisión en } \\
\text { la familia }\end{array}$ & cambios negativos \\
\hline $\begin{array}{c}\text { Valoración del impacto de prisión con } \\
\text { los amigos }\end{array}$ & cambios negativos \\
\hline $\begin{array}{c}\text { Valoración del impacto de prisión con } \\
\text { los compañeros }\end{array}$ & si tiene \\
\hline $\begin{array}{c}\text { Temores asociados a la experiencia de } \\
\text { prisión }\end{array}$ & No superada \\
\hline Silencio personal de la experiencia \\
\hline $\begin{array}{c}\text { Valoración de superación de la } \\
\text { experiencia }\end{array}$ & si mantuvo con relaciones interpersonales \\
\hline $\begin{array}{c}\text { Percepción de apoyo recibido post- } \\
\text { prisión }\end{array}$ & si tuvo \\
\hline Rechazo percibido post-prisión & Si percibe \\
\hline Persecución política & si refiere, post-prisión, realiza afrontamiento \\
\hline Valoración del régimen militar & valoración negativa \\
\hline Opinión de exilio & positiva \\
\hline
\end{tabular}

Tabla 129. Resumen de valoración de aspectos de reparación gubernamental

\begin{tabular}{|c|c|}
\hline Valoración etapas Informe Valech & insatisfacción \\
\hline Valoración medidas Informe Valech & insatisfacción \\
\hline $\begin{array}{c}\text { Valoración de políticos actuales y su } \\
\text { trabajo realizado en términos de } \\
\text { reparación }\end{array}$ & insatisfacción \\
\hline Reparación y justicia & no hay justicia en la reparación existente \\
\hline $\begin{array}{c}\text { Valoración de respuesta de la sociedad } \\
\text { chilena ante los derechos humanos }\end{array}$ & insatisfacción \\
\hline
\end{tabular}




\subsection{PARTE IV. RESULTADOS DEL ESTUDIO SINTÁCTICO DE PALABRAS ESPECÍFICAS Y DEL CRUCE DE ÉSTAS, ASOCIADAS AL IMPACTO EN ESTUDIO}

A continuación haremos el estudio de algunos términos cuya relevancia fuimos percibiendo subjetivamente en el transcurso de la fase de administración de la entrevista en profundidad y que no fueron codificados como temas en sí, formando parte las unidades textuales codificadas.

Este estudio de las palabras a las que hacemos referencia, será según las frecuencias obtenidas de su presencia por documentos y U.T.s codificadas. Éstas son las siguientes:

“muerte”, “injusticia”, “odio”, "libertad”, “miedo”, “temor”, "Pinochet”, “Lagos”, “represión”, “dictadura”, “soledad”, “cruel”, “respeto”, “dignidad”, “tristeza”, “felicidad”, “alegría”, “truncó” y finalmente añadimos la palabra "trunc*" (asociada a la posible referencia de un cese de la vida o de aspectos de ésta, que pudiesen estar asociados a la experiencia de prisión).

Para seleccionar las palabras que estudiaremos en esta sección, hicimos unan valoración subjetiva en que consideramos la posible relación de éstas con el impacto que estudiamos. Estas palabras nos llamaron la atención cuando realizamos las entrevistas, por el contenido que se asociaba a ellas y que en la fase de campo consideramos que nos aportarían información relevante.

La búsqueda que hicimos, está limitada a la presencia exacta del término excluyendo los caracteres añadidos. Lo que conseguimos marcando la opción "whole word or phrase only" de la paleta de documentos del programa Nvivo 6 (a excepción de la palabra trunc*). Hicimos esta restricción para evitar errores a la hora de analizar las frecuencias obtenidas que pudieran generarse por palabras que tuvieran el sentido contrario (e. g. justicia / injusticia). Finalmente, haremos algunas intersecciones por documento de algunos de estos términos. 
Tabla 130. Frecuencias obtenidos del análisis sintáctico de palabras específicas

\begin{tabular}{||c|c|c|c|c||}
\hline \multirow{2}{*}{ TÉRMINOS } & \multicolumn{2}{|c|}{ SUJETO } & \multicolumn{2}{c||}{ U.T.S } \\
\cline { 2 - 5 } & Frecuencias & $\%$ & Frecuencias & $\%$ \\
\hline Muerte & $\mathbf{3 0}$ & 50 & 40 & 0.40 \\
\hline Injusticia & 15 & 25 & 19 & 0.19 \\
\hline Odio & 14 & 23 & 21 & 0.21 \\
\hline Miedo & $\underline{\mathbf{4 8}}$ & 80 & $\underline{\mathbf{1 2 6}}$ & 1.3 \\
\hline Temor & $\mathbf{3 1}$ & 52 & $\mathbf{6 2}$ & 0.63 \\
\hline Represión & 9 & 15 & 11 & 0.11 \\
\hline Dictadura & $\mathbf{3 5}$ & 58 & $\mathbf{9 7}$ & 0.98 \\
\hline Tristeza & 1 & 1.7 & 1 & 0.01 \\
\hline Soledad & 12 & 20 & 19 & 0.19 \\
\hline Cruel & 5 & 8.3 & 14 & 0.14 \\
\hline Libertad & $\mathbf{2 8}$ & 47 & $\mathbf{5 9}$ & 0.60 \\
\hline Pinochet & $\mathbf{3 2}$ & 53 & $\mathbf{5 9}$ & 0.60 \\
\hline Dignidad & 8 & 13 & 16 & 0.16 \\
\hline Respeto & $\mathbf{2 9}$ & 48 & $\mathbf{6 0}$ & 0.61 \\
\hline Feliz & $\mathbf{3 5}$ & 58 & $\mathbf{6 8}$ & 0.69 \\
\hline Alegría & 10 & 17 & 12 & 0.12 \\
\hline Trunc* & 6 & 10 & 7 & 0.07 \\
\hline Promedios & 20 & & 41 & \\
\hline \hline
\end{tabular}

De acuerdo a los datos que nos entrega la Tabla 130, la palabra "miedo" obtuvo las modas por documentos y U.T.s, donde se presentó en el 80\% de los documentos con una frecuencia de dos y tres U.T.s por cada participante. Otras palabras que superaron la media de los términos buscados fueron el término “dictadura", "temor", “muerte”, "Pinochet", "respeto" y "feliz".

Nos parece relevante acentuar que las palabras que menos se presentaron en los discursos de las personas que conformaron la muestra de nuestro estudio, son aquellas que refieren emociones y sentimientos dolorosos, como son los términos "tristeza", "cruel” y "trunc*”.

A continuación presentamos los resultados obtenidos para las intersecciones que realizamos de algunos de los términos que nos ocupan en esta parte de los resultados: 
Tabla 131. Frecuencias obtenidas por la intersección de palabras específicas

\begin{tabular}{||c|c|c|c|c||}
\hline \multirow{2}{*}{ TEMAS } & \multicolumn{4}{|c||}{ UNIÓN } \\
\cline { 2 - 5 } & \multicolumn{2}{|c|}{ Sujeto } & \multicolumn{2}{c||}{ U.T.s } \\
\cline { 2 - 5 } & Frec. & $\%$ & Frec. & $\%$ \\
\hline Injusticia - muerte & 35 & 58 & 59 & 0.60 \\
\hline Temor - miedo & $\underline{\mathbf{5 7}}$ & 95 & $\underline{\mathbf{1 7 4}}$ & 1.8 \\
\hline Muerte - dictadura & 42 & 70 & 136 & 1.4 \\
\hline Libertad - respeto & 43 & 72 & 119 & 1.2 \\
\hline Trunc* - dictadura & 37 & 62 & 104 & 1.1 \\
\hline
\end{tabular}

De acuerdo a los resultados presentados en la Tabla 131, observamos que las palabras "temor" y “miedo" fueron las que más se presentaron por discurso. Esta unión apareció en casi la totalidad de la muestra en un promedio de tres veces por participante. Creemos que ambas palabras remiten a reacciones y sentimientos similares que pueden estar presentes en la vida de las personas que estudiamos y pueden asociarse a su experiencia de prisión.

\subsection{PARTE V. RESPUESTAS A PREGUNTAS DE INVESTIGACIÓN QUE PLANTEAMOS EN BASE A LA TEORÍA QUE SUSTENTA NUESTRO ESTUDIO}

A continuación desarrollaremos aquellas interrogantes que hemos considerado relevantes para entender el impacto emocional y social que estudiamos en este proyecto, para lo que realizaremos cruces de frecuencias obtenidas por variables (o nudos hijos), que hemos presentado en las partes precedentes de esta sección. El orden que seguiremos para presentar los resultados, comprenderá en primer lugar la pregunta de investigación, en segundo lugar describiremos los pasos que hemos seguido para desarrollarla, y finalmente un ejemplo de U.T.s asociado a la respuesta. Todo lo cual fue respondido mediante los operadores de búsqueda del programa Nvivo6 y en algunos casos contrastado con la prueba $\chi^{2}$ de Pearson.

1. ¿Cuántas unidades aluden directamente al impacto percibido en la propia vida de los EXPPS de la experiencia de prisión, la presencia de secuelas de tortura y la no superación de la experiencia?.

Para responder a esta interrogante, hicimos la interacción por sujetos de los tres temas que incluye la pregunta, para lo que pedimos al programa $\mathrm{N}$ vivo 6 , un collect de los nudos de las secuelas de los distintos tipos de experiencia de tortura, un collect de las respuestas que comprenden la afirmación de percibir impacto de la prisión política en sus vidas (ver Tabla 83), y la categoría negativa de la valoración de superación de la experiencia de prisión (ver Tabla 96). 
El resultado nos indicó que sólo una persona presenta una unidad textual que incluye las tres categorías. Esta es la siguiente:

Como secuela... como secuela... la secuela es, es en el subconsciente cuando llega un vefículo a mi casa, porque se paraba un vehículo y yo por años y años, yo no pude, no pude reconciliar el sueño hasta el otro día porque pensaba que me venían a buscar otra vez; y siempre, sobretodo los vehículos por la noche, no se pasa, nunca se ha pasado... jamás se ha pasado. Es la verdad, se para un vefículo pro la noche, y salto yo por el subconsciente. To puedo estar muy cansado pero el subconsciente, y miro y atrás viene alguien en un taxi, entonces, seguir durmiendo pero cuesta. Es como un... no lo ando trayendo permanente pero sale solo, sale solo (varón, 58 años).

2. De quienes refirieron haber sido víctimas de tortura sexual durante su reclusión en prisión, ¿qué porcentaje corresponde a mujeres?

Para responder a esta interrogante, hicimos un collect del nudo "refiere tortura"/ "sexual" de las categorías demográficas, al que restamos los casos de mujeres. Obtuvimos los siguientes resultados:

Tabla 132. Resultados de sujetos que afirmaron haber sufrido tortura sexual en prisión

\begin{tabular}{||c|c|c|c|c|c|c|c||}
\hline \multicolumn{2}{|c|}{$\begin{array}{c}\text { REFIEREN } \\
\text { TORTURA }\end{array}$} & \multicolumn{3}{c||}{ HOMBRES } & \multicolumn{3}{c||}{ MUJERES } \\
\hline $\begin{array}{c}\mathrm{N}^{\circ} \\
\text { sujetos }\end{array}$ & $\% \mathrm{~N}=60$ & Frecuencia & $\% \mathrm{~N}=60$ & $\% \mathrm{n}=14$ & Frecuencia & $\% \mathrm{~N}=60$ & $\% \mathrm{n}=14$ \\
\hline 14 & 23 & 6 & 10 & 43 & $\underline{\mathbf{8}}$ & 13 & 57 \\
\hline
\end{tabular}

El 23\% del total de la muestra que refirió haber sido víctimas de tortura sexual durante el cautiverio corresponde a mujeres. Este porcentaje corresponde al 57\% del grupo de personas que refirió haber sido víctima de este tipo de tortura, equivalente al 13\% de la muestra del estudio.

De acuerdo a los datos que presenta la Tabla 132, y consideramos que la mayoría de sujetos de la muestra son varones (68\%), los valores obtenidos adquieren diferencias tales como que el $42 \%$ del total de las mujeres participantes del estudio, refirió haber sido víctima de estos hechos, versus el 15\% de varones en relación al total de varones participantes. En cuanto al porcentaje por sexo en función del total de participantes, ninguno de los dos grupos de participantes según este criterio, superó el 13\% de la muestra. Lo que nos indica que un grupo menor de participantes del estudio fue víctima de violencia sexual, o en su defecto, guardaron silencio al respecto. 
Además realizamos la pruebas de $\chi^{2}$ de Pearson, para determinar si las variables son independientes o no. Hemos constatado la existencia de una asociación significativa entre las variables, lo que demostramos en las tablas que presentamos a continuación y que resumen estos resultados .

Tabla 133. Prueba $\chi^{2}$ de Pearson para las variables“sexo" y "tortura sexual”

\begin{tabular}{||l|r|r|r||}
\hline \hline & VALOR & GL & SIG. ASINTÓTICA (BILATERAL) \\
\hline Chi-cuadrado de Pearson & $5,477(\mathrm{~b})$ & 1 &, 019 \\
\hline
\end{tabular}

b. 1 casillas $(25,0 \%)$ tienen una frecuencia esperada inferior a 5. La frecuencia mínima esperada es 4,43.

La tabla nos indica que el grado de significación estadística de la prueba es inferior a 0.05 , con lo que rechazamos la hipótesis nula de independencia de las variables entre sí, y nos indica además que hay relación entre ambas variables estudiadas.

Tabla 134. Medidas de asociación simétricas para las variables "sexo" y "tortura sexual"

\begin{tabular}{|c|c|c|c|}
\hline & & VALOR & $\begin{array}{c}\text { SIG. } \\
\text { APROXIMADA }\end{array}$ \\
\hline $\begin{array}{l}\text { Nominal por } \\
\text { nominal }\end{array}$ & $\begin{array}{l}\text { Coeficiente de } \\
\text { contingencia }\end{array}$ & 289, & 019, \\
\hline \multicolumn{2}{|c|}{$\mathrm{N}$ de casos válidos } & 60 & \\
\hline
\end{tabular}

a Asumiendo la hipótesis alternativa.

b Empleando el error típico asintótico basado en la hipótesis nula.

Por su parte, la magnitud de la medida de asociación calculada para las variables en cuestión, y la significación estadística con un nivel de confianza del 95\%, nos permiten concluir que las asociaciones son estadísticamente significativas.

A continuación, presentamos algunas U.T.s que fueron codificadas bajo el nudo demográfico en cuestión.

El volver a revivir cuando he tenido que ira declarar, todo lo que yo viví, que no es una cosa menor, siendo yo una cabra. Que me hayan desnudado, que me hayan manoseado, que me hayan quemado el vello púbico, que me hayan quemado los pezones. Que hayan estado quince personas tocándome desnuda entera. El haber tenido que soportar un pene en la boca. Con todo eso, y que después, cuando se supone que estamos en una pseudo-democracia, por haber dicho mi verdad, se me empieza a sacar todo por haber sido casada dos veces, fui tratada hasta de prostituta, y por parte de altos personajes del gobierno (mujer, 50 años). 
"Conmigo se portó regio, cuando yo estaba con los ojos abiertos, pero cuando a mi me tenían vendada, igual me manoseaba. Después lo supe" (mujer, 50 años).

3. De quienes aludieron el sufrimiento vivido en prisión, ¿qué proporción de sujetos refirió haber estado privado de su libertad durante el primer período de la represión política?.

Mediante el operador coding del programa Nvivo6, hicimos una tabla del nudo "sufrimiento" que forma parte de las categorías conceptuales "Prisión política"/ "valoración experiencia"/ "en su vida", que contrastamos con la misma tabla de 1 nudo demográfico "antecedentes de prisión"/ "período"/ "sept-dic 1973". Con estas operaciones obtuvimos los resultados que presentamos a continuación:

Tabla 135. Resultados para pregunta 3

\begin{tabular}{||c|c|c|c|c|c|c||}
\hline \hline FRECUENCIAS & \multicolumn{3}{|c|}{ SUFRIMIENTO } & \multicolumn{3}{c||}{ SEPT-DIC 1973 } \\
\cline { 2 - 7 } Y & Frec. & $\%$ & $\%$ & Frec. & $\%$ & $\%$ \\
PORCENTAJES & & $\mathrm{n}=24$ & $\mathrm{~N}=60$ & & $\mathrm{n}=26$ & $\mathrm{~N}=60$ \\
POR SUJETO & & & & & & \\
\hline Sufrimiento & 24 & 100 & 40 & & & \\
\hline Sept-dic 1973 & 12 & 50 & 20 & 26 & 100 & 43 \\
\hline \hline
\end{tabular}

Como nos indica la Tabla 135, menos de la mitad de la muestra refirió el sufrimiento vivido en prisión, y la misma tendencia se presentó en quienes refirieron haber estado recluidos por motivos políticos en Chile entre septiembre y diciembre del año 1973.

Respondiendo a la interrogante planteada en la pregunta 3, los resultados presentados en la Tabla 135, nos indican que el 50\% de las personas que aludió al sufrimiento vivido en prisión, afirmó haber estado privado de su libertad durante el primer período de represión política en Chile.

4. De quienes refirieron el sufrimiento vivido en prisión, ¿cuántos personas aluden el propio sufrimiento experimentado y cuántas aluden el sufrimiento ajeno? 
Tabla 136. Resultados para pregunta 4

\begin{tabular}{|c|c|c|c|}
\hline DOCUMENTS & EXTREMO & MENOS QUE COMPAÑEROS & NO ESPECIFICA \\
\hline C14 & 0 & 0 & 1 \\
\hline C15 & 0 & 1 & 0 \\
\hline C16 & 0 & 1 & 0 \\
\hline $\mathrm{C} 17$ & 0 & 0 & 1 \\
\hline $\mathrm{C} 18$ & 0 & 1 & 0 \\
\hline $\mathrm{C} 20$ & 1 & 0 & 0 \\
\hline $\mathrm{C} 22$ & 1 & 1 & 1 \\
\hline $\mathrm{C} 27$ & 0 & 1 & 0 \\
\hline $\mathrm{C} 28$ & 1 & 0 & 0 \\
\hline $\mathrm{C} 29$ & 1 & 1 & 1 \\
\hline $\mathrm{C} 3$ & 1 & 1 & 0 \\
\hline $\mathrm{C} 31$ & 1 & 1 & 1 \\
\hline C34 & 0 & 1 & 0 \\
\hline $\mathrm{C} 35$ & 0 & 0 & 1 \\
\hline $\mathrm{C} 36$ & 0 & 1 & 0 \\
\hline C38 & 0 & 0 & 1 \\
\hline $\mathrm{C} 43$ & 0 & 0 & 1 \\
\hline C44 & 0 & 1 & 0 \\
\hline $\mathrm{C} 47$ & 0 & 0 & 1 \\
\hline $\mathrm{C} 53$ & 1 & 0 & 0 \\
\hline C56 & 1 & 0 & 0 \\
\hline C59 & 0 & 0 & 1 \\
\hline $\mathrm{C} 7$ & 0 & 0 & 1 \\
\hline C8 & 1 & 0 & 0 \\
\hline$(\mathrm{n}=24)$ & 9 & 11 & 11 \\
\hline
\end{tabular}

La Tabla 136, presenta en datos binarios donde "1" significa la presencia de la categoría, y "0" la ausencia de la misma, el listado que corresponde a todas las personas que aludieron el tema sufrimiento vivido en prisión. Esta tabla fue obtenida mediante el empleo operador coding y como podemos ver en ella, entre quienes refirieron la temática "sufrimiento" de la propia experiencia de prisión, las modas de frecuencias por sujetos las obtienen la alusión a que el propio sufrimiento experimentado en prisión fue menor que el de sus compañeros y la alusión no especificada de este sufrimiento. Vemos además, que algunos sujetos presentan más de una categoría cada uno. 
5. De las personas que refirieron haber estado en recintos no oficiales de reclusión, ¿cuál es la proporción de torturados?

Para responder a la pregunta en cuestión, hemos comparado dos tablas coding. Una de estas tablas se hizo de las alusiones de EXPPS que afirmaron haber estado recluidos en recintos no oficiales de las fuerzas armadas del gobierno de Chile ("datos demográficos"/ "antecedentes de prisión" / "lugar"/ "recinto no oficial FFAA"). Los resultados de esta tabla se compararon con los datos obtenidos de la tabla coding para la categoría demográfica "refiere tortura", que nos indicó las personas que refirieron haber sido torturados en distintas modalidades ("datos demográficos"/ “antecedentes de prisión"/ "valor exp. Tortura"/ "refiere tortura").

Tabla 137. Resultados para pregunta 5

\begin{tabular}{||c|c|c|c||}
\hline \hline INTERSECCIÓN & \multicolumn{3}{|c||}{ RECINTO NO OFICIAL FFAA = 25 } \\
\hline Refiere tortura $=53$ (88\% de la muestra) & Frec. & $\% \mathrm{~N}=25$ & $\% \mathrm{~N}=60$ \\
\cline { 2 - 4 } & 25 & 100 & 42 \\
\hline
\end{tabular}

De las 25 personas que refirieron haber estado en recintos no oficiales de reclusión, todos aludieron distintas temáticas que revelaron que fueron víctimas de tortura. La frecuencia alcanzada es del $42 \%$ del total de la muestra.

Los resultados además nos revelan que el $88 \%$ de la muestra refirió a nivel demográfico haber sido víctima de tortura. Lo que difiere de las frecuencias obtenidas en el nudo conceptual "tortura y violencia" de la rama "prisión política y tortura", que fue aludido solamente por cuatro personas. Esto nos da información acerca de cómo los EXPPS hablan de la tortura, resultando posiblemente más fácil para ellos aludir de manera demográfica a la experiencia de tortura y no a la valoración de la superación de estas experiencias. Las cuales fueron generalmente omitidas de sus discursos.

6. Nos interesa comparar las posibles diferencias en cuanto a la valoración del impacto de prisión en las vidas de las víctimas y su relación con el tiempo de permanencia en prisión.

Para resolver las relaciones entre el tiempo de prisión y la valoración del impacto, hemos agrupado en dos los datos de la tabla demográfica del tiempo de prisión. En un primer grupo (G1), hemos unido a quienes refirieron haber estado recluidos durante horas, días y semanas, y en un segundo grupo (G2), a quienes refirieron que su permanencia en prisión fue de meses y/ o años. Hicimos sumatorias de tablas coding para cada grupo. Lo que comparamos con la sumatoria de las respuestas "si percibe" de la Tabla 83 y la Tabla 85. 
Tabla 138. Resultados para pregunta 6.

\begin{tabular}{|c|c|c|c|c|c|c||}
\hline \hline $\begin{array}{c}\text { INTERSECCIÓN } \\
\text { POR SUJETOS }\end{array}$ & \multicolumn{3}{|c|}{ G1 = 23 } & \multicolumn{3}{c||}{ G2 = 36 } \\
\hline $\begin{array}{c}\text { Si percibe impacto en } \\
\text { vida y R.I.P. } \\
\text { N = 59 }\end{array}$ & Frec. & $\% \mathrm{~N}=23$ & $\% \mathrm{~N}=60$ & Frec. & $\% \mathrm{~N}=36$ & $\% \mathrm{~N}=60$ \\
\cline { 2 - 8 } & 23 & 100 & 38 & 36 & 100 & 60 \\
\hline
\end{tabular}

La Tabla 138, nos indica que todas las personas que refirieron el tiempo que permanecieron en prisión, independientemente del período de tiempo que estudiamos en esta pregunta, percibieron el impacto de la experiencia de prisión en aspectos de sus vidas entre los que se incluyen las relaciones interpersonales. La tabla en cuestión, además nos indica que casi la totalidad de la muestra refirió que la experiencia de prisión impactó en sus vidas. Por ello no podemos saber si hay relaciones significativas en el impacto percibido, según el tiempo de permanencia en prisión.

7. De quienes aludieron haber sido privados de su libertad por motivos políticos en más de una ocasión, cuántos afirmaron haber sufrido persecución política, y de ellos cuántos afirmaron tener temores en sus vidas.

Para responder a la interrogante $\mathrm{N}^{\circ} 7$, hemos comparado las tablas coding de los siguientes nudos:

-nudo demográfico "antecedentes de prisión" / "No de veces"/ "mas de una vez" (17 personas); -coding del nudo conceptual "presente" / "temores" / "si tiene" (34 personas); personas).

-coding del nudo conceptual "prisión política y tortura"/ "temores asociados"/ "si presenta" (21

Tabla 139. Resultados para pregunta 7.

\begin{tabular}{||c|c|c|c||}
\hline \multirow{2}{*}{ INTERSECCIÓN POR SUJETOS } & \multicolumn{3}{|c|}{$\begin{array}{c}\text { TEMORES EN PRESENTE } \\
+ \text { TEMORES ASOCIADOS A } \\
\text { EXPERIENCIA DE } \\
\text { PRISIÓN }\end{array}$} \\
\hline $\begin{array}{c}\text { Frecuencia de sujetos detenidos más de } \\
\text { una vez }=\begin{array}{c}17 \text { sujetos }(28 \% \text { de la } \\
\text { muestra) }\end{array}\end{array}$ & Frec. & $\% \mathrm{~N}=17$ & $\% \mathrm{~N}=60$ \\
\cline { 2 - 4 } & 11 & 65 & 18 \\
\hline
\end{tabular}

De las 17 personas que refirieron haber sido detenidos más de una vez, equivalentes al 28\% de la muestra, observamos que el $65 \%$ de ellos, refirió temores en sus vidas que fueron asociados a la experiencia de prisión y a otros aspectos. 
Buscamos relacionar estos temas, porque creemos que la concretización de un temor asociado a reincidir en prisión, puede ser causa de temores que posiblemente perdurarán en la vida de quienes son expuestos a estos sucesos. Por su parte, sólo tres personas refirieron haber sido privadas de su libertad en una ocasión, por lo que no disponemos de toda la información necesaria a nivel demográfico para contrastar con el grupo de EXPPS participante del estudio, que refirió haber sido detenido sólo una vez en su vida.

Pese a lo anterior, observamos que de las tres personas que afirmaron haber sido detenidas sólo una vez, dos de ellas presentan temores. Lo que aunque no nos otorga toda la información que requeríamos, nos indica que la mayoría de estas personas refiere temores en sus vidas.

Nuestra postura respecto a la respuesta $\mathrm{N}^{\circ} 7$, es que el número de detenciones no afecta diferencialmente en los temores presentes en los EXPPS, y sí en cambio, en otros aspectos asociados a la experiencia de prisión.

8. De quienes refirieron haber recibido malos tratos que no consideraron tortura, ¿qué argumentos presentan para valorar como tales sus experiencias de violencia política?

Para responder a esta pregunta, hicimos un collect de la categoría demográfica "antecedentes de prisión" / "valor. exp. tortura"/ "refiere no tortura"/ "mal trato no tortura", y los resultados arrojados nos indican lo siguiente:

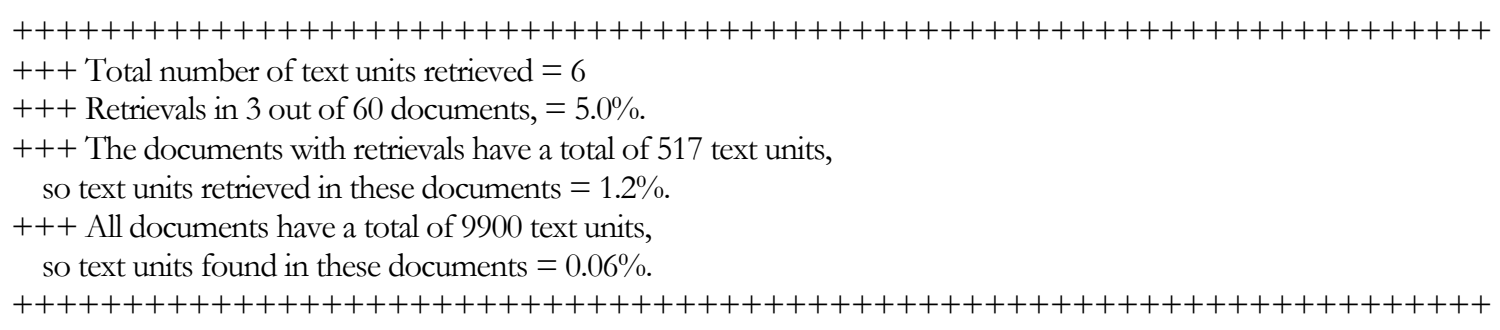

Como podemos observar en los resultados extraídos del informe para el nudo en cuestión, sólo tres personas aludieron a la temática en un promedio de dos U.T.s por discurso.

Al revisar los contenidos codificados por U.T.s, observamos que tales unidades presentaban principalmente alusiones a situaciones de violencia psicológica no especificada y a golpes que no calificaron como tortura. Presentamos un ejemplo a continuación:

malos tratos si. Más de un culatazo, más de una patada...psicológica, mucha psicológica, porque nos sacaban a las tres de la mañana a preguntar el nombre. los mismos guardias que nos cuidaban, maltrato (varón, 55 años). 
9. De quiénes refirieron secuelas de experiencias de tortura, ¿qué proporción de sujetos aludió directamente la presencia del impacto de la prisión en sus vidas?

Para responder a la interrogante $\mathrm{N}^{\circ}$ 9, comparamos con los resultados de una tabla coding que hicimos de uniones de los distintos tipos de secuelas de la tortura aludidas por los EXPPS ("antecedentes demográficos" / "valor. exp. Tortura" / "refiere tortura" / "física" + "psicológica" + "sexual" / "secuelas" de cada una); con los resultados de otra tabla coding que agrupó a los sujetos que afirmaron percibir un impacto directo de la experiencia de prisión en sus vidas (señalada por ejemplo en la pregunta $\mathrm{N}^{\mathrm{o}}$ 6).

Tabla 140. Resultados para la respuesta 9

\begin{tabular}{||c|c|c|c||}
\hline INTERACCIÓN & \multicolumn{3}{|c|}{ SECUELAS DE TORTURA N = 24 } \\
\hline $\begin{array}{c}\text { Percibe impacto experiencia } \\
\text { de prisión }=59\end{array}$ & Frec. & $\% \mathrm{~N}=24$ & $\% \mathrm{~N}=60$ \\
\cline { 2 - 4 } & 23 & 96 & 38 \\
\hline
\end{tabular}

Como nos indica la Tabla 140, del total de personas que manifestó tener secuelas de tortura, que equivale a menos de la mitad de la muestra, la mayoría afirmó que la experiencia de prisión política impactó en sus vidas y relaciones interpersonales.

Si nos fijamos que la mayoría de la muestra percibe el impacto de la prisión en sus vidas, era de esperar este resultado. Sin embargo, podemos interpretar de la tabla en cuestión, que no todas las personas que perciben tal impacto, refieren secuelas producto de la tortura en sus vidas. Lo que nos indica que este impacto puede estar asociado a secuelas concretas y observables como lesiones físicas, enfermedades, etc., pero no necesariamente su valoración se basa en ello.

10. De quienes refirieron secuelas de experiencias de tortura, ¿cuántas personas presentan antecedentes mórbidos en el presente?.

Para resolver la interrogante $\mathrm{N}^{\circ} 10$, hemos comparado la tabla coding de los sujetos que refirieron secuelas de tortura en sus discursos (que hemos empleado en la pregunta anterior), con la tabla coding del nudo "datos demográficos" / "antecedentes de salud” / refiere antecedentes mórbidos". De esta interacción se desprenden los siguientes resultados: 
Tabla 141. Resultados para la respuesta 10

\begin{tabular}{||c|c|c|c||}
\hline INTERACCIÓN & \multicolumn{3}{|c|}{ SECUELAS DE TORTURA N = 24 } \\
\hline $\begin{array}{c}\text { Refieren antecedentes } \\
\text { mórbidos } \mathrm{N}=27\end{array}$ & Frec. & $\% \mathrm{~N}=24$ & $\% \mathrm{~N}=60$ \\
\cline { 2 - 4 } & 15 & 63 & 25 \\
\hline
\end{tabular}

Como nos indica la Tabla 141, del total de personas que refirió la presencia de secuelas de la tortura en sus vidas en la actualidad, más de la mitad de ellos manifestó tener antecedentes mórbidos de salud. Podemos pensar que existe relación entre ambas variables y que los antecedentes mórbidos presentes en las personas que afirmaron tener secuelas de la tortura, fueron causados por estas experiencias.

Para cerciorarnos de la causalidad del estado de salud de los EXPPS que refirieron presentar secuelas de la tortura, revisaremos los contenidos de aquellas U.T.s, referidas simultáneamente por el 25\% de la muestra (mediante la unión de los nudos en cuestión).

Aunque la pregunta apuntaba a la unión de U.T.s por sujeto que hicieran referencia a los dos nudos de la tabla, realizamos mediante el operador intersection, una búsqueda de aquellas U.T.s que referían las dos variables a la vez. Para con esta acción, presentar de manera compacta algunas alusiones que incluyan las dos variables en una misma unidad textual.

En general observamos que quienes refieren la presencia de antecedentes mórbidos en su estado de salud actual, lo asocian a la experiencia de tortura.

A mi me hace sentirme mal, porque, por lo que yo tengo ahora actual. Mi estado de salud, eh... eh... Lo que más, lo que más es la columna, y el hombro lo que más me molesta. Y me vienen unos dolores a mi en invierno a los huesos. $\Upsilon$ me, me toma todo el lado izquierdo por lo que sufrí de este lado. Ahora me está reviniendo más (varón, 58 años).

Yo creo que, analizando con el tiempo dicen que los golpes aparecen después de años, ¿me entiende?. Yo hace tres años, tuve un cáncer a la vejiga. Cáncer a la vejiga, hace tres años me operaron a mi, a mi hace tres años me sacaron la vejiga completa y me hicieron una nueva. To to puedo asumir a golpes que se yo, que fueron hematomas que se incubaron afí y de repente después... porque yo después con el tiempo empecé a orinar sangre, me ficieron exámenes, me ficieron dos operaciones por la uretra con, con rayos, no pudieron extirparlo, así que tuvieron que hacerme una operación a tajo abierto, en, en mayo del 2003. En todo eso, todo eso de informes de biopsia yo los mandé a la comisión de exonerados políticos... (varón, 58 años). 
11. Nos interesa comparar la valoración de la experiencia de exilio con el hecho de haber vivido o no la experiencia.

Tabla 142. Resultados para la pregunta 11

\begin{tabular}{||c|c|c|c|c||}
\hline $\begin{array}{c}\text { INTERSECCIÓN } \\
\text { POR } \\
\text { DOCUMENTOS }\end{array}$ & \multicolumn{2}{|c|}{ DE EXPERIENCIA PERSONAL } & \multicolumn{2}{|c||}{$\begin{array}{c}\text { DE EXPERIENCIA DE } \\
\text { COMPANEROS }\end{array}$} \\
\hline No vivió $=17$ & $\begin{array}{c}\text { Valor. negativa }= \\
0\end{array}$ & $\begin{array}{c}\text { Valor. positiva }= \\
1\end{array}$ & $\begin{array}{c}\text { Valor. negativa }= \\
2\end{array}$ & $\begin{array}{c}\text { Valor. positiva }= \\
1\end{array}$ \\
\hline Si vivió $=12$ & $\begin{array}{c}\text { Valor. negativa }= \\
3\end{array}$ & $\begin{array}{c}\text { Valor. positiva }= \\
\text { Valor. negativa }=\end{array}$ & $\begin{array}{c}\text { Valor. positiva }= \\
0\end{array}$ \\
\hline
\end{tabular}

Como podemos observar en la Tabla 142, la mayoría de las personas que aludieron la temática exilio, refirieron no haber vivido la experiencia en sus vidas. En cuanto a la valoraciones que hicieran estas personas alusiva a esta experiencia, observamos que una de ellas valoró positivamente el no haber vivido la experiencia de expulsión del país durante el período militar del gobierno de Chile. En tanto, un grupo menor afirmó haber vivido la experiencia de exilio en sus vidas, de quienes la mayoría hace una valoración positiva de esta etapa en sus vidas.

En general observamos que de las personas que manifestaron haber vivido o no la experiencia de exilio en sus vidas, una minoría realiza juicios de valor de estas experiencias.

A continuación presentamos un ejemplo de U.T.s emitido por un EXPP que vivió el exilio y realizó una valoración positiva de su experiencia:

No. A estas alturas no. Porque mira, yo en, en la época en que eh... custodiaban mi casa, después pasaron como dos, tres años, yo me uní a la resistencia y trabajé como clandestina, después que estuve claro, como a los dos años después, que ya quedé tranquila, no me molestaron más, dejé de ver los vefículos. Ellos me dijeron a mi, "nunca más dirigenta de nada", y nunca más..., porque ahi si que... pasaron dos años, se aburrieron seguramente, veían que yo iba a mi trabajo, a la escuela, qué se yo, a, a estudiar, todo O.K., y afí es cuando me metí a trabajar en la clandestinidad. Trabajé, trabajé hasta el año 89. Incluso estuve en Iquique trabajando, y felizmente todo salió bien poh. Pero ¿qué pasó? de que... salió bien porque entre comillas, el año 88 me sacaron de aquí pero volando. Porque el 88, hasta el 88 trabajé, y el 89 me sacaron volando y fui a dar allá a Europa arrancando. Me sacaron. Me sacaron con un pasaporte y fui a dar al otro lado, y llegué cuando ganó el no. Si porque habian pasado muchos años ya estaba como... no, me tuve que ir sola. Estuve en Holanda, en Bélgica, en la Unión Soviética, y de ahí, el año que pasé esperando que me llegara el... no, no, el 89 me fui. Todo el 89 y me regresé el 90. Bueno, eh... lei harto. Lei bastante. $\Upsilon$ conocí la realidad que no era tal como se decía. Por allí. Lo viví así en carne propia... Lo viví, o sea, ojito en..., que no era tan como se decía. Y me tocó 
presenciar el derrumbe del sistema socialista, así en vivo y en directo. Entonces... fue una experiencia interesante, que me sirvió mucho a futuro (mujer, 64 años).

12. De quienes refirieron que sus parejas son EXPP o participan a favor de la izquierda política del país, ¿̇cuántos hicieron una valoración positiva del apoyo percibido post-prisión por parte de sus parejas y valoraron satisfactoriamente estas relaciones?.

Para obtener los resultados de esta tabla, hemos hecho reportes de los nudos que presentamos a continuación.

Antecedentes demográficos:

"Antecedentes familiares"/ "pareja" / "si tiene"/ "antecedentes de prisión"/ "si EXPP" = 8 personas,

"Antecedentes familiares"/ "pareja"/"si tiene"/ "participación política"/"si"/ "de izquierda" = 12 personas,

Antecedentes conceptuales:

"Presente" / "relaciones interpersonales actuales"/ "pareja" / "valoración apoyo suceso" = 8 personas,

"Presente"/ "relaciones interpersonales actuales" / "pareja"/ "valoración global satisfacción"/ "satisfecho" = 34 personas.

De cuya intersección por documentos, extrajimos los resultados que presentamos en la Tabla 143.

Tabla 143. Resultados para la pregunta 12

\begin{tabular}{||c|c|c||}
\hline \hline TOTAL DE DOCTS. $(\mathrm{A}+\mathrm{B})=16$ & VALOR APOYO SUCESO & VALOR. GLOBAL \\
\hline a) Pareja es EXPP $=8$ & Satisfacción $=1$ & Satisfacción $=6$ \\
\hline b) Pareja partidario de izquierda $=12$ & Satisfacción $=\underline{\mathbf{8}}$ & Satisfacción $=6$ \\
\hline
\end{tabular}

A modo general, podemos interpretar que menos de la mitad de sujetos refirió que sus parejas son EXPPS o activistas de partidos políticos de izquierda en Chile.

De quienes refirieron que sus parejas tienen participación política de izquierda, la mayoría valoró positivamente el apoyo percibido de estos vínculos, y la mitad de estas personas realizó una valoración global satisfactoria de las mismas relaciones.

De las personas que afirmaron que sus parejas son EXPPS, sólo una persona refirió satisfacción en torno al apoyo percibido de estas relaciones, y la mayoría refirió una valoración global positiva de estas relaciones.

A continuación presentamos un ejemplo de U.T.s que presenta simultáneamente las dos variables que obtuvieron las modas de la intersección realizada. 
(relación con señora) muy buena. ella siempre ha estado de acuerdo en muchas cosas. claro, siempre tenemos, usted sabe, como todos los matrimonios, desavenencias pero, pero en lo, en lo general acordamos las cosas y las pensamos los dos y ella también es una luchadora porque también ella luchó mucho acá en la dictadura. ella se hizo aquí en la, en la dictadura se hizo una colecta, una colecta popular como le llamaba la gente, y hacía poemas en contra de la dictadura y en contra del régimen que lo, lo oprimían en esa época. Incluso ahora todavía ella va a una radio, la "Puerta Norte" que se llama, acá en Arica que es muy, es muy escuchada por la gente, una radio muy popular, y ella va a la radio a decir los poemas. Los poemas son de ella. Son comprometidos. Comprometidos con el pueblo, comprometidos con la gente, y con los trabajadores, con el partido comunista, con todos (varón, 69 años).

13. De quienes afirmaron percibir la traspaso del trauma ocasionado en prisión a sus hijos, ¿`uántos refirieron que sus hijos ya había nacido al momento de su detención?, y estudiar relaciones con quienes refirieron que sus hijos fueron detenidos también.

Tabla 144. Resultados para la respuesta 13

\begin{tabular}{||c|c|c||}
\hline \multirow{2}{*}{$\mathrm{N}=60$} & $\begin{array}{c}\text { TRASPASO DEL TRAUMA A HIJOS } \\
\mathrm{N}=38(63 \% \text { DEL TOTAL DE LA } \\
\text { MUESTRA })\end{array}$ \\
\cline { 2 - 3 } & $\mathrm{Si}=31(82 \%)$ & No $=10(26 \%)$ \\
\hline $\begin{array}{c}\text { Hijos nacidos al momento } \\
\text { de la detención } \mathrm{N}=40 \\
(67 \% \text { del total de la muestra })\end{array}$ & $\underline{\mathbf{2 3}}$ & 7 \\
\hline
\end{tabular}

Los resultados que presenta la Tabla 144, fueron extraídos del collect que realizamos a la categoría demográfica "antecedentes familiares"/ "hijos"/ "si tiene"/ "media de edad detención", y a la categoría conceptual “prisión política" / "valor. impacto" / "traspaso del trauma a hijos”. Realizamos una interacción por sujetos de los resultados que obtuvimos.

La Tabla 144, nos indica que más de la mitad de sujetos entrevistados percibe que la experiencia traumática de la prisión y tortura por motivos políticos se traspasó a los hijos (63\%). De estas personas, la mayoría refiere que percibe la presencia de este impacto en sus vidas.

La tabla también nos indica que el $67 \%$ de la muestra refiere que sus hijos ya habían nacido al momento de su detención, de los cuales más de la mitad percibe un impacto producto de la experiencia de prisión en sus hijos. 
Nos interesa saber qué es lo que estas personas perciben del traspaso del trauma de la prisión y tortura a los hijos, y qué diferencias posibles hay entre quienes refirieron que sus hijos habían nacido antes de la experiencia de prisión de quienes negaron esta afirmación.

Después de revisar el contenido de las unidades textuales, observamos que los EXPPS que refieren este impacto, afirman asociarlo a actitudes y características de la personalidad de sus hijos, como inseguridad, violencia, tristeza, fobias, perturbaciones mentales específicas y hasta muerte. Lo que atribuyen a las dificultades económicas y el ausentismo del hogar durante el período de prisión.

A excepción de las alusiones de la percepción del traspaso del trauma a los hijos asociadas a los aspectos referidos en el párrafo anterior, vemos que muchos EXPPS hacen referencia a este impacto, pero no pueden especificarlo, pues no respondieron a la pregunta que buscaba indagar estas percepciones. Lo que nos hace pensar que no es un tema fácil de abordar para ellos, y no pueden valorar objetivamente este impacto. A continuación una U.T.s de ejemplo:

\footnotetext{
(se emociona- silencio) Es jodido porque más encima ellas eran chicas, entonces a ellas demás que las ha afectado... a ellas demás que las ha afectado, y también está aparte de su pareja, está viviendo con otro, y es super piola como pa' adentro, tiene que tener sus rollos también (mujer, 48 años).
}

14. De quienes refirieron la presencia de antecedentes disfuncionales en sus familias de origen, ¿cuántos presentan como motivación de su participación política actual, la ayuda social y hacen una valoración negativa del mundo?.

Para obtener los resultados que resuelven la pregunta 14, haremos una intersección por documentos, entre las categorías "presencia de dificultades relevantes" en las familias de origen de los EXPPS ("categorías conceptuales"/ "pasado"/ "relaciones interpersonales"/ "familia de origen"/ "ambiente"/ "presencia dific. relev."), la categoría “ayuda social” como motivación de la participación política de los EXPPS ("categorías conceptuales"/ "presente"/ "valor. particip. política"/ "motivación ppal."/ “ayuda social”), y aquellos documentos que refirieron una valoración global de mundo negativa ("categorías conceptuales"/ "presente"/ "concepción mundo"/ "valoración global" / "negativa"/"causa humana" + "causa naturaleza" + "tendencias actuales" + "no especifica u otro"). 
Tabla 145. Resultados para la pregunta 14

\begin{tabular}{||c|c|c|c||}
\hline $\begin{array}{c}\text { UNIÓN 3 VARIABLES }=57 \\
\text { INTERACCIÓN 3 VBLES. } \\
12\end{array}$ & $\begin{array}{c}\text { PRES. } \\
\text { DIFICULTADES } \\
\text { RELEVANTES } \\
\text { EN AMBIENTE } \\
\text { FAMILIAR DE } \\
\text { ORIGEN }\end{array}$ & $\begin{array}{c}\text { VALOR. } \\
\text { GLOBAL DE } \\
\text { MUNDO } \\
\text { NEGATIVO }\end{array}$ & $\begin{array}{c}\text { AYUDA } \\
\text { SOCIAL } \\
\text { (PRINCIPAL } \\
\text { MOTIVACIÓN } \\
\text { POLÍTICA) }\end{array}$ \\
\hline $\begin{array}{c}\text { Pres. dificultades relevantes en } \\
\text { ambiente familiar de origen }\end{array}$ & 46 & 33 & 0 \\
\hline $\begin{array}{c}\text { Valor. global mundo negativo } \\
\text { Ayuda social } \\
\text { (principal motivación política) }\end{array}$ & - & 46 & 0 \\
\hline
\end{tabular}

Como nos indica la Tabla 145, casi la totalidad de la muestra refirió al menos una de las tres variables que valoramos en la tabla. En cuanto a la pregunta 14, un total de 12 personas manifestó en sus discursos la presencia de dificultades relevantes en sus familias de origen, a la vez que refirieron que su principal motivación para trabajar en política es un tema social y presentaron una concepción actual de mundo negativa.

Por su parte, de quienes afirmaron la presencia de dificultades relevantes en el ambiente de sus hogares en la infancia y adolescencia, vemos que la mayoría tiene una visión de mundo negativo en la actualidad. Lo que relacionamos con los aspectos clasificados como dificultades relevantes, cuya alusión más frecuente fue la pobreza extrema de sus hogares, siendo la problemática que creemos puede influir en su valoración del mundo.

Por último, ninguna persona que refirió la presencia de dificultades relevantes en sus hogares de infancia, refirió exclusivamente tener una motivación política actual asociada principalmente a la "ayuda social". Esta motivación, tampoco se presentó en quienes refirieron una valoración general del mundo negativa.

El ejemplo de U.T.s que presentamos a continuación, fue extraído del discurso de un participante varón, de 65 años, que refirió en distintas unidades la presencia de dificultades relevantes en su familia de origen, y una visión del mundo negativa:

$\mathcal{N}$ o, me sentía insatisfecho, quería como vivíamos, nosotros éramos pobres, digamos vivíamos dos hermanos en una cama dormíamos, entonces no habian muebles nada, entonces quería tener cosas, porque veía otras casa que estaban un poquito más 
arregladas que la de nosotros; o tenían mejores ropas que nosotros, nosotros no poh, nosotros con los mismos zapatos, eh... dos pantaloncitos, dos camisitas, entonces...

Mire, el mundo... el mundo tiene muchos problemas. E[ mundo en primer lugar tenemos a un presidente norteamericano que derrotó, derrotó al comunismo y resulta que sigue con la guerra. La iglesia es otra cosa, es lo mismo, predica, predican, y predican, y no practican.. El resultado de que apoyan a los empresarios, a las multinacionales, y ¿ios trabajadores?, ¿los niños que mueren en África?, ¿los que mueren los niños por el mundo por el hambre?, esa enfermedad sucias que hay, que no se atacan con tantos millones de millones que se gastan en armamento en la salud, e la hambruna, el mundo tiene mucho problema, hay mucho problema en el mundo. Entonces cuando uno ve la televisión o lee los diarios, pucha que, que deja que desear. Aquí mismo, hay analfabetos, sueldos bajos, la droga... el tráfico de drogas lo más grande que hay en Estados Unidos, y pa Europa que ahora a abarcado, y ello saben, saben quiénes son los grandes, saben el lavado de dinero, pero son tapados por los mismos bancos o los mismos empresarios. Entonces digamos esto necesita digamos este mundo necesita un reglo, en general, en general.

"O sea, no me daba cuenta, pero yo ahora saco relación a que eso fue lo que me impulsó a ser dirigente, a estar al servicio de la, de la gente".

Como podemos ver en este ejemplo que refleja la tendencia predominante en las personas que aludieron las temáticas en cuestión, éstas valoraciones no se presentan simultáneamente en una misma unidad.

Por último, creemos que la relación de una valoración del mundo negativa puede haberse originado con anterioridad a la experiencia de prisión y no como consecuencia de estos sucesos.

Nos interesaba hacer la interacción de estas variables, porque creemos que el compromiso político surge de un malestar o insatisfacción que hemos valorado como dificultades relevantes en el ambiente familiar de sus hogares de origen, e influye en una valoración del mundo negativo. Esto lo fundamentamos, en la idea de que alguien que vive su infancia y adolescencia en un ambiente con dificultades como las incluidas en la categoría "presencia de dificultades relevantes" (ver Apéndice D), tendrá posiblemente una visión del mundo negativa. Dentro de tal contexto, la participación política sobretodo en partidos de izquierda, podría significar una vía de solución a la insatisfacción que está presente en sus vidas.

15. Queremos comparar las valoraciones globales de las relaciones interpersonales de los EXPPS en tiempo presente y pasado y su relación con la experiencia de prisión por motivos políticos.

De acuerdo a los datos resumidos que presentamos al final de la parte 5.3. de las tendencias en base a variables conceptuales agrupadas según las necesidades interpersonales planteadas por López (2008), podemos 
observar que las valoraciones que hicieran los EXPPS de sus relaciones interpersonales en el pasado, fueron mayoritariamente positivas, Esta tendencia también se presenta en la actualidad.

Por su parte, la concepción del mundo predominante cambió de positiva en el pasado, a negativa en el presente, pudiendo este cambio estar o no asociado a la experiencia de prisión. Para revisar la relación entre ambas variables, extraeremos los motivos negativos aludidos por los EXPPS, y las problemáticas aludidas a nivel político y social, por ser las problemáticas más aludidas.

Tabla 146. Resultados para la respuesta 15

\begin{tabular}{||c|c|c|c||}
\hline \multicolumn{4}{|c||}{$\begin{array}{c}\text { NEGATIVA } \\
\text { C }=52\end{array}$} \\
\hline Causa humana & Causa naturaleza & Tendencias actuales & No especifica \\
\hline$\underline{\mathbf{3 8}}$ & 6 & 10 & 10 \\
\hline
\end{tabular}

La tabla en cuestión, nos otorga información acerca de las causas negativas referidas por los EXPPS que fundamentan su valoración negativa del mundo. Observamos así, que la causa de naturaleza humana, es la más aludida por los entrevistados que refirieron estas valoraciones.

No obstante lo anterior, la moda presente en la Tabla 146, no nos entrega información de los motivos específicos asociados a la causa predominante de tales valoraciones. Por ello hemos hecho una extracción de la tabla que obtuvimos de nudos hijos para la categoría problemáticas del mundo, y la Tabla 147, nos muestra aquellas variables que obtuvieron la moda de todas las que conforman las categorías "sociales" y "políticas". De acuerdo a esta tabla, es la desigualdad social, la problemática del mundo más aludida por los EXPPS, seguida de la influencia de las potencias mundiales como problemática política.

Tabla 147. Otros resultados para pregunta 15

\begin{tabular}{||c|c|c||}
\hline \multirow{3}{*}{ NUDOS } & \multicolumn{2}{|c|}{ PROBLEMÁTICAS $\mathrm{n}=46$} \\
\cline { 2 - 3 } & Sociales & Políticas \\
& $\mathrm{C}=32$ & $\mathrm{C}=\underline{34}$ \\
\cline { 2 - 3 } & Desigualdad & Potencias mundiales \\
\hline \multirow{3}{*}{ Dcts. } & $\underline{\mathbf{2 0}}$ & 17 \\
\hline
\end{tabular}


Creemos que percibir como una problemática del mundo la influencia de las potencias mundiales, puede estar relacionado a la experiencia de prisión si consideramos el apoyo al régimen militar que Chile recibió de Estados Unidos, pero también podría estar asociado a un tipo de ideología política previa a la experiencia de prisión que no valora positivamente la influencia de las potencias mundiales en la actualidad.

En el caso de la alusión a problemáticas sociales como la desigualdad, esta puede relacionarse a la experiencia de prisión, pero más bien a las consecuencias de tales experiencias, que como describimos en el capítulo III, influenció en las vidas de los EXPPS que se vieron enfrentados durante años a la dificultad para encontrar trabajo por su condición de EXPPS y la consecuente pobreza asociada a la cesantía. En definitiva creemos que ambos temas están asociados a temas políticos, pero con los resultados obtenidos para la pregunta $\mathrm{N}^{\circ} 15$, no podemos concluir si la concepción de mundo negativa que presentan la mayoría de los EXPPS es causada por la experiencia de prisión.

16. De quienes refieren una concepción de mundo negativa, ¿qué proporción de personas lo atribuye a motivos políticos?.

Para responder a esta pregunta, hicimos un collect de la categoría "políticas" ("categorías conceptuales"/ "presente"/ “concepción mundo"/ "problemáticas"/ "políticas"/ "corrupción”+ "globalización"+ "guerras"+ “consumismo"+ "potencias mundiales"+ "futuro incierto"+ "sobre expl. Recursos nat."+ “exclusión política”+ “condic. Desfav. Tbjo."+ “terrorismo"+"regímenes políticos"+ “otro o no especif.”).

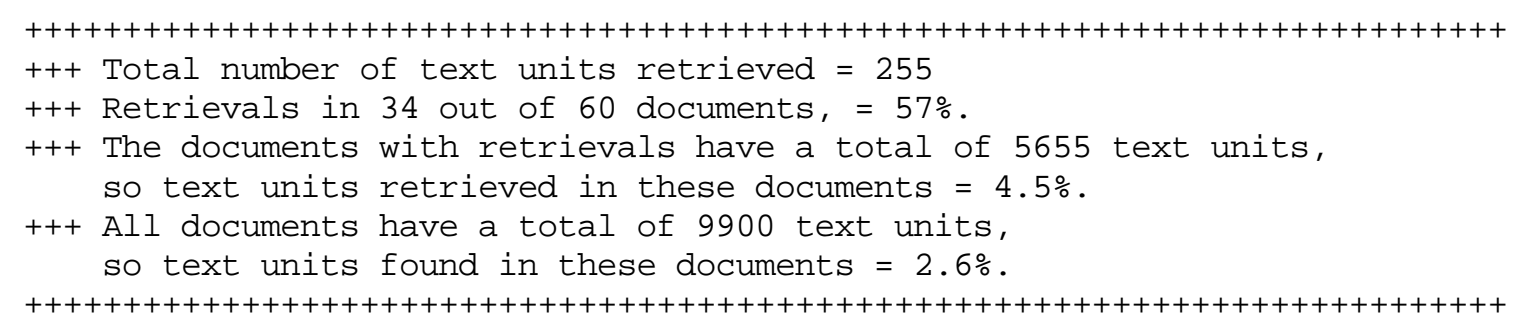

Como nos indica el informe que nos arrojó el programa Nvivo6, observamos que más de la mitad de participantes del estudio manifestó tener una valoración de mundo negativa, causada por motivos políticos.

$\mathrm{Al}$ relacionar la información recientemente expuesta con la Tabla 41, que nos indica que la totalidad de participantes del estudio tiene una visión de mundo negativa, vemos que más de la mitad lo atribuye a motivos políticos. Esto visto así, puede tener relación con la experiencia de prisión política y tortura. Para ello, 
indagaremos en los contenidos que presentan las 34 unidades que responden a la pregunta en cuestión, con el fin de estudiar su relación con la experiencia.

Al estudiar el contenido de las unidades a las que refieren una valoración de mundo negativa por motivos políticos, observamos cualitativamente que éstas en su mayoría refieren problemáticas de otros países, como guerras e injusticias que los EXPPS valoraron en el mundo, y que tienen una perspectiva político.

En cuanto a la relación de sus alusiones de mundo negativo por problemáticas políticas asociadas a la experiencia de prisión que experimentaron, vemos que ésta no es referida directamente por los EXPPS que hacen alusión a problemáticas políticas del país de Chile, y en el caso menor de quienes sí presentan una valoración negativa del mundo, lo hacen indirectamente como podemos observar en el caso que presentamos a continuación:

No yo me siento a disgusto por lo que está sucediendo, todas estas guerras y estas cosas que, que hay... Lo que nos ha pasado a nosotros. Porque aquí en Latinoamérica hubo un tiempo que pasaron tantas cosas crueles que uno se, se le grabaron en la, la mente que no las puede olvidar. Y además de eso sigue la cosa, porque claro, lo están pasando aquí en Latinoamérica, Lo están pasando en Europa, en medio oriente, tantas cosas que uno se informa por, por intermedio de la tecnología que hay ahora que uno sabe las cosas que están sucediendo en todas partes del mundo (varón, 69 años).

Esta información, nos indicaría que de los EXPPS que refirieron una valoración de mundo negativa, estas apreciaciones son hechas en base a problemas políticos mundiales que en pocas ocasiones asocian a la experiencia particular de prisión. Lo que nos hace pensar que la concepción de mundo negativa que los EXPPS presentan en la actualidad, se asocia a problemáticas sociales no relacionadas mayormente a la experiencia de prisión política y tortura vivida.

17. ¿Qué valor es el más aludidos por los EXPPS y qué relación tiene con la experiencia de prisión política?.

En cuanto a los valores aludidos por los EXPPS, observamos que la mayoría de ellos hizo referencia a éstos en sus discursos, de los que obtiene la moda la "honestidad", no alcanzando la media de sujetos de la muestra. 
Tabla. 148. Resultados para la respuesta 17

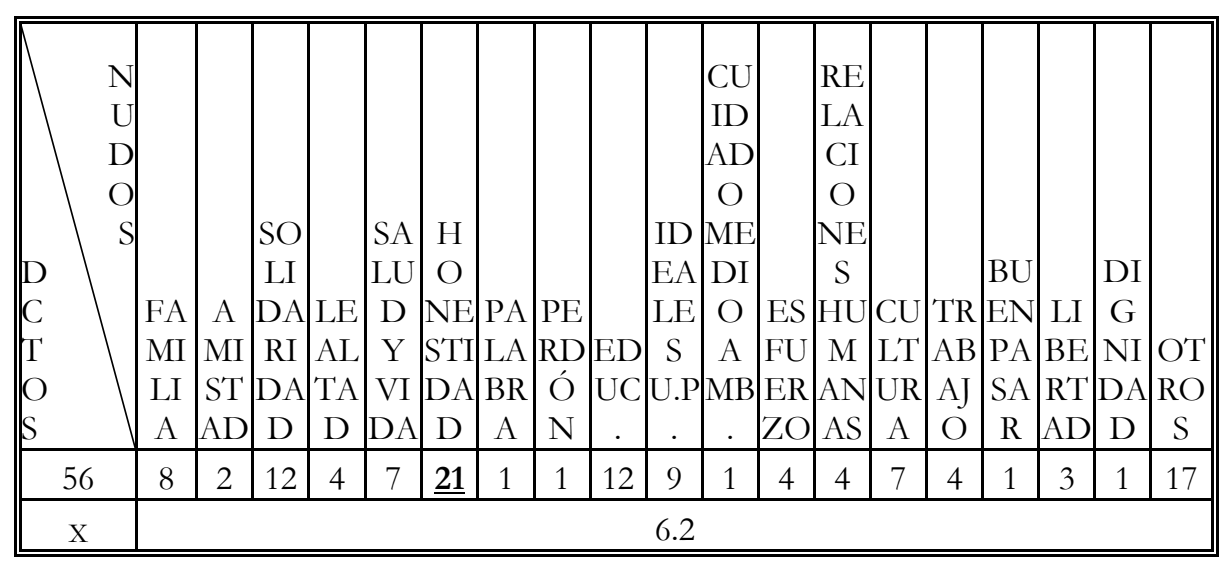

A continuación analizaremos cualitativamente la posible relación del valor más aludido por los EXPPS y la experiencia de prisión.

Bueno, la mayor el respeto no tanto, pero, pero honesta. Honesta. Honesta cabal. Tolerante. La honestidad y el respeto si.. Pa' mi el respeto es la base. Una persona que es respetuosa, ¿ya?, ef..., es honesta, ¿ah?. Respeta al otro como otro y no como, como, como yo quiero que sea; y mis hijos son así. Mi hijo con todas las dificultades que yo les puse, a mi me respetan, me aceptan, ¿ya?, me valoran, Los dos menores, ipuf!. (mujer, 43 años).

En este párrafo, podemos asociar la honestidad y el respeto como valores primordiales para la persona que emitió la U.T.s que hemos presentado. Creemos que aunque no se observa una relación directa a la experiencia de tortura (lo que era predecible porque la consigna fue "qué valores ha querido transmitir a sus hijos"), ambos valores aluden a algo que no ocurrió cuando fueron privados de su libertad por tener una ideología diferente a lo imperante a nivel político durante el régimen militar. Aparecería implícita la relación entre la experiencia de prisión y el valor aludido, que podría inferirse del párrafo, como por ejemplo en la línea que dice “....respeta al otro como otro y no como, como, como yo quiero que sea" (distinto en ideología y accionar político).

Del resto de personas que atribuyeron un valor a la honestidad, ninguno refiere directamente alguna relación con la experiencia de prisión. Como lo señala la U.T.s que presentamos a continuación:

\footnotetext{
Ah... yo creo que yo les he entregado a mis niños los mismos valores que mis padres me entregaron a mi, ser trabajador, ser honesto, aún dentro de la pobreza. A mis niños les enseñé eso, de lo cual me siento orgulloso hoy en día de lo que ellos son (varón, 62 años).
} 
18. De quienes hacen una valoración positiva del sentido que otorgan a la vida, ¿qué relación tiene esta valoración con la supervivencia a la experiencia de prisión?.

Para responder a la pregunta, hicimos una unión entre las U.T.s que refirieron una valoración global positiva del sentido de la vida ("categorías conceptuales"/ "presente"/ "Valor. global"/ "positiva") y satisfacción en cuanto a la valoración del disfrute de la vida ("categorías conceptuales"/ "presente" / "sentido de la vida"/ "valor. disfrute de vida" / "Satisfecho"). A continuación presentamos el reporte que nos arrojó el programa Nvivo6.

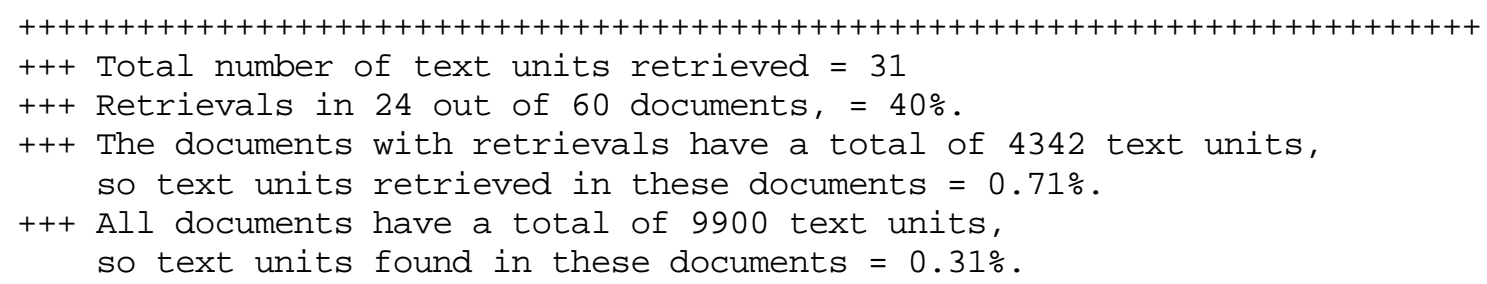

Tras hacer una lectura enfocada al contenido de las unidades textuales, observamos que de las personas que aludieron positivamente las dos temáticas que estudiamos en la pregunta 25, sólo una hizo mención de la experiencia de prisión en sus valoraciones. Esta persona comentó lo siguiente:

() a mi esposa, Cas relaciones claro las relaciones con mi esposa... también es importante, porque resulta de que... es importante porque con mi señora hemos pasado muchas cosas, ¿cierto?, como de juventud... a lo mejor ella estuvo ahi ... y aparte que tenemos nuestras hijas que, porque yo le doy un sentido a la vida porque yo pensé que ya desde el año 73 que ya no iba a existir. Entonces, ver que en estos momentos estoy vivo todavía, y veo a mis hijas y me satisface mucho en ese sentido (varón, 58 años).

Por su parte, la mayoría de los EXPPS que aludieron estas temáticas, refieren valoraciones asociadas a la familia en sus respuestas y otros factores independientes a la experiencia de prisión.

Sentido a la vida, 6ueno, en el caso mío, a mi vida, a mi vida son mis hijos, mis nietos. Esos son los que a mi me dan todos los días el ánimo, el... para seguir viviendo. Lo único que yo quiero es que me dé buena salud, para apoyar al que esté caído, eh... y estar fortalecida siempre, no perder mi lucidez, eso (mujer, 64 años).

De acuerdo a la revisión que realizamos de contenidos de personas que aludieron las dos temáticas que nos ocupan en la pregunta 25 , vemos que las alusiones positivas del sentido que otorgan a la vida, salvo en una persona, no se relacionan directamente con la experiencia de prisión política y tortura. Por lo que no podemos atribuir estas valoraciones al hecho de haber supervivido a la experiencia de prisión. 
19. En cuanto a la reparación, de las personas que refirieron insatisfacción en torno a las medidas gubernamentales, ¿qué porcentaje refirió que la reparación no es posible?

Para resolver esta pregunta, hicimos la intersección por sujetos con la ayuda de tablas coding de la sumatoria de todas las variables que aludieron insatisfacción de las distintas variables incluidas en el tema "reparación” / “informe Valech” (ver apéndice D), y en el nudo conceptual "reparación”/ "concepción” / "no es posible".

Tabla 149. Resultados para la respuesta 19

\begin{tabular}{||c|c|c||}
\hline \hline INTERSECCIÓN & \multicolumn{2}{|c|}{$\begin{array}{c}\text { INSATISFACCIÓN DE } \\
\text { MEDIDAS } \\
\text { GUBERNAMENTALES N } \\
=60\end{array}$} \\
\hline $\begin{array}{c}\text { Concepción de reparación: no } \\
\text { es posible N }=25\end{array}$ & Frec. & $\% \mathrm{~N}=60$ \\
\cline { 2 - 3 } & 25 & 42 \\
\hline
\end{tabular}

Como nos indica la Tabla 149, el 42\% de las personas que manifestaron insatisfacción con las medidas gubernamentales de reparación, considera que no es posible la reparación a la propia experiencia vivida de prisión política y/ o tortura. De esta información podemos interpretar por una parte, que los EXPPS en cuestión, refieren implícitamente en sus discursos que los hechos que experimentaron de prisión política, produjeron secuelas que no se borrarán jamás de sus vidas. Esto podría reflejar parte del impacto de la experiencia en sus vidas actuales.

Por otro lado, observamos que menos de la mitad de la muestra que en su totalidad manifestó insatisfacción ante las medidas gubernamentales de reparación, cree que la reparación no es posible. Lo que nos indicaría que sólo un grupo menor a la media de sujetos, refirió esta valoración, pudiendo estar la insatisfacción con las medidas gubernamentales, asociada a otros factores como aquellos comprendidos en las subcategorías que conforman esta rama de nuestro árbol conceptual.

Nos interesaba estudiar la interacción de los dos temas presentes en la Tabla 149, porque consideramos que la valoración de las medidas gubernamentales de reparación dependería mayoritariamente de la concepción de reparación que tuvieran los EXPPS. De haber sido así, pensaríamos que cualquier medida de reparación recibida sería considerada insatisfactoria, con independencia de los beneficios que comprendiera. No obstante, esto no se presentó así, lo que nos hace pensar que las medidas en sí son las que generan insatisfacción en los EXPPS chilenos. 
20. ¿Cuáles son los principales motivos por los que los EXPPS se sienten insatisfechos con las medidas gubernamentales recibidas?

Para responder a esta interrogante, hicimos una tabla coding de todos los nudos comprendidos en la categoría insatisfacción por medidas gubernamentales de reparación (datos que fueron presentados de manera agrupada en la Tabla 107), y de acuerdo a los resultados obtenidos, las modas por cada tipo de medida de reparación fueron obtenidas por las siguientes categorías:

\ Medidas económicas: Insuficiente

口 Medidas de salud (PRAIS) : salud general

๑ Medidas de educación: no heredable

๑ Medidas de vivienda: insatisfecho

De acuerdo a estos resultados, podemos observar que los EXPPS valoran que la pensión que reciben por la Ley Valech es insuficiente, no están conformes con el servicio de salud público al que tienen acceso, se sienten insatisfechos con que la beca de estudios universitarios que se les ha otorgado no sea heredable a los hijos, y manifiestan insatisfacción con los beneficios de vivienda.

A continuación un ejemplo de insuficiencia de las medidas económicas, y posteriormente otro ejemplo de insatisfacción por el carácter no heredable de las medidas de educación.

"() una buena reparación, sería, cómo se llama, que el gobierno reconociera que los 112 mil pesos actualmente acá en Chile, no se vive, no se come, no se paga arriendo"(mujer, 54 años).

$\mathcal{N}$ o, yo creo que no hay ninguna medida que subsane los hechos, porque no hay ninguna reparación que nos nos, nos, nos, nos pague el daño causado porque el daño no es solamente en to físico nuestro, sino que en lo psíquico en lo familiar, en todo en todo porque se ha transformado en todo, porque nuestros hijos no siempre pudieron estudiar. N Nuestros hijos como que heredaron nuestros mismos traumas provocados por esto otro. Vivimos la las limitaciones económicas para que nuestros hijos estudien. A hora nos gustaría si que las becas de las que hable la ley 19.992 sean traspasadas a nuestros hijos, o a nuestros nietos. En esas estamos, porque sino mis hijos ya son mayores y tienen una vida formada, pero los nietos, pero mis hijos fueron limitados en cuanto a su preparación para estudiar y esa limitación se ha ido transmitiendo a los nietos (varón, 58 años).

En efecto, al revisar el contenido de las unidades textuales que refirieron insatisfacción por las medidas educativas, vemos que la mayoría manifestó disconformidad con la imposibilidad de traspasar a los hijos la beca de estudios universitarios que el gobierno de Chile consideró dentro de las medidas de reparación. 
21. ¿Se sienten los EXPPS excluidos socialmente?

Tabla 150. Resultados para la respuesta 21

\begin{tabular}{||c|c|c|c|c|c|c|c||}
\hline \hline NUDOS & \multicolumn{9}{|c||}{ TENDENCIAS C $=\underline{55}$} & VALORACI \\
ÓN \\
GLOBAL \\
COCTS
\end{tabular}

Los datos de la Tabla 150, los hemos extraído de los resultados agrupados y presentados en la Tabla 59. En esta tabla observamos que sólo tres personas refieren directamente sentirse excluidos socialmente en la sociedad chilena. No obstante, vemos que todas aquellas tendencias que podríamos considerar "desfavorables" para la inclusión social de los EXPPS, fueron aludidas por casi la totalidad de la muestra. Dentro de las cuales, la "indiferencia" es la respuesta social percibida mayormente aludida (presente en alrededor de la media de sujetos participantes del estudio). Por su parte, la insatisfacción manifestada por los EXPPS de la respuesta de la sociedad chilena hacia el tema de los Derechos humanos en Chile, se presentó en más de la mitad de la muestra, y puede influir en la exclusión social de estas personas y en consecuencia, en la insatisfacción de sus necesidades interpersonales sociales.

A continuación estudiaremos el contenido de las U.T.s que refieren las valoraciones que consideramos que influyen en la percepción de exclusión social de los EXPPS.

Exclusión social:

Mira, yo creo que nos ven muy demasiado... nos siguen mirando como la, como la... como, como la basura que hay que echar debajo de la alfombra. o sea, eh... a nosotros se nos... se nos acalla y se nos, se nos, se nos burla (varón, 40 años).

Indiferencia:

Veo que hay una frialdad. Una frialdad. Todavía no, no, no sienten todavía, como ellos no pasaron lo que pasó uno. O sea, no hay ese, ese, cómo se llama, esa exigencia del pueblo chileno hacia los que nosotros fuimos víctimas. NNo hay ese tipo de cómo se llama de, no, no hay ese compromiso del pue6lo hacia nosotros (mujer, 53 años).

To creo que la sociedad chilena no está ni ahí. O sea, no, no to ha internalizado. Poco se ha internalizado con los compadres que sufrieron tanto, que fueron sumamente maltratados. Injusto, esto es así (varón, 52 años). 
Las ve lejanas. La sociedad chilena ve lejano. Si bien es cierto, que se lo ponen frente a las narices siempre lo ve lejano, lo ve lejano porque es tan brutal la realidad que genera una suerte de rechazo. Eh la gente se ha ido cegando, ha ido entumeciendo eh esa parte de la sensibilidad, y to peor de todo es que aquellos que se ciegan también es tan a nuestro juicio o a mi juicio afectados, la tortura no sólo fue para nosotros sino que fue para aquellos que no la recibieron, fue, fue científicamente direccionada para generar ese entumecimiento en la capacidad del sentir, de ser sensible. O es la política de disociación digamos de la realidad (varón, 54 años).

Jajaja, el Chile actual.. este es un país de Bilz y Pap (de fantasía) donde a nadie le importa nada. Donde a nadie... como que a nadie... cómo le dijera, como que somos un país que, que perdió la brújula hace rato. Basta ver los discursos por ejemplo de repente aparecía alguien diciendo aberraciones en la tele, del mismo gobierno, y alguien del mismo gobierno diciendo de los derechos

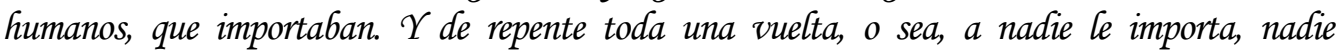
entiende... como que nadie entendiera nada (mujer, 52 años).

\section{Desconocimiento:}

Que, que no es un país solidario. La gente no, no le ha tomado asunto a, a eso porque yo creo que el 70 por ciento de la, de los jóvenes usted le pregunta y no saben ni lo que es un golpe de estado. Todavía creen que Allende se suicidó (varón, 62 años).

"Hay mucha desin... desinformación todavía con respecto a esto. produce rechazo y desconocimiento. Rechazo por desconocimiento, por desconocimiento" (varón, 62 años).

\section{Estigmatización:}

Mira yo al principio, la gente no creía, la gente creía que lo que, los que estábamos detenidos, la gente, éramos, éramos unos pa ellos unos asesinos, unos marxistas, porque la figura que nos daba el gobierno militar, donde mostraba todo tipo de, de cosas, en reafidad no eran...no eran hechos concretos, entonces la gente como que a uno lo miraba, como que extraño... (varón, 55 años).

Ah, eh, yo pienso que nos ven como bichos raros, y hay algunos que piensan de que nosotros no debiéramos estar vivos. Que nosotros tenían que habernos matado a todos. A todos los comunistas. Si, me he topado con gente que dice así me ha dicho eso. Si (varón, 72 años).

"Yo pienso que hay una gran parte que si, somos como peligrosos, somos una lacre para ellos y ojalá nos borraran del mapa" (mujer, 54 años).

Revisando las U.T.s que comprenden algunas de las tendencias desfavorables percibidas por los EXPPS, observamos que todas estas unidades refieren en alguna medida cierto grado de rechazo percibido por parte de los entrevistados de la sociedad chilena, atribuyendo como causa, su condición precisamente de EXPP. Esto creemos que podría incidir en la exclusión social que suelen presentar en distintos contextos otros grupos de supervivientes a experiencias de violencia política y tortura. 
22. ¿qué nudo hijo es el más aludidos por los EXPPS y qué relación tiene con la experiencia de prisión política?.

Para responder a esta interrogante, revisamos la tabla coding que hicimos de todas las categorías. Ésta nos indicó lo siguiente:

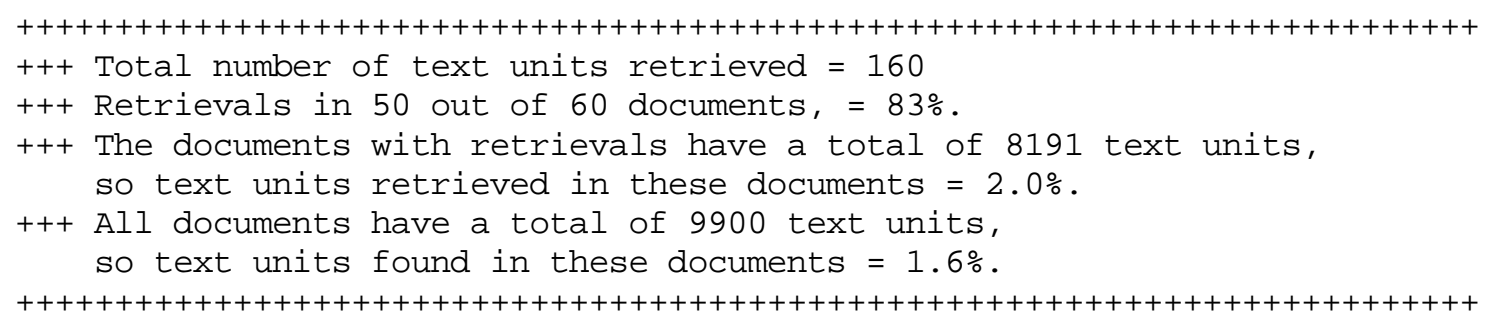

El programa Nvivo6 nos reportó que el nudo más aludido es el nudo conceptual del "presente"/ "ideología"/ "creencias"/ "religiosas o espirituales"/ "si". Este nudo se presentó en el 83\% de la muestra, con un total de 160 U.T.s equivalentes al 1.6\% de U.T.s codificadas en el proyecto. Lo que nos indica que la mayoría de los EXPPS entrevistados afirmaron tener creencias de este tipo, mencionándolo en aproximadamente 3 U.T.s cada uno.

23. ¿Qué tendencias se presentaron según frecuencias por sujeto en quienes aludieron sentirse solos a nivel de relaciones interpersonales actuales, y qué relación tiene con una concepción de mundo negativa?

Para responder a las dos interrogantes que conforman la pregunta 23, revisamos las frecuencias por nudos hijos para el tema “soledad" valorado por los EXPPS en sus relaciones interpersonales con la pareja, los hijos y los amigos. Esta información fue codificada en la información de las relaciones interpersonales del presente que fue indagada (“aspectos específicos de relación”). A continuación presentaremos las frecuencias de las respuestas obtenidas por sujeto para cada una de estas relaciones.

Tabla 151. Resultados para la pregunta 23

\begin{tabular}{|c|c|c|c|c|c|c|c|c|c|}
\hline $\mathrm{NU}$ & \multicolumn{3}{|c|}{ PAREJA N $=38$} & \multicolumn{3}{|c|}{ HIJOS N = 58} & \multicolumn{3}{|c|}{ AMIGOS N =49 } \\
\hline $\mathrm{S}$ & No & $\mathrm{Si}$ & Intermedio & No & $\mathrm{Si}$ & Intermedio & No & $\mathrm{Si}$ & Intermedio \\
\hline S. & $\underline{26}$ & 8 & 4 & $\underline{37}$ & 18 & 3 & $\underline{38}$ & 9 & 2 \\
\hline
\end{tabular}

La Tabla 151, presenta las respuestas de los participantes del estudio a la pregunta "con su (pareja/ hijos/ amigos) se siente solo?". 
Los resultados a la interrogante recién planteada, nos indican que más de la mitad de sujetos entrevistados aludió al tema de la percepción de soledad en relación a la pareja, los hijos y los amigos. Vemos así, que los EXPPS en su mayoría niegan sentirse solos en sus relaciones con la pareja, los hijos y los amigos, cuyas frecuencias superan la media de sujetos entrevistados en los dos últimos tipos de relaciones.

Quisimos hacer una interacción entre los nudos "si” de la Tabla 151, y las valoraciones que apuntan a una concepción de mundo negativa y que hemos agrupado según se ha explicitado en el capítulo IV. Sin embargo, vimos que todas las personas entrevistadas, presentan una concepción de mundo negativa. De esta información deducimos que quienes manifiestan soledad en sus relaciones interpersonales con la pareja, los hijos y los amigos, tienen una concepción de mundo negativa, que se presenta también en quienes no refieren sentirse solos con sus relaciones.

\subsection{PARTE VI. ANÁLISIS ESTADÍSTICO MEDIANTE LA APLICACIÓN DE LA PRUEBA DE $\boldsymbol{X}^{2}$ DE PEARSON PARA LAS VARIABLES DEMOGRÁFICAS SEXO, EDAD Y UBICACIÓN GEOGRÁFICA EN RELACIÓN A VARIABLES CONCEPTUALES SELECCIONADAS}

A continuación presentaremos aquellas variables conceptuales que relacionadas a las variables demográficas sexo, edad y zona geográfica, presentaron relaciones significativas a un nivel de significación estadística del 0.05 y con un grado de libertad, lo que nos permitió rechazar la hipótesis nula en todos estos casos, basándonos en la prueba de $\chi^{2}$ de Pearson. Para ello, presentaremos por cada variable demográfica que presentó este tipo de relaciones con una variable conceptual, una tabla resumen con los valores estadísticos, además de las tablas de contingencia por variables con el recuento de frecuencias. Comprendemos entonces que las diferencias de las variables demográficas con las variables conceptuales que están referidas en la lista de variables conceptuales pero no aparecen a continuación, presentan diferencias que estadísticamente se deben al azar.

a Variables demográficas

Sexo : Masculino - Femenino

Edad: Menor de 65 años - mayor de 65 años

Zona geográfica: Regiones - Capital 
- Variables conceptuales

\section{PRESENTE}

1. Relaciones interpersonales familiares $=$ satisfacción

2. Relaciones interpersonales familiares $=$ insatisfacción

3. Relaciones interpersonales sociales $=$ satisfacción

4. Relaciones interpersonales sociales $=$ insatisfacción

5. Valoración del Chile actual $=$ positiva

6. Valoración del Chile actual $=$ negativa

7. Concepción de mundo = negativa

8. Concepción de mundo $=$ positiva

\section{PASADO}

9. Relaciones interpersonales familiares $=$ satisfacción

10. Relaciones interpersonales familiares $=$ insatisfacción

11. Relaciones interpersonales sociales $=$ satisfacción

12. Relaciones interpersonales sociales $=$ insatisfacción

13. Concepción de mundo $=$ negativa

14. Concepción de mundo $=$ positiva

\section{PRISIÓN POLÍTICA}

15. Silencio-posterior $=$ no hizo

16. Silencio-posterior $=$ si hizo

17. Valoración de apoyo Post-Prisión = si tuvo

18. Valoración apoyo Post-Prisión $=$ no tuvo

19. Valoración rechazo Post-Prisión $=$ no vivió

20. Valoración rechazo Post-Prisión $=$ si vivió

21. Actitud post-prisión $=$ favorables

22. Actitud post-prisión $=$ desfavorables

23. Impacto en relaciones interpersonales y vida en general $=$ si percibe

24. Impacto en relaciones interpersonales y vida en general $=$ no percibe

25. Valoración superación experiencia $=$ no

26. Persecución política $=$ si vivió

\section{OTRAS VALORACIONES}

27. REPARACIÓN-Informe Valech = valoración positiva

28. REPARACIÓN-Informe Valech $=$ valoración negativa

29. Opinión sociedad chilena y DDHH = satisfacción

30. Opinión sociedad chilena y DDHH = insatisfacción 


\subsubsection{Variable sexo}

De las 30 variables conceptuales estudiadas con las variables de género, sólo dos de ellas presentaron diferencias estadísticamente significativas por género. A continuación estudiaremos estos resultados.

Tabla 152. Prueba de $\chi^{2}$ cuadrado para las variables 9 y 11 que presentan diferencias de género

\begin{tabular}{||c|c|c|c|c||}
\hline \hline VARIABLES & $\chi^{2}$ & GL & $\begin{array}{c}\text { SIG. } \\
\text { ASINTÓNICA } \\
\text { (BILATERAL) }\end{array}$ & $\begin{array}{c}\text { COEF. } \\
\text { CONTINGEN } \\
\text { CIA }\end{array}$ \\
\hline $\begin{array}{c}\text { 9. Pasado- Relaciones Interpersonales } \\
\text { Familiares -Satisfacción }\end{array}$ & 5.994 & 1 & 0.014 & 0.301 \\
\hline $\begin{array}{c}\text { 11. Pasado- Relaciones Interpersonales } \\
\text { Sociales -Satisfacción }\end{array}$ & 4.929 & 1 & 0,026 & 0,276 \\
\hline
\end{tabular}

Tabla 153. Contingencia para la variable sexo y la variable 9

\begin{tabular}{|c|c|c|c|c|}
\hline & & \multicolumn{2}{|c|}{$\begin{array}{l}\text { PASADO.RIP-FAM } \\
\text { SATISFACCIÓN }\end{array}$} & \multirow{2}{*}{$\begin{array}{c}\text { TOTAL } \\
0\end{array}$} \\
\hline & & 0 & 1 & \\
\hline \multirow[t]{2}{*}{ Documents } & Mujeres & 6 & 13 & 19 \\
\hline & Varones & 3 & 38 & 41 \\
\hline \multicolumn{2}{|l|}{ Total } & 9 & 51 & 60 \\
\hline
\end{tabular}

Los datos expuestos en la Tabla 152, nos indican que la satisfacción aludida por los EXPPS en cuanto a la valoraron que realizaron de sus relaciones interpersonales en el pasado, es dependiente de la variable sexo. Vemos en la tabla recuento, que estas diferencias apuntan a que son los hombres quienes predominantemente refieren satisfacción en estas relaciones. De acuerdo a lo anterior, rechazamos la hipótesis nula y aceptamos que hay relación estadística de la variable conceptual (9) con el género de los participantes que aludieron la temática.

Tabla 154. Contingencia para la variable sexo y la variable 11

\begin{tabular}{||l|l|r|r|r||}
\hline \hline \multicolumn{2}{||c|}{} & \multicolumn{2}{|c|}{$\begin{array}{c}\text { PASADO.RIP-SOC } \\
\text { SATISFACCIÓN }\end{array}$} & \multicolumn{1}{c||}{ TOTAL } \\
\cline { 3 - 5 } \multicolumn{2}{||c|}{} & 0 & 1 & 0 \\
\hline Documents & mujeres & 7 & 12 & 19 \\
\hline & varones & 5 & 36 & 41 \\
\hline Total & 12 & 48 & 60 \\
\hline
\end{tabular}


Los datos entregados en la tabla resumen para la variable 11 y la tabla de recuento respectiva, nos indican que existe una relación significativa entre la satisfacción expresada por los EXPPS en sus discursos, en términos de sus relaciones interpersonales sociales en el pasado. Se observa en la tabla recuento, que son los hombres quienes refieren mayoritariamente esta relación.

\subsubsection{Variable edad}

En cuanto a la variable edad, que estudiamos en relación a las 30 variables conceptuales que presentamos al principio de esta sección, observamos que dos variables conceptuales son dependientes a esta variable. A continuación presentamos los resultados.

Tabla 155. Prueba de $\chi^{2}$ cuadrado para las variables que presentan diferencias por edad para las variables 2 y 30

\begin{tabular}{||c|c|c|c|c||}
\hline VARIABLES & $\chi^{2}$ & GL & $\begin{array}{c}\text { SIG. } \\
\text { ASINTÓNICA } \\
\text { (BILATERAL) }\end{array}$ & $\begin{array}{c}\text { COEF. } \\
\text { CONTINGEN } \\
\text { CIA }\end{array}$ \\
\hline $\begin{array}{c}\text { 2. Presente - Relaciones interpersonales } \\
\text { familiares - insatisfacción }\end{array}$ & $6.271 \mathrm{~b}$ & 1 & 0.012 & 0.308 \\
\hline $\begin{array}{c}\text { 30.Otras valoraciones - Opinión sociedad } \\
\text { chilena y DDHH - Insatisfacción }\end{array}$ & $4.530 \mathrm{~b}$ & 1 & 0.033 & 0.265 \\
\hline
\end{tabular}

Tabla 156. Contingencia para la variable edad y la variable 2

\begin{tabular}{|c|c|c|c|c|}
\hline & \multicolumn{2}{|c|}{$\begin{array}{c}\text { PTE. RIP- } \\
\text { FAM.(insatisfacción) }\end{array}$} & \multirow{2}{*}{$\begin{array}{c}\text { Total } \\
0\end{array}$} \\
\hline & & 0 & 1 & \\
\hline \multirow[t]{2}{*}{ Documents } & mayor 65 & 6 & 5 & 1 \\
\hline & menor 65 & 9 & 40 & 4 \\
\hline \multicolumn{2}{|l|}{ Total } & 15 & 45 & 6 \\
\hline
\end{tabular}

Como observamos en las tabla resumen para la variable 2, hay relación estadísticamente significativa entre las variables edad e insatisfacción referida a las relaciones interpersonales familiares en la actualidad de los EXPPS. Vemos en la tabla recuento para esta variable, que quienes tenían menos de 65 años al momento de la entrevista, presentaron mayor insatisfacción general con sus familias en el presente, que las personas mayores de 65 años. 
Tabla 157. Contingencia para la variable edad y la variable 30

\begin{tabular}{||l|l|r|r|r||}
\hline \hline \multicolumn{2}{||c|}{} & \multicolumn{2}{|c|}{$\begin{array}{c}\text { OPINIÓN-SOC. CHI Y } \\
\text { DDHH (INSATISF.) }\end{array}$} & \multicolumn{2}{c||}{ TOTAL } \\
\cline { 3 - 5 } \multicolumn{2}{||c|}{} & 0 & 1 & 0 \\
\hline Documents & mayor 65 & 1 & 10 & 11 \\
\hline & menor 65 & 0 & 49 & 49 \\
\hline Total & 1 & 59 & 60 \\
\hline
\end{tabular}

La variable edad también se relaciona a la insatisfacción manifestada por los EXPPS en cuanto a la respuesta percibida por parte de la sociedad chilena ante los hechos de derechos humanos en Chile. Observamos así que son las personas menores de 65 años quienes manifiestan mayormente esta insatisfacción en relación a las personas mayores de 65 años. Lo que difiere significativamente.

A continuación presentamos el resumen de variables en las que existen diferencias por zona geográfica en las frecuencias de respuesta por sujetos.

Tabla 158. Prueba de $\chi^{2}$ cuadrado para las variables que presentan diferencias por zona geográfica para las variables $16,23,25$ y 24

\begin{tabular}{||c|c|c|c|c||}
\hline VARIABLES & $\chi^{2}$ & GL & $\begin{array}{c}\text { SIG. } \\
\text { ASINTÓNICA } \\
\text { (BILATERAL) }\end{array}$ & $\begin{array}{c}\text { COEF. } \\
\text { CONTINGENCIA }\end{array}$ \\
\hline $\begin{array}{c}\text { 16. Prisión política -Silencio posterior- si } \\
\text { hizo }\end{array}$ & $\begin{array}{c}4.043 \\
\mathrm{~b}\end{array}$ & 1 & 0.044 & 0.251 \\
\hline $\begin{array}{c}\text { 23. Prisión política - Impacto en relaciones } \\
\text { interpersonales y vida - si percibe }\end{array}$ & $\begin{array}{c}7.700 \\
\mathrm{~b}\end{array}$ & 1 & 0.006 & 0.337 \\
\hline $\begin{array}{c}\text { 25. Prisión política - Valoración superación } \\
\text { experiencia - No }\end{array}$ & $\begin{array}{c}6.484 \\
\mathrm{~b}\end{array}$ & 1 & 0.011 & 0.312 \\
\hline $\begin{array}{c}\text { 30. Otras valoraciones - Opinión sociedad } \\
\text { chilena y DDHH - insatisfacción }\end{array}$ & $\begin{array}{c}7.700 \\
\mathrm{~b}\end{array}$ & 1 & 0.006 & 0.337 \\
\hline
\end{tabular}

Tabla 159. Contingencia para la variable zona geográfica y la variable 16

\begin{tabular}{||l|l|r|r|rr||}
\hline \hline \multicolumn{2}{||c|}{} & \multicolumn{2}{|c|}{$\begin{array}{c}\text { PP-SILENCIO- } \\
\text { POSTERIOR-SI HIZO }\end{array}$} & \multicolumn{2}{c||}{ TOTAL } \\
\cline { 3 - 6 } \multicolumn{2}{||c|}{} & 0 & 1 & 0 \\
\hline Documents & Capital & 6 & 1 & 7 \\
\hline & Regiones & 24 & 29 & 53 \\
\hline Total & 30 & 30 & 60 \\
\hline \hline
\end{tabular}


Como nos indican las dos tablas que presentan antecedentes para la variable demográfica que alude a la situación geográfica de los EXPPS al momento de administración de la entrevista y la variable 16, existe una relación entre estas variables que es estadísticamente significativa. Lo que nos indica que la mayoría de personas que refirieron haber guardado silencio de su experiencia de prisión, residen en regiones del país.

Tabla 160. Contingencia para la variable zona geográfica y la variable 23.

\begin{tabular}{||l|l|r|r|r||}
\hline \hline \multirow{2}{*}{\multicolumn{2}{||c|}{}} & \multicolumn{2}{|c|}{$\begin{array}{c}\text { PP-IMPACTO EN RIP } \\
\text { Y VIDA-SI }\end{array}$} & \multicolumn{1}{c||}{ TOTAL } \\
\cline { 3 - 6 } \multicolumn{2}{||c|}{} & 0 & 1 & 0 \\
\hline Documents & Capital & 1 & 6 & 7 \\
\hline & Regiones & 0 & 53 & 53 \\
\hline Total & 1 & 59 & 60 \\
\hline
\end{tabular}

La variable "zona geográfica" está relacionada significativamente a la afirmación del impacto referido por los EXPPS de manera directa de la experiencia de prisión en aspectos de sus vidas y sus relaciones interpersonales. Son las personas de regiones quienes afirman percibir este impacto mayoritariamente en relación a las personas de la capital entrevistadas.

Tabla 161. Contingencia para la variable zona geográfica y la variable 25

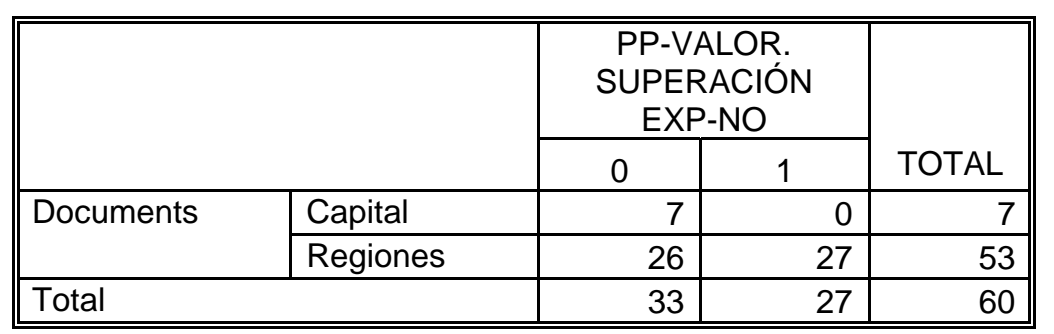

La misma relación presente para la variable 23, se presenta entre la variable demográfica "zona geográfica" y la valoración realizada por los EXPPS que aludieron a esta temática acerca de la superación de la experiencia de prisión, lo que fue negado exclusivamente por personas residentes en regiones de Chile. Por su parte, ninguna persona residente en la capital refirió no haber superado estas experiencias. 
Tabla 162. Contingencia para la variable zona geográfica y la variable 30

\begin{tabular}{||l|l|r|r|r||}
\hline \hline \multirow{2}{*}{\multicolumn{2}{||c|}{}} & \multicolumn{2}{|c||}{$\begin{array}{c}\text { OPINIÓN-SOC.CHI } \\
\text { Y DDHH } \\
\text { (INSATISF.) }\end{array}$} & \multirow{3}{*}{ TOTAL } \\
\cline { 3 - 4 } \multicolumn{2}{||c|}{} & 0 & 1 & 7 \\
\hline Documents & Capital & 1 & 6 & 7 \\
\cline { 2 - 4 } & Regiones & 0 & 53 & 53 \\
\hline Total & 1 & 59 & 60 \\
\hline
\end{tabular}

Por último, nuevamente vemos en los datos presentados en las tablas para la variable 30, que esta variable se relaciona significativamente con la variable "zona geográfica". Lo que nos indica que la insatisfacción referida por los EXPPS en cuanto a la respuesta percibida de la sociedad chilena frente a los hechos de derechos humanos en Chile, fue presentada mayoritaria y diferenciadamente por los EXPPS de regiones (quienes además aludieron en su totalidad a esta insatisfacción) por sobre aquellos de la capital.

\subsection{PARTE VII. ANÁLISIS CLUSTER DE VARIABLES AGRUPADAS Y SELECCIONADAS}

Por último, presentaremos los resultados obtenidos con el programa SPSS de un análisis cluster que realizamos con algunas de las categorías que estudiamos y presentamos en la parte VI de este capítulo. A continuación presentamos la representación gráfica o dendograma que nos arrojó el programa SPSS.

Debido al número de sujetos participantes del estudio, conformado por 60 EXPPS, nos vimos en la necesidad de reducir el número de variables, para lo que usamos dos criterios. El primero de ellos, fue elegir aquellas variables que dispusieran de su versión antagónica, y el segundo, aquellas que a nuestro juicio comprendían las dimensiones globales de las áreas indagadas en la entrevista en profundidad que administramos. Finalmente seleccionamos un total de 18 variables agrupadas, que incluyen variables o nudos hijos según la agrupación que especificamos en el capítulo IV.

Método: Se realizó un análisis de conglomerado jerárquico, con las 18 variables del estudio (que serán presentadas a continuación del dendograma), con las siguientes opciones:

Método de conglomeración: vinculación intergrupos

Medida: binaria, con distancia euclídea al cuadrado.

Este análisis se realizó a partir de la siguiente tabla: 
Tabla 162. Casos por variables para análisis de conglomerados jerárquicos

\begin{tabular}{|c|c|c|c|c|c|c|c|c|c|c|c|c|c|c|c|c|c|c|}
\hline 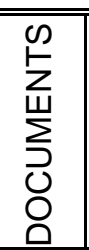 & 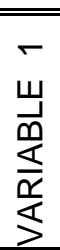 & 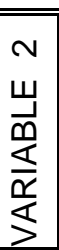 & 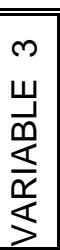 & 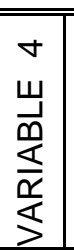 & 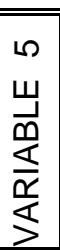 & 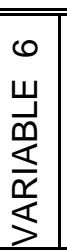 & 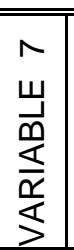 & 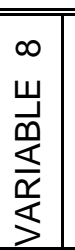 & 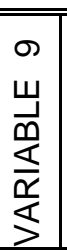 & 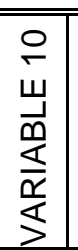 & 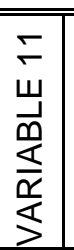 & 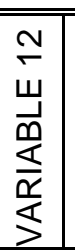 & 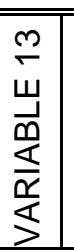 & 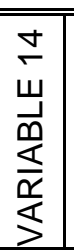 & 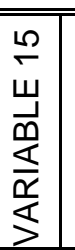 & 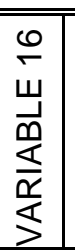 & 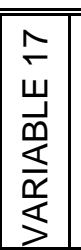 & 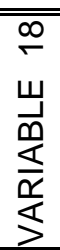 \\
\hline $\mathrm{V} 1$ & 1 & 1 & 1 & 1 & 0 & 1 & 1 & 1 & 1 & 1 & 1 & 1 & 0 & 1 & 0 & 0 & 0 & 0 \\
\hline M10 & 1 & 1 & 1 & 1 & 1 & 1 & 1 & 1 & 1 & 1 & 1 & 0 & 1 & 1 & 0 & 0 & 1 & 1 \\
\hline V11 & 1 & 1 & 1 & 1 & 1 & 1 & 1 & 1 & 0 & 1 & 1 & 0 & 0 & 1 & 0 & 0 & 0 & 1 \\
\hline M12 & 1 & 1 & 1 & 1 & 1 & 1 & 1 & 0 & 1 & 0 & 1 & 1 & 0 & 1 & 1 & 0 & 0 & 1 \\
\hline V13 & 1 & 1 & 1 & 1 & 1 & 1 & 1 & 1 & 1 & 1 & 1 & 1 & 1 & 0 & 0 & 0 & 1 & 0 \\
\hline M14 & 1 & 1 & 1 & 1 & 1 & 1 & 1 & 1 & 1 & 0 & 0 & 0 & 0 & 1 & 1 & 0 & 1 & 0 \\
\hline M15 & 1 & 1 & 1 & 1 & 1 & 1 & 1 & 1 & 1 & 1 & 1 & 1 & 1 & 1 & 0 & 1 & 0 & 0 \\
\hline V16 & 1 & 1 & 1 & 1 & 1 & 1 & 1 & 1 & 1 & 1 & 1 & 1 & 1 & 1 & 0 & 0 & 0 & 0 \\
\hline M17 & 1 & 1 & 1 & 1 & 1 & 1 & 1 & 1 & 1 & 1 & 1 & 0 & 1 & 0 & 0 & 0 & 1 & 1 \\
\hline M18 & 1 & 1 & 1 & 1 & 1 & 1 & 1 & 1 & 1 & 1 & 0 & 1 & 0 & 0 & 1 & 0 & 1 & 0 \\
\hline V19 & 1 & 1 & 1 & 1 & 1 & 1 & 1 & 1 & 1 & 1 & 0 & 1 & 0 & 0 & 1 & 0 & 0 & 0 \\
\hline $\mathrm{M} 2$ & 1 & 1 & 1 & 1 & 1 & 1 & 0 & 0 & 0 & 0 & 1 & 1 & 1 & 1 & 0 & 1 & 1 & 0 \\
\hline V20 & 1 & 1 & 1 & 1 & 1 & 1 & 1 & 1 & 1 & 1 & 1 & 0 & 0 & 0 & 0 & 0 & 0 & 0 \\
\hline V21 & 1 & 1 & 1 & 1 & 1 & 1 & 1 & 1 & 0 & 1 & 1 & 1 & 0 & 0 & 0 & 0 & 0 & 1 \\
\hline V22 & 1 & 1 & 1 & 1 & 1 & 0 & 0 & 1 & 0 & 1 & 1 & 0 & 0 & 1 & 1 & 0 & 1 & 0 \\
\hline V23 & 1 & 1 & 1 & 1 & 1 & 1 & 1 & 1 & 1 & 1 & 1 & 1 & 1 & 0 & 0 & 0 & 0 & 0 \\
\hline V24 & 1 & 1 & 1 & 1 & 1 & 1 & 1 & 1 & 1 & 1 & 0 & 1 & 0 & 1 & 1 & 1 & 0 & 0 \\
\hline V25 & 1 & 1 & 1 & 1 & 1 & 1 & 1 & 1 & 1 & 1 & 1 & 1 & 1 & 1 & 0 & 0 & 1 & 1 \\
\hline V26 & 1 & 1 & 1 & 1 & 1 & 1 & 1 & 0 & 1 & 1 & 0 & 1 & 1 & 1 & 0 & 0 & 0 & 1 \\
\hline V27 & 1 & 1 & 1 & 1 & 1 & 1 & 0 & 1 & 0 & 1 & 1 & 1 & 0 & 1 & 0 & 0 & 0 & 0 \\
\hline V28 & 1 & 1 & 1 & 1 & 1 & 1 & 1 & 1 & 1 & 1 & 1 & 1 & 1 & 0 & 0 & 0 & 0 & 1 \\
\hline M29 & 1 & 1 & 1 & 1 & 1 & 1 & 1 & 1 & 1 & 1 & 1 & 1 & 0 & 1 & 1 & 0 & 0 & 0 \\
\hline V3 & 1 & 1 & 1 & 1 & 1 & 1 & 1 & 0 & 1 & 1 & 1 & 0 & 1 & 1 & 0 & 0 & 0 & 1 \\
\hline V30 & 1 & 1 & 1 & 1 & 1 & 1 & 1 & 1 & 1 & 1 & 1 & 1 & 1 & 0 & 0 & 0 & 0 & 0 \\
\hline V31 & 1 & 1 & 1 & 1 & 1 & 1 & 0 & 1 & 1 & 1 & 1 & 1 & 1 & 1 & 0 & 0 & 1 & 0 \\
\hline V32 & 1 & 1 & 1 & 1 & 1 & 0 & 0 & 1 & 1 & 0 & 1 & 0 & 0 & 1 & 0 & 0 & 0 & 1 \\
\hline V33 & 1 & 1 & 1 & 0 & 1 & 1 & 1 & 1 & 1 & 1 & 1 & 0 & 0 & 1 & 0 & 0 & 0 & 0 \\
\hline V34 & 1 & 1 & 1 & 1 & 1 & 1 & 1 & 1 & 1 & 0 & 0 & 1 & 0 & 1 & 1 & 1 & 0 & 1 \\
\hline M35 & 1 & 1 & 1 & 1 & 1 & 1 & 1 & 1 & 1 & 1 & 0 & 1 & 1 & 0 & 0 & 0 & 0 & 0 \\
\hline V36 & 1 & 1 & 1 & 1 & 1 & 1 & 1 & 1 & 1 & 1 & 1 & 1 & 1 & 0 & 0 & 0 & 0 & 0 \\
\hline M37 & 1 & 1 & 1 & 1 & 1 & 1 & 0 & 1 & 1 & 1 & 1 & 1 & 1 & 1 & 0 & 0 & 1 & 0 \\
\hline V38 & 1 & 1 & 1 & 1 & 1 & 0 & 1 & 1 & 1 & 1 & 1 & 1 & 1 & 1 & 0 & 0 & 0 & 1 \\
\hline M39 & 1 & 1 & 1 & 1 & 1 & 1 & 1 & 0 & 1 & 0 & 1 & 1 & 1 & 1 & 0 & 1 & 0 & 1 \\
\hline V4 & 1 & 1 & 1 & 1 & 1 & 1 & 1 & 1 & 0 & 0 & 1 & 0 & 0 & 1 & 0 & 1 & 0 & 0 \\
\hline V40 & 1 & 1 & 1 & 1 & 1 & 1 & 1 & 1 & 1 & 1 & 1 & 1 & 1 & 0 & 0 & 0 & 0 & 1 \\
\hline M41 & 1 & 1 & 1 & 1 & 1 & 1 & 1 & 1 & 1 & 1 & 1 & 1 & 1 & 1 & 0 & 0 & 0 & 0 \\
\hline M42 & 1 & 1 & 1 & 1 & 1 & 1 & 1 & 1 & 0 & 0 & 1 & 1 & 0 & 1 & 0 & 0 & 0 & 0 \\
\hline V43 & 1 & 1 & 1 & 1 & 1 & 1 & 1 & 1 & 1 & 1 & 1 & 1 & 1 & 1 & 0 & 1 & 1 & 0 \\
\hline V44 & 1 & 1 & 1 & 1 & 1 & 1 & 1 & 1 & 1 & 1 & 1 & 1 & 0 & 0 & 1 & 0 & 0 & 0 \\
\hline V45 & 1 & 1 & 1 & 1 & 1 & 1 & 1 & 1 & 0 & 1 & 0 & 1 & 0 & 0 & 1 & 0 & 0 & 1 \\
\hline V46 & 1 & 1 & 1 & 1 & 1 & 1 & 1 & 1 & 1 & 1 & 1 & 0 & 0 & 0 & 1 & 0 & 0 & 0 \\
\hline V47 & 1 & 1 & 1 & 1 & 1 & 1 & 1 & 1 & 1 & 1 & 0 & 0 & 1 & 0 & 0 & 0 & 1 & 0 \\
\hline V48 & 1 & 1 & 1 & 1 & 1 & 1 & 1 & 1 & 1 & 1 & 0 & 1 & 1 & 0 & 0 & 0 & 0 & 1 \\
\hline M49 & 1 & 1 & 1 & 1 & 1 & 1 & 1 & 1 & 0 & 0 & 1 & 1 & 0 & 1 & 1 & 0 & 0 & 0 \\
\hline V5 & 1 & 1 & 1 & 1 & 1 & 1 & 1 & 1 & 1 & 0 & 1 & 0 & 0 & 1 & 1 & 0 & 1 & 0 \\
\hline M50 & 1 & 1 & 1 & 1 & 1 & 1 & 1 & 0 & 1 & 0 & 1 & 0 & 0 & 1 & 0 & 0 & 0 & 0 \\
\hline M51 & 1 & 1 & 1 & 1 & 1 & 1 & 1 & 1 & 1 & 1 & 0 & 1 & 0 & 1 & 1 & 0 & 0 & 0 \\
\hline
\end{tabular}




\begin{tabular}{|l|l|l|l|l|l|l|l|l|l|l|l|l|l|l|l|l|l|l||}
\hline \hline M52 & 1 & 1 & 1 & 1 & 1 & 1 & 1 & 0 & 1 & 1 & 1 & 1 & 0 & 0 & 1 & 0 & 1 & 0 \\
\hline V53 & 1 & 1 & 1 & 1 & 1 & 1 & 1 & 1 & 1 & 1 & 1 & 1 & 1 & 1 & 0 & 1 & 0 & 0 \\
\hline V54 & 1 & 1 & 1 & 1 & 1 & 1 & 1 & 1 & 1 & 1 & 1 & 1 & 1 & 0 & 0 & 0 & 0 & 0 \\
\hline V55 & 1 & 1 & 1 & 1 & 1 & 1 & 1 & 1 & 1 & 0 & 1 & 1 & 1 & 0 & 0 & 0 & 0 & 0 \\
\hline V56 & 1 & 1 & 1 & 1 & 1 & 1 & 1 & 1 & 1 & 1 & 1 & 1 & 1 & 0 & 0 & 0 & 1 & 1 \\
\hline V57 & 1 & 1 & 1 & 1 & 1 & 1 & 0 & 1 & 1 & 1 & 1 & 0 & 1 & 0 & 0 & 0 & 1 & 0 \\
\hline V58 & 1 & 1 & 1 & 1 & 1 & 1 & 0 & 1 & 1 & 1 & 0 & 0 & 1 & 0 & 0 & 0 & 0 & 1 \\
\hline V59 & 1 & 1 & 1 & 1 & 1 & 0 & 1 & 1 & 1 & 1 & 1 & 0 & 1 & 1 & 0 & 0 & 0 & 0 \\
\hline M6 & 1 & 1 & 1 & 1 & 1 & 1 & 1 & 0 & 1 & 1 & 1 & 0 & 0 & 1 & 0 & 0 & 1 & 0 \\
\hline V60 & 1 & 1 & 1 & 1 & 1 & 1 & 1 & 1 & 0 & 1 & 0 & 1 & 1 & 1 & 0 & 0 & 0 & 0 \\
\hline M7 & 1 & 1 & 1 & 1 & 1 & 0 & 1 & 1 & 1 & 1 & 0 & 1 & 1 & 0 & 0 & 0 & 0 & 0 \\
\hline V8 & 1 & 1 & 1 & 1 & 1 & 1 & 1 & 0 & 1 & 1 & 0 & 1 & 0 & 1 & 1 & 0 & 0 & 0 \\
\hline V9 & 1 & 1 & 1 & 1 & 1 & 1 & 0 & 1 & 1 & 1 & 1 & 1 & 1 & 1 & 0 & 0 & 0 & 0 \\
\hline
\end{tabular}

Se obtuvo la siguiente representación gráfica (dendograma), que pasamos a comentar:

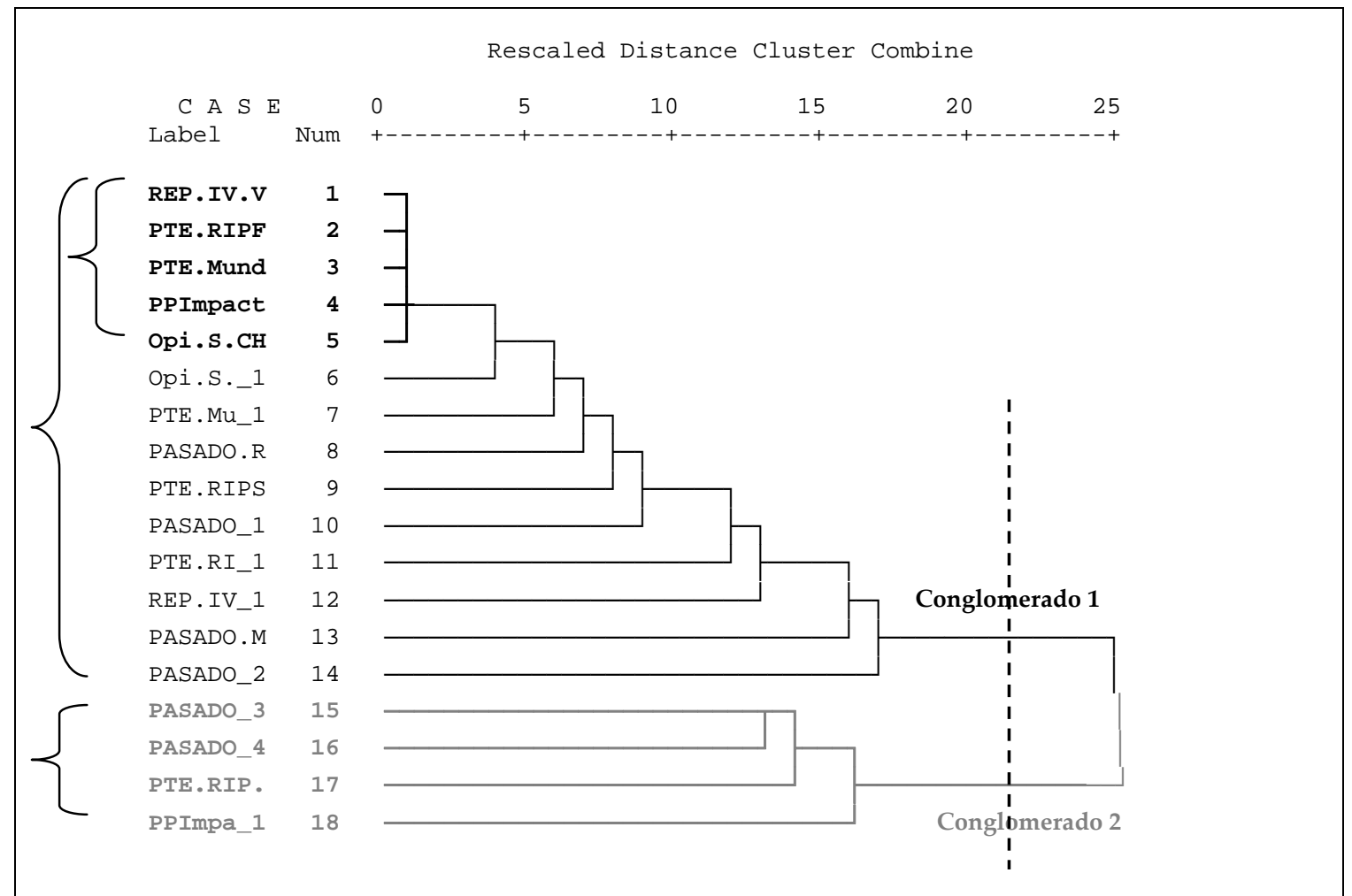

FIGURA 8. Dendograma 
Tabla 164. Variables para análisis de conglomerados jerárquicos

\begin{tabular}{||rll|}
\hline $\mathbf{1}$ & REP.IV.V & REPARACIÓN. Informe Valech. Valoración Negativa \\
\hline $\mathbf{2}$ & PTE.RIPF & PRESENTE. Relaciones interpersonales familiares - satisfacción \\
\hline $\mathbf{4}$ & PTE.Mund & PRESENTE. Valoración de mundo Negativa \\
\hline $\mathbf{5}$ & Opi.S.CH & Prisión Política - Valor. Impacto en relac. interpersonales y VIDA en general Si percibe. \\
\hline & & \\
\hline 6 & Opi.S._1 & Opinión Sociedad Chilena y Derechos Humanos - satisfacción \\
\hline 7 & PTE.Mu_1 & PRESENTE. Valoración de mundo Positiva \\
\hline 8 & PASADO.R & PASADO. Relaciones interpersonales familiares - satisfacción \\
\hline 9 & PTE.RIPS & PRESENTE. Relaciones interpersonales sociales - satisfacción \\
\hline 10 & PASADO_1 & PASADO. Relaciones interpersonales sociales - satisfacción \\
\hline 11 & PTE.RI_1 & PRESENTE. Relaciones interpersonales familiares - insatisfacción \\
\hline 12 & REP.IV_1 & REPARACIÓN. Informe Valech. Valoración Positiva \\
\hline 13 & PASADO.M & PASADO. Valoración de mundo Positiva \\
\hline 14 & PASADO_2 & PASADO. Relaciones interpersonales familiares - insatisfacción \\
\hline & & \\
\hline 15 & PASADO_3 & PASADO. Valoración de mundo Negativa \\
\hline 16 & PASADO_4 & PASADO. Relaciones interpersonales sociales - insatisfacción \\
\hline 17 & PTE.RIP. & PRESENTE. Relaciones interpersonales sociales - insatisfacción \\
\hline 18 & PPImpa_1 & Prisión Política - Valor. impacto en relac. interpersonales y VIDA en general No percibe. \\
\hline
\end{tabular}

Observamos que el dendograma parte de las 18 variables que queremos conocer si se conglomeran jerárquicamente. Si utilizamos como criterio de división de conglomerados donde la longitud de la distancia relativa se hace grande, es decir donde realiza el salto más brusco (Martín, Morán y Albajar, 1999), observamos dos conglomerados muy claros, uno conformado por cuatro variables (lo hemos marcado en gris ) y el otro por el resto de las variables.

Las variables del segundo conglomerado $(15,16,17$ y 18) que refieren insatisfacción en el pasado y el presente de las relaciones interpersonales sociales (16 y 17), la valoración en el pasado del mundo de manera negativa (15), y la no percepción del impacto en la vida y relaciones interpersonales de la experiencia de prisión (18), presentan atributos que les asemejan entre sí y se diferencian de las variables restantes que conforman el primer conglomerado. Hay que decir que tardan mucho en conglomerarse, por lo que estas variables están relacionadas, pero no son coincidentes en los diferentes testimonios recogidos. 
Primer conglomerado. En este primer conglomerado se puede observar que hay cinco variables (1, 2, 3, 4 y

5) que se conglomeran rápidamente, por lo que son coincidentes en los testimonios recogidos.

Esto significa que están íntimamente relacionadas:

1. REPARACIÓN. Informe Valech. Valoración Negativa

2. PRESENTE. Relaciones interpersonales familiares - satisfacción

3. PRESENTE. Valoración de mundo Negativa

4. Prisión Política - Valor. Impacto en relaciones interpersonales y VIDA en general - Si percibe

5. Opinión Sociedad Chilena y Derechos Humanos - Insatisfacción

Podemos ver que las variables "1" (insatisfacción con medidas del Informe Valech), y "2" (satisfacción en presente de relaciones interpersonales familiares), presentan la misma distancia que las variables “3” (valoración negativa del mundo en el presente), "4" (Si percibe el impacto de la prisión política en vida y relaciones interpersonales) y "5" (insatisfacción en relación a la respuesta de sociedad chilena con los derechos humanos). Lo que nos indica que son las más parecidas de todas las variables.

Las relaciones que pueden existir entre estas variables, pueden residir en que uno de los motivos principales de la insatisfacción que los EXPPS manifestaron de las medidas gubernamentales de reparación, se debe la imposibilidad de heredar las medidas otorgadas. Creemos que si ellos valoran satisfactoriamente sus relaciones interpersonales en el presente con sus familias, estarán a favor de que estos beneficios puedan traspasarse a la pareja y los hijos en caso de muerte o en el caso de la beca de educación profesional por ejemplo, cuando la víctima directa no desee estudiar.

La insatisfacción con la que los EXPPS valoran las medidas gubernamentales recibidas, creemos que puede relacionarse a una concepción de mundo negativa. Esta insatisfacción, aparece relacionada al impacto percibido de la experiencia de prisión en sus vidas y sus relaciones interpersonales. De acuerdo a esta última percepción, si los EXPPS sostienen que la experiencia de prisión ha afectado distintos ámbitos de sus vidas y sus relaciones interpersonales, el tema de la reparación gubernamental creemos que afectará en sus valoraciones de mundo y otras personas. Siguiendo esta tendencia, vemos que otra variable que se presenta a la misma distancia que las anteriores, es la insatisfacción en cuanto a la respuesta percibida de la sociedad chilena en el tema de los derechos humanos.

Las dos últimas variables, sumadas a aquella que refiere una concepción de mundo negativa, y la insatisfacción por las medidas gubernamentales de reparación, podríamos considerar que tienen un 
denominador común que es una valoración negativa de aspectos externos a la vida individual y familiar de los EXPPS, pudiendo estar asociados a la experiencia de prisión. Lo que puede verse reflejado en la similitud de estas variables con aquella que refiere la percepción del impacto de la experiencia de prisión en sus vidas.

El resto de las variables se van conglomerando progresivamente, por lo que comparten cuestiones en común, pero también aportan aspectos diferentes en los diferentes testimonios, ya que si fueran los valores coincidentes deberían conglomerarse antes. 
CAPÍTULO VI DISCUSIÓN. 
Privación de libertad y tortura política en Chile (1973-1990) 
Al llegar a este momento de la investigación, creemos haber conocido una multiplicidad de factores que influyen en el impacto emocional y social de la privación de libertad y tortura por motivos políticos, en un grupo de chilenos que vivieron estas experiencias hace más de 30 años.

A continuación, haremos la discusión que girará en torno al impacto emocional y social de la privación de libertad y tortura por motivos políticos en sus supervivientes chilenos observado según la teoría de las relaciones interpersonales básicas de López (2008) y otras teorías afines; y el aporte que supone el diseño metodológico que guió nuestro estudio basado en el análisis textual con la ayuda del programa informático QSR Nvivo 6, basado en la metodología cualitativa de análisis de contenido.

Nuestro interés investigativo, buscó desde una perspectiva histórica, establecer relaciones entre la satisfacción de las necesidades interpersonales emocionales y sociales de la muestra estudiada y variables demográficas y conceptuales que establecimos en base a aspectos emocionales y sociales, previamente estudiada en población superviviente a experiencias de prisión política y tortura en otros países, en combinación con aspectos relevantes desde el marco teórico que sustenta nuestro estudio. También estudiamos la motivación de la participación política actual de los EXPPS entrevistados y su relación con problemáticas actuales presentes, que están asociadas a la experiencia de prisión. Todo lo que nos indicará aspectos que pueden incidir en el impacto de la prisión política en sus vidas.

El orden de presentación de la información de los párrafos siguientes, comprenderá en primer lugar la discusión de las temáticas más omitidas en los participantes a nivel inter-sujeto; en segundo lugar, aquellos hallazgos asociados a factores contextuales de las problemáticas con que los EXPPS han tenido que lidiar desde la experiencia de prisión hasta la actualidad, que pueden haber incidido o incidir en el impacto que estudiamos, que en muchos temas corresponden a los temas más aludidos. También hemos incluido en este apartado, otros temas que fueron los más aludidos por los participantes; y en tercer lugar y considerando todo lo anterior, una sección de los hallazgos referidos a las necesidades emocionales y sociales que estudiamos en nuestra investigación.

Nuestro enfoque histórico a la hora de indagar las temáticas que consideramos relevantes para entender el impacto emocional y social de la experiencia de prisión y tortura en sus supervivientes, nos permitió detectar aspectos que influyeron en el impacto que estudiamos, y que se presentaron durante la prisión, en los años posteriores a esta experiencia, y en la actualidad. Creemos que esta diferenciación aporta conocimientos al entendimiento de nuestro objeto de estudio y a nivel social, da a conocer las principales problemáticas que presentan los EXPPS que estudiamos, y que inciden negativamente en el 
impacto de experiencias de prisión política y tortura en sus supervivientes. Este último aspecto, es un aporte social de nuestra investigación, para estas personas y la sociedad chilena, además de poblaciones supervivientes a estas experiencias de otros países con características similares.

\subsection{OMISIONES}

El sufrimiento aludido directamente, las dificultades laborales, sociales y políticas con las que se enfrentaron los EXPPS desde su liberación, y los síntomas de enfermedades y enfermedades asociadas a la misma experiencia de prisión, fueron los temas más omitidos por los participantes del estudio. Creemos que estos temas, refieren aspectos desfavorables con los que tuvieron que lidiar durante sus vidas con posterioridad a la experiencia de prisión, y que en la actualidad probablemente generan dolor en ellos por la dificultad que estos hechos han significado para su supervivencia. Vemos así, que la tendencia intencional o no, por parte de los EXPPS entrevistados, a silenciar estos hechos hacia los demás y hasta hacia ellos mismos, se debe a los sentimientos dolorosos o adversos que puedan generar sus recuerdos. Todo lo que nos indica un impacto emocional en sus vidas, de la experiencia de privación de libertad y tortura por motivos políticos.

El criterio que empleamos para determinar esta tendencia a la omisión, fue el haber realizado preguntas acerca de las temáticas en cuestión, a todos los participantes del estudio, las que en su mayoría no fueron respondidas o bien fueron respondidas con evasivas.

\subsubsection{Sufrimiento y dificultades producidos desde la experiencia de prisión y aludidos directamente, y su incidencia en el impacto estudiado}

En general, y como hemos referido recientemente, observamos que los participantes del estudio omitieron el sufrimiento vivido en prisión. Esto se evidenció en sus respuestas al ser consultados directamente sobre esta temática, habiendo respondido con evasivas o de manera no especificada.

De acuerdo a esta tendencia en sus discursos, podríamos pensar que los participantes del estudio, no sufrieron en prisión. Pero tenemos antecedentes demográficos obtenidos de ellos mismos, que nos señalan que en su mayoría estuvieron privados de su libertad en el período reconocido oficialmente como el más represivo del régimen militar en Chile, lo que nos indica que es muy probable que la mayoría de ellos, hayan supervivido a experiencias de cautiverio crueles y dolorosas, y por lo tanto, hayan sufrido severamente en prisión. Todo lo que nos permite sostener que el sufrimiento 
causado en prisión, es un tema difícil de abordar en la actualidad para los EXPPS entrevistados, probablemente porque no ha sido elaborado aún.

Esta tendencia difirió a la hora de aludir la severidad del sufrimiento vivido en los compañeros políticos, cuyas alusiones son referidas en los discursos de los participantes del estudio de manera abierta y espontánea. Esto nos indicaría que para estas personas es más fácil referirse al sufrimiento ajeno de la experiencia de prisión que al experimentado en sus vidas, y/ o que perciben que el sufrimiento ajeno padecido por sus compañeros políticos fue superior al experimentado por ellos mismos. Lo que nos puede dar indicadores indirectos del sufrimiento que padecieron en prisión, producto de presenciar el sufrimiento que fue causado a sus compañeros en las mismas condiciones.

Esta tendencia a la omisión del sufrimiento vivido en prisión, concuerda con la presencia de un sentimiento de culpa y vergüenza observada en supervivientes a experiencias de tortura política, quienes experimentan estos sentimientos por el hecho de haber supervivido a estas experiencias, a diferencia de compañeros que murieron en cautiverio (Turner y Gorst-Unworst; 1993). Al respecto, la alusión directa a la muerte en otros EXPPS en prisión, que fue aludida por un grupo cercano a la media de los participantes, puede ser reflejo de este sentimiento de culpa y las omisiones asociadas.

Otra explicación, refiere la presencia de efectos contextuales y políticos asociados a las experiencias de violencia política, que impiden que los supervivientes manifiesten el sufrimiento ocasionado en estas experiencias (Lira et al., 1989). Lo que nos indica la presencia de factores contextuales desfavorables para la superación del sufrimiento asociado a la experiencia de prisión. Estudiaremos estos factores posteriormente.

El hallazgo en cuestión, coincide con la tendencia presente en población superviviente al Holocausto, cuyas víctimas viven de por vida negando el sentimiento de tristeza, con un sufrimiento mental crónico causado por estas experiencias, sin buscar ayuda. Lo que nos indicaría la presencia actual del sufrimiento producido por la experiencia de prisión política en sus vidas.

La omisión del sufrimiento entendida como la inhibición de la expresión de emociones negativas, es entendida por la teoría del apego, como temor a alienarse a los demás, y en consecuencia, es una característica de un patrón de apego inseguro (Mikulincer y Shaver, 2003). Aunque no podemos establecer conclusiones del patrón de apego de los participantes de acuerdo a indicadores aislados como este. 
Lo más probable es que como las personas evitativas prefieran defenderse de los recuerdos dolorosos, no activándolos en su memoria y, por tanto, no hablando de ellos.

\subsubsection{Tortura}

La misma tendencia a la omisión se presentó en los entrevistados en torno a la afirmación directa de haber sido víctimas de tortura, tema que estuvo presente en un mínimo de discursos. Pero que fue indirectamente referido mediante la alusión a las secuelas de la tortura que presentaron con posterioridad al período de prisión y en la actualidad.

Nosotros creemos que esta tendencia se debe, a que el ejercicio de la tortura produjo un gran sufrimiento en sus víctimas, probablemente aún presente en sus vidas, lo que hizo que optaran por mantenerlo en silencio. También creemos que tales omisiones pueden deberse a una dificultad implícita en ellos para comunicar emociones asociadas, lo que concebimos como la presencia de un impacto emocional aún presente en sus vidas.

La omisión directa de referencias a la tortura en sus vidas por parte de los participantes, puede relacionarse a las dificultades existentes a la hora de delimitar hechos de tortura y violencia política (e. g. Garretón, 2004); y en nuestro estudio, vimos que a excepción de una persona, todos los participantes refirieron haber sido víctimas de algún tipo de maltrato o tortura durante su estancia en prisión. A lo que sumamos la consideración del padecimiento de tortura por hechos de presenciar la tortura en otros.

Lo anterior, nos permite considerar que todos los EXPPS que entrevistamos supervivieron a experiencias de tortura, y la tendencia predominante a la omisión, nos remite al sufrimiento que estas experiencias provocaron en sus vidas cuando ocurrieron y que, en un intento de evitar el recuerdo, prefieren silenciar.

Esta tendencia a la omisión de las experiencias de tortura experimentadas en sus vidas, concuerda con estudios de supervivientes de estas experiencias que han sido evaluados en Europa (e. g. Barker, 1992).

Para los supervivientes de experiencias de prisión política y tortura, creemos que es una tarea imposible, la de lograr olvidar tales experiencias. Por su parte, el hacer "como sî" no ha ocurrido nada, puede limitar a las víctimas en su forma de enfrentar y elaborar los recuerdos. Lo que sumado a factores 
contextuales como acontecimientos posteriores asociados a la impunidad vivida en Chile durante muchos años, afecta negativamente en el desarrollo de estas personas.

\subsubsection{Percepción de rechazo social}

El rechazo percibido con posterioridad a la experiencia de prisión, fue aludido escasamente por las personas entrevistadas, pero ENTRE quienes lo aludieron, todos refirieron percibirlo en la actualidad.

Creemos que este rechazo pudo haber sido percibido por la mayoría de los EXPPS entrevistados, y significó para ellos una dificultad con la que tuvieron que lidiar cuando fueron liberados. Esta percepción probablemente modificó sus estilos de relación a nivel social, y con ello influir negativamente en la satisfacción de sus necesidades sociales. La omisión en cuestión, podría referir nuevamente la tendencia a la omisión de aspectos dolorosos y difíciles en sus vidas y ser parte del impacto que estudiamos.

Creemos que el objetivo social de la tortura de atemorizar tanto a víctimas directas como a sociedades enteras, afectó en la sociedad y por ello en la respuesta social negativa percibida por los EXPPS participantes. Por otro lado, coincide con la tendencia mundial presente en sociedades que han presenciado directamente procesos de violencia política y tortura en masas, en que sus integrantes tienden a percibir a las víctimas directas como amenazantes, convirtiéndose en los principales constructores de la "conspiración del silencio" (Becker, 2003). Todo lo que nos confirmaría el impacto de estos hechos en la sociedad en general (e. g. Martín-Baró, 1988).

Este aspecto es sumamente relevante, si consideramos que la disrupción del orden civil que se produce en escenarios en que se emplea la tortura y los abusos relacionados, quebranta redes sociales, sistemas de justicia, servicios de salud y otras estructuras de apoyo, que deberían ser elementos favorecedores del reestablecimiento del entorno para el superviviente del trauma (Silove, 1999). Lo que dificultó aún más la supervivencia de los EXPPS chilenos.

Por otro lado, vemos que la participación política presente en la vida actual de la mayoría de los participantes del estudio, nos revela que la tortura no logró su objetivo de quebrantar ideológicamente a los opositores, pues ellos en su mayoría han mantenido su rol de dirigentes políticos. Creemos que este es un aspecto positivo en sus vidas, y que podría favorecer la superación de la experiencia traumática de la prisión y tortura política, porque les permitiría continuar con la consecución de ideales políticos que 
defendieron desde antes de la experiencia de prisión y encontrar un canal para expresar sus sentimientos asociados a la vulneración de derechos humanos que vivieron al ser privados de su libertad y torturados por presentar un pensamiento político distinto al del gobierno militar.

\subsubsection{Estado de salud mental}

Según los hallazgos obtenidos, y desde la postura del DSM-IV para el SEPT, la presencia de síntomas asociados a la experiencia de prisión y principalmente a la tortura, fue otra temática que en general no estuvo presente en los discursos de los EXPPS. De acuerdo a esta tendencia, y al planteamiento previamente expuesto, no podemos establecer la ausencia del síndrome en cuestión, en la muestra. Pero podríamos pensar que de presentarse su sintomatología, los EXPPS pueden tender a omitirla como otras temáticas que prefieren no aludir.

En todo caso, debe tenerse en cuenta que han pasado muchos años y que es muy posible que muchos de los que llegaran a sufrir estrés postraumático pudieron superarlo hace mucho tiempo, siendo éste un recuerdo que prefieren olvidar.

Sin embargo, podemos decir, según los antecedentes históricos de los sucesos de violencia política y tortura en Chile, que pese a la ausencia de estos indicadores en la muestra, todos los supervivientes experimentaron o presenciaron acontecimientos caracterizados por amenazas a su integridad física o la de otros, o muertes, presentes en hechos como la violencia política y la tortura. Con ello, cumplen la primera condición del DSM-IV-R para el diagnóstico de SEPT. No obstante, las condiciones que deben presentarse para diagnosticar SEPT, como respuesta de temor, desesperanza $u$ horror, e intensidad en la respuesta a tales sucesos por parte de los EXPPS, no ha sido aludida por ellos de manera espontánea, y no han sido temáticas consultadas directamente.

Por otro lado, creemos que la aceptación a participar en nuestro estudio y la actividad política que en su mayoría realizan, nos indica que estas personas no intentan evitar cualquier referencia a los hechos de prisión política, como personas y/ o actividades asociadas a los hechos. Esto sumado a los resultados obtenidos en términos de relaciones interpersonales actuales, podría reflejar que ellos no presentan desapego o enajenación a otras personas, y no manifiestan restricción en su vida afectiva.

De acuerdo a los indicadores que observamos en los participantes y al criterio diagnóstico de SEPT para el DSM-IV, podríamos decir que la muestra no presentaría -salvo algunas excepcionesindicadores significativos de SEPT. 
Aunque nuestro objetivo no fue evaluar el SEPT, y por ello no indagamos más en sus indicadores, vemos que su sintomatología no estuvo mayormente presente en los discursos de los EXPPS entrevistados, lo que coincide con la tendencia mundial en estudios de este síndrome en población superviviente a violencia política, cuya incidencia se presenta en una baja proporción en estas personas (Mollica et al., 1993; Shrestha et al.; 1998).

\subsubsection{Silencio y violencia sexual en mujeres}

El silencio traducido en ausencia de aspectos de tortura sexual manifestados por sus víctimas, concuerda con la tendencia presentada por mujeres víctimas de este tipo de tortura de países como Afganistán, Bosnia y Sudán, quienes mantienen en silencio estas experiencias (Tanking, 2006). Esta actitud, se asocia a una estrategia de autoprotección a humillaciones o vulnerabilidad social, y al tabú cultural de la violencia sexual, que creemos se presenta en menor proporción en el caso de Chile que en los países antes mencionados, pero que de igual modo existe.

\subsection{ALUSIONES}

6.2.1. Aspectos contextuales y problemáticas posteriores a la experiencia de prisión y actuales, que inciden en el impacto emocional y social de la experiencia de prisión

Desde una perspectiva evolutiva acorde con los planteamientos que sustentan nuestra investigación en el estudio del impacto de la experiencia de prisión en la vida emocional y social de los EXPPS que estudiamos, la identificación de aquellos antecedentes históricos a nivel político y social acontecidos con posterioridad a la experiencia de prisión, que dificultaron la supervivencia de estas personas, forman parte del impacto que estudiamos, aunque no hayan ocurrido en el momento de la experiencia de prisión, ni sean consecuencia directa de ésta.

La particularidad de estos factores, nos remite a aspectos contextuales ocurridos desde que fueron liberados, hasta el momento que accedimos a ellos, y son un aporte al estudio de los efectos de la prisión política a largo plazo, y especialmente a los supervivientes chilenos, y de otros países que presentan los mismos problemas en el presente. Además, nos permiten comparar nuestros resultados con los de otros estudios a largo plazo, realizados a víctimas de estos hechos. 
La presencia espontánea, reiterada y presente en la totalidad o la mayoría de los EXPPS entrevistados, de temáticas asociadas a problemas actuales que enfrentan, y que están vinculados a la experiencia de prisión, nos indican que estos temas tienen gran relevancia para todos ellos.

Creemos que esta tendencia refleja el interés que presentan estos temas para ellos, y como refieren aspectos que valoran con insatisfacción, inciden en la superación de las experiencias de prisión en sus vidas y en consecuencia, en el impacto que estudiamos.

Los temas más presentes en los discursos de los EXPPS entrevistados, comprenden problemáticas y valoraciones actuales asociadas a la experiencia de prisión. Estos incluyen temas políticos: reparación, régimen militar, sociedad chilena, y su respuesta ante las problemáticas de derechos humanos en Chile; y temas sociales: concepción del mundo y seres humanos, además de la valoración del Chile actual.

Relacionamos la frecuente presencia en los discursos de los EXPPS de los temas políticos mencionados, con la lucha política actual de las agrupaciones de derechos humanos, manifestado por el lema "verdad, justicia y reparación". Esto, nos indica que son temas que este grupo de personas suele tratar en sus reuniones y manifestar abiertamente, siendo parte importante de sus preocupaciones actuales, y por ello, temas de gran interés para ellos. Posiblemente, hasta el motivo principal de su participación política actual.

La insatisfacción asociada a estos temas por su parte, refiere factores contextuales que podrían afectar negativamente en el impacto inicial de la experiencia de prisión, y que se asocian a las necesidades mentales y culturales planteadas por López (2008).

\subsubsection{Trauma}

Creemos que la noción contextual planteada por Becker (2003), que concibe el trauma como un proceso social y político, y la noción de continuidad planteada por Bracken et al. (1995), son aplicables al caso de las personas que estudiamos. Desde esta perspectiva, el impacto de la experiencia de prisión o trauma se generó cuando los EXPPS estuvieron en cautiverio por motivos políticos, pero se perpetuó, además de por las propias secuelas físicas y psicológicas de estas experiencias, por las dificultades y problemas que tuvieron que enfrentar con posterioridad a la experiencia. 
Siguiendo con los planteamientos de Becker, el trauma desde una definición contextual incluye para el caso de Chile, y según los antecedentes entregados en el Informe Valech, los siguientes aspectos: casi la totalidad de los EXPPS chilenos fueron víctimas de experiencias de tortura, y estuvieron detenidos entre septiembre y diciembre de 1973 (con las características represivas de aquel período, por haber sido partidarios del régimen político gobernante de Chile en el período previo al régimen militar).

Por otra parte, en cuanto a aspectos acontecidos durante los 33 años posteriores hasta nuestro acceso a la muestra, destacan la persecución política; la permanencia de la mayoría de los EXPPS en un país que mantuvo por años el mismo gobierno que les privó de su libertad por motivos políticos; la insatisfacción con la justicia y la imagen de Pinochet vivo y en calidad de senador vitalicio; la insatisfacción en torno a la reparación; y una percepción negativa por parte de la sociedad chilena en torno al tema de los derechos humanos. Todo lo que creemos debe ser considerado a la hora de definir el trauma en el caso de las víctimas que nos ocupan en este estudio.

Nos referimos a experiencias que acontecieron en la vida de los EXPPS desde que precisamente comenzaron a ser EXPPS, generando dificultades adicionales a las propias de la supervivencia a experiencias de prisión política y tortura. Todas las que en concordancia con los aspectos planteados por Keilson (1992), incluyen aspectos traumáticos que están inscritos en la historia de Chile y que se traducen en la impunidad que ha caracterizado a la justicia chilena en el tema de los derechos humanos; la insatisfacción de todos los participantes en cuanto a la reparación recibida a más de 30 años de acontecidos los hechos; y la insatisfacción manifiesta de la respuesta percibida de la sociedad chilena ante los hechos de violación a los derechos humanos vividos en Chile.

La impunidad a la que hacemos referencia, alude al concepto de perpetuidad del trauma planteado por Becker (2003). Esta problemática fue una de las más presentes en los discursos de los EXPPS entrevistados, lo que afecta negativamente en el trauma causado por la experiencia de tortura, y hace que las víctimas tengan que lidiar con frecuencia con los recuerdos de las injusticias sufridas (Silove, 1999).

Sumamos a lo anterior, aquellas tendencias demográficas presentes en los resultados de nuestro estudio, que nos indican que la mayoría de los EXPPS que aludieron el período en el que estuvieron privados de su libertad, estuvieron recluidos en el primero de ellos, comprendido entre septiembre de 1973 y diciembre del mismo año, y debieron lidiar durante años bajo el régimen militar que cesó oficialmente el año 1990. 
La permanencia de los EXPPS en Chile durante los años de dictadura, significó para ellos dificultades laborales que observamos en el aumento del trabajo no calificado y desocupación en los períodos post-prisión y en la actualidad. Lo que creemos se vio perjudicado por el sometimiento a juicio referido predominantemente entre quienes fueron procesados en prisión, lo que sin duda limitó legalmente sus posibilidades de trabajo. Todo lo que se vio agravado por los períodos de clandestinidad y exoneración aludidos por algunos EXPPS entrevistados, que implicaron sin duda, la separación obligada de sus familias, en circunstancias adversas.

Otro aspecto que creemos incidió en la continuidad del trauma, es el temor asociado a la persecución política a la que se vio expuesta la mayoría de la muestra en el período post-prisión. Este temor, se vio concretizado por el reingreso en prisión, que creemos reactivó amenazas vitales propias de regímenes políticos represivos.

El modelo de trauma planteado por Simon (1987), nos permite entender la resolución del trauma que a más de 33 años puede verse reflejada en la vida de los EXPPS. De a cuerdo a sus planteamientos, estas personas presentan algunos indicadores o racionalizaciones que justificarían cierto grado de aislamiento social en relación a la sociedad.

Presentarían además temor, pero no recriminación hacia su persona por su participación política. En efecto, la mayoría de los EXPPS participantes de nuestro estudio, manifestaron poseer una valoración personal positiva, en relación a su participación política..

En general, el hecho que los EXPPS participantes del estudio hayan formado familia y dispongan en la actualidad de soporte social externo, nos indica que ellos han podido continuar con sus vidas, posiblemente satisfaciendo sus necesidades emocionales, sobreponiéndose a la experiencia traumática de la prisión política y tortura. La participación en organizaciones de DDHH en la actualidad, también apunta en este sentido, a la resolución o adaptación al trauma.

Concordando con Silove (1999), creemos que la percepción de acontecimientos amenazantes presentados con posterioridad a la experiencia de prisión en la vida de sus supervivientes, como por ejemplo, la experiencia de persecución política, afectó negativamente en la vida de estas personas, y por tanto, constituye parte de las causas del impacto en estudio. 


\subsubsection{Silencio y lugar de residencia}

Todo lo anterior, sumado a factores personales y sociales como el silencio, mayoritariamente aludido por quienes hicieron mención en su discurso al tema, creemos que pudo haber modificado los estilos de relación a nivel interpersonal de los EXPPS. Esta tendencia que se presentó en mayor proporción en las personas residentes en regiones que en aquellas residentes en la capital del país, se debe a que en regiones y debido al número reducido de habitantes por localidad en comparación a Santiago de Chile, la identidad de las personas es más reconocida por los demás habitantes, y los EXPPS tienden a percibir que la sociedad chilena en general les valora de manera negativa. Por estos motivos, creemos que los EXPPS de regiones tienden a silenciar su experiencia de prisión de manera significativa en relación a los EXPPS de la capital.

A lo anterior, se añade la diferencia estadísticamente significativa encontrada entre los participantes de regiones y los de Santiago, acerca de la valoración de la superación de la experiencia de prisión. Siendo los primeros, los más afectados en la no superación de la experiencia.

Esto puede deberse a que las personas de regiones están más expuestas a encontrarse con los autores de la represión política en sus localidades, y a ser estigmatizados socialmente por su condición de EXPPS. Lo que se traduce en la presencia de mayores dificultades para los EXPPS de regiones, de comunicar experiencias y sentimientos asociados a la prisión, viéndose más afectados que los EXPPS de la capital de Chile.

Todo lo que para Silove (1999), aumenta el impacto de la violencia política y la tortura. La densidad poblacional capitalina que puede permitir que las víctimas de prisión política puedan mantener su anonimato social, es más difícil de presentarse en las localidades del norte y sur del país, donde la densidad poblacional permite que la sociedad identifique a los habitantes de sus ciudades, volviéndose habitual coincidir con las personas en lugares públicos, en que el encuentro entre víctimas y victimarios no es demasiado ocasional. De hecho, consideramos que cualquier contacto de este tipo, tiene los atributos necesarios para ser considerado traumático en sí.

\subsubsection{Imagen de los ejecutores del régimen militar}

En cuanto a la noción de transferencia negativa planteada por Corrado y Tompkins (1989), creemos que ésta no se presentó en la muestra de nuestro estudio, debido a que al ser consultados acerca de su opinión personal de los ejecutores del régimen, todos los participantes hicieron 
valoraciones negativas. Este es un factor que consideramos favorable para la supervivencia de los EXPPS, pues denota que hay una marcada diferenciación entre víctimas y victimarios, dada por una lectura a los hechos realizada en base a ideas negativas de quienes actuaron a favor del régimen militar, ejerciendo la represión política en Chile.

\subsubsection{Reparación}

En el período presente al momento de hacer las entrevistas, la insatisfacción manifestada por la totalidad de la muestra en relación a las medidas de reparación, y la respuesta negativa percibida de la sociedad chilena ante los hechos de derechos humanos en Chile, incide de igual manera en este aspecto del trauma. Insatisfacciones que se traducen en la vinculación actual de todos los EXPPS con agrupaciones de EXPPS y derechos humanos.

\subsubsection{Participación política}

En cuanto a los antecedentes políticos de los participantes del estudio, la mayoría aludió haber participado de manera activa en política antes de prisión, cuya tendencia se mantuvo con posterioridad a la experiencia de prisión y en la actualidad. Al respecto, referimos que la muestra obtenida ha sido intencional, y el acceso a las personas que entrevistamos fue mediante agrupaciones de derechos humanos. Por este motivo, pensamos que esta tendencia no necesariamente representa a la mayoría de los EXPPS de Chile, pero nos indica que las personas que entrevistamos, son en su mayoría activistas políticos de izquierda. Lo que significa que su actividad política actual está asociada al tema de la privación de libertad y tortura, estando sus motivaciones orientadas hacia la consecución de mejoras de las medidas de reparación y el respeto a los derechos humanos. Esta opción, creemos que les permite -a quienes la llevan a cabo- pertenecer a un grupo social con otras víctimas a los mismos hechos de prisión y tortura por motivos políticos, que es un soporte social para ellos, donde pueden buscarle un sentido a la experiencia en sí, y sentirse parte de un grupo, satisfaciendo la necesidad de sentirse vinculados (Deci y Ryan; 1985, 2000), en conexión por medio del accionar político y comprendido por los demás. Ambos factores, es muy probable que favorezcan la supervivencia actual a tales experiencias, y permitan la satisfacción de necesidades sociales en el grupo de EXPPS. 


\subsubsection{Estado de salud}

En cuanto al estado de salud de los EXPPS entrevistados, nos interesó conocer la proporción de sujetos que presentaron secuelas físicas producto de experiencias de violencia política y tortura, pues creemos que además de afectar directamente en su vida diaria y con ello, mantener el recuerdo presente, puede significar limitaciones que afectan su calidad de vida y por ende, afectar en el impacto que estudiamos. Vimos así que una proporción menor a la media de participantes de nuestro estudio, afirmó tener estas secuelas.

Otros resultados del estado de salud de los EXPPS y relacionados a la experiencia de prisión y tortura por motivos políticos, no fueron contemplados en nuestra investigación. Pero en general, no podríamos decir que observamos en los EXPPS entrevistados dificultades para llevar una vida normal e integrada a su realidad, tal y como plantea Martín (2002). Pese a ello, vimos signos de tortura física, como la inmovilidad de una de las extremidades superiores en una persona que tenía un oficio de panadero, y que esta limitación si le significaba una dificultad en su labor; sordera, y hendiduras en huesos producto de golpes; además de relatos que evidenciaron que algunos EXPPS fueron intervenidos quirúrgicamente por presentar tumores que asociaron a los golpes recibidos en prisión, y que hicieron que jubilaran anticipadamente.

De acuerdo a lo anterior, suponemos que todas las marcas físicas por muy invisibles que parezcan a los ojos de los demás, remiten en quienes las presentan, recuerdos de la experiencia de prisión y tortura por motivos políticos, y las limitaciones asociadas a discapacidades físicas, han marcado la existencia de estas personas, afectando negativamente en la calidad de vida de estas personas y por lo tanto, en la satisfacción de sus necesidad de autonomía y de competencia (Deci y Ryan $(1985,2000)$.

\subsubsection{Concepción de mundo, seres humanos y sentido otorgado a la vida}

Otros temas aludidos por la mayoría de los EXPPS, fueron las concepciones negativas del mundo y los seres humanos, y un sentido positivo otorgado a la propia vida. La concepción de mundo negativa aludida por la mayoría de los EXPPS entrevistados, es un aspecto que según los planteamientos de Doyal y Gaugh, influye en los deseos y aspiraciones de las personas. Esta tendencia, coincide con hallazgos de otros estudios relacionados (e. g. Mollica et al., 1987; Mollica y Coworkers, 1993), y lo atribuimos al impacto estudiado. 
La concepción de los seres humanos, del mundo y del Chile actual, que presentaron los EXPPS en el presente, fueron mayoritariamente negativas. Vemos que la causa humana en la concepción de mundo negativa, está presente en más de la mitad de la muestra, y la problemática más aludida es aquella de tipo política. Esto si lo asociamos a la participación política y/ o la experiencia de prisión en sus valoraciones, y específicamente a la tortura (hechos ejercidos por personas desde una posición oficial), pudo haber generado un cambio significativo en la forma de ver el entorno. O bien, haber mantenido o aumentado una percepción negativa previa de estos temas.

Lo anterior, puede explicarse por el planteamiento de Silove (1999), que sostiene que la maldad y crueldad de la tortura, pueden alterar las creencias de los supervivientes en cuanto a la bondad de la vida y la humanidad. Siendo éste, un impacto percibido de la experiencia de prisión.

Esto, asociado al apego, es más característico en personas con apego inseguro (Casullo y Fernández, 2005). Lo que nos remitiría a la insatisfacción presente en la mayoría de EXPPS en torno a sus necesidades mentales y cognitivas (López, 2008).

En relación al sentido de la vida aludida en el presente, los EXPPS manifestaron una valoración global positiva que nosotros asociamos al hecho de haber supervivido a la experiencia de prisión, a diferencia de otros de sus compañeros políticos.

La concepción del mundo en la infancia y adolescencia, remitió valoraciones predominantemente positivas aludida por más de la mitad de la muestra de EXPPS entrevistados, además de una visión optimista del futuro, satisfacción en torno a la valoración de su estar en el mundo, y un sentido predominantemente positivo de la vida. Todas estas valoraciones difieren de las mismas en el presente, lo que podemos atribuir a la experiencia de prisión, con lo que se demuestra que la teoría de las necesidades usada como referencia en esta tesis (López, 2008) ayuda a comprender los efectos sufridos por las víctimas, en este caso de prisión y tortura.

\subsection{NECESIDADES EMOCIONALES Y SOCIALES}

A continuación discutiremos las áreas que nos darán indicadores del impacto emocional y social de la experiencia de prisión política y tortura en Chile, según otras necesidades descritas en el marco teórico que sustenta nuestra investigación. 


\subsubsection{Necesidades emocionales}

\subsubsection{Soledad}

A nivel demográfico, vemos que todos los participantes tienen hijos y la mayoría de ellos tienen además pareja y amigos. Pero, no podemos decir que los EXPPS no se sienten solos por el hecho de disponer de vínculos familiares y de amistad.

En general, vemos que más de la mitad de la muestra refiere no sentir soledad en sus relaciones interpersonales con la pareja, los hijos y los amigos, lo que podría indicarnos que no presentan soledad emocional ni social. Pero un grupo un poco inferior a la media de participantes sí refiere la presencia de soledad en general sus vidas; y dentro de las relaciones interpersonales, aquellas establecidas con los hijos, son las más referidas a la hora de manifestar la presencia de soledad.

El sentimiento de soledad se presentada principalmente en relación con los hijos, seguramente por no haber hablado con ellos abiertamente de su experiencia de tortura y prisión. Esto, por la brecha emocional que significa mantener en silencio una experiencia de vida tan trascendente como la prisión política y la tortura, que podría incidir en la soledad e incomunicación que sienten con los hijos. Discutiremos posteriormente este hallazgo.

Para la mayoría, la tendencia a no sentir soledad en sus relaciones interpersonales con la familia y los amigos, podrían reflejar satisfacción de las necesidades interpersonales afectivas y sociales en los EXPPS en general; y podría ser expresión de una buena elaboración de la experiencia de prisión, al menos en relación a los seres más queridos.

Por tanto, los resultados sobre soledad emocional y social son complejos y muy diversos, dividiéndose la muestra de manera bastante clara entre quienes han conseguido una buena relación con la familia y los amigos y quienes, sobre todo en el caso de los hijos, no han conseguido comunicarse o hacerse entender.

Nosotros coincidiendo con los planteamientos de Weiss (1973), esperábamos encontrar soledad emocional y social en los EXPPS de manera más generalizada, causada por una situación de vida tan trascendente como la experiencia de prisión. Pero vemos que no se presenta mayormente en la muestra participante del estudio, a excepción de las relaciones con los hijos. Creemos que esto se debe a capacidades de los EXPPS como la resiliencia, y otras características de personalidad previas a la 
experiencia, como la extroversión, seguridad y una autoestima adecuada, que les han permitido supervivir a estos hechos y lograr relaciones interpersonales satisfactorias en la actualidad, que no se caracterizan por la presencia de soledad emocional ni social.

\subsubsection{Silencio}

El silencio emocional y social, refiere insatisfacción en las necesidades emocionales y sociales de los EXPPS. Al respecto, más de la mitad de la muestra guardó silencio de la experiencia de prisión política y/ o tortura, y de quienes refirieron la presencia de este silencio en sus relaciones interpersonales, la mayoría de ellos (no superando la media de sujetos), refirió haberlo mantenido en secreto, principalmente con los hijos.

Creemos que el silencio de la experiencia de prisión con los hijos, fue posible porque la mayoría de los hijos de los EXPPS eran infantes al momento de su detención, pudiendo éstos muy probablemente no recordar la ausencia del padre cuando éste permaneció en cautiverio, o no recordar la ocurrencia de este acontecimiento en la vida de sus padres, o recordarla y mantenerla en silencio. De cualquier modo, esta actitud tal y como lo hemos referido anteriormente, puede ser parte del impacto que estudiamos.

El silencio de la experiencia de prisión, aludido directamente por los EXPPS en sus vidas y específicamente en sus relaciones interpersonales, nos confirmaría que la experiencia de prisión política vivida por los EXPPS, es un tema que ellos prefieren no comunicar, posiblemente por sentimientos dolorosos asociados al recuerdo de tales experiencias. Creemos que esta actitud, marca una distancia importante de estas personas con quienes lo establecen, sobretodo cuando estas relaciones interpersonales tienen un vínculo emocional. Lo que podría indicarnos un impacto de la experiencia de prisión y tortura en las vidas y relaciones interpersonales de sus supervivientes. Posteriormente, volveremos a referirnos al silencio de la experiencia de prisión en las relaciones afectivas.

El silencio mantenido principalmente con los hijos, concuerda con la tendencia observada en otros estudios científicos que sostienen que éste se presenta principalmente en torno a estas relaciones. Se una conspiración del silencio que suele crearse en las familias de los supervivientes a estas experiencias, en un intento de ocultar la experiencia a los hijos (e. g. Johnston, 1995; Myers et al., 1999).

Por todo ello, por nuestra parte, con independencia de los efectos directos sobre el sentimiento de soledad, creemos que silenciar un hecho tan relevante en la vida de una persona, determinará un tipo 
de relación particular con las personas con quienes se mantenga, y refleja un aspecto del impacto que estudiamos.

Por último, no debemos olvidar que un grupo importante, aunque inferior a la media de sujetos participantes del estudio, refirió soledad asociada a sus relaciones interpersonales con la pareja, los hijos y los amigos. Lo que nos indica que parte de la muestra presentaría soledad emocional y social, y con ello, insatisfacción en sus necesidades emocionales planteadas por López (2008).

\subsubsection{Necesidades emocionales y apego}

Aunque no podemos establecer criterios del patrón de apego de los participantes, y la influencia de la experiencia de prisión en éste, hemos valorado algunos indicadores de los distintos tipos de apego, en las relaciones interpersonales familiares presentes y pasadas de los EXPPS.

Como ya hemos sostenido anteriormente, la mayoría de los participantes del estudio disponen de relaciones de pareja, y todos tienen hijos. Lo que nos indica la presencia de figuras de apego en sus vidas. Además, un grupo aludió la presencia de nietos en sus vidas, con la presencia de afectos en estas relaciones. Considerando estos antecedentes, discutiremos aquellos indicadores de apego que hemos traducido a nuestras variables.

Un indicador importante, refiere la valoración positiva que los EXPPS hicieron de sus relaciones con la pareja, los hijos, los nietos, los compañeros políticos y los amigos en el presente, además de la familia de origen y los amigos en el pasado. Lo que nos manifiesta la presencia de un primer indicador de la satisfacción de las necesidades emocionales y sociales de los participantes.

La disposición de apoyo incondicional en la vida de las personas, es otro indicador asociado al apego y se presentó en la mayoría de la muestra, encontrándose esta disponibilidad principalmente en integrantes de la familia actual, específicamente los hijos. Lo que nos revelaría un indicador de apego seguro en sus vidas, asociado a la familia actual. Sin embargo, el silencio y la soledad percibida principalmente con los hijos, nos haría dudar acerca de este indicador de apego.

La valoración positiva que los EXPPS hicieron del sentido que otorgan a sus relaciones afectivas, es otro indicador que asociamos a un patrón de apego seguro, y nos indica que para ellos estas relaciones son satisfactorias, permitiéndoles alcanzar un grado óptimo de bienestar en sus vidas. 
A nivel específico, podríamos ver indicadores de apego seguro con la pareja, como por ejemplo, al valorar positivamente estas relaciones, y hacer una valoración global satisfactoria, además de referir satisfacción en torno al apoyo percibido del suceso de prisión, y sentirse comprendidos, apoyados, queridos y no solos, no ignorados, ni en conflicto con estas relaciones.

Creemos precisamente que en las relaciones de pareja los EXPPS se sienten seguros, y estos vínculos han sido el principal apoyo para los EXPPS en cuanto a la supervivencia de la experiencia de prisión. Lo que haría que estos vínculos dispongan de un elevado grado de compromiso, permitiendo que los EXPPS que perciben su entorno de manera negativa, logren satisfacer sus necesidades emocionales.

En los vínculos paterno-filiales, constatamos la presencia predominante de una valoración positiva de estas relaciones en la mayoría de los participantes. La misma tendencia se presentó, aunque en una escasa proporción de participantes que no superó la media de ellos, la satisfacción en cuanto al apoyo en política percibido por parte de los hijos, además de la aceptación percibida del suceso de prisión por parte de los mismos. Todo lo que podría indicar la presencia de indicadores de apego seguro en estos vínculos.

Por otro lado, vemos que refieren la presencia de sentimientos de culpa hacia sus hijos y tienden a sentirse responsables por sus vidas. Lo que podría referir indicadores de no haber cuidado de forma totalmente eficaz a los hijos. Estas últimas valoraciones, se presentan en proporciones inferiores a la media de sujetos participantes.

En los vínculos paterno-filiales constatamos además, que en general los EXPPS se sienten comprendidos, apoyados y queridos, y no se sienten solos, ni ignorados, ni en conflicto. La misma tendencia se presentó en relación a los nietos, aunque en un grupo muy por debajo por la media de sujetos entrevistados.

En cuanto a la valoración que los EXPPS hicieran de sus familias de origen en el presente, las tendencias predominantes, que no superó la media de sujetos, refirió la presencia de afectos en estas relaciones, además de una valoración positiva de apoyo a nivel político y satisfacción a la hora de valorar globalmente estas relaciones. 
Otro aspecto que denota apego seguro, refiere la valoración positiva del sí mismo, que fue positiva en la mayoría de sujetos que aludieron esta temática, aunque no superó la media de sujetos entrevistados.

Todo lo anterior, y de acuerdo a los postulados planteados en el capítulo I, nos refiere la presencia de indicadores de apego en la mayoría de las relaciones interpersonales que mantienen en la actualidad los EXPPS participantes del estudio, de forma que estas experiencias tan dolorosas no han destruido sus capacidades para relacionarse de forma satisfactoria con la familia en la mayor parte de los casos.

Por último, los participantes de nuestra investigación, no refieren mayormente la presencia de antecedentes disfuncionales en sus familias en la actualidad. Lo que es más probable en personas con apego seguro (e. g. Mikulincer y Florian, 1999).

En cuanto a las relaciones existentes en sus vidas en el pasado durante su infancia y adolescencia, las tendencias predominantes refieren una valoración positiva de las relaciones interpersonales con la familia de origen, y de acuerdo a estos vínculos de apego en el pasado, vemos que en general estas personas hacen una valoración positiva de sus relaciones con ambos padres y hermanos, y valoran satisfactoriamente los afectos en estas relaciones. Lo que podría remitirnos a indicadores de un estilo de apego seguro en el pasado.

Por tanto, y esto es lo más importante, en la mayor parte de los casos, a pesar de los sufrimientos y secuelas, las relaciones familiares son un verdadero refugio y sostén emocional de las personas que fueron víctimas, si bien el grado de logro en estas relaciones es diverso, destacando, como efecto más sobrecogedor, el que un número relativamente importante de víctimas no haya podido o querido hablar de este tema, tan importante, con sus hijos.

\subsubsection{Necesidades sociales}

\subsubsection{Participación política}

La participación de la mayoría de la muestra en agrupaciones de EXPPS y derechos humanos, puede remitirnos a espacios en los que estas personas encuentran redes sociales que favorecen la satisfacción de sus necesidades sociales, según los planteamientos de Weiss (1973), Deci y Ryan, (1985, 2000) y López (2008). A la vez, buscan es en estos espacios, donde los EXPPS encuentran las 
soluciones a los problemas que presentan actualmente en torno a la reparación y otros temas. Estos espacios y relaciones, serían favorecedores en sus vidas, y creemos que la condición de EXPPS les ha motivado en este accionar político actual que desempeñan.

Por otra parte, el compromiso con el tema de los derechos humanos reflejado en el accionar político de la mayoría de los participantes en agrupaciones de EXPPS y de derechos humanos, puede ser, según Bettelheim (1979), parte del impacto que estudiamos, y que concibe este tipo de participación, como una reacción posterior a períodos de cautiverio, que involucra el compromiso de toda una vida por tratar los efectos emocionales de estas experiencias.

La participación política se mantuvo desde el período posterior a la prisión hasta la actualidad, aunque se observó una leva baja de esta participación del total de sujetos, en el período posterior a la experiencia de prisión (superando la media de sujetos en todos los momentos). Lo que era predecible, si consideramos que en este período, era el régimen militar el que permanecía al mando del gobierno de Chile.

Estos antecedentes reflejan que la represión política no cumplió, en la muestra entrevistada, su objetivo de exterminar todo pensamiento y accionar izquierdista. Lo que queda demostrado en la participación política aludida anteriormente. Vemos así, de manera contraria a lo que pensábamos encontrar, que los EXPPS entrevistados pudieron posiblemente desarrollar en estos espacios de relación, sus necesidades de tipo intelectuales asociadas a su ideología política.

La participación política actual de la mayoría de los participantes, asociado al silencio y las omisiones que referimos anteriormente, podrían ser aspectos contradictorios. Pues, los activistas políticos de agrupaciones de EXPPS y organizaciones de derechos humanos, suelen ser la cara visible a nivel social de la represión acontecida en Chile.

De acuerdo a lo anterior, creemos que la omisión de temáticas asociadas al sufrimiento en prisión y particularmente a la experiencia de tortura, además del silencio que los participantes afirmaron presentar en sus vidas en general y en sus relaciones interpersonales, puede estar limitado a aspectos emocionales asociados a la experiencia y no al trabajo político asociado a aspectos históricos y sociales de los hechos.

La presencia de la tortura en la mayoría de las experiencias de cautiverio de los participantes, asociado a la participación política actual que ellos realizan, y que en general no dejaron de realizar con 
posterioridad a la experiencia de prisión, nos indica que la tortura no consiguió en ellos su objetivo de producir un quiebre en sus convicciones e inhabilitarlos como opositores políticos, como planteaba Silove (1996).

Supervivir a estas experiencias, puede deberse a características personales como la resiliencia y un adecuado soporte emocional y social previo y posterior a la experiencia de prisión. Volveremos a este último aspecto, cuando discutamos el impacto en estudio en las necesidades emocionales y sociales planteadas por López (2008).

\subsubsection{Sociedad chilena y derechos humanos}

La valoración negativa que los EXPPS realizaron de la sociedad chilena y su respuesta a los hechos de violación a los derechos humanos en Chile, puede incidir en la limitación de las redes sociales de los EXPPS a aquellas relaciones de amistad y política. Lo que creemos restringe sus posibilidades de relacionarse socialmente a nivel interpersonal, y por tanto, nos indicaría un impacto de los factores contextuales asociados a la experiencia de prisión, coincidente con los planteamientos de Weiss.

A lo anterior, añadimos el temor percibido por los EXPPS de la sociedad chilena hacia ellos. Aunque vemos que un tercio de la muestra manifestó que percibe que la sociedad les teme, otras valoraciones desfavorables como la estigmatización, el desconocimiento y la indiferencia social percibida, podrían confirmar nuestro planteamiento inicial acerca de la presencia de temor por parte de la sociedad chilena hacia los EXPPS, y su influencia en la forma de relacionarse de estos últimos con la sociedad en general. Esto refleja en consecuencia, el impacto social de la experiencia de prisión en Chile y en los EXPPS.

La presencia de temor en los discursos de los EXPPS entrevistados, no estuvo presente directamente en los textos, pero sí de modo indirecto, y fue el término más presente en sus discursos del total de términos buscados. Esto pudo haberse generado por la difícil diferenciación de los dos bandos representantes de la izquierda y la derecha chilena durante el régimen militar en la sociedad chilena, debido a que ambos grupos estaban conformados por chilenos.

La difícil diferenciación entre los partidarios del régimen militar y los opositores a este régimen, principalmente durante el período del régimen militar, provocó en los EXPPS actitudes de desconfianza y hermetismo a la hora de expresar la propia ideología política con los chilenos en general, 
y en consecuencia, relaciones interpersonales superficiales y limitadas. Todo lo que coincide con nuestros planteamientos iniciales en base al modelo teórico de la soledad social y emocional de Weiss.

\subsubsection{Estado de salud}

El estado de salud de los EXPPS y su relación con las secuelas producto de la violencia y tortura recibida en prisión, es un aspecto que tiene relación con el impacto estudiado en esta tesis. Según los planteamientos de Doyal y Gaugh (1992/ 1994), las necesidades básicas humanas aluden al concepto de salud asociado a la ausencia de enfermedad. Desde esta perspectiva, las secuelas de los distintos tipos de tortura aludidas por menos de la mitad de los EXPPS entrevistados, nos indican que estas personas no satisfacen sus necesidades básicas humanas.

Lo anterior, se traduciría en que las secuelas de la tortura afectaron a sus víctimas en sus niveles de autonomía, lo que Doyal y Gaugh, asocian a un factor que dificulta la participación social de estas personas.

\subsubsection{La experiencia de prisión política}

La experiencia de prisión política en sí, entendida desde la injusticia de sancionar a una persona por su ideología distinta a la deseable por el régimen de turno, apunta a este mismo aspecto. La falta de libertad política que estos hechos significan, coincidiendo con Doyal y Gaugh, creemos que impidió el curso normal de desarrollo de autonomía de libertad de agencia y de libertad política, además de autonomía crítica en los EXPPS.

\subsubsection{Dificultades posteriores a la experiencia de prisión y producto de su condición de EXPPS}

En adición a la supervivencia de la experiencia de prisión política y tortura propiamente tal, los EXPPS tuvieron que superar problemas que se presentaron en sus vidas producto de su condición de EXPPS, que fueron promovidos por un sistema gubernamental represivo. Estos problemas, afectaron directamente en su calidad de vida y dificultaron su supervivencia en los años posteriores a la experiencia de prisión. En la actualidad, creemos que deben ser considerados para entender el impacto que estudiamos. A ellos nos referiremos a continuación. 
Según los hallazgos encontrados, vimos que más de la mitad de la muestra refirió que la experiencia de prisión política afectó negativamente en su actividad laboral o estudiantil, afectando principalmente en la cancelación de sus trabajos y la imposibilidad de trabajar por la condición de EXPPS. Creemos que estos aspectos, entre otros, limitaron el desarrollo de sus capacidades para iniciar nuevos objetivos y estrategias para la satisfacción de necesidades básicas materiales planteadas por Doyal y Gaugh, orientando el objetivo principal de sus vidas, a la satisfacción de necesidades fisiológicas como comida y abrigo.

Lo anterior, entendido como falta de oportunidades objetivas por parte de la sociedad para los EXPPS, según Doyal y Gaugh, puede haber afectado negativamente en la autonomía de ellos.

\subsubsection{Relaciones interpersonales sociales}

En cuanto a las relaciones de amistad en el presente, la mayoría de los EXPPS refiere disponer de estos vínculos, y los valoran globalmente con satisfacción. Además la mayoría de sujetos entrevistados refieren sentirse comprendidos, apoyados, queridos y no solos, no ignorados, ni en conflicto con sus amigos.

Las relaciones con los compañeros políticos, fueron aludidas por menos de la mitad de entrevistados, quienes en su mayoría, las valoraron con satisfacción.

Las tendencias presentadas en las distintas alusiones que hicieron los EXPPS de los vínculos de amistad, y que no superan la media de sujetos entrevistados pero sí la tendencia más aludida, refiere que la naturaleza de estas relaciones es predominantemente política, con presencia de confianza, incondicionalidad, y la disposición de años de relación.. Sin embargo, un grupo menor aludió el tema intimidad en estas relaciones, denotando su ausencia. Este indicador podría revelar que las relaciones de amistad de los EXPPS son poco íntimas, y con un bajo compromiso, pudiendo influir negativamente en la insatisfacción de necesidades sociales.

\subsubsection{Edad e impacto estudiado}

En general, no observamos diferencias significativas según el criterio de edad de los participantes. Sin embargo, se presentaron dos diferencias significativas que nos indican que las personas mayores de 65 años, a diferencia de aquellas menores de esta edad, presentan menos insatisfacción a la hora de valorar sus relaciones interpersonales familiares en la actualidad, y la 
valoración de la respuesta social chilena percibida ante los hechos de violación a los derechos humanos en Chile. Ambas diferencias, pueden significar que estas personas aceptan de mejor manera, la realidad social y familiar de su entorno que las personas entrevistadas menores de 65 años.

\subsection{ANÁLISIS DE CONGLOMERADOS JERÁRQUICOS DE VARIABLES: ¿DE QUÉ SE QUEJAN LAS VÍCTIMAS?}

Tras buscar relaciones estadísticas entre una selección de las variables agrupadas que establecimos en nuestro esfuerzo por sintetizar la información obtenida, el análisis de conglomerados jerárquicos que hicimos, nos reveló que la insatisfacción manifestada por la totalidad de EXPPS participantes del estudio en torno a las medidas gubernamentales de reparación, se debe principalmente a la imposibilidad de heredar la beca de estudios universitarios a la descendencia. Al respecto, vimos en el capítulo III, que los EXPPS gozan de una beca de estudios universitarios, pero que muchos de ellos no han hecho uso de ésta, pues consideran que no están en un momento evolutivo apropiado para iniciar estudios de esta naturaleza, o no pueden dejar de trabajar, para dedicarse a estudiar una carrera. Esto último, por las responsabilidades que todos ellos tienen, en cuanto a su rol como jefes de hogar y padres de familia. Por otra parte, el interés por traspasar esta beca a uno de los hijos y/ o hasta uno de los nietos, es una idea que a muchos de los EXPPS les interesa, pues además de considerar que sus hijos también fueron afectados por la propia experiencia de prisión y tortura por motivos políticos, al tener que lidiar con las necesidades económicas y la ausencia del padre por períodos significativos durante su infancia, merecen ser reparados por el gobierno, y en muchos casos, es aplicable la beca a ellos en la actualidad, por presentar la motivación para estudiar, muchas veces sin disponer de los recursos necesarios para hacerlo.

Las relaciones que pueden existir entre estas variables, pueden residir en que uno de los motivos principales de la insatisfacción que los EXPPS manifestaron de las medidas gubernamentales de reparación, se debe la imposibilidad de heredar las medidas otorgadas. Creemos que si ellos valoran satisfactoriamente sus relaciones interpersonales en el presente con sus familias, estarán a favor de que estos beneficios puedan traspasarse a la pareja y los hijos en caso de muerte o en el caso de la beca de educación profesional por ejemplo, cuando la víctima directa no desee estudiar.

La insatisfacción manifiesta por los EXPPS con las medidas gubernamentales de reparación, se asoció además a una concepción de mundo negativa. Creemos que percibir el mundo en el que se vive de manera hostil y negativa, hace que quienes lo conciban así, sientan insatisfacción general de su estar en este mundo, y probablemente tiendan a centrarse en los aspectos negativos de la misma, incluida la reparación. Esta 
insatisfacción, se relacionó además al impacto percibido por los EXPPS de la propia experiencia de prisión en sus vidas y sus relaciones interpersonales, lo que nos indica que quienes refirieron directamente percibir la influencia de la experiencia de prisión y tortura en sus vidas, presentan más insatisfacción con las medidas gubernamentales de reparación. Esto tiene sentido, si pensamos que quienes reconocen que tales experiencias han afectado en su vida, no habrá reparación posible a los daños de estas experiencias en sus vidas. Por último, asociada a las variables anteriores, se encuentra la insatisfacción manifestada por los EXPPS en cuanto a la respuesta percibida de la sociedad chilena en el tema de los derechos humanos. este aspecto, creemos que se asocia a la concepción de mundo negativa por causa humana y pueden ser atribuibles a la experiencia de prisión y tortura por motivos políticos.

Todo lo anterior, nos indica la presencia de una valoración negativa de aspectos externos a la vida individual y familiar de los EXPPS, probablemente asociado a la experiencia de prisión, que podemos ver reflejado en la similitud de estas variables con aquella que refiere la percepción del impacto de la experiencia de prisión en sus vidas. Lo que llevado a los objetivos de nuestra investigación, nos indica que la prisión y tortura políticas, muy probablemente afectó en sentido negativo en las cogniciones del mundo y los seres humanos de los EXPPS que entrevistamos, pudiendo afectar igualmente de manera negativa en la lectura que estas personas hacen de las medidas gubernamentales de reparación, lo que sumado a percibir de manera hostil a los chilenos en su respuesta social hacia el tema de los derechos humanos en Chile, perpetúan el trauma de la experiencia de prisión y tortura en las víctimas que estudiamos. Por último, esta insatisfacción presente en los EXPPS hacia factores externos y contextuales, hace que ellos se avoquen a sus relaciones interpersonales emocionales con la familia, lo que vemos reflejado en la satisfacción manifiesta con estas relaciones. Creemos que esto último, es positivo en el sentido que ellos son capaces de satisfacer sus necesidades emocionales dentro del grupo familiar que forman parte, pero les limita en satisfacer sus necesidades interpersonales sociales que se desarrollan en relaciones externas a estos vínculos.

\subsection{EL DISEÑO METODOLÓGICO EMPLEADO PARA ESTUDIAR EL IMPACTO EMOCIONAL Y SOCIAL DE LA PRIVACIÓN DE LIBERTAD Y TORTURA POR MOTIVOS POLÍTICOS EN UN GRUPO DE CHILENOS.}

\subsubsection{El marco referencial teórico}

Al llegar a este momento de la investigación, creemos que la teoría de las necesidades interpersonales humanas básicas de López, nos ha permitido conocer el impacto emocional y social de la privación de libertad y tortura por motivos políticos en un grupo de chilenos que formaron parte de nuestro estudio. El empleo de 
esta teoría para estudiar el fenómeno en cuestión, comprende una aportación original de nuestro estudio, no tan solo para el caso de Chile, sino que también para las víctimas de estas experiencias en distintos contextos, y nos ha ofrecido la posibilidad de indagar la atribución del trauma de la experiencia de prisión y tortura política, en la satisfacción e insatisfacción de las necesidades de estas personas, es decir, en su bienestar psicológico.

Por otra parte, lo que el estudio demuestra es que finalmente, como era de esperar, son los vínculos familiares y de amistad lo que más y mejor han servido a las víctimas para sobrevivir, como demuestra el hecho de que en la mayoría de los casos estas relaciones han llegado a construirse de forma satisfactoria. Pero no es menos importe señalar esa fisura silenciosa que han establecido una parte importante de los padres con los hijos, seguramente para protegerlos, no generar odios en ellos, no mostrar su vulnerabilidad como padres o, en otros casos, para no reavivar su propio sufrimiento al compartirlo con los hijos. Por todo ello, lo que hace la teoría de las necesidades es poner de manifiesto la importancia de estos vínculos para entender el sufrimiento y su superación en el caso de las víctimas.

\subsubsection{La metodología empleada}

\subsubsection{La entrevista en profundidad}

El instrumento que diseñamos para la recogida de datos, nos permitió indagar desde la teoría de las necesidades interpersonales humanas básicas de López y teorías afines, el impacto emocional y social de la privación de libertad y tortura por motivos políticos en Chile. Elegimos esta herramienta ante otras análogas para los fines que requeríamos, porque nos permitía desde una perspectiva clínica e histórica, realizar entrevistas con el fin de conseguir información precisa, compleja y personalizada, de cada una de las personas participantes del estudio. Otro motivo de nuestra elección, fue la temática que indagábamos, tabú a nivel social, político y hasta familiar para algunos de los EXPPS y en general para la sociedad chilena. Dentro de un contexto caracterizado por el silencio de los hechos de prisión y tortura política, consideramos imprescindible la confidencialidad que sólo podíamos obtener en la entrevista uno a uno con las víctimas. Con esto, intentamos con éxito obtener información específica y que forma parte de la intimidad de estas personas, imposible de obtener con cuestionarios estructurados propios de test psicométricos. En efecto, intentamos administrar test psicométricos de apego, SEPT, calidad de vida, que los mismos EXPPS repararon en algunos de sus ítem por considerar que no eran aplicables a su realidad.

Nosotros, aunque intentaremos posteriormente adaptar algunos de estos instrumentos con el objeto de contrastar nuestros datos para estudios posteriores, creemos que la riqueza de información obtenida con el 
diseño que empleamos, no se puede obtener por técnicas cuantitativas. Por otro lado, cuando no existen estudios previos a la población estudiada, en el momento que accedimos a ella, la metodología cualitativa permite explorar un fenómeno para luego determinar líneas de investigación atingentes a los factores predominantes observados para con ello formular nuevas investigaciones.

\subsubsection{El análisis de contenido}

El análisis de contenido como técnica cualitativa para tratar los datos que obtuvimos con la entrevista en profundidad, nos permitió investigar el discurso de los participantes desde sus códigos y expresiones, considerando el contexto en el que surgieron. Pudimos con el empleo de esta metodología, analizar detalladamente el contenido de los discursos de los participantes del estudio y cuantificar sus enunciados por temas, de manera objetiva, sistemática, cuantitativa y cualitativa a la vez, representativa, exhaustiva y generalizada.

\subsubsection{El mapa conceptual}

El establecimiento de un mapa jerárquico compuesto por dos grandes grupos temáticos referidos a antecedentes demográficos y conceptuales, nos permitió organizar la amplia cantidad de información que obtuvimos con las entrevistas que realizamos, establecer relaciones entre variables a nivel intra e inter-grupo y agruparlas por tópicos más generales, además de extraer conclusiones acerca de las tendencias según temas más presentes y ausentes en los discursos de los EXPPS.

Para un estudio exploratorio como el nuestro, su elaboración fue de gran utilidad, porque nos permitió ir creando, a medida que iba aumentando nuestro conocimiento del tema en estudio, un sistema de categorías jerárquicas que emergieron inicialmente desde la teoría de las necesidades que sustenta nuestra investigación y el Informe Gubernamental sobre Prisión Política y Tortura (Gobierno de Chile, 2004), y finalizaron con el discurso de los EXPPS en torno a temáticas asociadas a la experiencia de prisión y tortura, y la satisfacción de sus necesidades interpersonales básicas.

\subsubsection{El aporte del programa informático QSR Nvivo}

El soporte informático que nos otorgó el programa QSR Nvivo para el análisis del material textual que analizamos, nos permitió manejar el amplio caudal de información que obtuvimos (alrededor de 9900 párrafos), cuyo análisis a mano, que comprendía la tarea de escribir las unidades de significado o nudos cada 
vez que las asignábamos, hubiera sido prácticamente imposible. Pues nuestro mapa conceptual abarcó más de mil nudos que con el empleo del programa informático en cuestión, era muy fácil consultar reiteradamente.

Además, el programa QSR Nvivo 6, y en concordancia con las utilidades de esta herramienta reconocidas por investigadores en otras tesis doctorales (e. g. Lasaga, 2004), es ideal para el empleo de textos, permitiéndonos durante todas las fases del proceso de codificación, que tanto ideas, como anotaciones, que iban emergiendo en esta etapa de la investigación, pudieran contrastarse cualitativa y cuantitativamente con el análisis de las relaciones lógicas de los temas incluidos en nuestro mapa conceptual jerárquico, permitiendo la flexibilidad de niveles y la incorporación de nuevas categorías. Por último, sus herramientas nos permitieron exportar datos al SPSS y a programas gráficos que nos facilitaron el entendimiento de nuestro mapa de categorías.

\subsubsection{El aporte del programa informático SPSS}

El programa SPSS nos permitió estudiar relaciones estadísticamente significativas, entre dos y más variables, que podían escapar a nuestra atención y lógica deductiva, y que aportaron información relevante para confirmar aspectos del fenómeno del impacto emocional y social de la privación de libertad y tortura por motivos políticos en una muestra de chilenos supervivientes a estas experiencias. Además de aportar información única no observada con la parte cualitativa del estudio.

\subsection{LIMITACIONES DEL ESTUDIO}

A través de todo el desarrollo de nuestra investigación, hemos constatado que dada la naturaleza única e irrepetible que tenemos como seres humanos, el impacto de la experiencia de prisión y/ o tortura, afectó de manera diferente en distintos aspectos de la vida de cada EXPP entrevistado; y dada la magnitud de información obtenida, nos vimos imposibilitados de centramos en el análisis individual de estas diferencias. Esta restricción que hicimos de los resultados a nivel inter-sujeto, limitó nuestro estudio, pero creemos que permitió la comprensión del impacto que estudiamos desde sus generalidades presentes en la muestra. El motivo de esta decisión nos permitió resolver los problemas de investigación planteados en nuestro estudio.

Pese a lo anterior, el estudio del contenido de las unidades textuales nos ha permitido acceder a las alusiones directas de las personas entrevistadas que nos remiten a antecedentes de cada persona. Esperamos hacer posteriormente estudios de caso único con la información que disponemos. 


\subsubsection{Instrumento}

Dentro de las limitaciones del instrumento, creemos que el abordaje de los temas mediante una pregunta abierta, facilitó en algunos discursos alusiones a otros temas no comprendidos en nuestro estudio, que aunque en algunas ocasiones fueron un aporte para el entendimiento del fenómeno, también lentificó el tratamiento de tratamiento de los datos.

Debido a la diversidad de temas comprendidos en la entrevista en profundidad, y al amplio caudal de información obtenido, la administración de la entrevista fluctuó entre 45 minutos y una hora y media. Tiempo que consideramos relativamente extenso, sobretodo porque nos requirió disponer de meses para realizar la transcripción de las 60 entrevistas.

Otra limitación de nuestro estudio, tiene que ver con la contrastación de nuestros hallazgos con otras fuentes de información como test psicométricos que evalúen las necesidades que estudiamos. Como ya hemos dicho anteriormente, inicialmente habíamos contemplado la administración de técnicas cualitativas y cuantitativas. Sin embargo, pese a la inexistencia en Chile de estudios similares, y en consecuencia, la disposición en el mismo país de instrumentos psicométricos validados que evalúen apego, calidad de vida, bienestar psicológico, y estrés post-traumático; además de características propias de la muestra, como la edad superior a los 65 años de una proporción importante de EXPPS, y la imposibilidad de estudiar a un mínimo de 100 personas en un período de cinco meses que destinamos para la fase de recogida de datos en Chile, nos vimos en la necesidad de excluir estos resultados del actual proyecto.

No obstante lo anterior, hemos administrado un total de 6 cuestionarios que evalúan apego, calidad de vida, bienestar psicológico y soledad, a un grupo de 100 EXPPS y su descendencia. Información que esperamos forme parte de estudios posteriores.

\subsubsection{Factores contextuales}

Una limitación de tipo contextual que consideramos inevitable, tiene que ver con los hechos que suceden constantemente en Chile en relación al tema de los derechos humanos. Vemos así, por citar un ejemplo, la muerte de Pinochet en medio de múltiples procesos judiciales que quedaron inconclusos, y la representación individual y social de este acontecimiento en la vida de los EXPPS, y la sociedad chilena, como un factor que pudo haber influido en los procesos de reparación ante las experiencias de prisión vividas por las personas que estudiamos en nuestro estudio. 
Sumado a lo anterior, realizamos la fase de recogida de información en un momento históricopolítico que generaba incertidumbre a los EXPPS. Nos referimos específicamente al proceso de elecciones presidenciales del año 2005, en que se presentaban dos candidatos uno asociado a la derecha del país y otro a la izquierda. Esta última, elegida finalmente presidenta de Chile, Michelle Bachelet, tiene la particularidad de ser una EXPP, y con ello, percibimos grandes expectativas por parte de los EXPPS que entrevistamos, acerca de las mejoras en las medidas gubernamentales de reparación. Creemos que esta situación no dejaba indiferente a los EXPPS, quienes manifestaron sentimientos de temor y preocupación asociados a este momento histórico-político en Chile.

En general, no podemos concluir aspectos exclusivos del trauma de la experiencia de prisión después de 33 años. Pues de acuerdo a la continuidad del trauma planteado por distintos autores, la influencia de experiencias posteriores a la misma, y asociadas a ella, han afectado en el impacto en cuestión, y son imposibles de evaluar de manera aislada.

De acuerdo a lo anterior, no podemos diferenciar el impacto de la experiencia de prisión, del mismo impacto producto de sucesos posteriores a la experiencia y asociados a ella. Por esto, nuestros hallazgos comprenden el impacto en el tiempo causado desde la experiencia de prisión hasta el momento que accedimos a entrevistar a la muestra participante de nuestro estudio. Pero por ejemplo, podemos pensar que la implicación actual de los EXPPS en el ámbito político y la lucha por el respeto de los DDHH, nos pueden indicar uno de los efectos a largo plazo del trauma descrito por Bettelheim (1979).

\subsubsection{Síndrome de estrés postraumático}

Otra limitación de nuestro estudio, concierne la imposibilidad de establecer diagnósticos con el instrumento que empleamos, según la nosología psiquiátrica tradicional del trauma, SEPT, y apego. Pero podemos referirnos a indicadores de estos fenómenos.

\subsubsection{Apego}

Lamentablemente, no hemos podido contrastar con el instrumento administrado, los indicadores que obtuvimos del patrón de apego de los participantes del estudio, pues para ello consideramos apropiado evaluar este tipo de patrón, con evaluaciones psicométricas validas y fiables para la población estudiada, siendo este aspecto, otra limitante en nuestro estudio. 


\subsubsection{Dirigentes de agrupaciones de Derechos humanos y EXPPS}

El criterio de selección de la muestra mediante agrupaciones de derechos humanos y partidos políticos en Chile, refiere una selección sesgada de la muestra de EXPPS participantes del estudio. Creemos que este tipo de participación, es un factor que podría influir en la satisfacción de sus necesidades sociales. Esta limitación, nos impidió evaluar el impacto emocional y social de la privación de libertad y tortura por motivos políticos en una parte de la población de EXPPS chilenos que cesó su participación política. Creemos que este es un grupo de personas que podría presentar resultados diferentes a los obtenidos en esta investigación, pero lamentablemente no pudimos constatarlo en nuestro estudio. 
Privación de libertad y tortura política en Chile (1973-1990) 


\section{CAPÍTULO VII}

\section{CONCLUSIONES Y SUGERENCIAS.}


Privación de libertad y tortura política en Chile (1973-1990) 
Después de haber desarrollado el modelo teórico que sustenta nuestra investigación y el diseño metodológico que empleamos para conocer los efectos a largo plazo de la prisión política y la tortura en un grupo de 60 supervivientes chilenos, concluimos que el diseño metodológico que desarrollamos y la teoría de las necesidades interpersonales que enmarcó nuestro estudio, nos permitieron acceder a un conocimiento específico del impacto emocional y social que experiencias de prisión política y tortura provocaron a un grupo de supervivientes chilenos. Este impacto se evidenció en la particularidad de las tendencias presentes en los participantes a nivel inter-sujeto, que nos permiten concluir la presencia de efectos emocionales y sociales de la prisión y tortura por motivos políticos evidenciados en aspectos interpersonales con la familia, los amigos y la pareja.

La información obtenida, nos permitió además describir los efectos de estas experiencias traumáticas y de acuerdo a ello, concluimos que:

Los EXPPS participantes de nuestro estudio, refieren mayoritariamente satisfacción en torno a las relaciones interpersonales emocionales que mantienen con la familia actual y la familia de origen; y a nivel social, con los amigos y los compañeros políticos. La satisfacción con la que estas personas valoran las relaciones interpersonales recién aludidas, se mantiene desde antes de la experiencia de prisión política y tortura. Además afirman disponer de apoyo incondicional por parte de familiares y amigos, lo que se presentó desde la infancia. No obstante, la valoración positiva que los EXPPS hicieron de la familia de origen en el presente, disminuyó en relación a la misma en el pasado, y las demás valoraciones que hacen del resto de sus relaciones interpersonales, aumentó positivamente en la actualidad. Esto nos indica, que en general los EXPPS participantes del estudio, valoran satisfactoriamente sus relaciones interpersonales actuales principalmente con la familia que han formado en torno a la pareja actual, lo que nos indica que estas personas han podido resolver sus necesidades interpersonales básicas emocionales planteadas por López (2008).

De acuerdo a las necesidades mentales y culturales, concluimos que la valoración negativa que presentan la mayoría los EXPPS en relación al mundo, los seres humanos, la justicia en Chile, la respuesta social chilena percibida hacia el tema de los derechos humanos y las medidas gubernamentales de reparación, nos reflejan insatisfacción asociada a factores contextuales y específicamente a factores sociales que son producto de los efectos que estudiamos, y que inciden principalmente de manera negativa en las vidas de estas personas. 
Podemos asociar estas valoraciones negativas a la experiencia de prisión y la condición de EXPPS que disponen. Estas apreciaciones difieren de las mismas en el período pre-prisión, remitiéndonos a un impacto de la experiencia de prisión que influye a nivel interpersonal, y que hace que ellos busquen satisfacer sus necesidades interpersonales básicas con la familia. Al respecto, la mayoría de los EXPPS participantes del estudio manifiestan satisfacción asociada a sus relaciones de este tipo.

La tortura sexual aplicada principalmente a mujeres, y su consecuencia en la vida emocional y social de estas personas, nos remiten al género como un aspecto demográfico significativo de la experiencia de prisión, en comparación con los hombres. De las personas que refirieron haber estado en recintos no oficiales de reclusión, todos afirmaron haber sido víctimas de experiencias de tortura. El tiempo de permanencia en prisión no afectó de manera diferenciada en el impacto percibido de la misma experiencia en la propia vida y las relaciones interpersonales. Para los EXPPS que estuvieron detenidos más de una vez, la mayoría refiere temores asociados a tales experiencias. En general, de quienes eran padres al momento de su detención, la mayoría percibe el traspaso del trauma causado por la experiencia de prisión a los hijos.

Concluimos que en cuanto al género de los participantes, los hombres presentaron mayor satisfacción que las mujeres acerca de sus relaciones interpersonales familiares y sociales en el pasado; en relación a la edad, fueron las personas menores de 65 años quienes presentaron mayor insatisfacción con sus relaciones interpersonales familiares en la actualidad, y con la opinión de la sociedad chilena frente al tema de los derechos humanos, que las personas mayores de 65 años.

De acuerdo al lugar de residencia (regiones y capital de Chile), fueron los participantes de regiones los que mayormente guardaron en silencio sus experiencias de prisión y tortura, los que perciben mayormente el impacto de la prisión en sus vidas y sus relaciones interpersonales, refieren no haber superado la experiencia de prisión y tortura, y manifiestan mayor insatisfacción en relación a la respuesta social chilena que perciben en torno a los derechos humanos en Chile, que aquellas personas participantes del estudio residentes en la capital del país.

Concluimos además, que los EXPPS tienden a mantener en silencio el sufrimiento que experimentaron cuando fueron privados de su libertad por motivos políticos, producto de la dificultad que significa para ellos la no superación del trauma causado por esta experiencia, que entendemos como la perpetuidad del trauma. Esta tendencia se evidenció en la tendencia a la evasión manifestada por estas 
personas que no aludieron directamente temáticas asociadas al sufrimiento experimentado en prisión, y la tendencia a referir el sufrimiento experimentado por los compañeros políticos. Aunque esto fue aludido desde una perspectiva histórica de la propia experiencia de prisión y tortura, que evidenció que todos ellos vivieron situaciones dolorosas en prisión, causadas por el daño infligido hacia ellos mismos y sus compañeros. Además de la presencia de factores contextuales desfavorables presentes a lo largo de los años, desde el acontecimiento de prisión hasta la actualidad.

Este silencio, además es mantenido en las relaciones interpersonales, principalmente con los hijos, lo que denota el impacto de la experiencia de prisión en las relaciones paterno-filiales de estas personas, además de efectos del trauma que han sido traspasados a la descendencia. La valoración de este último efecto, ha sido aludida directamente por los EXPPS.

Los EXPPS hacen en su totalidad una valoración negativa de los agentes sociales que estuvieron implicados en la violación a los derechos humanos acontecida en Chile entre septiembre del año 1973 y marzo del año 1990. Es a estas personas a quienes atribuyen la respuesta negativa que perciben por parte de la sociedad chilena hacia el tema de los derechos humanos en Chile, y en especial hacia ellos mismos. Pues ellos consideran que fueron los personeros del gobierno militar los encargados de promover la estigmatización que perciben en la actualidad por parte de la sociedad chilena, habiendo afectado directamente en la exclusión y el rechazo social que refieren experimentar en la actualidad. Por su parte, la injusticia percibida de los personeros de gobierno que participaron durante el régimen militar y de la respuesta social chilena en la actualidad, es una valoración que los EXPPS hacen en común a los dos temas, y lo asocian a su experiencia de prisión y su condición actual de EXPPS.

Mayoritariamente los participantes del estudio refieren percibir el impacto de la experiencia de prisión en sus vidas. Esto lo perciben en la presencia de temores asociados a la experiencia de prisión, y principalmente en el traspaso de la experiencia traumática a su descendencia. En general, manifiestan cambios que son valorados negativamente en el ámbito interpersonal con la familia, los amigos, y los compañeros políticos. Lo que asociado a la predominante tendencia de una valoración de mundo negativa por causa humana, y específicamente por motivos políticos, que difiere de la valoración de mundo positiva que los EXPPS afirmaron presentar durante su infancia y adolescencia previa a la experiencia de prisión, nos permite concluir el impacto de la experiencia de prisión en sus vidas.

La valoración negativa de los seres humanos en la actualidad, producto de la experiencia de prisión política y tortura, sumado al rechazo percibido de la sociedad chilena, a la no superación de la 
experiencia de prisión, y al impacto percibido de la misma en sus vidas, forman parte de los efectos de la experiencia de prisión política que estudiamos y que vemos reflejado en sus problemas actuales asociados a la experiencia política. Todo lo que sumado nos remite a aspectos contextuales valorados negativamente por los participantes de la investigación, y a la presencia de aspectos desfavorables en sus vidas, que afectan negativamente en la satisfacción de sus necesidades interpersonales básicas.

Concluimos que en la muestra estudiada, el impacto de la experiencia de prisión no es causado solamente por el hecho específico de la experiencia de prisión y tortura, sino que muy probablemente se inició en ese momento, o en algunos casos, en un momento previo cuando eran perseguidos por los mismos motivos políticos, pero se mantiene durante años por diversos factores contextuales que en el caso de la muestra estudiada, se han presentado desde que fueron liberados, hasta la actualidad. Nos referimos a aspectos tales como las dificultades de reinserción al mundo laboral por antecedentes penales, la estigmatización y el rechazo percibidos por parte de la sociedad chilena, la insatisfacción en relación a las medidas gubernamentales de reparación en torno a temas económicos, educativos, de vivienda y salud, que son vitales para el desarrollo saludable de todo ser humano, y principalmente para personas que han sufrido una quiebra en sus vidas y presentan síntomas y enfermedades físicas y mentales asociadas a la experiencia de tortura.

La insatisfacción con la que los EXPPS valoran las medidas gubernamentales de reparación y la respuesta social chilena, forman parte de los factores contextuales que inciden en la perpetuidad de los efectos traumáticos que estas personas presentan.

Finalmente, sostenemos que el impacto causado por la experiencia de prisión presente en los EXPPS participantes de esta tesis doctoral, estará presente durante toda la vida de estas personas, y los recuerdos de sus experiencias, no podrán borrarse jamás de sus memorias. Sin embargo, atender a los factores que inciden en la perpetuidad del trauma que corresponden a problemáticas actuales que presentan los EXPPS y que están relacionados a la experiencia de prisión, podría disminuir los efectos adversos en estas personas. Esto se logrará en la medida que estas personas perciban que sus peticiones son atendidas y se les otorguen espacios y reconocimientos sociales que apunten a reparar el respeto y la dignidad de todos ellos. El Informe Valech en un intento por reparar a las víctimas, fue pionero en otorgar medidas compensatorias a las víctimas chilenas, aunque éstas no fueron bien valoradas por los EXPPS participantes del estudio, y fueron valoradas con insatisfacción. Actualmente, es posible la mejora de éstas. 
Este es un tema complejo, porque en general, y de acuerdo a los resultados que obtuvimos en esta investigación, la reparación real en la vida de quienes supervivieron a hechos extremos de represión política, no es posible. Esto hace difícil establecer criterios que sean valorados positivamente por las víctimas. Pero creemos que la reparación no sólo debe incluir a las víctimas directas y a su descendencia, sino que también a toda la sociedad chilena que también se vio afectada por estos hechos, y que actualmente es percibida negativamente por los EXPPS. Para ello, escuchar las necesidades y problemas de los mismos EXPPS sería importante para conocer desde los más afectados, los problemas que les aquejan. Esto podría subsanar la perpetuidad del trauma que presentan actualmente.

Para futuras investigaciones en el tema, sugerimos que se realicen evaluaciones que comprendan los factores contextuales que hemos estudiado en nuestra investigación, y las características demográficas de la experiencia de prisión.

Sugerimos además, que se estudie el impacto de la experiencia de prisión en la descendencia de hijos y nietos, porque consideramos que el impacto de la experiencia de prisión y tortura por motivos políticos afecta a todo el entorno familiar y social de las victimas.

En cuanto a diseños metodológicos, consideramos importante la validación de test psicométricos que puedan aplicarse a estas personas de acuerdo a sus características demográficas que determinan su particularidad como grupo.

A nivel clínico, creemos que en la atención en salud mental de estas personas, deben considerarse protocolos de atención que consideren las problemáticas actuales de los EXPPS y sus cogniciones acerca del mundo, la vida y los seres humanos. Aspectos que deben ser vistos como parte de la perpetuidad del trauma que presentan estas personas. 
Privación de libertad y tortura política en Chile (1973-1990) 


\section{CAPÍTULO VIII}

\section{REFERENCIAS BIBLIOGRÁFICAS.}


Privación de libertad y tortura política en Chile (1973-1990) 
Abdilgaard, U., Daugaard, G., Marcussen, H., Jess, P., Petersen, H. D., y Wallach, M. (1984). Chronic syndrome in Greek torture victims. Danish Medical Bulletin, 31, 239-242.

Ackerman, L. K. (1997). Health problems of refugees. Journal of the American Board of Family Practice, 10, 337-348.

Ainsworth, M. D. S., Blehar, M., Waters, E. y Wall, S. (1978). Patterns of Attachment: a Psychological Study of Strange Situation. Hillsdale, Nueva Jersey: Erlbaum.

Allden, K., Poole, C., Chantavanich, S., Ohmar, K., Aung, N. N. y Mollica, R. F. (1996) Burmese political dissidents in Thailand: Trauma and survival among young adults in exile. American Journal of Public Health, 86, 1561-1569.

Allodi, F. (1991). Assessment and treatment of torture victims: a critical review. The Journal of Nervous and Mental Disease, 179, 4-11.

Allodi, F. y Cowgill, G. (1982). Ethical and psychiatric aspects of torture: a Canadian study. The Canadian Journal of Psychiatry, 27, 98-102.

Allodi, F. y Stiasny, S. (1990). Women as torture victims. The Canadian Journal of Psychiatry, 35, 144-148.

Allotey, P. (1998). Travelling with "excess baggage": Health problems of refugee women in Western Australia. Women Health, 28, 63-81.

American Psychiatric Association. (1980). Diagnostic and statistical manual of mental disorders (3a. ed.). Washington, DC, EE. UU.: Autor.

American Psychiatric Association. (1987). Diagnostic and statistical manual of mental disorders (3a. ed. rev.) Washington, DC, EE. UU. : Autor.

Amnesty International. (1987). Amnesty International Report 1987. Londres, Reino Unido: Autor.

Amnesty International. (2001). Amnesty International Report. Oxford, Reino Unido: Autor.

Amnesty International Danish Medical Group. (1979). Manual for medical groups. Dinamarca: Autor.

Andreason, N. C. (1980). Posttraumatic stress disorder. En H. I. Kaplan, A. M. Freedman y B. J. Sadock (Eds.), Comprehensive textbook ofpsychiatry ( $3^{\mathrm{a}}$ Ed.). Baltimore, MD: Williams and Wilkins Co. 
Anguera, M. T. (1986). La investigación cualitativa. Educar, 10, 23-50.

Arregui, R. (2002). Resiliencia: una estrategia en la rehabilitación en pacientes víctimas del terrorismo de Estado. En D. Kersner y Madariaga, C. (Eds.), Paisajes del dolor, senderos de esperanza. Salud mental y derechos bumanos en el Cono Sur (pp. 245-254). Buenos Aires, Argentina: Polemos.

Askevold, F. (1980). The war sailor syndrome. Danish Medical Bulletin, 27, 220-223.

Baker, R. (1992). Psychological consequences for tortured refugees seeking asylum and refugee status in Europe. En M. Basoglu (Ed.), Torture and its consequences: Current treatment approaches (pp 83- 106). Cambridge, Reino Unido: Cambridge University Press.

Bardín, L. (1986). Análisis de contenido. Madrid: Akal.

Bar-On, D., Eland, J., Kleber, R.-J., Krell, R., Moore, Y., Sagi, A., et al. (1998). Multigenerational perspectives on coping with the Holocaust experience: An attachment perspective for understanding the developmental sequelae of trauma across generations. International Journal of Behavioral Development, 22, 315-338.

Barudy, J. y Dantagnan, M. ( 2005). Los buenos tratos en la infancia. Parentalidad, apego y resiliencia. Barcelona, España: Gedisa.

Basoglu, M., Livanou, M. y Crnobaric, C. (2007). Torture versus other cruel, inhuman and degrading treatment: Is the distinction real or apparent?. Archives of General Psychiatry, 64, 277-285.

Basoglu, M., y Marks, I. (1988). Torture: Research needed into how to help those who have been tortured. British Medical Journal, 297, 1423-1424.

Basoglu, M., Mineka, S., Paker, M., Aker, T., Livanou, M. y Gok, S. (1997). Psychological preparedness for trauma as a protective factor in survivors of torture. Psychological Medicine, 27, 1421-1433.

Basoglu, M., Ozmen, E., Sahin, D., Paker, M., Tasdemir, O., Ceyhanli, A., Incesu, C., Sarimurat, N. (1996). Appraisal of self, social environment, and state authority as a possible mediator of posttraumatic stress disorder in tortured political activists. Journal of Abnormal Psychology, 105, 232-236.

Basoglu, M. y Paker, M. (1995) Severity of trauma as predictor of long-term psychological status in survivors of torture. Journal of Anxiety Disorders, 9, 339-350. 
Becker, D. (2003, octubre). Mental Health and Human Rights: Thinking About the Relatedness of Individual and Social Processes. Documento presentado en la International Conference “Towards a Better Future Building Healthy Communities", Belfast, Reino Unido.

Becker, D., Castillo, M. I., Gómez, E., Kovalskys, J. y Lira, E. (1989). De la estrategia del silencio a la ética del conflicto. En D. Becker y Lira, E. (Eds.), Derechos humanos: todo es según el dolor con que se mira. Santiago de Chile: Instituto latinoamericano de salud mental y derechos humanos.

Beiser, M., Cargo, M. y Woodbury, M. A. (1994). A comparison of psychiatric disorder in different cultures: Depressive typologies in Southeast Asian refugees and resident Canadians. International Journal of Methods in Psychiatric Research, 4, 157-172.

Beiser, M., Johnson, P. J. y Turner, R. J. (1993). Unemployment, underemployment and depressive affect among Southeast Asian refugees. Psychological Medicine, 23, 731-743

Bendfeldt-Zachrisson, F. (1985). State (political) torture: Some general, psychological and particular aspects. International Journal of Health Services, 15, 339-349.

Benyakar, M., Kutz, E., Dasberg, H. y Stern, M. J. (1989). The collapse of a structure: A structural approach to trauma. Journal of Traumatic Stress, 2, 431-449.

Bettelheim, B. (1979). Surviving and other essays. Nueva York: Alfred A. Knopf.

Bettelheim, B. (1981). Sobrevivir: el holocausto una generación después. Barcelona: Crítica.

Blaszczynski, A., Gordon, K., Silove, D., Sloane, D., Hillman, K., Panasetis, P. (1998). Psychiatric morbidity following motor vehicle accidents: A review of methodological issues. Comprehensive Psychiatry, 39, 111 121.

Bowlby, J. (1969). Attachment and loss: Vol. 1. Attachment. Nueva York: Basic Books.

Bowlby, J. (1973). Attachment and loss: Vol. 2. Separation. New York: Basic Books.

Bowlby, J. (1980). Attachment and loss: Vol. 3. Loss, sadness and depression. Nueva York: Basic Books.

Bowlby, J. (1984). Violence in the family as a disorder of the attachment and caregiving systems. American Journal of Psychoanalysis, 44, 9-27. 
Bracken, P. J., Giller, J. E. y Summerfield, D. (1995). Psychological responses to war and atrocity: The limitations of current concepts. Social Science and Medicine, 40, 1073-1082.

Brett, E. A. y Ostroff, R. (1985). Imagery and posttraumatic stress disorder: an overview. American Journal of Psychiatry, 142, 417-424.

Brinkmann, B. (2002). La labor de CINTRAS en el contexto de los derechos humanos en Chile. En D. Kersner y C. Madariaga (Eds.), Paisajes del dolor, senderos de esperanza. Salud mental y derechos bumanos en el Cono Sur (pp. 45-60). Buenos Aires, Argentina: Polemos.

British Medical Association (1986). The Torture Report. Londres, Reino Unido: Autor.

Bronfenbrenner, U. (1979). The Ecology of Human Development: Experiments by Nature and Design. Cambridge, Reino Unido: Harvard University Press.

Burgess, A. W. y Holmstrom, L. L. (1974). Rape trauma syndrome. American Journal of Psychiatry, 131,981-986.

Cabero, J., Loscertales, F. (1996). Elaboración de un sistema categorial de análisis de contenido para analizar la imagen del profesor y la enseñanza en la prensa. Bordón: Revista de orientación pedagógica, 48, 375-392.

Calderón, M. (1989). Transición política en Chile: posibilidades de la reconceptualización de la democracia. En D. Becker y E. Lira (Eds.), Derechos humanos: todo es según el dolor con que se mira. Santiago de Chile: Instituto latinoamericano de salud mental y derechos humanos.

Carcedo, R. (2005). Necesidades sociales, emocionales y sexuales. Estudio en un centro penitenciario. Salamanca: Servicio de Publicaciones de la Universidad de Salamanca.

Carreras, M. A., Brizzio, A., Casullo, M. M. y Saavedra, E. (2006, agosto). Evaluación de los estilos de apego en adolescentes y su relación con los síntomas psicopatológicos. Sesión de cartel presentada en las XIII Jornadas de Investigación y Segundo Encuentro de Investigadores en Psicología del MERCOSUR, Argentina: Universidad de Buenos Aires.

Castillo, M. I. y Gómez, E. (1989). Te escribo para contarte que el sol quema fuerte por estos lados. En D. Becker y E. Lira (Eds.), Derechos bumanos: todo es según el dolor con que se mira (pp. 22-54). Santiago de Chile: ILAS. 
Casullo, M. M. y Fernández Liporace, M. (2004). Los estilos de apego. Teoría y medición. Buenos Aires: JVE.

Cathcart, L.M., Berger, P. y Knazan, B. (1979). Medical examination of torture victims applying for refugee status. Canadian Medical Association Journal, 121, 179-184.

Chung, R. C. y Kagawa-Singer, M. (1993) Predictors of psychological distress among southeast Asian refugees. Social Science and Medicine, 36, 631-639.

Cohn, J., Danielsen, L., Holzer, K. I. M., Koch, L., Severin, B., Thogersen, S. y Aalund, O. (1985). A study of Chilean refugee children in Denmark. The Lancet, 2, 437-438.

Corrado, R. R. (1988). Victims of extreme state terrorism. En E. Fattah (Ed.), Theplight ofthe victim in modern society. Londres: MacMillan Press Ltd.

Corrado, R. R. y Tompkins, E. (1989). A comparative model of the psychological effects on the victims of state and anti-state terrorism. Interntional Journal of Law and Psychiatry, 12, 281-293.

Crittenden, P. (1992). Quality of attachment in the preschool years. Development and Psychopathology, 4, 209-242.

Deci, E. L. y Ryan, R. M. (1985). Intrinsic motivation and self-determination in human behavior. New York: Plenum.

Deci, E. L., y Ryan, R. M. (2000). The "what" and "why" of goal pursuits: Human needs and the selfdetermination of behavior. Psychological Inquiry, 11, 227-268.

DiTomasso, E. y Spinner, B. (1993). The development and initial validation of the Social and Emotional Loneliness Scale for Adults (SELSA). Personality and Individual Differences, 14, 127-134.

Dor-Shav, N. K. (1978). On the long-range effect of conceptration camp internment on nazi victims: 25 yeans later. Journal of Consulting and Clinical Psychology, 46, 1-11.

Doyal, L. y Gough, I. (1994). Teoría de las necesidades humanas (Trads. J. A. Moyano y A. Colás). Barcelona: Icaria. (Trabajo original publicado en 1992).

Eisenbruch, M. (1991). From post-traumatic stress disorder to cultural bereavement: Diagnosis of Southeast Asian refugees. Social Science \& Medicine, 33, 673-680. 
Ekblad, S. y Roth, G. (1997). Diagnosing posttraumatic stress disorder in multicultural patients in a Stockholm psychiatric clinic. The Journal of Nervous and Mental Disease, 185, 102-107.

Erikson, E. (1968). Identidad, Juventud y Crisis. Buenos Aires, Argentina: Paidos.

Flynn, E. (1987). Victims of terrorism: Dimensions of the victim experience. En P. Wilkinson y A. M. Stewart (Eds.), Contemporary research on terrorism (pp. 337-357). Aberdeen, Reino Unido: The University Press.

Fornazzari, X. y Freire, M. (1990) Women as victims of torture. Acta Psychiatrica Scandinavica, 82, 258-260.

Fundación de Ayuda Social de las Iglesias Cristianas. (1987). Trauma, Duelo y Reparación. Santiago de Chile: Interamericana.

Garbolino, P. y Taroni, F. (2002) Evaluation of scientific evidence using Bayesian networks, Forensic Science International, 125, 149-155.

Garretón, R. (2004). Una perspectiva desde el derecho internacional de los derechos humanos. En P. Verdugo (Ed.), De la tortura NO se habla: Agüero versus Meneses (pp. 141-180). Chile: Catalonia.

Gobierno de Chile. (2004). Informe de la Comisión Nacional sobre Prisión Política y Tortura. Recuperado el 9 de noviembre de 2005 en: http://www.gobiernodechile.cl/comision_valech/index.asp

Goldfeld, A.E., Mollica, R. F., Pesavento, B. H. y Faraone, S. V. (1988). The psysical and psychological sequelae of torture. Journal of the american medical association, 259, 2725-2729.

Gorst-Unsworth, C. y Goldenberg, E. (1998). Psychological sequelae of torture and organized violence suffered by refugees in Iraq: Trauma-related factors compared with social factors in exile. The British Journal of Psychiatry, 172, 90-94.

Gorst-Unsworth, C., Van Velsen, C., Turner, S. (1993). Prospective pilot study of survivors of torture and organized violence: examining the existential dilemma. The Journal of Nervous and Mental Disease, 181, 263264.

Green, B. L. (1996). Traumatic stress and disaster: Mental health effects and factors influencing adaptation. En F. L. Mak y C. C. Nadelson (Eds.), International review of psychiatry (pp 177-210). Washington, DC: American Psychiatric Press. 
Gutiérrez, P. (Ed.). (2005) Memorias de ocupación: violencia sexual contra mujeres detenidas durante la dictadura. Santiago de Chile: Fundación Instituto de la Mujer.

Hatcher, C. (1987). A conceptual framework in victimology: The adult and child hostage experience. En P. Wilkinson y A. M. Stewart (Eds.), Contemporary research on terrorism (pp. 357-376). Aberdeen: University Press.

Hauff, E. y Vaglum, P. (1993). Vietnamese boat refugees: the influence of war and flight traumatization on mental health on arrival in the country of resettlement: A community cohort study of Vietnamese refugees in Norway. Acta Psychiatrica Scandinavica, 88, 162-168.

Hauff, E. y Vaglum, P. (1995). Organised violence and the stress of exile: Predictors of mental health in a community cohort of Vietnamese refugees three years after resettlement. The British Journal of Psychiatry, 166, 360-367.

Hazan, C. y Shaver, P. R. (1987). Romantic love conceptualized as an attachment process. Journal of Personality and Social Psychology, 52, 511-524.

Herman, J. L. (1993). Sequelae of prolonged and repeated trauma: evidence for a complex posttraumatic stress syndrome (DESNOS). En J. R. T. Davidson y E. D. Foa (Eds.), Post-traumatic stress disorder: DSM-IV and beyond (pp. 213-228). Washington, DC, EE. UU.: American Psychiatric Press.

Hinton, W.L., Chen, Y. C., Du, N., Tran, C. G., Lu, F. G., Miranda, J. y Faust, S. (1993) DSM-III-R disorders in Vietnamese refugees: Prevalence and correlates. The Journal of Nervous and Mental Disease, 181, 113122.

Hinton, W. L., Tiet, Q., Tran, C.G. y Chesney, M. (1997). Predictors of depression among refugees from Vietnam: A longitudinal study of new arrivals. The Journal of Nervous and Mental Disease,185, 39-45.

Hobfoll, S. E. (1985). Stress, Social Support, and Women. Nueva York: Hemisphere.

Holtz, T. H. (1998). Refugee trauma versus torture trauma: a retrospective controlled cohort study of Tibetan refugees. The Journal of Nervous Mental Disease, 186, 24-34.

Horowitz, M. (1986). Stress Response Syndrome. Northvale, Nueva Jersey: Aronson. 
Horowitz, M. J. (1976). Stress response syndromes (2a ed.). New York: Jason Aronson.

Hougen, H. P., Kelstrup, J. , Petersen, H. D. y Rasmussen, O. V. (1988) Sequelae to torture. A controlled study of torture victims living in exile. Forensic Science International, 36, 153-160.

Human Rights and Equal Opportunity Commission. (1998). Those who've come across the seas: Detention of unauthorised arrivals. Sydney, Australia: Autor.

Hunter, E. J. (1991). Prisoners of war: readjustment and rehabilitation. En R. Gal, y A. D. Mangelsdorf (Eds.), Handbook of Military Psychology (pp. 491-505). Nueva York: Wiley.

Hunter, E. J. (1993). The Vietnam prisoner of war experience. En J. P. Wilson, y B. Raphal, (Eds.), International Handbook of Traumatic Stress Syndromes (pp. 297-303). Nueva York: Plenum Press.

Igartua, J. J. y Humanes, M. L. (2004). El método científico aplicado a la investigación en comunicación social. Recuperado el 2 de marzo de 2006, del sitio Web del Portal de la Comunicación del Instituto de la comunicación de la Universidad Autónoma de Barcelona: http://www.portalcomunicacion.com/esp/n_aab_lec_3.asp?id_llico=6

Igreja, V. (2003). The effects of traumatic experiences on the infant-mother relationship in the Former war zones of central mozambique: The case of madzawde in gorongosa Infant mental health journal, Vol. 24, 469-494.

Instituto Nacional de Estadísticas. (2004). Chile: proyecciones y estimaciones de población. Total país, 19502050. ( $N^{o}$ de publicación OI No 208). Santiago de Chile: CEPAL.

Johnston, D. (1995). Effects of parental incarceration. En K. Gabel y D. Johnston (Eds.), Children of incarcerated parents (pp. 59-88). Nueva York: Lexington Books.

Keilson, H. (1992). Sequential Traumatization in Children. Jerusalem: Magnes Press, Hebrew University.

Kellermann, N. P. F. (1999). Diagnosis of holocaust survivors and their children. Israel Journal of Psychiatry \& Related Sciences, 36, 56-65.

Kennedy-Moore, E. y Watson, J. C. (1999). Expressing emotion. Nueva York: The Guilford Press.

Kinzie, J. D. (1985). Cultural aspects of psychiatric treatment with Indochinese refugees. American Journal of Social Psychiatry, 5, 47-53. 
Kinzie, J. D., Fredrickson, R. H., Ben, R., Fleck, J. y Karls, W. (1984). Post-traumatic stress disorder among survivors of Cambodian concentration camps. American Journal of Psychiatry, 14, 645-650.

Kobak, R. R. y Sceery, A. (1988). Attachment in late adolescence: working models, affect regulation, and representations of self and others, Child Development, 59, 135-146.

Kozaric-Kovacic, D., Folnegovic-Smalc, V., Skrinjaric, J., Szajnberg, N. M. y Marusic, A. (1995). Rape, torture, and traumatization of Bosnian and Croatian women: Psychological sequelae. American Journal of Orthopsychiatry, 65, 428-433.

Krippendorff, K. (1990). Metodología del análisis de contenido. Barcelona: Paidós.

Krystal, H. y Niederland, W. G. (1968). Clinical observations on the survivor syndrome. En H. Krystal (Ed.), Massive psychic trauma (pp 327-348). Nueva York: International Universities Press.

Lagos, R. (2004). Discurso de S. E. El Presidente de la República, Ricardo Lagos, en la presentación del Informe de la comisión nacional sobre prisión política y tortura [Reseña del Informe de la comisión nacional sobre prisión política y tortura]. Recuperado el 9 de noviembre de 2005 en: http://www.comisionprisionpoliticaytortura.cl/discurso.html

Laplanche, J. y Pontalis, J. B. (1981). Diccionario de Psicoanálisis. Barcelona: Editorial Labor.

Lasaga, O. (2004). La identidad europea como construcción social compleja: análisis de la borrosidad en el discurso de la identidad europea generado mediante escenarios de futuro. Tesis doctoral no publicada. Universitat de Barcelona, España.

Lavik, N. J., Hauff, E., Skrondal, A. y Solberg, O. (1996). Mental disorder among refugees and the impact of persecution and exile: Some findings from an outpatient population. The British Journal of Psychiatry, 169, 726-732.

Levi, P. (1987). If this is a man: The truce. Londres: Penguin Books.

Lira, E. (1991). Psicología del miedo y conducta colectiva en Chile. En I. Martín-Baró (Ed.), Psicología social de la guerra (pp. 175-196). San Salvador, El Salvador: UCA.

Lira, E. (1989). Psicología de la amenaza política y el miedo. Santiago de Chile: ILAS. 
Lira, E., Becker, D. y Castillo, M. I. (1989). Psicoterapia de víctimas de represión política bajo dictadura: un desafío terapéutico, teórico y político. En D. Becker y E. Lira (Eds.), Derechos humanos: todo es según el dolor con que se mira (pp. 22-54). Santiago de Chile: ILAS.

Lira, E., Becker, D. y Castillo, M. I. (1990). Psychotherapy with victims of political repression in Chile: A therapeutic and political challenge. In J. Gruschow y K. Hannibal (Eds). Health Services for the Treatment of Torture and Trauma Survivors. (pp. 91-114). Washington, D.C., EE. UU.: American Academy for the Advancement of Science.

Lira, E., Becker, D., Kovalskys, J., Gómez, E. y Castillo, M. I. (1989). Daño social y memoria colectiva: perspectivas de reparación. En D. Becker y E. Lira (Eds.), Derechos humanos: todo es según el dolor con que se mira. Santiago de Chile: Instituto latinoamericano de salud mental y derechos humanos.

López, F. (1995a). Necesidades de la Infancia y Protección Infantil I. Fundamentación teórica, clasificación y criterios educativos de las necesidades infantiles. Madrid: Ministerio de Asuntos Sociales.

López, F. (1995b). Necesidades de la Infancia y Protección Infantil II. Actuaciones frente a los malos tratos y desamparo de menores. Madrid: Ministerio de Asuntos Sociales.

López, F. (2008). Necesidades infantiles: Respuesta familiar, escolary social. España: Pirámide, S. A.

López, F., Etxebarria, I., Fuentes, M. A. y Ortiz, M. J. (1999). Desarrollo afectivo y social. Madrid: Pirámide, S. A.

López, F., Gómez, J., Apodaca, P., Delgado, A. y Marcos, C. (1994). Historia familiar y de apego, estilo educativo, empatía y estilo de apego actual, como mediadores del grado de satisfacción en las relaciones generales, afectivas y sexuales de la pareja. Cuadernos de Medicina Psicosomática, 28/29, 19-34.

Lunde, I., Ramussen, O.V., Lindholm, J., y Wagner, G. (1980). Gonadal and sexual functions in tortured Greek men. Danish Medical Bulletin, 27, 243-245.

MacDonald, B., Mummery, C. y Heaney, D. (2001). Health needs of asylum seekers and refugees: Head injury needs to be taken into consideration in survivors of torture [Versión electrónica]. British Medical Journal, 322, 544-547. 
Madariaga, C. (2000). Trauma psicosocial, trastorno de estrés postraumático y tortura. En ECAP, ODHAG e IRCT (Eds.), Primer Seminario Latinoamericano y del Caribe, Red Salud DDHH: La tortura y otras violaciones de los derechos bumanos (pp. 1-24). Antigua, Guatemala: Autor.

Madariaga, C. (2002). Modernidad y retraumatización: lo público y lo privado en el sujeto social chileno. En D. Kersner y Madariaga, C. (Eds.), Paisajes del dolor, senderos de esperanza. Salud mental y derechos humanos en el Cono Sur (pp. 71-84). Buenos Aires, Argentina: Polemos.

Madariaga, C. (2006) Retraumatización: hacia una conceptualización necesaria [versión electrónica], Revista Reflexión, 32, 4-8.

Main, M. y Cassidy, J. (1988). Categories of response to reunion with the parents at age 6: predictable from infant attachment classifications and stable over a month period. Developmental Psychology, 24, 415-426.

Main, M. y Hesse, E. (1990). Parents' unresolved traumatic experiences are related to infant disorganized attachment status: Is frightened and/or frightening parental behavior the linking mechanism?. En M. Greenberg, D. Cicchetti, y M. Cummings (Eds.), Attachment in the preschool years: Theory, research, and intervention (pp. 161-182). Chicago, IL: University of Chicago Press.

Martín, A. (2002). El fracaso del leteo o la imposibilidad del olvido. En D. Kersner y Madariaga, C. (Eds.), Paisajes del dolor, senderos de esperanza. Salud mental y derechos humanos en el Cono Sur (pp. 203-214). Buenos Aires, Argentina: Polemos.

Martín, Q., Morán, M. y Albajar, R. (1999) Paquetes estadísicos SPSS 8.0. Bases teóricas, prácticas propuestas, resueltas y comentadas. Salamanca: Hespérides.

Martín-Baró, I. (1988). La violencia política y la guerra como causas en el país del trauma psicosocial en El Salvador. Revista de Psicología de El Salvador, 28, 123-141.

Martín-Baró, I. (1989). Introducción. En E. Lira (Ed.), Todo es según el dolor con que se mira (pp. 8-11). Santiago de Chile: ILAS.

McFarlane, A. C. (1987). Life events and psychiatric disorder: The role of a natural disaster. British Journal of Psychiatry, 151, 362-367. 
McNally, R. (1992). Psychopathology of post-traumatic stress disorder: Boundaries of the syndrome. En M. Basoglu (Ed.), Torture and its consequences: Current treatment approaches (pp 229-252). Cambridge, UK: Cambridge University Press.

Mickelson, K. D., Kessler, R. C. y Shaver, P. R. (1997). Adult attachment in a nationally representative sample. Journal of Personality and Social Psychology,73, 1092-1106.

Mikulincer, M. y Florian, V. (1999). The association between parental reports and attachment style and family dynamics, and offspring's reports of adult attachment style. Family Process, 38, 243-258.

Mikulincer, M. y Shaver, P. R. (2003). The Attachment behavioral system in adulthood: activation, psychodynamics, and interpersonal processes. In M. P. Zanna (Ed.), Advances in Experimental Social Psychology (Vol. 35, pp. 53-152). New York: Academic Press.

Moisander, P. A. y Edston, E. (2003). Torture and its Sequel - A Comparison between Victims from six Countries. Forensic Science International, 137, 133-140.

Mollica, R. F. y Caspi-Yavin, Y. (1992). Overview: The assessment and diagnosis of torture events and symptoms. En M. Basoglu (Ed.), Torture and its consequences (pp 253-274). Cambridge, Reino Unido: Cambridge University Press.

Mollica, R. F., Donelan, K., Tor, S., Lavelle, J., Elias, C., Frankel, M., et al. (1993). The effect of trauma and confinement on functional health and mental health status of Cambodians living in Thailand-Cambodia border camps. JAMA 270, 581-586.

Mollica, R. F., Wyshak, G., y Lavelle, J. (1987). The psycho-social impact of war trauma and torture on southeast Asian refugees. American Journal of Psychiatry, 144, 1567-1572.

Moreno, A., y Grodin, M. A. (2002). Torture and its neurological sequelae. Spinal Cord, 40, 213-223.

Moulian, T. (1998). Chile actual: Anatomía de un mito. Santiago de Chile: LOM-Universidad Arcis.

Murillo, S. (2004). Introducción a las técnicas cualitativas en un marco documental. En J. A. Frías y A. B. Ríos (Eds.), Metodologías de investigación en información y documentación (pp. 213-224) España: Universidad de Salamanca. 
Myers, B. J., Smarsh, T. M., Amlund-Hagen, K., y Kennon, S. (1999). Children of incarcerated mothers. Journal of Child and Family Studies, 8, 11-25.

Ochaita, E., Espinoza, M. A. (Eds.) (2004). Hacia una teoría de las necesidades infantiles y adolescentes. España: Editorial McGraw-Hill.

Peters, E. (1985). Torture. Oxford, Inglaterra: Blackwell.

Petersen, H. D., Abildgaard, U., Daugaard, G., Jess, P., Marcussen, H. y Wallach, M. (1985). Psychological and physical long-term effects of torture. Scandinavian Journal of Social Medicine, 13, 89-9 3.

Pinto, M. y Gálvez, C. (1999). Análisis documental de contenido. Madrid: Editorial Síntesis.

Pitman, M. A. y Maxwell. J. A. (1992). Qualitative Approaches to Evaluation: Models and Methods. En M. D. LeCompte, W. L. Millroy y J. Preissle (Eds.), The Handbook of Qualitative Research in Education, (pp. 727770). Londres: Academic Press.

Piwowarczyk, L., Moreno, A. y Grodin, M. (2000). Health Care of Torture Survivors. JAMA 284, 539-541.

QSR International Pty Ltd. (1997). NUD*IST (Versión 4) [Software de cómputo]. Melbourne, Australia.

QSR International Pty Ltd. (2002). N6 qualitative data analysis software (Versión 6) [Software de cómputo]. Melbourne, Australia.

Rachman, S. (1980). Emotional processing. Behaviour Research and Therapy,18, 51-60.

Ramanujam, B. K. (1992). Implications of some psychoanalytic concepts in the Indian context. En D. Spain (Ed.), Psychoanalytic anthropology (pp. 121-133). Nueva York: Psyche Press.

Raphael, B. y Middleton, W. (1988). After the horror. British Medical Journal, 296, 1142-1143.

Rasmussen, O. V. (1990) Medical aspects of torture. Danish Medical Bulletin, 37 (1), 1-88.

Rasmussen, O. V. y Lunde, I. (1980). Evaluation of investigation of 200 torture victims. Danish Medical Bulletin, 27, 241-243. 
Rasmussen, O.V. y Marcussen, H. (1982). The somatic sequelae to torture. Copenhague, Dinamarca. International Center for Rehabilitation of Torture Victims.

Real Academia Española. (2001). Diccionario de la lengua española (22 Edición) [ versión electrónica]. Consultado el 10 de octubre de 2004, de http://rae.es

Revuelta, F. I. y Sánchez, M. A. (2003). Programas de análisis cualitativo para la investigación en espacios virtuales de formación. Teoría de la educación: educación y cultura en la sociedad de la información, 4, . Recuperado el 20 de enero de 2005, de http://www.usal.es/ teoriaeducacion/ rev_numero_04/ n4_art_revuelta_sanchez.htm

Rey, P. (2005). Análisis temático de la obra narrativa y periodística de Manuel Vásquez. Montalbán. Tesis doctoral no publicada. Pontificia Universidad de Salamanca, España.

Reynolds, J. y Shackman, J. (1993). Refugees and Mental Health: Issues for Training. Mental Health News, Spring, 15-17.

Robaina, M. C. (2002). Tortura e impunidad. En D. Kersner y Madariaga, C. (Eds.), Paisajes del dolor, senderos de esperanza. Salud mentaly derechos humanos en el Cono Sur (pp. 101-108). Buenos Aires, Argentina: Polemos.

Rubenstein, C. M. y Shaver, P. (1982). The experience of loneliness. En L. A. Peplau y D. Perlman (Eds.), Loneliness: $A$ sourcebook of current theory, research and therapy (pp. 206-223). Nueva York: Wiley-Interscience.

Russell, D. (1982). The measurement of loneliness. En L. A. Peplau y D. Perlman (Eds.), Loneliness: A sourcebook of current theory, research and therapy (pp. 81-104). Nueva York: Wiley-Interscience.

Russell, D., Cutrona, C. E., Rose, J. y Yurko, K. (1984). Social and emotional loneniless: An examination of Weiss's typology of loneliness. Journal of Personality and Social Psychology, 46, 1313-1321.

Sagi, A., Van-Ijzendoorn, M. H., Joels, T. y Scharf, M. (2002). Disorganized reasoning in Holocaust survivors. American Journal of Orthopsychiatry, 72, 194-203.

Sagi-Schwartz, A., Koren-Karie, N. y Joels, T. (2003). Failed mourning in the Adult Attachment Interview: The case of Holocaust child survivors. Attachment and Human Development, 5, 398-408. 
Sagi-Schwartz, A., Van-Ijzendoorn, M. H., Grossmann, K.-E., Joels, T., Scharf, M., Koren-Karie, N., et al. (2003). Attachment and Traumatic Stress in Female Holocaust Child Survivors and Their Daughters. American Joumal of Psychiatry, 160, 1086-1092.

Schlapobersky, J. y Bamber, H. (1988, febrero). Rehabilitation and therapy with the victims of torture and organized violence. Documento presentado en la Annual Meeting of the American Association for the Advancement of Science. Washington, DC, EE. UU.

Shore, J.H., Tatum, E.L., y Vollmer, W.M. (1986). Psychiatric reactions to disaster: The Mount St. Helens experience. American Journal of Psychiatry, 143, 590-595.

Shrestha, N.M., Sharma, B., van Ommeren, M., Regmi, S., Makaju, R., Komproe, I., et al. (1998). Impact of torture on refugees displaced within the developing world: symptomatology among Bhutanese refugees. JAMA 280, 443-448.

Silove, D. (1996). Torture and refugee trauma: implications for nosology and treatment of posttraumatic syndromes. En F.L. Mak y C.C. Nadelson (Eds.), International Review of Psychiatry (pp. 211-232). Washington, DC, EE. UU.: American Psychiatric Press.

Silove, D. (1999). The Psychosocial Effects of Torture, Mass Human Rights Violations, and Refugee Trauma: Toward an Integrated Conceptual Framework. The Journal of Nervous \& Mental Disease, 187, 200-207.

Silove, D., McIntosh, P. y Becker, R. (1993). Risk of retraumatisation of asylum-seekers in Australia. Australian and New Zealand Journal of Psychiatry, 27, 606-612.

Silove, D., Sinnerbrink, I., Field, A., Manicavasagar, V. y Steel, Z. (1997). Anxiety, depression and PTSD in asylum seekers: Associations with pre-migration trauma and post-migration stressors. The British Journal of Psychiatry, 170, 351-357.

Simon, R. I. y Blum, R. A. (1987). After the terrorist incident: Psychotherapeutic treatment of former hostages. American Journal of Psychotherapy, 2, 194-200.

Solomon, Z., Ginzburg, K., Mikulincer, M., Neria, Y. y Ohry, A. (1998). Coping with war captivity: the role of attachment style. European Journal of Personality, 12, 271-285. 
Somasundaram, D. J. y Sivayokan, S. (1994). War trauma in a civilian population. The British Journal of Psychiatry 165, 524-527.

Spitzer, R.L., Williams, J.B.W. y Skodol, A.E. (1980). DSM-III: The major achievements and an overview. American Journal of Psychiatry, 137, 151-164.

Spradley, J. P. (1979). The ethnographic interview. Nueva York: Holt, Rinehart and Winston.

Steel, Z., Silove, D., Bird, K., McGorry, P. y Mohan, P. (1999). Pathways from war trauma to posttraumatic stress symptoms among Tamil asylum seekers, refugees and immigrants. Journal of Traumatic Stress, 12, 421-435.

Steverink, N. y Lindenberg, S. (2006). Which social needs are important for subjective well-being? What happens to them with aging? Psychology and Aging, 21, 281-290.

Stover, E. y Nightingale, E. O. (1985). The breaking of bodies and minds. Nueva York: W. H. Freeman.

Symonds, M. (1980). The "second injury" to victims and acute responses of victims to terror [Ejemplar especial]. Evaluation and Change, 36-38.

Tankink, M. (2006, Noviembre). Silence as a means of controlling the explosive nature of sexual violence. Documento presentado en la Conferencia CARE FULL, Medico-legal Reports and the Istanbul Protocol in Asylum Procedures. Amsterdam, Holanda.

Thygeson, P. (1980). The concentration camp syndrome. Danish Medical Bulletin, 27, 224-228.

Turner, S. W. y Gorst-Unworst, C. (1993). Psychological sequelae of torture. En Wilson, J. P. y Raphael, B. (Eds.), International Handbook of Traumatic Stress Syndromes (pp. 451-460). Nueva York: Plenum Press.

Ullman, R., y Brothers, D. (1988). The shattered self: A psychoanalytic study of trauma. Londres: Analytic Press.

Van Geuns, H. (1987). The concept of organized violence. En O. Aalund, P. Riss, P. G. Svensson, P. Thorvaldsen, y H. Van Geuns (Eds.), Health hazards of organized violence. La Haya, Holanda: Distribution Center of Government Publications, Ministry of Welfare, Health and Cultural Affairs. 
Vera, C., Marty, G., Muñoz, Y. y Madariaga, C. (2002). Afectados por la dictadura en Chile: una mirada a la realidad actual. En D. Kersner y C. Madariaga (Eds.), Paisajes del dolor, senderos de esperanza. Salud mentaly derechos humanos en el Cono Sur (pp. 191-196). Buenos Aires, Argentina: Polemos.

Weine, S. M., Becker, D.F., McGlashan, T.H., Laub, D., Lazrove, S., Vojvoda, D. y Hyman, L. (1995). Psychiatric consequences of "ethnic cleansing": Clinical assessments and trauma testimonies of newly resettled Bosnian refugees. The American Journal of Psychiatry, 152, 536-542.

Weinstein H, Dansky L, Iacopino V. (1996). Torture and war trauma survivors in primary care. The Western Journal of Medicine, 165, 112-118.

Weiss, R. S. (1973). Loneliness: The experience of emotional and social isolation. Cambridge, Mass.: MIT Press.

Weiss, R. S. (1974). The provisions of social relationships. En Z. Rubin (Ed.), Doing unto others (pp. 17-26). Nueva Jersey: Prentice Hall.

Weiss, R. S. (1982). Issues in the study of loneliness. En L. A. Peplau y D. Perlman (Eds.), Loneliness: a Sourcebook of current theory research and therapy (pp. 71-80). Nueva York: Wiley-Interscience.

West, M., Livesley, W. J., Reiffer, L. y Sheldon, A. (1986). The place of attachment in the life events model of stress and illness. Canadian Journal of Psychiatry. 31, 202-207.

Westermeyer, J. y Williams, M. (1998). Three categories of victimization among refugees in a psychiatric clinic. En J. Jarason y M. Popkin (Eds). Caring for Victims of Torture. Washington, DC: American Psychiatric Press.

Wilson, J. P. (1988). Understanding the Vietnam veteran. En F. M. Ochberg (Ed.), Post-traumatic therapy and victims of violence (pp. 227-253). Nueva York: Brunner-Mazel.

Wilson, J. P. (1989). Trauma, Transformation and Healing: An Integrative Approach to Theory. Research and Post-Traumatic Therapy. Nueva York: Brunner/Mazel.

Wirtz, P.W. y Harrell, A.V. (1987). Effects of post-assault exposure to attack-similar stimuli on long-term recovery of victims. Journal of Consulting and Clinical Psychology, 55, 10-16. 
Woodcock, J. (2000). A Systemic Approach to Trauma . The Magazine for Family Therapy and Systemic Practice, $51,2-4$.

World Medical Association. (1975). Declaration of Tokyo. Ferney-Voltaire, Francia: Author.

Yager, T., Laufer, R., y Gallops, M. (1984). Some problems associated with war experience in men of the Vietnam generation. Archives of General Psychiatry, 41, 327-333. 
APÉNDICES. 
Apéndice A: ejemplo de la entrevista en profundidad empleada

$\underline{\text { Entrevista en profundidad }}$

Caso 1. Mujer, 52 años. Separada, 3 hijos.

$16 / 01 / 2006$

Primera parte:

PRESENTE

Relaciones interpersonales actuales

Quisiera que me hable de aquellas personas que se encuentran actualmente más cerca de Ud. y que me describa cómo es la relación que tiene con cada una de ellas.

R: de mi familia, podría ser mi hijo +++; y de las personas así amigas, como que no tengo; y como que me he aferrado mucho a mi psicóloga.

(relación con el hijo) No es buena, era buena, hasta que yo empecé a hacer este trámite de la Comisión Valech, y... en el ESSMA [servicio de salud atención secundaria] me dijeron que tenía que tener apoyo en alguien, y que tenía que decirle a mis hijos lo que había vivido.

Esos 30 años no dije nada a nadie. Nadie se imagina las cosas que yo viví hace 30 años atrás, y yo después de tener a mi hijo, me fui a otra parte, y me puse una careta y seguí siendo una persona como que nada le había pasado nunca, pero después de haber estado en terapia empecé como a tomarle el peso a las cosas y mirar para atrás, y decir, cómo pude sobrevivir con esta máscara, y no contándole a nadie, y no opinando al respecto. Y cuando se supo tenía que contarle a alguien, y le conté a mi hijo, o sea, con la psicóloga, y ahí como que se derrumbó un poco la relación. Y bueno, me trató mal, me mandó a la "Conches+++": pero siempre pensé que era bueno para ellos, el que no lo supieran y siempre pensé que cuando fueran grandes les iba a contar. Primero pensé que a los 15 años les contaría, cuando llegó la edad de 15 años, encontré que estaban muy pequeños todavía. La edad que empezó la Comisión Valech les conté, y ahí hubo un cambio fuerte en su vida, porque su papá perteneció a las fuerzas armadas.

Entonces no habérselo comentado a nadie y yo miro hacia atrás y a lo único que me dediqué fue a trabajar, trabajar, trabajar, y a hacer cosas. Estar siempre ocupada en algo, siempre ocupada en algo ... ( ) ... para no pensar.

Y a veces pienso que fue bueno, y a veces pienso que no, porque como me perdí muchas cosas de la vida. Me dediqué a trabajar, trabajar, comprar, comprar, comprar casa, y esto.. miro para atrás y no disfruté nada. Y ahora vengo yo a hacer fuego porque... porque él (Ex esposo) tiene una mentalidad totalmente pinochetista, o sea, él es milico $100 \times 100$. entonces de qué me sirve haber tenido tantas cosas, digo yo, cuando ahora estamos peleando por las propiedades.

(con el hijo) pasó un tiempo y estuvo mal, su polola (novia) me dijo un día, Ud. le cagó la vida a +++ , y yo conversé con él y me dijo que si que le había cagado la vida, que yo era una cínica. Pero después como que empezó a entender más cosas. Además que en la Universidad le pasaron el tema de la re-traumatización, la psiquiatra que le hizo clases, y fue como aceptando. Fue como entendiendo cosas mías también, o sea, por qué yo a veces actuaba de una forma. Como él estudia psicología, es más fácil para él.

Con la chica (hija menor 20 años, vive en santiago) pésimo.

Yo encuentro que me faltó, no dejo que nadie me tome, me haga cariño. Esas cosas no. 


\begin{tabular}{|c|c|c|c|c|c|c|c|c|}
\hline \multirow{4}{*}{ Familia } & \multicolumn{3}{|c|}{ Nombre y rol } & \multicolumn{5}{|c|}{ Calidad de la relación } \\
\hline & \multicolumn{3}{|c|}{ hijo de 22 años. } & \multicolumn{5}{|c|}{ No es buena. } \\
\hline & \multicolumn{3}{|c|}{ hijo mayor, 35 años } & \multicolumn{5}{|c|}{$\begin{array}{l}\text { Distante. este hijo vive en Santiago y no hay relación } \\
\text { afectiva. }\end{array}$} \\
\hline & \multicolumn{3}{|c|}{ Hija menor, 20 años } & \multicolumn{5}{|c|}{$\begin{array}{l}\text { Pésima. Esta hija vive en Santiago también y se } \\
\text { llevan muy mal. }\end{array}$} \\
\hline Amigos & \multicolumn{3}{|l|}{ No tiene } & & & & & \\
\hline Pareja & No tiene & & & \multicolumn{5}{|c|}{$\begin{array}{l}\text { Estuvo casada alrededor de } 20 \text { años y se ha } \\
\text { separado hace dos meses. Él fue militar y ella no lo } \\
\text { sabía. }\end{array}$} \\
\hline \multicolumn{2}{|c|}{$\begin{array}{l}\text { En su familia, Ud. se } \\
\text { siente... }\end{array}$} & $\begin{array}{l}\text { Totalmen } \\
\text { te en } \\
\text { desacuer } \\
\text { do }\end{array}$ & & $\begin{array}{l}\text { ante } \\
\text { acuer }\end{array}$ & $\begin{array}{l}\text { Algo en } \\
\text { desacuer } \\
\text { do }\end{array}$ & $\begin{array}{l}\text { Algo de } \\
\text { acuerdo }\end{array}$ & $\begin{array}{l}\text { Bastante } \\
\text { de } \\
\text { acuerdo }\end{array}$ & $\begin{array}{l}\text { Totalmente } \\
\text { de } \\
\text { acuerdo }\end{array}$ \\
\hline \multicolumn{2}{|c|}{...comprendida } & $1 X$ & 2 & & 3 & 4 & 5 & 6 \\
\hline \multicolumn{2}{|c|}{... sola } & 1 & 2 & & 3 & 4 & 5 & $6 \mathrm{X}$ \\
\hline \multicolumn{2}{|c|}{...apoyada } & $1 \mathrm{X}$ & 2 & & 3 & 4 & 5 & 6 \\
\hline \multirow{2}{*}{\multicolumn{2}{|c|}{...ignorada }} & 1 & 2 & & $3 X$ & 4 & 5 & 6 \\
\hline & & $1 \mathrm{X}$ & 2 & & 3 & 4 & 5 & 6 \\
\hline \multicolumn{2}{|c|}{...querida } & $1 \mathrm{X}$ & 2 & & 3 & 4 & 5 & 6 \\
\hline
\end{tabular}

*** Ignorada: no porque soy necesaria. Soy la que trabaja.

En general con su familia se siente:

\begin{tabular}{|l|l|l|l|l|l|}
\hline $\begin{array}{l}\text { Muy } \\
\text { insatisfecho }\end{array}$ & $\begin{array}{l}\text { Bastante } \\
\text { insatisfecho }\end{array}$ & $\begin{array}{l}\text { Algo } \\
\text { insatisfecho }\end{array}$ & $\begin{array}{l}\text { Algo } \\
\text { satisfecho }\end{array}$ & $\begin{array}{l}\text { Bastante } \\
\text { satisfecho }\end{array}$ & $\begin{array}{l}\text { Muy } \\
\text { satisfecho }\end{array}$ \\
\hline 1 & $2 \mathrm{x}$ & 3 & 4 & 5 & 6 \\
\hline
\end{tabular}

Amigos: Pienso que esta parte podría eliminarse porque es reiterativo (pamela)

\begin{tabular}{|l|l|l|l|l|l|l|}
\hline $\begin{array}{l}\text { Con sus amigos, Ud. } \\
\text { se siente... }\end{array}$ & $\begin{array}{l}\text { Totalmen } \\
\text { te en } \\
\text { desacuer } \\
\text { do }\end{array}$ & $\begin{array}{l}\text { Bastante } \\
\text { desacuer } \\
\text { do }\end{array}$ & $\begin{array}{l}\text { Algo en } \\
\text { desacuer } \\
\text { do }\end{array}$ & $\begin{array}{l}\text { Algo de } \\
\text { acuerdo }\end{array}$ & $\begin{array}{l}\text { Bastante } \\
\text { de } \\
\text { acuerdo }\end{array}$ & $\begin{array}{l}\text { Totalmente } \\
\text { de } \\
\text { acuerdo }\end{array}$ \\
\hline ...comprendida & $1 \mathrm{X}$ & 2 & 3 & 4 & 5 & 6 \\
\hline ... Sola & 1 & 2 & 3 & 4 & 5 & $6 \mathrm{X}$ \\
\hline ....ignoyada & $1 \mathrm{X}$ & 2 & 3 & 4 & 5 & 6 \\
\hline ...querida & 1 & 2 & 3 & $4 \mathrm{X}$ & 5 & 6 \\
\hline$\ldots$... & $1 \mathrm{X}$ & 2 & 3 & 4 & 5 & 6 \\
\hline
\end{tabular}

Tengo una relación (con las personas) como tengo negocio, la gente va a comprar, escuchar, y conversar, pero no hay amistad de contar los problemas. Aprendí a guardar todo.

En general con sus amigos se siente:

\begin{tabular}{|l|l|l|l|l|l|}
\hline $\begin{array}{l}\text { Muy } \\
\text { insatisfecho }\end{array}$ & $\begin{array}{l}\text { Bastante } \\
\text { insatisfecho }\end{array}$ & $\begin{array}{l}\text { Algo } \\
\text { insatisfecho }\end{array}$ & $\begin{array}{l}\text { Algo } \\
\text { satisfecho }\end{array}$ & $\begin{array}{l}\text { Bastante } \\
\text { satisfecho }\end{array}$ & $\begin{array}{l}\text { Muy } \\
\text { satisfecho }\end{array}$ \\
\hline $1 \mathrm{X}$ & 2 & 3 & 4 & 5 & 6 \\
\hline
\end{tabular}

\section{Pareja:}

(cuando le contó a su esposo) Nunca me sentí comprendida. Cuando comenzó la relación hace veintitantos años, un día le dije lo que me había pasado (prisión política), pero sin mayores... sólo le dije que había estado detenida, y su reacción fue como "no se si podré seguir viviendo 
contigo". O sea, como si haber estado detenida, fuera como un latre, no se. Pero después nunca más se tocó el tema, NUNCA MÁS.

Esa vez y no teníamos hijos, y después como si nada hubiera pasado; y yo me encerré tanto, que él hablaba acá de Pinochet, y los niños lo seguían en la línea, y yo jamás dije nada. O sea cuando la gente salía a hacer protestas, por parte de él era como siempre mal mirado, y yo era como que estaba tan adentro, como que lo escondí tanto...

Pero hacía falta (sacarlo), pero ha sido fuerte porque hay cosas que tu has hecho por años, y ves por qué las hiciste... y yendo de médico en médico. En el día totalmente haciendo una cosa, trabajando en la iglesia, con los niños, con el grupo de ++++ , siempre algo. No teniendo momentos de.. yo creo que nunca viví en paz. Porque en la noche cuando estaba como relajada para dormir, me tomaba pastillas.

\begin{tabular}{|c|c|c|c|c|c|c|}
\hline $\begin{array}{l}\text { Con su pareja, Ud. } \\
\text { se siente... }\end{array}$ & $\begin{array}{l}\text { Totalmen } \\
\text { te en } \\
\text { desacuer } \\
\text { do }\end{array}$ & $\begin{array}{l}\text { Bastante } \\
\text { desacuer } \\
\text { do }\end{array}$ & $\begin{array}{l}\text { Algo en } \\
\text { desacuer } \\
\text { do }\end{array}$ & $\begin{array}{l}\text { Algo de } \\
\text { acuerdo }\end{array}$ & $\begin{array}{l}\text { Bastante } \\
\text { de } \\
\text { acuerdo }\end{array}$ & $\begin{array}{l}\text { Totalmente } \\
\text { de } \\
\text { acuerdo }\end{array}$ \\
\hline ...comprendida & $1 \mathrm{X}$ & 2 & 3 & 4 & 5 & 6 \\
\hline$\ldots$ sola & 1 & 2 & 3 & 4 & 5 & $6 \mathrm{X}$ \\
\hline ...apoyada & $1 X$ & 2 & 3 & 4 & 5 & 6 \\
\hline ...ignorada & 1 & 2 & 3 & $4 X$ & 5 & 6 \\
\hline ...querida & $1 X$ & 2 & 3 & 4 & 5 & 6 \\
\hline ...conflictuada & 1 & 2 & 3 & 4 & 5 & $6 \mathrm{X}$ \\
\hline
\end{tabular}

En general con su pareja se siente:

\begin{tabular}{|l|l|l|l|l|l|}
\hline $\begin{array}{l}\text { Muy } \\
\text { insatisfecho }\end{array}$ & $\begin{array}{l}\text { Bastante } \\
\text { insatisfecho }\end{array}$ & $\begin{array}{l}\text { Algo } \\
\text { insatisfecho }\end{array}$ & $\begin{array}{l}\text { Algo } \\
\text { satisfecho }\end{array}$ & $\begin{array}{l}\text { Bastante } \\
\text { satisfecho }\end{array}$ & $\begin{array}{l}\text { Muy } \\
\text { satisfecho }\end{array}$ \\
\hline $1 X$ & 2 & 3 & 4 & 5 & 6 \\
\hline
\end{tabular}

Hay alguna persona que usted sienta que estará ahí cuando la necesite de manera incondicional, que no le va a fallar nunca?

Quién es?

No se, encuentro que no. Me siento como que si yo necesito a alguien, y la persona vaya en un momento. No.

\begin{tabular}{|l|l|l|}
\hline $\begin{array}{l}\text { Familia/ } \\
\text { amigo/ } \\
\text { pareja }\end{array}$ & \begin{tabular}{l} 
Nombre y rol \\
\cline { 2 - 2 } \\
incondicione de la \\
relación
\end{tabular} & Calidad de la relación \\
\hline
\end{tabular}

-Concepción del mundo
-Concepción de seres
humanos
-Sentido de la vida
-Sentido de vínculos
emocionales y sociales

Me gustaría que se refiriera ahora a la consideración que le merece el mundo tal y como está. Cómo ve la realidad de su entorno y lo que está ocurriendo en la actualidad. En general. 
R: encuentro negativo, o sea... encuentro que, mira, siempre tengo algo bien grabado que leí una vez: "de qué le sirve al hombre ganar el mundo si se pierde a sí mismo".

Luchar tanto por algo, tanto, tanto, y al final: te perdiste la vida. O después de haber trabajado por 16 años, y ahora digo: y para qué.

\begin{tabular}{|l|l|l|l|l|l|l|}
\hline $\begin{array}{l}\text { Cree que el mundo } \\
\text { es un lugar.... }\end{array}$ & $\begin{array}{l}\text { Totalmen } \\
\text { te en } \\
\text { desacuer } \\
\text { do }\end{array}$ & $\begin{array}{l}\text { Bastante } \\
\text { desacuer } \\
\text { do }\end{array}$ & $\begin{array}{l}\text { Algo en } \\
\text { desacuer } \\
\text { do }\end{array}$ & $\begin{array}{l}\text { Algo de } \\
\text { acuerdo }\end{array}$ & $\begin{array}{l}\text { Bastante } \\
\text { de } \\
\text { acuerdo }\end{array}$ & $\begin{array}{l}\text { Totalmente } \\
\text { de } \\
\text { acuerdo }\end{array}$ \\
\hline $1^{*} \ldots$ acogedor & 1 & 2 & $3 X$ & 4 & 5 & 6 \\
\hline $2^{*} \ldots$ hostil & 1 & 2 & 3 & 4 & $5 X$ & 6 \\
\hline $3^{*} \ldots$ con sentido & 1 & 2 & 3 & 4 & 5 & 6 \\
\hline$\ldots$ difícil & 1 & 2 & 3 & 4 & 5 & 6 \\
\hline$\ldots$ agradable & 1 & 2 & 3 & 4 & 5 & 6 \\
\hline$\ldots$.riesgoso/peligroso & 1 & 2 & 3 & 4 & 5 & 6 \\
\hline
\end{tabular}

1* eso es como relativo, depende de en qué momento se esté. La situación, con qué persona... en qué lugar me imagino.

$2^{*}$ a mi lo que me tiene en este momento atormentada, son las elecciones. Como ha afectado. O sea, veo que se puede volver a tiempos... ( ). Mientras yo no saqué eso de adentro, yo no sentía esto, estaba tan guardado, tan guardado...

$3^{*}$ mira, es que tu, vienes a preguntarme cosas en un momento en que yo estoy además de estar con una re-traumatización, de haber revivido todo, y en que aún sigan apareciendo cosas, ahora el quiebre matrimonial, entonces en estos momentos estoy como, si tu me preguntas algo, no se, si tu me hubieras preguntado algo antes de que mi marido se fuera, hubiera sido totalmente diferente.

(se descarta seguir preguntando por "difícil, agradable, y riesgoso)

Yo digo, valía la pena vivir con esto tantos años, tomando pastillas y tomando pastillas, y yendo hasta a médicos. Imagínate, qué ignorantes, yo no soy ignorante, pero yendo al médico por tratamiento del sueño porque en las noches no se, como que igual paso mal, aunque no quiera, aparecen recuerdos y cosas. Y no haberlo frenado antes. No haber vivido los duelos correspondientes.

( ) y esto fue cuando joven, o sea, toda mi vida cagada, tenía 17 - 18 años, entonces de ahí, como el caballo que corre, corre, corre, corre, corre, y de repente PARA!, que es lo que me pasó con la terapia y las cartas, y te das cuenta por qué tuve que pasar esto.

Yo ya llevo dos años, desde que comenzó la $C$. Valech que yo estoy con licencia. Esta último problema que tuve con la ida de mi marido, me pasó, que - siempre he usado reloj- de repente me empezó a dar alergia y me lo ponía y yo pensaba que eran los nervios, no se. Entonces ahí con la psicóloga, una vez conversando con ella, y como que el cuerpo me rechazaba las cosas así como abrazaderas (en la muñeca), y conversando un día con ella, como que volvió el momento, y me daba alergia en esta mano porque recordé que estuve esposada de esta mano. Como que las cosas van saliendo así. Y de repente muchas quedaron adentro. $Y$ me siento como cajoneada cuando pasan estas cosas. $Y$ mi problema es que no tengo apoyo.

Mi hijo en estos días está como cansado, y me dice "es una excusa que tienes".

yo creo que la gente no tenía idea de cómo pasaron las cosas, y la gente como yo, callaron. Mira y yo a veces digo: para qué hablé si yo antes vivía como tranquila. A lo mejor tranquila entre comillas, pero con todas esas cosas adentro, yo creo que me podía trastornar; y ahí entendí muchas cosas, entendí por qué enterré a mi hijo así tan rápido, por qué no lo lloré. Yo lo quería enterrar altiro y ahora me di cuenta que era como sacarse una cosa que te está marcando porque en (ciudad) antes eran pocas personas y "ah que estuvo presa, y tuvo una guagua,... entonces ya era un peso. Mirarlo a él era complicado Pamela, porque pensaba qué le iba a decir, qué le iba a contar. Él murió a los 4 años. 
En general en relación al mundo se siente:

\begin{tabular}{|l|l|l|l|l|l|}
\hline Muy a gusto & $\begin{array}{l}\text { Bastante a } \\
\text { gusto }\end{array}$ & Algo a gusto & $\begin{array}{l}\text { Algo a } \\
\text { disgusto }\end{array}$ & $\begin{array}{l}\text { Bastante a } \\
\text { disgusto }\end{array}$ & $\begin{array}{l}\text { Muy a } \\
\text { disgusto }\end{array}$ \\
\hline 1 & 2 & 3 & 4 & 5 & $6 \mathrm{X}$ \\
\hline
\end{tabular}

En qué cree Ud.?

R: ¿En qué creo? Creo en Dios, pero yo en lo que más me aferro, es en la virgen. Es como más cercana, como que me va a entender más, como que me apoya. No se, a lo mejor me siento tan sola a veces que digo a veces cuando no me puedo dormir en las noches, digo "virgencita, envuélveme en tu manto", cuando no puedo dormir. La verdad es que siempre le he rezado a ella.

( ) mira, estoy como reacia a creer en la justicia y en la democracia que hay en el país. Yo recordé lo que viví con la comisión Valech. Me sentí una vez más pasada a llevar en mis intereses. O sea, me los pasaron a llevar en la dictadura, y me los pasaron a llevar ahora, porque, por qué me cambiaron mi testimonio. Yo digo, hasta qué punto, el tipo que me hizo daño, todavía tiene influencias. Porque para mi eso es tener influencias. Haber cambiado el relato y haber puesto hasta donde que fui detenida entre tales fechas y que fui violada, nada más. Porque es militar. Y mi testimonio decía que había quedado embarazada que estuve detenida embarazada. Es la ironía de la vida.

\begin{tabular}{|l|l|l|l|l|l|l|}
\hline Cree en... & $\begin{array}{l}\text { Totalmen } \\
\text { te en } \\
\text { desacuer } \\
\text { do }\end{array}$ & $\begin{array}{l}\text { Bastante } \\
\text { desacuer } \\
\text { do }\end{array}$ & $\begin{array}{l}\text { Algo en } \\
\text { desacuer } \\
\text { do }\end{array}$ & $\begin{array}{l}\text { Algo de } \\
\text { acuerdo }\end{array}$ & $\begin{array}{l}\text { Bastante } \\
\text { de } \\
\text { acuerdo }\end{array}$ & $\begin{array}{l}\text { Totalmente } \\
\text { de } \\
\text { acuerdo }\end{array}$ \\
\hline $1^{*} \ldots$ el amor & 1 & 2 & 3 & 4 & $5 X$ & 6 \\
\hline$\ldots$.la justicia & 1 & 2 & 3 & 4 & $5 X$ & 6 \\
\hline $2^{*} \ldots$ la paz & 1 & 2 & 3 & 4 & 5 & 6 \\
\hline $3^{*} \ldots$ la felicidad & 1 & 2 & 3 & 4 & $5 X$ & 6 \\
\hline $4^{*} \ldots$ Ias personas & 1 & $2 X$ & 3 & 4 & 5 & 6 \\
\hline$\ldots$..en Dios & 1 & 2 & 3 & 4 & 5 & $6 \mathrm{X}$ \\
\hline
\end{tabular}

$1^{*}$ si me gustaría vivir siempre enamorada, pero no he encontrado eso de sentirme de que alguien me quiera, de que yo al final pueda decir, estoy acá y esa persona me pueda llevar en brazos. He tenido siempre que cargar con todo.

$2^{*}$ espero que lleguemos a tener paz.

$3^{*}$ creo que la felicidad es corta, pero hay momentos. O sea, la felicidad no es algo que tu vayas a ser feliz para siempre. Siempre hay algo que te echa a perder eso.

$4^{*}$ no mucho.

En general en relación a lo que usted cree, se siente:

\begin{tabular}{|l|l|l|l|l|l|}
\hline $\begin{array}{l}\text { Muy } \\
\text { satisfecho }\end{array}$ & $\begin{array}{l}\text { Bastante } \\
\text { satisfecho }\end{array}$ & $\begin{array}{l}\text { Algo } \\
\text { satisfecho }\end{array}$ & $\begin{array}{l}\text { Algo } \\
\text { insatisfecho }\end{array}$ & $\begin{array}{l}\text { Bastante } \\
\text { insatisfecho }\end{array}$ & $\begin{array}{l}\text { Muy } \\
\text { insatisfecho }\end{array}$ \\
\hline 1 & 2 & 3 & $4 X$ & 5 & 6 \\
\hline
\end{tabular}

Qué sentido tienen en su vida las relaciones que tiene actualmente con la gente (emocional y social). Esta pregunta se vuelve reiterativa, pues ya ha hecho referencia en preguntas anteriores.

$R$ : es superficial, no tengo en quien confiar.

En general en relación a sus vínculos afectivos actuales se siente:

\begin{tabular}{|l|l|l|l|l|l|}
\hline $\begin{array}{l}\text { Muy } \\
\text { satisfecho }\end{array}$ & $\begin{array}{l}\text { Bastante } \\
\text { satisfecho }\end{array}$ & $\begin{array}{l}\text { Algo } \\
\text { satisfecho }\end{array}$ & $\begin{array}{l}\text { Algo } \\
\text { insatisfecho }\end{array}$ & $\begin{array}{l}\text { Bastante } \\
\text { insatisfecho }\end{array}$ & $\begin{array}{l}\text { Muy } \\
\text { insatisfecho }\end{array}$ \\
\hline 1 & 2 & 3 & 4 & 5 & $6 \mathrm{X}$ \\
\hline
\end{tabular}




\begin{tabular}{l}
\hline Segunda parte: PASADO \\
-Relaciones \\
interpersonales de infancia \\
y adolescencia
\end{tabular}

Quisiera ahora hacerle algunas preguntas acerca de su historia de vida pasada. Pedirle que piense en su infancia y adolescencia y preguntarle por aquellos recuerdos que tiene de estas etapas de su vida en relación a la gente que tenía cerca.

Quiénes eran las personas que recuerda estuvieron más cerca de usted en su infancia y qué recuerdos tiene de ellos / Cómo eran estas relaciones.

Sabes que estando en terapia ahora, veo hacia atrás y yo no se cómo he podido salir bien y estar parada y ser como soy. Tuve una infancia que no fue buena, y yo siempre me he preguntado por qué. Porqué murió una hermana cuando yo tenía 7 años, y yo decía que ojalá se muera, y así me van a querer a mí.

Éramos 3, porque +++ era guagua de meses, pero murió la penúltima (ella era la mayor) y después venía +++ , y después venía +++ que falleció. Y yo me recuerdo que ese dolor, de esa pérdida haber pensado así; y siempre lo tuve como bien escondido. Era como un pensamiento malo. $Y$ después mi papá fallece cuando tenía como 8 años, y entonces mi mamá se tuvo ir a trabajar y yo me tuve que hacer cargo de mis hermanas, y yo ahora, en este momento, antes no, yo nunca había estado con una psicóloga. Había ido al psiquiatra, pero que me den pastillas y listo, pero alguien así que me oyera y me conversara y le contara mis cosas, no. Encuentro que mi vida ha sido una cagá. Yo no me explico como estoy parada, y como bien parada. La psicóloga me dice que no ha conocido a una mujer con más resiliencia como la mía, con más fortaleza. Porque con todo lo que me ha pasado, podría tener un vicio, y ni siquiera fumo. O no se, estaría ahí llorando y esperando que me vengan a hacer algo, y no, no he esperado nunca, y nadie nunca me ha dado nada.

Si volviera a vivir, no se si viviría igual. Con esta terapia que tengo, he estado incluso con mi madre media... yo me digo, cómo me pudo haber explotado así. y ahora entiendo por qué, a los niños por ejemplo aunque tuviera que trabajar más, les tenía empleada. Mi hija no se lavó nunca un calzón. Que ellos no hicieran nada, y con la terapia salió que fui casi explotada. O sea, mi mamá se iba a trabajar y había que levantarse, darles desayuno a mis hermanas, llevarlas al colegio, volver, cocinar, darles el almuerzo a mis hermanas, volver, porque teníamos jornada doble. Llegábamos a las 5 y media. Lavar las tazas del desayuno, lo del almuerzo; tomar té, y después había que cocinar porque no había como para dejar comida de un día de la mañana para la tarde. Y no se en qué rato estudiaba. Ahora mi vida es más calmada, pero antes de esto yo era acelerada hasta para hablar. Me acuerdo que los días sábado tenia que lavar sábanas. Yo odiaba los días viernes a los 9 años hasta grande.

( ) (hermana) está en (otra ciudad), y también la relación es lejana. Con (hermana) hubo más contacto, pero llegó el momento - no si todo esto me ha pasado después de la terapia- porque soy yo la que siempre llamo. De repente un día, pasaban 3-4 días sin llamar, y cuando llamaba me preguntaban cómo estás ingrata; y después de esta navidad, yo me atreví a decirle algo a mi mamá. De decirle, estoy llamando y les voy a decir algo: por qué Uds. no me llaman? No creo que ustedes estén tan pobres como para no tener una moneda para llamar. Mi hermana tiene teléfono en la casa. Porque soy yo la que estoy llamándolas a Uds. Y mi mamá me dijo: "ay no te pongas peleadora hoy es navidad". Mamá no es que esté peleando, es lo que yo he sentido siempre, que no me atrevía a decirlo es otra cosa.

(madre) es como fuerte y a veces como víctima. Yo nunca me acuerdo haberle llevado la contraria en algo. Quizás por no hacerle problemas. 
(Amigos de infancia) cuando chica no tenía tiempo, aunque me daba tiempo para todo, cocinar, lavar, jugar, porque era tan acelerada. Ahora me encuentro tan cambiada, pero es porque me tomo pastillas. Me cuesta dar vuelto. Estoy con reacción lenta.

(Alguien en quien confiar o contar) sabes que tuve una amiga, era como parte mía; y cuando ella una vez se vino a (ciudad) a vivir, yo nunca había llorado por una pena así por algo. Y tenía como 12 años. Ella se vino a (ciudad), yo la vine a dejar al aeropuerto, y era como que me sacaban parte de mi, lloraba. Nunca más supe de ella.

\begin{tabular}{|c|c|c|c|c|}
\hline \multirow{7}{*}{ Familia } & \multirow[t]{2}{*}{ Nombre y rol } & \multirow[t]{2}{*}{ Recuerdos del tipo de relación } & \multicolumn{2}{|c|}{$\begin{array}{l}\text { Se mantienen } \\
\text { en el presente }\end{array}$} \\
\hline & & & Si & no \\
\hline & Hermana & Estaba a cargo de su cuidado & $\mathrm{X}$ & \\
\hline & Hermana & Estaba a cargo de su cuidado & $\mathrm{X}$ & \\
\hline & Madre & Se sentía explotada y no querida & $\mathrm{X}$ & \\
\hline & Padre & Fallece cuando ella tiene 8 años & & $\mathrm{X}$ \\
\hline & Hermana & Fallece cuando tiene 7 años & & $\mathrm{X}$ \\
\hline Amigos & 1 amiga & "... era como parte mia" & & $\mathrm{X}$ \\
\hline Otro & No & & & \\
\hline
\end{tabular}

En general con su familia se sentía:

\begin{tabular}{|l|l|l|l|l|l|}
\hline $\begin{array}{l}\text { Muy } \\
\text { insatisfecho }\end{array}$ & $\begin{array}{l}\text { Bastante } \\
\text { insatisfecho }\end{array}$ & $\begin{array}{l}\text { Algo } \\
\text { insatisfecho }\end{array}$ & $\begin{array}{l}\text { Algo } \\
\text { satisfecho }\end{array}$ & $\begin{array}{l}\text { Bastante } \\
\text { satisfecho }\end{array}$ & $\begin{array}{l}\text { Muy } \\
\text { satisfecho }\end{array}$ \\
\hline $1 X$ & 2 & 3 & 4 & 5 & 6 \\
\hline
\end{tabular}

En general con sus amigos se sentía:

\begin{tabular}{|l|l|l|l|l|l|}
\hline $\begin{array}{l}\text { Muy } \\
\text { insatisfecho }\end{array}$ & $\begin{array}{l}\text { Bastante } \\
\text { insatisfecho }\end{array}$ & $\begin{array}{l}\text { Algo } \\
\text { insatisfecho }\end{array}$ & $\begin{array}{l}\text { Algo } \\
\text { satisfecho }\end{array}$ & $\begin{array}{l}\text { Bastante } \\
\text { satisfecho }\end{array}$ & $\begin{array}{l}\text { Muy } \\
\text { satisfecho }\end{array}$ \\
\hline $1 X$ & 2 & 3 & 4 & 5 & 6 \\
\hline
\end{tabular}

En general con su pareja (u ex parejas) se sentía:

\begin{tabular}{|l|l|l|l|l|l|}
\hline $\begin{array}{l}\text { Muy } \\
\text { insatisfecho }\end{array}$ & $\begin{array}{l}\text { Bastante } \\
\text { insatisfecho }\end{array}$ & $\begin{array}{l}\text { Algo } \\
\text { insatisfecho }\end{array}$ & $\begin{array}{l}\text { Algo } \\
\text { satisfecho }\end{array}$ & $\begin{array}{l}\text { Bastante } \\
\text { satisfecho }\end{array}$ & $\begin{array}{l}\text { Muy } \\
\text { satisfecho }\end{array}$ \\
\hline $1 X$ & 2 & 3 & 4 & 5 & 6 \\
\hline
\end{tabular}

Recuerda alguna persona en especial con la que usted sintiera que contaba o que estaría ahí de manera incondicional en su infancia o adolescencia? Quién era?

\begin{tabular}{|l|l|l|}
\hline $\begin{array}{l}\text { Familia, o } \\
\text { amigo, o } \\
\text { pareja }\end{array}$ & Nombre y rol & Recuerdos de la calidad de la relación \\
\cline { 2 - 3 } & & \\
\hline
\end{tabular}

\section{Segunda parte: PASADO \\ -Percepción del mundo \\ -Valores \\ -Bienestar}

En su adolescencia, que recuerdos tiene de cómo veía la vida, y el futuro.

R: me vine a (ciudad) buscando metas, con sueños de que me iba a ir bien. Me vine sola a trabajar. Estudiaba y trabajaba, salía del trabajo y me iba a estudiar, y me vine buscando metas y sueños que se interrumpieron el 72. Entonces fueron poquitos mis días bien.

En general en relación al mundo de ese entonces ud. se sentía: 


\begin{tabular}{|l|l|l|l|l|l|}
\hline Muy a gusto & $\begin{array}{l}\text { Bastante a } \\
\text { gusto }\end{array}$ & Algo a gusto & $\begin{array}{l}\text { Algo a } \\
\text { disgusto }\end{array}$ & $\begin{array}{l}\text { Bastante a } \\
\text { disgusto }\end{array}$ & $\begin{array}{l}\text { Muy a } \\
\text { disgusto }\end{array}$ \\
\hline 1 & $2 \mathrm{X}$ & 3 & 4 & 5 & 6 \\
\hline
\end{tabular}

En general en relación a la vida se sentía:

\begin{tabular}{|l|l|l|l|l|l|}
\hline $\begin{array}{l}\text { Muy } \\
\text { optimista }\end{array}$ & $\begin{array}{l}\text { Bastante } \\
\text { optimista }\end{array}$ & $\begin{array}{l}\text { Algo } \\
\text { optimista }\end{array}$ & $\begin{array}{l}\text { Algo } \\
\text { pesimista }\end{array}$ & $\begin{array}{l}\text { Bastante } \\
\text { pesimista }\end{array}$ & $\begin{array}{l}\text { Muy } \\
\text { pesimista }\end{array}$ \\
\hline 1 & $2 X$ & 3 & 4 & 5 & 6 \\
\hline
\end{tabular}

En general en relación a lo que sentía consigo mismo en su infancia y adolescencia, usted se sentía:

\begin{tabular}{|l|l|l|l|l|l|}
\hline $\begin{array}{l}\text { Muy } \\
\text { satisfecho }\end{array}$ & $\begin{array}{l}\text { Bastante } \\
\text { satisfecho }\end{array}$ & $\begin{array}{l}\text { Algo } \\
\text { satisfecho }\end{array}$ & $\begin{array}{l}\text { Algo } \\
\text { insatisfecho }\end{array}$ & $\begin{array}{l}\text { Bastante } \\
\text { insatisfecho }\end{array}$ & $\begin{array}{l}\text { Muy } \\
\text { insatisfecho }\end{array}$ \\
\hline 1 & $2 X$ & 3 & 4 & 5 & 6 \\
\hline
\end{tabular}

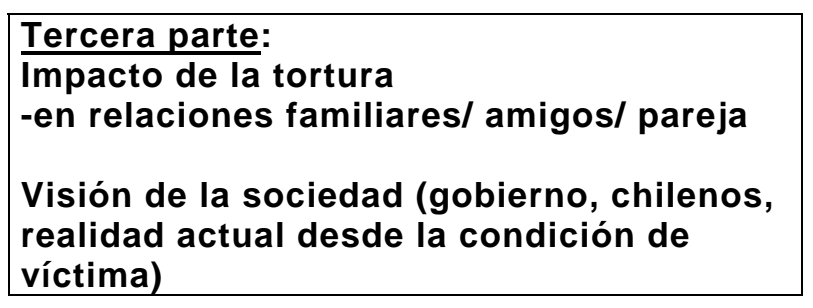

Quisiera ahora que se refiera a su vida después de haber sido detenido político.

Para esto, quisiera preguntarle qué año ocurrió, qué edad tenía en ese entonces, y cuánto tiempo estuvo detenido.

R:

AÑO DE OCURRENCIA: 1974/enero

EDAD: 18 años

TIEMPO: enero-mayo (pero tuvo que ir cada día hasta octubre)

Tuve que ir cada día al regimiento con el temor si me iban a dejar. Nació mi bebé el 11 de septiembre y después iba con mi guagua (bebé) hasta el 30 de octubre. Ese día me dijeron no venga que nosotros la vamos a ir a buscar. $Y$ con eso no sabes nunca si te van a venir a buscar o no.

\section{Relaciones interpersonales}

Trabajo yo trabajaba para textiles $X$, y entré como operaria el año 72 cuando llegué a (ciudad), y empecé a estudiar. Entonces, como no tenía recursos y necesitaba escribir a máquina a veces, hablé con mi jefe de personal y le pedí si podía ir por las tardes a practicar escribir a máquina, y entonces ahí iba y hacía mis trabajos y de repente alguien me decía que escribiera algo y yo era feliz sirviendo. Después se aprovechaban de mi, pero a mi me servía como para aprender.

Y después de que me hice conocida arriba, era muy trabajadora, responsable, buenamoza, no te lo voy a negar, entonces un día faltó la niña que estaba en gerencia y a mi me pusieron, y trabajé en gerencia, y a la persona que estaba, le gustó porque era joven, trabajadora, y o no tenía amistades para llamar por teléfono, que era el problema con la otras personas jóvenes que las están llamando a cada rato; y me encantaba lo que hacía, entonces como estaba aprendiendo, y siempre lo que he intentado hacer lo he intentado hacer bien.

(después del nacimiento del hijo) yo volví a trabajar ahí, yo volví, y el gerente me dijo que no podía entrar a trabajar, y yo era joven pero hice valer mis derechos, yo tenía foro maternal, y fui a la inspección (del trabajo), todavía quedaba gente que me conocía de antes, entonces fueron a la empresa y les dijeron que si no me recibían, tenían que pagarme el año que me correspondía por el fuero maternal. Entonces el que me hizo entrar detenida, dijo que bueno, y me mandó a trabajar 
lejos en la oficina de personal, y después con el tiempo yo volví a trabajar a gerencia, pero cuando habían vuelto los dueños y busqué el papel y ahí encontré una carta en la que este tipo denuncia a personas y entre ellas estaba yo. (El gerente) dice que a él no le consta, que es lo que le ha informado el Depto. de personal. Como Pilato, él denunció pero que a él solamente le constaba lo de un Sr. Viejito que murió, y así fue como.

Se fueron,++++++ que era enfermera... después era horrible, cuando me fueron a buscar me Ilevaron en un Geep, con dos milicos con una metralleta, como si yo fuera una mujer muy mala. Para mi, yo era joven, y eso era como tener que contar algo. O sea, a mi me daba risa, si yo no tenía nada que ver, yo era tan frágil y tan inocente, y con dos milicos así. Entonces pensé que me van a llevar y no me imaginé nunca las cosas que me iban a pasar.

Porque después llegó un militar a cargo de la empresa. Como el 18-19 de septiembre. Y trabajé con él, era un viejito, y me recuerdo que el jefe de personal le preguntó si quería que le cambien de secretaria, y él dijo que no, que muy bien, que yo era muy eficiente.

Yo seguí ahí, solamente que después llegó otro gerente, y ese me sacó de gerencia, me mandó a trabajar a personal.

Sabes que yo cuando leí esa carta, porque yo después como al año volví a trabajar a gerencia, porque justo faltó la secretaria y yo me sabía el trabajo al revés y al derecho y él me dejó ahí. Y ahí yo me sentí como... fue a la primera persona que yo le conté. Porque encontré que era como desleal no decirle, ya que me tenía en un puesto así tan de confianza.

( ) Él me preguntó si era comunista y le dije que no. Y me dijo: tengo una buena imagen del comunismo pero del buen comunismo. Son responsables, respetuosos.

Lo que si me dijo fue que eso no iba a salir de su boca. Pero yo me sentí con la obligación de contarle.

Yo en mi vida le conté a muy pocas personas, le conté a él que me dejó trabajando ahí, le conté a ++++, a mi marido, que fue como bien suave, le dije después de 6 meses (de relación) sabes que yo estuve detenida, y me dijo: "no se si puedo seguir viviendo contigo". Yo me digo: por qué esa vez si no teníamos ni hijos no me fui, de haber sabido que mi vida iba a ser así. Ahora yo digo fue por cobardía, o sentí que a lo mejor iba a estar más segura y nadie me iba a hacer daño.

(Siguiendo con compañeros de trabajo)

cuando volví, fíjate lo que son las cosas de la vida, había una persona que yo le tenía mala, lo encontraba medio fascista, él tenía vehículo y yo también le caía mal a él, y cuando yo volví a trabajar con mi guagua en brazos, y todos hablaban "mira, estuvo detenida y llegó con guagua", pero yo siempre no se, como que lo metí tan adentro que no lo guardé, no sentía los comentarios, y ahí me acuerdo que me invitó a una convivencia del trabajo y sabes que yo a esa persona me aferré harto, y si mi hijo tuvo a alguien como un padre, fue a él. Iba a la sala cuna... y sabes que nunca me preguntó qué te pasó.. Te violaron?, nada. Y después nunca más supe de él, después de 30 años, y después que lo encontré porque me encontré con una amiga y me dijo que se había muerto su madre, y lo sentí en el alma y lo contacté, y le dije: juntémonos; pero en esos días yo fui a declarar. Entonces todo ese proceso que viví, como que lo viví todo el tiempo al lado de él. Cuando yo cargaba con mi niño. Y él notó el cambio totalmente, él me dijo que él me hablaba y yo siempre con las manos cruzadas, y lo miraba de reojo, yo ya me había puesto todas las máscaras, tomé una personalidad que no era mía. Me hice la fuerte, cuando leí el caballero de la armadura oxidada, ahí de repente como que la armadura se hace parte tuya.

El hecho de ir a terapia me da la impresión de que me sacó la armadura. Porque yo antes hasta iba a vender al regimiento y no me pasaba nada. Era como que veía a un sacerdote. Y después que empecé a hablar y un día tocaron el timbre y era un militar, porque un vecino iba a entrar a la escuela me quedé en blanco y cuando me voy a dar cuenta me había hecho pipí. Y otra vez iban por la calle unos geeps y me recuerdo cuando me llevaron y me volví a hacer pipí.

(miedo) claro, cuando lo hablé, para mi viví todo lo que tenía que haber vivido antes. Fue como si recién hubiera pasado. Y lo peor, en Santiago me subí a un ascensor chico y se subió un militar, y sentí un ahogo y sentí que me iba achicando, achicando, achicando y paf, me fui al suelo, y después el ascensor llegó abajo y yo me hice pichí, me hice caca. Y yo lo único que me di cuenta que me empecé a achicar y me desmayé.

Como se siente en relación a su trabajo actual? 
R: Ahora con todo esto, insatisfecha.

\begin{tabular}{|c|c|c|c|c|c|c|c|c|}
\hline \multicolumn{2}{|c|}{$\begin{array}{l}\text { Sus relaciones } \\
\text { laborales... }\end{array}$} & $\begin{array}{l}\text { Totalmen } \\
\text { te en } \\
\text { desacuer } \\
\text { do }\end{array}$ & $\begin{array}{l}\text { Bastante } \\
\text { desacuer } \\
\text { do }\end{array}$ & \multicolumn{2}{|c|}{$\begin{array}{l}\text { Algo en } \\
\text { desacuer } \\
\text { do }\end{array}$} & $\begin{array}{l}\text { Algo de } \\
\text { acuerdo }\end{array}$ & $\begin{array}{l}\text { Bastante } \\
\text { de } \\
\text { acuerdo }\end{array}$ & $\begin{array}{l}\text { Totalmente } \\
\text { de } \\
\text { acuerdo }\end{array}$ \\
\hline \multicolumn{2}{|c|}{$\ldots$ fueron las mismas } & $1 X$ & 2 & \multicolumn{2}{|l|}{3} & 4 & 5 & 6 \\
\hline \multicolumn{2}{|c|}{...fueron distantes } & $1 X$ & 2 & \multicolumn{2}{|l|}{3} & 4 & 5 & 6 \\
\hline \multicolumn{2}{|c|}{...una fuente de apoyo } & 1 & 2 & \multicolumn{2}{|l|}{3} & 4 & 5 & $6 \mathrm{X}$ \\
\hline \multicolumn{2}{|c|}{...se perdieron } & $1 \mathrm{X}$ & 2 & \multicolumn{2}{|l|}{3} & 4 & 5 & 6 \\
\hline \multicolumn{2}{|c|}{...fuente de protección } & 1 & 2 & \multicolumn{2}{|l|}{3} & 4 & 5 & $6 \mathrm{XX}$ \\
\hline \multicolumn{2}{|c|}{...fueron un peligro } & 1 & 2 & \multirow[t]{2}{*}{3} & & 4 & 5 & $6 \mathrm{X}$ \\
\hline & \multirow{2}{*}{\multicolumn{4}{|c|}{$\begin{array}{l}\text { Antes } \\
\text { Secretaria en gerencia }\end{array}$}} & \multicolumn{4}{|c|}{ Después } \\
\hline $\begin{array}{l}\text { Actividad } \\
\text { laboral }\end{array}$ & & & & & \multicolumn{4}{|c|}{$\begin{array}{l}\text { Secretaria en gerencia, no obstante } \\
\text { tuvo problemas para reinsertarse a su } \\
\text { puesto de trabajo por haber sido presa } \\
\text { política. }\end{array}$} \\
\hline $\begin{array}{l}\text { Relación } \\
\text { con } \\
\text { compañeros } \\
\text { de trabajo }\end{array}$ & \multicolumn{4}{|c|}{$\begin{array}{l}\text { No tenía relaciones de amistad dentro } \\
\text { del trabajo }\end{array}$} & \multicolumn{4}{|c|}{$\begin{array}{l}\text { Cambió con un compañero en especial } \\
\text { quien la apoyó con su hijo nacido } \\
\text { producto de abusos sexuales en } \\
\text { prisión. }\end{array}$} \\
\hline motivación & \multicolumn{4}{|c|}{$\begin{array}{l}\text { Alta. Siempre se interesó por aprender } \\
\text { y ayudar en distintas tareas. }\end{array}$} & \multicolumn{4}{|c|}{ Alta } \\
\hline
\end{tabular}

En general con su trabajo se siente actualmente:

\begin{tabular}{|l|l|l|l|l|l|}
\hline $\begin{array}{l}\text { Muy } \\
\text { insatisfecho }\end{array}$ & $\begin{array}{l}\text { Bastante } \\
\text { insatisfecho }\end{array}$ & $\begin{array}{l}\text { Algo } \\
\text { insatisfecho }\end{array}$ & $\begin{array}{l}\text { Algo } \\
\text { satisfecho }\end{array}$ & $\begin{array}{l}\text { Bastante } \\
\text { satisfecho }\end{array}$ & $\begin{array}{l}\text { Muy } \\
\text { satisfecho }\end{array}$ \\
\hline $1 X$ & 2 & 3 & 4 & 5 & 6 \\
\hline
\end{tabular}

¿Qué opinión tiene Ud. del Chile actual?.

¿Cómo piensa que la sociedad chilena ve a las víctimas de privación de libertad y tortura política de Chile?

R: mira yo pienso que con la comisión Valech, la gente empezó a tomar conciencia de lo que había pasado, porque yo creo que nadie... por ejemplo en las otras comisiones la gente estaba muerta y nadie podía encontrar lo que les hicieron. Los encontraron con balas, pero ya había que imaginárselo.

No había nadie que dijera me pasó esto o esto, yo lo viví lo que te estoy contando.

(cree que la gente tiene más conciencia) si, porque cuando comenzó lo de la comisión Valech he visto que la gente ahora sabe.

Yo cuando fui a (ciudad), vi que la gente no estaba toda conforme, porque no todos dijimos todas las cosas, como lo más esencial no más, en ese momento eran cosas tan personales mías que no se.

Yo fui acá a la gobernación, y la abogada, y le empecé a contar y no podía. Ella me mandó al ESMA, y la psicóloga me ayudó con la asistente social para que me hicieran el relato. Yo estaba agotada y había que armar el rompecabezas. Yo fui a (ciudad), porque era más fácil en un lugar que no me conocieran, con una persona que no me conociera, incluso ahí, un caballero que iba a hacer el trámite me lo contó y le dije, yo también estuve detenida. "y presentó los documentos?", no le dije yo. Y me dijo "vamos que hoy es el último día, se le va a pasar el plazo". Sabes que me llevó y le dije: pero hoy no voy a ir, voy a ir otro día. Y el caballero me llevó, para que yo supiera donde era y a la secretaria le dijo: mira ella es de (ciudad), y también está en la comisión. Yo creo que ese fue el quiebre más grande de mi vida. Porque la niña me preguntó: y usted dónde estuvo. Y yo no podía decir C a r c e I, esa palabra, y ahí dije en la ca ca ca, era una oficina grande y yo me movía como loca. Pero yo sabía que había algo en mi que me decía que tenía que decirlo en ese momento, o sino no iba a poder hablar. Y me costó hasta que dije cárcel. Era como que salió lo primero. Y yo sabía que si la decía completa de una vez y no la evadía como lo había echo siempre, no iba a poder hablar. Y tomé un abogado y me dijo: (EXPP), para que no pase más en Chile. Eso me 
motivó, primero era un hombre que yo no conocía, estaba lejos de (ciudad), y yo había dicho la palabra aunque sea como loca. Después que dije la palabra sentí como que estaba en remojo alguien.

\begin{tabular}{|l|l|l|l|l|l|l|}
\hline $\begin{array}{l}\text { Cree que la sociedad } \\
\text { chilena... }\end{array}$ & $\begin{array}{l}\text { Totalmen } \\
\text { te en } \\
\text { desacuer } \\
\text { do }\end{array}$ & $\begin{array}{l}\text { Bastante } \\
\text { desacuer } \\
\text { do }\end{array}$ & $\begin{array}{l}\text { Algo en } \\
\text { desacuer } \\
\text { do }\end{array}$ & $\begin{array}{l}\text { Algo de } \\
\text { acuerdo }\end{array}$ & $\begin{array}{l}\text { Bastante } \\
\text { de } \\
\text { acuerdo }\end{array}$ & $\begin{array}{l}\text { Totalmente } \\
\text { de } \\
\text { acuerdo }\end{array}$ \\
\hline ...conoce los hechos & 1 & 2 & 3 & 4 & $5 \mathrm{X}$ & 6 \\
\hline ...ignora los hechos & 1 & $2 \mathrm{X}$ & 3 & 4 & 5 & 6 \\
\hline ...está sensibilizada & 1 & 2 & 3 & 4 & $5 \mathrm{X}$ & 6 \\
\hline ... rechaza a expresos p. & 1 & 2 & 3 & 4 & 5 & $6 \mathrm{X}$ \\
\hline ...se responsabiliza & 1 & 2 & 3 & 4 & $5 \mathrm{X}$ & 6 \\
\hline ...teme a expresos p. & $1 \mathrm{X}$ & 2 & 3 & 4 & 5 & 6 \\
\hline
\end{tabular}

(sociedad rechaza a expresos?) no se como decirte. Yo creo que si. No, pienso que sirvió de algo el hablar.

Antes del informe creo que la gente rechazaba.

Yo en la única parte que he encontrado una atención especial con la tarjeta Prais (credencial de salud pública para ex presos políticos), es en el Esma (Equipo de salud mental del servicio de Salud). Fui una vez con la tarjeta a pedir remedios y la tipa me quedó mirando y la tipa me quedó mirando así como si fuera escoria.

(teme) no, yo creo que no.

En relación a su percepción de la sociedad chilena con los hechos de prisión política y tortura en Chile usted se encuentra:

\begin{tabular}{|l|l|l|l|l|l|}
\hline $\begin{array}{l}\text { Muy } \\
\text { insatisfecho }\end{array}$ & $\begin{array}{l}\text { Bastante } \\
\text { insatisfecho }\end{array}$ & $\begin{array}{l}\text { Algo } \\
\text { insatisfecho }\end{array}$ & $\begin{array}{l}\text { Algo } \\
\text { satisfecho }\end{array}$ & $\begin{array}{l}\text { Bastante } \\
\text { satisfecho }\end{array}$ & $\begin{array}{l}\text { Muy } \\
\text { satisfecho }\end{array}$ \\
\hline 1 & 2 & 3 & 4 & $5 X$ & 6 \\
\hline
\end{tabular}

Qué piensa de las medidas de reparación que el gobierno ha adoptado para estos hechos?

R: yo si tuviera que vivir de nuevo lo que pasé, no creo que yo hablaría. Porque en el fondo no es algo que digamos que "oh que reparada estoy". Me gasto 70 mil pesos en remedios y me da 112000. no subsanan los hechos, yo creo que nada me va a pagar todo lo que yo viví. Lo que viví a lo mejor si yo no hubiera hablado, lo que estoy viviendo ahora es como lo más fuerte.

(tardías?) Demasiado. Demasiado tardías. Creo que tienen que haber comenzado mucho antes. (piensa que el gobierno hizo lo que pudo?) pudo haber hecho mucho más.

Por ejemplo en mi, en ese tiempo yo era tan joven, que me cagaron la vida, yo no pude seguir estudiando, en ese tiempo yo trabajaba y estudiaba. Nunca más pude estudiar. Entonces te da beca para estudiar y quien va a ir a estudiar si yo ya tengo 52 años y era de las más jóvenes. Y los demás tienen 70 años, y quien va a ir a estudiar. El problema es que esto no se traspasa a nadie. Yo con mi licencia y todo, era antes una persona que me movía y tengo dos hijos en la universidad. A mi me hizo mal económicamente.

(no tienen relación con lo que se necesita?) No, mira yo supe que acá se mandó una plata para que a los sistemas Prais, tuvieran médicos como una clínica chica para sistema Prais, y yo creo que se lo gastaron. Y te voy a decir más. Antes estaba la señora del ESMA, yo me sabía su nombre, ah imagínate yo estoy así ahora. Antes era peor. Pero la señora que era encargada de este problema, yo veía que iba e iba y perdía el tiempo. Yo le pedí un carnet hace como 5 meses y todavía no lo puedo tener. Entonces de repente encuentro que la gente echa a perder el sistema. 


\begin{tabular}{|l|l|l|l|l|l|l|}
\hline $\begin{array}{l}\text { las medidas } \\
\text { gubernamentales... }\end{array}$ & $\begin{array}{l}\text { Totalmen } \\
\text { te en } \\
\text { desacuer } \\
\text { do }\end{array}$ & $\begin{array}{l}\text { Bastante } \\
\text { desacuer } \\
\text { do }\end{array}$ & $\begin{array}{l}\text { Algo en } \\
\text { desacuer } \\
\text { do }\end{array}$ & $\begin{array}{l}\text { Algo de } \\
\text { acuerdo }\end{array}$ & $\begin{array}{l}\text { Bastante } \\
\text { de } \\
\text { acuerdo }\end{array}$ & $\begin{array}{l}\text { Totalmente } \\
\text { de } \\
\text { acuerdo }\end{array}$ \\
\hline$\ldots$ subsanan los hechos & $1 \mathrm{X}$ & 2 & 3 & 4 & 5 & 6 \\
\hline$\ldots$ son tardías & 1 & 2 & 3 & 4 & 5 & $6 \mathrm{X}$ \\
\hline$\ldots$ se ha hecho lo posible & $1 \mathrm{X}$ & 2 & 3 & 4 & 5 & 6 \\
\hline$\ldots$ no tienen relación & 1 & 2 & 3 & 4 & 5 & $6 \mathrm{X}$ \\
\hline$\ldots$ son justas & $1 \mathrm{X}$ & 2 & 3 & 4 & 5 & 6 \\
\hline$\ldots$ no tienen sentido & 1 & 2 & 3 & $4 \mathrm{X}$ & 5 & 6 \\
\hline
\end{tabular}

En relación a estas medidas del gobierno usted se siente:

\begin{tabular}{|l|l|l|l|l|l|}
\hline $\begin{array}{l}\text { Muy } \\
\text { insatisfecho }\end{array}$ & $\begin{array}{l}\text { Bastante } \\
\text { insatisfecho }\end{array}$ & $\begin{array}{l}\text { Algo } \\
\text { insatisfecho }\end{array}$ & $\begin{array}{l}\text { Algo } \\
\text { satisfecho }\end{array}$ & $\begin{array}{l}\text { Bastante } \\
\text { satisfecho }\end{array}$ & $\begin{array}{l}\text { Muy } \\
\text { satisfecho }\end{array}$ \\
\hline $1 X$ & 2 & 3 & 4 & 5 & 6 \\
\hline
\end{tabular}

Agradecimiento y cierre. 


\section{Apéndice B. Reflexiones durante el trabajo de campo}

\section{B. 1 Documento 1}

Impacto psicosocial en víctimas de privación de libertady tortura politica de Chile.

"La comprensión de cómo la violencia política y organizada produce un impacto emocional, afectivo y social en sus víctimas será estudiado en esta investigación. En concreto se estudiará el efecto de la tortura”.

Generalidades: apreciaciones subjetivas a partir de más de 60 entrevistas en profundidad realizadas en siete ciudades de Chile.

A nivel emocional se observan distintas formas de expresar emociones asociadas a experiencias de prisión política y tortura.

A- Personas que aparentemente no sufrieron malos tratos y tortura en prisión, a pesar de haber estado en campos de concentración o casas de tortura.

$\mathrm{Al}$ indagar en el tipo de trato que vivieron, afirman haber sido golpeados y haber visto tortura o muerte en sus compañeros o vecinos de celda, además afirman, haber sido víctimas en alguna ocasión de simulacro de fusilamiento. Ellos dicen: "es que lo que me pasó a mi, no fue nada en comparación con lo que le pasó a otros".

Estas personas asisten a la agrupación por la que he podido contactarles, porque militan en algún partido político y están calificados como EXPP en el informe Valech, recibiendo beneficios del gobierno en la actualidad. Pero intentan no tratar el tema de la prisión política y se refieren a este período de manera cronológica y no desde las emociones.

B- Personas que sienten que en sus vidas hubo un antes y un después marcado por la experiencia real de haber vivido la prisión política y/o la tortura, sumado a las consecuencias posteriores también reales como la separación de su pareja por el exilio, la pérdida de uno de los hijos durante la prisión, la exoneración política o la imposibilidad de seguir estudiando, etc.

Reconocen haber sido víctimas de tales sucesos pero no pueden referirse explícitamente a éstos. Afirman haber vivido el terror político y sienten tristeza al recordar. Brotan lágrimas en sus ojos durante la entrevista. 
C- Personas que sienten orgullo de haber sido parte de la historia. Para ellos ser un EXPP juega un rol importante en su identidad. Tienen una visión heroica de su participación durante el gobierno militar, análoga a la de un Ché Guevara o Salvador Allende y ven su experiencia como algo para lo que estaban preparados y volverían a vivir si tuvieran que hacerlo. Muchos de ellos presentan un sentimiento de culpa por haber expuesto a sus hijos menores de edad a los allanamientos en sus casas y persecución, o haber estado alejados de su familia por tener que vivir en la clandestinidad durante años. Estas personas afirman que en época de dictadura, los ideales relacionados a un cambio social tenían más fuerza que el pensar en el futuro y el bienestar familiar. Muchos de ellos tienen un discurso como si el conflicto político estuviera vigente en la actualidad.

D- personas que se sienten avergonzadas de haber sido víctimas de prisión política y tortura y que solamente han salido a luz pública como EXPP, por la publicación de la nómina oficial en internet del libro sobre prisión política y tortura elaborado por la comisión que el gobierno creó para tales fines. Muchas de ellas no reconocer haber tenido participación política, y si no fuera por el beneficio económico que reciben desde el año 2005, la familia aún no tendría conocimiento que la madre o padre es un EXPP.

Esta vergüenza se debe en parte a la tortura (sexual en muchas mujeres) que es mal vista socialmente. Esto no ha permitido que elaboren la experiencia y estos acontecimientos estarían de alguna manera disociados en sus mentes. A este grupo de personas fue muy difícil acceder y sólo una o dos han aceptado participar de este estudio.

E- Existe un grupo de personas que acuden a las asambleas de la agrupación por el interés de obtener información específica a la cual sólo tienen acceso por los dirigentes en el tema salud, educación, vivienda y otros beneficios de la ley Valech.

F- Un grupo de personas que se sienten muy vulnerables por lo vivido y son muy dependientes del dirigente del pueblo donde viven. Hacen lo que éste les dice y en las reuniones no participan dando su opinión. Se dejan guiar por el grupo.

G- Existe un grupo de personas emocionalmente muy afectada. A muchos los definen sus compañeros políticos como "locos", o muy enfermos. Muchos han fallecido, otros están aislados y tengo conocimiento de ellos, por comentarios de algunos dirigentes.

Dentro de la muestra contactada vienen a mi mente dos casos: el de un Sr. de cerca de 40 años que se ofreció para participar y me citó al día siguiente en su casa para la entrevista. Cuando llegué al lugar apareció su madre quien me dijo que su hijo no estaba por motivos de viaje. Luego de algunas llamadas para preguntar si el 
Sr. había regresado, la madre me confidenció que su hijo estaba mal, producto de lo que vivió en prisión y que lo mantienen en su habitación aislado por crisis nerviosas (no pudo darme un diagnóstico preciso). Por este motivo ellos lo negaban. Me dijo que prefería que no lo entrevistara porque cada vez que oía alguna noticia relacionada, le venía la crisis y debían encerrarlo. Para esta madre, la enfermedad de su hijo había ocasionado la separación de su pareja y sus hijos y la pérdida de su trabajo.

El segundo caso corresponde al de una mujer de alrededor de 40 años del sur de Chile, casada con dos hijos que vivía en una parcela fuera de la ciudad. Un señor que me ayudó en esa ciudad a contactar a las personas insistía en que le hiciera la entrevista a ella, pues él la veía muy afectada. Cuando la visité, parecía que vivía postrada en una cama. Su marido atribuía a la persecución de uniformados que afirmaba sufrir hasta en la actualidad, el estado de ánimo y las enfermedades de su señora. Daba la sensación que esa familia estaba viviendo el terror producido por la prisión política, y distintos episodios ocurridos en la vida familiar, eran asociados por ellos a la persecución política (como el allanamiento en su casa).

\section{Perfil general de los entrevistados:}

* Todos los entrevistados militaban en política antes de la detención.

* Muchos de ellos tienen un origen humilde y comenzaron a trabajar desde que eran niños (12 años aprox.) .

* Todos o casi todos tienen una elevada conciencia social y creían en ideales de igualdad y mejores oportunidades laborales.

* Muchos de ellos están desilusionados de la evolución post dictadura de los partidos políticos y a pesar de mantener sus ideales, no militan activamente.

* No vi odio hacia los torturadores o la figura de Pinochet, en ningún entrevistado. Algo que me sorprendió en un principio y luego entendí que en la lucha actual que mantienen por una reparación integral que involucre verdad, justicia y reconciliación, es donde cambia el sentimiento por una causa.

* Muchos de ellos afirman haber tenido una infancia difícil con una relación disfuncional entre sus padres y/o entre su(s) padre(s) y ellos.

* Muchos creen en Dios, a pesar de ser comunistas y algunos practican algún tipo de religión cristiana. 


\section{Desde lo afectivo}

Existe un grupo de personas que comunican el tema de la prisión con su pareja e hijos cuando éstos cumplen la mayoría de edad. Otros en cambio, prefieren ocultar lo vivido y sus esposos o esposas se han enterado tardíamente. Esto último pienso que crea un espacio de distanciamiento afectivo que les impide compartir e involucrarse totalmente con el otro. Las experiencias en prisión marcaron la vida de la mayoría de la gente y muchos de ellos no tienen pareja e hijos. Optaron por la soltería y algunos lo atribuyen directamente a la experiencia traumática de la prisión.

Muchas personas quieren demostrar que no se encuentran afectados por la prisión, pero en algún momento de la entrevista que les administramos, reconocieron que algo cambió en ellos con la experiencia de prisión.

La situación individual en que ocurrieron los episodios de violencia política varían mucho de un caso a otro. Por ejemplo no podría compararse a alguien que por tener un cargo político público fue detenido, con alguien que ha sido delatado por la esposa o su propio padre, lo que sin duda debe producir una quiebra significativa en la relación (ambos casos no volvieron a ver a este familiar).

Existe una relación digna de estudiar entre los uniformados y los EXPPS, que comienza antes de la prisión y no termina. Existen muchos casos en que los hijos de EXPP son uniformados, o las hijas se han casado con carabineros o militares.

En agrupaciones de carácter político, se observa un tipo de comunicación caracterizado por bromas o comentarios relacionados al tema de la tortura. Por ejemplo decirse entre compañeros que se tengan cuidado entre ellos mismos, porque sino le practicarán una técnica determinada de tortura. Bromas que impactan, pues denotan una forma sutil de violencia entre hombres que son compañeros políticos.

Para la mayoría de las personas evaluadas, la etapa posterior a la prisión política fue muy difícil. Esto debido a que a muchos les juzgaron por terrorismo y posesión de armas, y esto les impidió trabajar en cualquier sitio. Muchos fueron exonerados a otras ciudades de norte a sur y perdieron el contacto con sus familias. Lo mismo ocurrió con la gente que se fue en el exilio y que al volver después de 20 años, se encontró con un desconocido(a).

La persecución siguió desde el año 1973 al año 1989 y constantemente los hogares de los EXPPS eran allanados por las noches por personeros de las fuerzas armadas que buscaban armas o a los mismos EXPPS. 
Esta situación, les impedía vivir con tranquilidad y los hijos crecieron viendo ingresar reiteradamente a uniformados a sus hogares, con armas que violentaban mediante amenazas en busca de algún miembro del grupo familiar.

Uno de los objetivos de la tortura era imponer temor en la población mas allá de los propios torturados. Por este motivo posiblemente muchos familiares, amigos y vecinos de EXPP se alejaron de éstos, lo que dificultó aún más la vida de los EXPP, y produjo un quiebre en la relación entre familias.

Así mismo, muchos reconocen no haber sido apoyados por el partido en el que militaban después de la prisión, por haberse convertido en un peligro para quienes eran sus compañeros al estar claramente identificados, mientras que los militantes que trabajaban en la clandestinidad podían verse perjudicados por esto. Esto hizo que muchos EXPP se sintieran desilusionados de los partidos políticos y dejaran de militar.

\section{Desde lo social}

Casi todos los entrevistados, afirman tener compañeros de militancia política con quienes compartir sus ideas, inquietudes, y que les ayudan a solucionar problemas; pero afirman que su familia es la única fuente de apoyo y protección, reconociendo no tener amigos. Un grupo menor afirma tener amigos que se mantienen de la infancia u otros que han conocido en prisión.

Muchos EXPP se dedican a trabajar en sus casas y con sus hijos (trabajos en metal, madera, mecánica automotriz, contabilidad, etc.), y están totalmente dedicados al oficio. No teniendo en muchos casos, vida social. Esto, en ocasiones asociado al sentimiento de culpa por haber estado mucho tiempo ausente en casa debido a la militancia política. Un sentimiento de culpa también por haber podido estar muerto y haber dejado a una mujer e hijos pequeños.

Pienso que la represión política produjo el miedo a hablar de política en el país, debido a que no se sabía quien era el otro que escuchaba. Podría ser un delator, pues éstos eran civiles que apoyaban al gobierno de Pinochet. Entonces ese temor, incluso entre compañeros de partido, produjo un distanciamiento en la forma de relacionarse socialmente, y por este motivo muchos solamente confían exclusivamente en su familia.

En algunos casos les llamé por teléfono y luego de presentarme, sentí temor en el tono de voz y me hacían preguntas del tipo: "¿quién le dio mi teléfono?” " "pues dígale a él que me traiga personalmente los cuestionarios". 
Por este motivo decidí no hacer el primer contacto por teléfono y la estrategia fue asistir a las asambleas y presentarme personalmente en un momento en que se celebraban estas reuniones, explicando en qué consistía la investigación. A algunas personas sin embargo se contactó por teléfono, pero el que llamaba era uno de los dirigentes que contactaba a sus conocidos y les decía que posteriormente les llamaría.

\section{B.2. Documento 2}

1. La politización de las víctimas: ¿puede condicionar el contenido de las entrevistas y cómo?. 2.Su expresión física: gestos y mirada cansada. 3.- Su sentimiento " de miedo o paranoia" de que aun les persiguen, etc. 4.- Su sentimiento psicológico de inseguridad, nerviosismo, miedo, etc. 5.- La respuesta de tu familia: en lo positivo y en los temores.

1. El lenguaje habitual de las víctimas tiene una fuerte connotación política, esto podría tener su origen en la cosmovisión de ellos, que surge desde los ideales políticos.

En Chile y pienso que en el mundo, partidos políticos con ideologías como la del partido comunistas, y el MIR (Movimiento de Izquierda Revolucionaria) forman parte de la extrema izquierda que se ha caracterizado por una participación política reactiva de quienes conforman estos grupos.

Esta tendencia se vería reflejada en el grado de participación de los simpatizantes y militantes a agrupaciones de esta índole, que en congruencia con las respectivas ideologías, requieren de un compromiso que involucra en su totalidad o casi totalidad al individuo y sus relaciones.

La ideología del Partido Comunista, desde lo social, busca la igualdad de clases y oportunidades, y el grado de compañerismo existente entre ellos es uno de los pilares fundamentales de su organización y funcionamiento, siendo quizás la principal red de apoyo social para sus integrantes EXPPS.

El trabajo de la militancia política fue y es para muchos de ellos (sobretodo para sus dirigentes) la principal motivación en sus vidas, que alcanzó su máxima expresión cuando fueron adolescentes. Con frecuencia en el transcurso de la entrevista, se manifestaron sentimientos de culpa por el hecho de no haber considerado las consecuencias de sus actos, pues la ideología política era más fuerte y más importante que sus vidas, la familia o el trabajo. Ahora, después de más de 30 años, piensan en qué sería de sus familias si ellos no hubieran sobrevivido a la prisión por motivos políticos, y en el posible daño causado a sus esposas/ os e hijos. 
Muchos sabían lo que les iba a suceder, y recibieron entrenamiento previo para enfrentarse a la tortura, reconociendo que sabían que eran buscados y serían privados de su libertad por motivos políticos. En muchos casos estas personas militaban clandestinamente en períodos de dictadura, viéndose muchas veces en la necesidad de separarse por períodos prolongados de sus familias, y privados de cualquier tipo de contacto familiar por el peligro que ello implicaba. Situaciones de este tipo, en algunos casos duraron años.

Además, un elevado número de víctimas no terminó sus estudios secundarios (un grupo menor no terminó sus estudios primarios, y un grupo también menor si cursó estudios universitarios), y para muchos de ellos, la única vía de acceso al conocimiento fue la vía política, pues dentro de los partidos les instruían mediante literatura proveniente de Europa, Cuba, o el resto de países latinoamericanos, como si se tratase de una escuela, y para ellos es el tema que en muchos de los casos, más dominio teórico tienen.

Lo anterior, sumado a la cultura, el país de origen, familia y sociedad, la historia individual y familiar, hacen que las víctimas tengan en su mayoría una cosmovisión con un marcado prisma político. Y exista un antes y un después en sus vidas determinado por la experiencia de prisión. Aunque para algunos no sea así a nivel consciente.

Todo lo anterior, podría haber politizado las respuestas de los entrevistados, quienes de preferencia querían hablar de política antes de escuchar la primera pregunta. Por nuestra parte, al introducir la entrevista, aclaramos que el objetivo de este estudio era evaluar el impacto de la prisión desde la psicología y no desde la historia o la política. Además, las preguntas correspondientes a la primera parte de la entrevista que evaluaban relaciones interpersonales actuales, y las mismas en el pasado (tercera parte de la entrevista), no tenían relación directa con política. Pese a lo anterior, la entrevistadora, tuvo en ocasiones que reiterar el sentido de la pregunta, una vez escuchado el matiz político, para obtener la información que se esperaba en estas preguntas. Esto, con posterioridad a cada respuesta de este tipo, pues existe una realidad concreta, marcada por la prisión política que si que afectó directamente en sus vidas.

En aquella segunda parte que evalúa la concepción del mundo, creencias, valores, sentido de la vida y de los seres humanos, si hubo una connotación política marcada, por la cosmovisión que tienen estas personas, y que ya hemos referido anteriormente. No obstante, se buscó indagar algo más personal en estas respuestas.

La parte final de la entrevista, que refiere el impacto de la tortura y la prisión, tiene una alta connotación política, pues es la parte específica de la entrevista que busca además de indagar posibles indicadores del impacto que estudiamos, variables tales como edad al momento de la detención, época, tiempo 
de prisión, y lugares de reclusión, entre otros. No obstante, se buscó indagar tales efectos desde la psicología, información que esperamos poder rescatar con un análisis acucioso de las respuestas.

Cabe destacar que los EXPPS denotan prejuicios en torno a las consecuencias, y aunque ellos reconocen el cambio en sus vidas, en la mayoría de los casos quieren demostrar que no tienen secuelas. Lo que se contrasta reiteradamente con preguntas concretas tales como aquellas relacionadas al tema amigos o relaciones familiares.

El hecho de haber supervivido, a diferencia de compañeros de celda o amigos que perdieron la vida, les hace pensar que lo que vivieron "no fue tanto" como lo que le pasó a otros que fallecieron. Y el tema de la locura, tienden a verlo de manera cercana en algunos EXPP que no participan en las agrupaciones, pero de quienes si tienen conocimiento de su estado de salud mental. Pienso que existe cierto prejuicio en relación a la salud mental en muchos EXPP, que podría asociarse a la cercanía tanto afectiva como de vivencias personales, que son fácilmente identificables en el otro en el que surge cierta empatía por haber vivido las mismas experiencias que sus compañeros que perdieron la razón, y que hace que exista una tendencia al rechazo de efectos psicológicos asociados a la locura.

En ese sentido, pienso que las respuestas no fueron politizadas y a pesar de la necesidad de contar lo sucedido en muchos casos, se pudo conseguir el objetivo de la entrevista.

No obstante lo anterior, existe mucha información anexa desde la política, pues se les permitió que hicieran referencia a sus temas de interés, como una forma de lograr un buen contacto que favoreciera el desarrollo de la entrevista.

2. Su expresión física: gestos y mirada cansada.

Es difícil determinar los factores que influyen en una apariencia física cansada. Pues podría ser debido en el caso de la muestra a: a)etapa de ciclo vital, b) tipo de ocupación, c) recursos económicos, d) valores, e) capacidad de disfrutar la vida, f) preocupaciones, g)relaciones familiares, h)lucha por los derechos humanos.

a) la mayoría de las personas que asisten a las agrupaciones de EXPP son mayores de 60 años.

b) Muchos de ellos reconocen haber trabajado desde muy temprana edad (cuando eran niños) en trabajos que requerían de gran esfuerzo físico como la agricultura o en oficios manuales durante extensas jornadas laborales. Dos de ellos han reconocido trabajar hasta el día de hoy, de lunes a domingo, de ocho 
de la mañana a doce de la noche, no teniendo días vacaciones. Uno de ellos, afirma no tener vacaciones desde el año 73.

c) Disponer de escasos recursos económicos como en el caso de algunos EXPP que viven de la pensión Valech (aprox. 175 euros mensuales), sin ningún otro tipo de ingreso familiar, teniendo a cargo un hogar.

d) Valores relacionados a trabajar por la igualdad y los derechos humanos, hasta el día de hoy, podría influir en un cansancio de muchos años por una lucha que no siempre es entendida como tal y que con el paso de los años se vuelve cada vez más difícil por el esfuerzo físico y mental que ello significa.

e) Cuando no existen los recursos para satisfacer siempre las necesidades básicas de alimentación, vivienda y abrigo en un grupo familiar, la capacidad de disfrute de la vida se vuelve prácticamente imposible, pudiendo incluso, no haberse desarrollado nunca esta capacidad. Lo que posiblemente sumado a las experiencias de prisión podría verse acentuado.

f) Preocupaciones cotidianas, sumadas a preocupaciones por mejora de la ley Valech, y preocupaciones por el bienestar familiar. Entre otras.

g) Muchos EXPP no han hablado el tema de la prisión con sus hijos. Este fue un impedimento significativo en este estudio, pues muchos de ellos aceptaron participar pero sin ellos. El motivo en algunos casos es vergüenza de lo sucedido, o diferencias en ideas políticas, además de protección de familiares. Esto en muchos casos, exige que la madre o el padre estén siempre presentes y no puedan manifestar conflictos asociados a las experiencias de prisión, en su familia.

h) La permanente lucha por los derechos humanos en Chile les significa muchas horas de reuniones, actividades, manifestaciones, encuentros, que desde los mismos EXPP, tienen escasa acogida. Esto se traduce en una insatisfacción y decepción generalizada en torno al gobierno y a sus pares que podría influir en su aspecto físico.

3.- Su sentimiento "de miedo o paranoia" de que aun les persiguen, etc.

El grado de miedo de estar siendo vigilados o perseguidos por fuerzas de derecha, varía dependiendo de la zona geográfica en que cada EXPP vive. Esto, por las características de la ciudad en que residen. Mucha gente después de la prisión cambió su ciudad de residencia.

Otros en cambio mantuvieron sus viviendas y en aquellos que residen en una ciudad pequeña, el miedo pareciera estar más presente. Pues es parte de su cotidianeidad encontrarse con el militar que le torturó en el almacén de la esquina. 
En la capital, este miedo no se manifiesta, pues Santiago de Chile tiene más de cinco millones de habitantes y es menos probable reencontrarse con un ex torturador que en pueblos con un escaso número de habitantes. Además la individualidad tiende a confundirse como en todas las capitales, y es difícil identificar a un EXPP de uno que no lo es.

Existe una tendencia a dar significados a las experiencias cotidianas vinculándolas a la experiencia política de prisión. En algunos casos, fundamentada en hechos reales de persecución.

Hay casos de personas que atribuyen a personeros del régimen militar, todos aquellos sucesos que han resultado perjudiciales en sus vidas. Sin evaluarlo objetivamente. Esto puede deberse a que la tortura en el mayor de los casos fue aplicada previo vendaje de ojos del torturado. Entonces, el desconocimiento del violador, el agresor, el uniformado que la ejercía, podría favorecer que éste se vuelva un fantasma en la vida del individuo. Un fantasma que hizo el mayor daño que ha sufrido, y que aparecería cada vez que ocurre un acontecimiento doloroso en la vida de la víctima. A nivel vincular, podría explicarse esta idea.

4.- Su sentimiento psicológico de inseguridad, nerviosismo, miedo, etc.

En escasas ocasiones cuando se realizó el contacto vía telefónica observamos una actitud de desconfianza y posiblemente miedo manifestado en sus voces. Era fácil de dilucidar por el tono de voz, los silencios, las pausas, y las expresiones verbales.

El recibir un llamado en su residencia de alguien que investigaba el impacto de la prisión política, y saber que conformaban un listado, sin conocer personalmente a quien les llamaba y que además tenía sus antecedentes, activaba en algunos de ellos, un sentimiento psicológico de inseguridad, nerviosismo y miedo.

A nivel explícito y explícito, observamos códigos de relación particulares en este grupo de personas, asociados a la experiencia de prisión en sus vidas. Sus temas, sus bromas, sus intereses y actitudes lo denotan. Esperamos con este estudio, conocer todos aquellos factores que comprenden los efectos de la experiencia de prisión en su forma de ver la vida, el mundo y los seres humanos, y en sus relaciones interpersonales. 


\section{Tesis: Impacto emocional y social en víctimas de privación de libertad y tortura por motivos políticos de Chile.}

Tesista: Pamela Zapata S.

Directores: Félix López Sánchez - Mª Cruz Sánchez Gómez

INSTRUCCIONES: A continuación se presentan algunos párrafos que hemos extraído al azar de los discursos de un grupo de supervivientes chilenos a experiencias de prisión política y tortura.

Mediante este test, solicitamos que valores en cada párrafo, la presencia o ausencia de las categorías señaladas a la izquierda de cada párrafo, indicándonos tu apreciación en la casilla correspondiente. Ante cualquier duda, rogamos te abstengas.

\begin{tabular}{|c|c|}
\hline El " $x$ "(hijo) mire, también es un poco así. El problema que el " $x$ " (hijo) & Alcoholismo en hijo \\
\hline está metido en el vicio... En el trago. Si, tiene buen porcentaje... Claro & $\square \mathrm{NO} \quad \square \mathrm{SI}$ \\
\hline que hay veces que él corta y deja de tomar tres - cuatro meses, pero & Problemas con hijo \\
\hline $\begin{array}{l}\text { después vuelve. Es que el medio ambiente que tiene él en... En la mar } \\
\text { es así, ¿ve?. En la mar, marisca... En arica. }\end{array}$ & $\square \mathrm{SI} \quad \square \mathrm{NO}$ \\
\hline Esos 30 años no dije nada a nadie. Nadie se imagina las cosas que yo & Silencio \\
\hline viví hace 30 años atrás, y yo después de tener a mi hijo, me fui a otra & $\square \mathrm{NO} \quad \square \mathrm{SI}$ \\
\hline parte, y me puse una careta y seguí siendo una persona como que & Rechazo hijo \\
\hline nada le había pasado nunca, pero después de haber estado en terapia & $\square \mathrm{NO} \quad \square \mathrm{SI}$ \\
\hline empecé como a tomarle el peso a las cosas y mirar para atrás, y decir: & Relación hijo/ "mala" \\
\hline “cómo pude sobrevivir con esta máscara y no contándole a nadie y no & $\square \mathrm{NO} \quad \square \mathrm{SI}$ \\
\hline opinando al respecto". Y cuando se supo tenía que contarle a alguien, & Negación Experiencia \\
\hline $\begin{array}{l}\text { y le conté a mi hijo, o sea, con la psicóloga, y ahí como que se } \\
\text { derrumbó un poco la relación Y bueno me trató mal me mandó a la }\end{array}$ & $\square \mathrm{NO} \quad \square \mathrm{SI}$ \\
\hline c..., pero siempre pensé que era bueno para ellos, el que no lo supieran & Asiste a psicoterapia \\
\hline y siempre pensé que cuando fueran grandes les iba a contar. & $\square \mathrm{NO} \quad \square \mathrm{SI}$ \\
\hline $\begin{array}{l}\text { ¿En qué creo? creo que la vida tiene sentido, creo en la trascendencia, } \\
\text { creo que hay algo más allá de la vida, creo en un Dios interno que está }\end{array}$ & $\begin{array}{l}\text { Creencias religiosas o } \\
\text { espirituales }\end{array}$ \\
\hline en todos & $\square \mathrm{NO} \quad \square \mathrm{SI}$ \\
\hline $\begin{array}{l}\text { nosotros, eh... que se expresa a través de nuestras obras, de lo que } \\
\text { hacemos. Creo de que lo que uno haga en esta vida, eh... mientras más } \\
\text { coherente sea con lo que uno piensa, con lo que uno siente, será mejor } \\
\text { estado para pasar a otro estado. Mientras más resueltas las cosas acá, } \\
\text { mejor situación para desligarse. }\end{array}$ & \\
\hline $\begin{array}{l}\text { Injusto, injusto. Injusto porque no pueden, no pueden tan pocas } \\
\text { personas ser dueñas de casi todo el mundo, de la riqueza. No pueden }\end{array}$ & $\begin{array}{l}\text { Concepción de mundo/ } \\
\text { Negativa por acción del hombre }\end{array}$ \\
\hline haber mas de dos mil millones de personas que, que no tengan agua & $\square \mathrm{NO} \quad \square \mathrm{SI}$ \\
\hline simplemente para su higiene básica; y otras, otras miles de millones & Desigualdad social \\
\hline que no tengan servicios higiénicos. No pueden haber personas que no & $\square \mathrm{NO} \quad \square \mathrm{SI}$ \\
\hline $\begin{array}{l}\text { tengan su comida mínima diaria, hay otras que están enarboladas. En } \\
\text { este país que pocos son dueños de todas las cuestiones básicas. La }\end{array}$ & $\begin{array}{l}\text { Concepción de mundo/ } \\
\text { negativa por iniusticias }\end{array}$ \\
\hline justicia es para algunos. & $\square \mathrm{NO} \quad \square \mathrm{SI}$ \\
\hline $\begin{array}{l}\text { Yo creo que... que somos, que nos falta mucho aprender de nosotros. } \\
\text { Que, }\end{array}$ & No tiene pareja actual \\
\hline
\end{tabular}




\begin{tabular}{|c|c|}
\hline $\begin{array}{l}\text { que nos faltan armas y que... y de... y } \ldots \text { y tener no se, generosidad, } \\
\text { voluntad. }\end{array}$ & $\begin{array}{l}\square \text { NO } \quad \square \text { SI } \\
\text { Visión negativa de seres } \\
\text { humanos } \quad \square \text { SI } \\
\square \text { NO } \quad \square \text { personas } \\
\text { Creencia en las pe } \\
\square \text { NO } \quad \square \text { SI }\end{array}$ \\
\hline $\begin{array}{l}\text { No yo nunca lo voy a superar, no. Para nada. Lo que sí he hecho yo } \\
\text { con mi persona y familia eh... me he reparado yo, ¿ah?. Porque no he } \\
\text { esperado nada de los, de los otros. El hecho de que si el gobierno } \\
\text { cambiará su, su, su forma de, de marchar, y dar mayor satisfacción, } \\
\text { crear nuevas situaciones. Eh... ahí estaríamos reparando situaciones. } \\
\text { Porque estamos, estamos creyendo que efectivamente se nos está } \\
\text { haciendo una verdadera justicia. }\end{array}$ & $\begin{array}{l}\text { No superación de experiencia } \\
\square \text { NO } \quad \square \text { SI } \\
\text { Medidas gubernamentales de } \\
\text { reparación/ Insatisfacción } \\
\square \text { NO } \quad \square \text { SI } \\
\text { Medidas gubernamentales de } \\
\text { reparación/ Injustas } \\
\square \text { NO } \quad \square \text { SI }\end{array}$ \\
\hline $\begin{array}{l}\text { Bueno en ese instante, bueno el primer paso es que estuve cinco días } \\
\text { incomunicado a través de ellos, perdido de Arica con... claro, con... a } \\
\text { través de esas, de esas personas. Eh... bajo... bueno, bajo todo lo que } \\
\text { corresponde al interrogatorio. Todas esas cosas que son, son normales } \\
\text { en ello. }\end{array}$ & $\begin{array}{l}\text { Refiere haber sufrido tortura } \\
\text { psicológica } \\
\square \text { NO } \quad \square \text { SI } \\
\text { Refiere haber sufrido tortura } \\
\text { física } \quad \square \text { SI } \\
\square \text { NO } \quad \square \\
\end{array}$ \\
\hline $\begin{array}{l}\text { Mal. Y la... ella, o sea, ella lo... lo sobrellevó pero no, no lo acepaba } \\
\text { cuando decía que, que quién me mandaba a meterme en leseos, cosas } \\
\text { así. Que la mujer siempre reprocha "porque yo te dije que te iba a } \\
\text { pasar esto". Pero lo... en Santiago no afectó porque en Santiago le... yo } \\
\text { tengo tíos que son militares. Entonces, ellos le fueron a decir que ni } \\
\text { preguntaran por mi. Que no fueran ni a preguntar ni a averiguar por } \\
\text { mi, porque yo estaba en la lista de los cabros. Que como yo había ido } \\
\text { en la marcha... dirigiendo la marcha contra la guerra civil que se hizo } \\
\text { el año } 73 \text { antes del golpe... entonces, me ubicaban por fotos. Me } \\
\text { ubicaban eh... porque salía en la tele pero no sabían quién era. Porque } \\
\text { yo no tenía ningún cargo grande ni que se hiciera público. Yo era di... } \\
\text { dirigente sindical y era de las juventudes comunistas que ahí nadie } \\
\text { sabía que yo eh... ocupaba el cargo que ocupaba porque era obvio, si } \\
\text { yo estaba encargado de, de controlar a la gente que... de... co... era un } \\
\text { "control y cuadra" se llamaba porque uno controlaba para ir } \\
\text { evaluándolos y subiéndolos de cargo. Entonces, menos podrían haber } \\
\text { andado diciendo "oye, cuidado que yo soy control de cuadra". } \\
\text { Entonces nadie, cuando fueron a decirme que no preguntaran por mi } \\
\text { porque yo estaba en la lista de fusilamiento. Yo tendría que haber } \\
\text { muerto cuando venía el helicóptero y después lo devolvieron de } \\
\text { Iquique. Hasta ahí nomás llego. Y ahí Pinochet dijo "estamos ma... } \\
\text { metiendo las patas", hizo devolverse a Arellano. Llegó hasta Pisagua } \\
\text { nomás. }\end{array}$ & 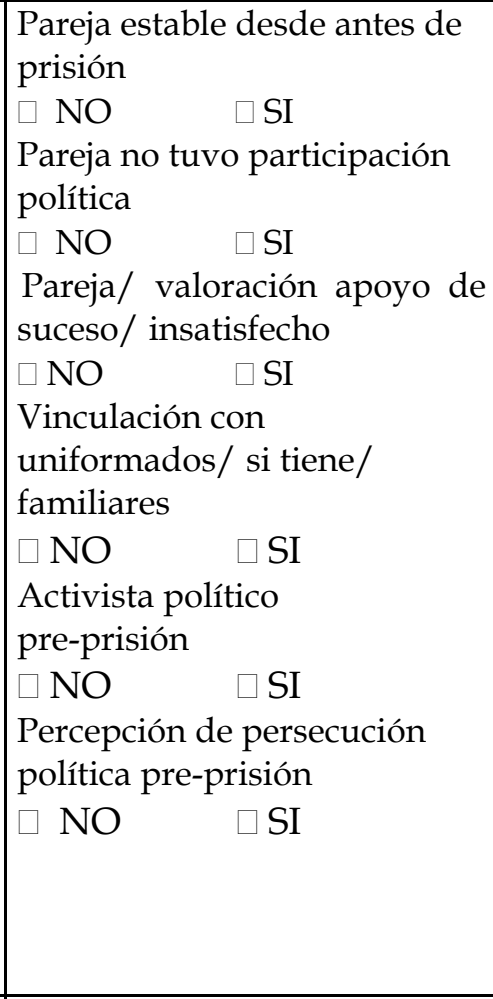 \\
\hline $\begin{array}{l}\text { Bueno la vida es lo principal para mi porque me dio, se me dio otra } \\
\text { oportunidad. Y sería malo si yo dijera "no, la vida para mi no tiene } \\
\text { ningún incentivo", porque se me dio una oportunidad y por algo me la } \\
\text { dieron. }\end{array}$ & $\begin{array}{l}\text { Valores/ la vida } \\
\square \mathrm{NO} \quad \square \mathrm{SI} \\
\text { Actitud post prisión/ deseo } \\
\text { de superación } \\
\square \mathrm{NO} \quad \square \mathrm{SI}\end{array}$ \\
\hline
\end{tabular}




\begin{tabular}{|c|c|}
\hline $\begin{array}{l}\text { yo les cuente, a quien yo le cuente "sabís que tengo un problema flaco, } \\
\text { me pasa esto..", no, no. } \\
\text { Eh, son mi... mi motor. Todas estas personas que involucran mi vida } \\
\text { diaria, son mi motor. Yo creo que si no las tuviera, me costaría } \\
\text { mucho... y te hablo de todo, de mi familia, mis amigos, de mi vida } \\
\text { política, eh... activa o inactiva, eh... son, son lo que me mueve. No } \\
\text { camino por la vida solo por caminar. }\end{array}$ & $\begin{array}{l}\square \mathrm{NO} \quad \square \mathrm{SI} \\
\text { Sentido de relaciones afectivas } \\
\text { disponibles/ positivo } \\
\square \mathrm{NO} \quad \square \mathrm{SI}\end{array}$ \\
\hline $\begin{array}{l}\text { ¡Uy! mi adolescencia fue como la más triste si. Porque... porque } \\
\text { empecé a crecer y me di cuenta del mundo en el que vivíamos. Bueno } \\
\text { ahí empezó, digamos, mi... mi posición política en la vida de alguna } \\
\text { manera. Me di cuenta de lo que pasaba en este país, me di cuenta... } \\
\text { estoy hablando de los } 13-14 \text { años, } 14-15 \text { años... }\end{array}$ & $\begin{array}{l}\text { Valoración de la vida en } \\
\text { adolescencia/ negativa } \\
\square \text { NO } \quad \square \text { SI } \\
\text { Valoración del futuro en } \\
\text { adolescencia/ pesimista } \\
\square \text { NO } \quad \square \text { SI } \\
\text { Vinculación política pre- } \\
\text { prisión/ activista } \\
\square \text { NO } \quad \square \text { SI }\end{array}$ \\
\hline $\begin{array}{l}\text { En la reparación hay mucha injusticia, gente que se quedó fuera, gente } \\
\text { que también sufrió junto a sus familiares y de ninguna manera le } \\
\text { llegan los beneficios a ellos. }\end{array}$ & $\begin{array}{l}\text { Valoración medidas } \\
\text { gubernamentales de } \\
\text { reparación/ injustas } \\
\square \mathrm{NO} \quad \square \mathrm{SI} \\
\text { Valoración global medidas } \\
\text { gubernamentales de } \\
\text { reparación/ insatisfecho } \\
\square \mathrm{NO} \quad \square \mathrm{SI} \\
\end{array}$ \\
\hline $\begin{array}{l}\text { Es hostil, es un mundo violento, en relación al entorno, lo que } \\
\text { pasa es que uno ya se olvidó y convive con eso, pero hay agresiones } \\
\text { permanentes, hasta un sonido fuerte es una agresión. }\end{array}$ & 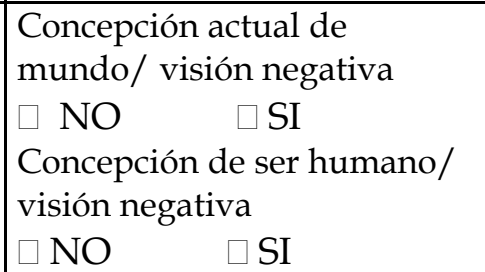 \\
\hline $\begin{array}{l}\text { Mira, yo creo que nos ven muy demasiado... nos siguen mirando como } \\
\text { la, } \\
\text { como la... como, como la basura que hay que echar debajo de la } \\
\text { alfombra. O sea, eh... a nosotros se nos... se nos acalla y se nos... se } \\
\text { nos... se nos burla. }\end{array}$ & $\begin{array}{l}\text { Valoración respuesta sociedad } \\
\text { chilena/ exclusión social } \\
\square \mathrm{NO} \quad \square \mathrm{SI} \\
\text { Valoración respuesta sociedad } \\
\text { chilena/ indiferencia. } \\
\square \mathrm{NO} \quad \square \mathrm{SI}\end{array}$ \\
\hline
\end{tabular}

\section{MUCHAS GRACIAS POR TU COLABORACIÓN EN ESTE ESTUDIO.}


Tabla C1. Categorías incluidas en el test de fiabilidad y su correspondencia con nuestro sistema de codificación.

\begin{tabular}{|c|c|}
\hline CATEGORÍAS & CORRESPONDENCIA \\
\hline 1 = HIJOS alcoholismo & Si \\
\hline $2=$ HIJOS problemas & No \\
\hline $3=$ EXPERIENCIA Silencio & Si \\
\hline 4 = HIJOS Rechazo & Si \\
\hline 5 = HIJOS "mala" relación & No \\
\hline $6=$ EXPERIENCIA Negación & $\mathrm{Si}$ \\
\hline 7 = PSICOTERAPIA asiste & Si \\
\hline $8=$ CREENCIAS religiosas o espirituales & Si \\
\hline 9 = MUNDO concepción negativa por causa humana & Si \\
\hline 10 = MUNDO concepción negativa por desigualdad social & $\mathrm{Si}$ \\
\hline 11 = MUNDO concepción negativa por injusticias & Si \\
\hline $12=$ PAREJA no tiene & no \\
\hline $13=$ SERES HNOS. visión negativa & Si \\
\hline $14=$ CREENCIAS en personas & No \\
\hline $15=$ EXPERIENCIA no superada & $\mathrm{Si}$ \\
\hline 16 = REPARACIÓN insatisfacción & Si \\
\hline 17 = TORTURA psicológica & Si \\
\hline $18=$ TORTURA física & No \\
\hline $19=$ PAREJA desde antes de prisión & $\mathrm{Si}$ \\
\hline $20=$ PAREJA no participa en política & $\mathrm{Si}$ \\
\hline $21=$ PAREJA insatisfactorio apoyo en política & No \\
\hline $22=$ VINC. POLÍTICA tiene con uniformados & $\mathrm{Si}$ \\
\hline 23 = PARTICIP. POLÍTICA activista pre-prisión & Si \\
\hline 24 = PERSEC. POLÍTICA si tuvo pre-prisión & No \\
\hline $25=$ VALORES la vida & Si \\
\hline 26 = ACTITUD POST-PRISIÓN deseo de superación & No \\
\hline $27=$ AMIGOS no tiene & $\mathrm{Si}$ \\
\hline $28=$ SENTIDO RELAC. AFECTIVAS positivo & Si \\
\hline $29=$ VIDA ADOLESC. Valoración negativa & $\mathrm{Si}$ \\
\hline 30 = FUTURO ADOLESC. Valoración pesimista & No \\
\hline 31 = PARTIC. POLÍTICA activista pre-prisión & $\mathrm{Si}$ \\
\hline 32 = REPARACIÓN medidas injustas & Si \\
\hline $33=$ REPARACIÓN insatisfacción global & No \\
\hline 34 = MUNDO concepción negativa & $\mathrm{Si}$ \\
\hline $35=$ SERES HUMANOS concepción negativa & No \\
\hline 36 = SOC. CHILENA valoración negativa por exclusión social & Si \\
\hline 37 = SOC. CHILENA valoración negativa por indiferencia & no \\
\hline
\end{tabular}




\section{Apéndice D: Mapa conceptual jerárquico}

* la representación gráfica de este mapa, sitúa los nudos (1) y (2) uno al lado del otro, y de ahí se desprenden las categorías.

(1)Datos Demográficos

(1) Sexo

(1 2) Edad

(1 11 1)Masculino

(1 11 2)Femenino

(1 2 1 1 ) menor de 54 años

$\left(\begin{array}{lll}1 & 2 & 2\end{array}\right)$ entre 55 y 65 años

(1 2 ( 3 3)mayor de 65 años

(1 3)Zona geográfica
(1 3 1 1 ) Norte
$\left(\begin{array}{lll}1 & 3 & 2\end{array}\right)$ Centro
(1 33 3)Sur

(1 4)Estado civil

(1 4 1)Soltero

(1 $\left.4 \begin{array}{lll} & 1 & 1\end{array}\right)$ desde antes de prisión

(1 $\left.4 \begin{array}{lll} & 1 & 2\end{array}\right)$ desde después de prisión

(1 $\left.4 \begin{array}{lll}1 & 1\end{array}\right)$ No especifica

(1 4 2) Casado o en convivencia

(1 $\left.4 \begin{array}{lll} & 2 & 1\end{array}\right)$ desde antes de prisión

(1 $\left.4 \begin{array}{lll} & 4 & 2\end{array}\right)$ desde después de prisión

(1 $\left.4 \begin{array}{lll} & 2 & 3\end{array}\right)$ No especifica

(1 4 3)Divorciado o separado de hecho

(1 $\left.4 \begin{array}{lll} & 3 & 1\end{array}\right)$ desde antes de prisión

(1 $\left.4 \begin{array}{lll} & 3 & 2\end{array}\right)$ desde después de prisión

(1 $\left.4 \begin{array}{llll} & 3 & 2 & 1\end{array}\right)$ No expp

(1 $\left.\begin{array}{llll}4 & 3 & 2 & 2\end{array}\right)$ Si expp

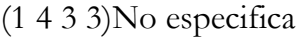

(1 4 4)Viudo

(1 44 1) hace menos de dos años

(1 444 2)hace más de dos años

(1 444 3)No especif.

(1 5)Nivel educativo

(1 5 1)Estudios primarios

(1 5 2)Estudios secundarios

(1 5 3 3 )Estudios técnicos

(1 5 4)Estudios universitarios

(1 5 5)Ninguno

(1 6)Antecedentes ocupacionales

(1 6 1)Ocupación pre-prisión

(1 $\left.6 \begin{array}{lll} & 1 & 1\end{array}\right)$ Ninguna

(1 $\left.\begin{array}{llll} & 6 & 1 & 2\end{array}\right)$ Trabajador no calificado

(1 $\left.\begin{array}{llll}1 & 6 & 1 & 3\end{array}\right)$ Trabajador calificado

$\left(\begin{array}{llll}1 & 6 & 1 & 4\end{array}\right)$ Estudiante

(1 $\left.6 \begin{array}{lll} & 1 & 5\end{array}\right)$ No especifica tbjo.

(1 616 6)Dueña de casa

(1 $\left.6 \begin{array}{llll} & 1 & 7\end{array}\right)$ trabajador independiente

(1 6 2) Ocupación post-prisión

(1 $\left.6 \begin{array}{lll} & 2 & 1\end{array}\right)$ Ninguna

(1 $\begin{array}{lll}1 & 6 & 2\end{array}$ 2)Trabajador no calificado

(1 $\left.\begin{array}{llll}1 & 6 & 2 & 3\end{array}\right)$ Trabajador calificado

(1 $\left.\begin{array}{llll}1 & 6 & 2 & 4\end{array}\right)$ Estudiante

(1 $\begin{array}{lll} & 6 & 2\end{array}$ 5)Trabajador independiente

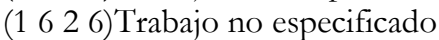

(1 $\left.6 \begin{array}{lll}1 & 2 & 7\end{array}\right)$ Dueña de casa

(1 6 3) Ocupación actual

(1 $\left.6 \begin{array}{lll} & 3 & 1\end{array}\right)$ Ninguna 


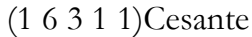

(1 $\left.\begin{array}{lllll} & 6 & 3 & 1 & 2\end{array}\right)$ Pensionado

(1 $\left.\begin{array}{lllll} & 6 & 3 & 1 & 3\end{array}\right)$ Jubilado

(1 63314 )No especifica

(1 $\left.\begin{array}{llll}1 & 6 & 3 & 2\end{array}\right)$ Trabajador no calificado

(1 $\left.\begin{array}{llll}1 & 6 & 3 & 3\end{array}\right)$ Trabajador calificado

(1 $\left.6 \begin{array}{lll}1 & 6 & 3\end{array}\right)$ Trabajador independiente

$\left(\begin{array}{llll}1 & 6 & 3 & 5\end{array}\right)$ Estudiante

(1 63 6)trabajador no espec.

(1 7)Antecedentes políticos

(1 7 1)Filiación política pre-prisión

(1 7 1 1)Ninguna

(1 $\left.7 \begin{array}{ll}1 & 2\end{array}\right)$ Activista político

(1 7 2)Filiación política post-prisión

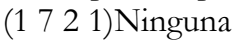

(1 $\left.7 \begin{array}{ll}1 & 2\end{array}\right)$ Activista político

(1 7 3)Filiación política actual

(1 73 1)Ninguna

(1 73 2)Activista político

(1 7 4)Clandestinidad

(1 74 1)No vivió

(1 74 2)Si vivió

(1 7 5)Exoneración

(1 $\left.7 \begin{array}{lll} & 5 & 1\end{array}\right) \mathrm{No}$

(1 75 2) Si

(1 8)Antecedentes de prisión

(1 8 1) Edad

(1 $\left.8 \begin{array}{lll} & 1 & 1\end{array}\right)$ Menor de 21 años

(1 81 2)Mayor de 21 y menor de 40

(1 $\left.8 \begin{array}{lll}1 & 1\end{array}\right)$ Mayor de 40

(1 8 2)Período

(1 $\left.8 \begin{array}{lll}1 & 2 & 1\end{array}\right)$ Sept-Dic 1973

(1 8 2 2)Ene 1974-Ago 1977

(1 82 3)Ago 1977-Mar 1990

(1 82 4)Post-marzo 1990

(1 8 3)Lugar

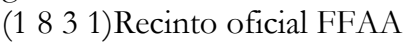

(1 $\left.\begin{array}{llll}1 & 8 & 3 & 2\end{array}\right)$ Recinto no oficial FFAA

(1 8 8 3 3)Lugar de relegación

(1 8 4)Tiempo

(1 844 1)Horas

(1 844 2)Días

(1 84 3)Meses

(1 84 4)Años

(1 84 5)Semanas

(1 8 5) $\mathrm{N}^{\mathrm{o}}$ de veces

(1 $\left.\begin{array}{llll}1 & 8 & 5 & 1\end{array}\right) 1 \mathrm{vez}$

(1 $8 \begin{array}{ll}1 & 5\end{array}$ 2)más de una vez

(1 8 6)Aspectos legales

(1 86 1)Procesamiento

(1 86 1 1)Detención sin juicio

(1 8661 2)Sometido a juicio

(1 86 2)Resolución

(1 $\left.8 \begin{array}{lll} & 6 & 2\end{array}\right)$ Condena de presidio

(1 $\left.8 \begin{array}{lll}1 & 6 & 2\end{array}\right)$ Sobreseimiento temporal

(1 8662 3)Condena de relegación

$\left(\begin{array}{llll}1 & 8 & 6 & 2\end{array}\right)$ Exilio

(1 $\left.8 \begin{array}{lll} & 6 & 2\end{array}\right)$ Libertad por falta mérito

(1 $\left.8 \begin{array}{lll} & 6 & 2\end{array}\right)$ ) Otra o no especif. 
(1 8 7) Valor. exp. tortura

(1 87 1)Refiere no tortura

(1 877 1)Ningún mal trato

(1 871 2)Mal trato no tortura

(1 87712 1)Físico

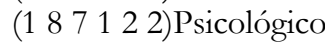

(1 87 2)Refiere tortura

(1 $\left.8 \begin{array}{llll}1 & 7 & 1 & 2\end{array}\right)$ Sexual

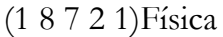

(1 87221 1)No especifica

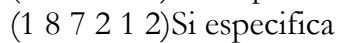

(1 872123 )Modalidad

(1 8722123 1)No especifica

(1 8721232 )Si especifica

(1 87221232 1)Electricidad

(1 $\left.872 \begin{array}{lll}1 & 232 & 2\end{array}\right)$ Submarino

(1 87212323 )Teléfono

(1 872212324$)$ Golpes

(1 872212325 )Quemaduras

(1 87212326$)$ Otras

(1 8721 5)Secuelas

(1 $\left.8 \begin{array}{lllll} & 2 & 1 & 5 & 1\end{array}\right) \mathrm{No}$

$(1872152) \mathrm{Si}$

(1 872152 1)Momento

(1 8721521 1)Post prisión

(1 87215212 )Pre o post I.V.

(1 87215213 )Presente

(1 872152 2)Síntomas

(1 8721522 1)Discapacidad

(1 8721522 2)Otros signos físicos

(1 87215223 )signos "no relevantes"

$\left(\begin{array}{llll}1 & 872 & 5 & 23\end{array}\right)$ Enf. asociada

(1 8721523 1)Otras

$\left(\begin{array}{lllll}1 & 8 & 72 & 152 & 5\end{array}\right)$ Atte en salud

(18721524 1)No

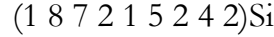

(1872152421)En pasado

(1872152422)En presente

(1 $8 \begin{array}{lll} & 7 & 2\end{array}$ 2)Psicológica

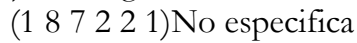

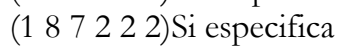

(1 87222 3)Modalidad

(18722231)Amenazas

(1 8722223 2)Simul. fusilamiento

(1 8722223 3)Humill. pública

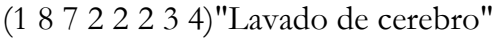

(1 87722223 5)Insultos

(1 8722 4)Secuelas

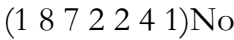

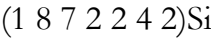

(18 72242 1)Momento

(1 8722421 1)Post prisión

(1 87224212 )Pre o post I.V.

(187224213)Presente

(1 872242 2)Síntomas

(1 8722422 1)Alterac. sueño

(1 8722422 2)Lab. emocional

(187224223)Retraimiento

(1 87224224 )Agresividad 
(1 8722422 5)Ansiedad

(1 87224226 ) Otros o no espec.

(1 8722423 )Enf. asociada

(1 87222423 1)S.E.P.T.

(1 8722423 2)Depresión

(1 8722423 3)Trast. del sueño

(1 872224234$)$ S. ansioso

(1 87222423 5)Disf. sexual

(1 87224236 )Otra o no espec.

(1 872242 4)Atte. en S.M.

(1 8722424 1)No

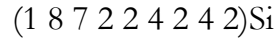

(1 87224242 1)En pasado

(1 8772 3)Sexual

(1 87224242 2)En presente

(1 87723 1)No especifica

(1 87223 2)Si especifica

(1 87232 3)Modalidad

(1 8722323 1)Vejaciones

(1 872323 2)Violación

(1 8723 4)Secuelas

(1 8723233 )Ab. animales

$(187234$ 1) No

(1 877234 2) Si

(1 872342 1)Momento

(1 8723421 1)Post prisión

(1 8723421 2)Pre o post I.V.

(187234213)Presente

(1 872342 2)Síntomas

(1 8723422 1)Alterac. del sueño

(1 8723422 2)Lab. emocional

(187234223)Retraimiento

(1 87234224 )Agresividad

(1 8723422 5)Ansiedad

(1 87234226 ) Otros o no espec.

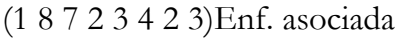

(1 8723423 1)S.E.P.T.

(1 87223423 2)Depresión

(1 87234233 )Trast. del sueño

(1 872234234 )S. ansioso

(1 8723423 5)Disf. sexual

(1 87234236 )Otra o no espec.

(1 8723424$)$ Atte. en salud

(1 8723424 1) No

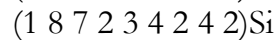

(1 87234242 1)En pasado

(18 8234242 2)En presente

(1 $8723 \quad 425$ )Embarazo no deseado

(1 872 4)No especifica

(1 8724 1)Secuelas

(1872411)No o no especif.

(1 9)Experiencia exilio

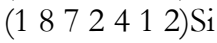

(1 9 1) No

(1 9 2) $\mathrm{Si}$

(1 10)Antecedentes familiares

(1 10 1)Pareja

(1 10101 1)No tiene

(1 101 2)Si tiene 
(1 1012 1)Tpo. de relac.

(1 10121 1)Desde antes de prisión

(1 101212 2)Desde después de prisión

(1 101213 )No especifica

(1 1012 2)Antecedentes de prisión

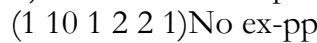

(1 1010122 2)Si ex-pp

(1 1012 3)Particip. política

(1 10123 1) No

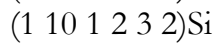

(1 101232 1)De derecha

(1 10121232 2)De izquierda

(1 10 2)Hijos

(1 1012232 3)No especifica

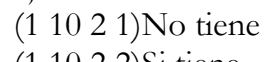

(1 10 2 2)Si tiene

(1 10222 1) $\mathrm{N}^{\mathrm{o}}$ de hijos

(1 1022221 1) 1 hijo

(1 10221 2)Más de 1 y menos de 5

(1 1022213$) 5$ o más

(1 1022 2)Media de edad

(1 10222 1)Menos de 12

(1 1102222 2)de 12 a 18

(1 10222 3)Mayor de 18

(1 1022 3)Media de edad detención

(1 10223 1)No habían nacido

(1 1102223 2)Niños

(1 10223 3)Adolescentes

(1) 10223 4)Adultos

(1 1022 4)Ocupación

(1 102224 1)Ninguna

(1 10224 2)Estudiante

(1 10224 3)Trabajador

(1 102224 4)Estudiante y trabajador

(1 10224 5)Dueña de casa

(1 1022 5)Antecedentes políticos

(1 10225 1)Participación actual o pasada

(1 102251 1)Ninguna

(1 1022511 1)Simpatizantes de izquierda

(1 1022511 2)Simpatizantes de derecha

(1 10225113 Apolíticos

(1 102251 2)Si participan o han participado

(1 1022512 1)Activistas de derecha

(1 1022512 2)Activistas de izquierda

(1 1022 6)Antecedentes de prisión

(1 10226 1)Ninguno es ex-pp

(1 10226 2)1 o más son ex-pps

(1 10 3)Nietos

(1 10222 7)No especifica

(1 11)Antecedentes de ocio

(1 103 1)No tiene

(1 103 2)Si tiene

(1 11 1)No realiza activ.

(1 111 2)Si realiza activ.

(1 12)Antec. de salud

(1 12 1)Refiere antec. mórbidos

(1 12 2)No refiere antec. mórbidos

(1 13)Antec. atte. en salud

(1 13 1)Momento 
(1 131 1)Pasado

(1 131311 1)Atte. médica

(1 131112$)$ Atte. psicol.

(1 131 2)Presente

(1 131312 1)Atte. médica

(1 131312 2)Atte. psicol.

(1 131 3)No especif.

(1 13 2)Relac. exp.

(1 132 1)Ninguna

(1 14)Vincul. uniformados

(1 132 2 2)Si

(1 14 1)No tiene

(1 14 2)Si tiene

(1 142 1)Familia

(1 14221 1)Pareja

(1 14221 2)Hijos

(1 142 2)Amigos

(1 142213$)$ Nietos

(1 142 3)Fam. de origen

(1 142 4)Trabajo

(2)Categorías conceptuales

(2 1)Presente

(2 1 1)Relac. interpers. actuales

(2 111 1) Familia

(2 1111 1)Pareja

(2 $\left.\begin{array}{lllll}1 & 1 & 1 & 1 & 1\end{array}\right)$ Valor. tipo de relac.

(2 11111111 )"Buena"

(2 $\left.\begin{array}{llllll}1 & 1 & 1 & 1 & 1 & 2\end{array}\right)$ "Mala"

$\left(\begin{array}{llllll}2 & 1 & 1 & 1 & 1 & 1\end{array}\right) \mathrm{Ni}$ buena ni mala

(2 $\begin{array}{llll}1 & 1 & 1 & 1\end{array}$ 2)Valor. satisf. sexual

(2) 1111112 1)Insatisfecho

(2 1111112 2)Satisfecho

(2 1111112 3)Regular

(2 111113 )Valor. aspectos de relac.

(2 111113 1)Comprendido

(2 111111311 )No

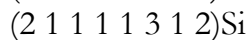

(2 11111313 )Más o menos

(2 1111113 2)Solo

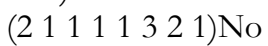

$\left(\begin{array}{lllllll}2 & 1 & 1 & 1 & 1 & 3 & 2\end{array}\right) \mathrm{Si}$

(2 1111132 3)Más o menos

(2 111113 3)Apoyado

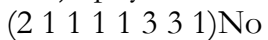

$\left(\begin{array}{lllllll}2 & 1 & 1 & 1 & 1 & 3 & 3\end{array}\right) \mathrm{Si}$

(2 11111133 3)Más o menos

(2 111113 4)Ignorado

(2 111111334 1) No

(2 $\left.\begin{array}{llllll}2 & 1 & 1 & 1 & 3 & 4\end{array}\right) \mathrm{Si}$

(2 111134 3)Más o menos

(2 111113 5)Querido

(2 111111355 1)No

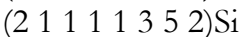

(2 1111135 3)Más o menos

(2 11113 6)Conflictuado

(2 111113361$) \mathrm{No}$

(2 111111362$) \mathrm{Si}$

(2111136 3)Más o menos 
(2 1111114 )Valor. global satisf.

(2) 111114 1)Insatisfecho

(2 111114 2)Satisfecho

(2 111115 )Valor. apoyo suceso

(2) 111115 1)Insatisfecho

(2 111115 2)Satisfecho

(2 111116$)$ Comunic. del suceso

(2) 11111161$) \mathrm{No}$

(2 111161 1)Pareja no desea recordar

(2 111111162$) S i$

(2 11111612 )Ex-pp no desea recordar
(2 1111162 1)Frecuentemente
(2 11111622$)$ Algunas veces
(2 11111623 )Rara vez
(2 1111162 4)No especif.

(2 1111 2)Hijos

(2 $\left.\begin{array}{lllll}1 & 1 & 1 & 2 & 1\end{array}\right)$ Valor. tipo de relación

(2 11111211 )"Buena"

(2 $\left.\begin{array}{llllll}2 & 1 & 1 & 2 & 1 & 2\end{array}\right)$ "Mala"

(2 $\left.\begin{array}{llll}1 & 1 & 1 & 2\end{array}\right)$ Valor. aspectos de relac.

(2) 111122 1)Comprendido

(2 1111122211$)$ No

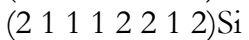

(2 111112213 Más o menos

(2 11111222 Solo
(2 11122221$) \mathrm{No}$

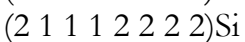
(2 111222 3)Más o menos

(2 1111122 3)Apoyado
(2 111122231$) \mathrm{No}$
(2 $\left.\begin{array}{llllll}2 & 1 & 1 & 2 & 2 & 3\end{array}\right) \mathrm{Si}$
(2 111223 3)Más o menos

(2 111122 4)Ignorado

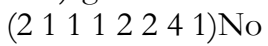

(2 111112244 )Si

(2 1111224 3)Más o menos

(2 1111122 5)Querido

(2 11112251$) \mathrm{No}$

(2 111112255 2) Si

(2 111225 3)Más o menos

(2 1111226$)$ Conflictuado

(2 11112226 1) No

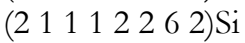

(2 111226 3)Más o menos

(2 $\left.\begin{array}{llll}1 & 1 & 1 & 2\end{array}\right)$ Valor. global satisf.

(2) 1111223 1)Insatisfecho

(2 $\begin{array}{lllll}1 & 1 & 1 & 2 & 3\end{array}$ 2) Satisfecho

(2 111123 3)Más o menos satisfecho

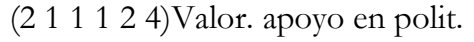

(2) 111124 1)Insatisfecho

(2 111124 2) Satisfecho

(2 11112 5)Valor. apoyo suceso

(2) 111125 1)Rechazo

(2 11125 2)Aceptación

(2 1111126$)$ Culpa

(2 1111126 ) No

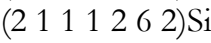

(2 11112 7)Respons. de sus vidas

(2 111127 1) No 
(2 $\left.1 \begin{array}{llll}2 & 1 & 1 & 3\end{array}\right)$ Nietos

(2 1111272$) \mathrm{Si}$

(2 111113 1)Valor. afectos

(2) 1111331 1)Ausencia

(2 1111312 )Presencia

(2 11113 2) Valorac. global satisf.

(2) 1111332 1)Insatisfecho

(2 111132 2)Satisfecho

(2 11114$)$ Antec. disfuncionales

(2) 111114 1)Violencia

(2 11114 2)Abuso de sustancias

(2) 111142 1)Alcohol

(2 111142 2)Drogas

(2 1114 3)Problemas legales

(2 111114 4)No especifica

(2 1111 5)Fam. origen en pte.

(2) 11115 1)Valor. afectos

(2) 111551 1)Ausencia

(2 11151 2)Presencia

(2 11115 2)Valor. apoyo en política

(2 1111152 1)Negativa

(2 11152 2)Positiva

(2 $\begin{array}{llll}1 & 1 & 1 & 5\end{array}$ 3) Valor. global satisf.

(2) 111153 1)Insatisfecho

(2 11153 2)Satisfecho

(2 1112 )Amigos

(2 11115 4)No especifica

(2 1112 1)No tiene

(2 1112211 )Ninguno

(2 $\left.\begin{array}{lllll}2 & 1 & 2 & 1 & 2\end{array}\right)$ Amistades no amigos

(2 111213$)$ No especif.

(2 $\left.\begin{array}{llll}1 & 1 & 2\end{array}\right)$ Si tiene

(2 111222 1)naturaleza

(2) 11122211 Política

(2 1112212$)$ No política

(2) 1112221 3)Infancia***

(2 11122214$)$ Confianza

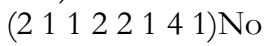

(2 111222142$) S i$

(2 111221 5)Incondicionalidad

(2 1112215 1)No

(2 111222152$) \mathrm{Si}$

(2 111221 7)Intimidad

(2 11122171$) \mathrm{No}$

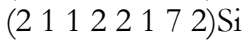

(2 1122218$)$ Tiempo

(2 1122218 1)Menos de un año

(2 11122218 2)De años

(2 111222 2)Valor. aspectos de relac.

(2) 11222 1)Comprendido

(2 1112222211$) \mathrm{No}$

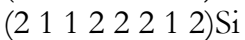

(2 1122221 3)Más o menos

(2 11122222 Solo

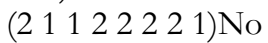

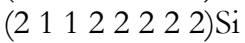

(2 112222 3)Más o menos

(2 111222 3)Apoyado

(2 11222231$) \mathrm{No}$ 
(2 111222232$) S i$

(2 112223 3)Más o menos

(2 11122224$)$ Querido

(21 1122224 1)No

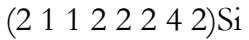

(2 112224 3)Más o menos

(2 1112222 5)Ignorado

(2) 11222251$)$ No

$\left(\begin{array}{lllllllll}2 & 1 & 1 & 2 & 2 & 2 & 5 & 2\end{array}\right) \mathrm{Si}$

(2 112225 3)Más o menos

(2 1122226$)$ Conflictuado

(2) 11222661$)$ No

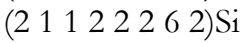

(2 112226 3)Más o menos

(2 11122 3)Valor. global satisf.

(2) 112223 1)Insatisfecho

(2) $\left.\begin{array}{llllll}1 & 1 & 2 & 2 & 3 & 2\end{array}\right)$ Satisfecho

(2 11223 3)Más o menos satisf.

(2 11122 4)No especifica

(2 1112 3)Concepción

(2 $\left.\begin{array}{lllll}2 & 1 & 2 & 3 & 1\end{array}\right)$ No existe

$\left(\begin{array}{lllll}2 & 1 & 1 & 2 & 3\end{array}\right)$ Si existe

(2 11 3)Compañeros

(2 $\left.\begin{array}{lllll}2 & 1 & 3 & 1\end{array}\right)$ No tiene relación

(2 1113 2)Si tiene relación

(2 11132 1)Valor. global satisf.

(2) 113321 1)Insatisfecho

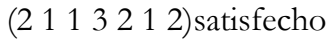

(2 113213 )Más o menos satisf.

(2 1132214$)$ No especifica

(2 11 4)Apoyo incondicional

(2 1114 1)No dispone

(2 1114 2)Si dispone

(2 11142 1)Familia

(2 1142211 )Pareja

(2 11421 2)Hijos

(2 114213 )Hermanos

(2 114214 )Padres

(2 114221 5)Otro o no especif.

(2114216)Nietos

(2 11142 2)Amigos

(2 11142 3)Compañeros

(2 11142 4)Conocidos

(2 11142 5)Ex-pareja

(2 1114426$)$ Dios

(2 11142 7) Otro o no especif.

(2 1 2)Concepción mundo

(2 12 2 1) Valor. global

(2 1221 1)Negativa

(2 12211 1)Causa humana

(2 1221112$)$ Causa naturaleza

(2 $\left.\begin{array}{lllll}2 & 2 & 1 & 1\end{array}\right)$ Tendencias actuales

(2 12114 )No especifica u otro

(2 121 2)Positiva

(2 $\left.12 \begin{array}{llll}2 & 1 & 2 & 1\end{array}\right)$ Causa humana

(2 $\left.\begin{array}{llll}2 & 2 & 1 & 2\end{array}\right)$ Causa naturaleza

(2 $\left.\begin{array}{llll}2 & 2 & 1 & 2\end{array}\right)$ Tendencias actuales

(2 121212 4)No especif. u otro

(2 112 2)Infl. dictadura 
(2 $\left.12 \begin{array}{lll}2 & 2 & 1\end{array}\right)$ No observa

(2 1212 2)Si observa

(2 12 3)Problemáticas

(2 1223 1)Sociales
(2 12231 1)Desigualdad
(2 122312$)$ Exclusión
(2 $\left.\begin{array}{lllll}2 & 2 & 3 & 1 & 3\end{array}\right)$ Pobreza
(2 122314 )Desunión
(2) 122315$)$ Violencia
(2 122316 )Delincuencia
(2 12331 7)Consumo drogas
(2 1231 8)Otro o no especif.

(2 12123 2)Políticas

(2) 12532 1)Corrupción

(2 121232 2) Globalización

(2 $\left.\begin{array}{lllll}2 & 2 & 3 & 2 & 3\end{array}\right)$ Guerras

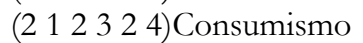

(2 121232 5)Potencias mundiales

(2 121232 6)Futuro incierto

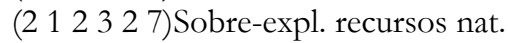

(2 12232 8)Exclusión política

(2 12232 9)Condic. desfav. tbjo.

(2) 12232 10)Terrorismo

(2 1232 11)Régimenes políticos

(2 1232 12)Otro o no especif.

(2 123 3)Personales

(2 12233 1)Individualismo

(2 $\left.\begin{array}{lllll}2 & 2 & 3 & 3 & 2\end{array}\right)$ No lucha

(2 1233 3)Pérdida de ideales

(2 122334 )Ausencia de valores

$\left(\begin{array}{lllll}2 & 1 & 2 & 3 & 3\end{array}\right.$ 5)Soledad

(2 1233 6) Otro o no especif.

(2 123 4)otros motivos

(2 121 4)Valor. aspectos

(2 1224 1)Acogedor

(2 124 1 1) No

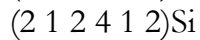

(2 1241 3)Más o menos

(2 12 ( 4 2)Hostil

(2 12442 1)No

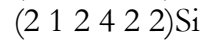

(2 1242 3)Más o menos

(2 124 3)Tiene sentido

(2 1243 1) No

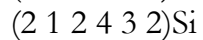

(2 1243 3)Más o menos

(2 1224 4)Difícil

(2 1244 1) No

(2 $\left.12 \begin{array}{llll}2 & 2 & 4 & 4\end{array}\right) \mathrm{Si}$

(2 1244 3)Más o menos

(2 124 5)Agradable

(2 1245 1) No

(2 121245 2) Si

(2 1245 3)Más o menos

(2 124 6)Peligroso

(2 1246 1)No

(2 12246 2) Si

(2 1246 3)Más o menos

(2 112 5) Valor. de su estar 
(2 125 1)A disgusto

(2 125 2)A gusto

(2 125 3)Más o menos a gusto

(2 12 6)Aspectos positivos

(2 126 1)Naturaleza

(2 126 2)Cambios políticos A.L.

(2 1 3)Ideología

(2 126 3)Avances tecnológicos

(2 13 1) Valores

(2) 131 1)Familia

(2 131312 )Amistad

(2 $\left.\begin{array}{lllll}2 & 3 & 1 & 3\end{array}\right)$ Solidaridad

(2 131314 )Lealtad

(2 131 5)Confidencialidad

(2 $\left.\begin{array}{lllll} & 1 & 3 & 1 & 6\end{array}\right)$ Salud y vida

(2 1331 7)Honestidad

(2 1311 8)Palabra

(2 131 9)Perdón

(2) 131 10)Educación

(2 1311 11)Ideales U.P.

(2 1331 12)Cuidado medio amb.

(2 13113 )Esfuerzo

(2 131 14)Relac. humanas

(2 13115 )Cultura

(2 1331 16)Trabajo

(2 131 17)Buen pasar

(2 131 18)Otros

(2) 13131 19)Libertad

(2 131 20)Dignidad

(2 113 2)Creencias

(2 $\left.1 \begin{array}{lll} & 2 & 2\end{array}\right)$ Valor. específica

(2 13221 1)Religiosas o espirituales

(2) 1322111 ) No

(2 $\left.1 \begin{array}{llllll} & 3 & 2 & 1 & 1 & 2\end{array}\right) \mathrm{Si}$

(2 13211 3)Más o menos

(2 13221 2)Justicia

(2) 1322121$)$ No

$\left(\begin{array}{llllll}2 & 1 & 3 & 2 & 1 & 2\end{array}\right)$ Si

(2 13212 3)Más o menos

(2 132213$)$ Amor

(213213 1)No

(2 $\left.1 \begin{array}{llllll} & 3 & 2 & 1 & 3 & 2\end{array}\right) \mathrm{Si}$

(2 13213 3)Más o menos

(2 132214$) \mathrm{Paz}$

(2) 13214 1)No

(2 $\left.1 \begin{array}{lllll}3 & 2 & 1 & 4\end{array}\right) \mathrm{Si}$

(2 13214 3)Más o menos

(21321 5)Personas

(213215 1)No

(2 1322152$) \mathrm{Si}$

(2 13215 3)Más o menos

(213216)Felicidad

(2 132161$) \mathrm{No}$

(21 1322162$) \mathrm{Si}$

(2 $1 \begin{array}{lll} & 3 & 2\end{array}$ 2) Valor. global

(2132163)Más o menos

(2 13222 1)Insatisfecho

(2 $\left.\begin{array}{lllll}1 & 3 & 2 & 2 & 2\end{array}\right)$ Satisfecho

(2 13222 3)Más o menos satisfecho 
(2 13 3)Sentido rel. afec.

(2 133 1)Características

(2) 13331 1)Sólidas

(2 1331 2)Básicas

(2 133313 Superficiales

(2) 133314 )Difíciles

(2 13331 5)Cercanas

(2) 133 2)Atribución

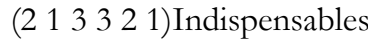

(2 1332 2)Importantes

(2) 13332 3)De ayuda

(2 1332 4)Necesarias

(2 11333 ) Valor. global

(2) 1333 1)Insatisfecho

(2 $\left.1 \begin{array}{lllll}2 & 3 & 3 & 3 & 2\end{array}\right)$ Satisfecho

(2 1333 3)Más o menos satisfecho

(2 1 4)Concepción sres. hnos.

(2 14 1)Visión negativa

(2 14 2)Visión positiva

(2 14 3) Visión positiva y negativa

(2 1 5)Valor. personal

(2 15 1)Negativa

(2 15 2)Positiva

(2 1 6) Valor. ocup. actual

(2 10 l 1 )Motivación
(2) 161 1)Baja
$\left(\begin{array}{lllll}2 & 1 & 6 & 1 & 2\end{array}\right)$ Alta
(2 1613 )No especifica

(2 16 2) Valor. global
(2 162 1)Insatisfecho
(2 162 2) Satisfecho

(2 1 7) Valor. particip. política

(2 17 1)Motivación ppal.

(2 171 1)Defensa ideal. U.P.

(2 171 2)Mejora reparación

(2 171 3)Ayuda social

(2 171 4)Otro motivo

(2 17 2)Autocrítica asociada

(2 1772 1)Negativa

(2 172 2)Positiva

(2 17 3) Valor. global

$$
\text { (2 } 173 \text { 1)Insatisfecho }
$$

(2 173 2)Satisfecho

(2 1 8)Sentido de la vida

(2 18 1) Valor. disfrute de vida
(2) 18 1 1)Insatisfecho

(2 181 2)Satisfecho

(2 18 2) Valor. global
(2 18 2 2 1)Negativa
(2 18 2 2 2)Positiva

(2 1 9)Valor. Chile actual

(2 19 1)Negativa

(2 19 2)Positiva

(2 1 10)Temores

(2 110 1)No tiene

(2 110 2)Si tiene
(2 1102 1)Enferm. o daño a fam.
(2 1102 2)Enferm. indiv.
(2 1102 3)Otro 
(2 2 1)Relac. interpers.

(2 211 1)Familia origen

(2 2211 1)Madre

(2 $\left.2 \begin{array}{llll}2 & 1 & 1 & 1\end{array}\right)$ No tuvo relación

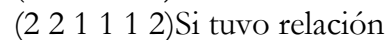

(2 211112 1)Valor. relación

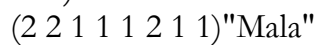

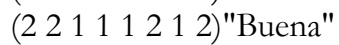

(2 211112 2) Valor. afectos

(2) 211122 1)Insatisfecho

(2 2111122 2)Satisfecho

(2 211 2)Padre

(2 $\left.2 \begin{array}{llll}1 & 1 & 1 & 2\end{array}\right)$ No especifica

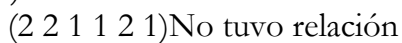

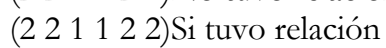

(2 211122 1)Valor. relación

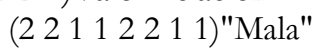

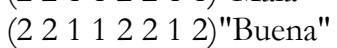

(2 211122 2) Valor. afectos

(2 2111222 1)Insatisfecho

(2 21112222 2)Satisfecho

(2 211222 3)No especifica

(2 211 3)Hermanos

(2 221113 1)No tuvo relación

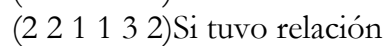

(2 211332 1)Valor. relación

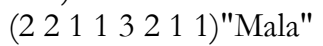

(2 21113212 )"Buena"

(2 211132 2) Valor. afectos

(2 2111322 1)Insatisfecho

(2 2111322 2) Satisfecho

(2 211132 3)No especifica

(2 21114 Ambiente

(2 21114 1)Ausencia dific. relev.

(2 21114 2)Presencia dific. relev.

(2) 211142 1)Violencia

(2 211142 2)Alcoholismo

(2 21142 3)Drogadicción

(2 211142 4)Pobreza extrema

(2 211142 5)Muerte

(2 2111426 )Trabajo infantil

(2 211142 7)Crianza de hnos.

(2 21142 8)Imposib. estudios

(2 211142 9)Crianza cuidadores

(2 21142 10)Abuso sexual

(2 21142 11)Separación

(2 2111 5)Valor. global afectos

(2 21142 12)Otro o no especif.

(2 21115 1)Insatisfecho

(2) 21115 2) Satisfecho

(2 211 6)Ideología política

(2) 211 6 1)Apolíticos

(2 211 6 2)De derecha

(2 21116 3)De izquierda

(2 21 2)Amigos inf. y adol.

(2 $\left.2 \begin{array}{llll}2 & 1 & 2 & 1\end{array}\right)$ No tuvo

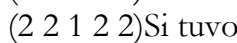


(2 21222 1)Insatisfacción

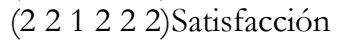

(2 $\left.\begin{array}{llll}2 & 1 & 2 & 2\end{array}\right)$ Se mantienen

(2 21122 4)No se mantienen

(2 21122 5)No especifica

(2 21 3) Pareja adol.

(2 $\left.2 \begin{array}{llll}2 & 1 & 3 & 1\end{array}\right)$ No tuvo

(2 $\left.\begin{array}{llll}2 & 1 & 3 & 2\end{array}\right)$ Si tuvo

(2 $\left.2 \begin{array}{llll}2 & 1 & 2 & 1\end{array}\right)$ Insatisfacción

(2 $\left.\begin{array}{llll}2 & 1 & 3 & 2\end{array}\right)$ Satisfacción

(2 $\left.2 \begin{array}{llll}2 & 1 & 3 & 2\end{array}\right)$ No especifica

(2 21 4)A. incond. inf. y adol.

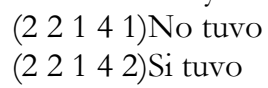

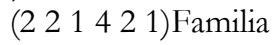

(2 21142 2)Amigos

(2 21422 3)Pareja

(2) 2142 4)otro cuidador

(2 2142 5)Conocido

(2 2 2)Concepción mundo

(2 22 1)No pensaba en ello

(2 252 2)Si pensaba en ello

(2 2 3)Visión de futuro

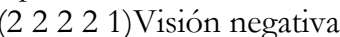
(2 $\left.\begin{array}{llll}2 & 2 & 2 & 2\end{array}\right)$ Visión positiva

(2 223 1)No pensaba en ello

(2 25 2)Si pensaba en ello
(2 2532 1)Pesimista
(2 $\left.\begin{array}{llll}2 & 3 & 2 & 2\end{array}\right)$ Optimista
(2 2522 3)No especifica

(2 2 4) Valor. de su estar

(2 24 1)Insatisfecho

(2 24 2) Satisfecho

(2 2 5)Sentido de la vida

(2 25 1)No pensaba en ello

(2 25 2)Si pensaba en ello
(2 2522 1) Valor. disfrute de vida (2) 2521 1)Insatisfecho
(2 2521 2)Satisfecho
(2 252 2) Valor. global
(2 25222 1)Negativa
(2 2522 2)Positiva

(2 3)Prisión política y tortura

(2 3 1)Valor. experiencia

(2 $3 \quad 1$ 1)En su vida

(2) 31111 ) Sufrimiento
(2 31111 1)Mínimo
(2 $\left.\begin{array}{lllll}2 & 1 & 1 & 1 & 2\end{array}\right)$ Medio
(2 3111113$)$ Extremo
(2 311114 )Menos que compañeros
(2 31111 5)No especifica cantidad

(2 3112 )En otros ex-pps

(2 $\left.3 \begin{array}{lll}2 & 2 & 1\end{array}\right)$ En salud mental

(2 $\left.\begin{array}{lllll}2 & 1 & 2 & 1 & 1\end{array}\right)$ Debilidad

(2 31121 2)Depresión

(2) 3121213 )Locura

(2 $\left.\begin{array}{lllll}2 & 1 & 2 & 1 & 4\end{array}\right)$ Alcoholismo

(2 31121 5)Drogadicción

(2 31216 )Deterioro general 
(2) 3121217 Miedo

(2 3112 2)En calidad de vida

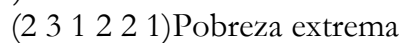

(2 31122 2)Imp. de educación

(2 $\left.\begin{array}{lllll}2 & 1 & 2 & 2 & 3\end{array}\right)$ Cesantía

(2) $\left.\begin{array}{lllll}2 & 1 & 2 & 2 & 4\end{array}\right)$ Vivienda deficitaria

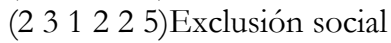

(2 $\left.\begin{array}{llll}2 & 1 & 2 & 2\end{array}\right)$ Inseguridad

(2 $\left.\begin{array}{lllll}2 & 1 & 2 & 2 & 7\end{array}\right)$ Insatisf. nec. básicas

(2 $\left.3 \begin{array}{lll} & 2 & 3\end{array}\right)$ En familia

(2) 312123 1)Disfunción

(2 $\begin{array}{lllll}2 & 3 & 1 & 2 & 3\end{array}$ 2)Ruptura

(2 $\left.\begin{array}{llll}2 & 1 & 2 & 3\end{array}\right)$ Prostitución

(2 312 4)En ideología y accionar polít.

(2 3124 1)Retracción

(2 31124 2)Delatores

(2 312 5)Muerte

(2 $\left.3 \begin{array}{lll}2 & 1 & 2\end{array}\right)$ En salud física

(2 3126 1) No

(2 312262$) \mathrm{Si}$

(2 3 2)Actitud post-prisión

(2 32 1)Reacción inmediata

(2 32 1 1)Victimización

(2 321 2)Deseo de morir

(2 321 3)Bloqueo

(2 3214 )Evitación

(2 32 2)Sentimientos

(2) 322 1) Odio

(2 3222211 ) No

(2 $\left.\begin{array}{lllll}3 & 2 & 2 & 1 & 2\end{array}\right) \mathrm{Si}$

(2) 3222 2)Temor

(2 322222 1) No

(2 $\left.\begin{array}{lllll}3 & 2 & 2 & 2 & 2\end{array}\right) \mathrm{Si}$

(2 322 3)Aflicción

(2 32223 1) No

(2 $\left.\begin{array}{lllll}2 & 2 & 2 & 3 & 2\end{array}\right) \mathrm{Si}$

(2 322 4)Frustración

(2 32224 1) No

(2 32224 2) Si

(2 3222 5)Orgullo

(2 3225 1) No

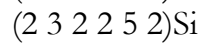

(2 3222 6) Verguenza

(2 322261$) \mathrm{No}$

(2) 325262 ) Si

(2 3222 7)Culpa

(2 32227 1)No

(2) 32227 2) Si

(2 322 8)Rabia

(2) 32228 1) No

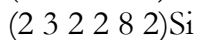

(2 3222 9)Soledad

(2 32 3)Afrontamiento

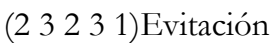
(2 $\begin{array}{lll}2 & 2 & 3\end{array}$ 2)Estrategia superación
(2) 3223 3)Subversión
(2) $\left.\begin{array}{lllll}2 & 2 & 3 & 4\end{array}\right)$ Ironizar
(2 $\left.3 \begin{array}{llll}2 & 3 & 5\end{array}\right)$ Negación
(2 323 6)Real. acciones legales 
(2 322 4)Lectura

(2 $322 \quad 4$ 1) Una valiosa experiencia

(2 324 2) Una etapa más de vida

(2 324 3)Algo que tenía que suceder

(2 3254 4) Una muy mala experiencia

(2 324 5) Una nueva oportunidad de vida

(2 32 5)Acción política

(2 325 1)Cese militancia

(2 325 2)Continúa militancia

(2 3 3)Valor. impacto

(2 33 1)Trabajo o estudio

(2 333 1 1)No impactó

(2 3331 2)Si impactó

(2) 3312 1)Cancelación

(2 33312 2)Condiciones desfav.

(2 333123$)$ Inestabilidad

(2) 333124 Impos. tbjo. por antec. pen.

(2 3312 5)Otro o no especif.

(2) 33 2)Economía

(2 $\left.\begin{array}{llll}2 & 3 & 2 & 1\end{array}\right) \mathrm{No}$

(2) $\left.\begin{array}{llll}2 & 3 & 2 & 2\end{array}\right) \mathrm{Si}$

(2) 33 3)Relac. interp.

(2) 3333 1)Familia

(2 3331 1)Pareja

(2 333311 1)No percibe cambios

(2 3333112 )Si percibe cambios

(2 3333112 1)Negativos

(2 3331112 2)Positivos

(2 33331123 )No especif.

(2 33312 )Hijos

(2 33312 1)No percibe cambios

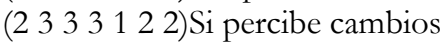

(2) 333122 1)Causas

(2) 33331221 1)Ausencia

(2 333312212 Precariedad

(2 333312213 )No especifica

(2 33312214 )Separación

(2 333122 2)Efectos

(2 333312222 1)Trans. trauma

(2 33331222 2)Di.f id. polít.

(2 33331222 3)Imposib. educación

(2 33331222 )Valor. global

(2 33331223 1)Negativa

(2 33331223 2)Positiva

(2) 333 2)Amigos

(2 33332 1)No percibe cambio

(2 $\left.\begin{array}{llll}3 & 3 & 3 & 2\end{array}\right)$ Si percibe cambio

(2 3333222 1)Negativos

(2 333322 2)Positivos

(2 $\begin{array}{lllll}2 & 3 & 3 & 2 & 2\end{array}$ 3)No especifica

(2 333 3)Laborales o estudiantiles

(2) 3333 1)Las mismas

(2) 333331 1)No

(2 3333312$)$ Si

(2) 3333 2)Más distantes

(2) 33333321$) \mathrm{No}$

(2 3333322 ) $\mathrm{Si}$

(2) 333 3)Fuente de protección

(2) 33333 1) No 
(2 333332$) \mathrm{Si}$

(2 3333 4)Fuente de peligro

(233334 1) No

(2 3333344 ) Si

(2 3333 5)Fuente de apoyo

(2) 33351$) \mathrm{No}$

(2 3333352 ) Si

(2 3333 6)Se perdieron

(2333361)No

(2 3333362 ) Si

(2) 333 4)Compañeros

(2 3334 1)No percibe cambios

(2) 3334 2)Si percibe cambios

(2 333342 1)Negativos

(2 33342 2)Positivos

(2 33342 3)No especif.

(2 333 5)Otros o no especifica

(2 3335 1)No percibe cambios

(2) 33335 2)Si percibe cambios

(2 33352 1)Negativos

(2 33352 2)Positivos

(2 333523 )No especifica

(2 33 4)Identidad

(2) 3344 1) No

(2 3334 2) Si

(2 334 3)No sabe

(2) 33 5)Salud

(2) 335 1)Refiere enfermedad asociada

(2 335 2)No refiere enfermedad asociada

(2 33 6)Transgeneracionalidad

(2) 336 1)No percibe

(2 336 2) Si percibe

(2) 33 7) Vida

(2 336 3)No sabe o no responde

(2 337 1)No disfrute de la vida

(2 337 2)Disfrute de la vida

(2 337 3)Ilusión

(2 33773 1) No

(2 33732$) \mathrm{Si}$

(2) 37 4)Calidad de vida

(2 3374 1) No

(2 3374 2) Si

(2 337 5)Otro o no especif.

(2 33 8)Caract. de pd.

(2) 3338 1) No

(2 $\left.\begin{array}{llll}3 & 3 & 8 & 2\end{array}\right) \mathrm{Si}$

(2 3 4)Temores asociados

(2 34 1)No presenta

(2 3 4 2)Si presenta

(2 342 1)A cambios políticos

(2 3442 2)Cese partic. polit.

(2 342 3)Nueva exp. prisión

(2 342 4)A uniformados

(2 342 5)A daño familiar

(2 3426 )No especifica

(2 342 7)Muerte por motiv. polit.

(2 3 5)Silencio personal

(2 35 1) No

(2) 352 2) Si 
(2 352 1)Tiempo

(2 3521 1)Desde prisión hasta pte.

(2 3521 2)Desde prisión hasta antes I.V.

(2 35213 )Desde prisión hasta I.V.

(2 3521 4)No especifica

(2 352 2)Relac. interp.

(2) 35222 1)Consigo mismo

(2) 3522211 ) No

(2 3522212$)$ Si

(2 3522 2)Pareja

(2) 352222 1)No

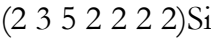

(2 352223$)$ Hijos

(2) 3522231 ) No

(2 3552232 ) Si

(2) 3522 4)Fam. origen

(2 3522244 ) No

(2 3522242$)$ Si

(2 35222 5)Amigos

(2) 3522551 ) No

(2 3552252 ) Si

(2 3522 6)Comp. tbjo. - est.

(23 352261$) \mathrm{No}$

(2 3522262$) \mathrm{Si}$

(2 352227 Con sociedad

(2 35227 1) No

(2 3522272 ) Si

(2 3522 8)No especif.

(2 352 3)Causas

(2) 3523 1)Temor

(2) 3523 2)Protección

(2) 3523 3)Verguenza

(2 3523 4)Negación

(2 3523 5)Miedo al rechazo

(2 3523 6)Menoscabo

(2 3524 )Consecuencias

(2 3524 1)No percibe

(2 3524 2)Si percibe

(2 35242 1)Negativas

(2 35242 2)Positivas

(2 352 5)No especifica

(2 3 6)Tortura y violencia

(2 36 1)Valor. superac. exp.

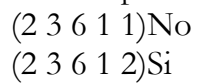

(2 36 2)Relac. torturador

(2 $\left.36 \begin{array}{lll} & 6 & 1\end{array}\right)$ Ninguna

(2 362 2) Si tiene

(2 3 7)Re-traumatización

(2 37 1)No presenta

(2 37 2)Si presenta

(2 372 1)Acontecer asoc.

(2 372 2)Informe Valech

(2) 372 3)Otro

(2 372 4)No especifica

(2 3 8) Valor. superac. exp.

(2 $\left.\begin{array}{lll}2 & 8 & 1\end{array}\right) \mathrm{No}$

(2 $\left.3 \begin{array}{lll} & 8 & 2\end{array}\right) \mathrm{Si}$

(2 3 9)Apoyo post prisión 
(2 39 1)No tuvo

(2 39 2) Si tuvo

(2 3 10)Rechazo post prisión

(2 310 1)No percibe

(2 310 2)Si percibe

(2 4)Otras valoraciones

(2 4 1)Persec. política

(2 $\left.\begin{array}{lll}2 & 1 & 1\end{array}\right) \mathrm{No}$

(2 $\left.4 \begin{array}{lll} & 1 & 2\end{array}\right) \mathrm{Si}$

(2 $\left.4 \begin{array}{lll}1 & 2 & 1\end{array}\right)$ Momento

(2 41221 1)Pre prisión

(2 41121 2)Post prisión

(2 $4 \begin{array}{llll} & 1 & 2 & 1\end{array}$ 3)Presente

(2 $\left.4 \begin{array}{lll} & 1 & 2\end{array}\right)$ Área

(2 411214 )No especifica

(2 $\left.\begin{array}{lllll}4 & 1 & 2 & 2 & 1\end{array}\right)$ Laboral

(2 $\left.4 \begin{array}{llll}2 & 2 & 2 & 1\end{array}\right)$ Listas negras

(2 $\left.4 \begin{array}{llll}4 & 2 & 2 & 1\end{array}\right)$ Amenazas anónimas

(2 $4 \begin{array}{llll}1 & 2 & 2 & 1\end{array}$ 3)Antec. legales

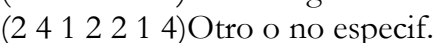

$\left(\begin{array}{lllll}2 & 4 & 1 & 2 & 2\end{array}\right)$ Familiar

(2 412222 1)Vigil. perman. domic.

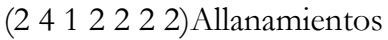

(2 $\begin{array}{lllll}4 & 1 & 2 & 2 & 2\end{array}$ 3)Agr. física o verbal

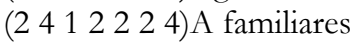

(2 41122 3)Personal

(2 $4 \begin{array}{llll} & 2 & 2 & 3\end{array}$ 1)Agr. física vía pub.

(2 $4 \begin{array}{llll}1 & 2 & 2 & 3\end{array}$ 2)Agr. verbal vía pub.

(2 412223 3)Detenciones posteriores

(2 $4 \begin{array}{llll}4 & 1 & 2 & 3\end{array}$ 4)Amenazas anónimas

(2 $4 \begin{array}{llll} & 2 & 2 & 3\end{array}$ 5)Otra o no especif.

(2 $\left.4 \begin{array}{llll}4 & 1 & 2 & 2\end{array}\right)$ Política

(2 41224 1)Nueva detención

(2 $\left.4 \begin{array}{lll} & 1 & 2\end{array}\right)$ Ejecutores

(2 $4 \begin{array}{llll} & 1 & 2 & 3\end{array}$ ) Uniformados

(2 4123 2)Comp. de tbjo.

(2 $\left.4 \begin{array}{llll}1 & 2 & 3 & 3\end{array}\right)$ Amistades

(2 $4 \begin{array}{lll} & 2 & 3\end{array}$ 4)Vecinos

(2 4112 4)Afrontamiento

(2 41224 1)No realiza

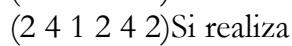

(2 412242 1)Enfrent. directo

(2 41242 2)Cambio de ciudad

(241242 3)Medidas legales

(2 41242 4)Renuncia

(2 4 2)Régimen militar

(2 42 1)Valor. aspect. específ.

(2 42 1 1)Proceder régimen

(2 422111 1)Ilegalidad

(2 $\left.4 \begin{array}{llll}2 & 1 & 1 & 2\end{array}\right)$ Injusticia

(2 42113 )Caos

(2 421114$)$ Error

(2 4211 5)Sistematización

(2 4211 6) Otra valor. negativa

(2 421 2)Ejecutores

(2 42212 1)Desequilibrados

(2 42112 2)Drogodependientes

(2 $\left.\begin{array}{llll}4 & 2 & 1 & 2\end{array}\right)$ Alcohólicos

(2 4212 4)Perversos 
(2 421212 5)Inexplicable

(2 4212 6)Enfermos

(2 421 3)Obj. percibido

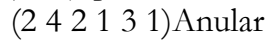

(2 $\left.4 \begin{array}{llll}2 & 1 & 3 & 2\end{array}\right)$ Excluir

(2 $\left.42 \begin{array}{llll}2 & 1 & 3\end{array}\right)$ Exterminar

(242134)Represión

(2 4214 )Resultado percib.

(2 4214 1)Anulación

(2 42214 2)Exclusión

(2 $\left.42 \begin{array}{llll}4 & 4\end{array}\right)$ Exterminio

(2 4214 4)Temor sociedad

(2 4214 5)Represión

(2 4214 6)Condic. desfav. de vida

(2 4214 7)Condic. desfav. de tbjo.

(2 4214 8)Daño familiar

(2 421 5)Influencias

(2 42215 1)EEUU

(2 4215 2)Otros países

(2 4216$)$ Actualidad

(2 4216 1)No presenta influencia

(2 4216 2)Si presenta influencias

(2 4 3)Reparación

(2 43 1)Informe Valech

(2 4331 1)Etapas

(2 4311 1)Convocatoria

(2 4331111 1)Insatisfecho

(2 433111111 ) Tiempo reducido

(2 4331111 2)Difusión limitada

(2431112)Satisfecho

(243 4112$)$ Evaluación

(2 433112 1)Insatisfecho

(2 433111221 1)Dific. situac.

(2 433112212$)$ Sentirse juzgado

(24 4311213 )Errores en identif.

(2 433111214 )Inapropiado

$(2431112$ 2)Satisfecho

(24 43113 )Difusión

(243113 1)Insatisfecho

(24311311)Protección info. tort.

(2 43111312 )Public. lista víctimas

(2 431113 2)Satisfecho

(243 41332 1)Reconoc. social

(2 431 2)Medidas

(24 4311332 2)Conoc. mundial

(24 4312 1)Tipos

(2431211)Económicas

(2 433122111 )Insatisfecho

(2 431221111 1)Exclusión jubilación

(2 4312111 2)Exclusión benef. exon.

(243121113)Insuficiente

(2 43121114 )No heredable

(24312112)Satisfecho

(24 43121112 1)Estab. econ.

(2 4312112 2)Mejora condic. vida

(2 $\left.4 \begin{array}{lllll}4 & 1 & 2 & 1 & 2\end{array}\right)$ Salud (PRAIS)

(2 4331212 1)Insatisfecho

(2 4331212211 )S. salud gral.

(2 431221212 )S. salud mental 
(2 431212 2)Satisfecho

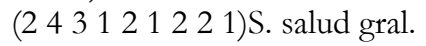

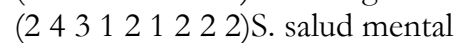

(2431213)Educación

(243 1213 1)Insatisfecho

(243 421331 1)No heredable

(2 43121213312$)$ No desea estudiar

(2 43121313 )No especifica

(2 431213 2)Satisfecho

(2 4312132 1)Desea estudiar

(2 4331214 )Vivienda

(2 4331214 1)Insatisfecho

(24312 44 2)Satisfecho

(2 $\left.\begin{array}{llll}4 & 3 & 1 & 2\end{array}\right)$ Valor. aspectos

(2 431222 1)Subsanan

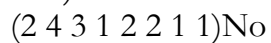

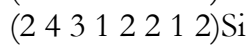

(24312213)Más o menos

(2 $\left.4 \begin{array}{llll}4 & 1 & 2 & 2\end{array}\right)$ Tardías

(2 43312221$) \mathrm{No}$

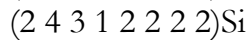

(2 431222 3)Más o menos

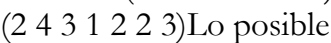

(243 4223 1)No

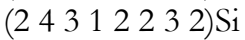

(2 4312233 )Más o menos

(2 431224$)$ No tienen relac.

(2 4331224 1)No

$\left(\begin{array}{lllllll}2 & 4 & 3 & 1 & 2 & 2 & 4\end{array}\right) \mathrm{Si}$

(24312243)Más o menos

(2 433122 5) Justas

(24) 3122251 ) No

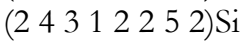

(2 431225 3)Más o menos

(243122 6)No tienen sentido

(24 4312261$) \mathrm{No}$

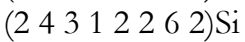

(2 431226 3)Más o menos

(2 $\left.4 \begin{array}{lll}3 & 1 & 2\end{array}\right)$ Valor. global

(2 43123 1)Insatisfecho

(2 43123 2) Satisfecho

(2 43 2)En uniformados

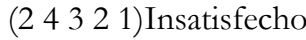

(2 4432 2) Satisfecho

(2 43 3)Lectura

(2 453 1)Negativa

(2 433 2)Positiva

(2 434 4)Concepción

(2 434 1)No es posible

(2 434 2) Es posible

(2 43 5)Valor políticos actuales

(2435 1)De derecha

(2435 5 1)Insatisfecho

(2 4351 2)Satisfecho

(2 435 2)De izquierda

(24 352 1)Insatisfecho

(2 4352 2)Satisfecho

(2 43 6) Justicia

(2 436 1) No 
(2 4362$) \mathrm{Si}$

(2 4 4)Soc. chilena y DDHH

(2 44 1) Valor. respta.

(2 444 1)Valor. en tiempo

(2 $\left.44 \begin{array}{lll}1 & 1\end{array}\right)$ Cambios

(2 441111 1)Negativos

(2 4411112$)$ Positivos

(2 4441 2)Infl. I.V.

(2 $\left.44 \begin{array}{lll}2 & 1\end{array}\right)$ Negativa

(24 4121 1)Beneficios econ.

(2 44112 2)Positiva

(2 44122 1)Mayor conoc.

(2 44413 )Tendencias

(2 4413 1)Desfavorables

(244 433 1)Negación

(2441312)Indiferencia

(2 4441313 )Olvido

(2 441314 )Apoyo a régimen

(2 44131 5)Estigmatización

(2 44131 6)Exclusión social

(2 44131 7)Desconocimiento

(2 4413 2)Favorables

(244 432 1)Reconocimiento

(2 444132 2)Apoyo causa

(244132 3)Interés en tema

(2 441324 )Respeto

(24413 4 5)Conciencia social

(2 44132 6)Otro o no especif.

(2 4414 )Silencio soc.

(2 4414 1)Ausencia

(2 4414 2)Presencia

(2 441 5)Valor. aspect. espec.

(244151)Conoce

(2 44151 1)No

(24415 12 )Si

(2441513)Más o menos

(2 4415 2)Ignora

(244152 1) No

(2 $\left.44 \begin{array}{lll}1 & 5 & 2\end{array}\right)$ Si

(244152 3)Más o menos

(2 44153 )Sensibilizada

(244153 1)No

(24415 32 2) Si

(24 4153 3)Más o menos

(2 4415 4)Rechaza

(244154 1) No

(2441542) Si

(2 44154 3)Más o menos

(2 4415 5)Se responsabiliza

(244 155 1)No

(2441552)Si

(2441553)Más o menos

(24415 6)Teme

(24415 61 ) No

(2441562)Si

(244156 3)Más o menos

(2 4416 )Valor. global

(2 4416 1)Insatisfecho

(2 4416 2)Satisfecho 
(2 4416 3)Intermedio

(2 4411 7)Justicia

(2 4417 1) No

(2 44417 2) Si

(2 4 5)Opinión exilio

(2 45 1)De exp. personal

(2 451 1) Valor. negativa

(2 451 2) Valor. positiva

(2 45 2)De compañeros

(2 452 1)Valor. negativa

(2 4552 2) Valor. positiva 